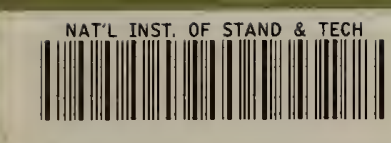

A】l106 138665

\title{
Selected Values of Chemical Thermodynamic Properties
}

Tables for the First Thirty-Four Elements In the Standard Order of Arrangement 


\section{THE NATIONAL BUREAU OF STANDARDS}

The National Bureau of Standards is a principal focal point in the Federal Government for assuring maximum application of the physical and engineering sciences to the advancement of technology in industry and commerce. Its responsibilities include development and maintenance of the national stand. ards of measurement, and the provisions of means for making measurements consistent with those standards; determination of physical constants and properties of materials; development of methods for testing materials, mechanisms, and structures, and making such tests as may be necessary, particu. larly for government agencies; cooperation in the establishment of standard practices for incorporation in codes and specifications; advisory service to government agencies on scientific and technical problems; invention and development of devices to serve special needs of the Government; assistance to industry, business, and consumers in the development and acceptance of commercial standards and simplified trade practice recommendations; administracion of programs in cooperation with United States business groups and standards organizations for the development of international standards of practice; and maintenance of a clearinghouse for the collection and dissemination of scientific, technical, and engineering information. The scope of the Bureau's activities is suggested in the following listing of its four Institutes and their organizational units.

Institute for Basic Standards. Applied Mathematics. Electricity. Metrology. Mechanics. Heat. Atomic Physics. Physical Chemistry. Laboratory Astrophysics." Radiation Physics. Radio Standards Laboratory:" Radio Standards Physics; Radio Standards Engineering. Office of Standard Reference Data.

Institute for Materials Research. Analytical Chemistry. Polymers. Metallurgy. Inorganic Materials. Reactor Radiations. Cryogenics." Materials Evaluation Laboratory. Office of Standard Refer. ence Materials.

Institute for Applied Technology. Building Research. Information Technology. Performance Test Development. Electronic Instrumentation. Textile and Apparel Technology Center. Technical Analysis. Office of Weights and Measures. Office of Engineering Standards. Office of Invention and Innovation. Office of Technical Resources. Clearinghouse for Federal Scientific and Technical Information." *

Central Radio Propagation Laboratory.* Ionospheric Telecommunications. Tropospheric Telecommunications. Space Environment Forecasting. Aeronomy.

* Located at Boulder, Colorado 80301.

** Located at 5285 Port Royal Road, Springfield, Virginia 22171. 


\title{
NBS TECHNICAL NOTE 270-3 ISSUED JANUARY 1968
}

\section{Selected Values of Chemical Thermodynamic Properties \\ Tables for the First Thirty-Four Elements \\ in the Standard Order of Arrangement}

\author{
D. D. Wagman, W. H. Evans, V. B. Parker, \\ I. Halow, S. M. Bailey, and R. H. Schumm \\ Institute for Basic Standards \\ National Bureau of Standards \\ Washington, D.C. 20234 \\ [ This Technical Note supersedes Technical Notes 270-1 and 270-2] \\ NBS Technical Notes are designed to supplement the \\ Bureau's regular publications program. They provide a \\ means for making available scientific data that are of \\ transient or limited interest. Technical Notes may be \\ listed or referred to in the open literature.
}

For sale by the Superintendent of Documents, U.S. Government Printing Office Washington, D.C., 20402 - Price $\$ 1.25$ 



\section{PREFACE}

Technical Note $270-3$ is the third in a series of publications containing material prepared as a revision of the tables of Series I of National Bureau of Standards Circular 500, Selected Values of Chemical Thermodynamic Properties, by F. D. Rossini, D. D. Wagman, W. H. Evans, S. Levine, and I. Jaffe. This Note extends the revision to Tables 23,33 , and 34 , covering the compounds of the elements carbon, zinc, and cadmium in the Standard Order of Arrangement. In addition this Note contains all of the Tables of Technical Note 270-1 and 270-2, including corrections for a number of minor errors. Thus this Note supersedes Technical Notes $270-1$ and $270-2$.

Donald D. Wagman, Chief, Thermochemistry Section. 
Preface - -

Introduction

Table A Conversion Factors

Table 1 Oxygen

Table 2 Hydrogen

Table 3 Helium -......... 15

Table 4 Neon

Table 5 Argon -

Table 6 Krypton -

Table 7 Xenon

Table 8 Radon -...-...-. 20

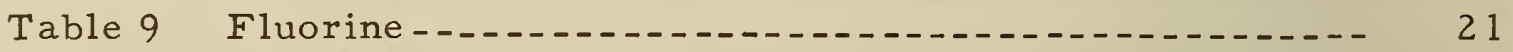

Table 10 Chlorine-_.-.-.

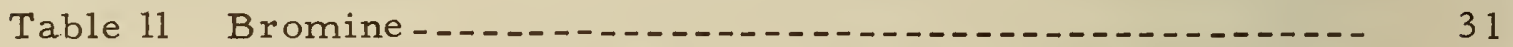

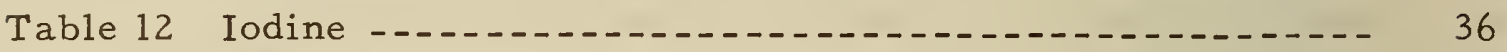

Table 13 Astatine -............ 42

Table 14 Sulfur _._._.

Table 15 Selenium-_._._.

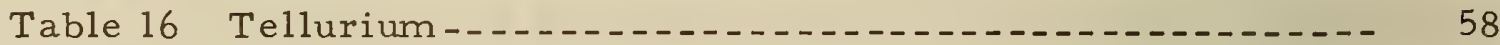

Table 17 Polonium - 60

Table 18 Nitrogen

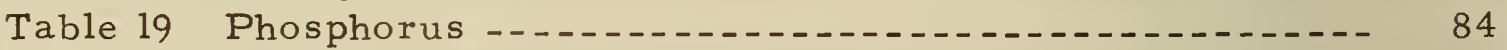

Table 20 Arsenic

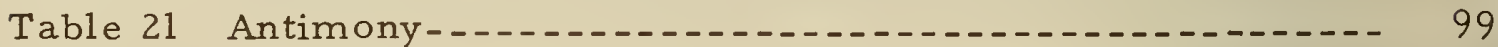

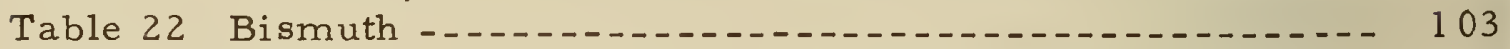

Table 23 Carbon -........................................ 106

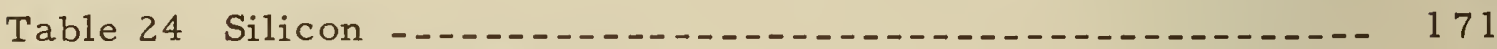

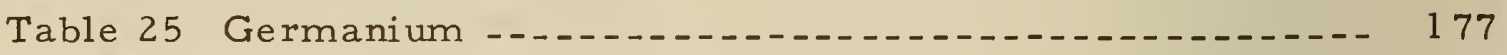

Table 26 Tin

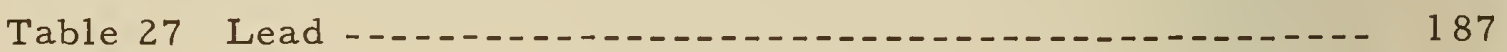

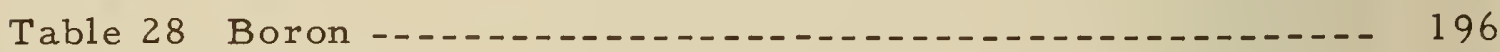

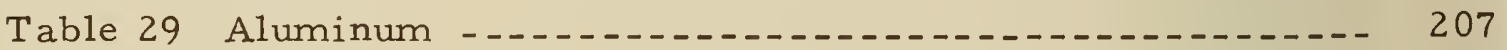

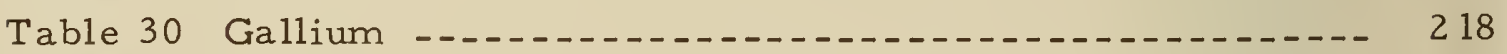

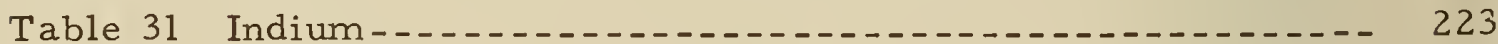

Table 32 Thallium_.................................. 227

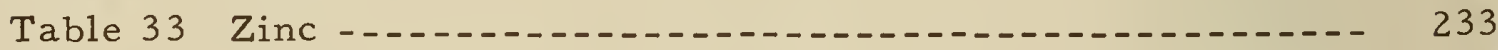

Table 34 Cadmium _................................... 248

Appendix _.............. 262

Table B

Index 


\title{
SELECTED VALUES OF CHEMICAL THERMODYNAMIC PROPERTIES
}

\author{
by \\ Donald D. Wagman, William H. Evans, Vivian B. Parker, \\ Iva Halow, Sylvia M。Bailey, and Richard H。Schumm
}

\section{INTRODUCTION}

Substances and Properties Included in the Tables

The tables contain values where known of the enthalpy and Gibbs energy of formation, enthalpy, entropy and heat capacity at $298.15^{\circ} \mathrm{K}$ $\left(25^{\circ} \mathrm{C}\right)$, and the enthalpy of formation at $0^{\circ} \mathrm{K}$, for all inorganic substances and organic molecules containing not more than two carbon atoms. In some instances such as metal-organic compounds, data are given for substances in which each organic radical contains one or two carbon atoms.

No values are given in these tables for metal alloys or other solid solutions, fused salts, or for substances of undefined chemical composition.

\section{Physical States}

The physical state of each substance is indicated in the column headed "State" as crystalline solid (c), liquid (liq), glassy or amorphous (amorp), or gaseous ( $g$ ). Solutions in water are listed as aqueous (aq). For non-aqueous systems the physical state is that normal for the indicated solvent at $298.15^{\circ} \mathrm{K}$.

\section{Definition of Symbols}

The symbols used in these tables are defined as follows: $P=$ pressure; $\mathrm{V}=$ volume; $\mathrm{T}=$ absolute temperature; $\mathrm{E}=$ intrinsic or internal energy; $\mathrm{S}=$ entropy; $\mathrm{H}=\mathrm{E}+\mathrm{PV}=$ enthalpy (heat content); $\mathrm{G}=\mathrm{H}-\mathrm{TS}=$ Gibbs energy (formerly the free energy); $\mathrm{C}_{\mathrm{p}}=(\mathrm{dH} / \mathrm{dT})_{\mathrm{P}}=$ heat capacity at constant pressure. 
The values of the thermodynamic properties of the pure substances given in these tables are for the substances in their standard states (indicated by the superscript ${ }^{\circ}$ on the thermodynamic symbol). These standard states are defined as follows:

For a pure solid or liquid, the standard state is the substance in the condensed phase under a pressure of one atmosphere.

For a gas the standard state is the hypothetical ideal gas at unit fugacity, in which state the enthalpy is that of the real gas at the same temperature and at zero pressure.

The values of $\Delta \mathrm{Hf}^{\circ}$ and $\Delta \mathrm{Gf}^{\circ}$ given in the tables represent the change in the appropriate thermodynamic quantity when one gram-formula weight of the substance in its standard state is formed, isothermally at the indicated temperature, from the elements, each in its appropriate standard reference state. The standard reference state at $25^{\circ} \mathrm{C}$ for each element except phosphorus has been chosen to be the standard state that is thermodynamically stable at $25^{\circ} \mathrm{C}$ and at one atmosphere pressure. For phosphorus the standard reference state is the crystalline white form; the more stable forms have not been well characterized thermochemically. The same reference states have been maintained for the elements at $0^{\circ} \mathrm{K}$ except for the liquid elements bromine and mercury, for which the reference states have been chosen as the stable crystalline forms. The standard reference states are indicated in the tables by the fact that the values of $\Delta \mathrm{Hf}^{\circ}$ and $\triangle \mathrm{Gf}^{\circ}$ are exactly zero.

The values of $\mathrm{H}_{298}^{\circ}-\mathrm{H}_{0}^{\circ}$ represent the enthalpy difference for the given substance between $298.15^{\circ} \mathrm{K}$ and $0^{\circ} \mathrm{K}$. If the indicated standard state at $25^{\circ} \mathrm{C}$ is the gas, the corresponding state at $0^{\circ} \mathrm{K}$ is the hypothetical ideal gas; if the state at $25^{\circ} \mathrm{C}$ is solid or liquid, the corres ponding state at $0^{\circ} \mathrm{K}$ is the thermodynamically "stable crystalline solid, unless otherwise specifically indicated.

The values of $\mathrm{S}^{\circ}$ represent the virtual or "thermal" entropy of the substance in the standard state at $298.15^{\circ} \mathrm{K}$, omitting contributions from nuclear spins. Isotope mixing effects, etc, are also excluded except in the case of the hydrogen-deuterium $\left({ }^{1} \mathrm{H}-{ }^{2} \mathrm{H}\right)$ systenı. Where data have been available only for a particular isotope, they have been corrected when possible to the normal isotopic composition.

The values of the enthalpies of formation of gaseous ionic species are computed on the convention that the value of $\Delta \mathrm{Hf}^{\circ}$ for the electron is zero. Conversions between 0 and $298.15^{\circ} \mathrm{K}$ are calculated using the value of $\mathrm{H}_{29}^{\circ}{ }^{-\mathrm{H}_{0}^{\circ}}=1.481 \mathrm{kcal}$ per mole of electrons, and assuming that the values of $\mathrm{H}_{298}{ }^{-\mathrm{H}_{0}}$ for the ionized and un-ionized molecules are the same. 


\section{Conventions Regarding Solutions}

Solutions in water are designated as aqueous (aq); other solvents are designated by name or chemical formula. The concentration of the solution is expressed in terms of the number of moles of solvent associated with one mole of the solute. If no concentration is indicated, the solution is assumed to be "dilute".

The standard state for a solute in aqueous solution is taken as the hypothetical ideal solution of unit molality (indicated as "std. state, $\left.\mathrm{m}=1^{\prime \prime}\right)$. In this state the partial molal enthalpy and heat capacity of the solute are the same as in the infinitely dilute real solution. For nonaqueous solutions the standard state of the solute is the hypothetical ideal solution of unit mole fraction of solute ("std. state, $\mathrm{x}_{2}=1$ ").

The value of $\Delta \mathrm{Hf}^{\circ}$ given in the tables for a solute in its standard state is the apparent molal enthalpy of formation of the substance in the infinitely dilute real solution. At this dilution the partial molal enthalpy is equal to the apparent molal quantity. At concentrations other than the standard state, the value of $\Delta \mathrm{Hf}^{\circ}$ represents the apparent enthalpy of the reaction of formation of the solution from the elements comprising the solute, each in its standard reference state, and the appropriate total number of moles of solvent. In this representation the value of $\triangle \mathrm{Hf}^{\circ}$ for the solvent is not required. The experimental value for a heat of dilution is obtained directly as the difference between the two values of $\Delta \mathrm{Hf}^{\circ}$ at the corresponding concentrations.

The values of the the rmodynamic properties tabulated for the individual ions in aqueous solution are based on the usual convention that the values of $\triangle \mathrm{Hf}^{\circ}, \Delta \mathrm{Gf}^{\circ}, \mathrm{S}^{\circ}$ and $\mathrm{C}_{\mathrm{p}}{ }^{\circ}$ for $\mathrm{H}^{\perp}(\mathrm{aq}$, std. state, $\mathrm{m}=1$ ) are zero. The properties of a neutral electrolyte in aqueous solution in the standard state are equal to the algebraic sum of the se values for the appropriate kinds and number of individual ions assumed to constitute the molecule of the given electrolyte. When the undissociated species, rather than the sum of the ions, is meant, the notation "undissociated" or "un-ionized" is used. For an ionic species the properties tabulated refer to that undissociated ion. By adopting the above convention with respect to aqueous $\mathrm{H}^{+}$, it follows that the thermodynamic relation $\Delta \mathrm{Gf}{ }^{\circ}$ $=\Delta \mathrm{Hf}^{\circ}-\mathrm{T} \Delta \mathrm{Sf}^{\circ}$ will not hold for an individual ionic species. However no problem arises when neutral chemical systems are considered. 
All of the energy values given in these tables are expressed in terms of the thermochemical calorie. This unit, defined as equal to 4.1840 joules, is generally accepted for the presentation of chemical thermodynamic data. Values reported in other units have been converted to calories by means of the conversion factors for molecular energy given in Table A.

The following values of the fundamental physical constants have been used in these calculations:

$$
\begin{aligned}
& \mathrm{R}=\text { gas constant }=8.3143 \pm 0.0012 \mathrm{~J} / \mathrm{deg} \mathrm{mol}=1.98717 \pm 0.00029 \\
& F=\text { Faraday constant }=96487.0 \pm 1.6 \text { coulombs } / \mathrm{mol} \\
& \mathrm{cal} / \mathrm{deg} \mathrm{mol} \\
& =23060.9 \pm 0.4 \mathrm{cal} / \mathrm{volt} \text { equivalent } \\
& \mathbf{Z}=\mathrm{Nhc}=11.96258 \pm 0.00107 \mathrm{~J} / \mathrm{cm}^{-1} \mathrm{~mol}=2.85912 \pm 0.00026 \mathrm{cal} / \mathrm{cm}^{-1} \mathrm{~mol} \\
& \mathrm{c}_{2}=\text { second radiation constant }=\mathrm{hc} / \mathrm{k}=1.43879 \pm 0.00015 \mathrm{~cm} \mathrm{deg} \\
& 0^{\circ} \mathrm{C}=273.15^{\circ} \mathrm{K}
\end{aligned}
$$

These constants are consistent with those given in the Table of General Physical Constants, recommended by the National Academy of Sciences National Research Council ${ }^{1}$. The formula weights in the tables have been calculated for the molecular formula given in the Formula and Description column using the 1961 Table of Relative Atomic Weights based on the atomic mass of ${ }^{12} \mathrm{C}=12$ exactly ${ }^{2}$.

\section{Internal Consistency of the Tables}

All of the values given in these tables have been calculated from the original articles, using consistent values for all subsidiary and auxiliary quantities. The original data were corrected where possible for differences in energy units, molecular weights, temperature scales, etc. Thus we have sought to maintain a uniform scale of energies for all the substances in the tables. In addition the tabulated values of the properties of a substance satisfy all the known physical and thermodynamic relationships among these properties. The quantities $\Delta \mathrm{Hf}^{\circ}, \Delta \mathrm{Gf}^{\circ}$, and $\mathrm{S}^{\circ}$ at $298.15^{\circ} \mathrm{K}$ satisfy the relation:

$$
\Delta \mathrm{Gf}^{\circ}=\Delta \mathrm{Hf}^{\circ}-\mathrm{T} \Delta \mathrm{Sf}^{\circ} .
$$

INBS Technical News Bulletin, October 1963.

${ }^{2}$ A. E. Cameron and E. Wichers, J. Am. Chem. Soc. 84, 4192 (1962). 
Furthermore the calculated value of any thermodynamic quantity for a reaction is independent of the path chosen for the evaluation.

In some cases newer data may have become available on certain substances after the values were selected for these tables. Because of the need to maintain the internal consistency of the tables, it is not always possible to incorporate the se newer data into the tables without a detailed analysis of the effect of such a change. Unless great care is used, relatively significant errors in calculated values of $\Delta H^{\circ}$ or $\Delta G^{\circ}$ for specific reactions may result from the introduction of such data.

\section{Uncertainties}

The uncertainty in any value in the tables depends on the uncertainties of all the determinations in the total chain of reactions used to establish the value.

A discussion of the uncertainties will be included in the final publication of these tables in the National Standard Reference Data System. However we have followed certain rules with respect to significant figures to indicate these uncertainties. Values are tabulated in general such that the overall uncertainty lies between 2 and 20 units of the last figure. On the other hand, values are given so that the experimental data from which they are derived may be recovered with an accuracy equal to that of the original quantities. Thus the number of significant figures for any one value in the tables need not represent the absolute accuracy of that value. For solutions of varying composition values are frequently tabulated to more figures to make possible the recovery of enthalpies of solution and dilution. Similarly values of $\Delta \mathrm{Hf}_{0}^{\circ}$ and $\Delta \mathrm{Hf}_{298.15}^{\circ}$ may be given to different numbers of significant figures. In this instance the quantity with the lesser number of figures is used to represent the uncertainty estimate. The larger number of figures is used for the other quantity to retain the significance of the temperature correction term.

\section{Arrangement of the Tables}

The compounds in the tables are entered according to the Standard Order of Arrangement; (see Figure 1), by the principle of latest position. In this scheme, a compound is listed under the element occurring latest in the list; water of hydration is neglected. Within a given elementtable will be found all of the compounds of that element with elements occurring earlier in the order; the arrangement within a table follows the same ordering. An exception occurs in the carbon tables (Table 23), which is divided into subgroups consisting of all compounds with one carbon atom, then all with two carbon atoms, etc. 


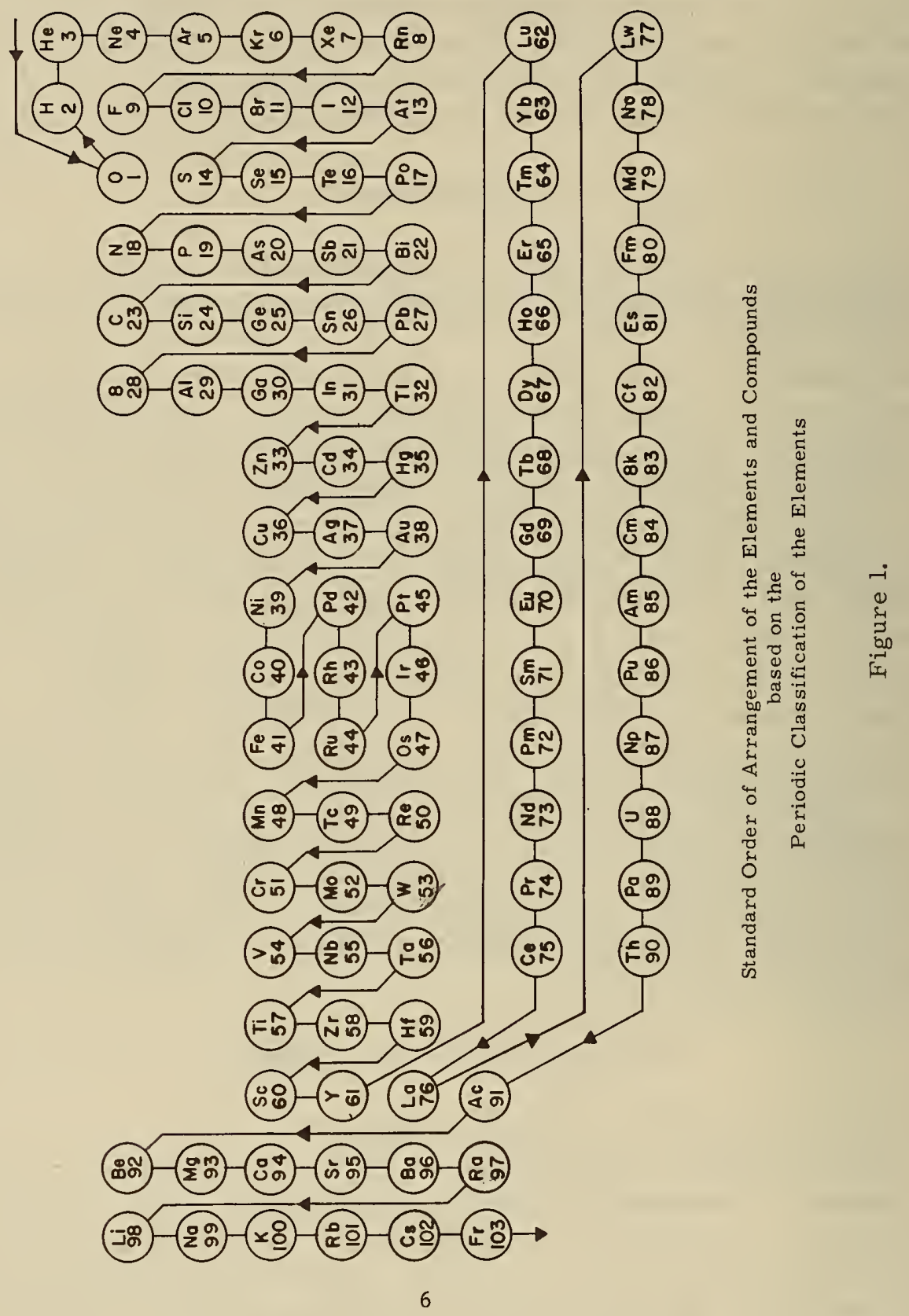




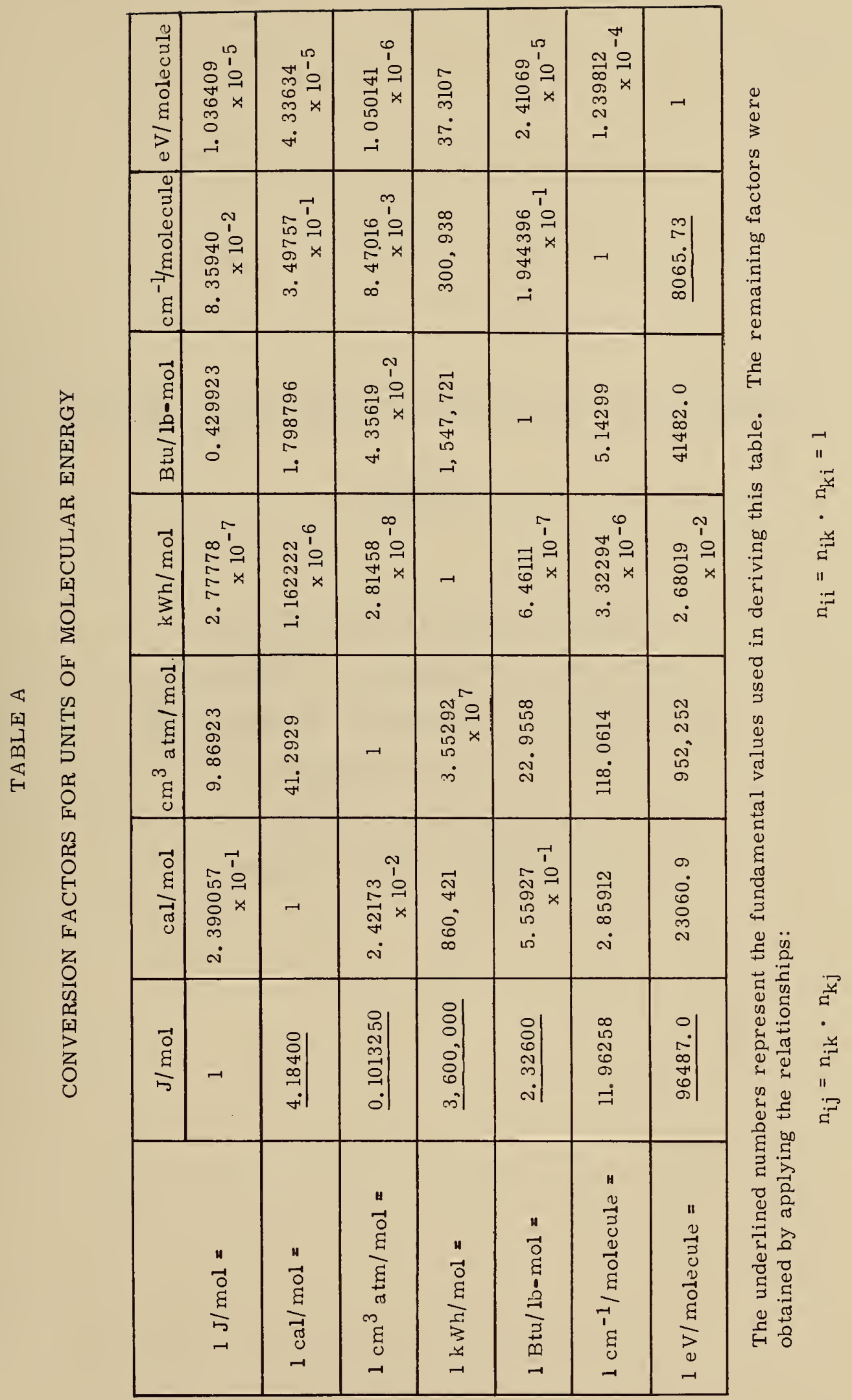



TABLES OF SELECTED VALUES OF PROPERTIES

\section{SERIES I}

Enthalpy of Formation at $0^{\circ} \mathrm{K}$ Enthalpy of Formation at $298.15^{\circ} \mathrm{K}$

Gibbs Energy of Formation at $298.15^{\circ} \mathrm{K}$

Enthalpy at $298.15^{\circ} \mathrm{K}$

Entropy at $298.15^{\circ} \mathrm{K}$

Heat Capacity at $298.15^{\circ} \mathrm{K}$ 



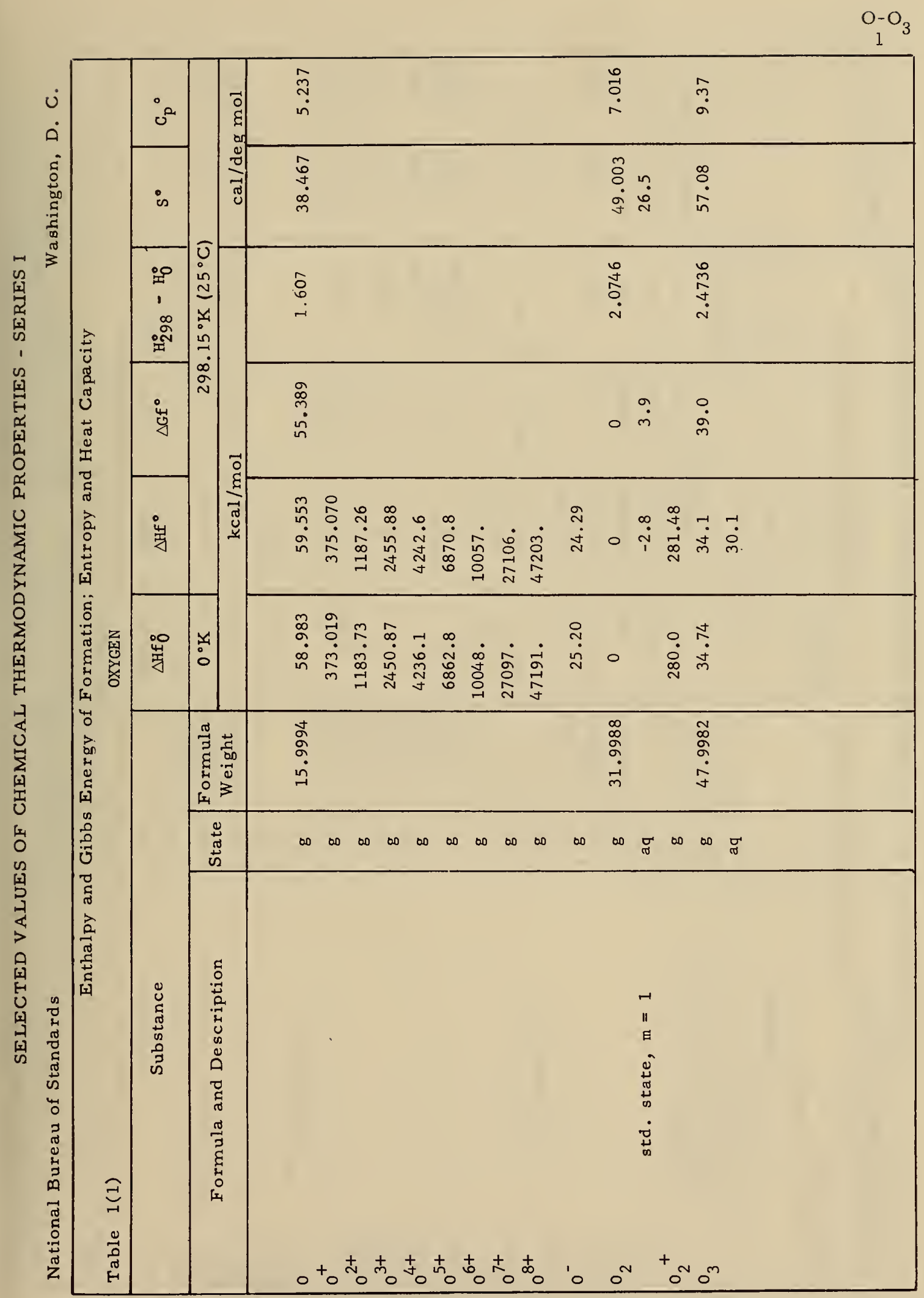




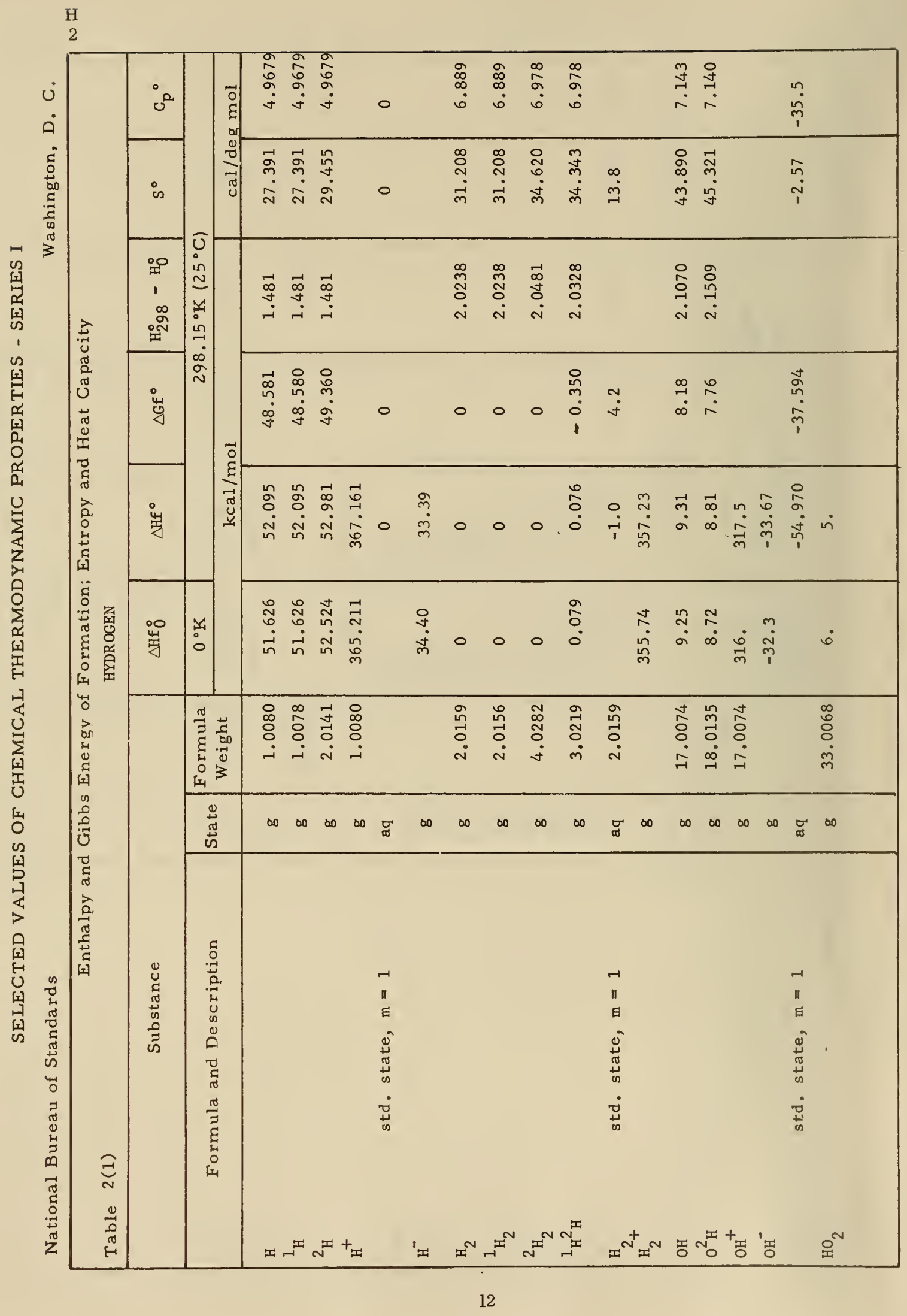




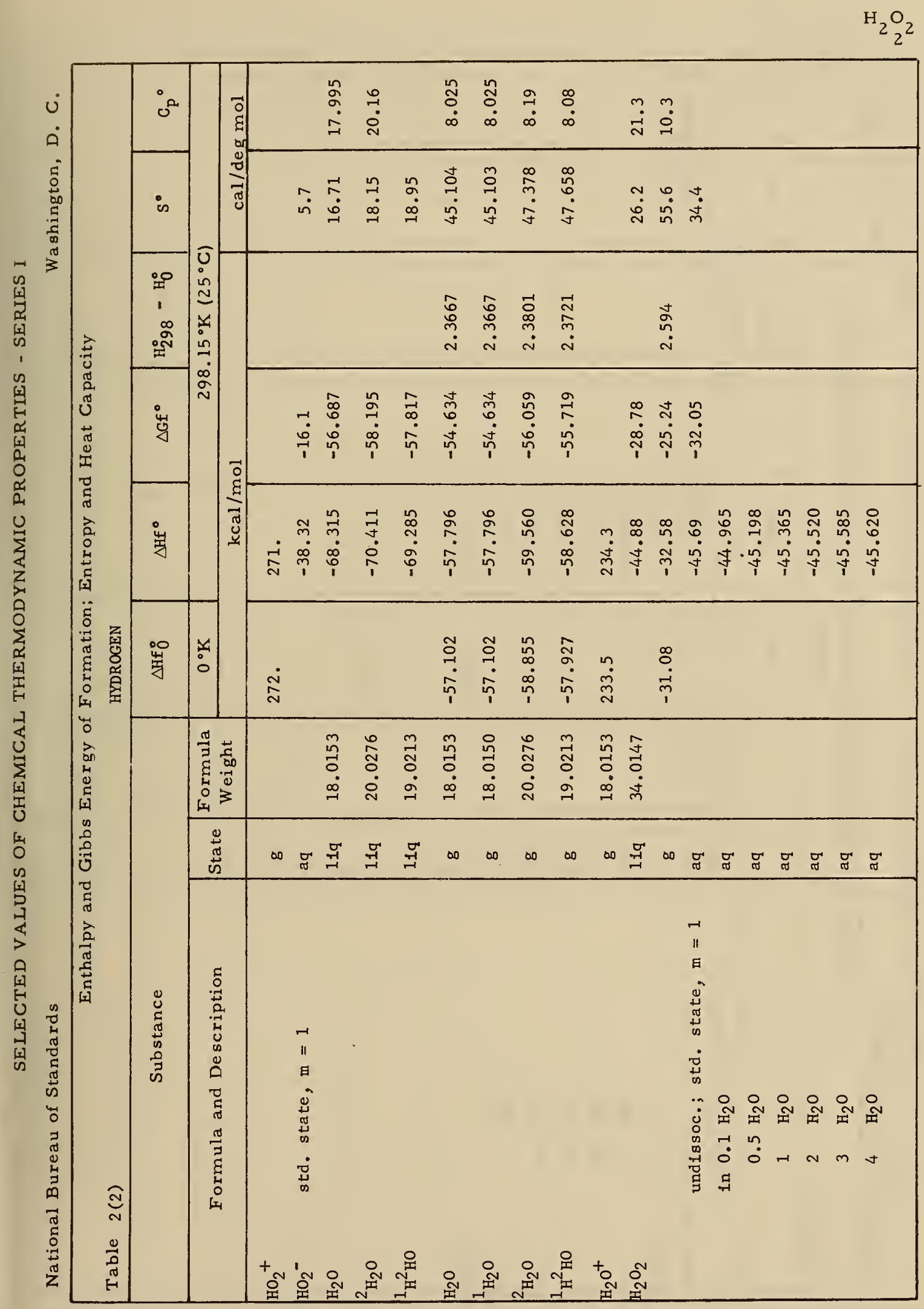




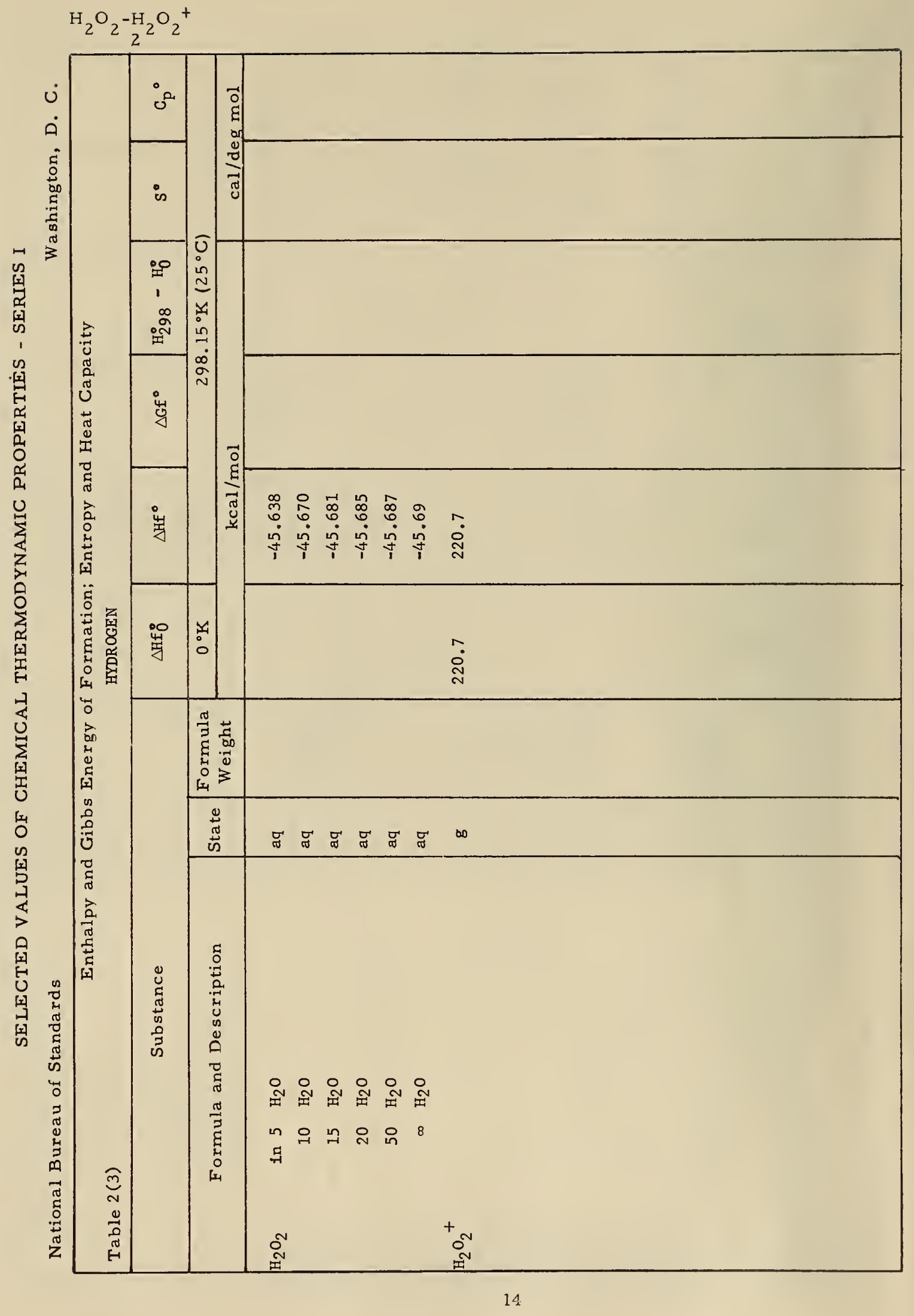




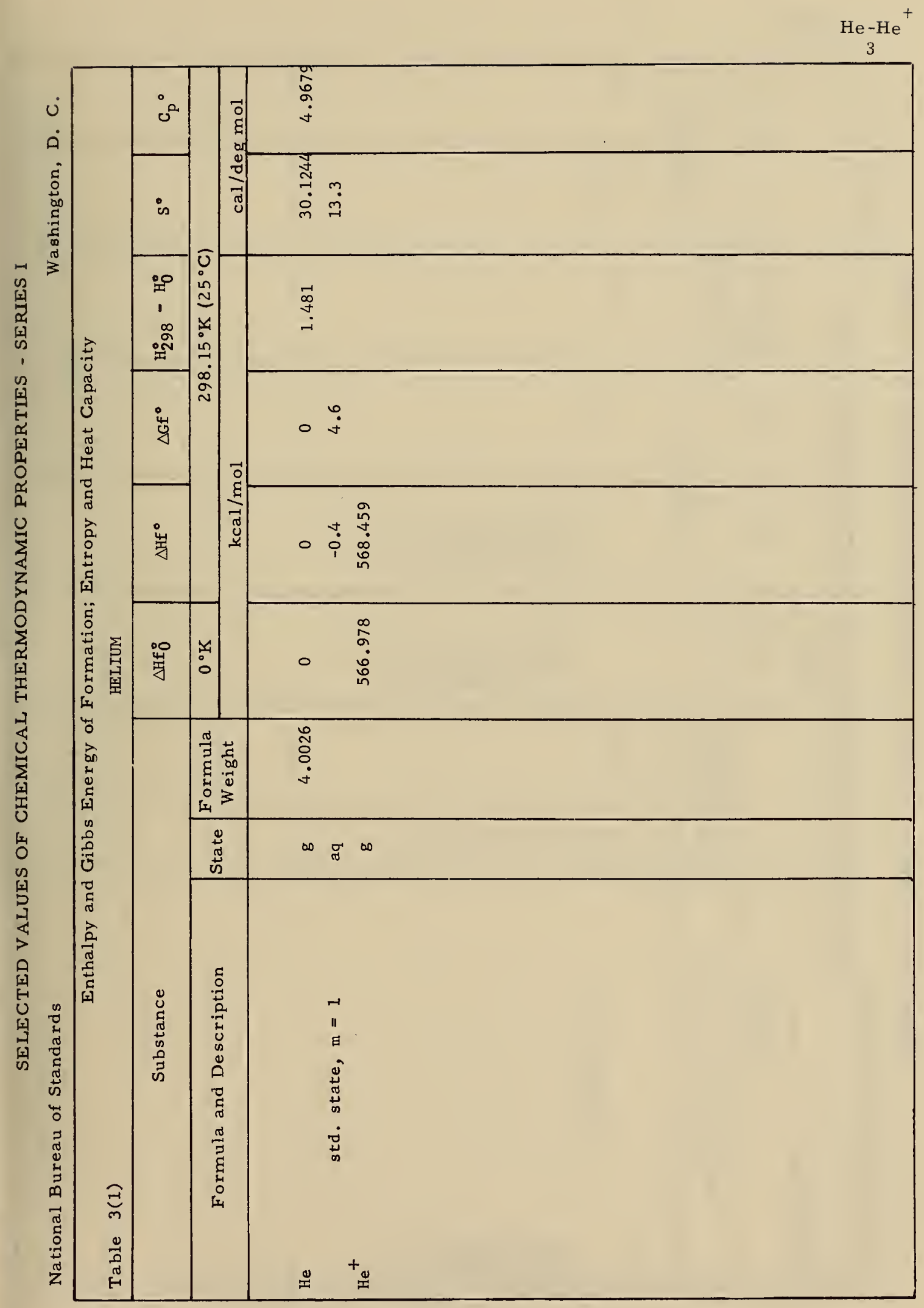




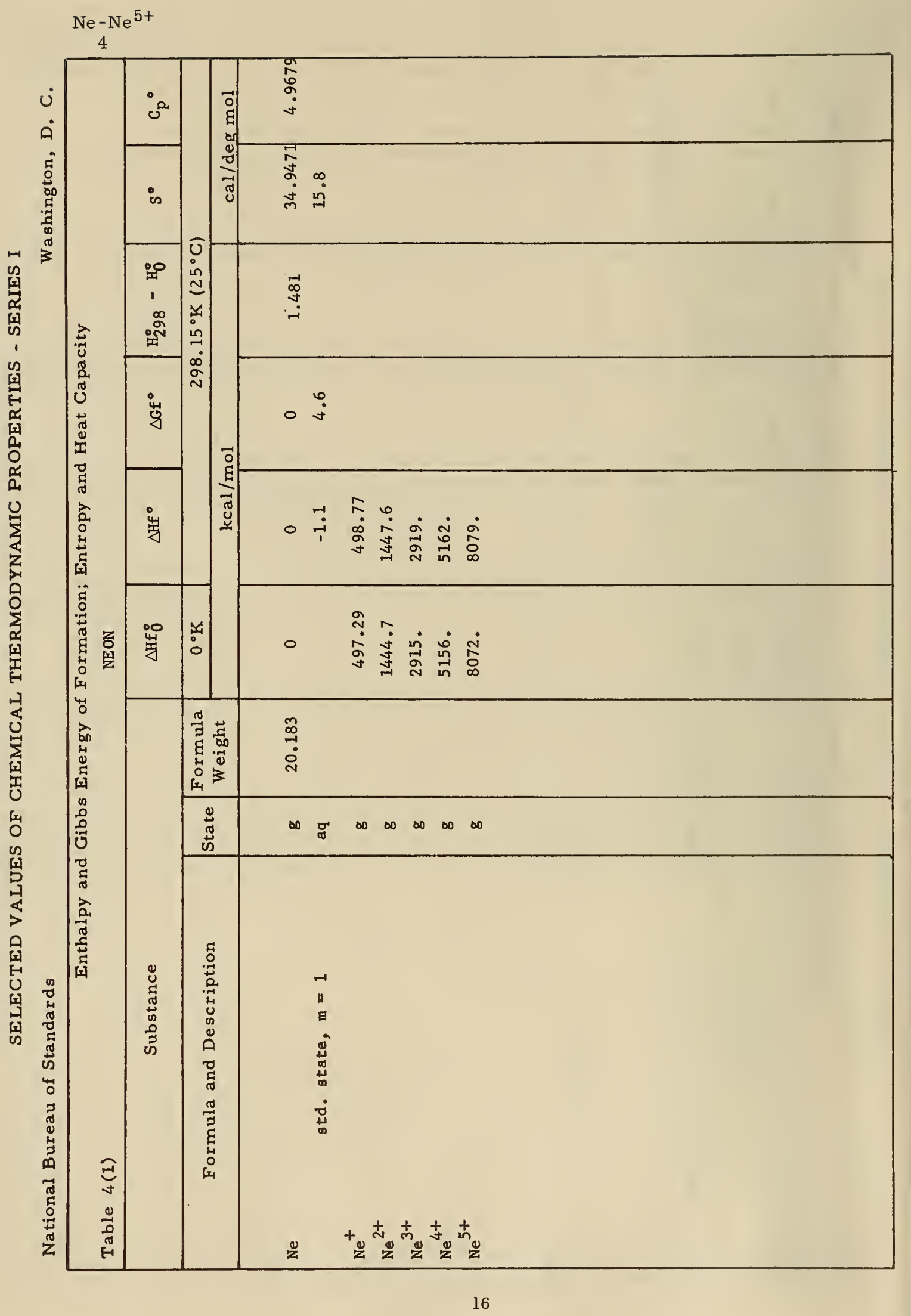




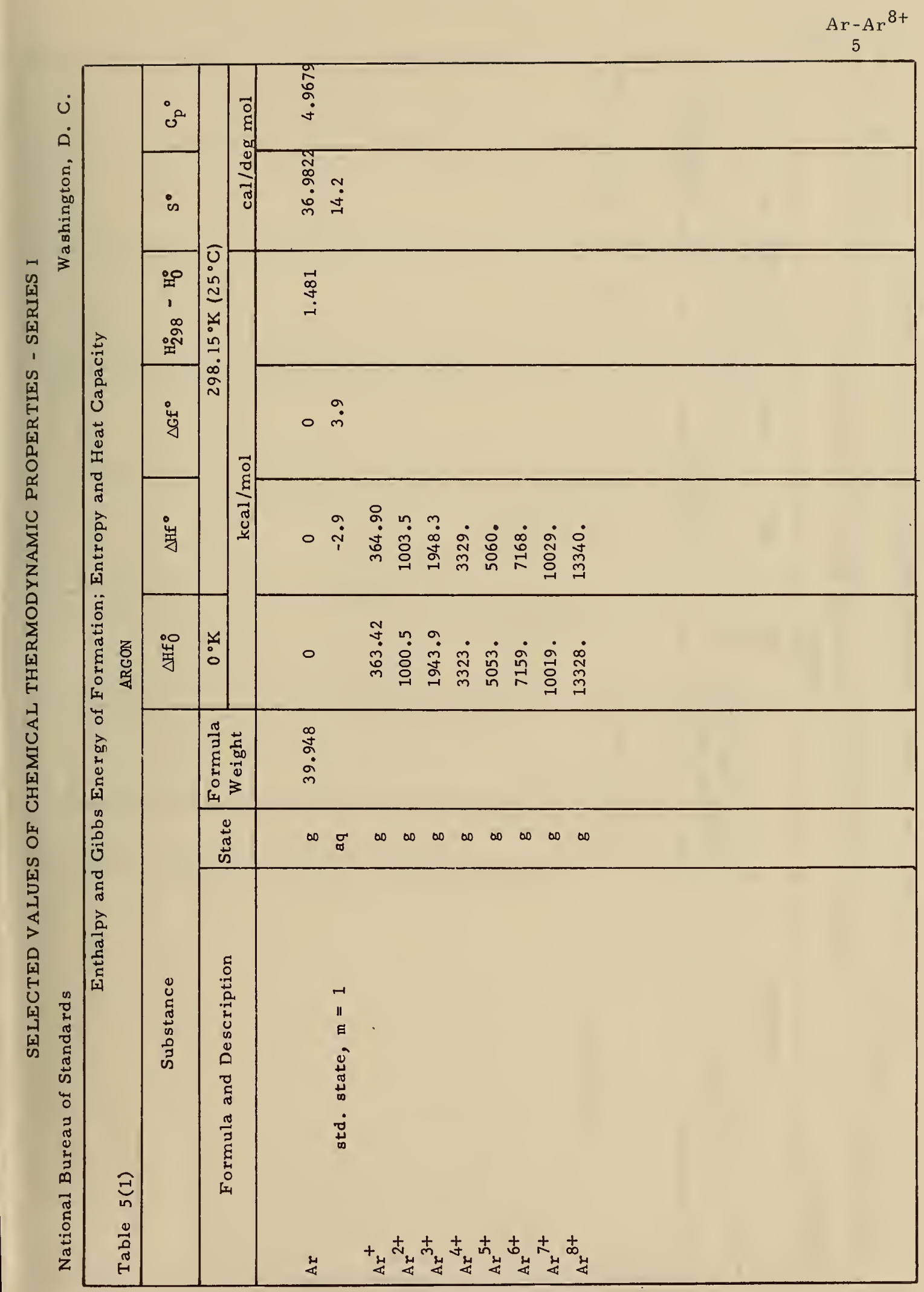




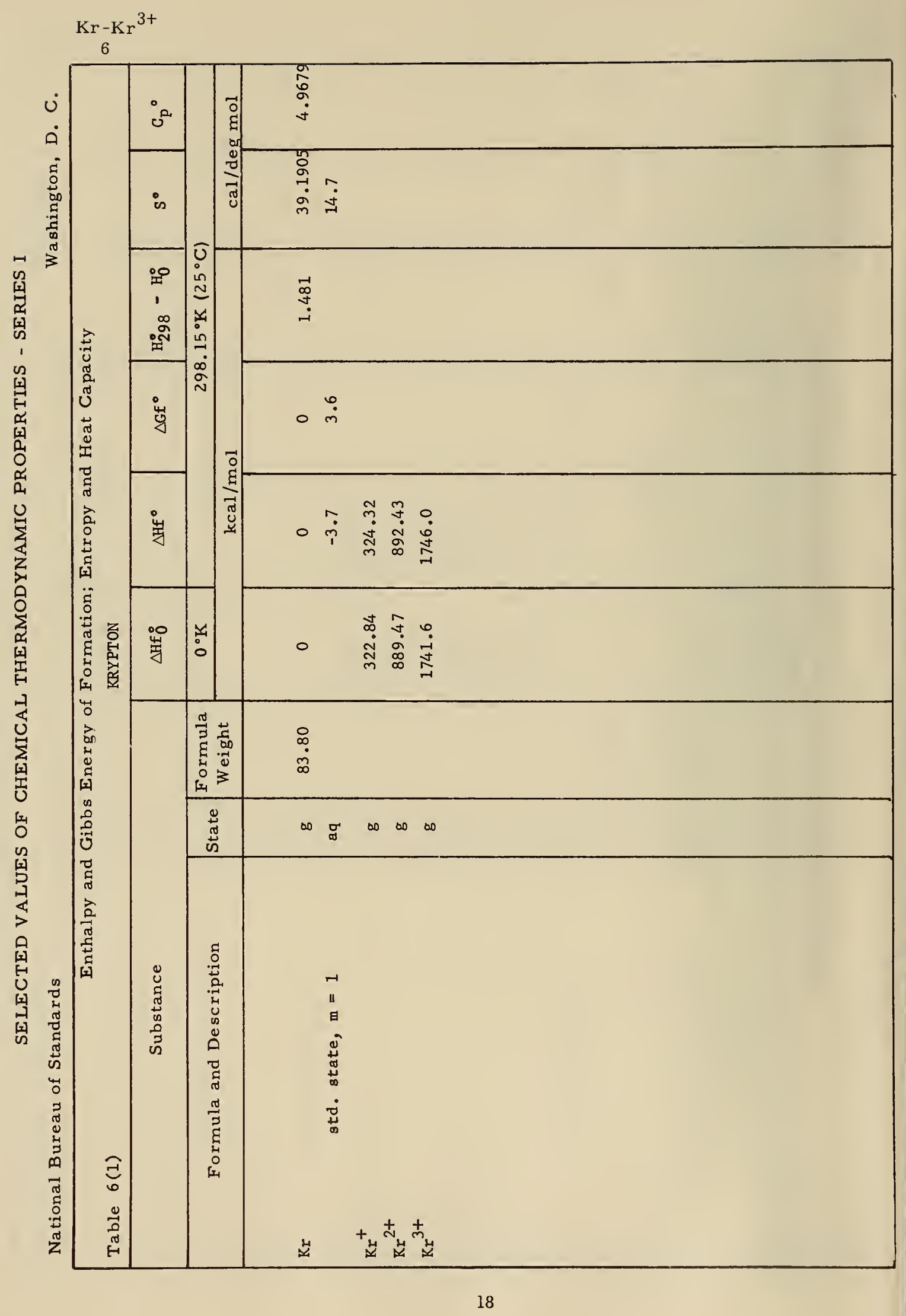




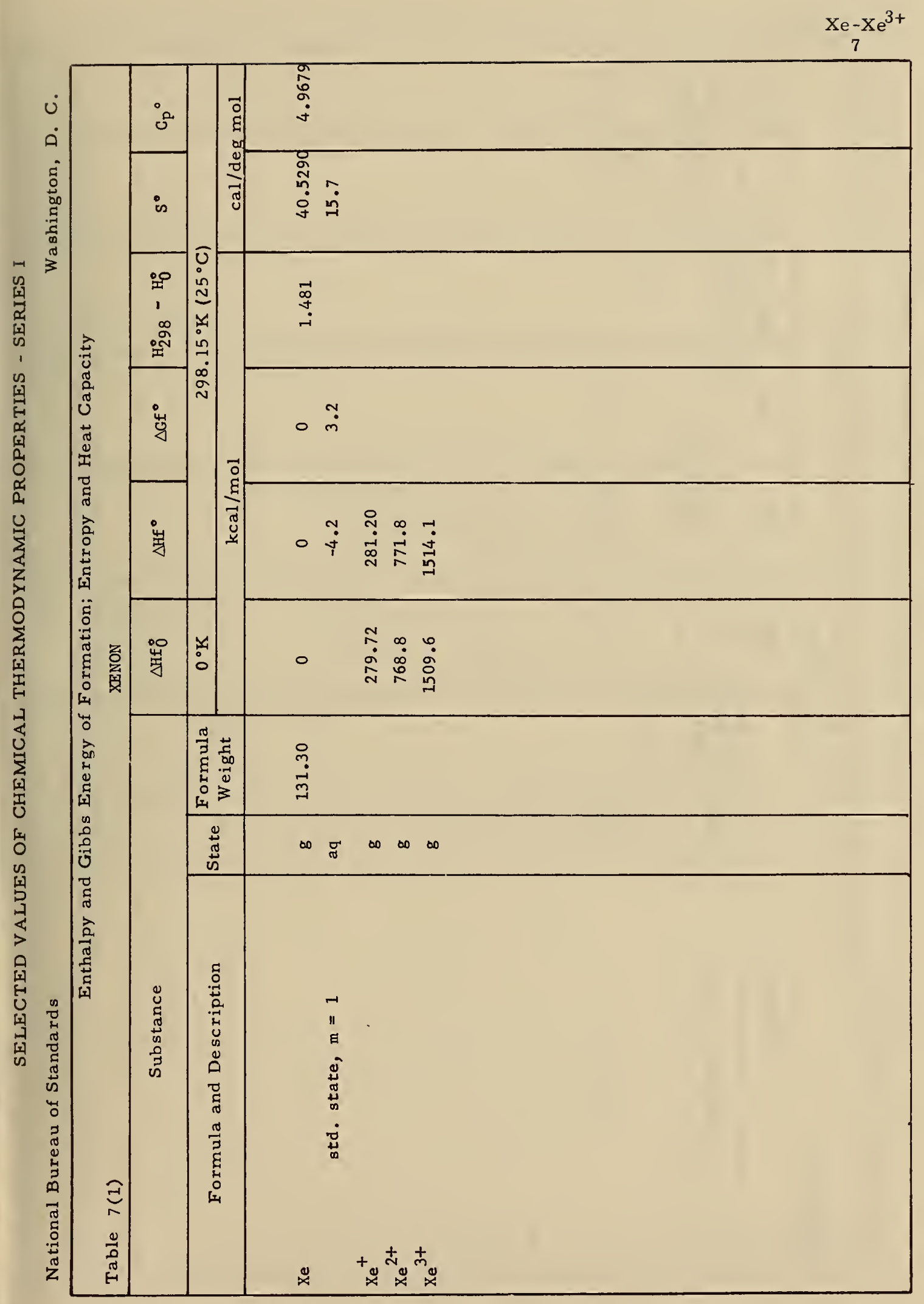




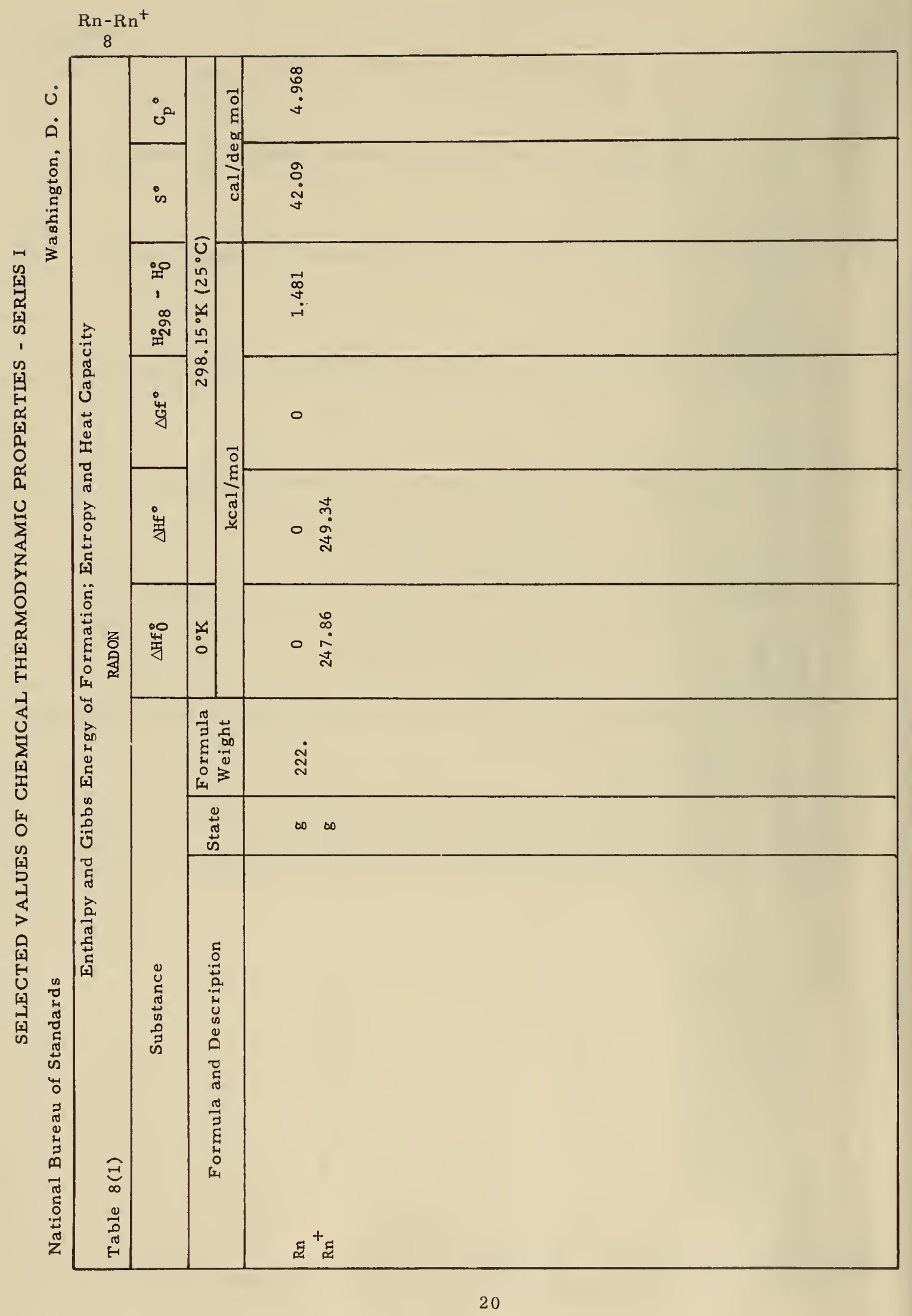




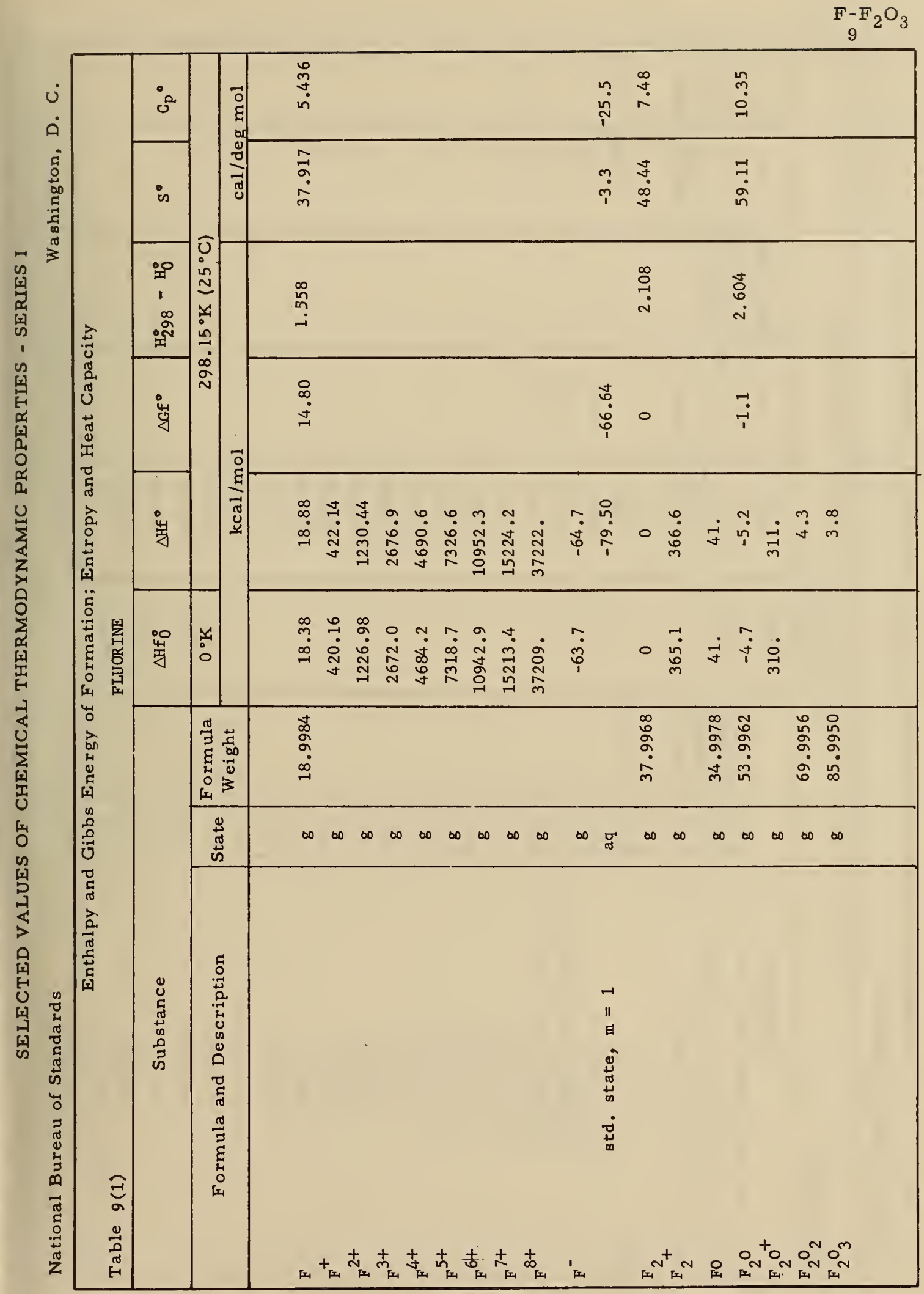




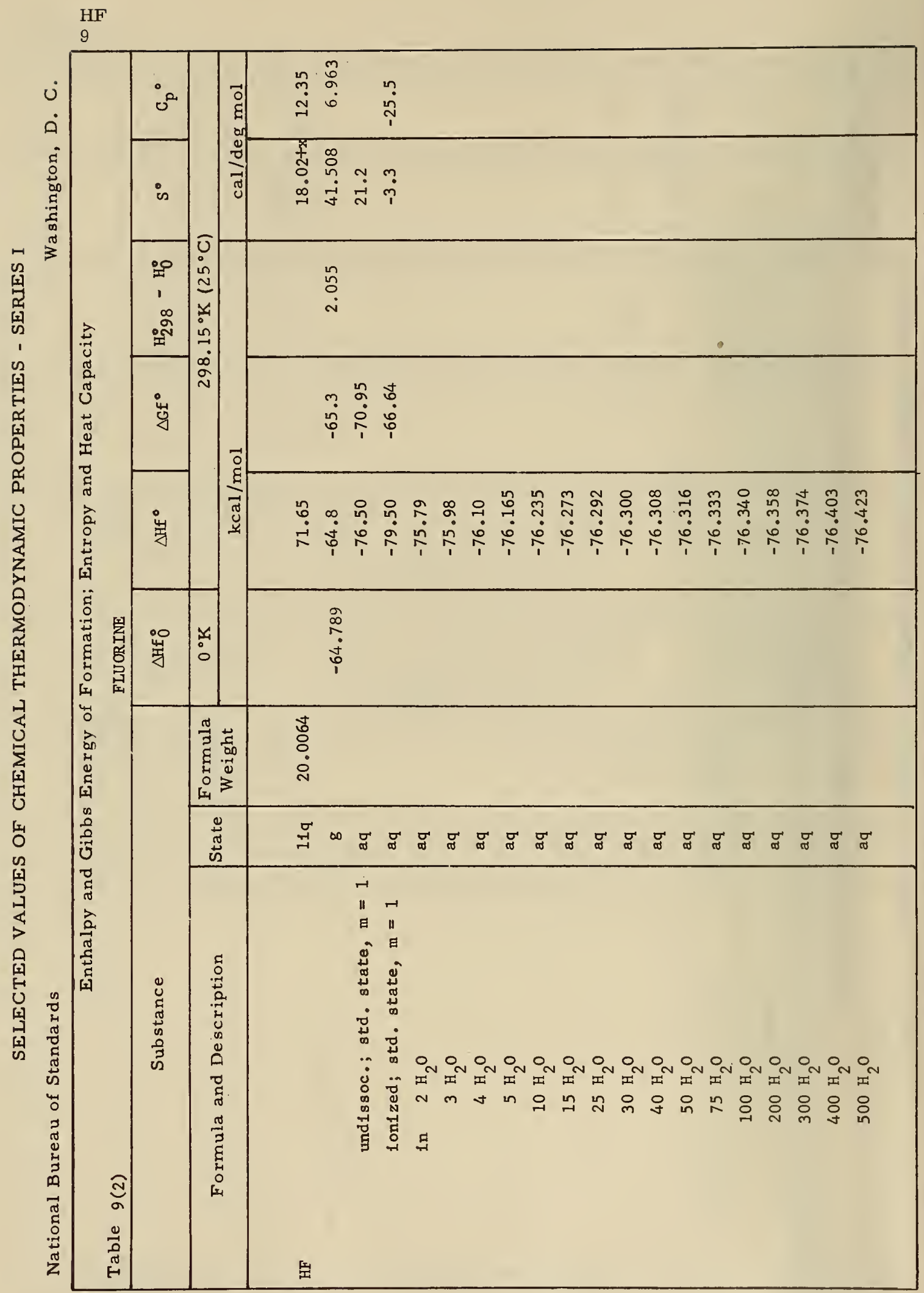




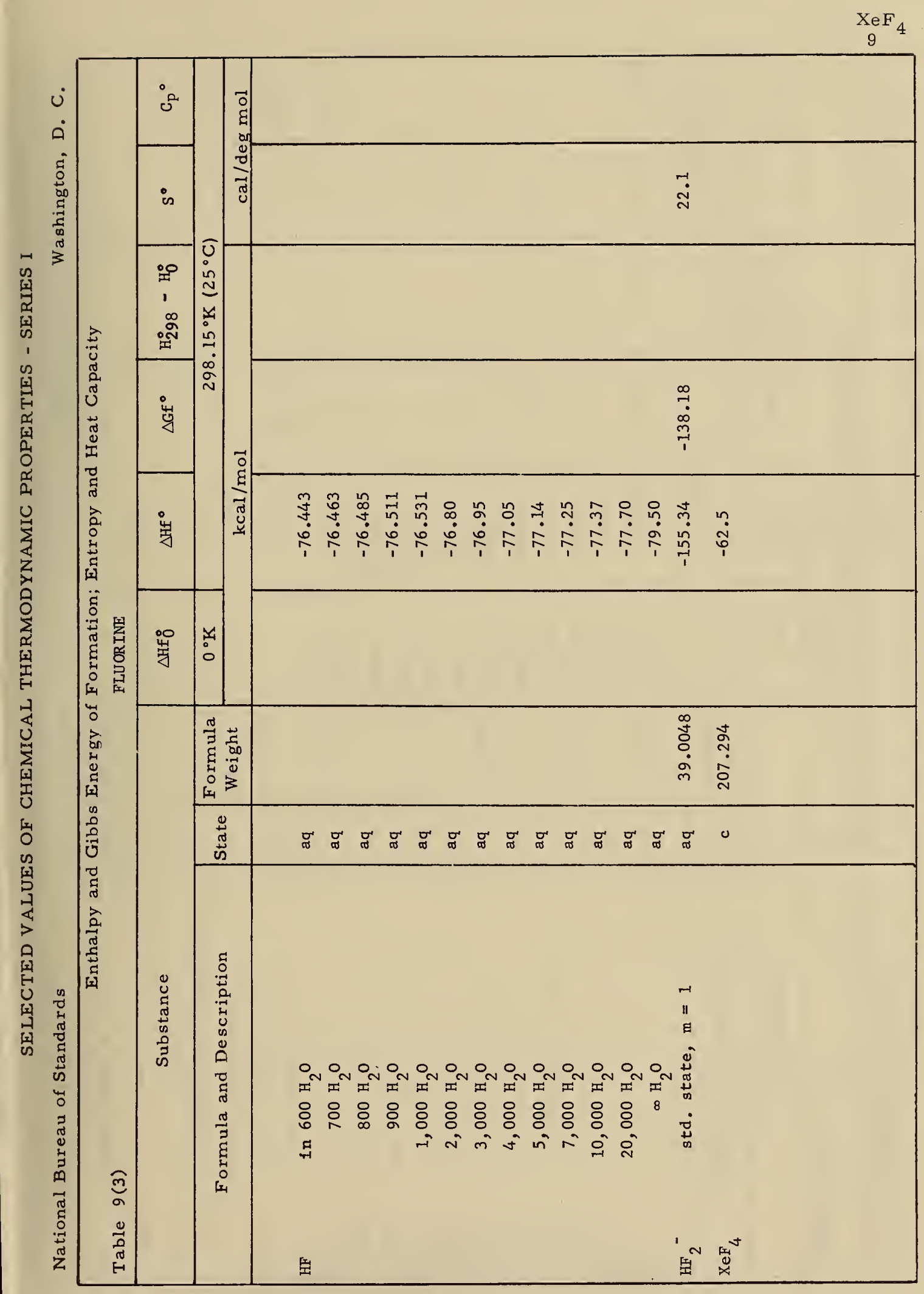




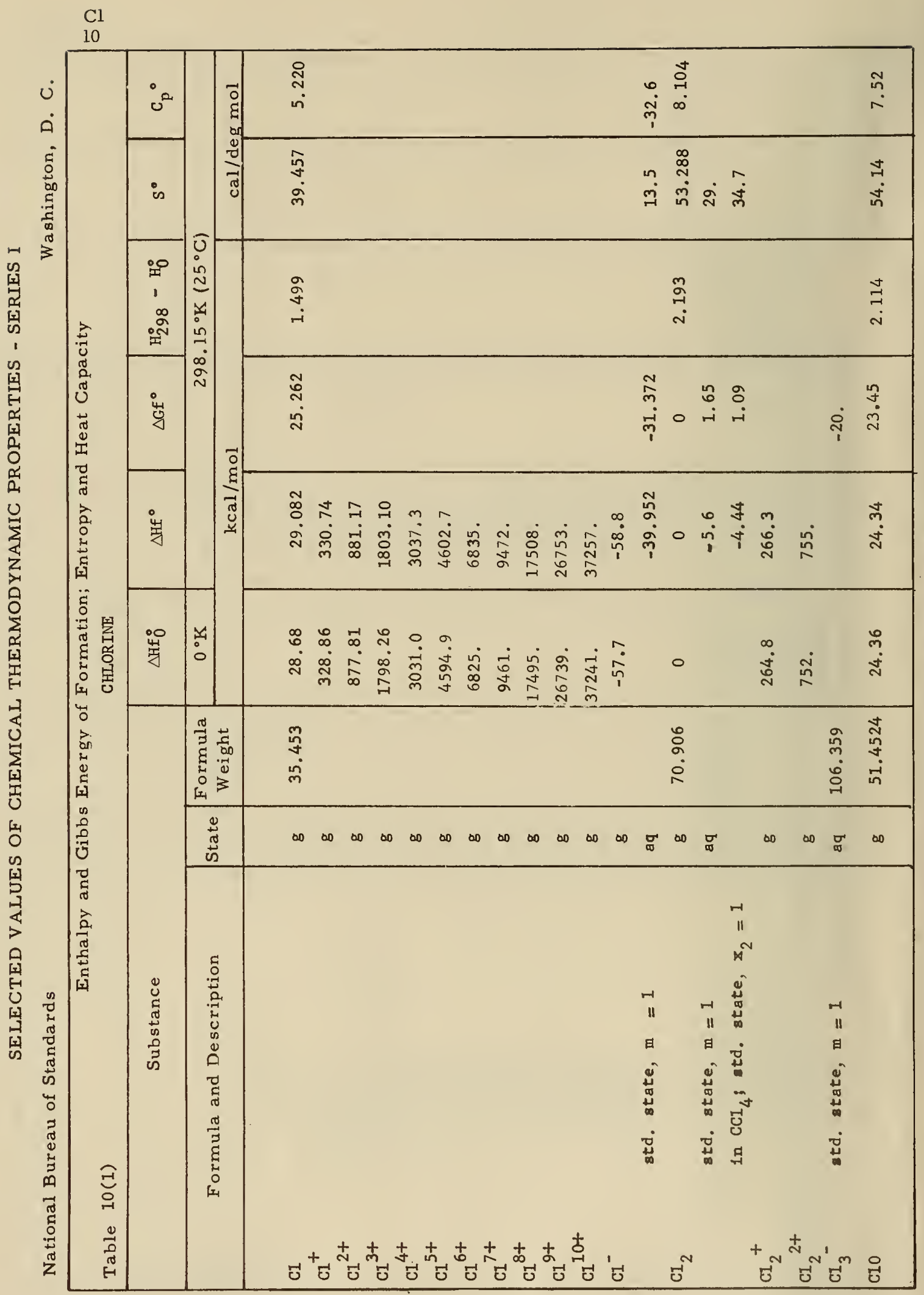




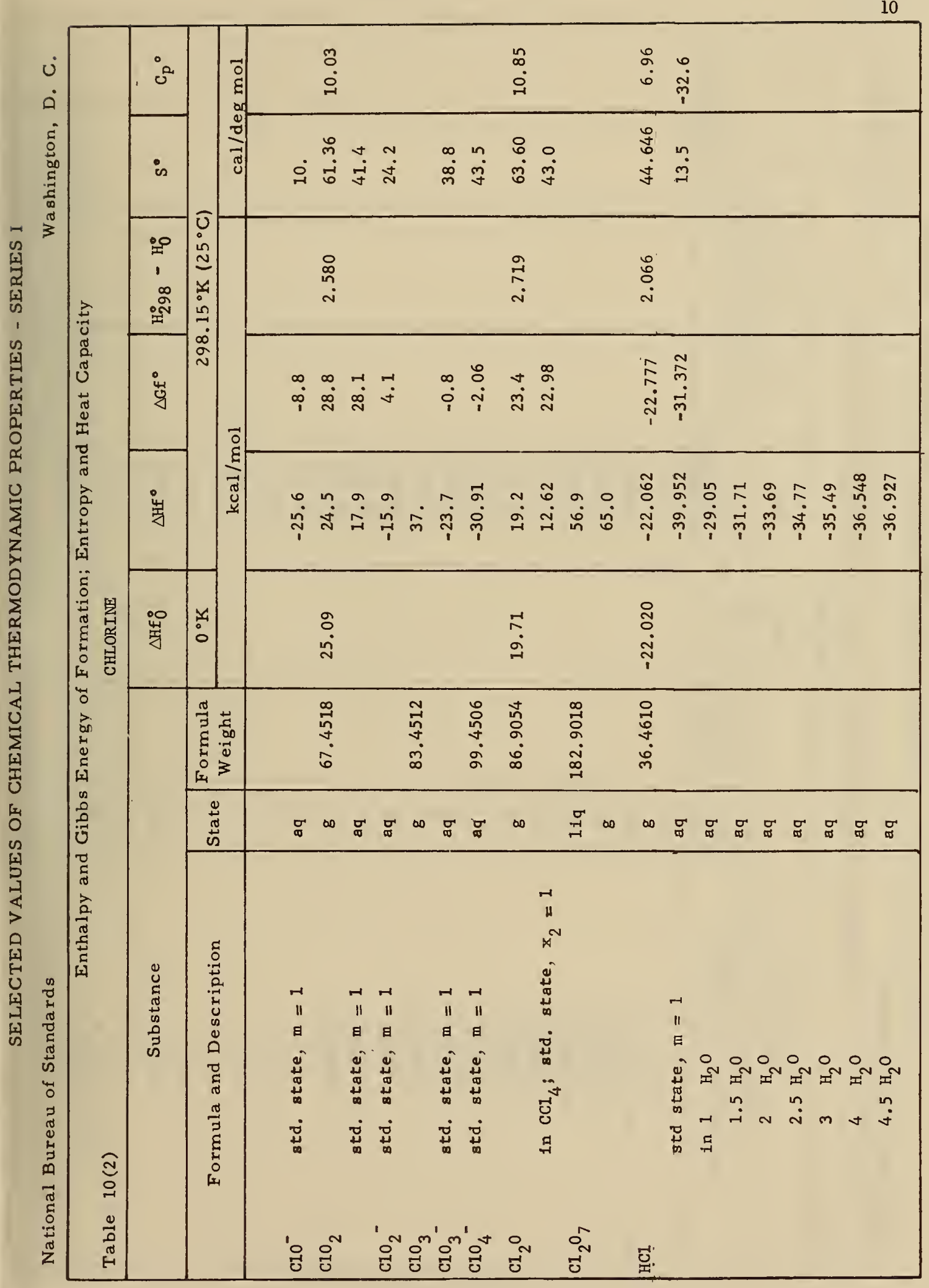




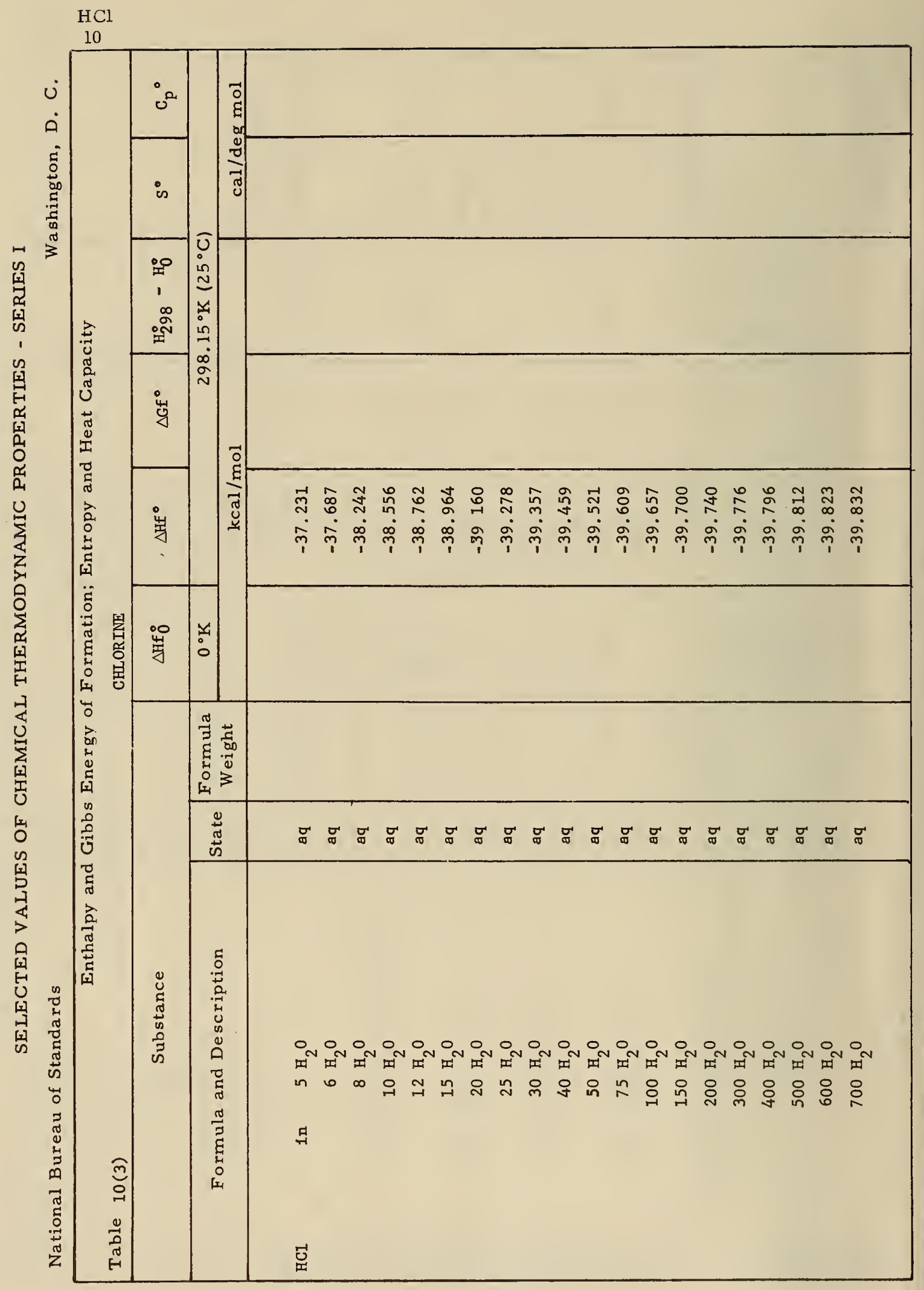




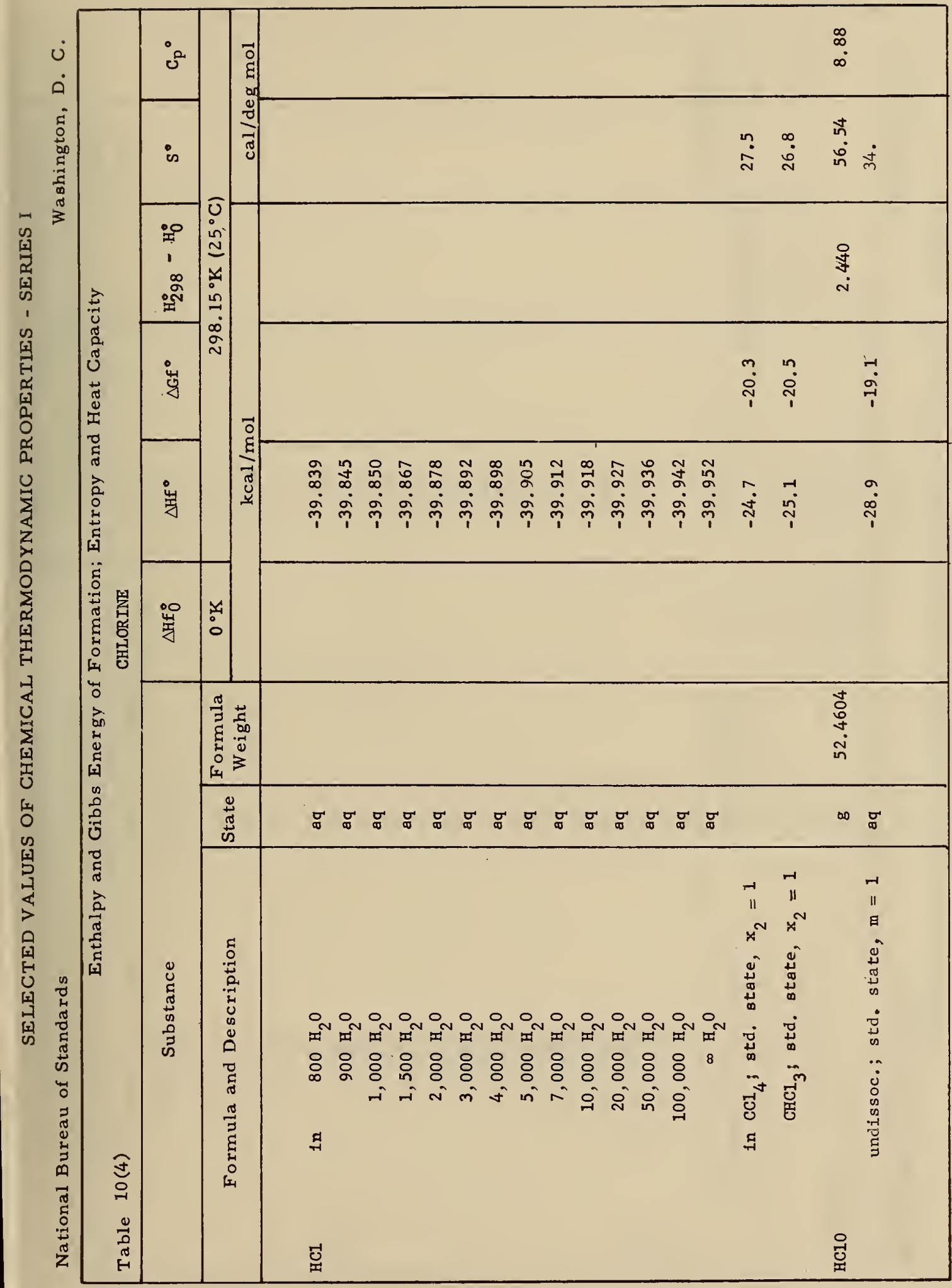




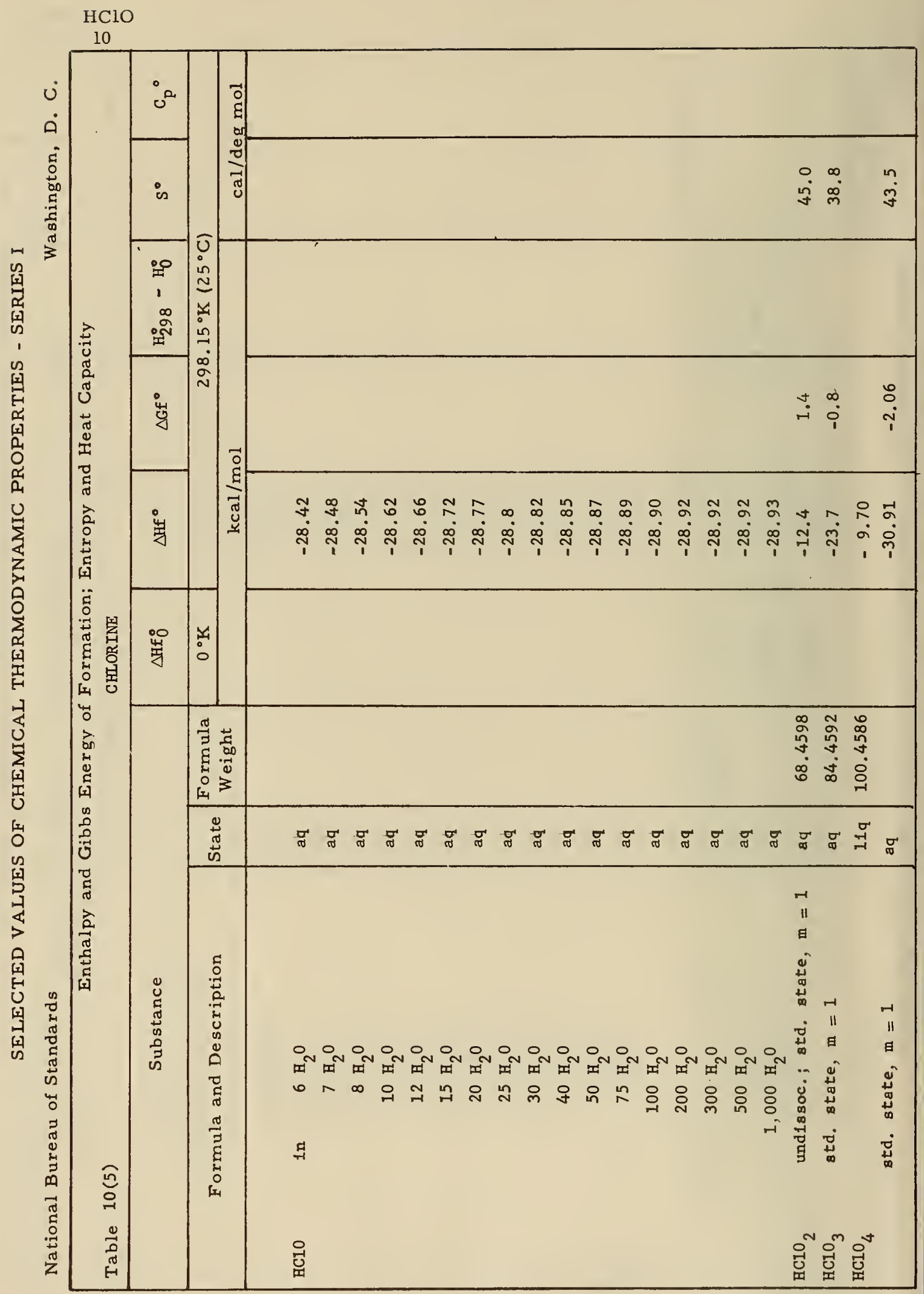




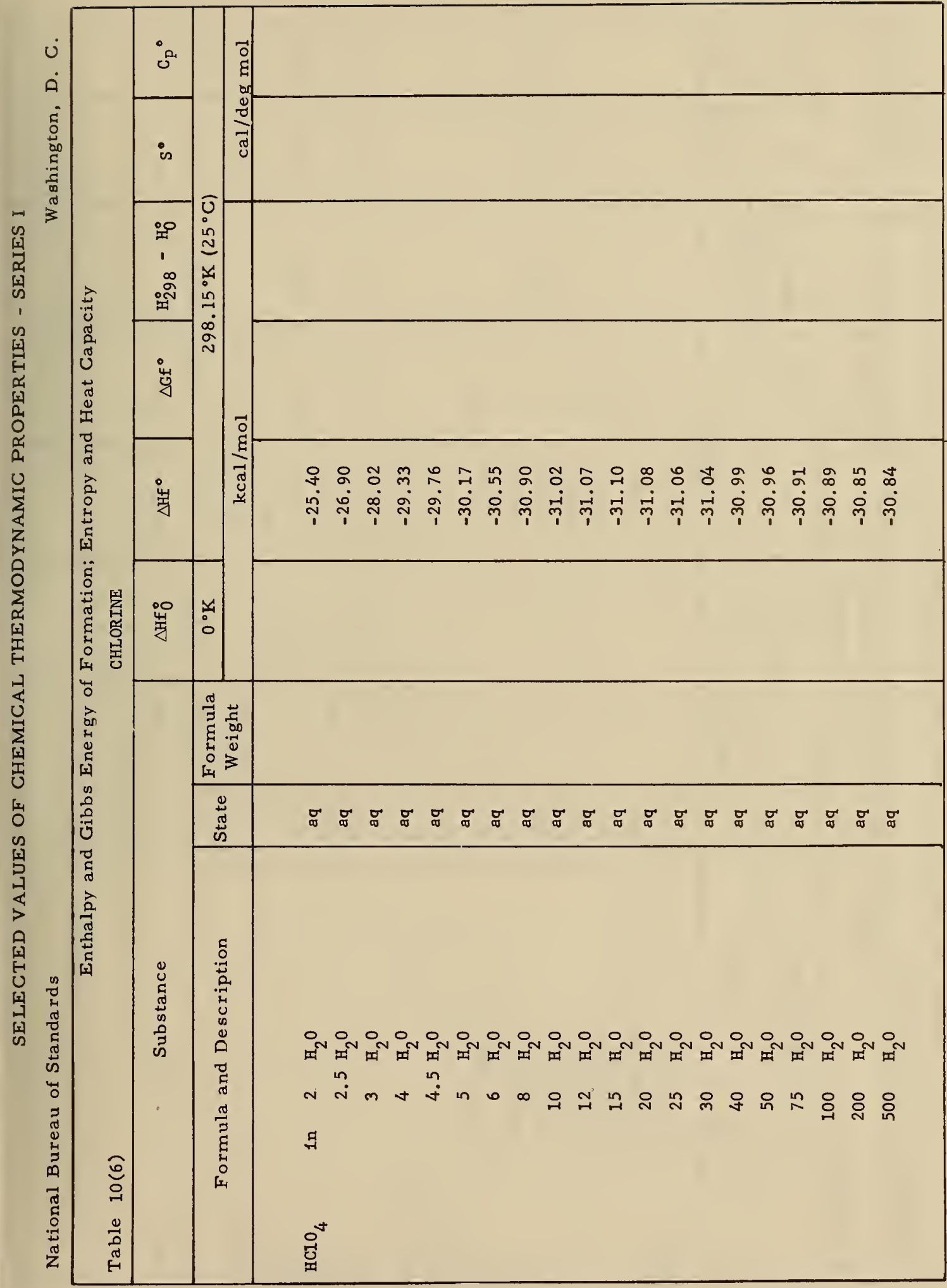




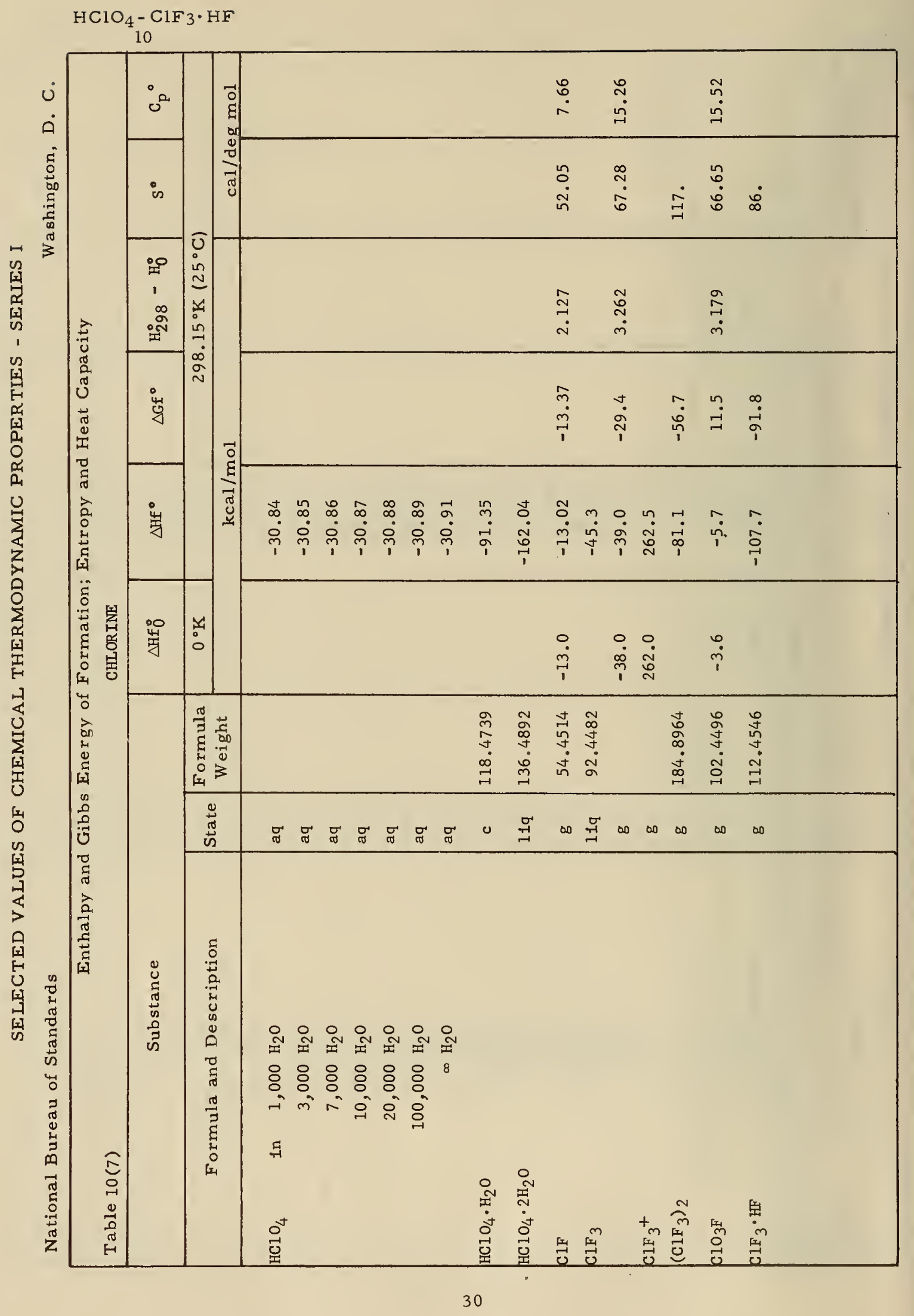




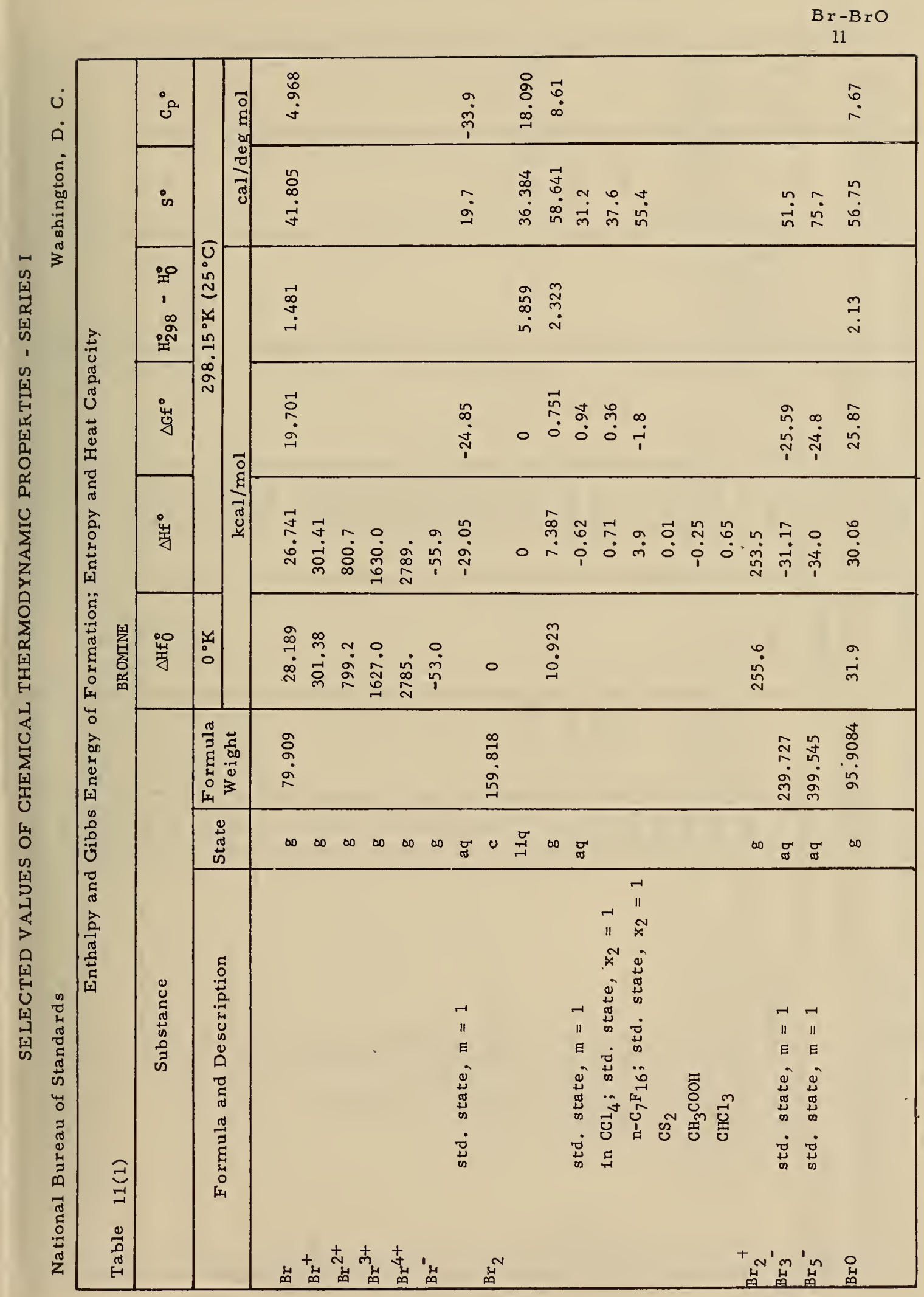




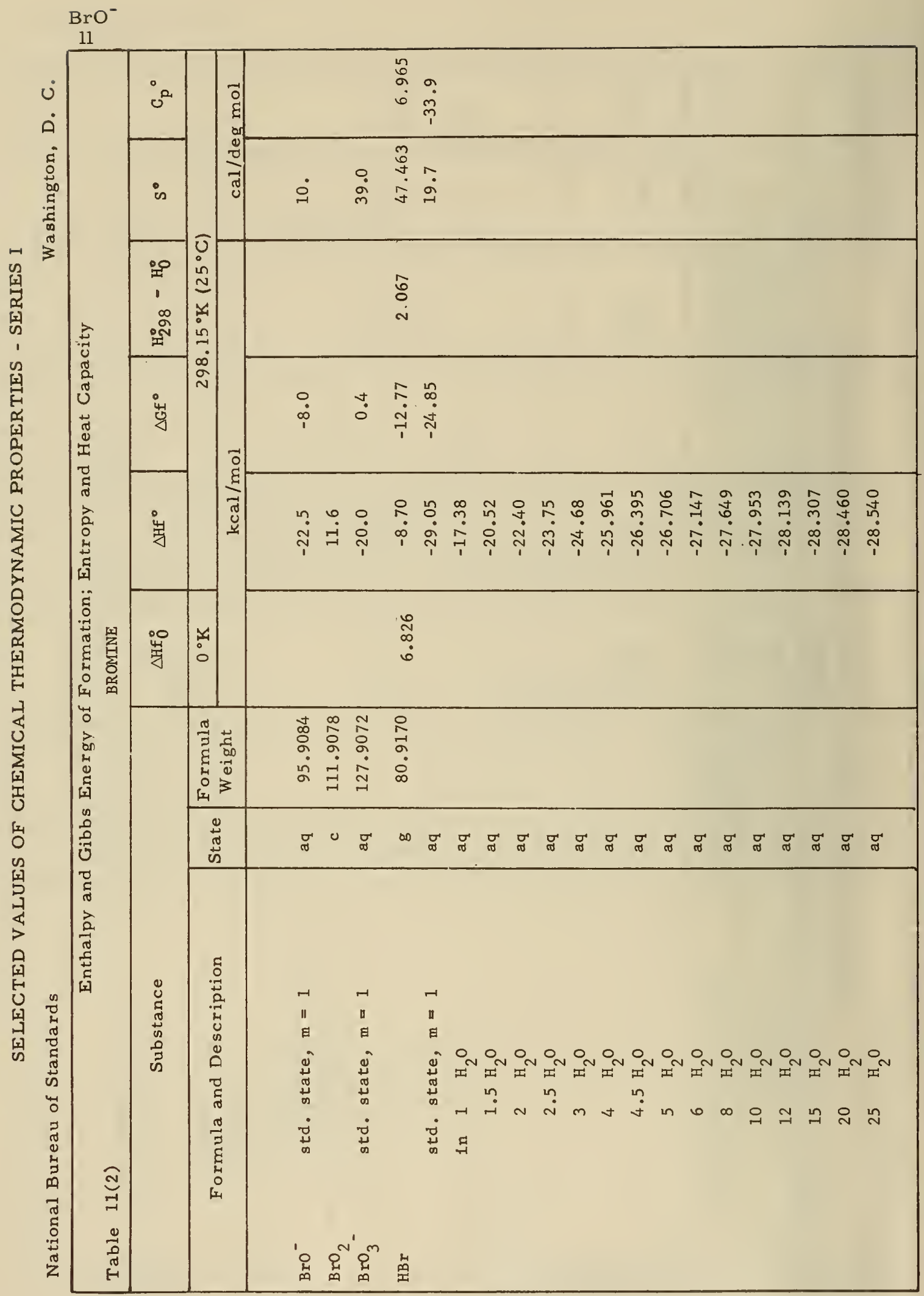




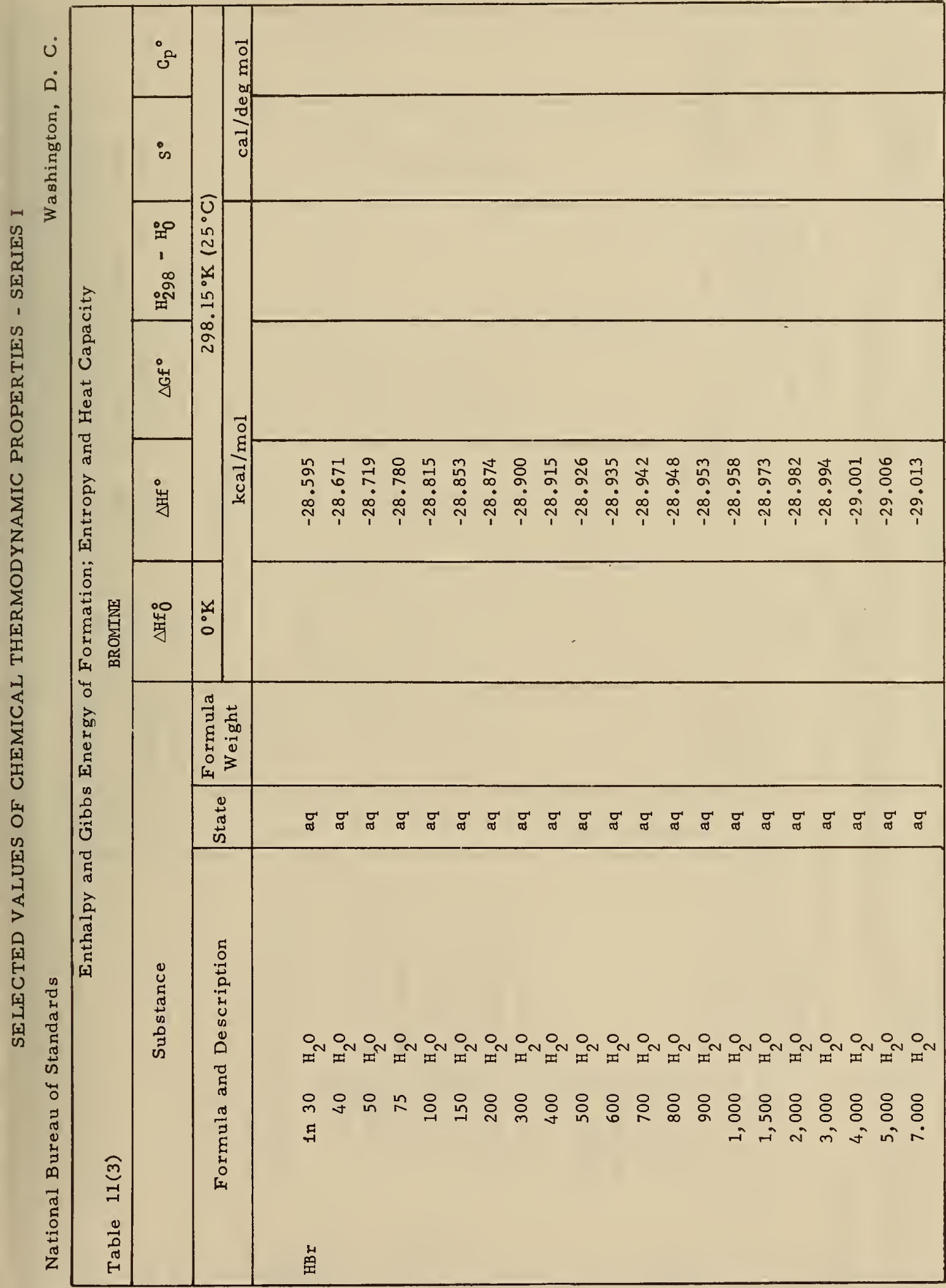




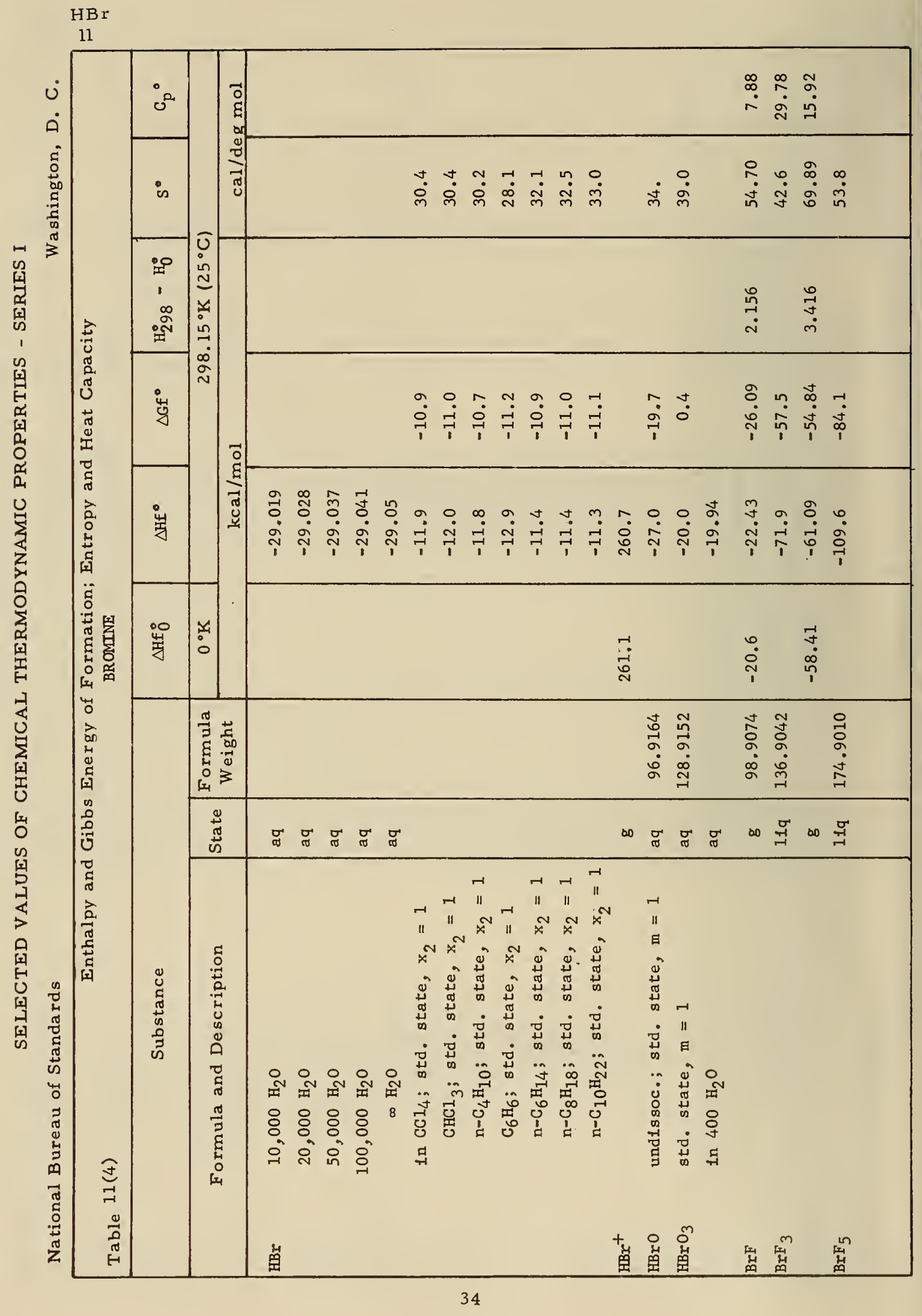




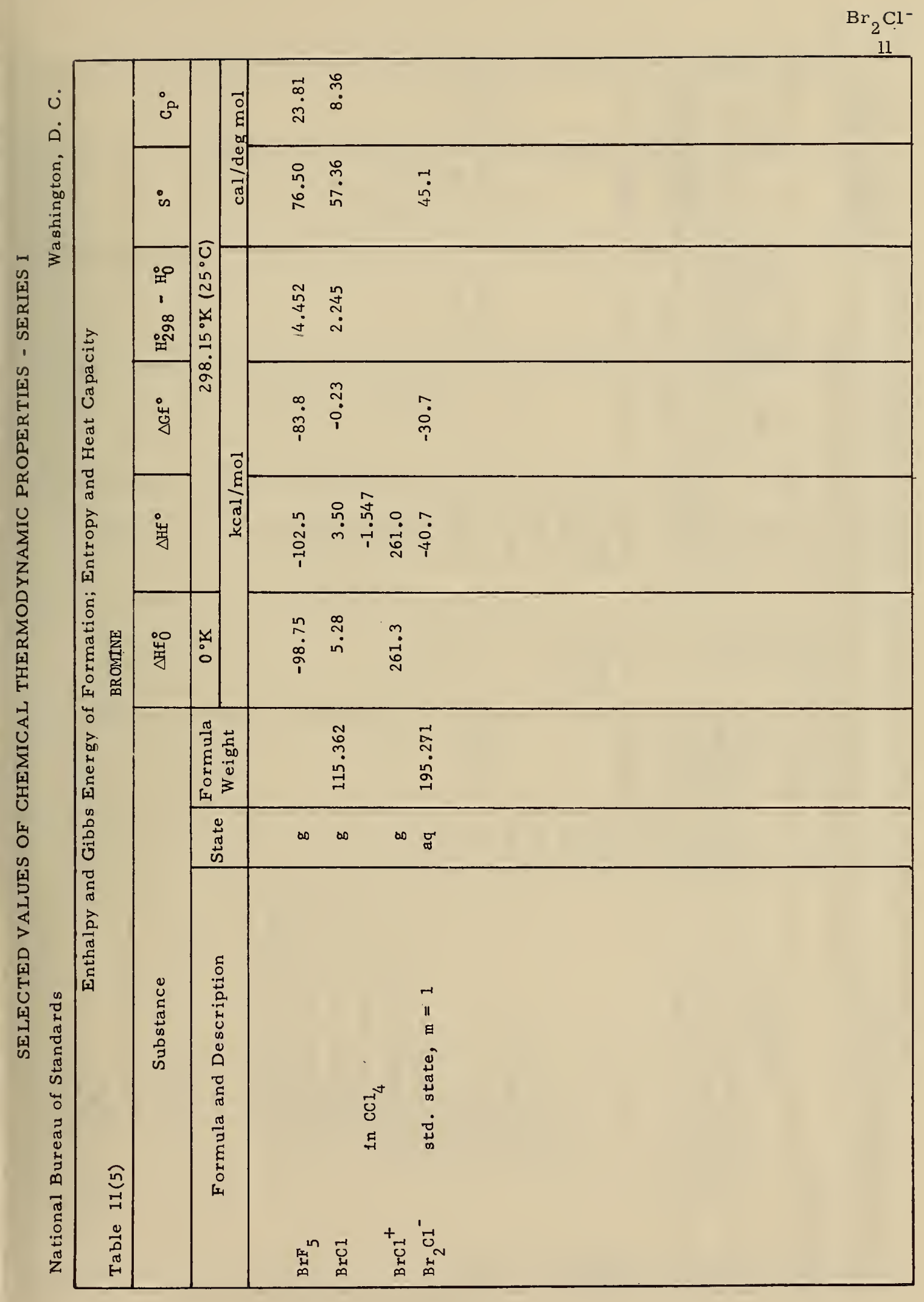




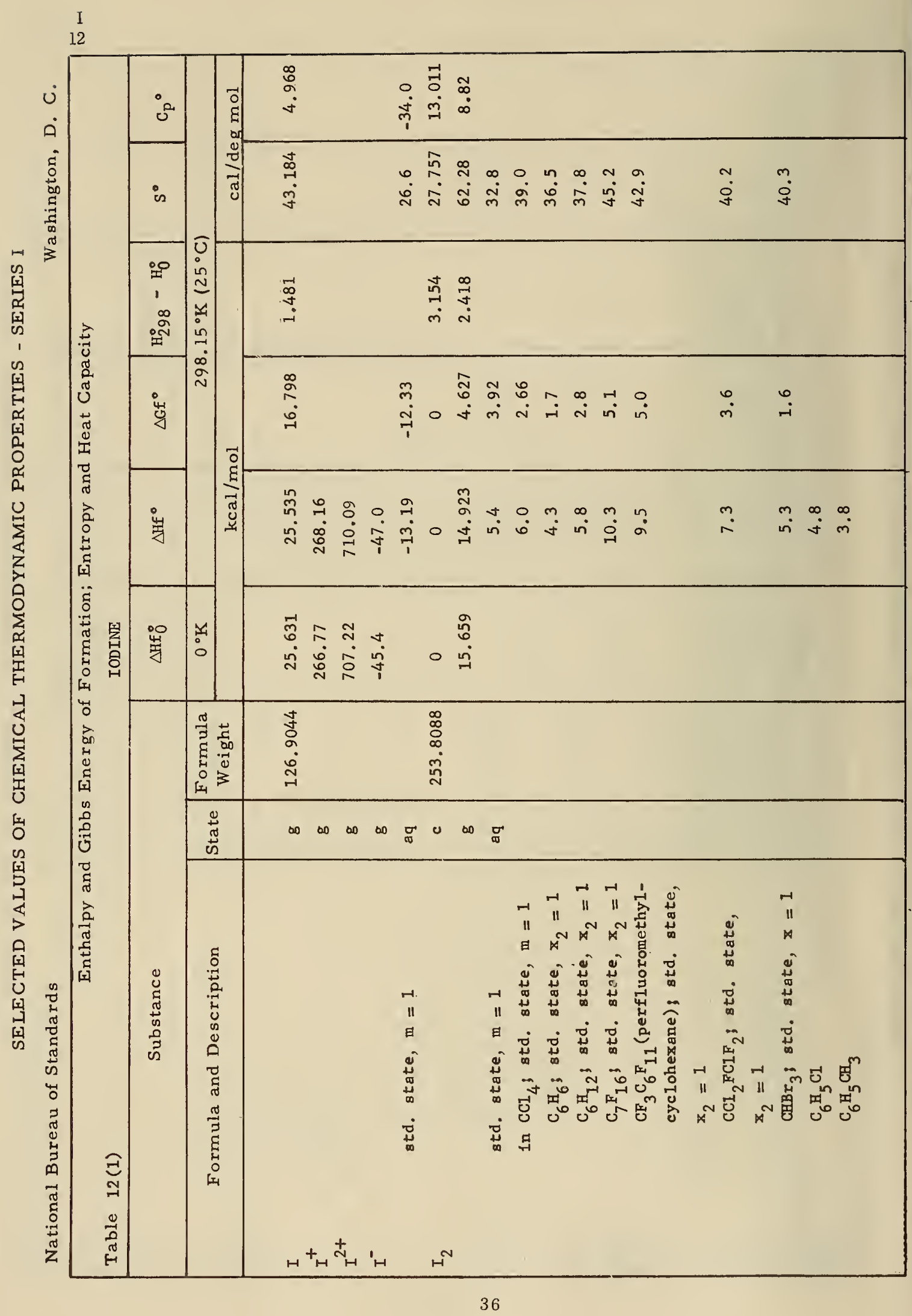




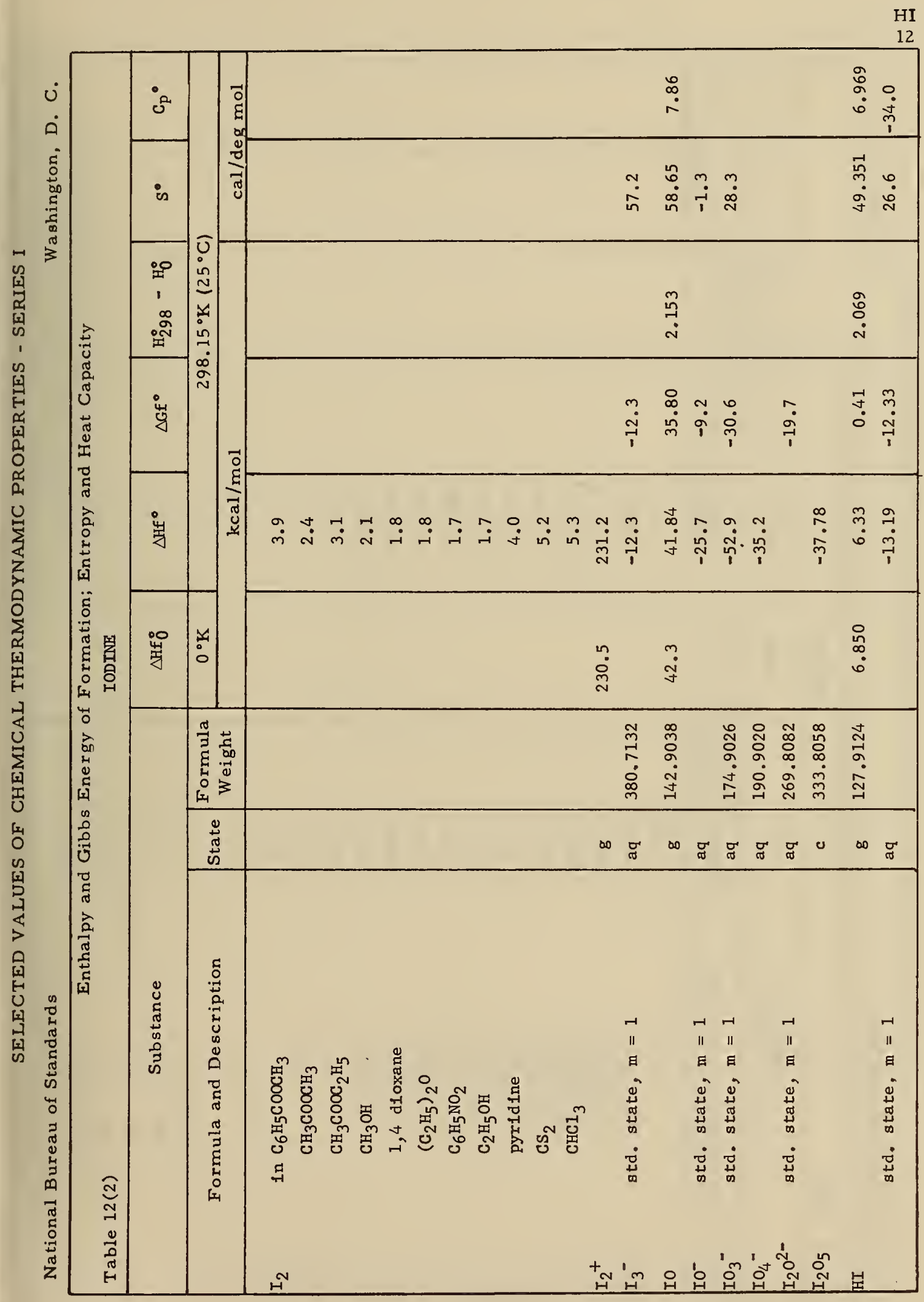




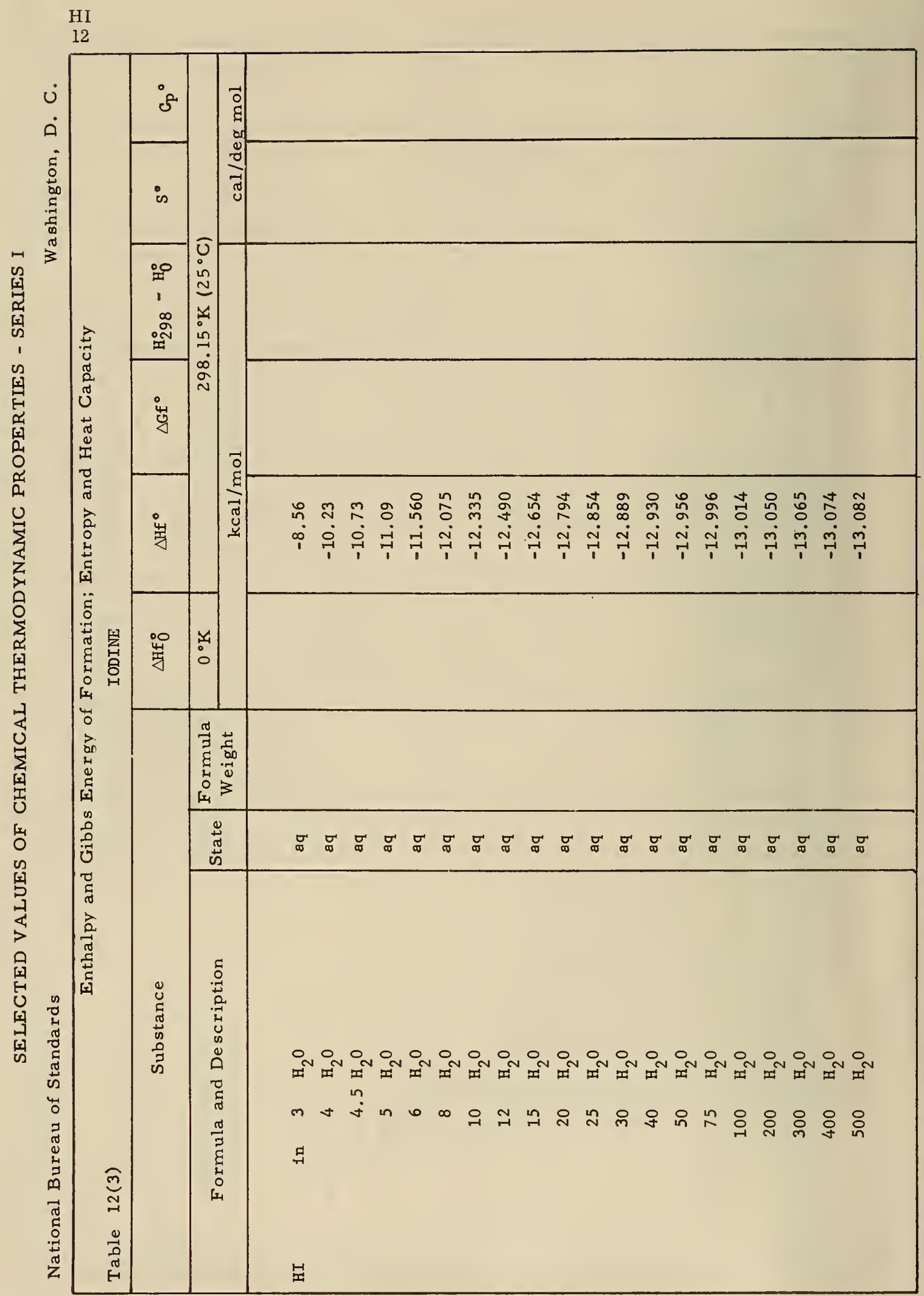




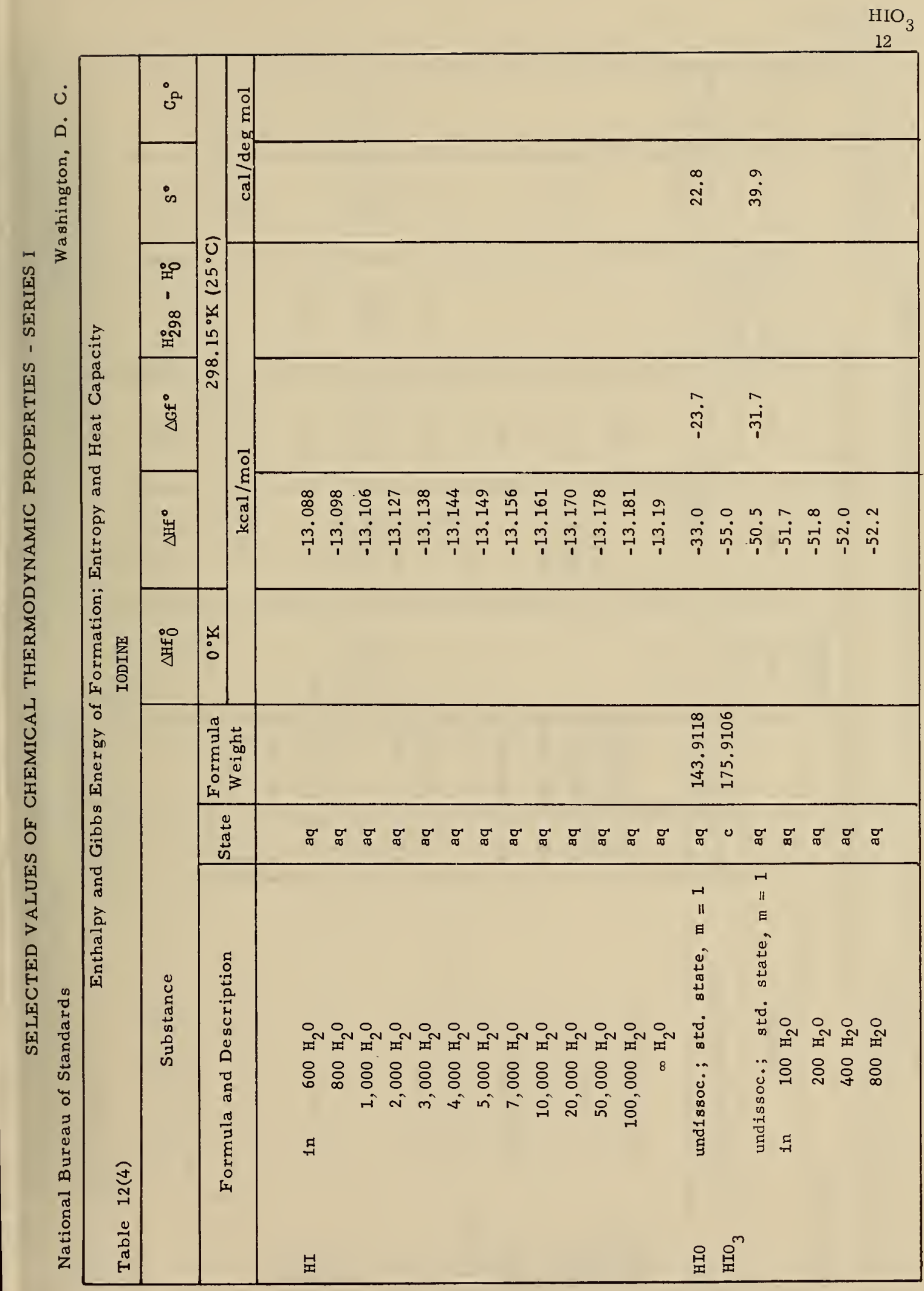




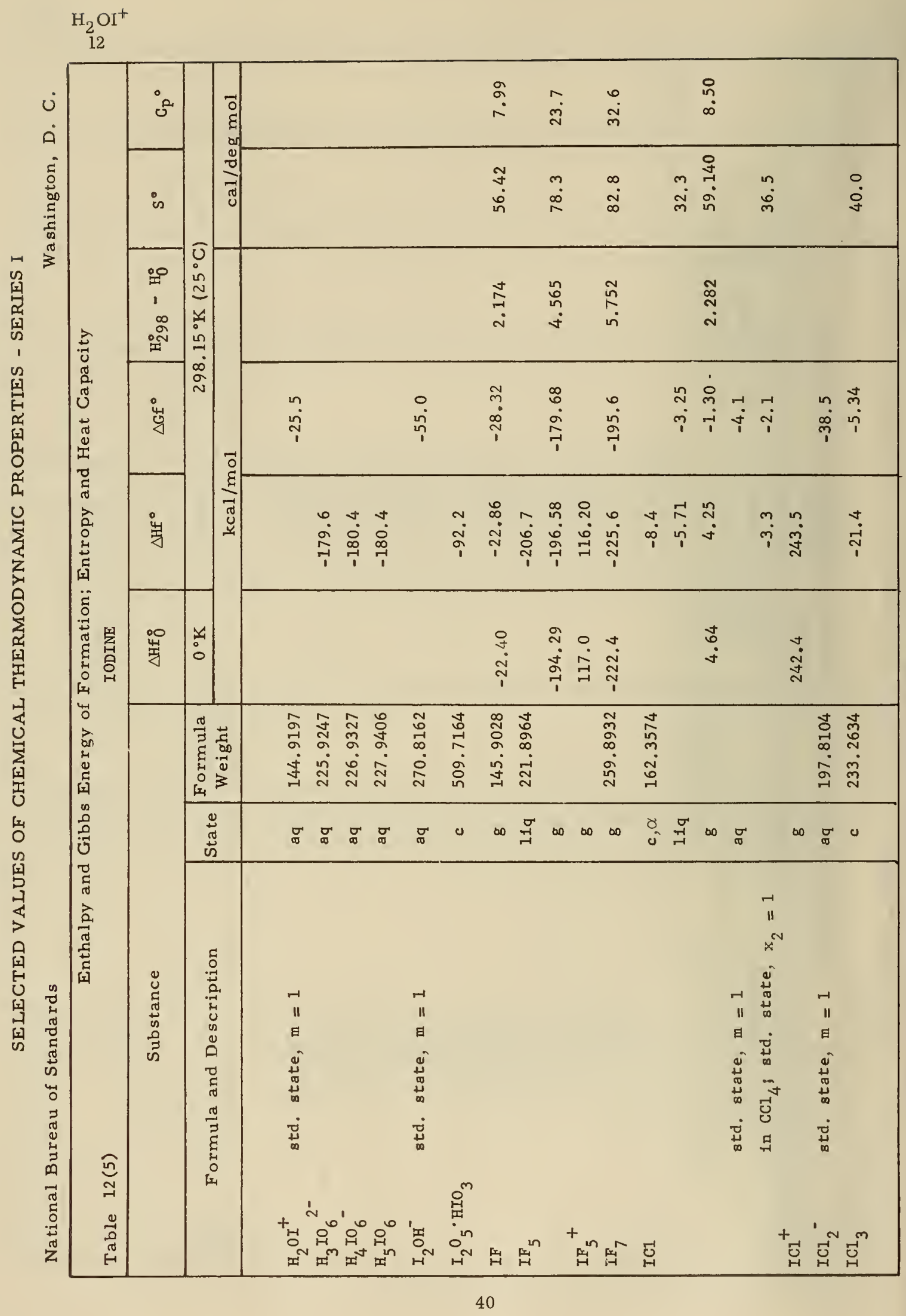




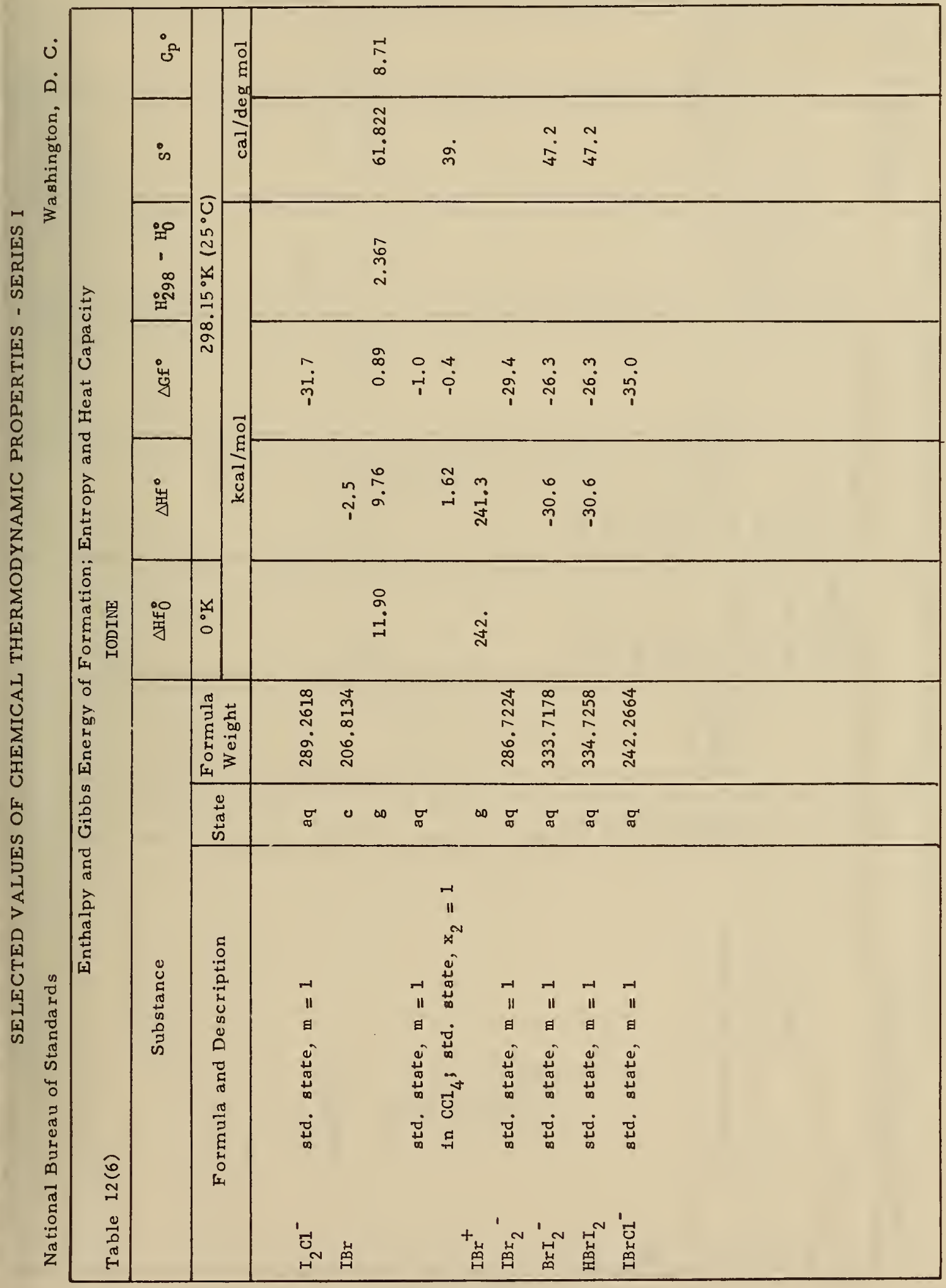




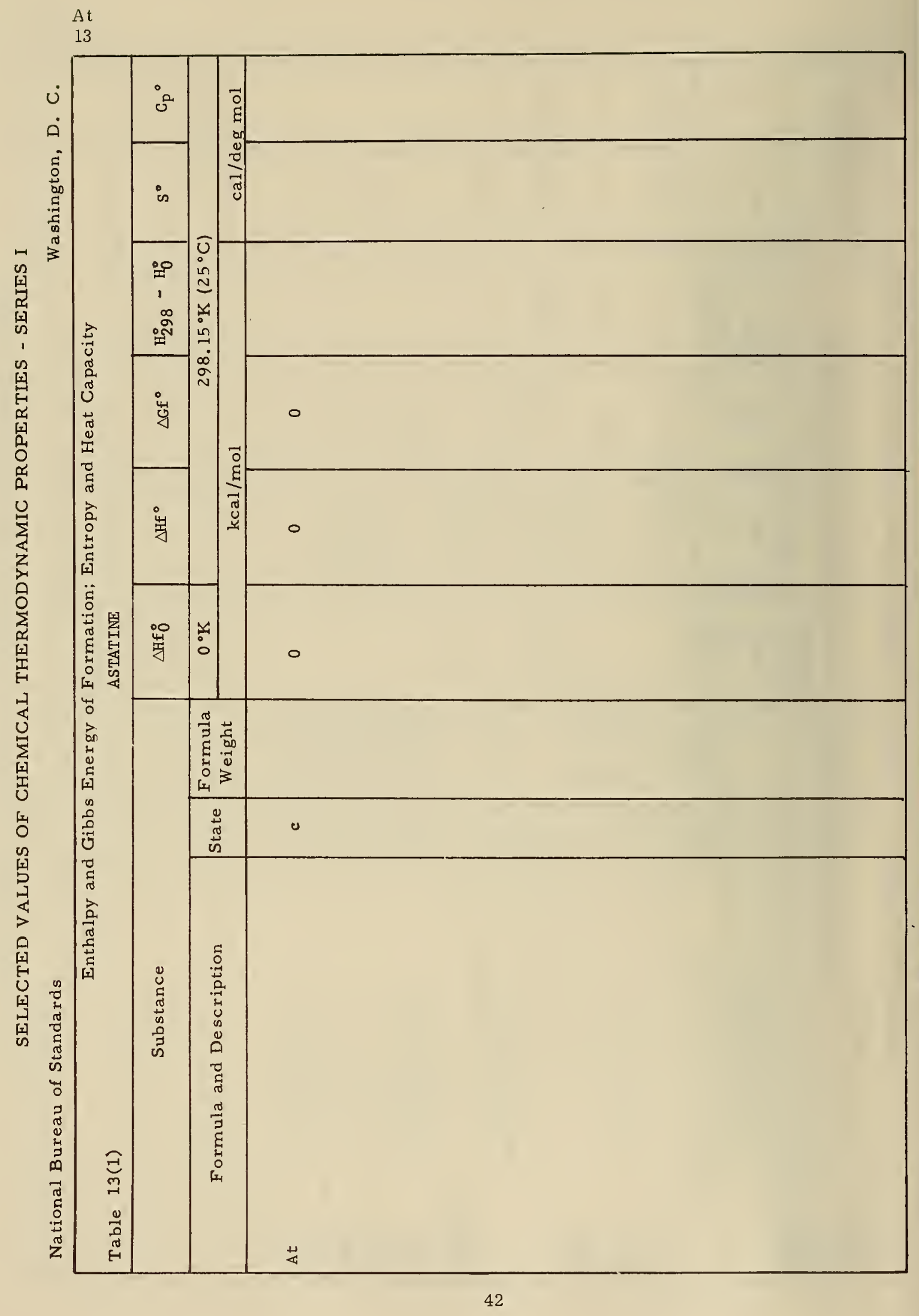




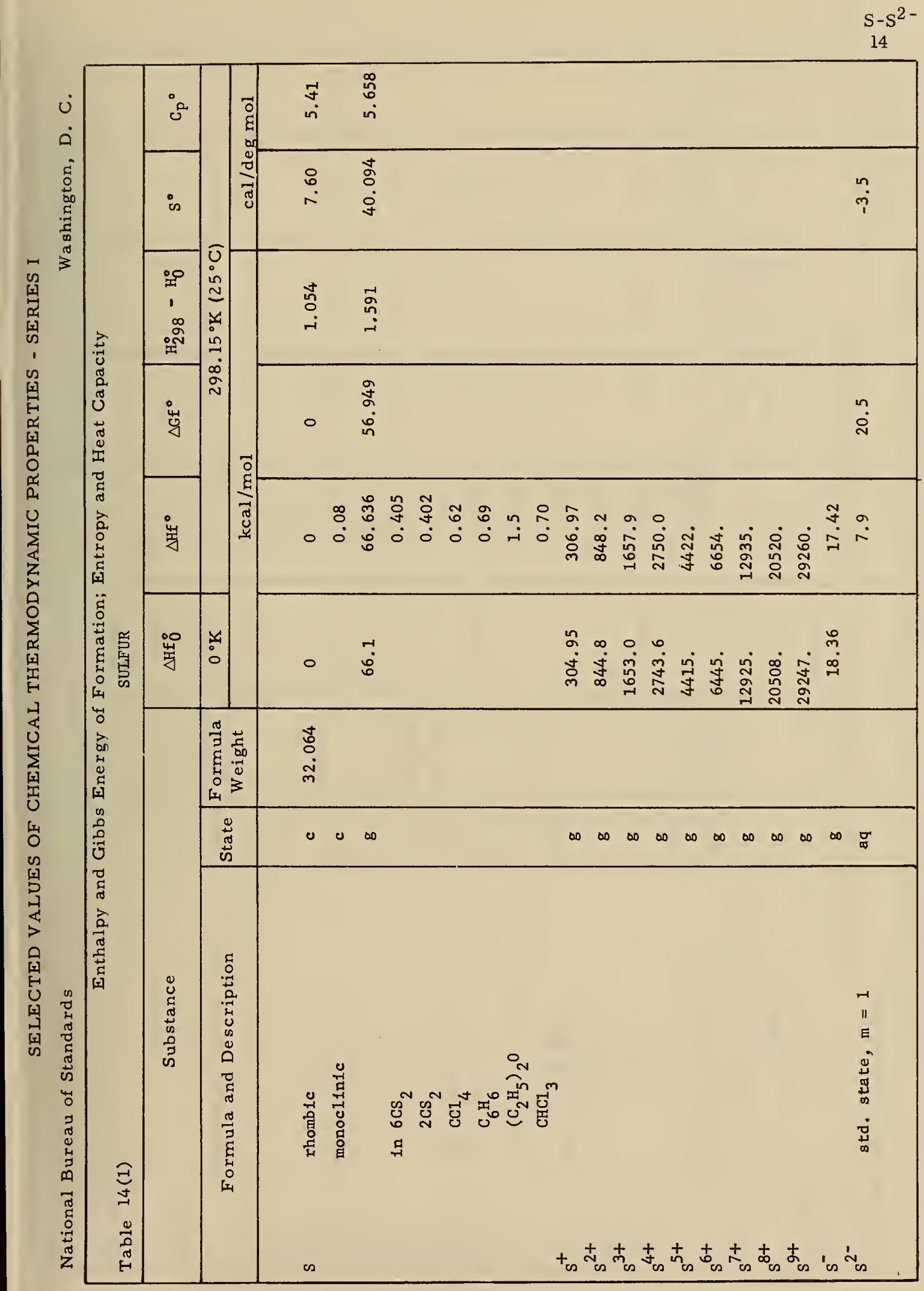




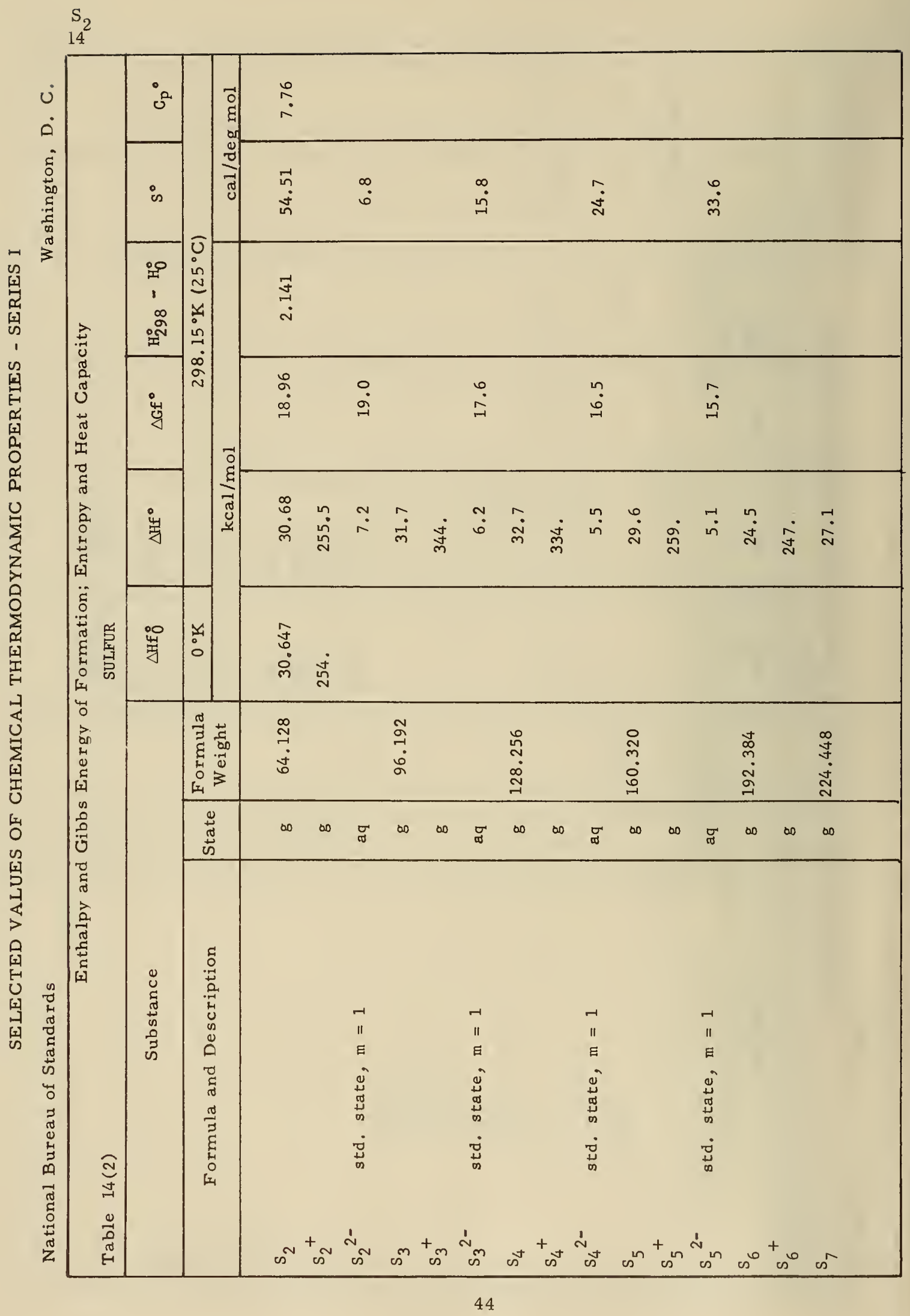




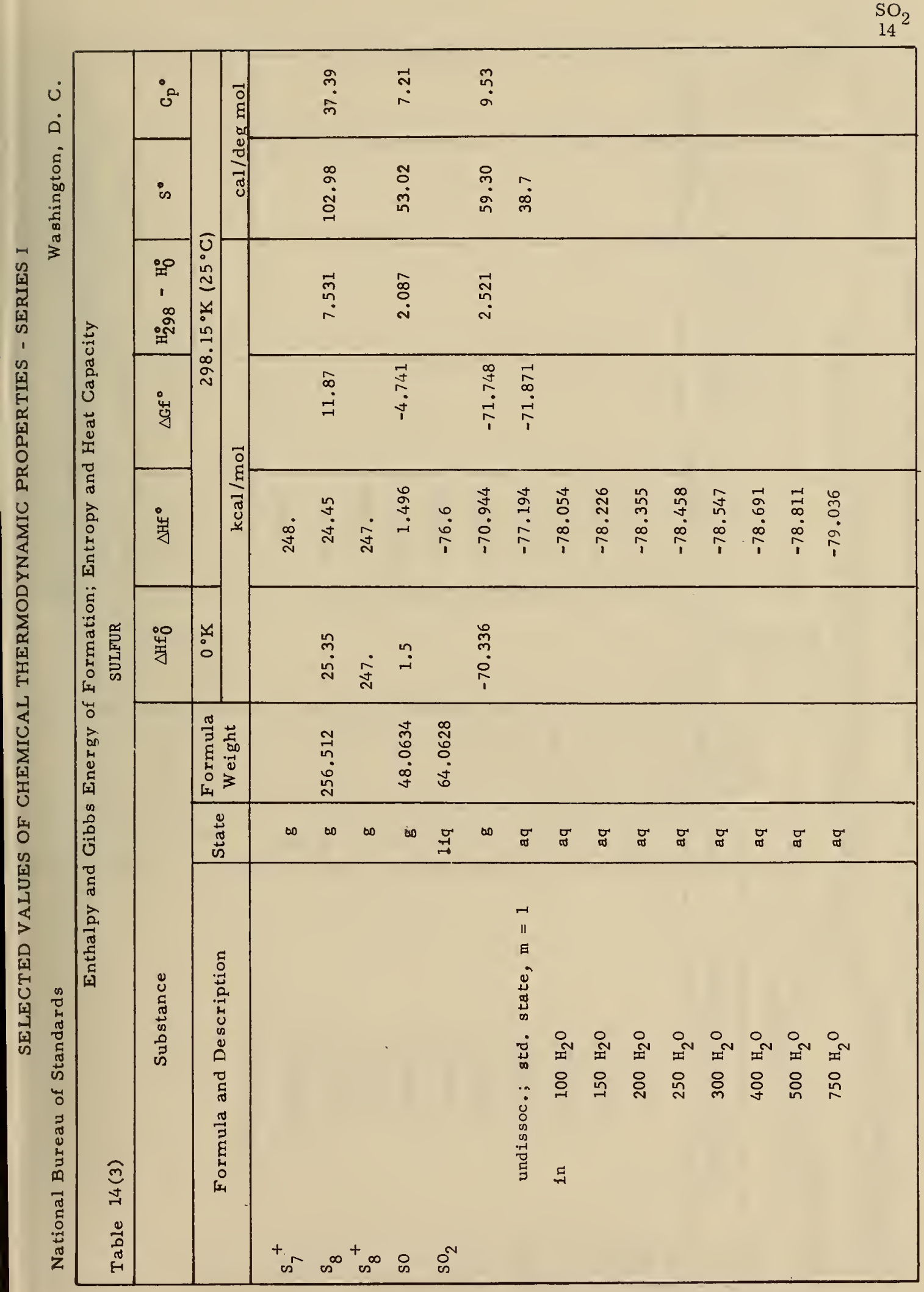




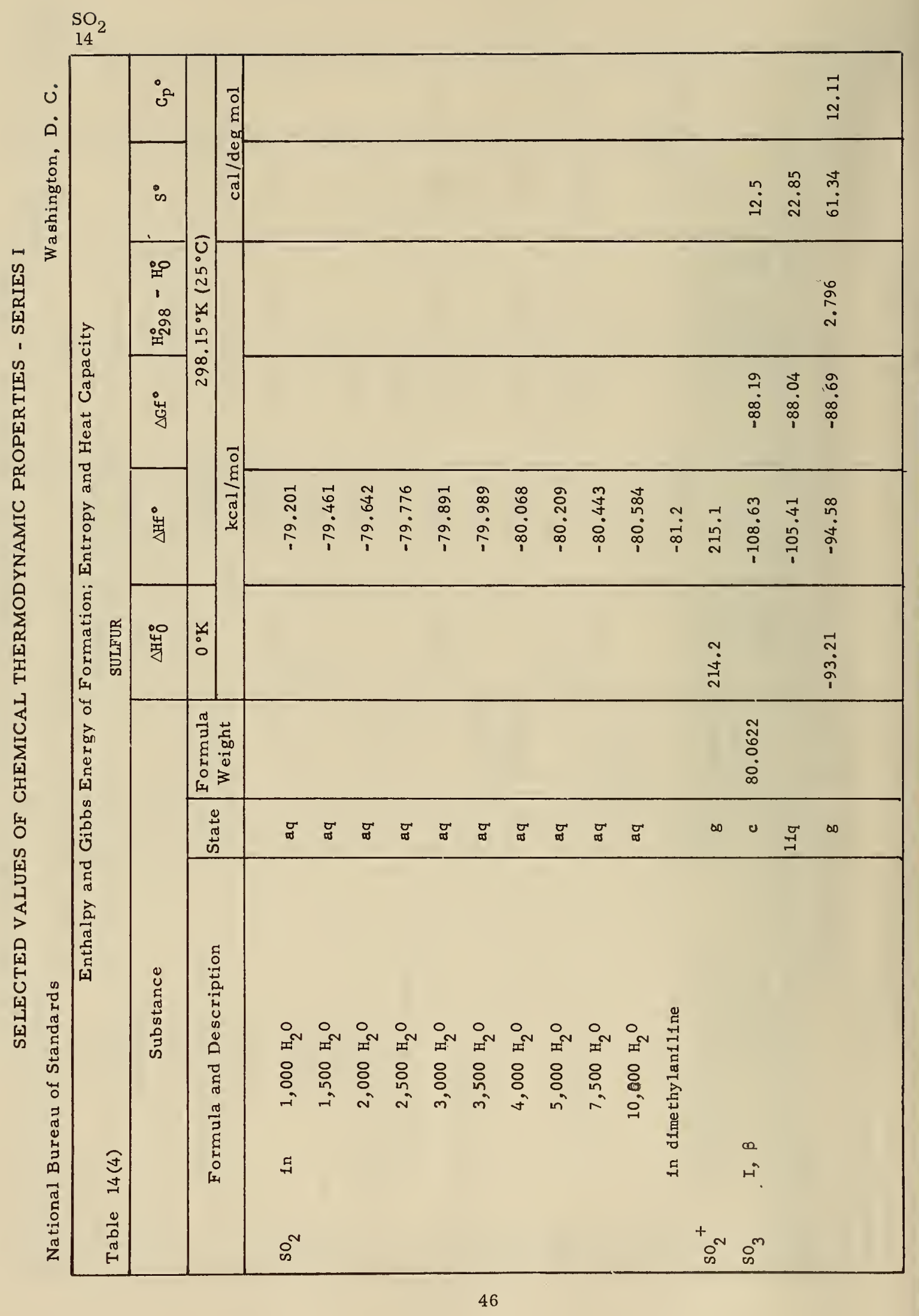




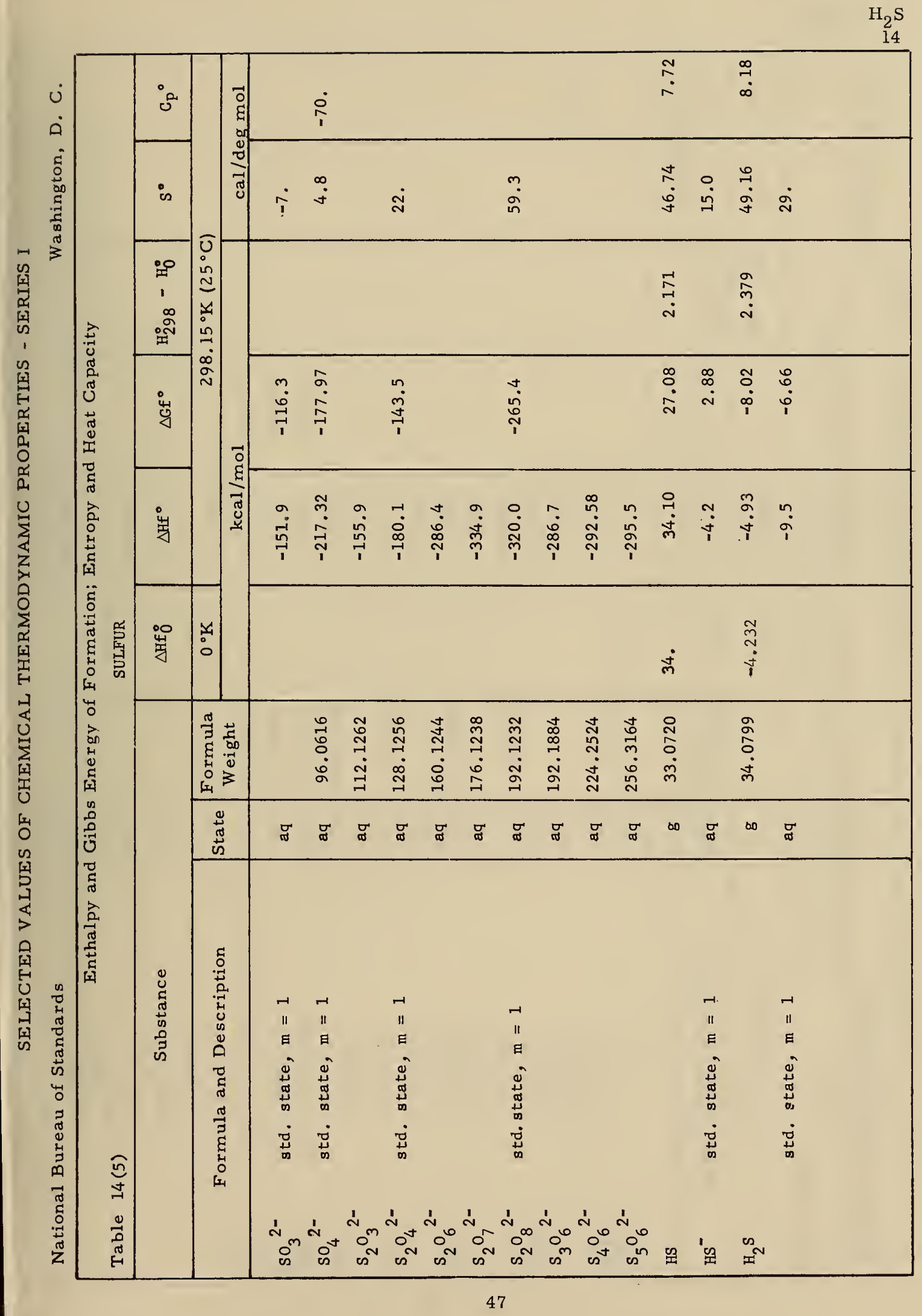




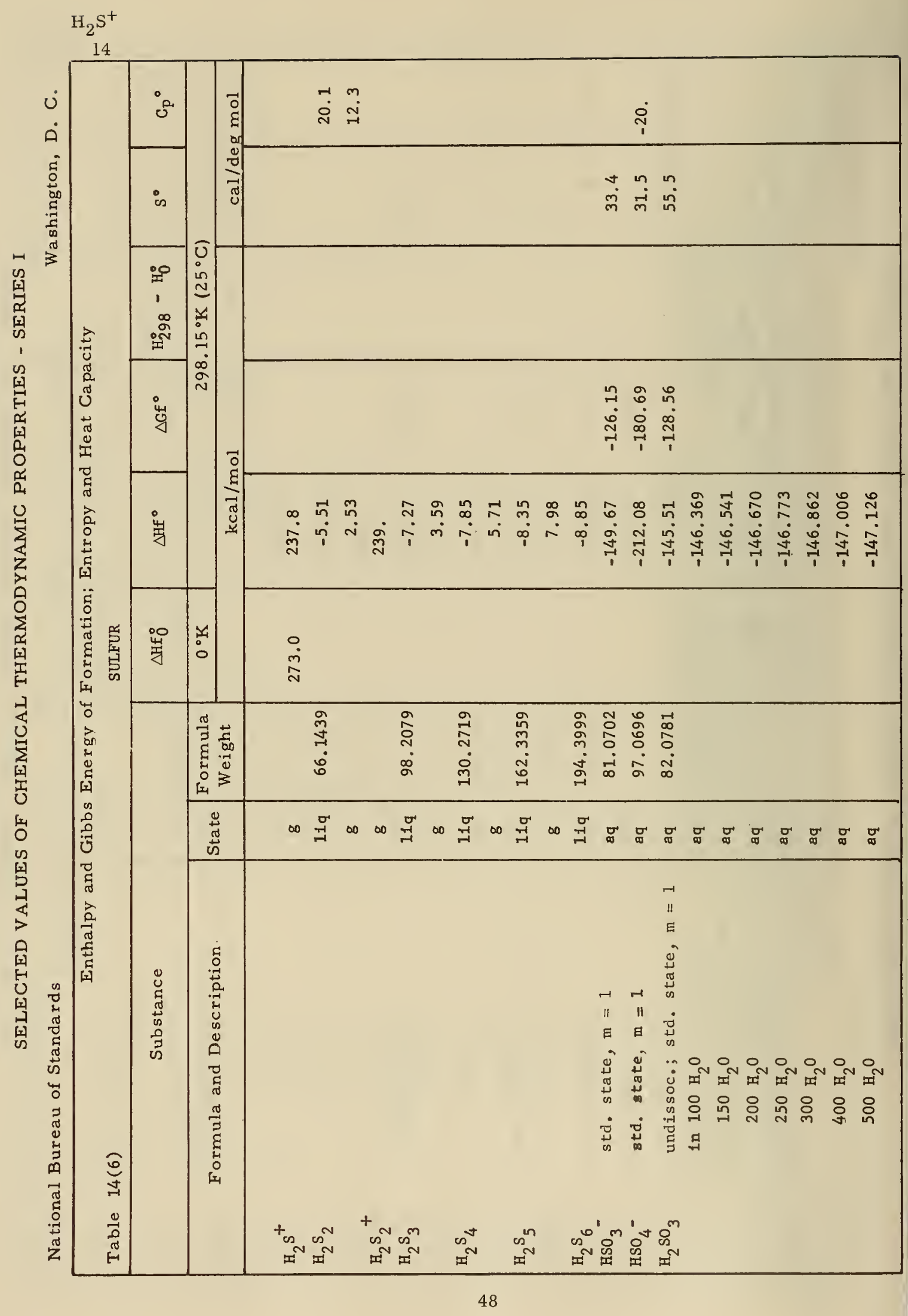




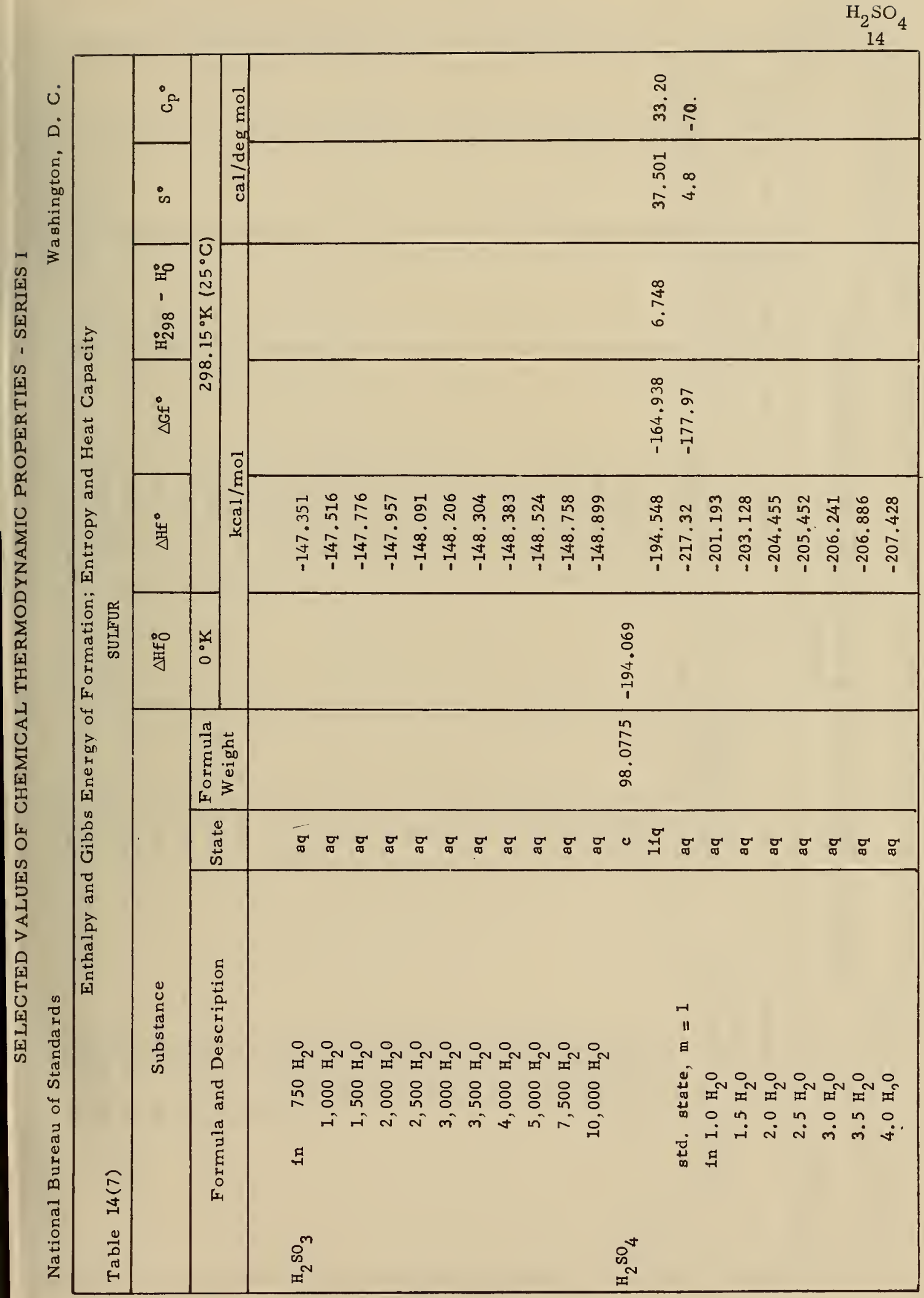




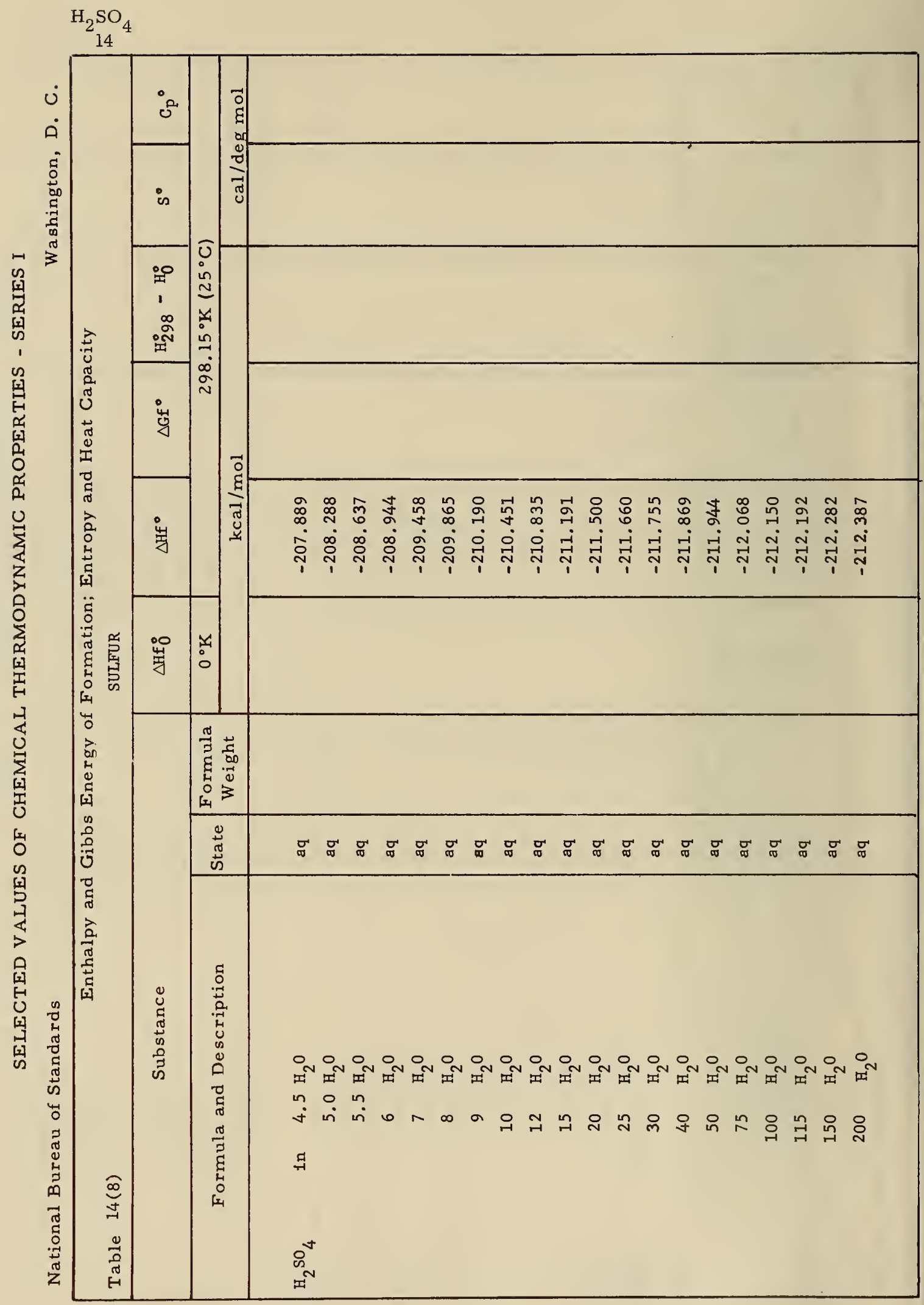




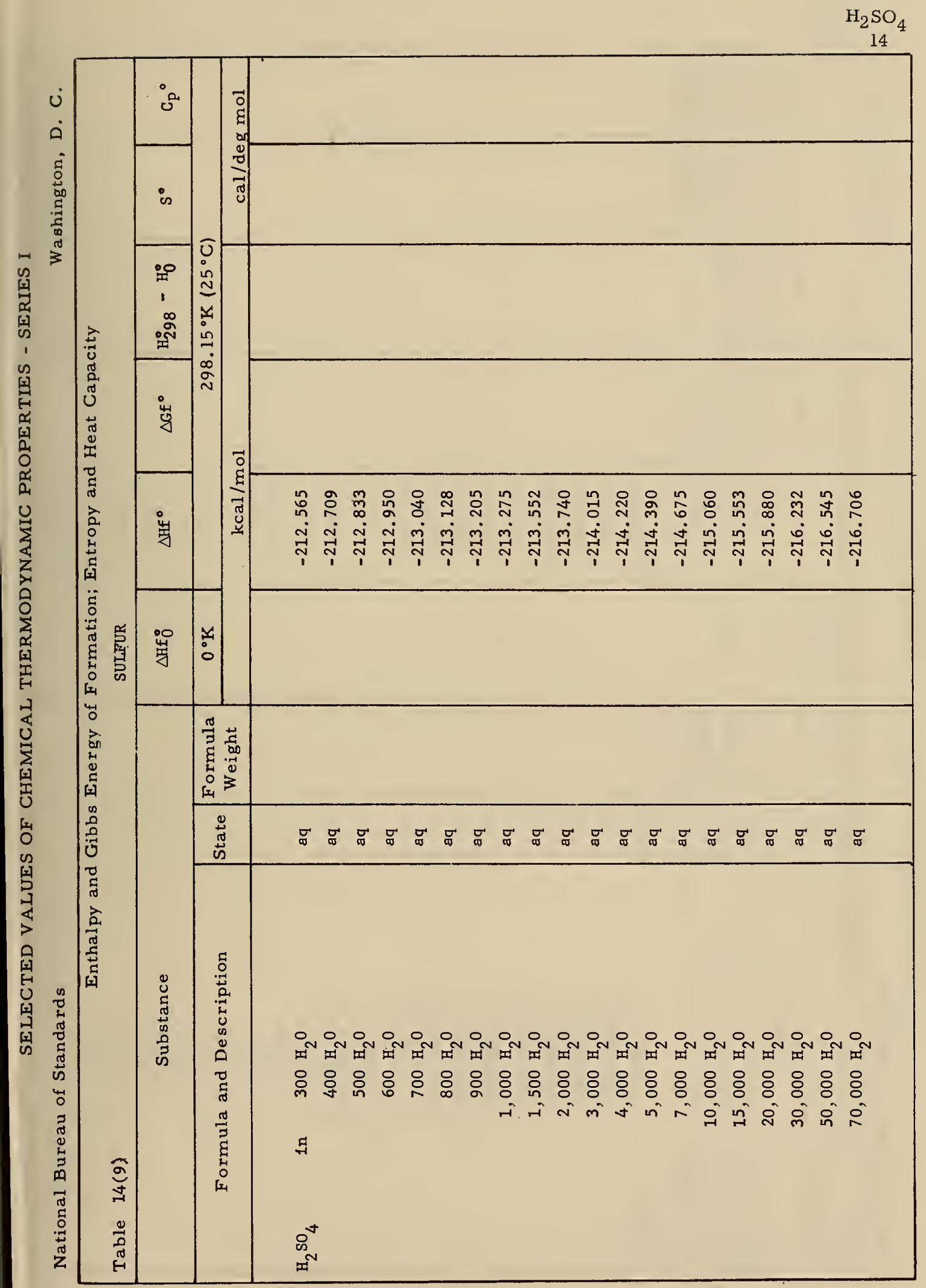




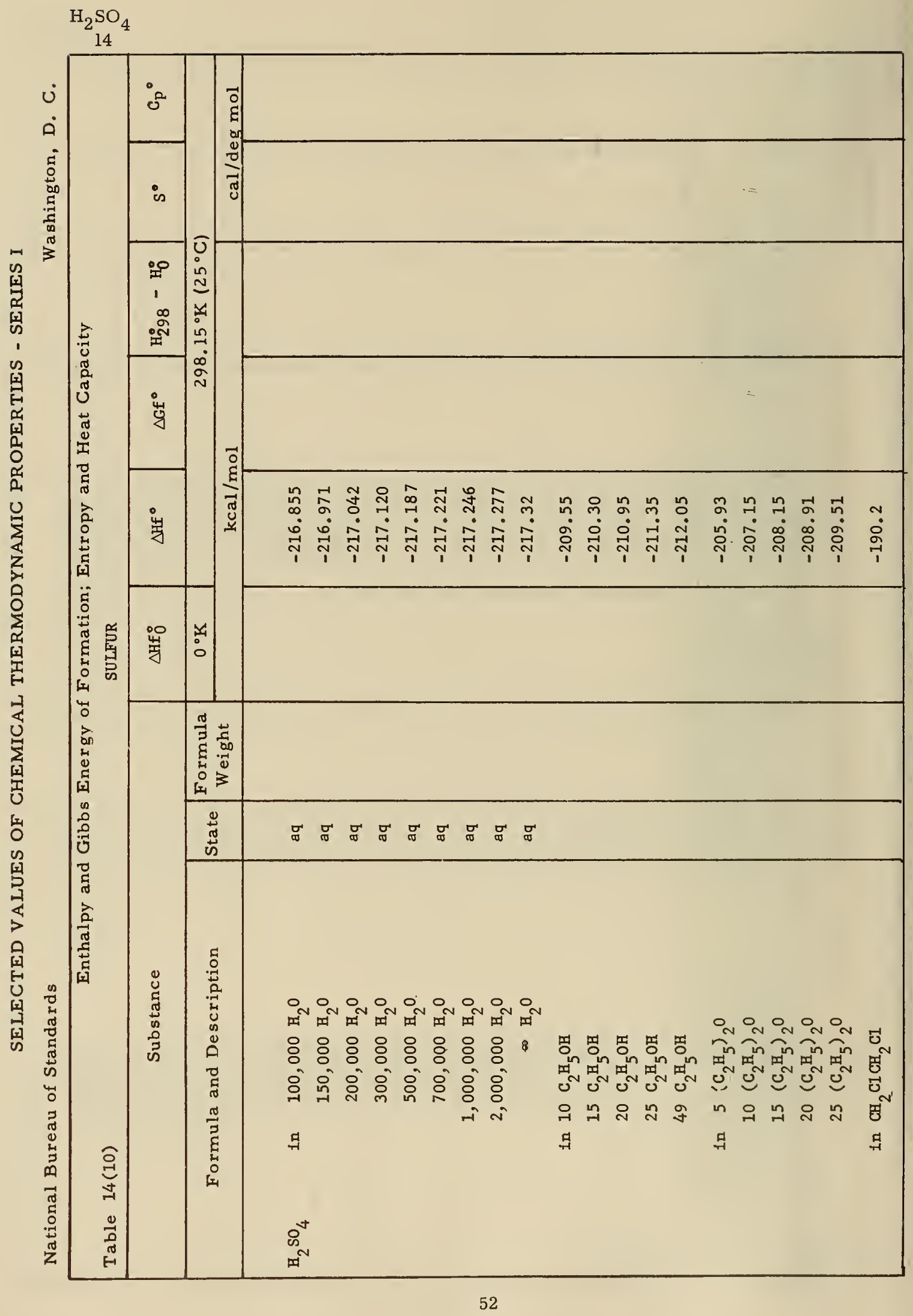




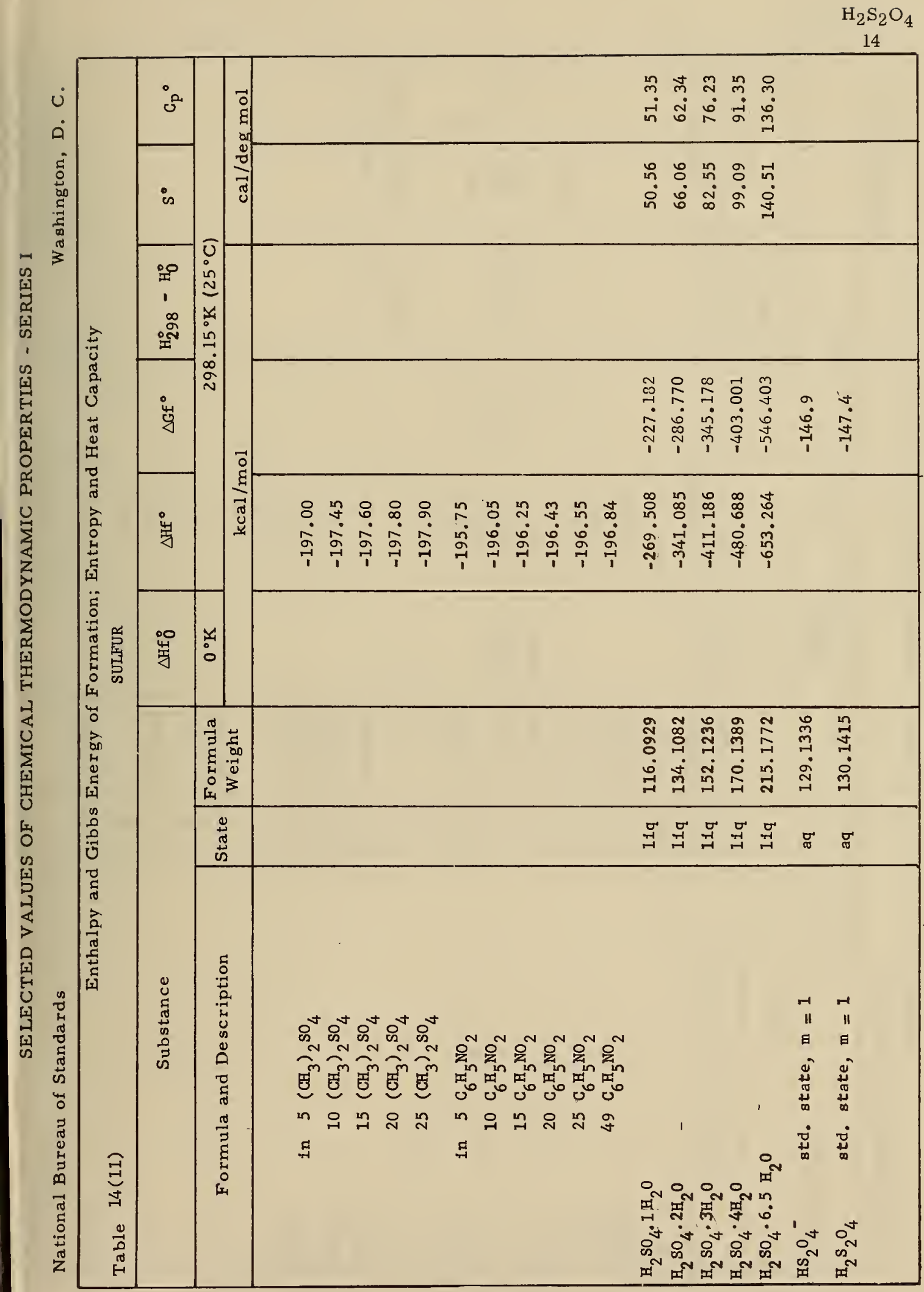




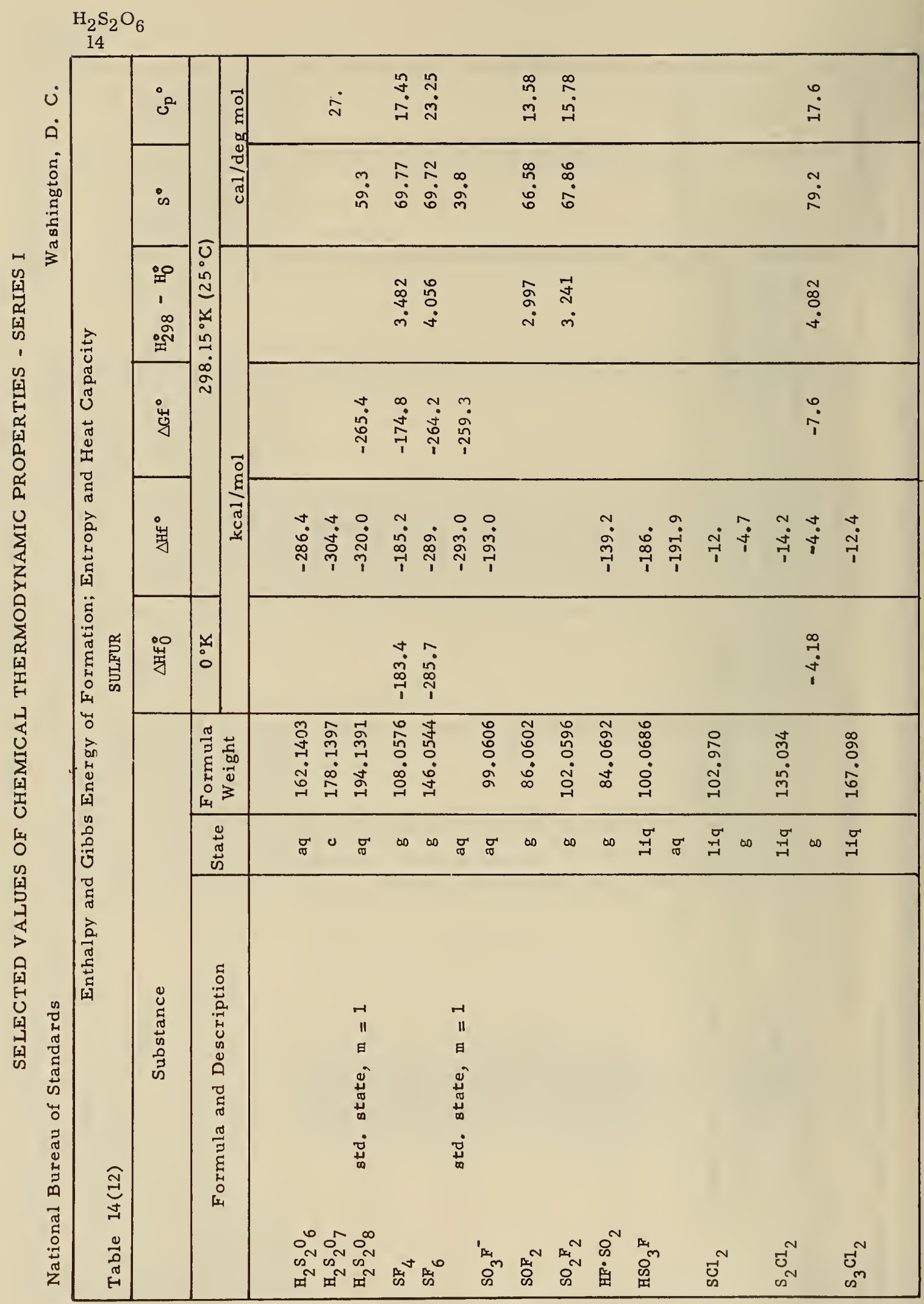




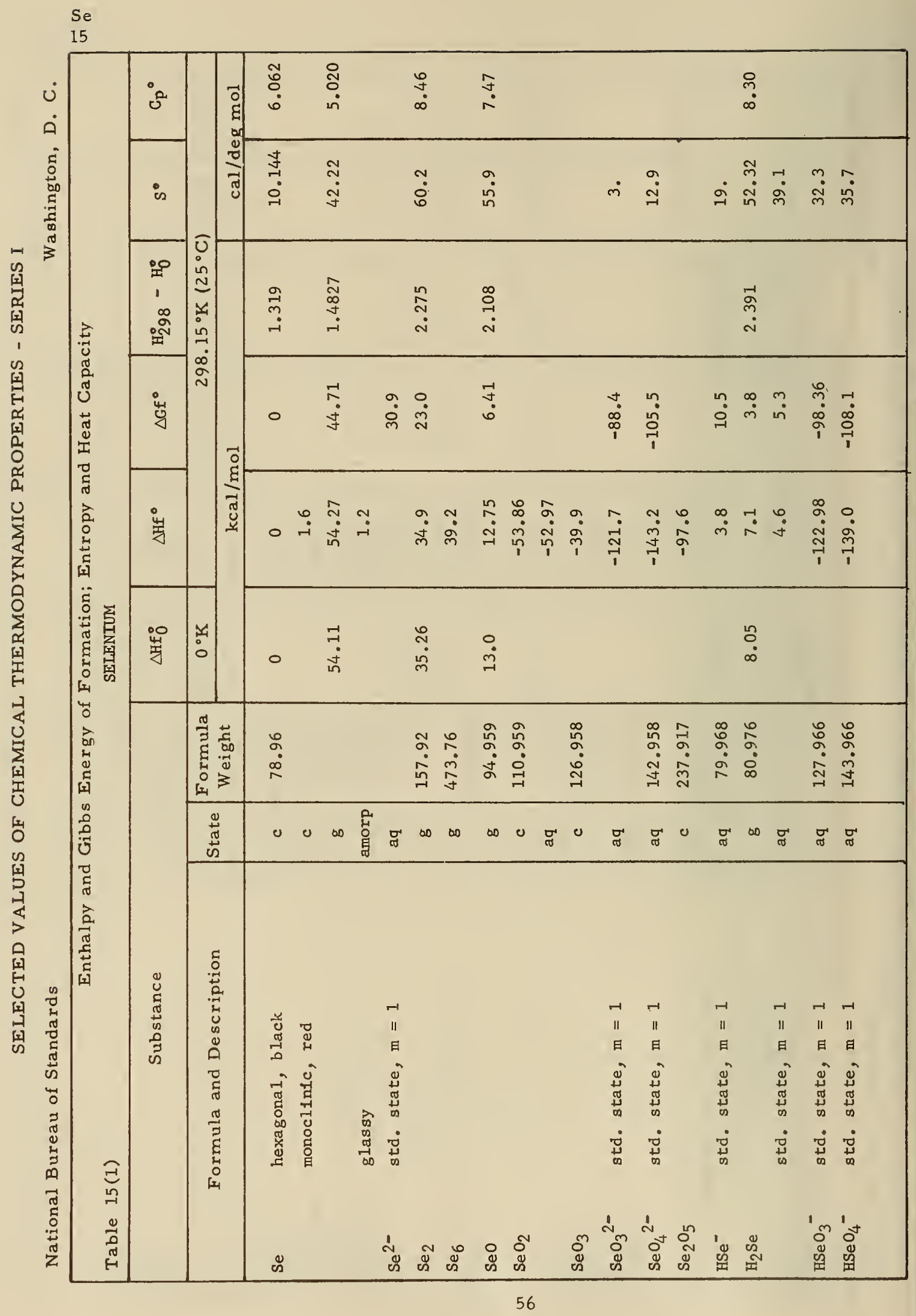




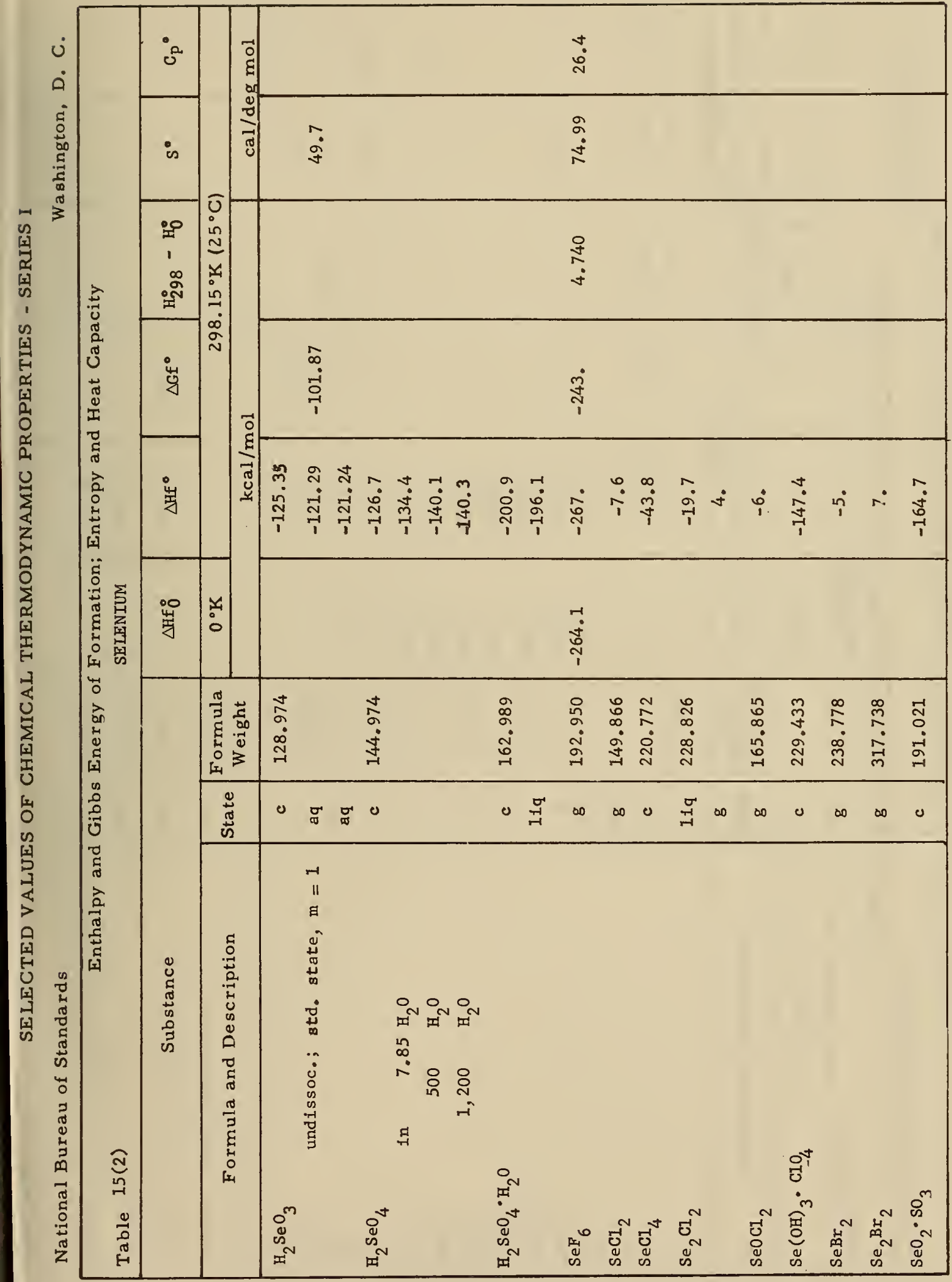




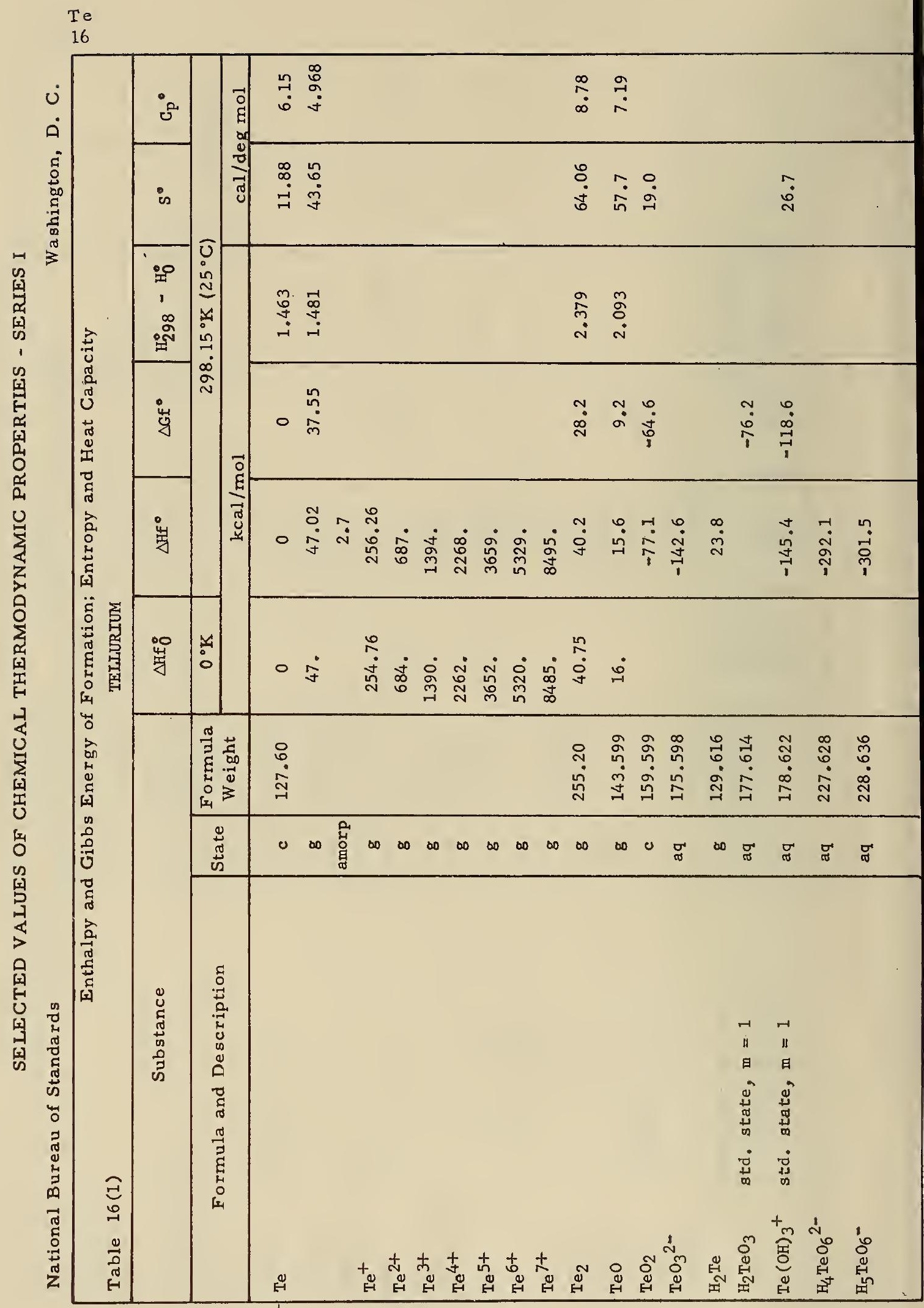




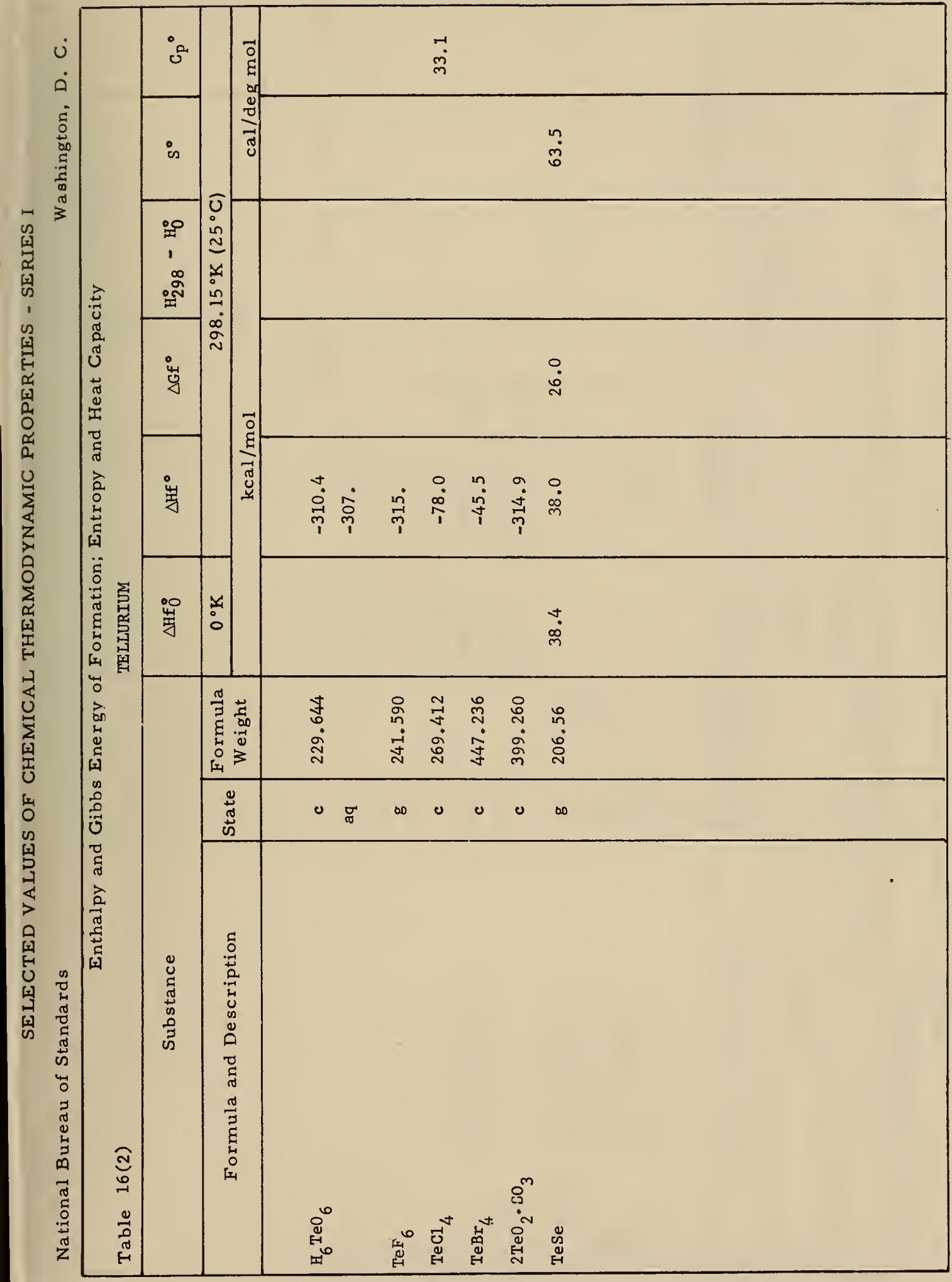


Po-PoS

17

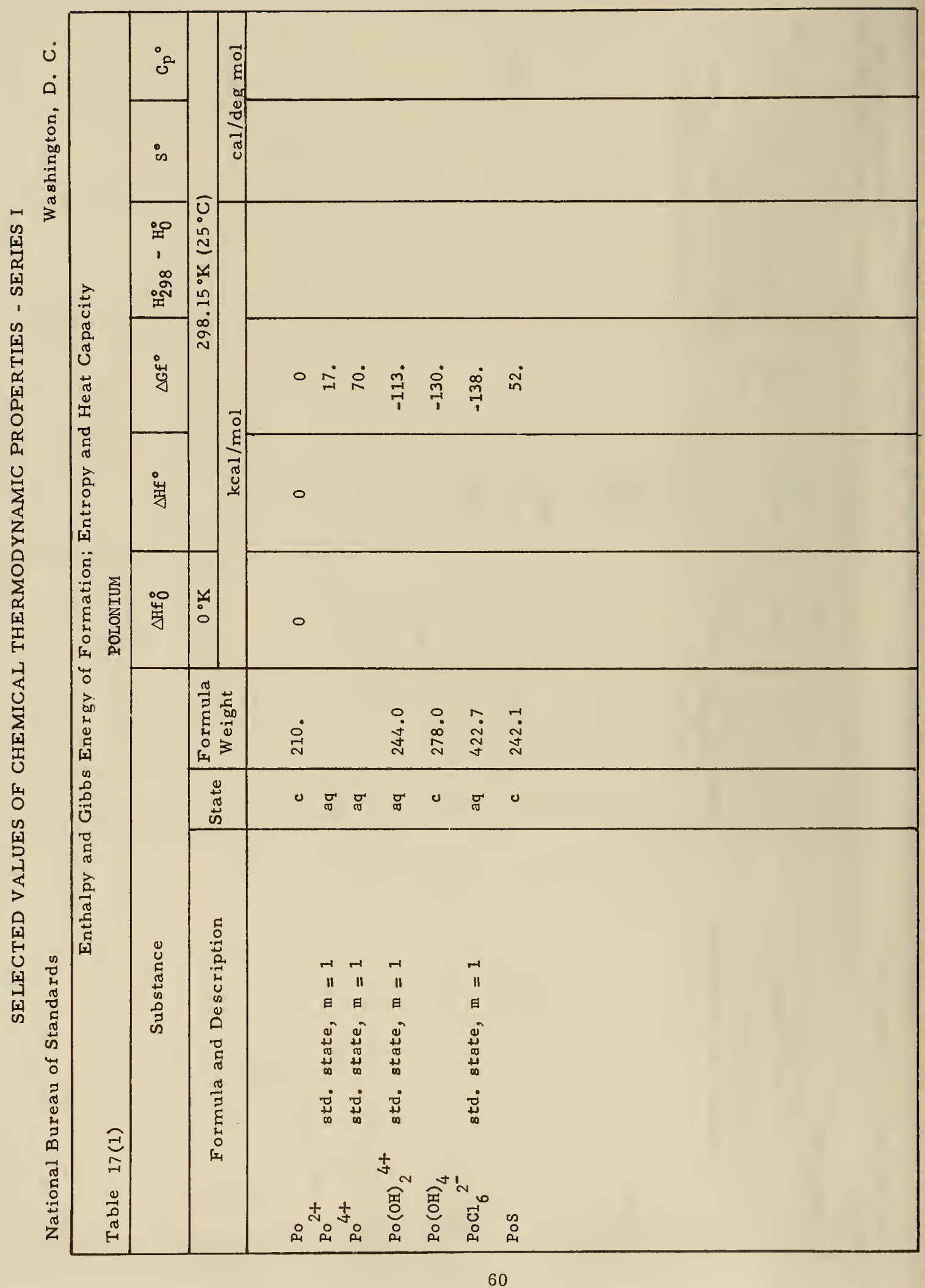




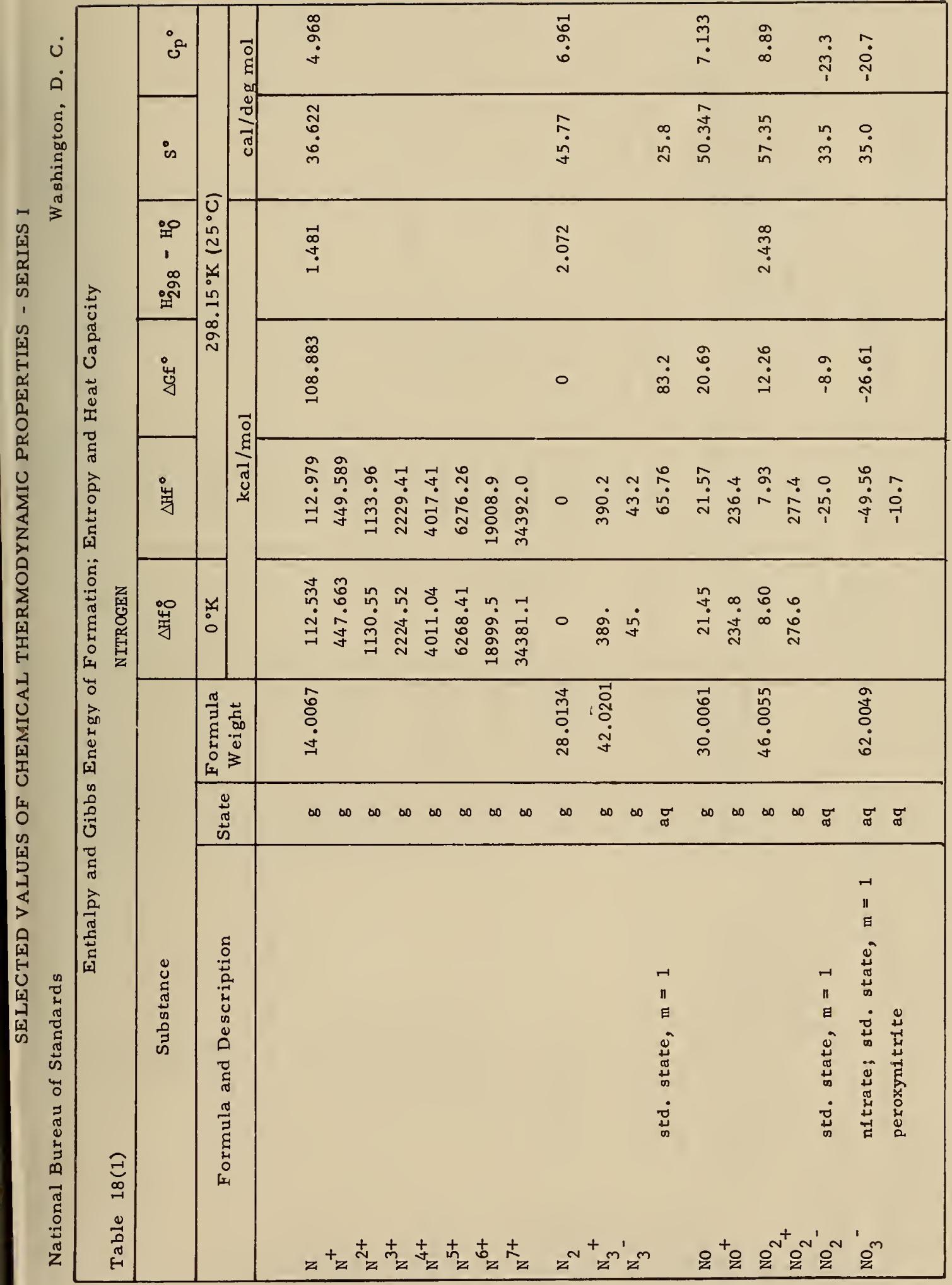




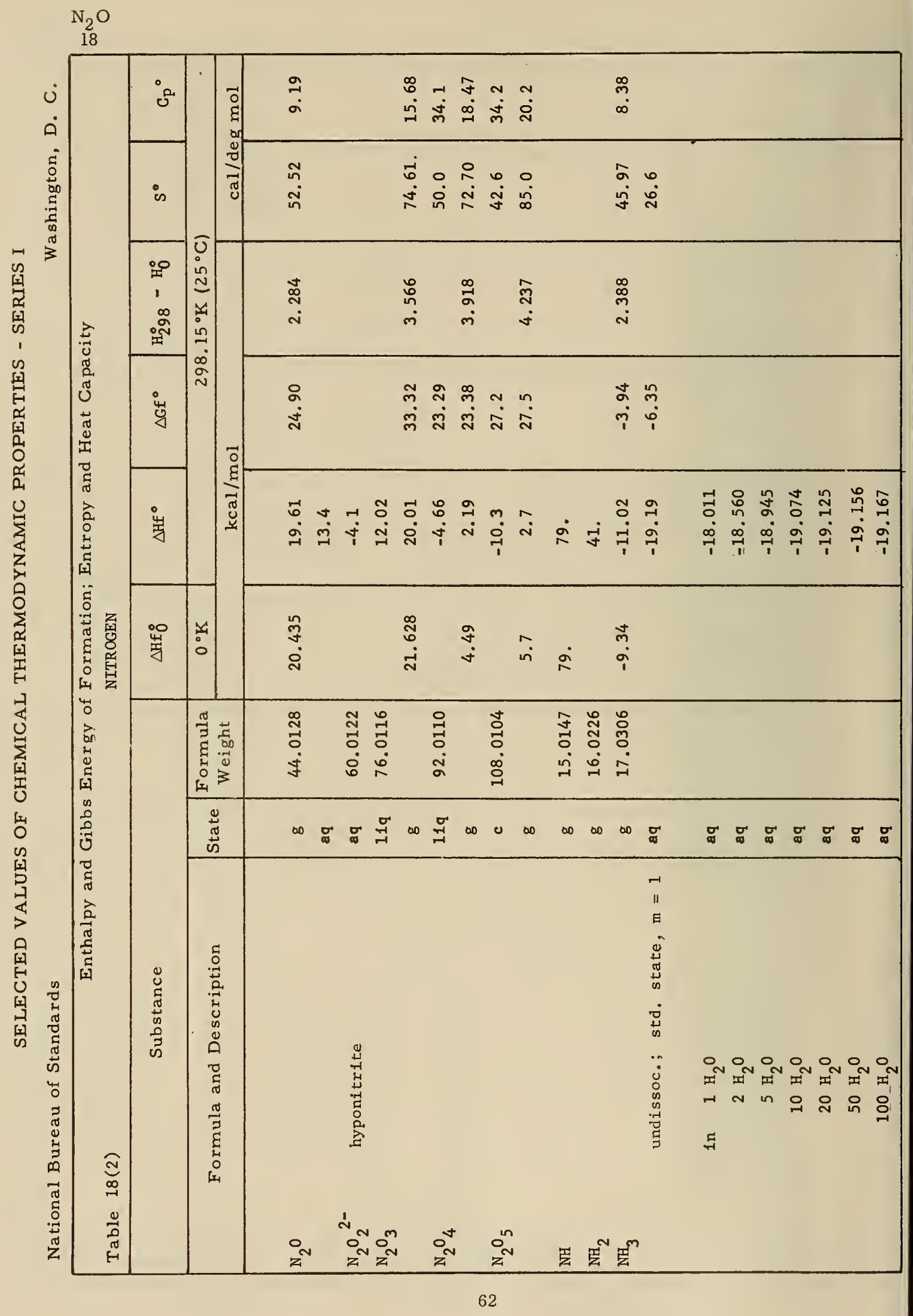




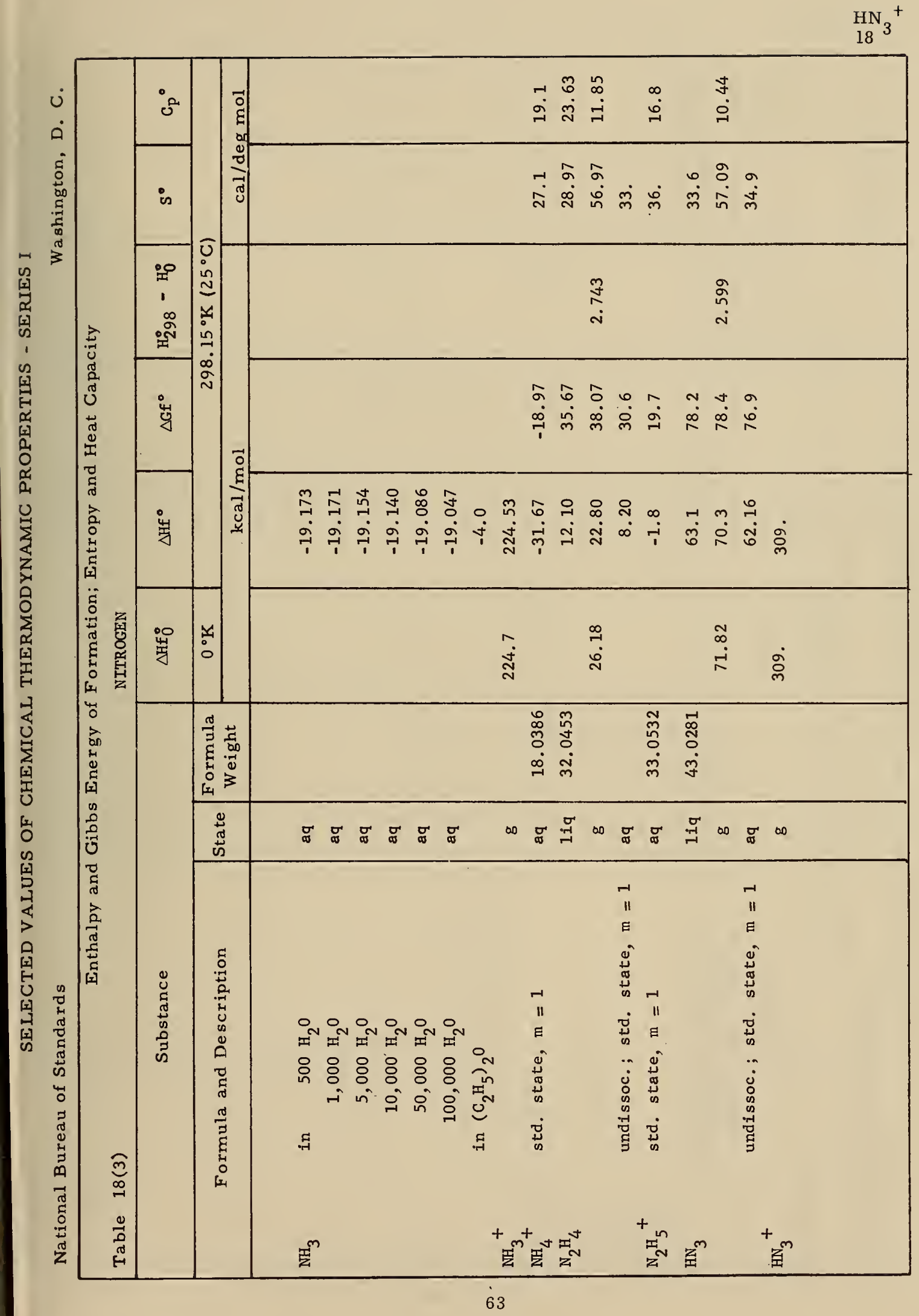




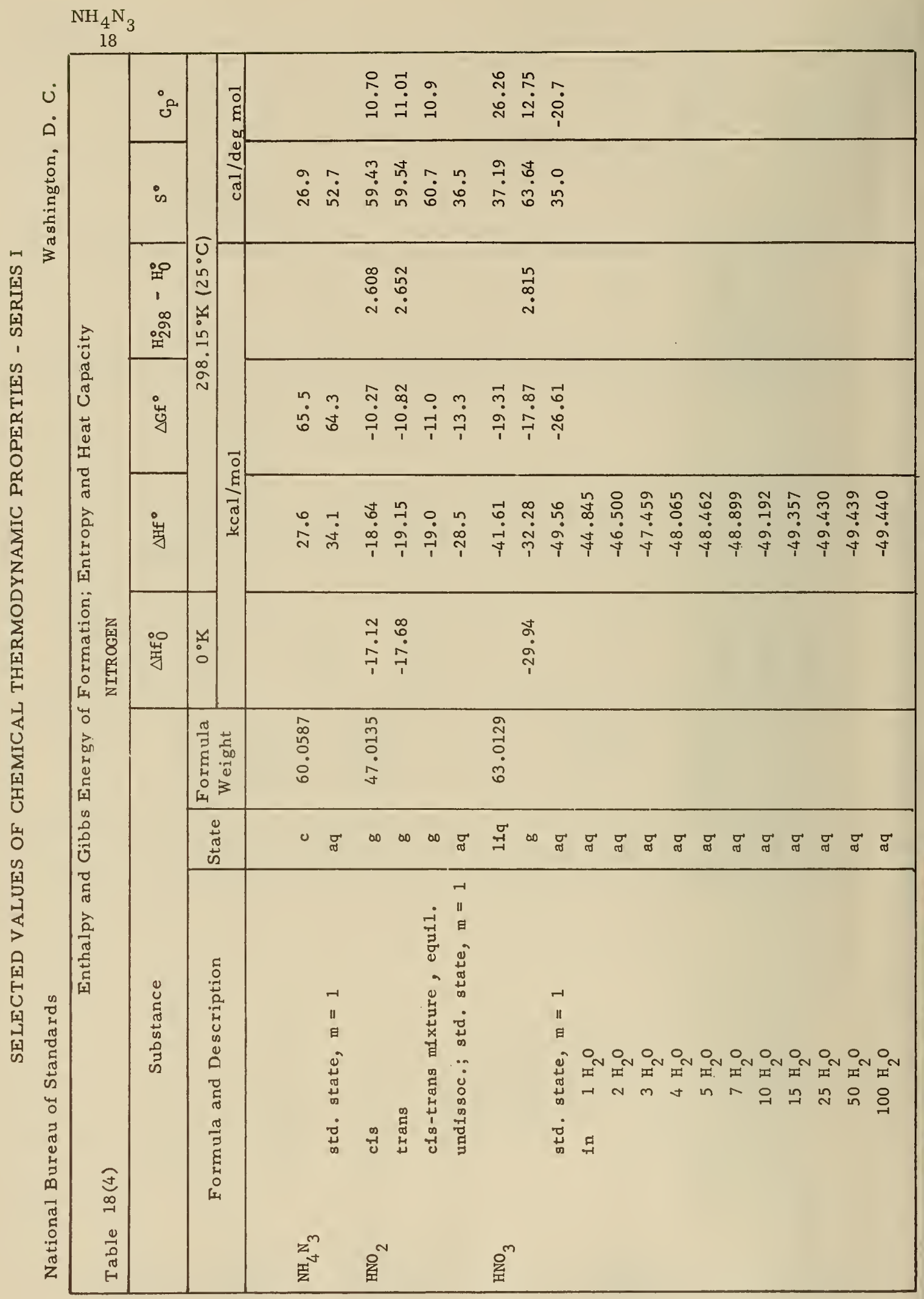




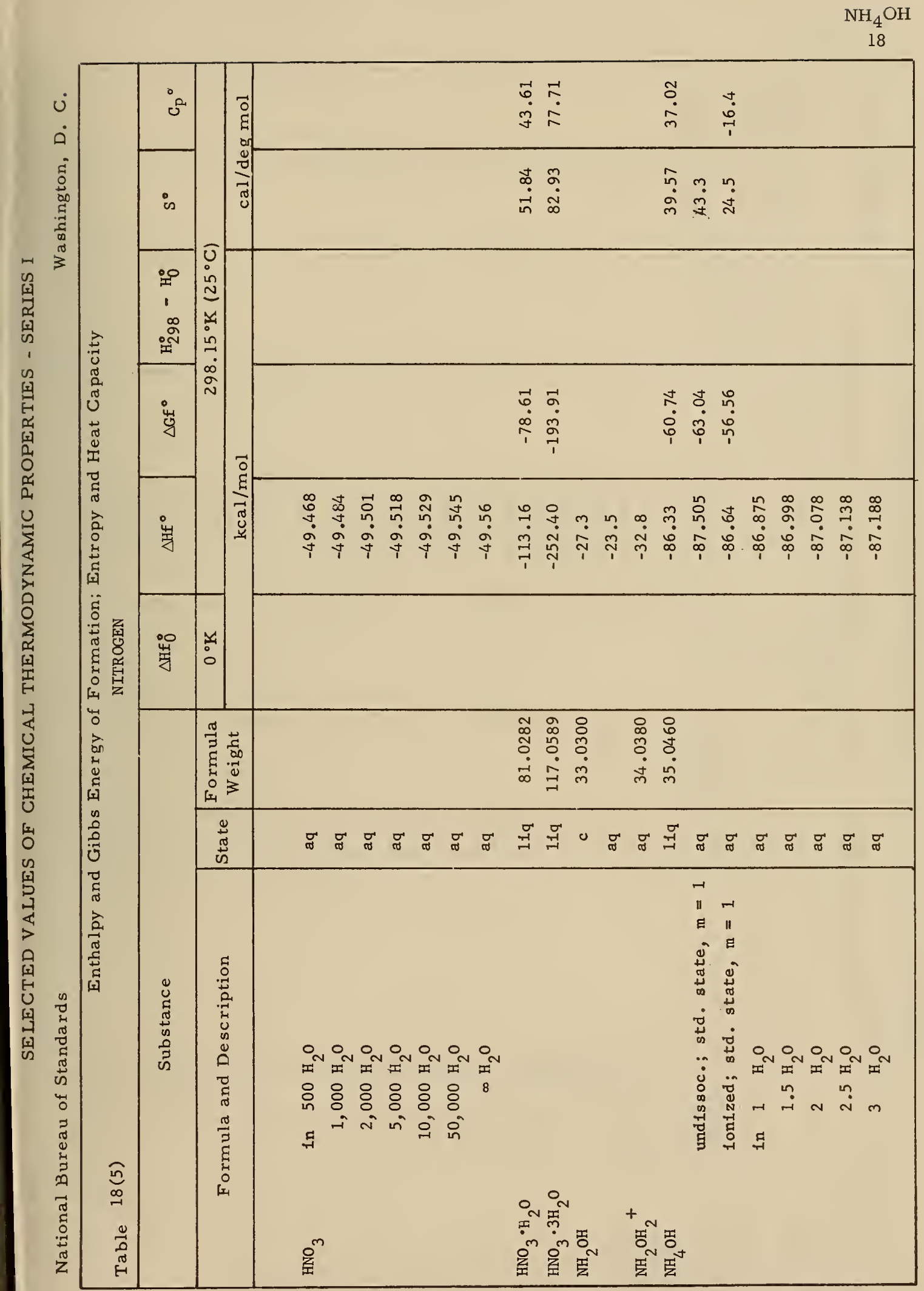




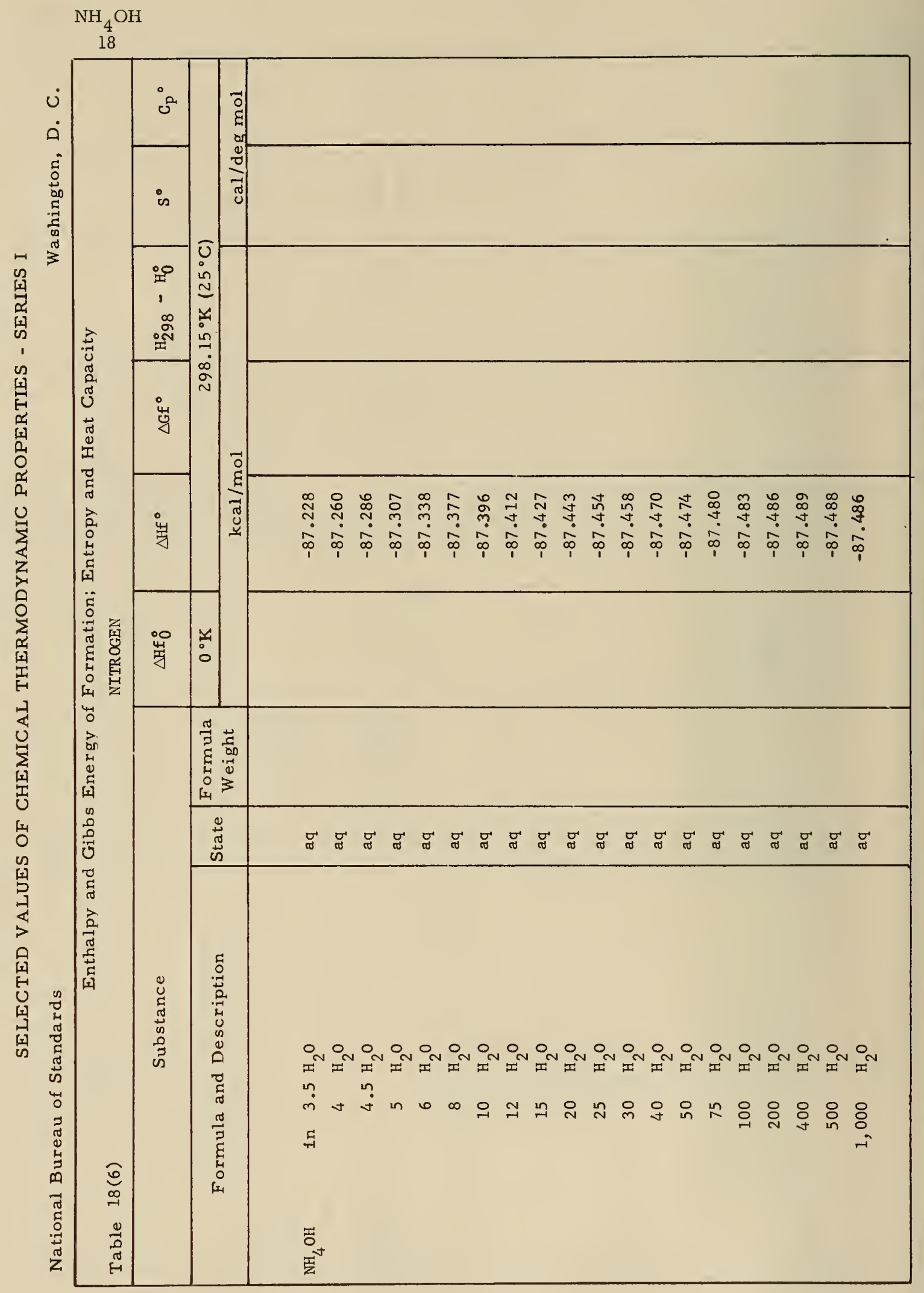




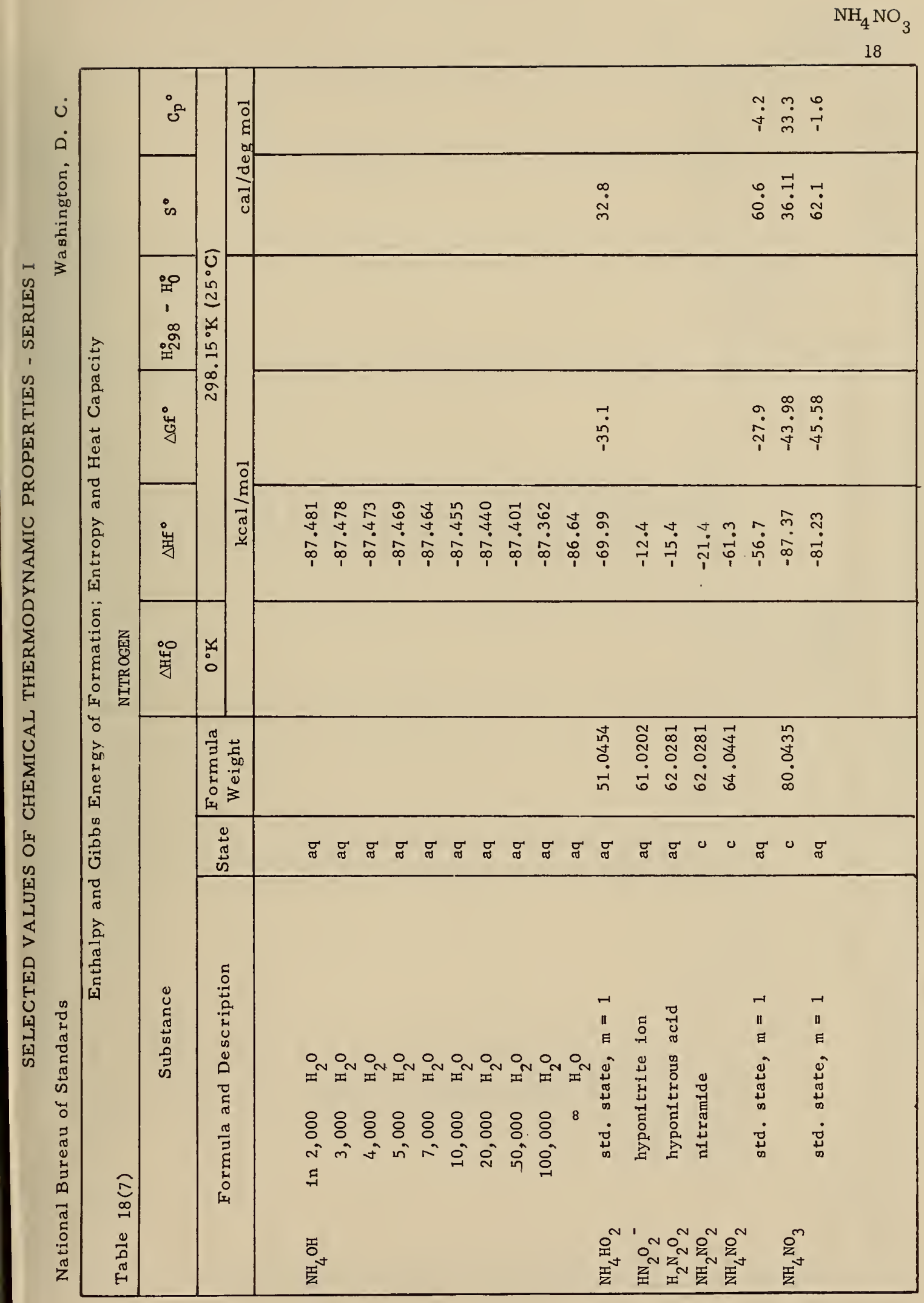




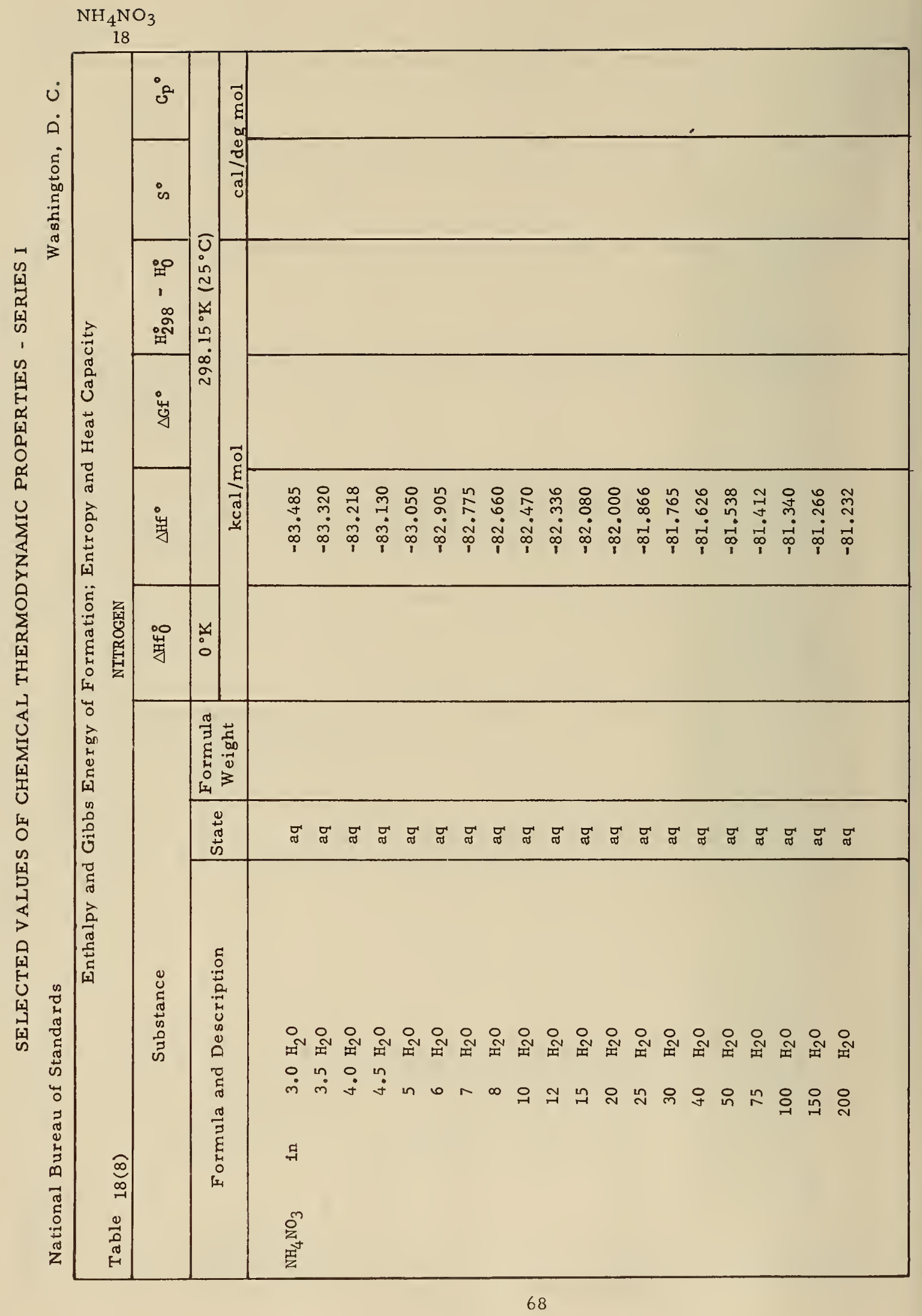


$\mathrm{NH}_{4} \mathrm{NO}_{3}$

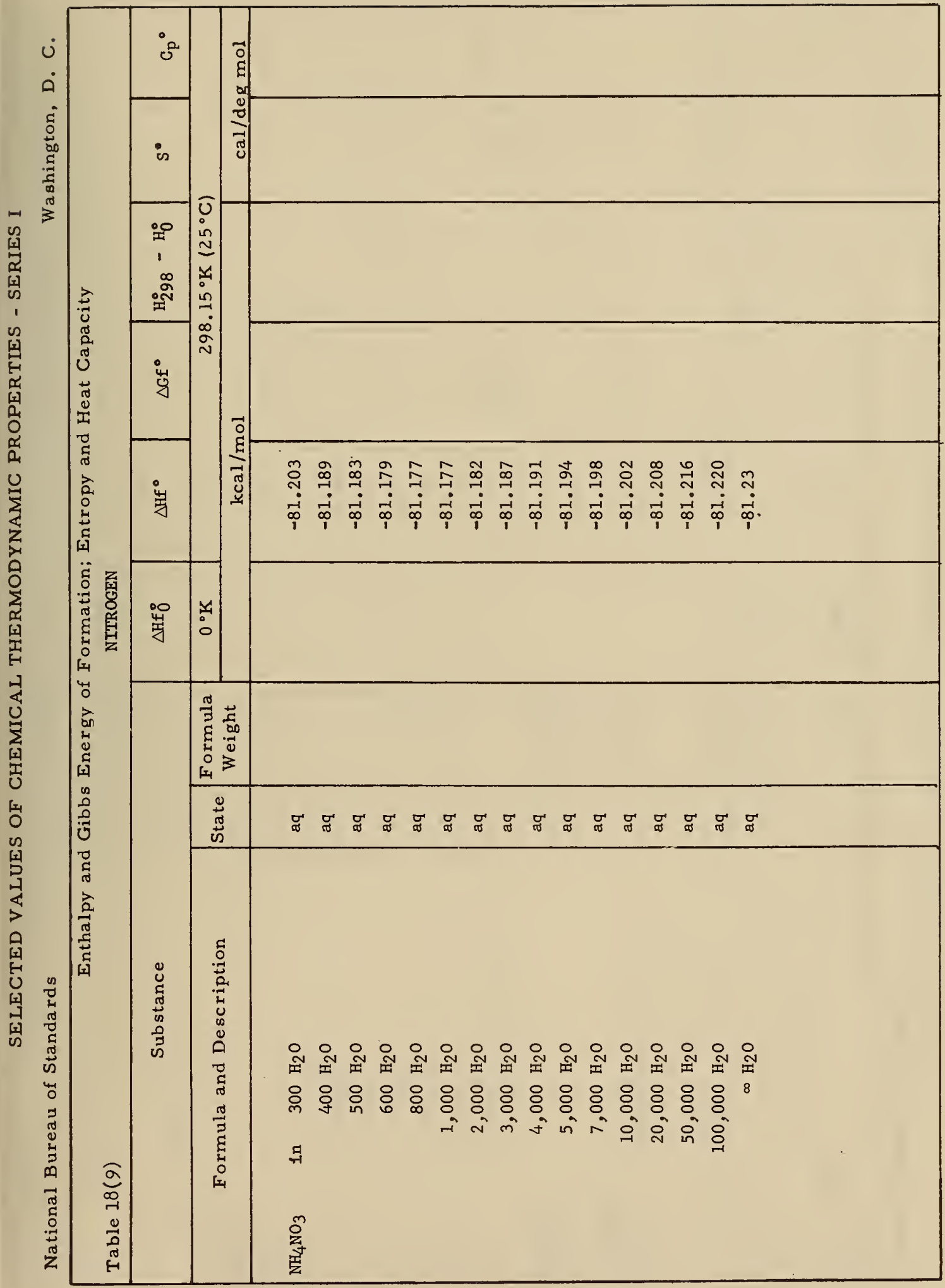




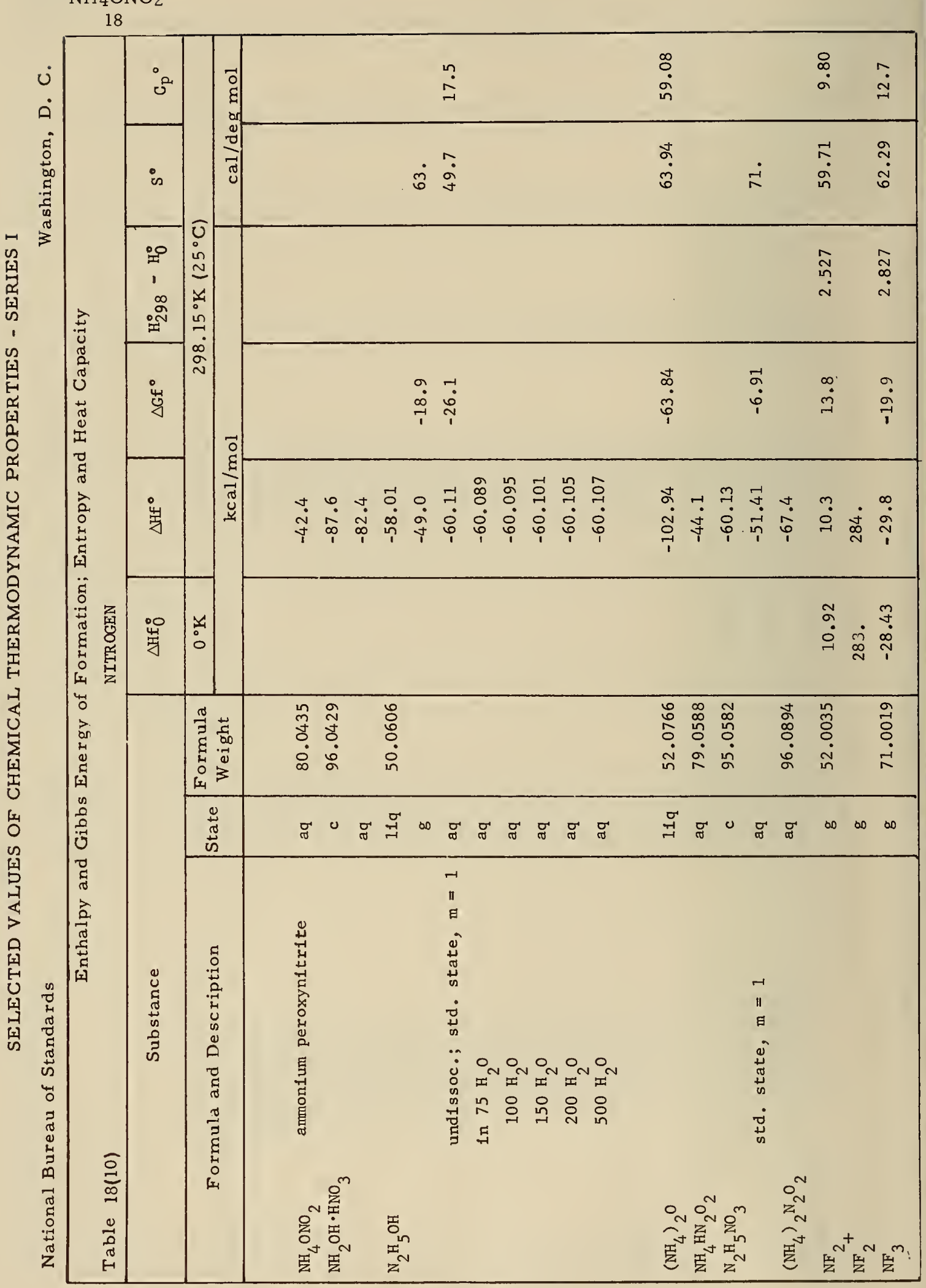




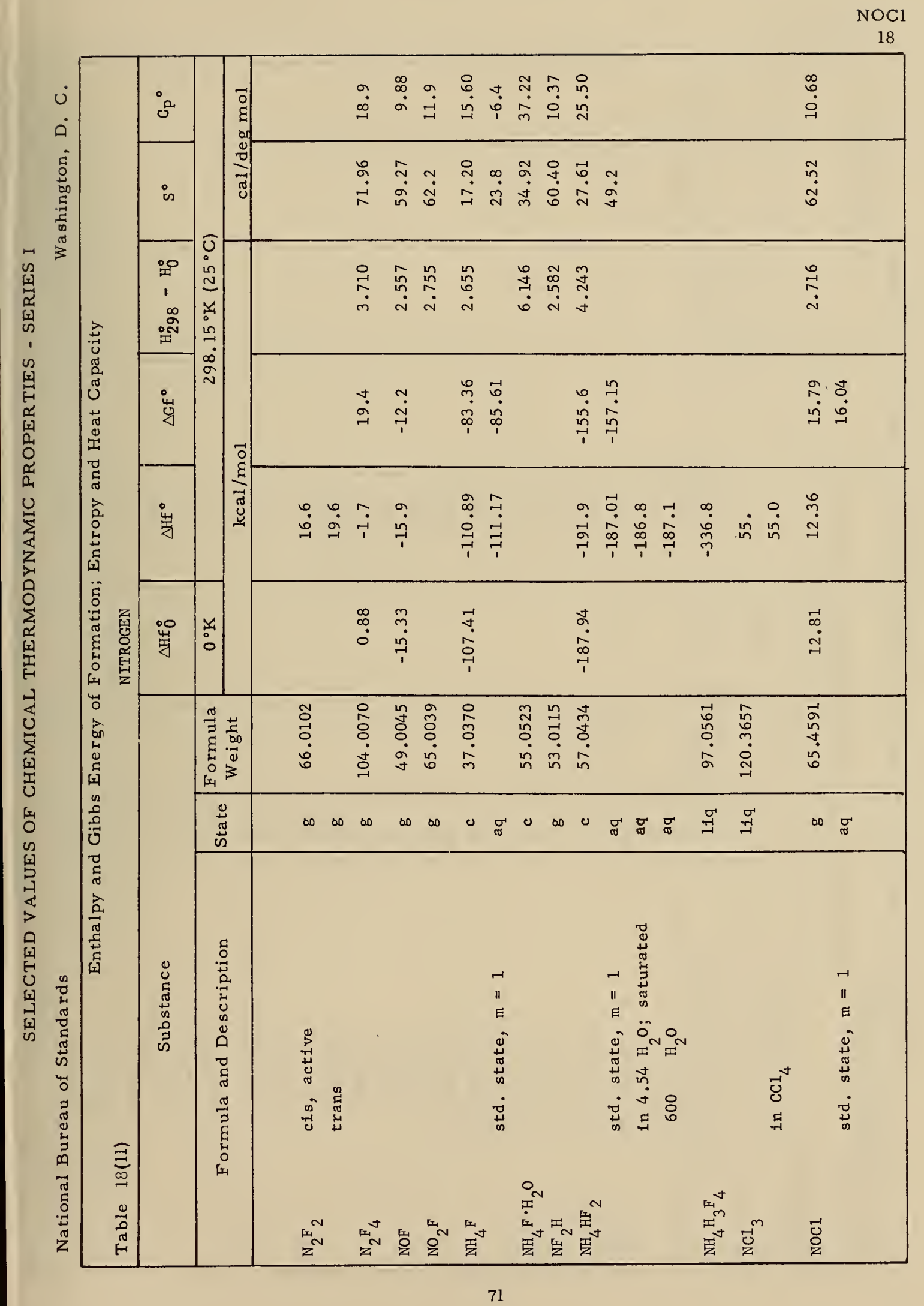




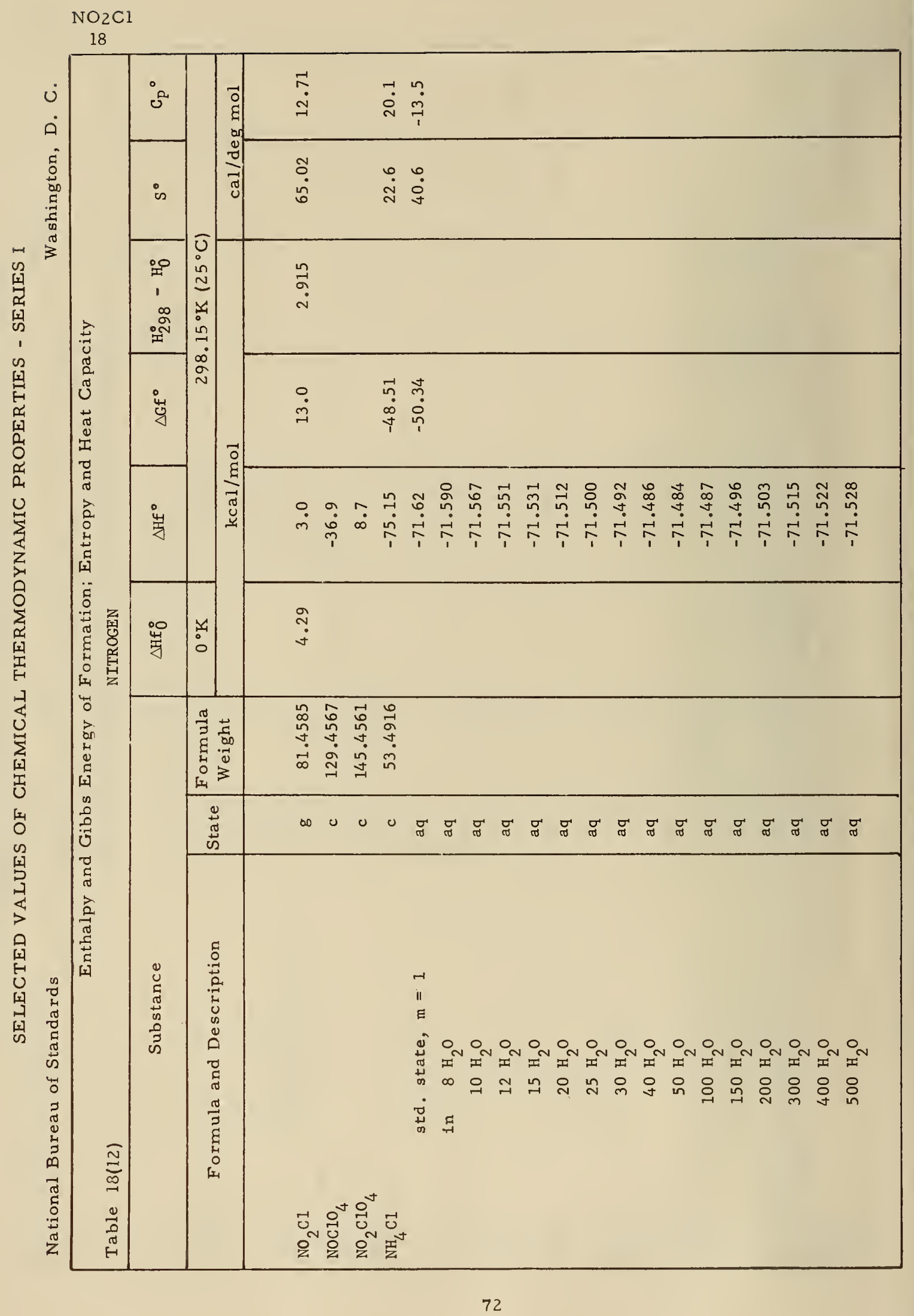




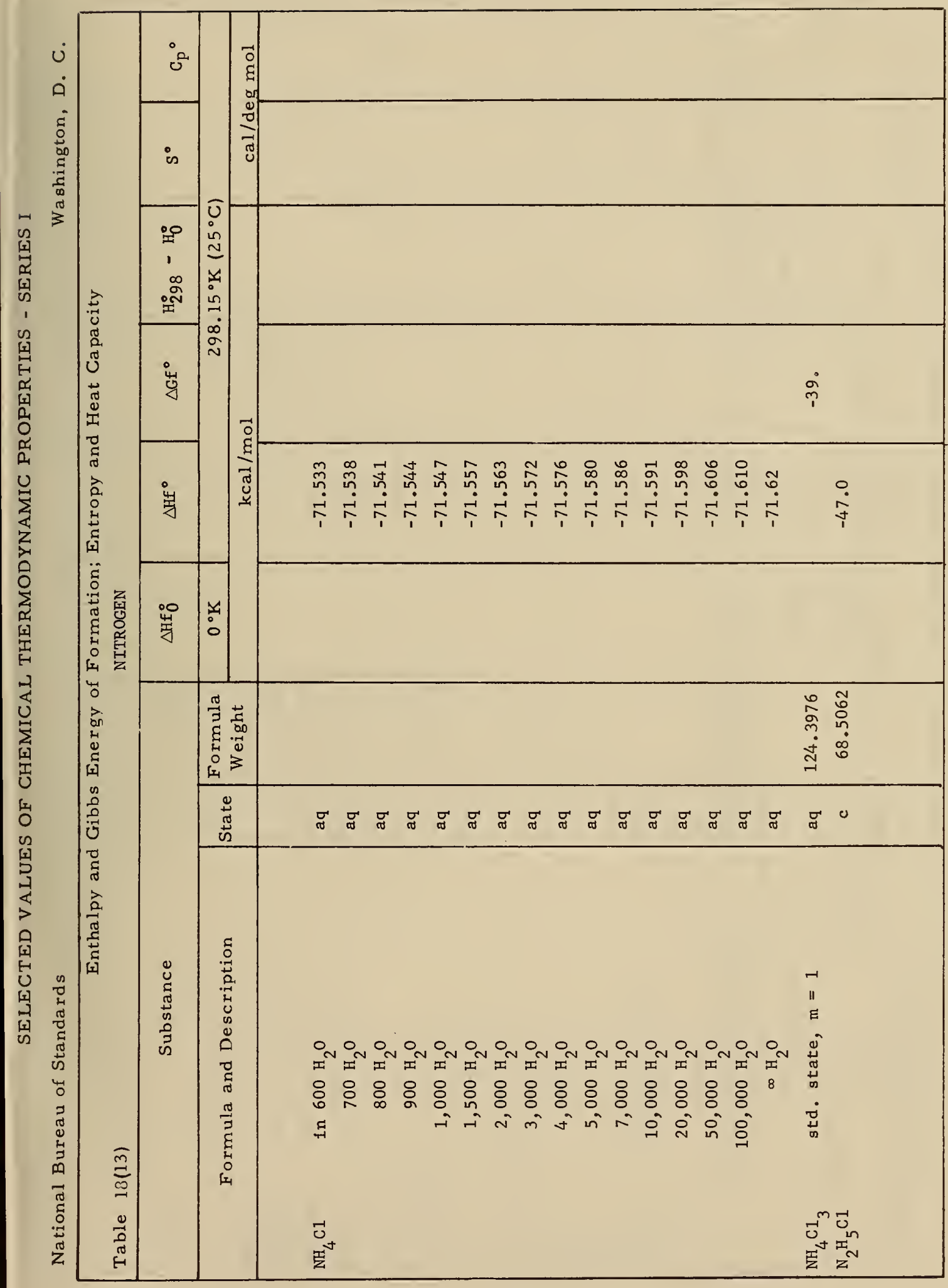




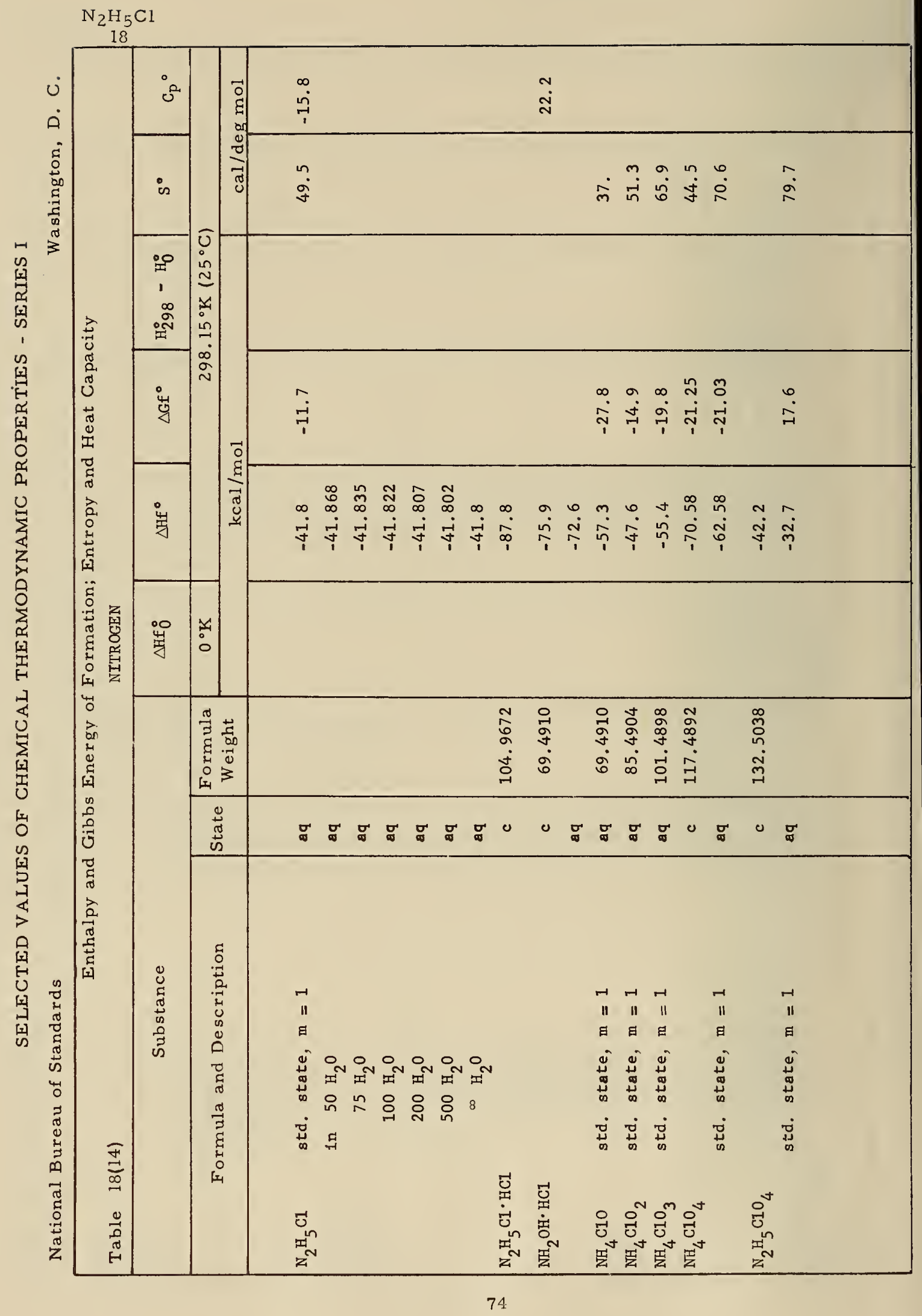




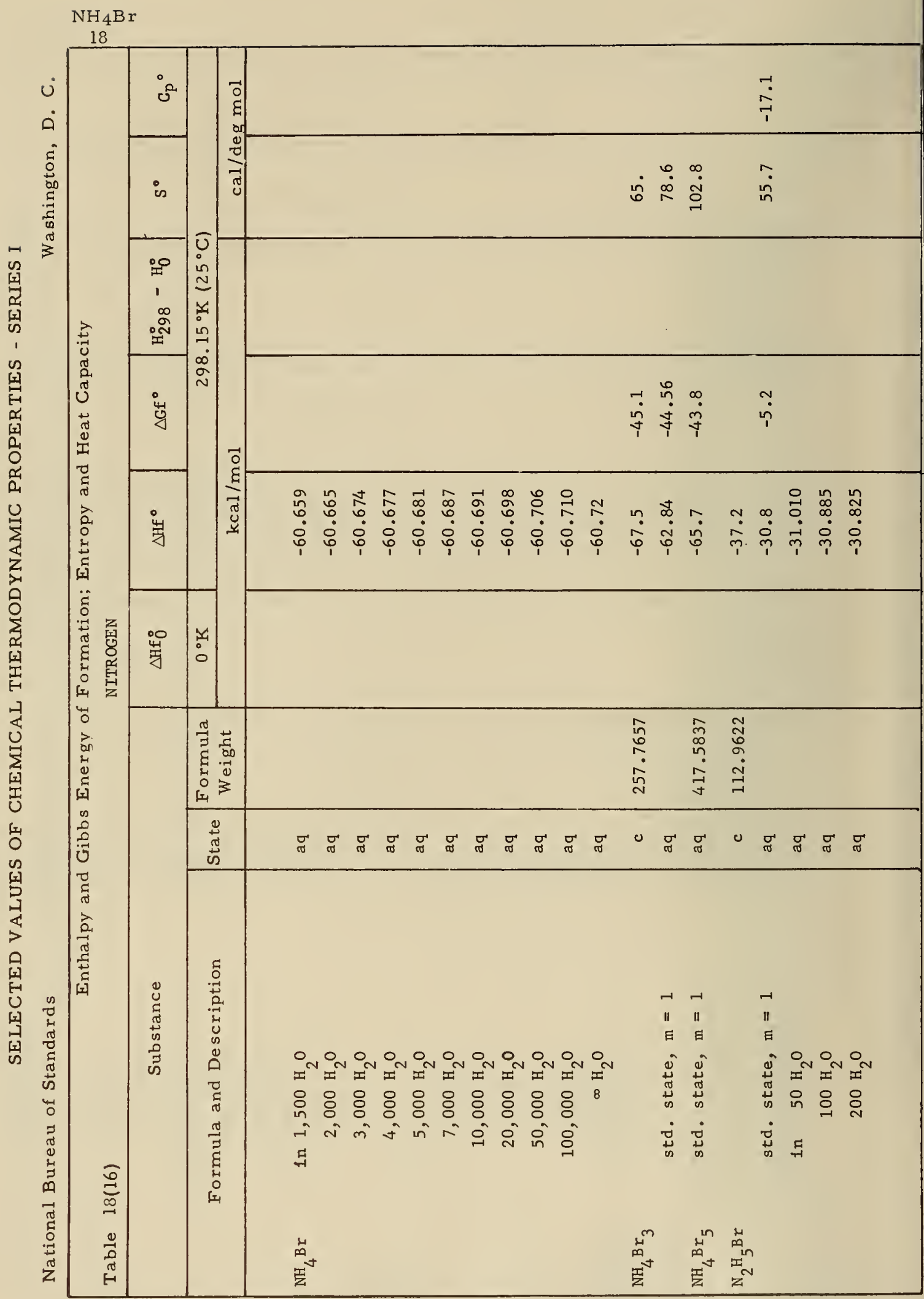




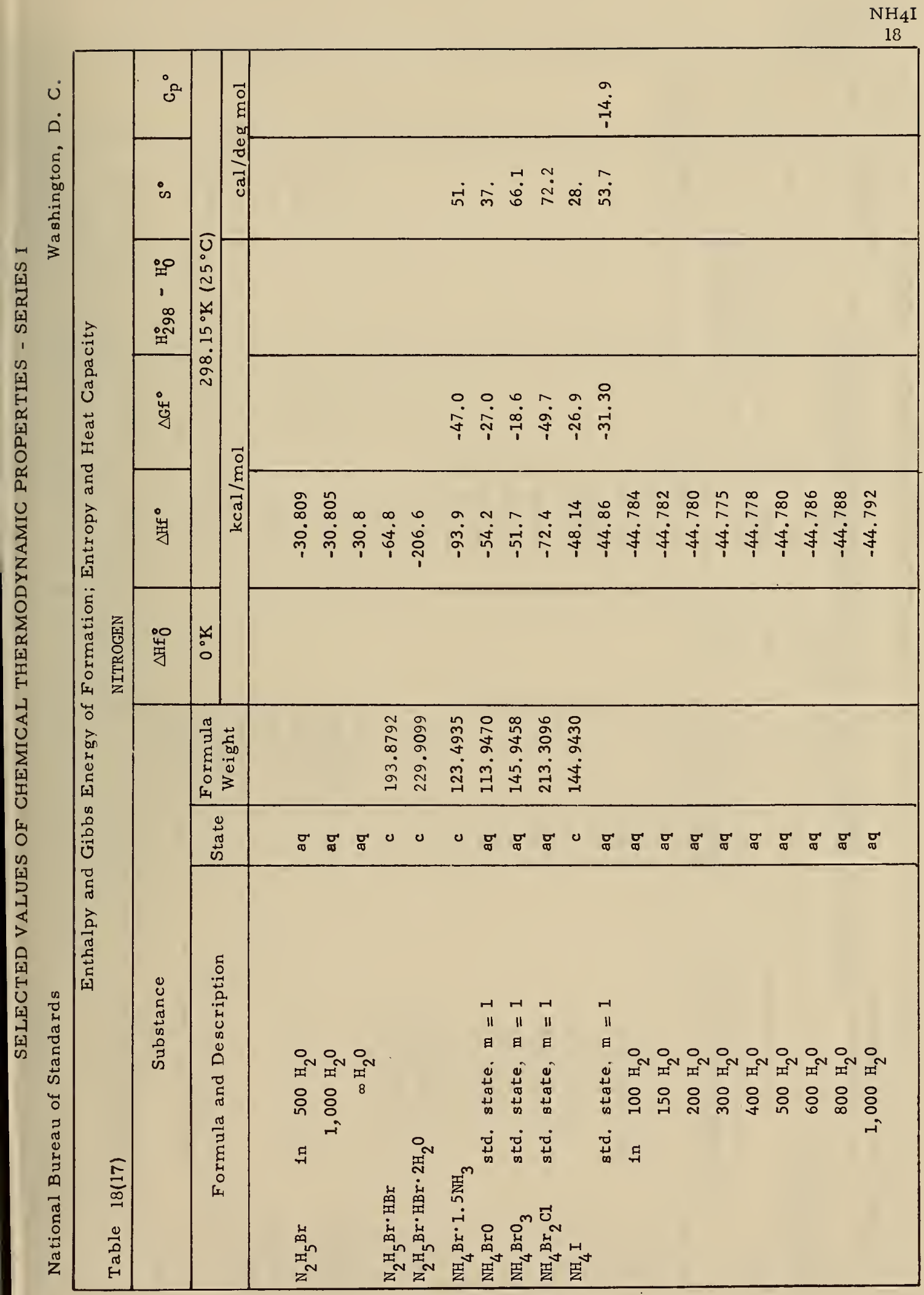




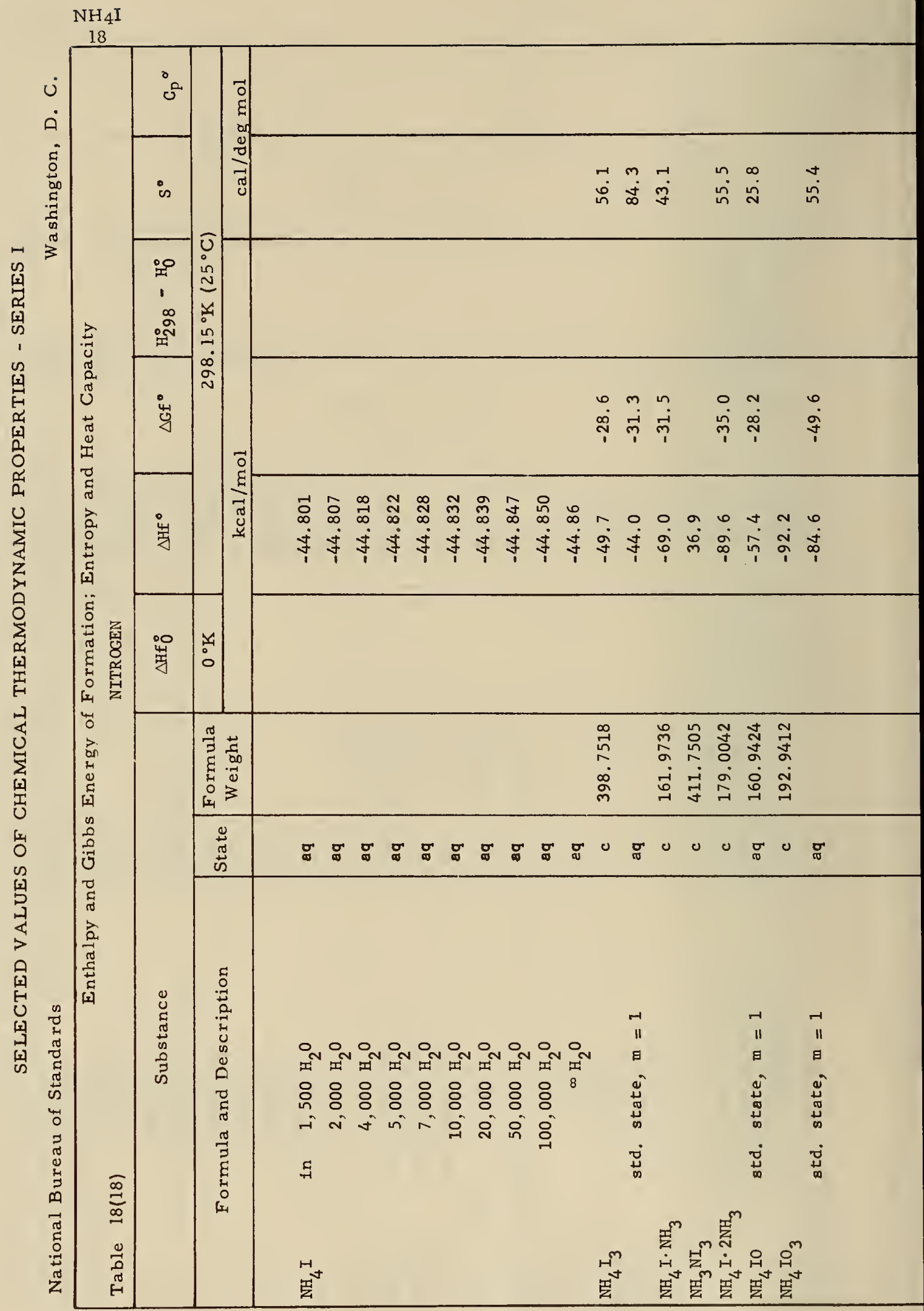




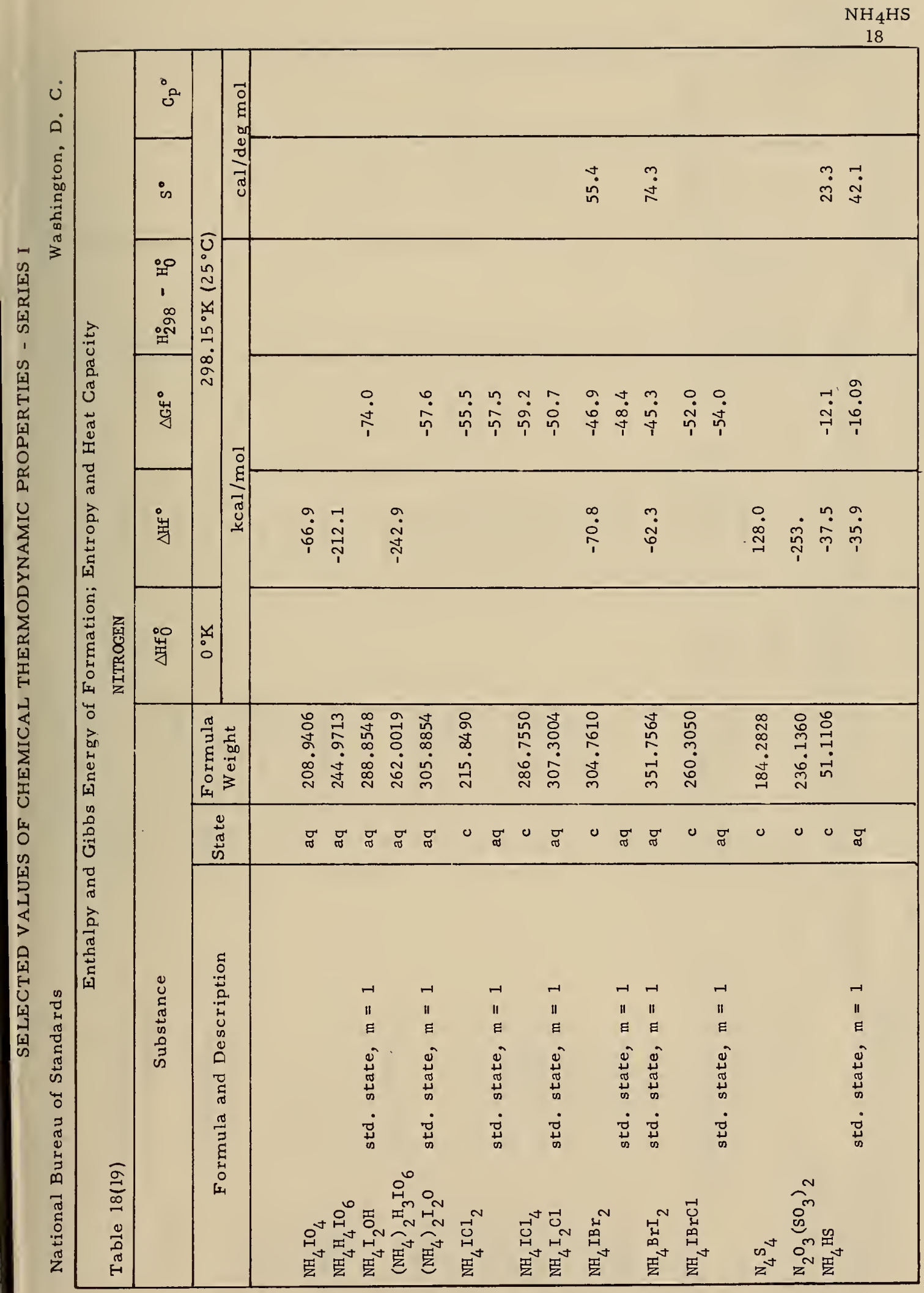




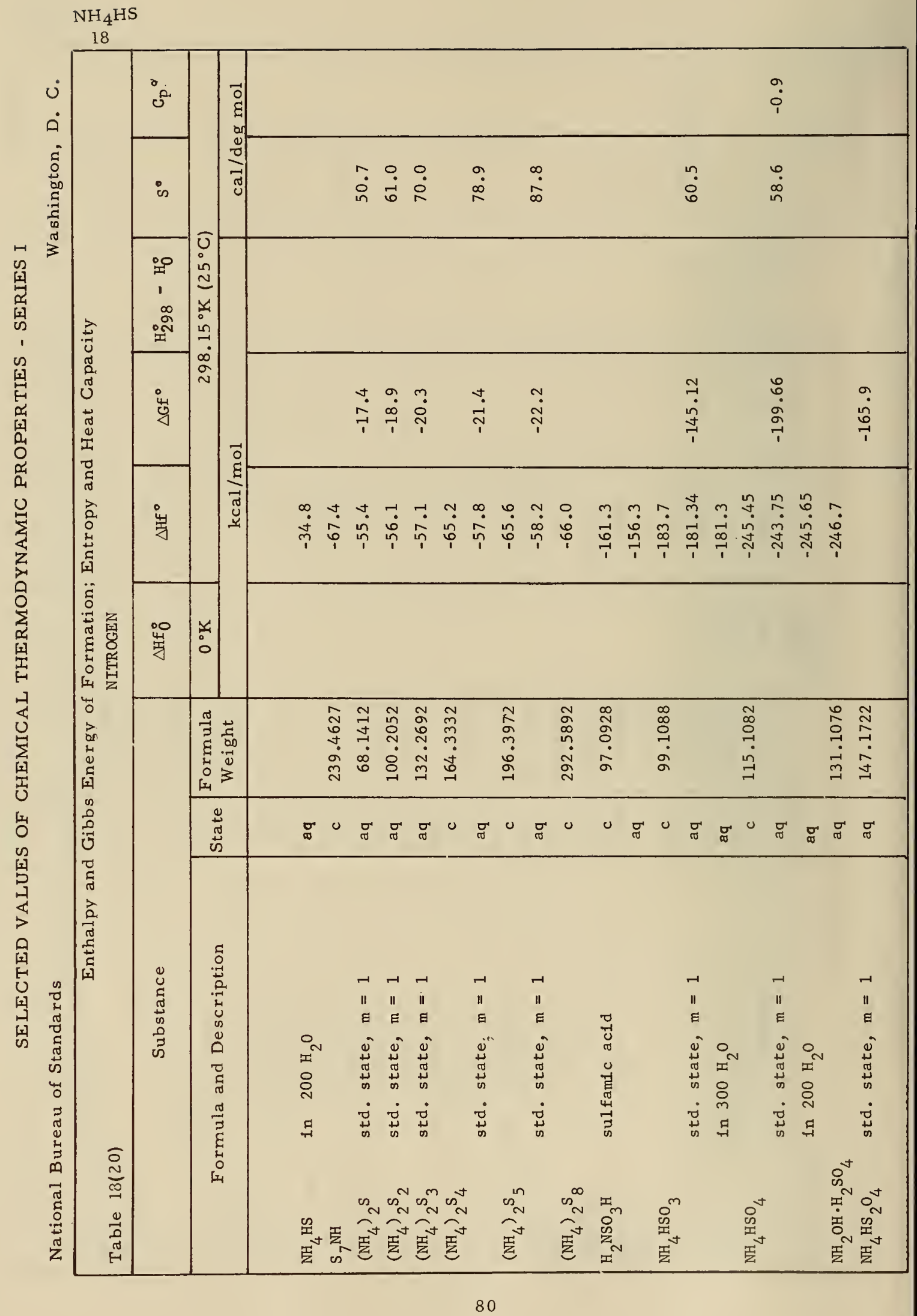




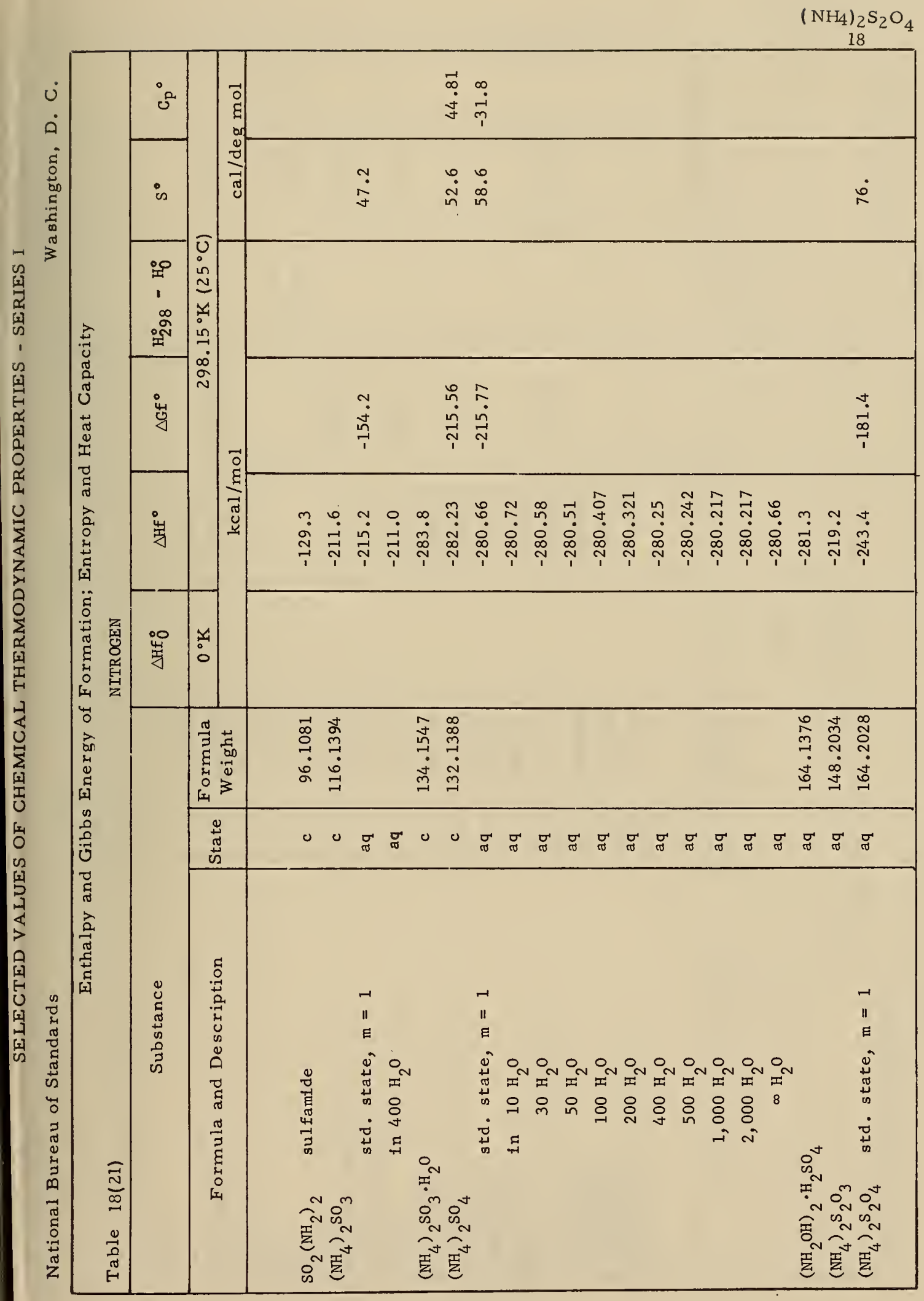




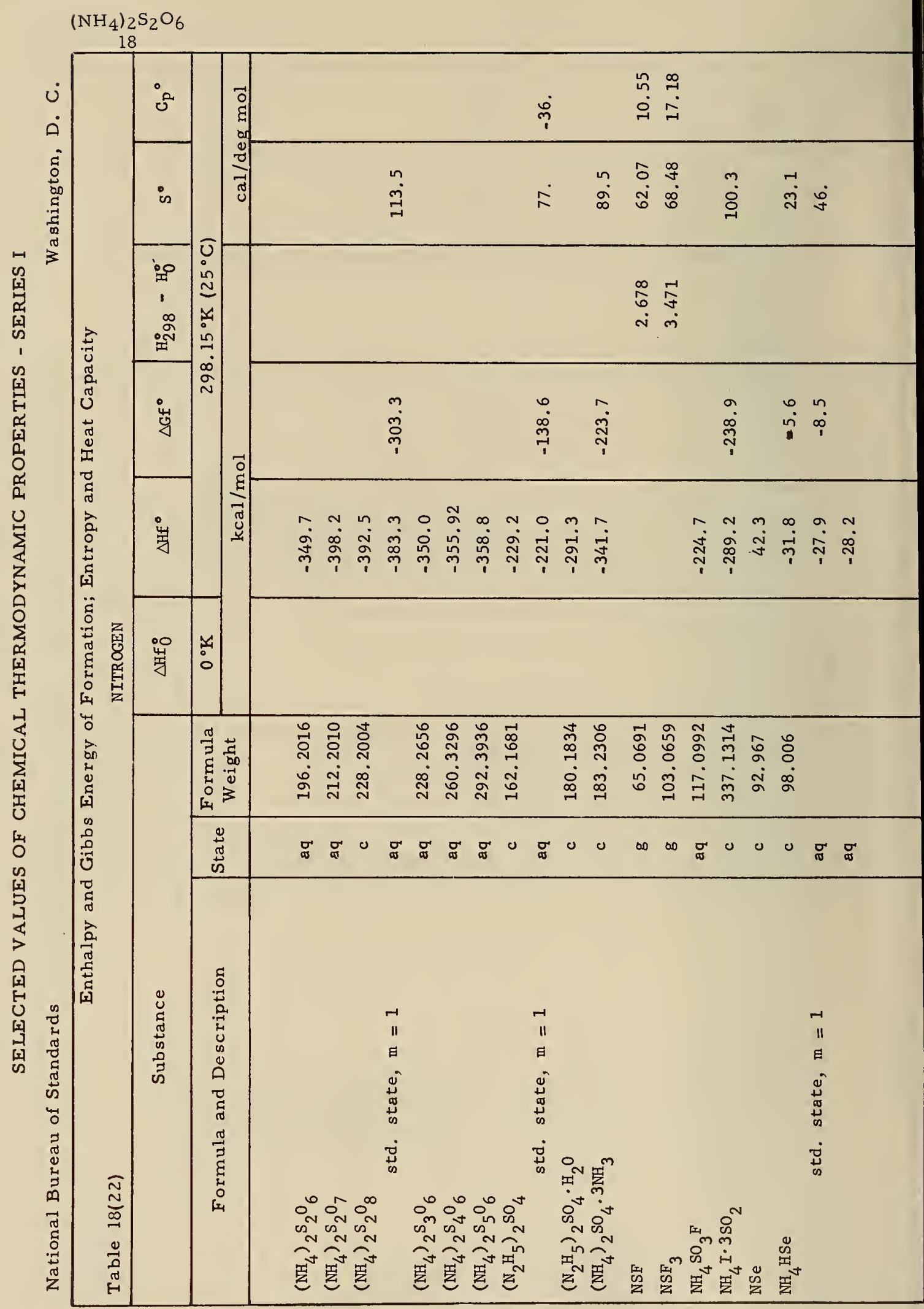




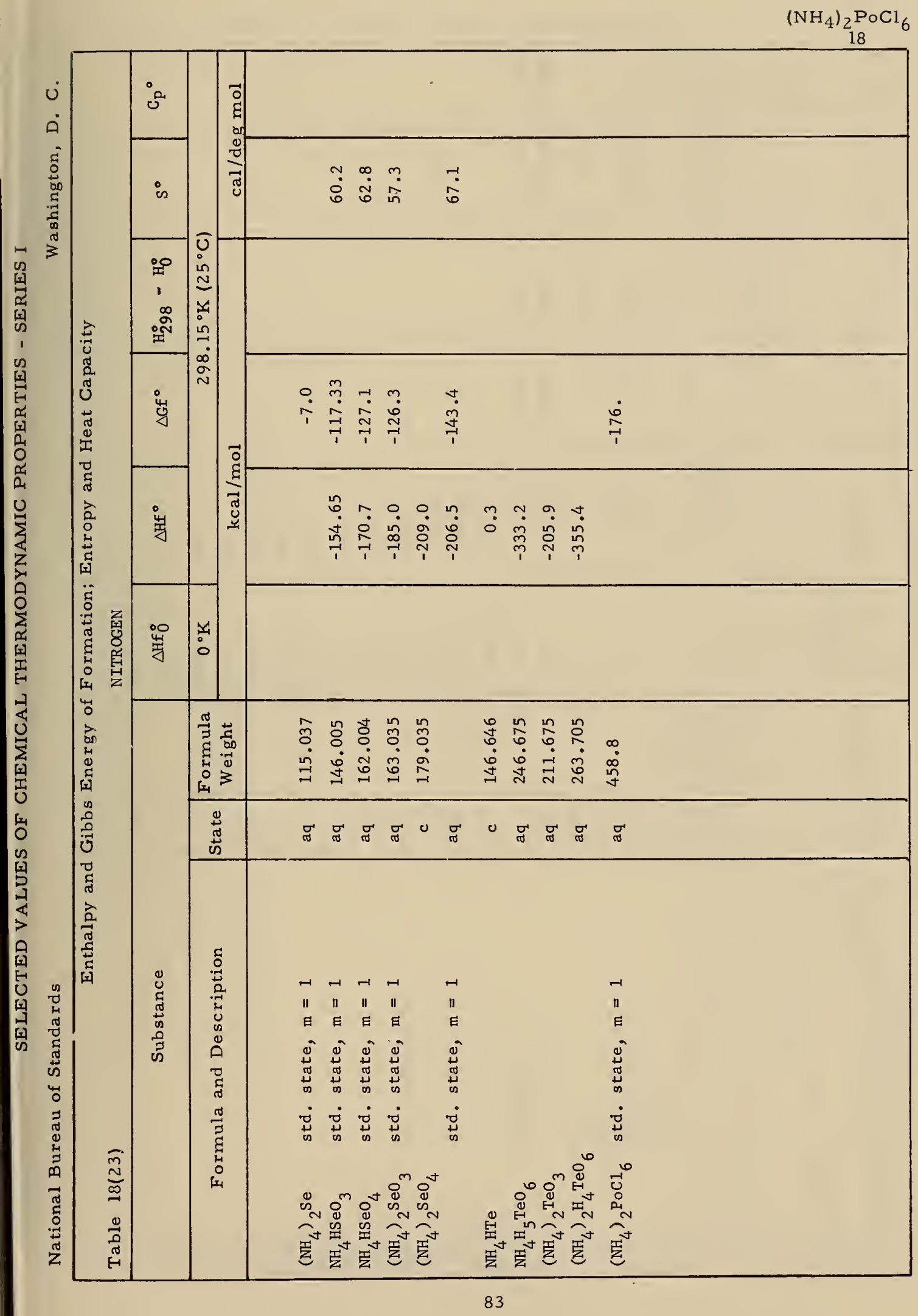




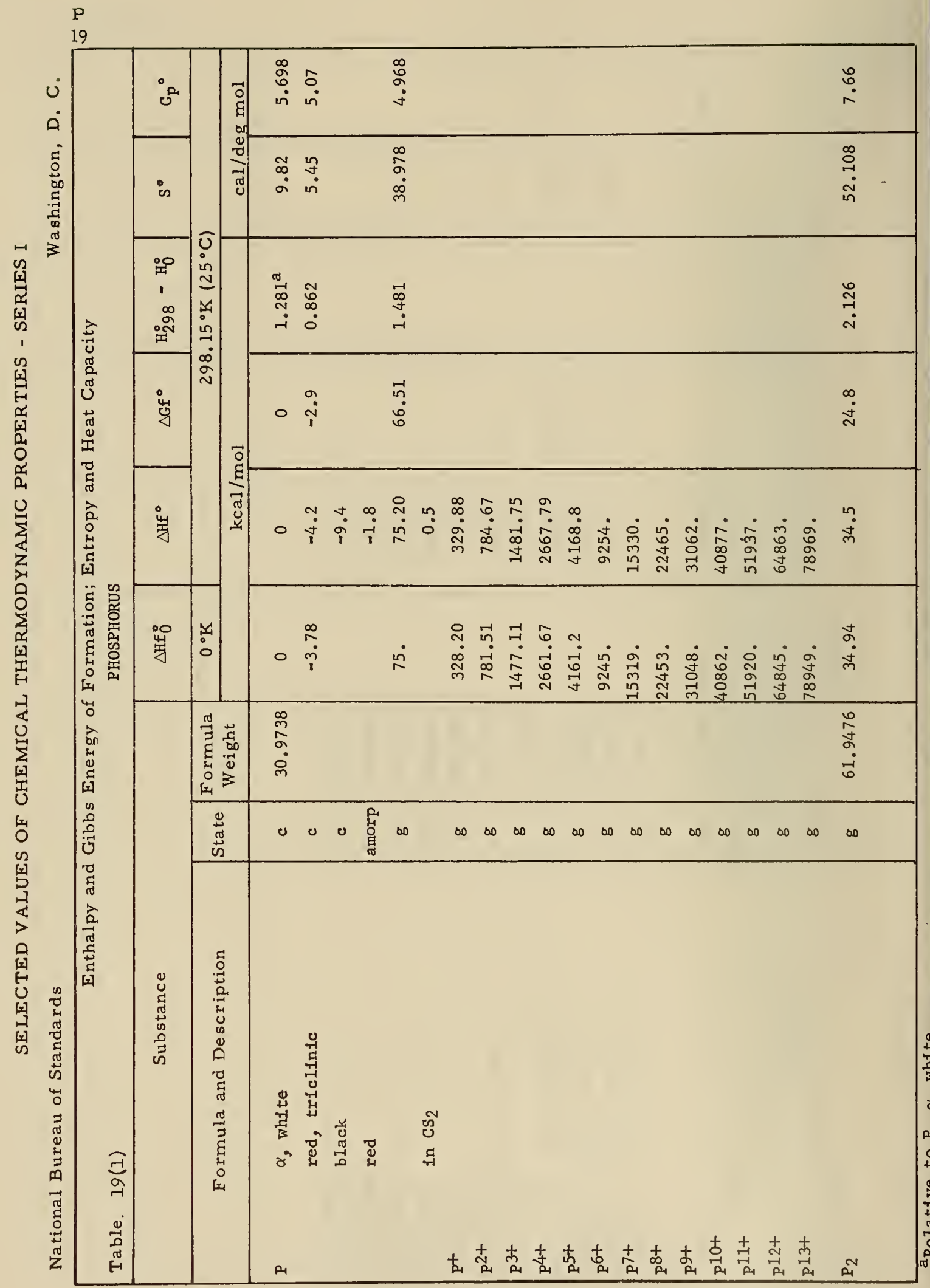




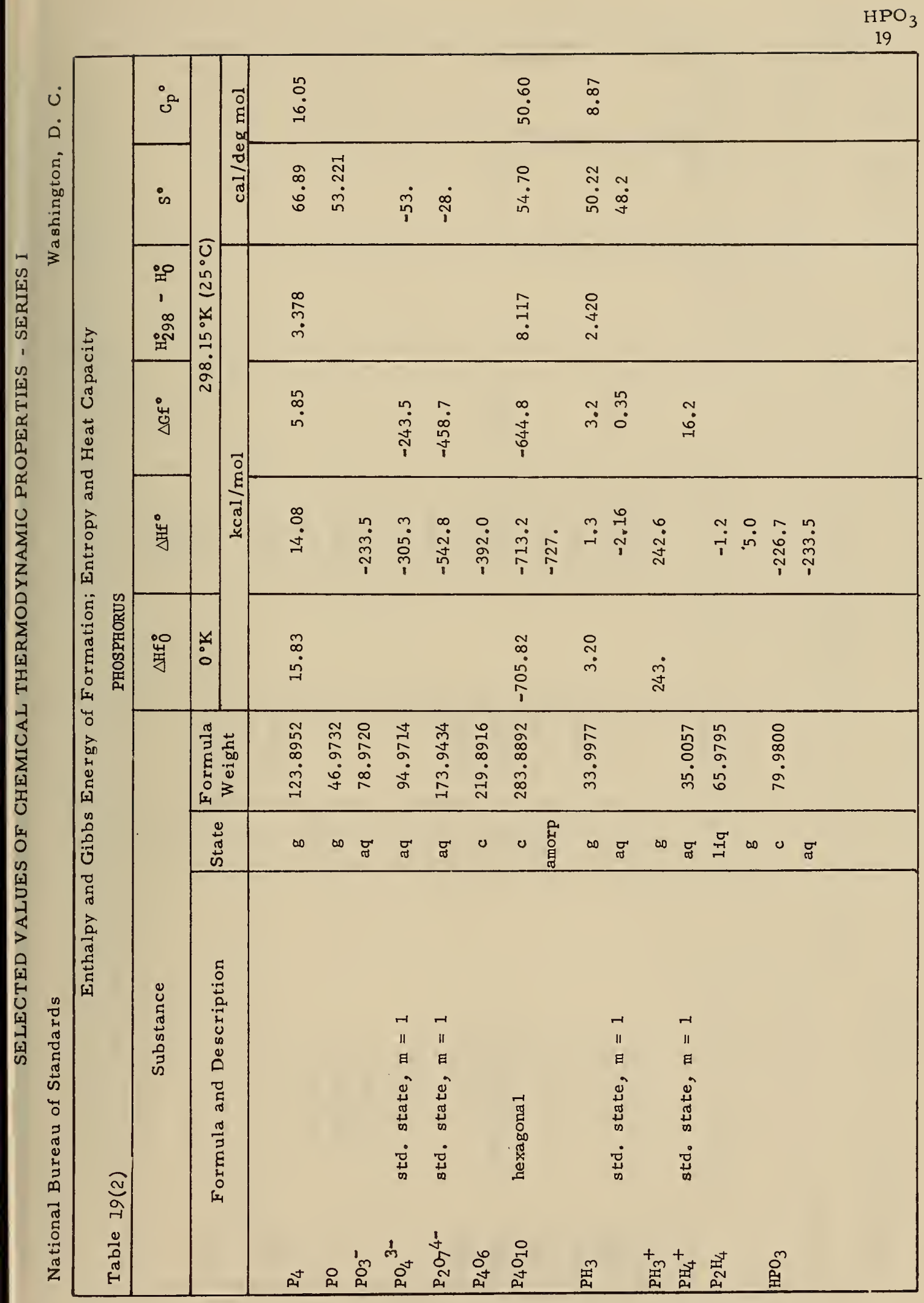




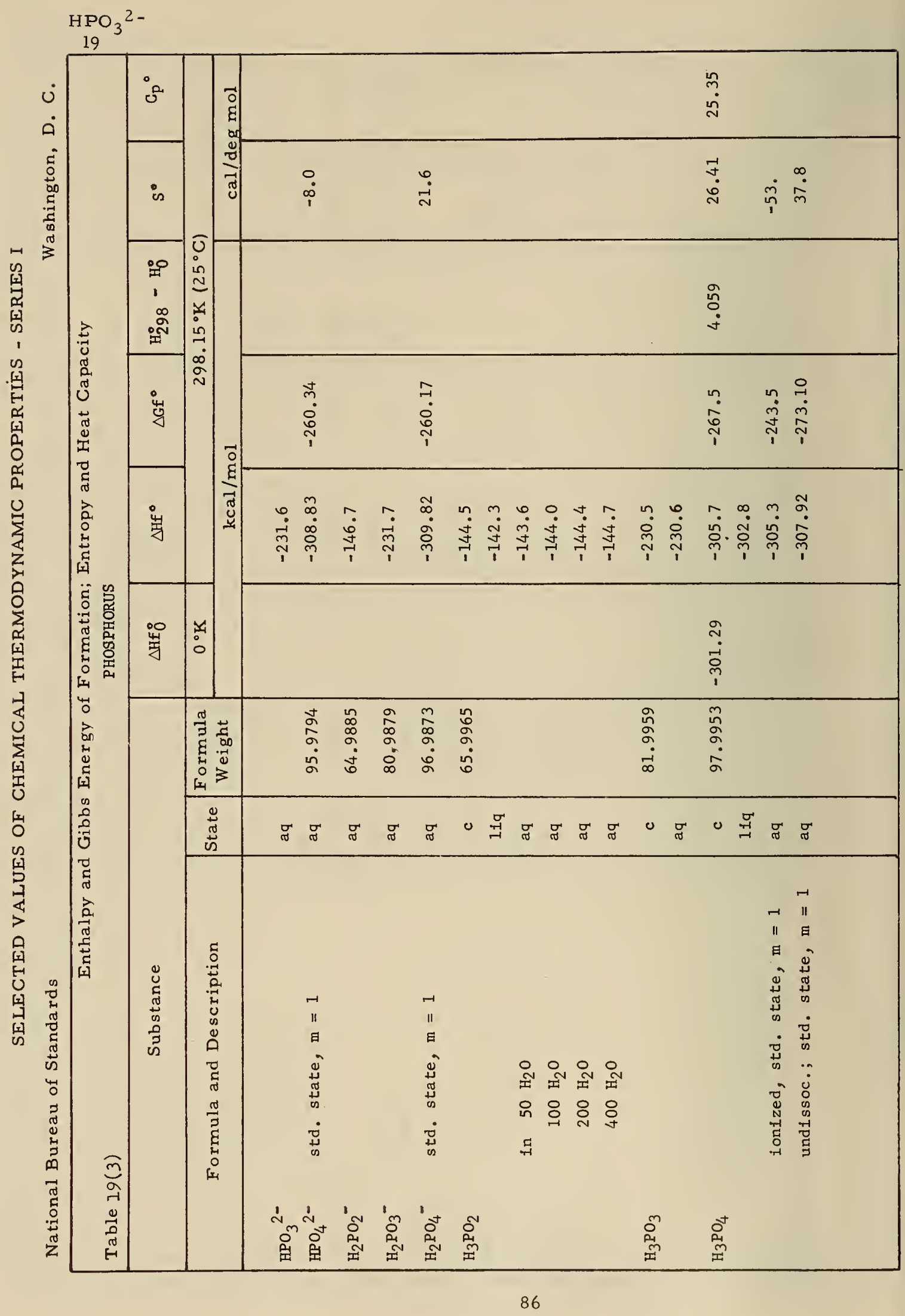




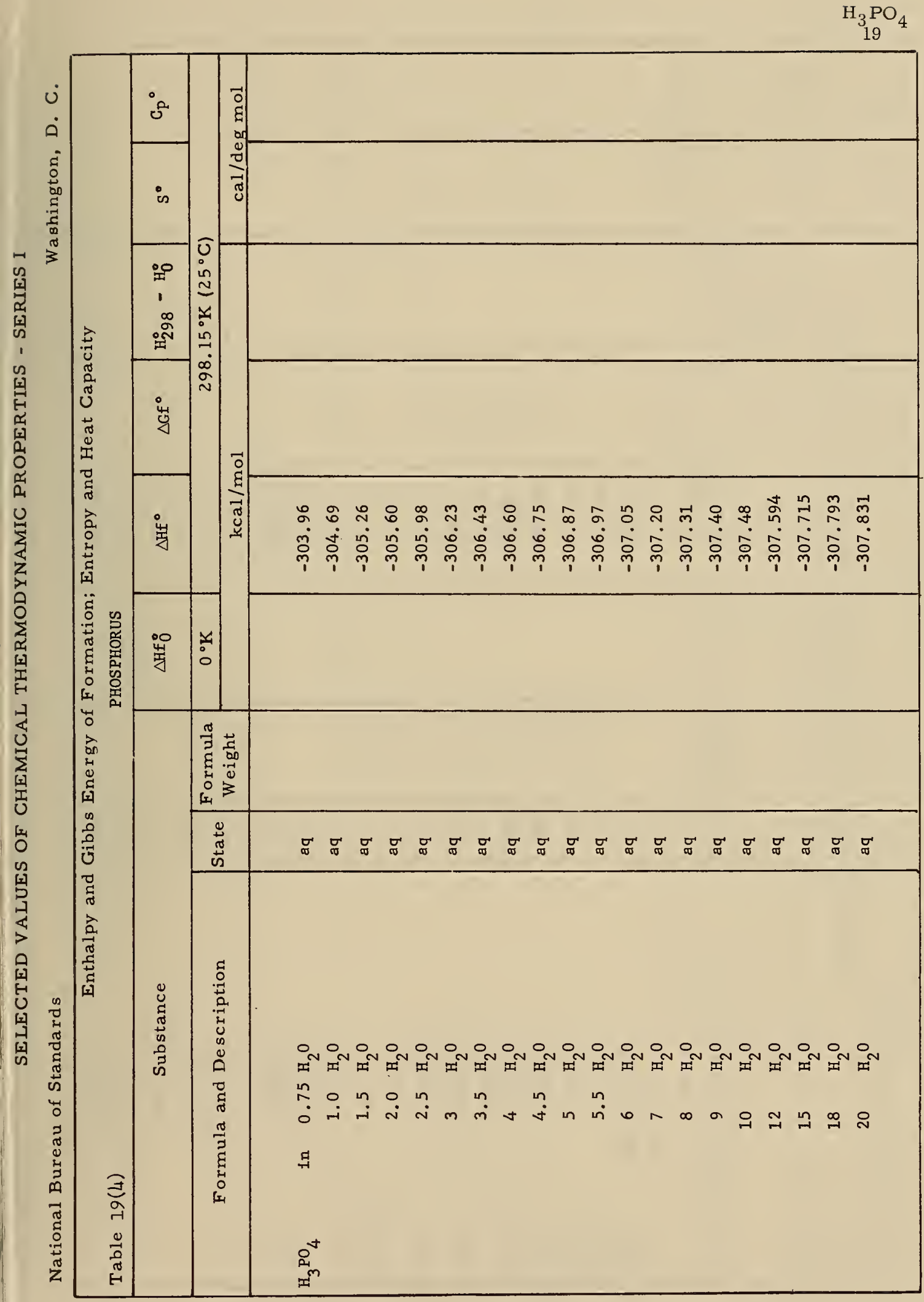




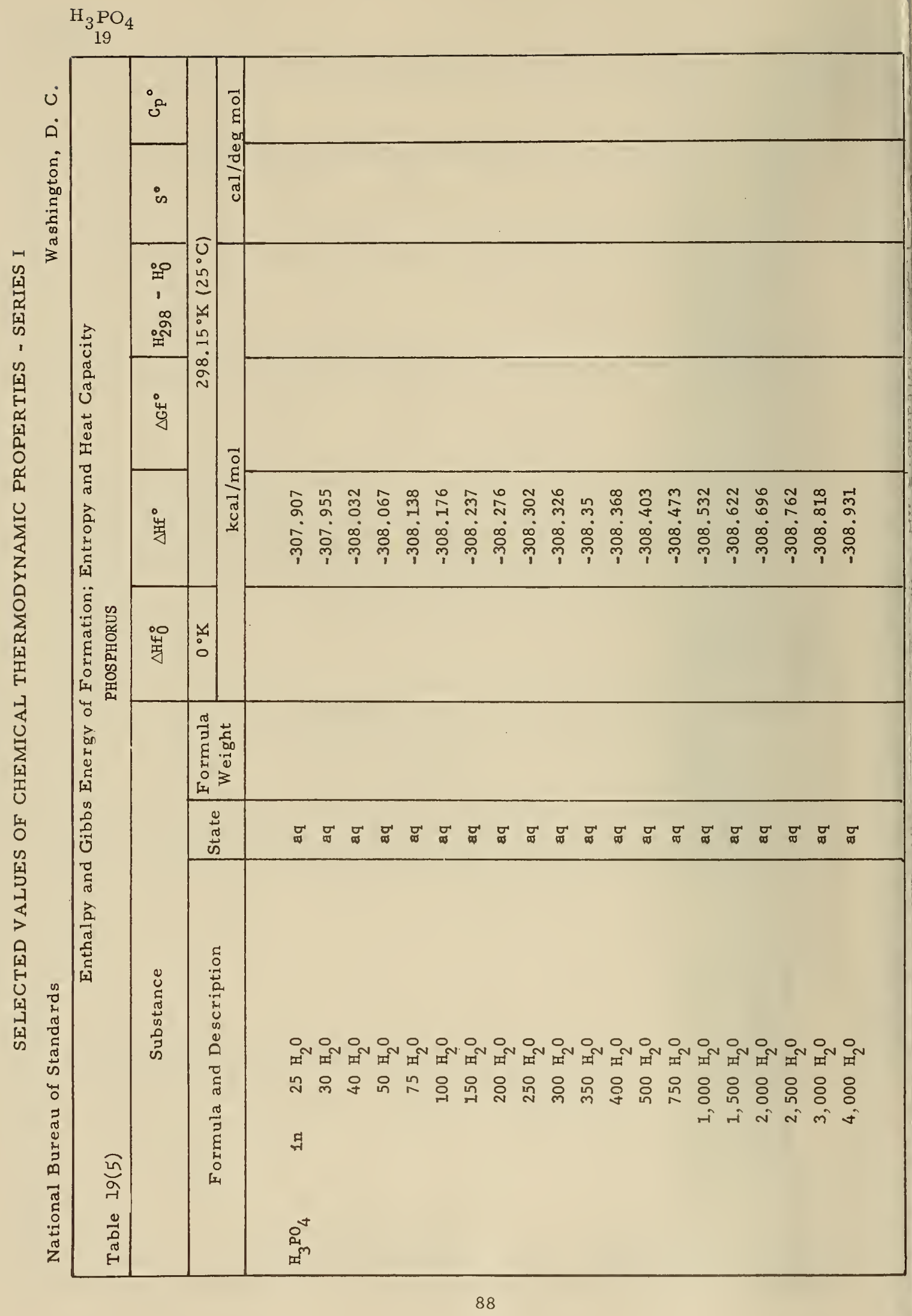




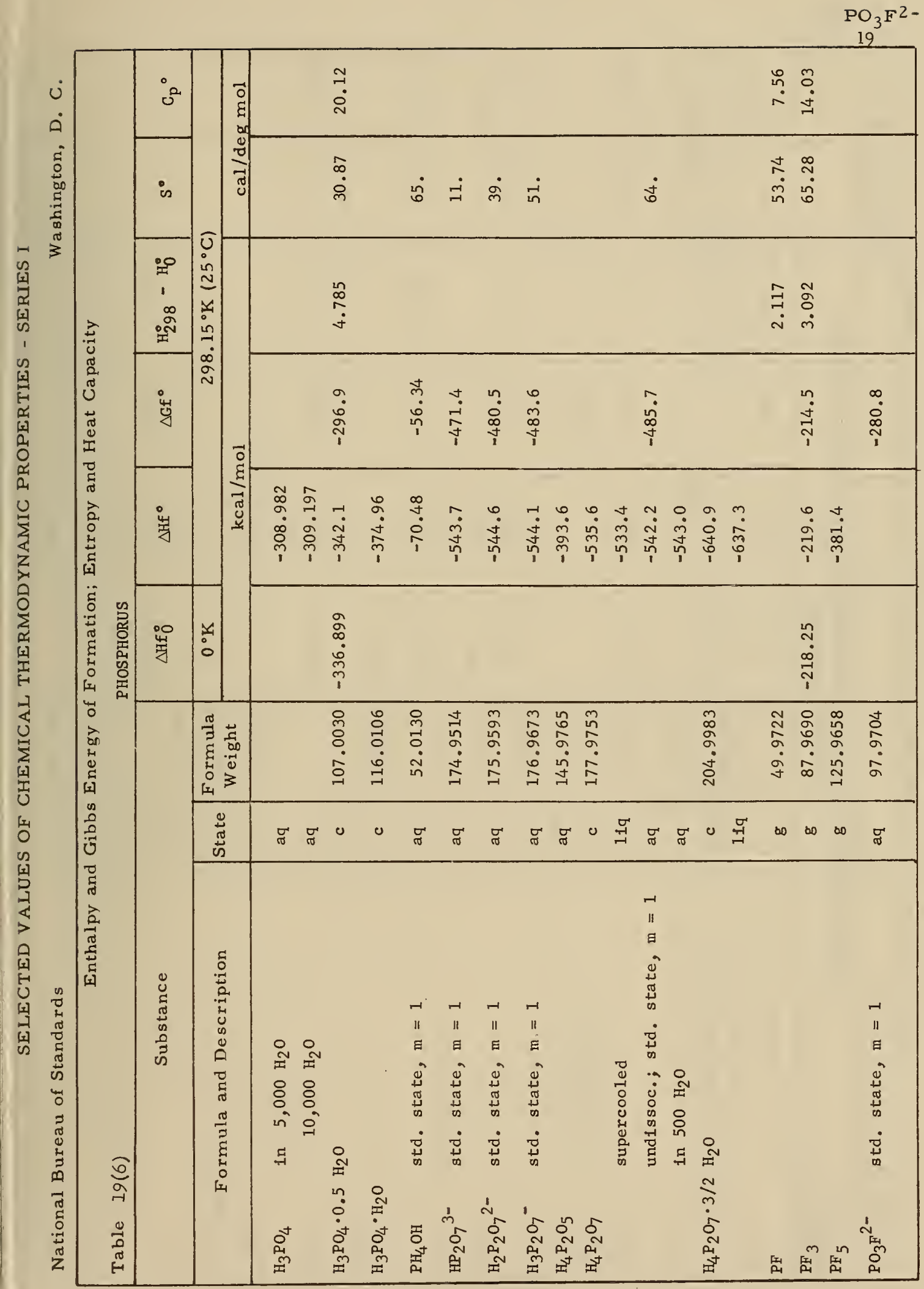




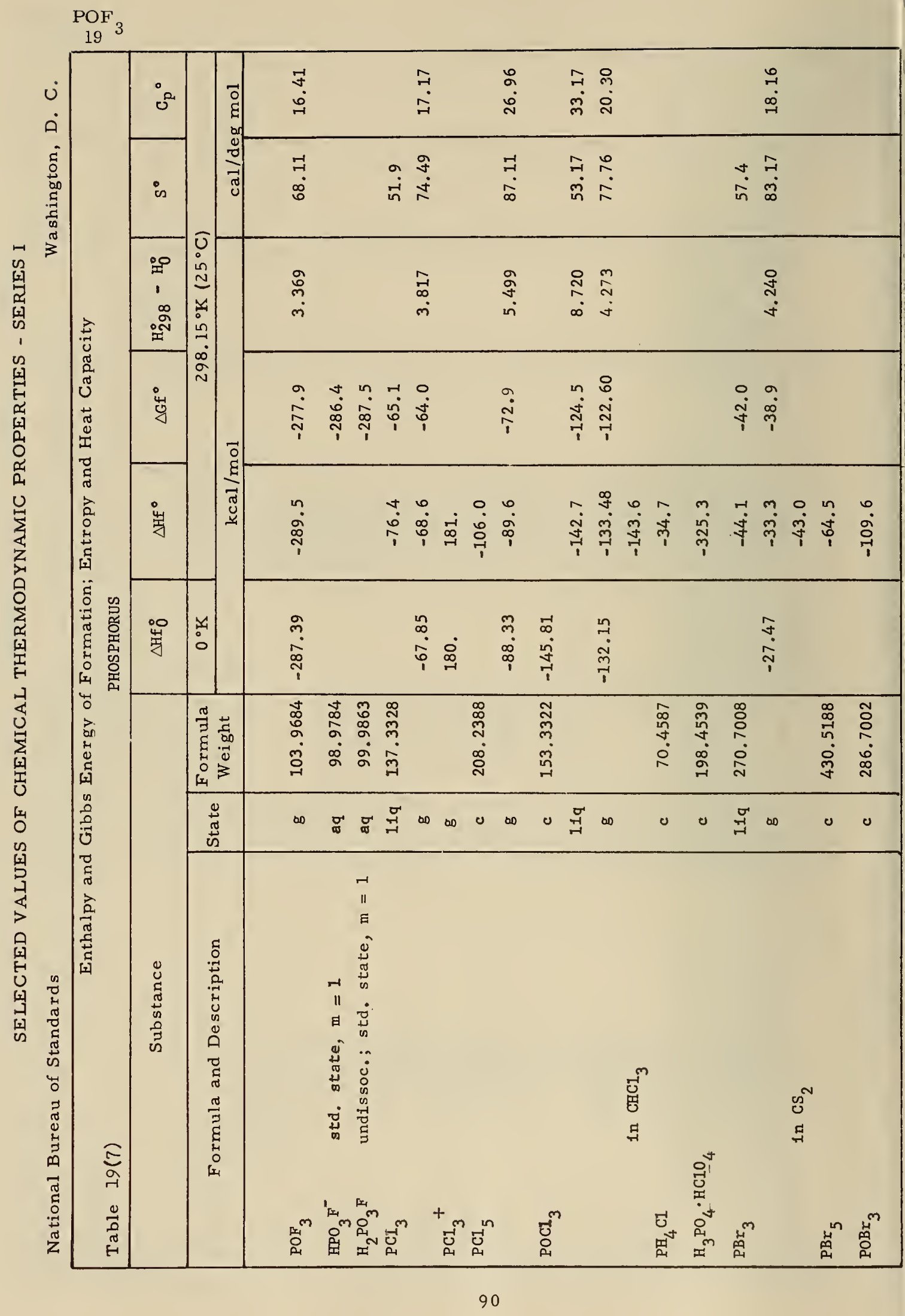




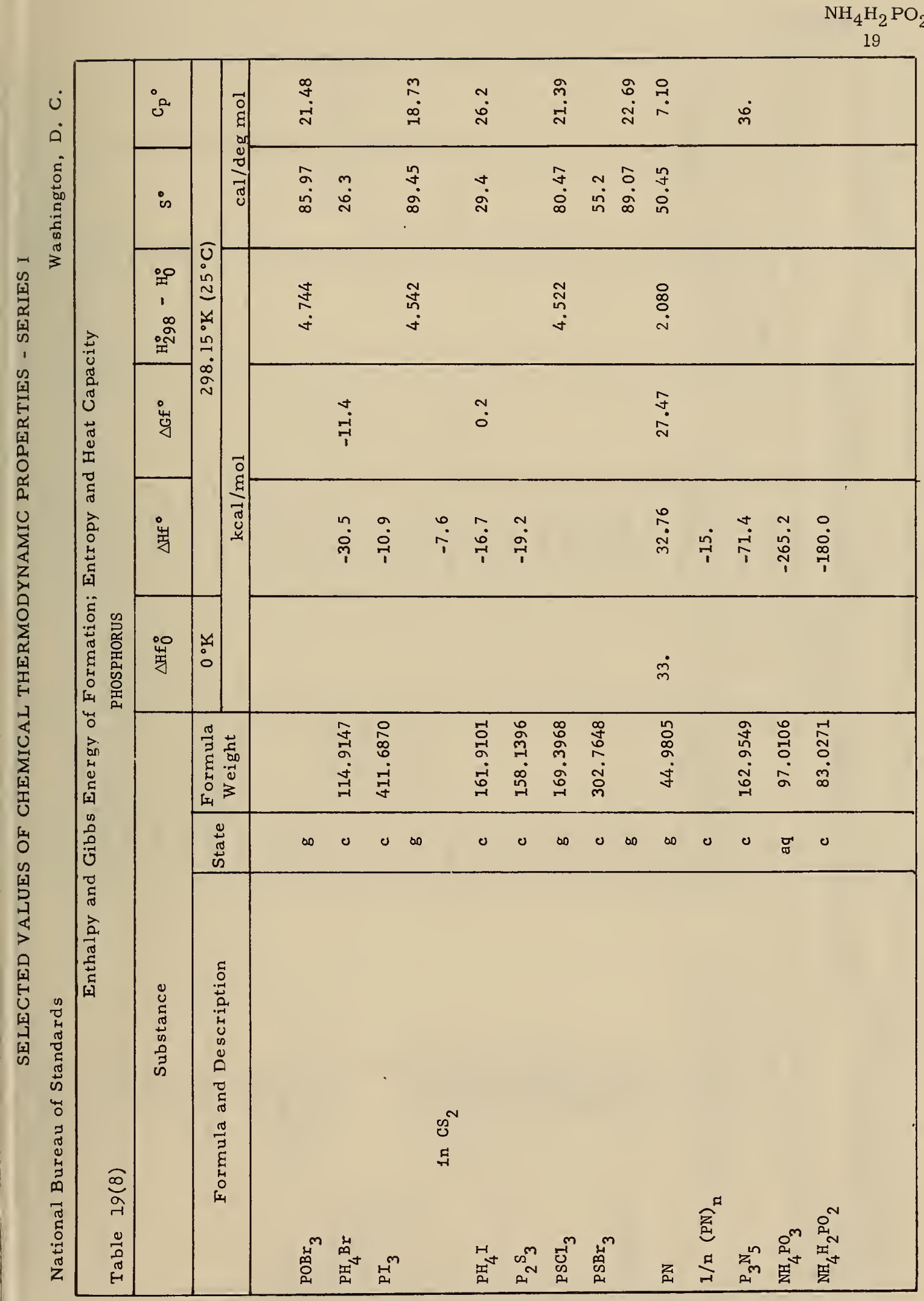




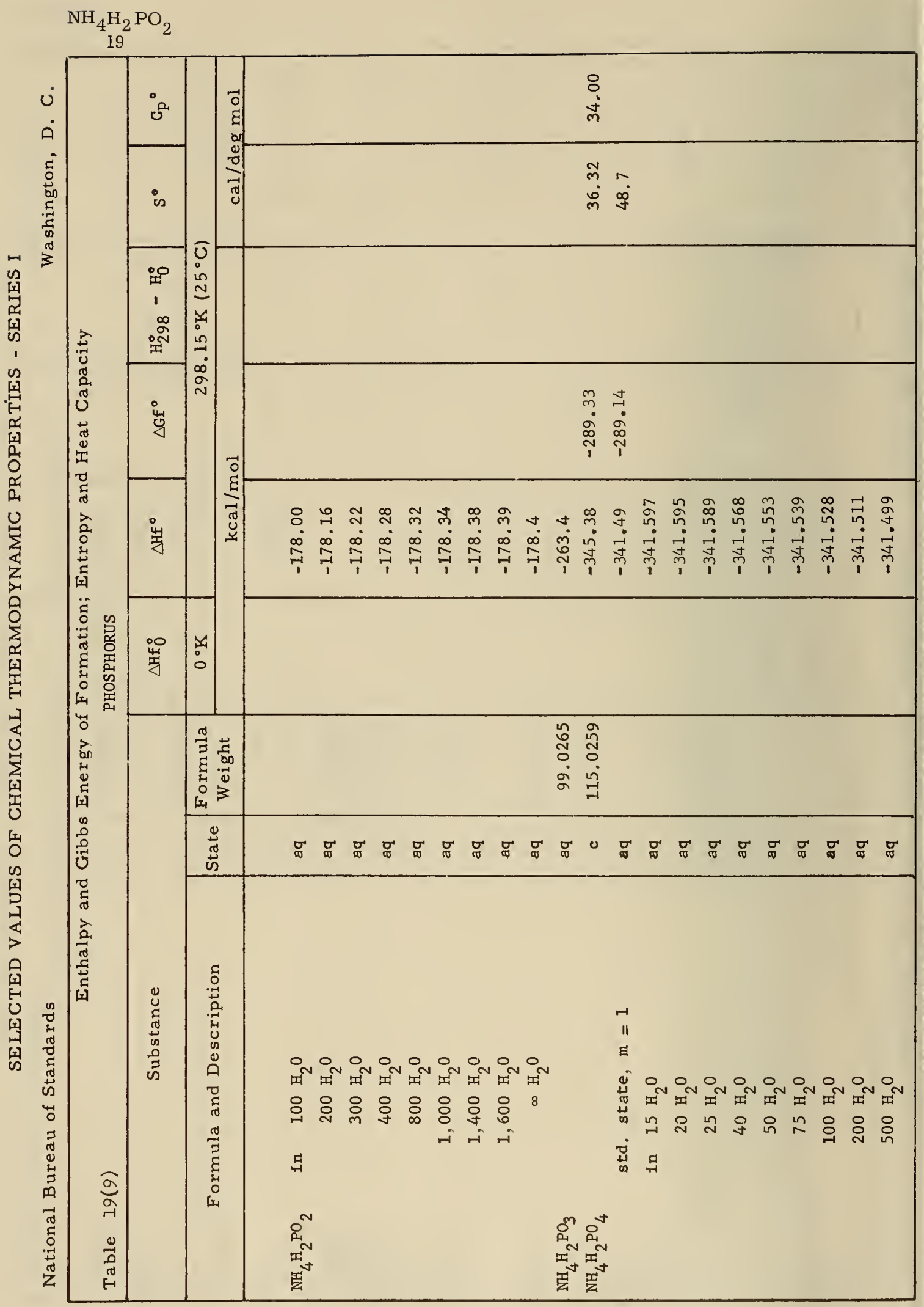




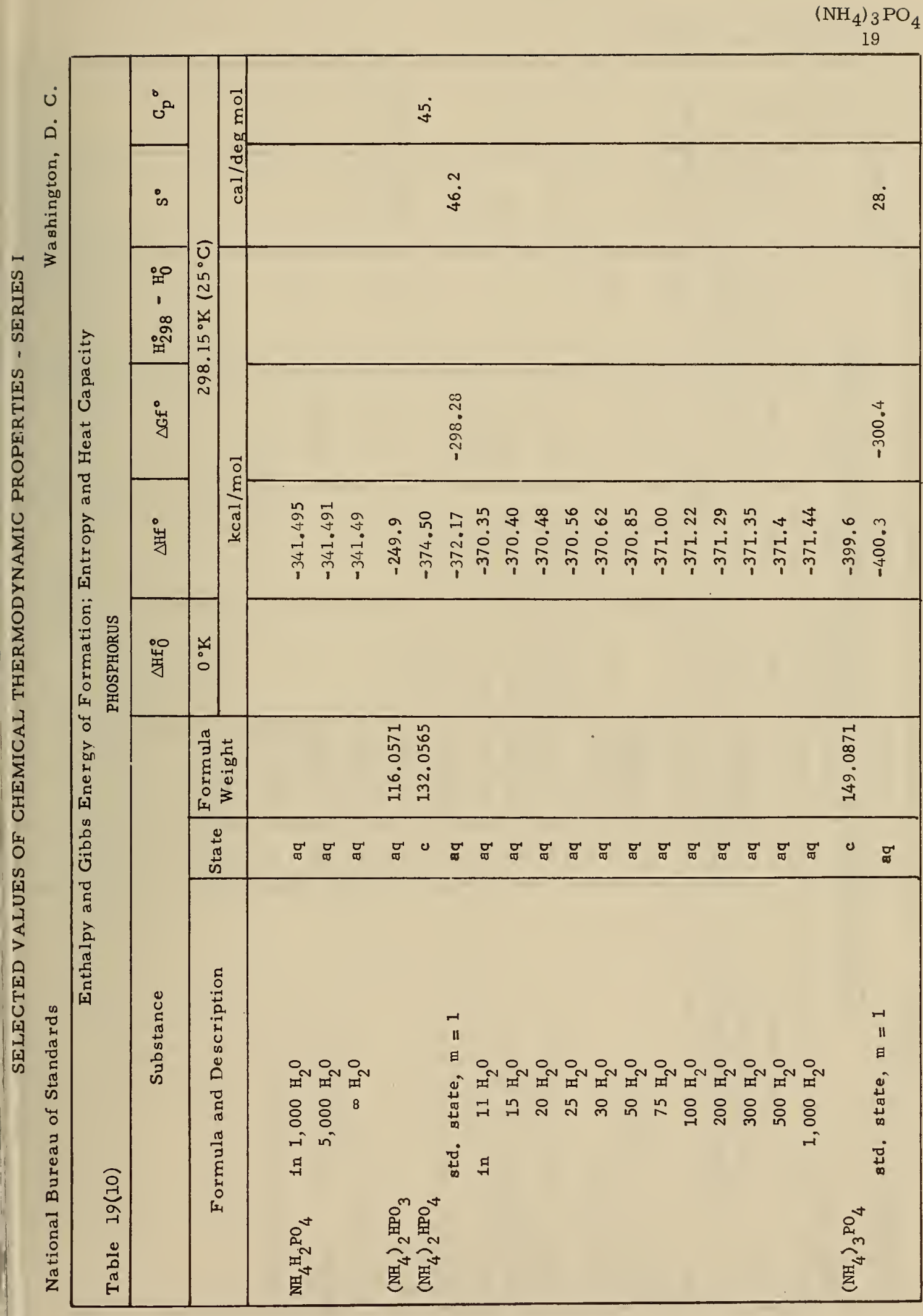




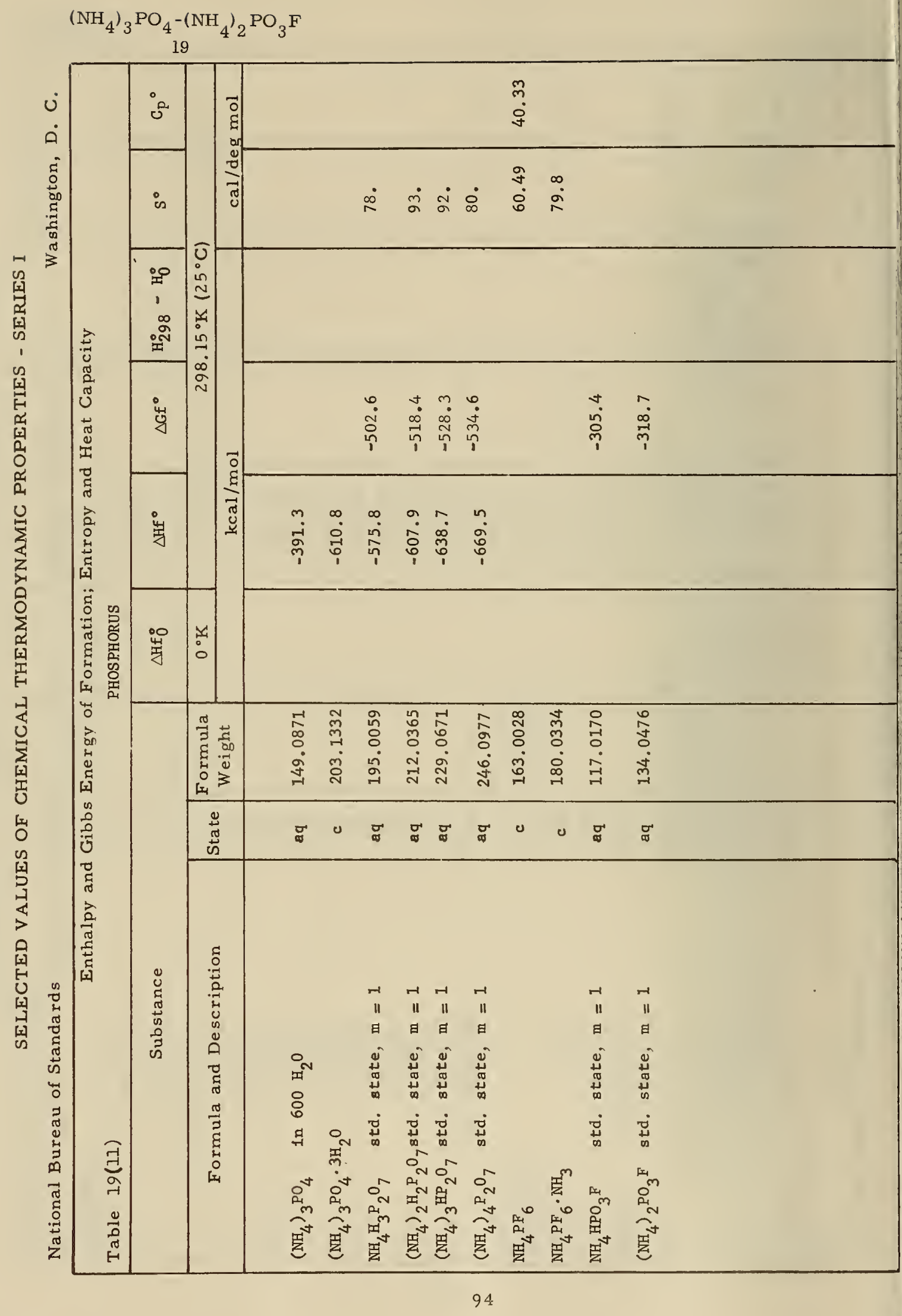




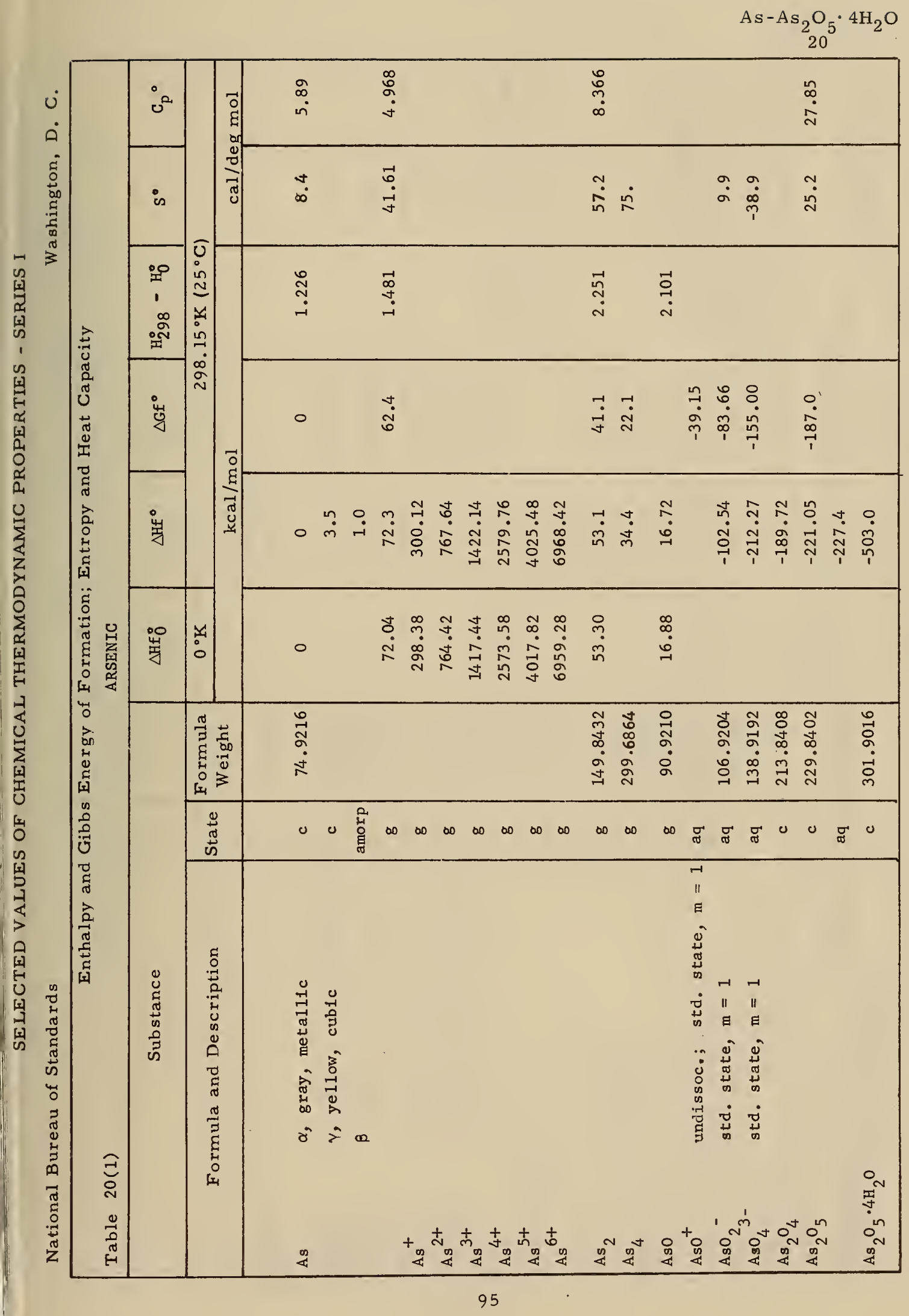




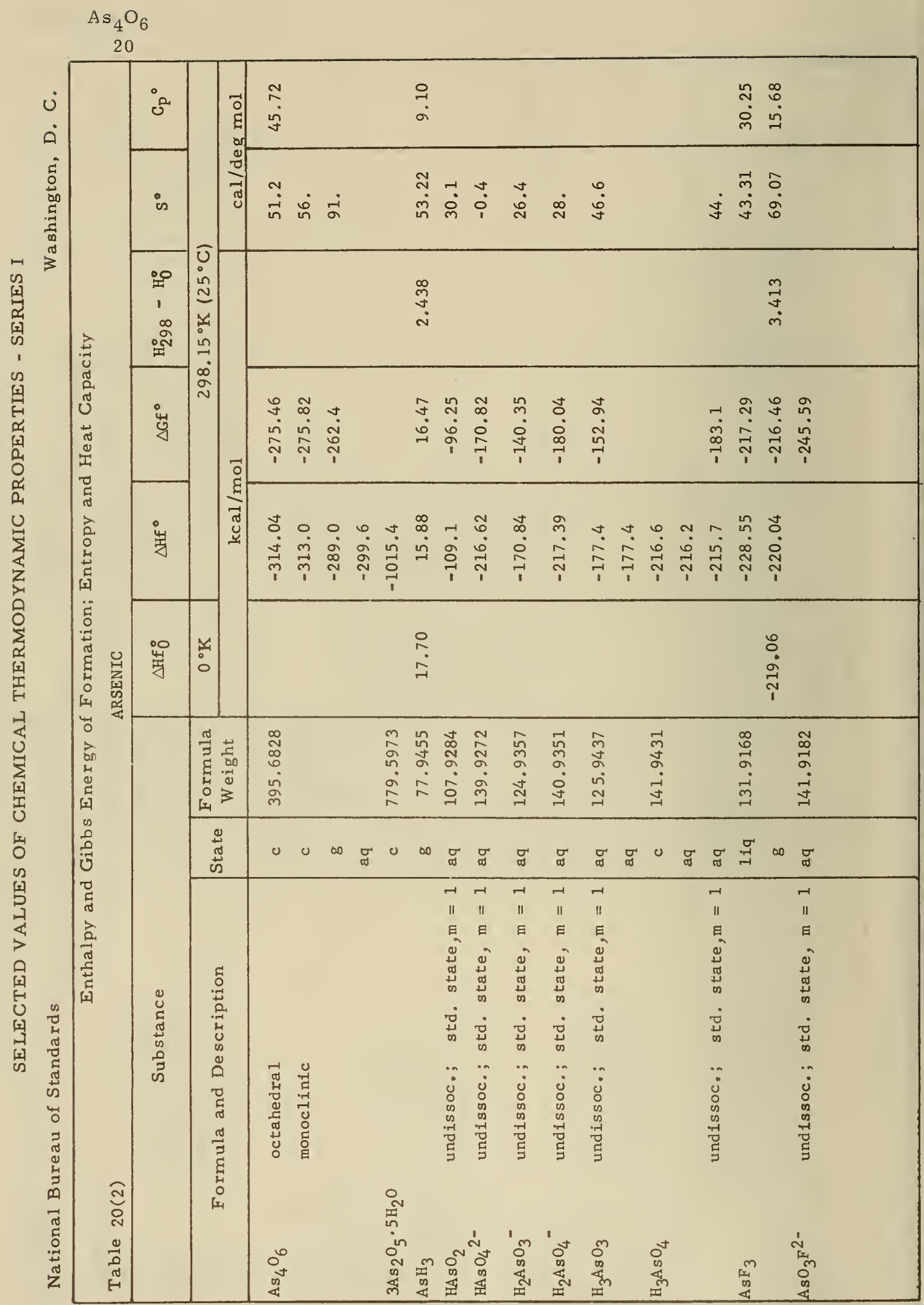




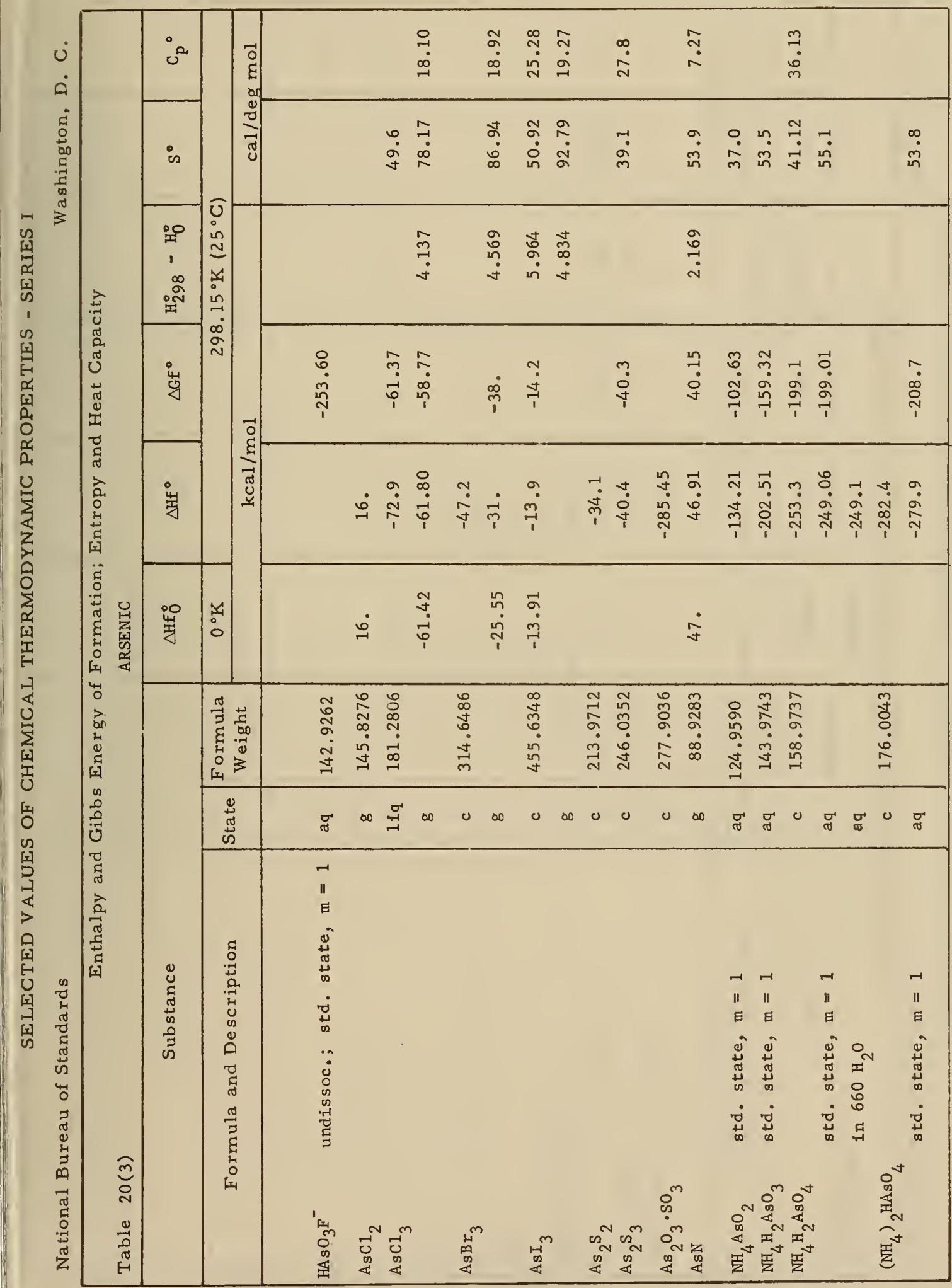




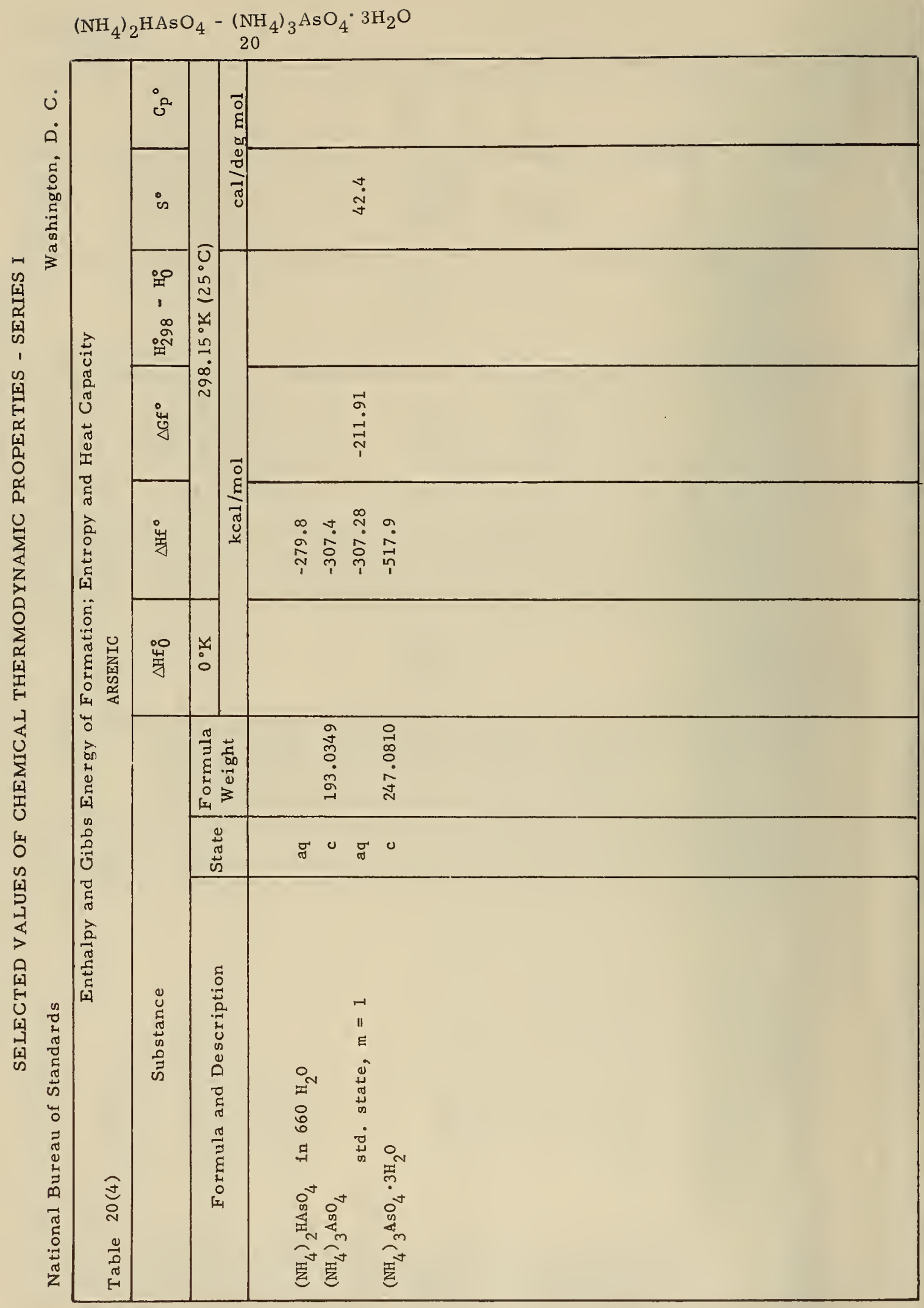




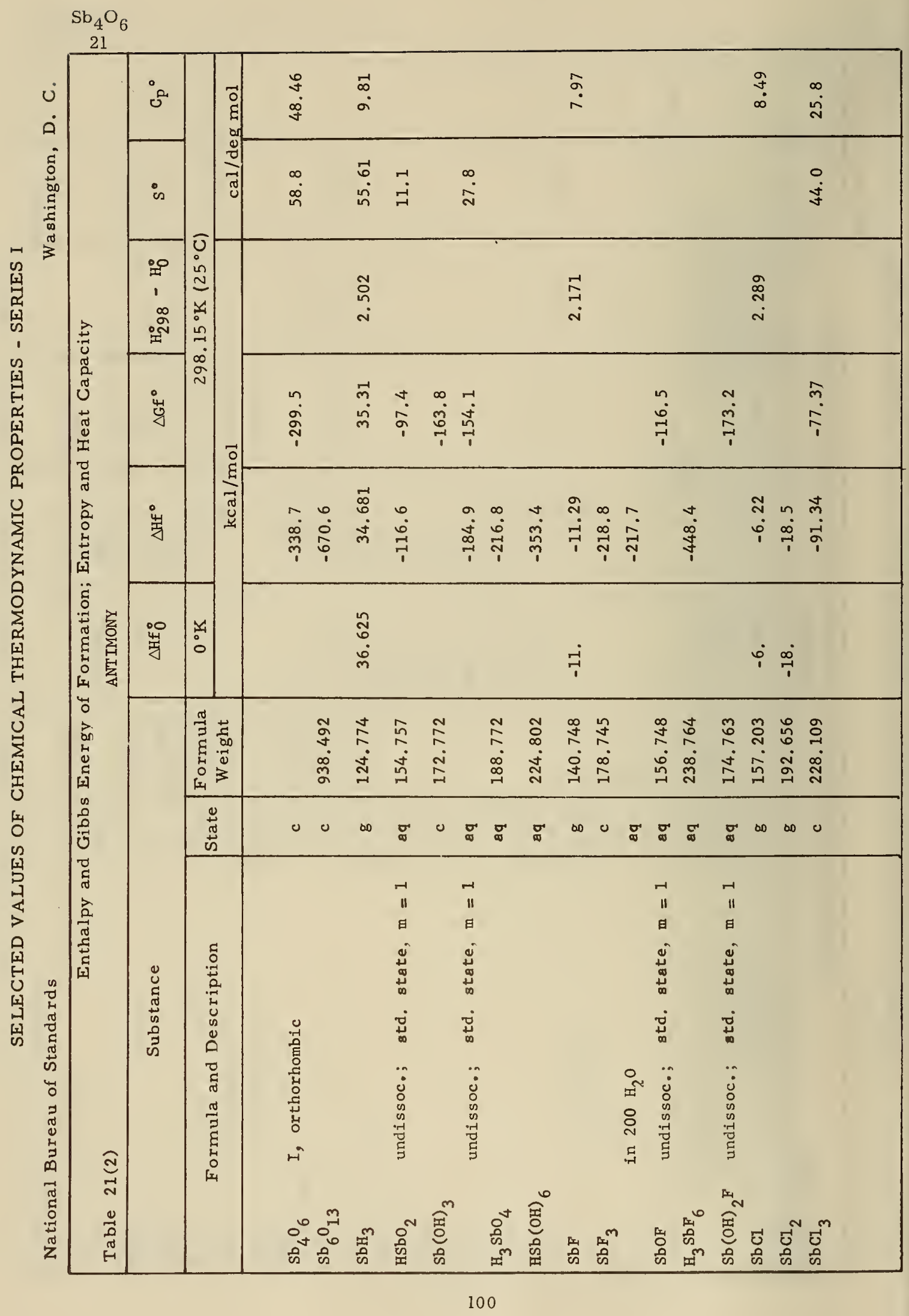




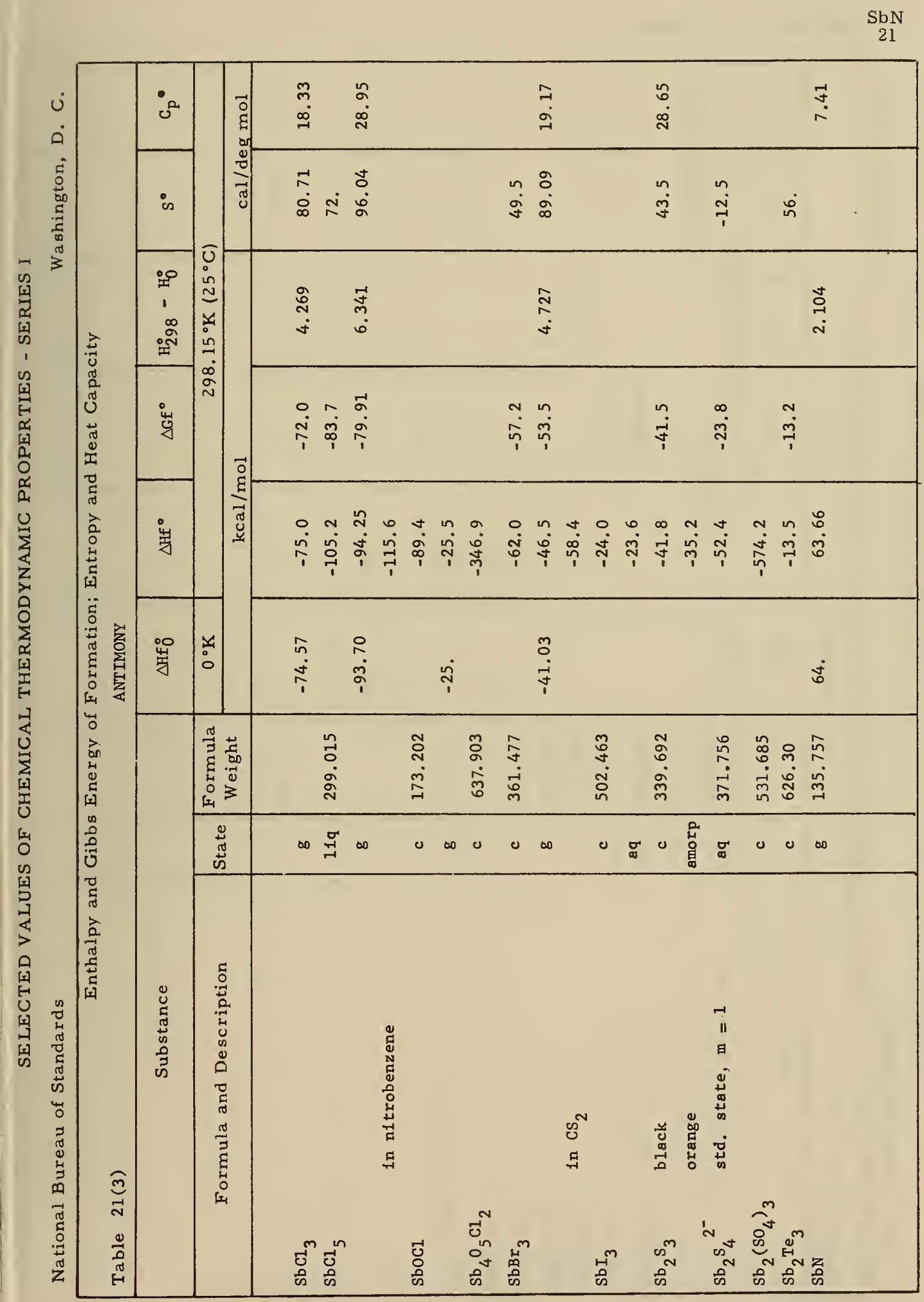




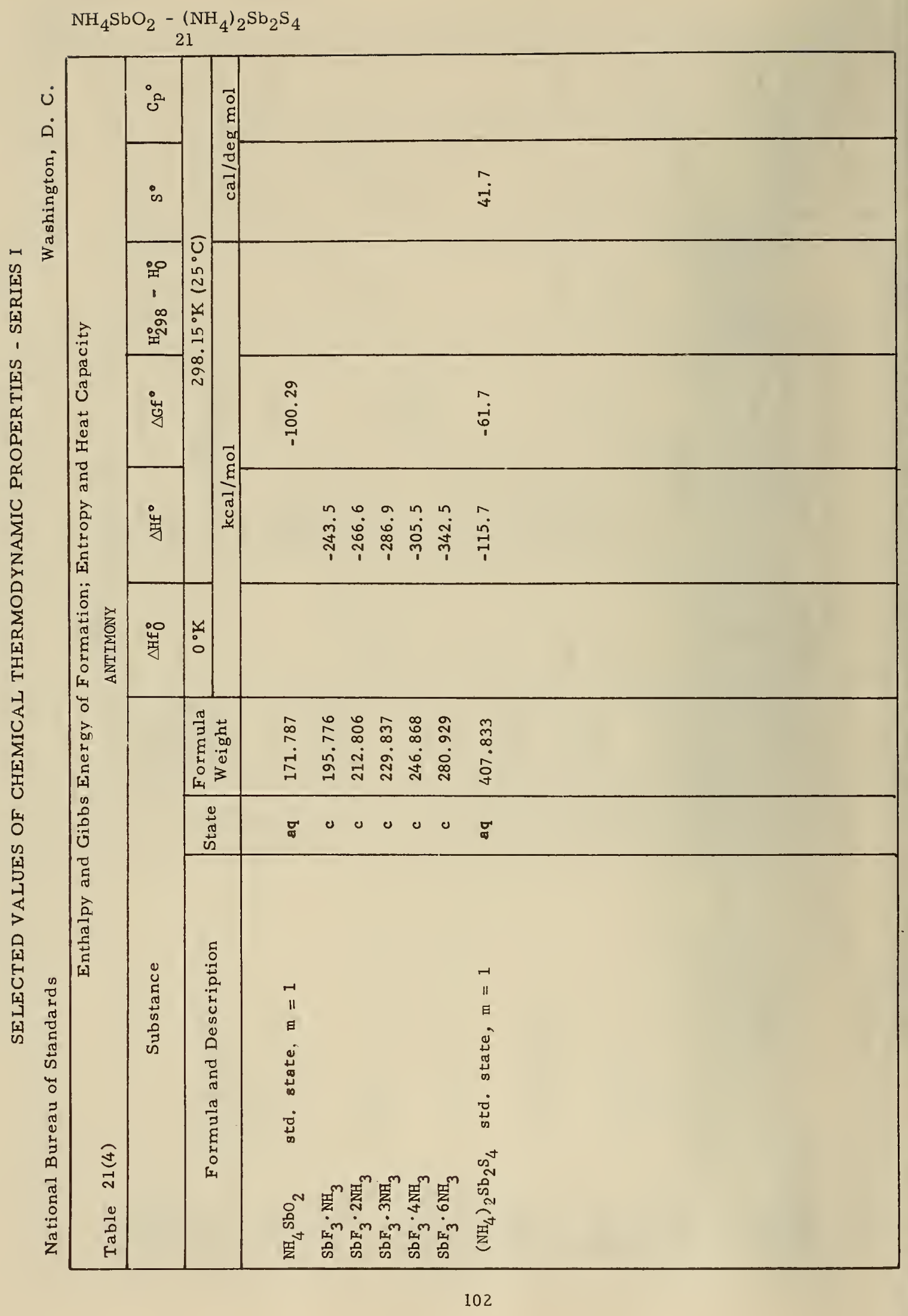




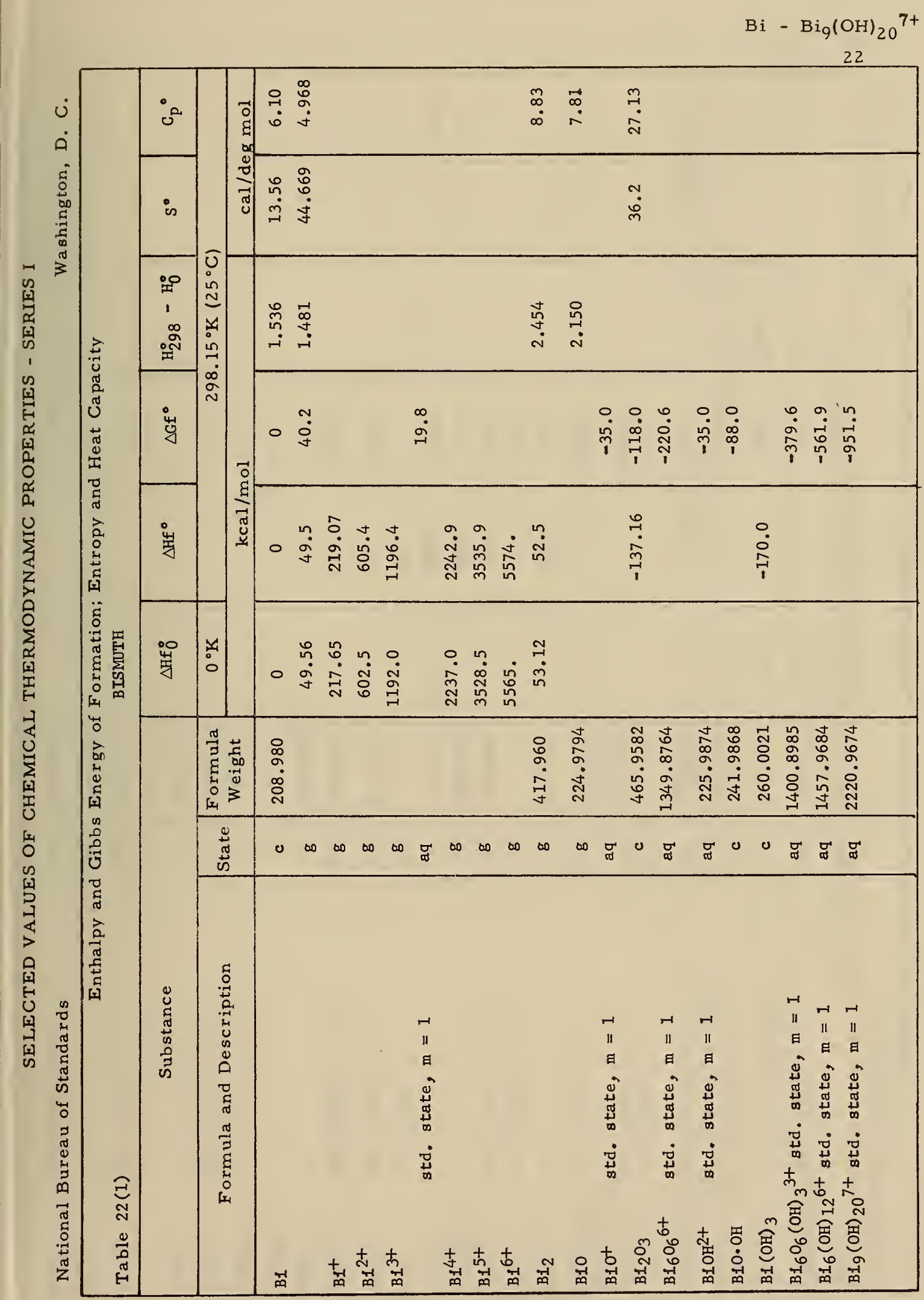


$\mathrm{Bi} 9(\mathrm{OH})_{21}{ }^{6+}$

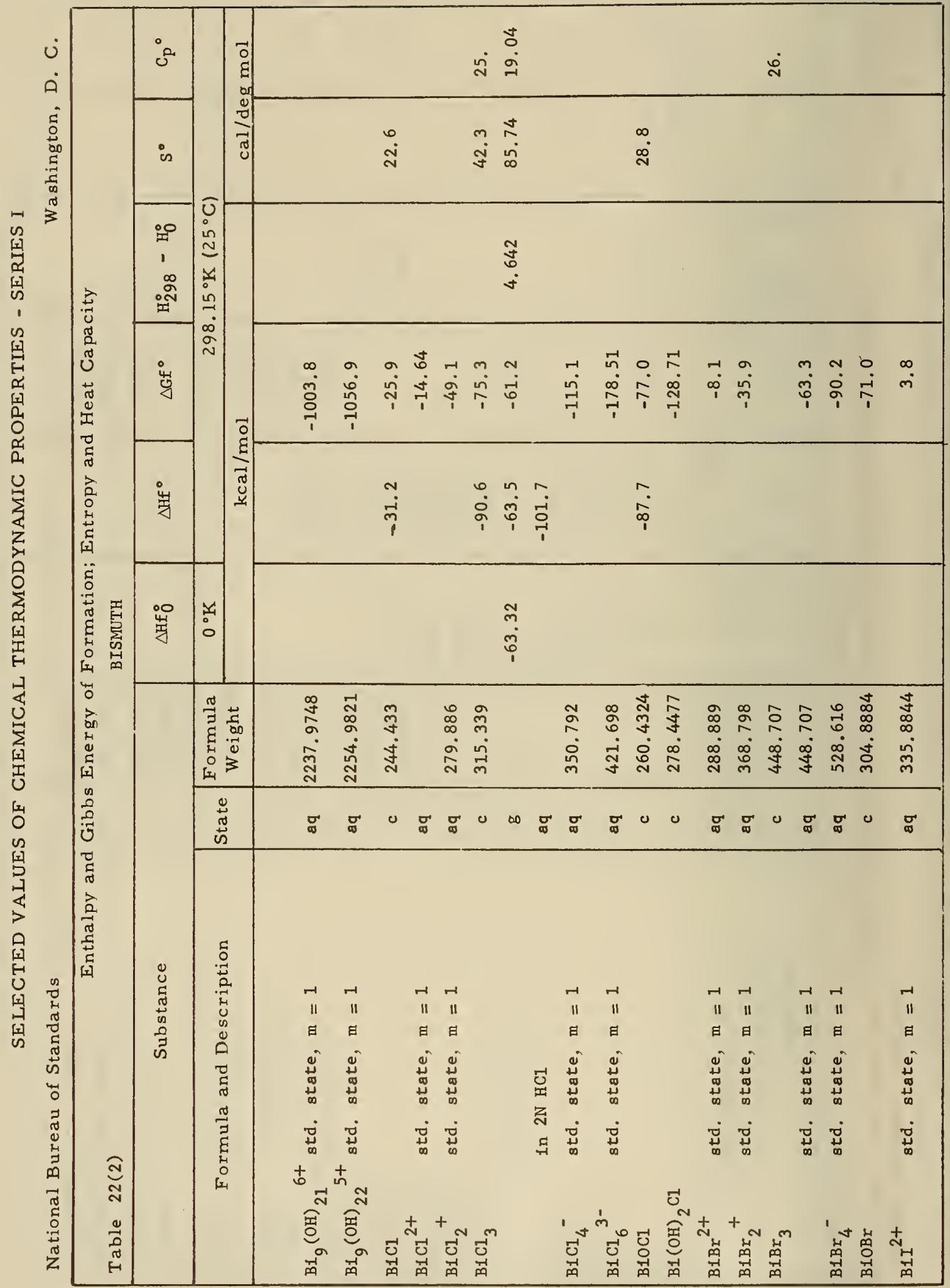


$\mathrm{BiAsO}_{4}$

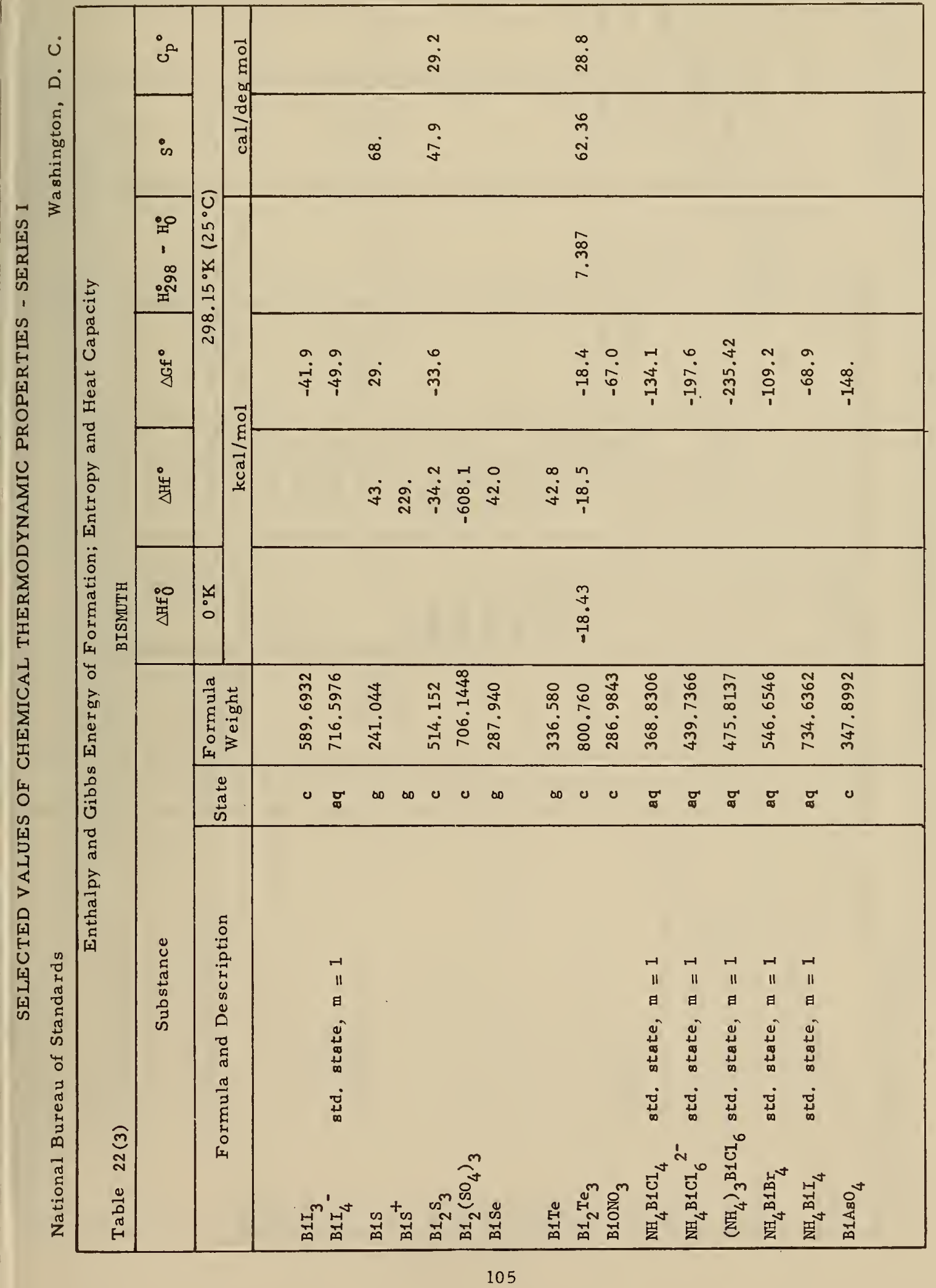




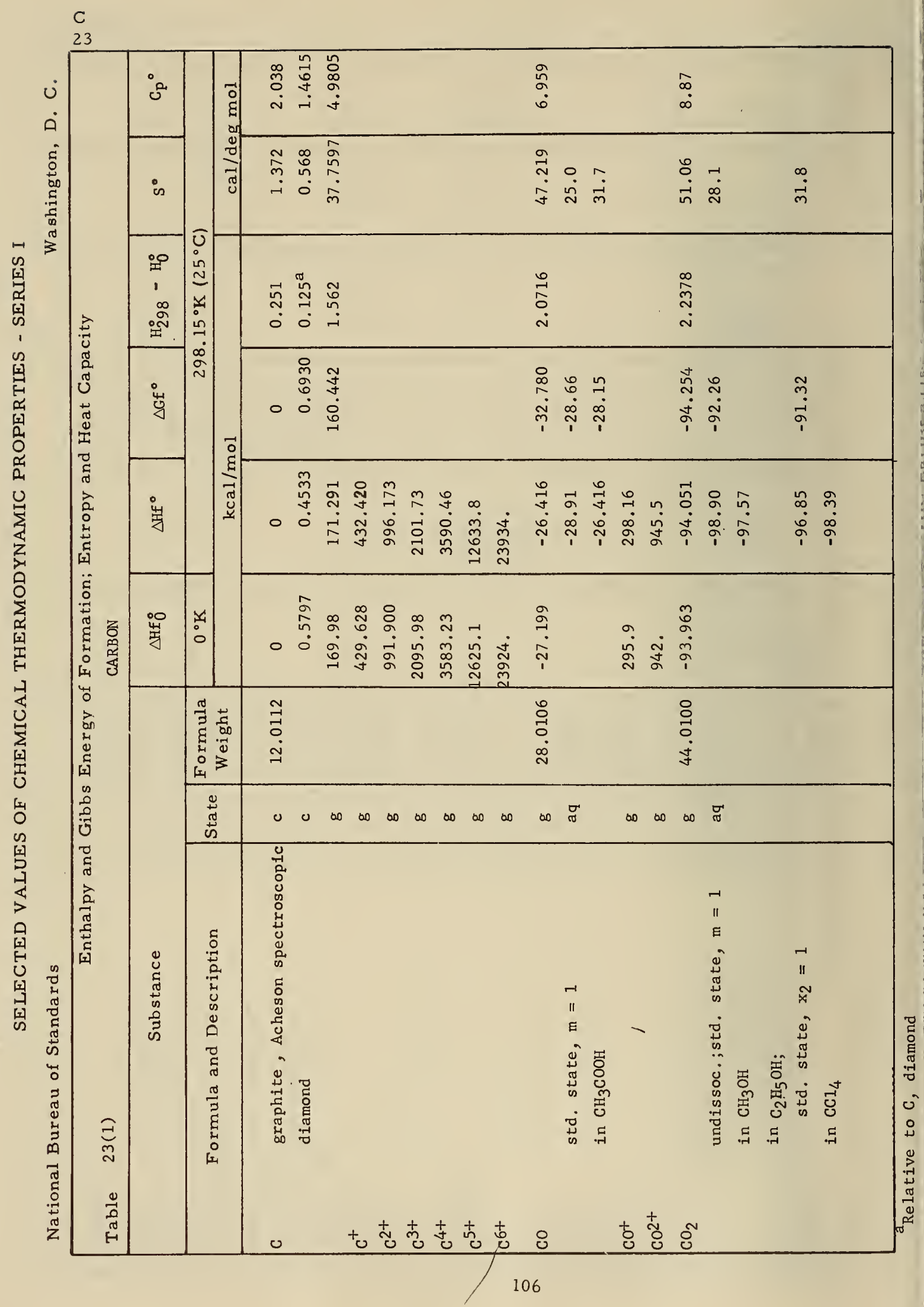




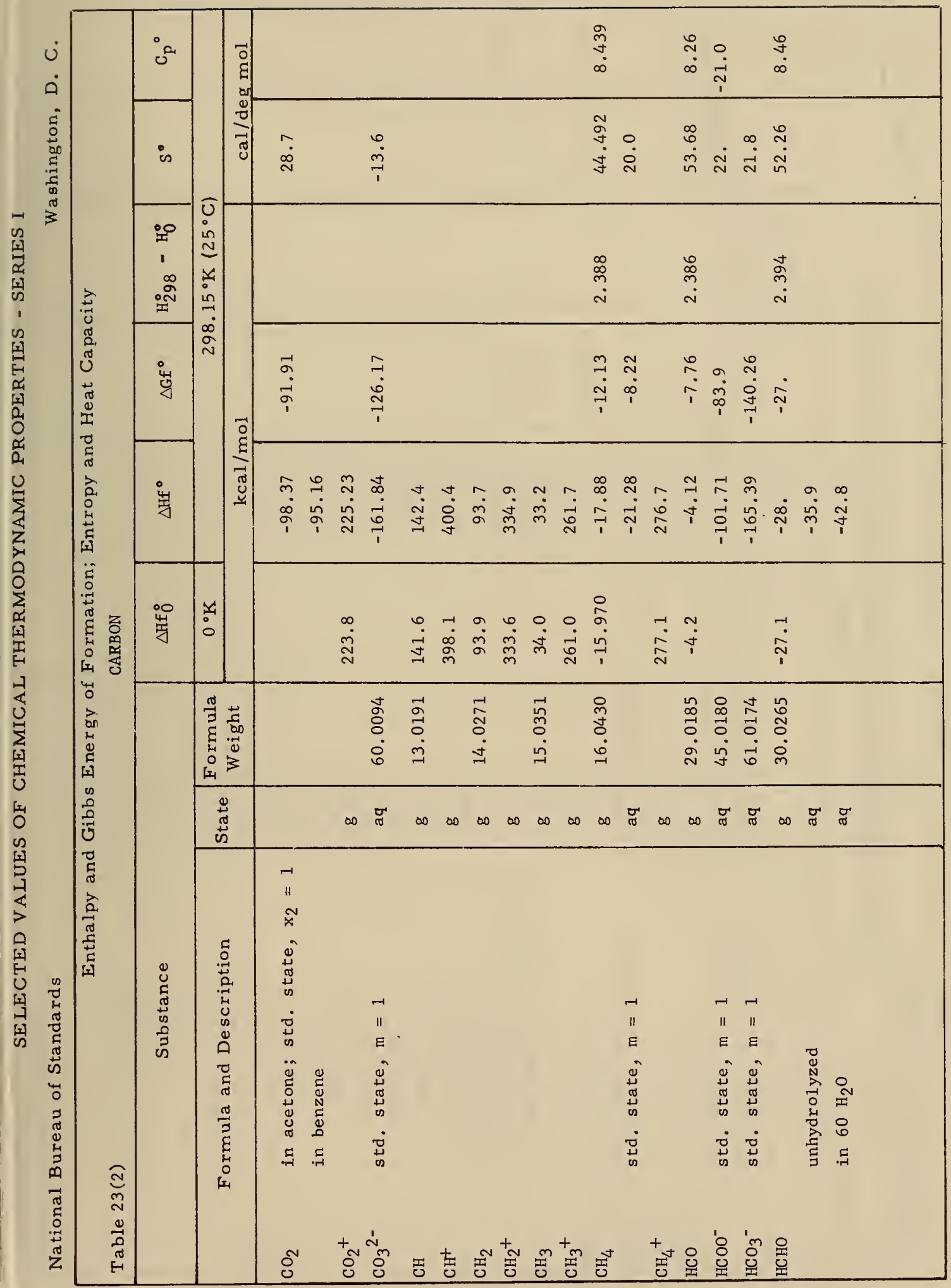




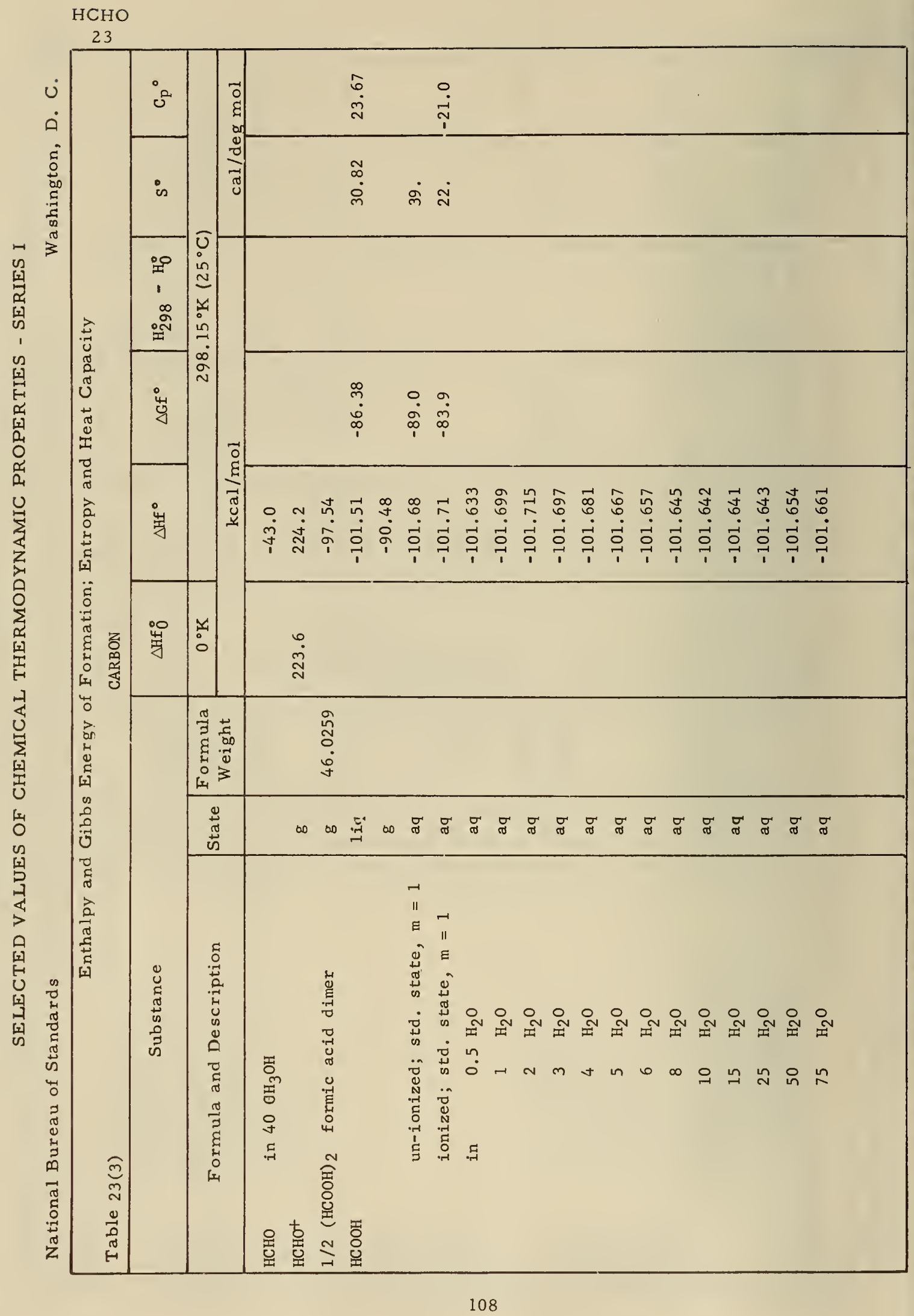




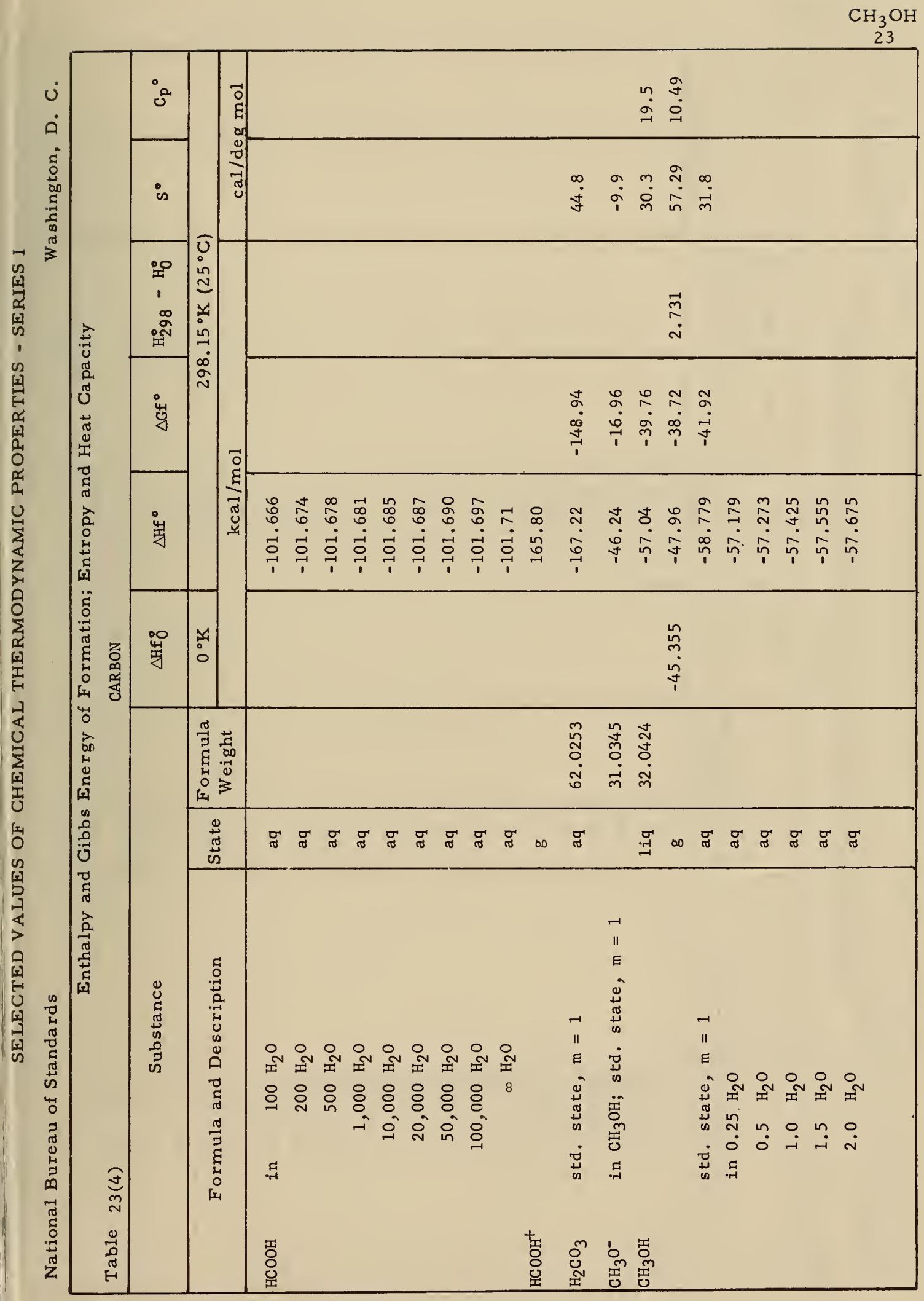




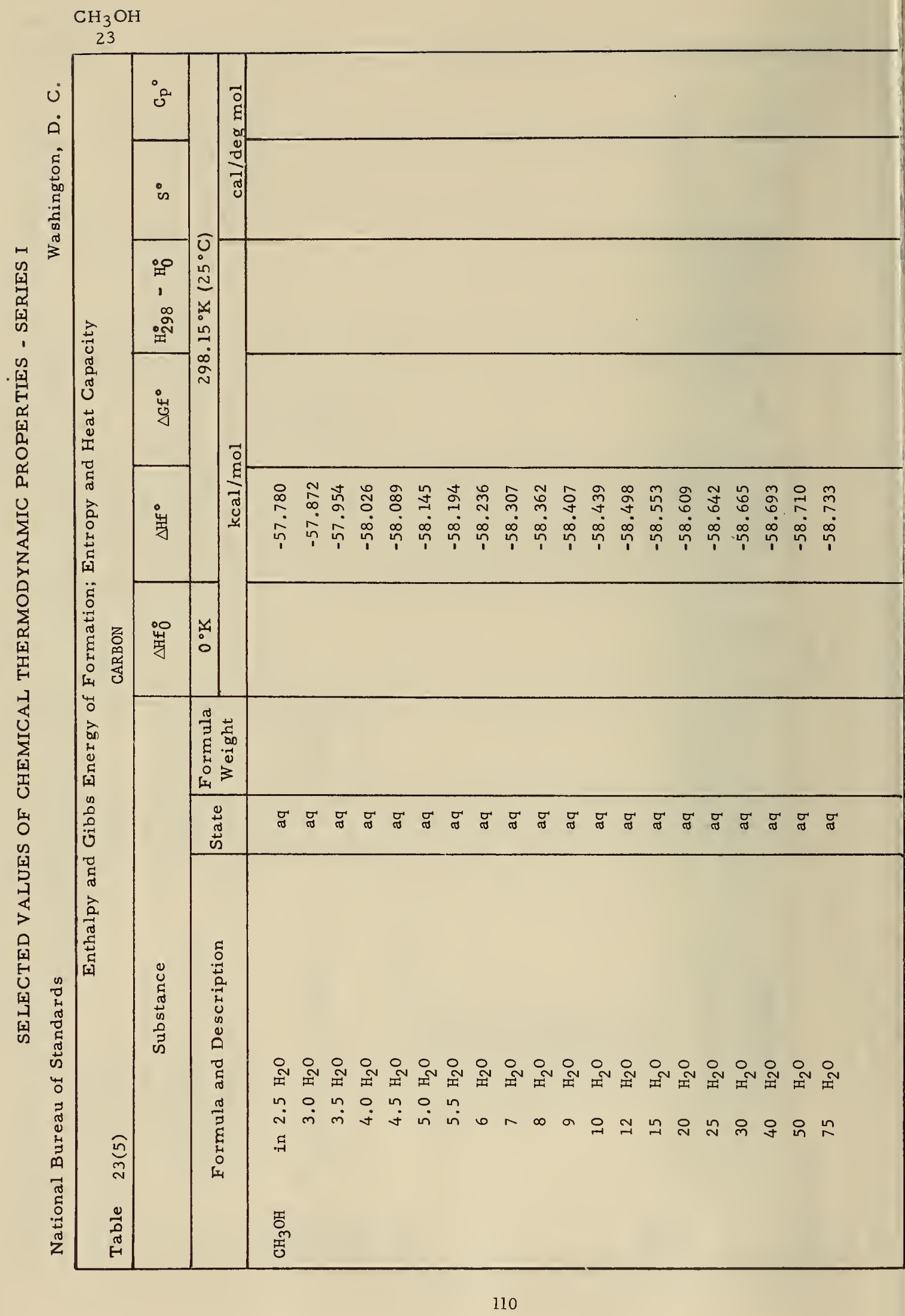




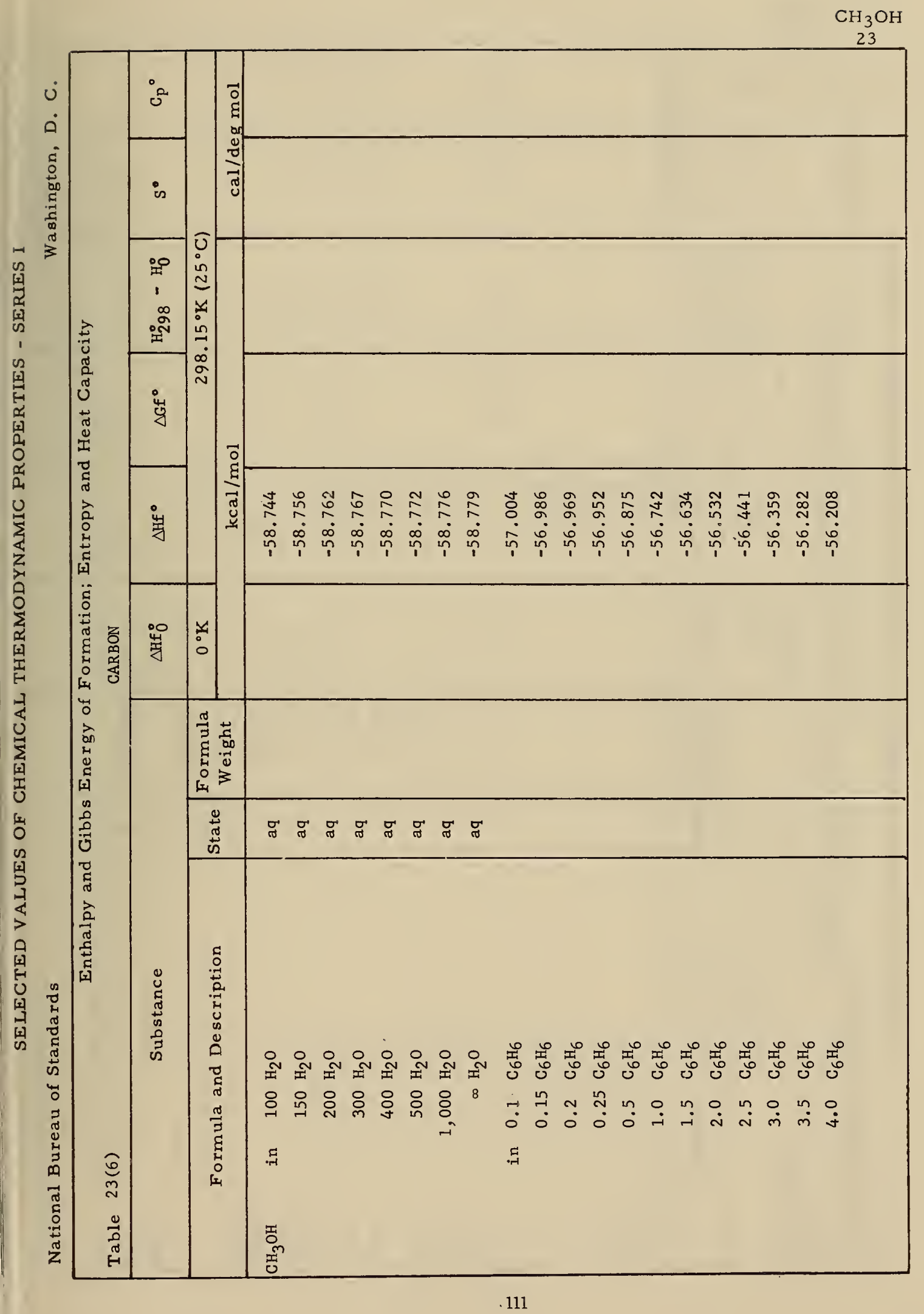




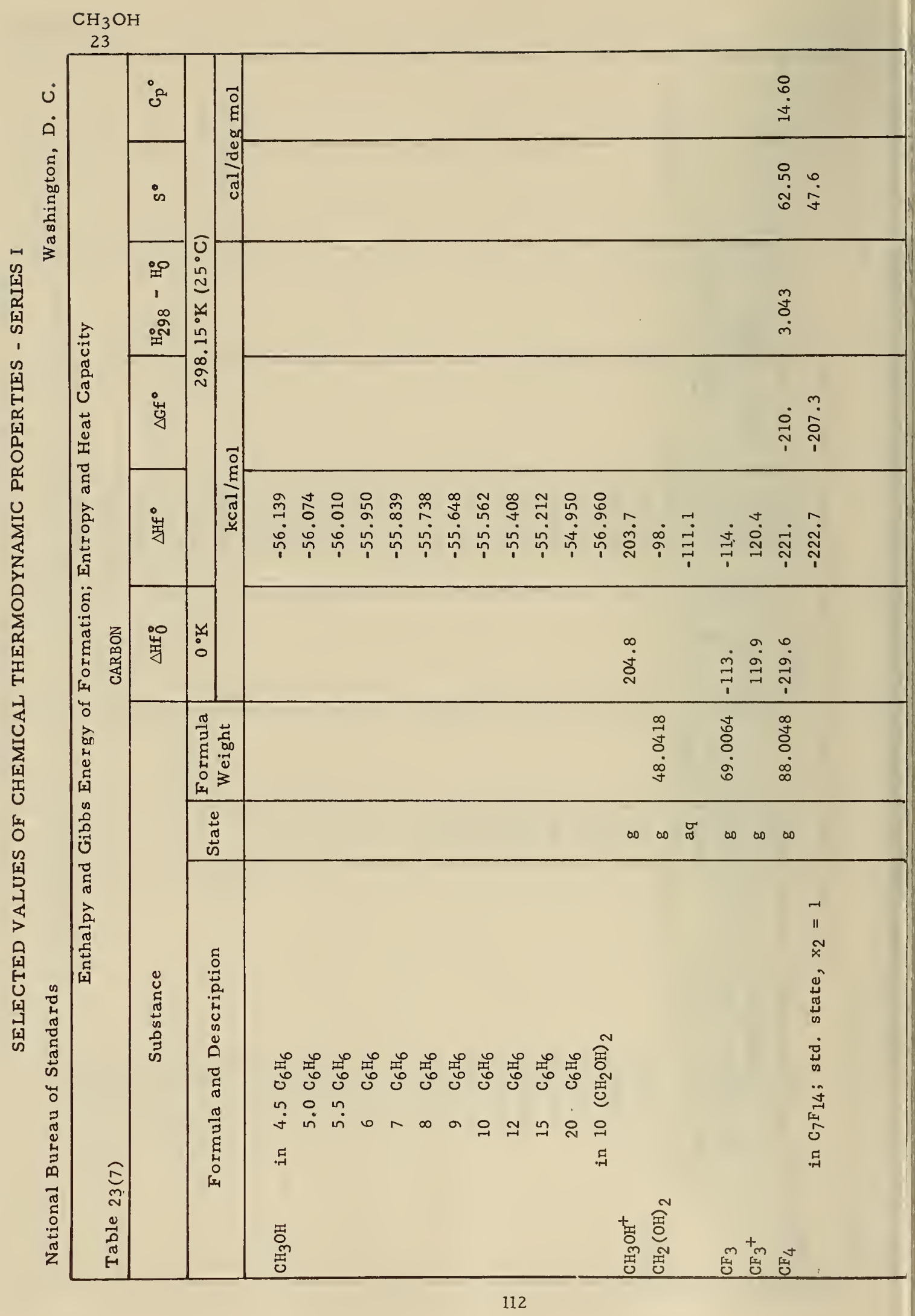




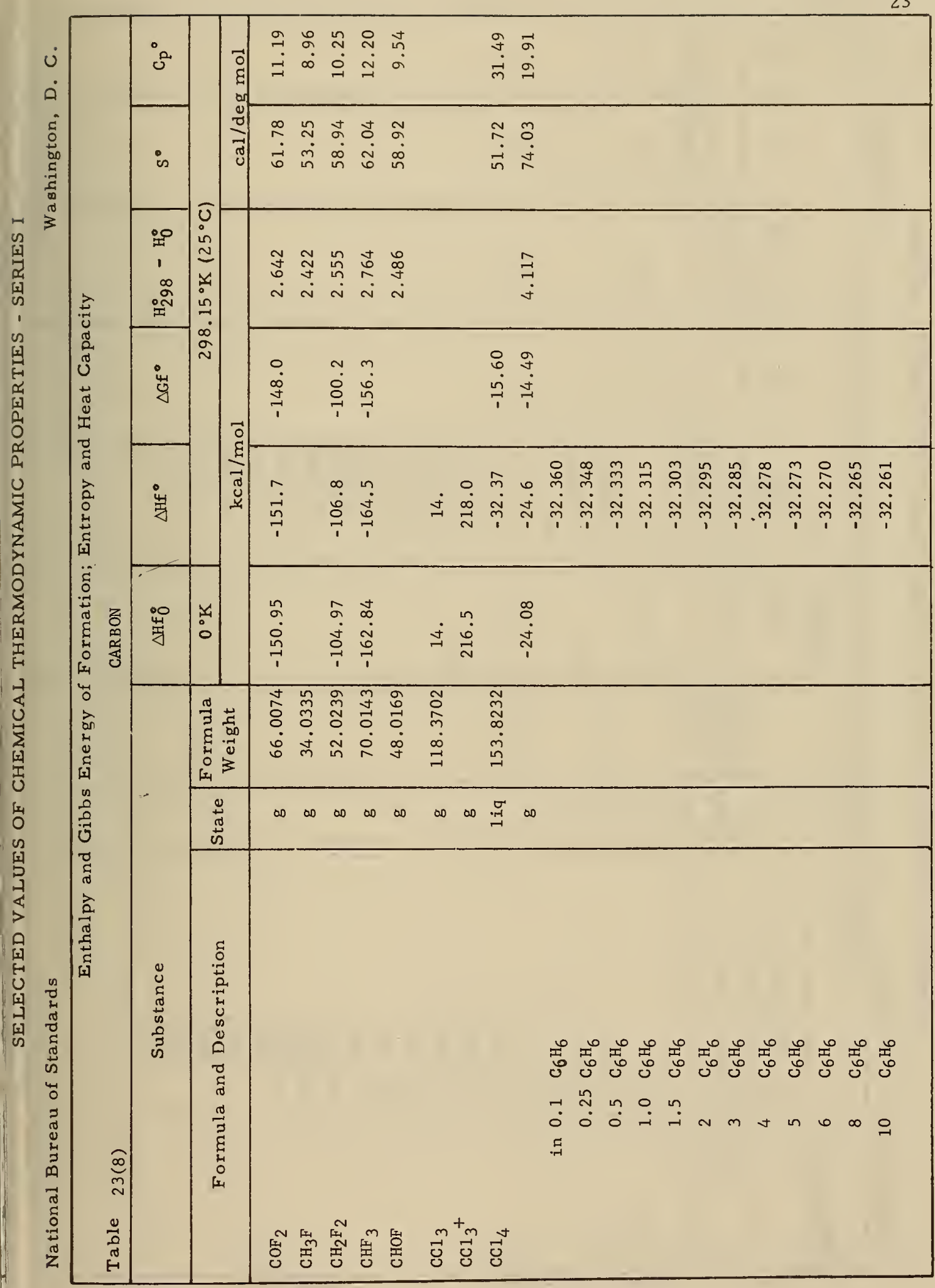




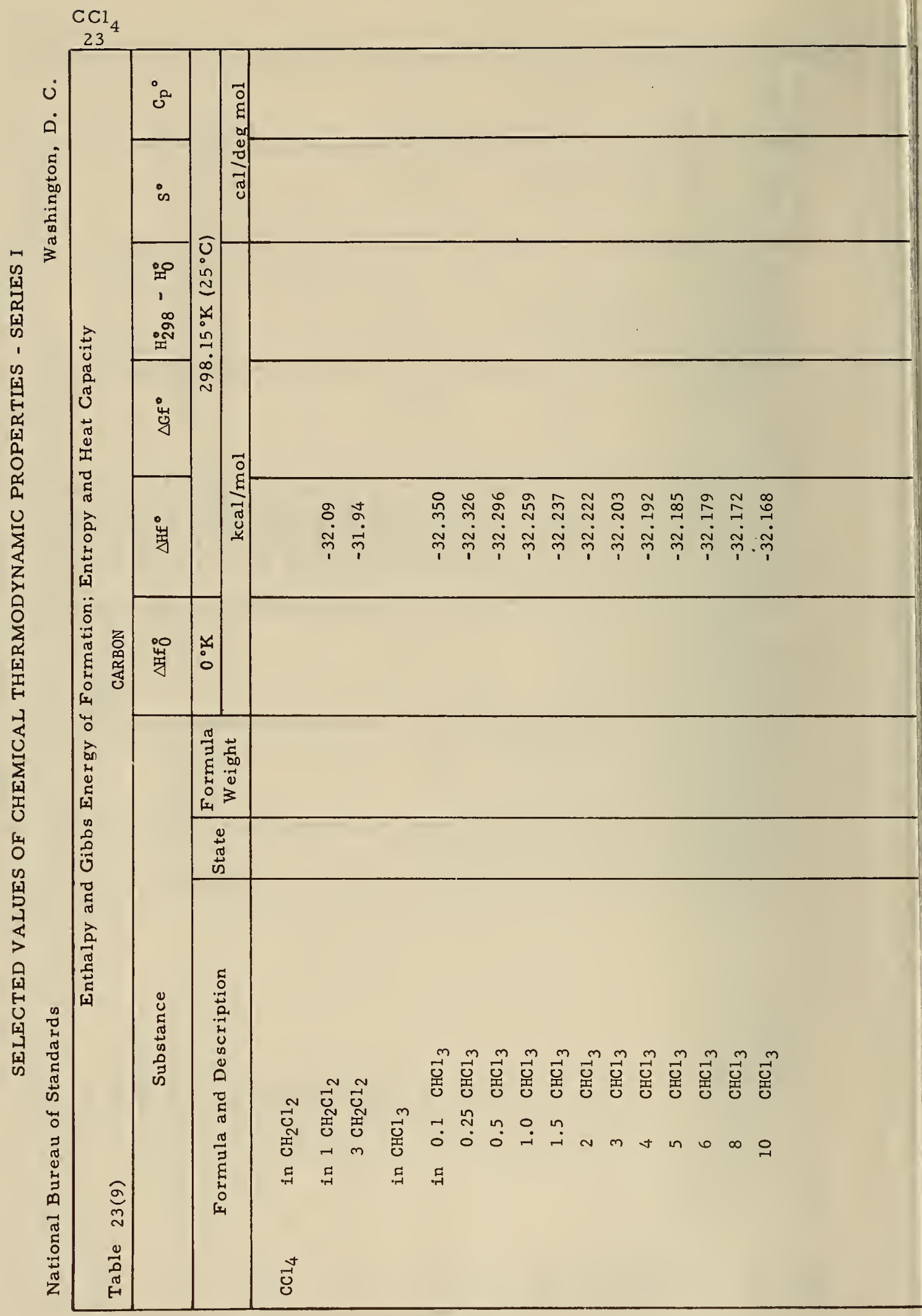




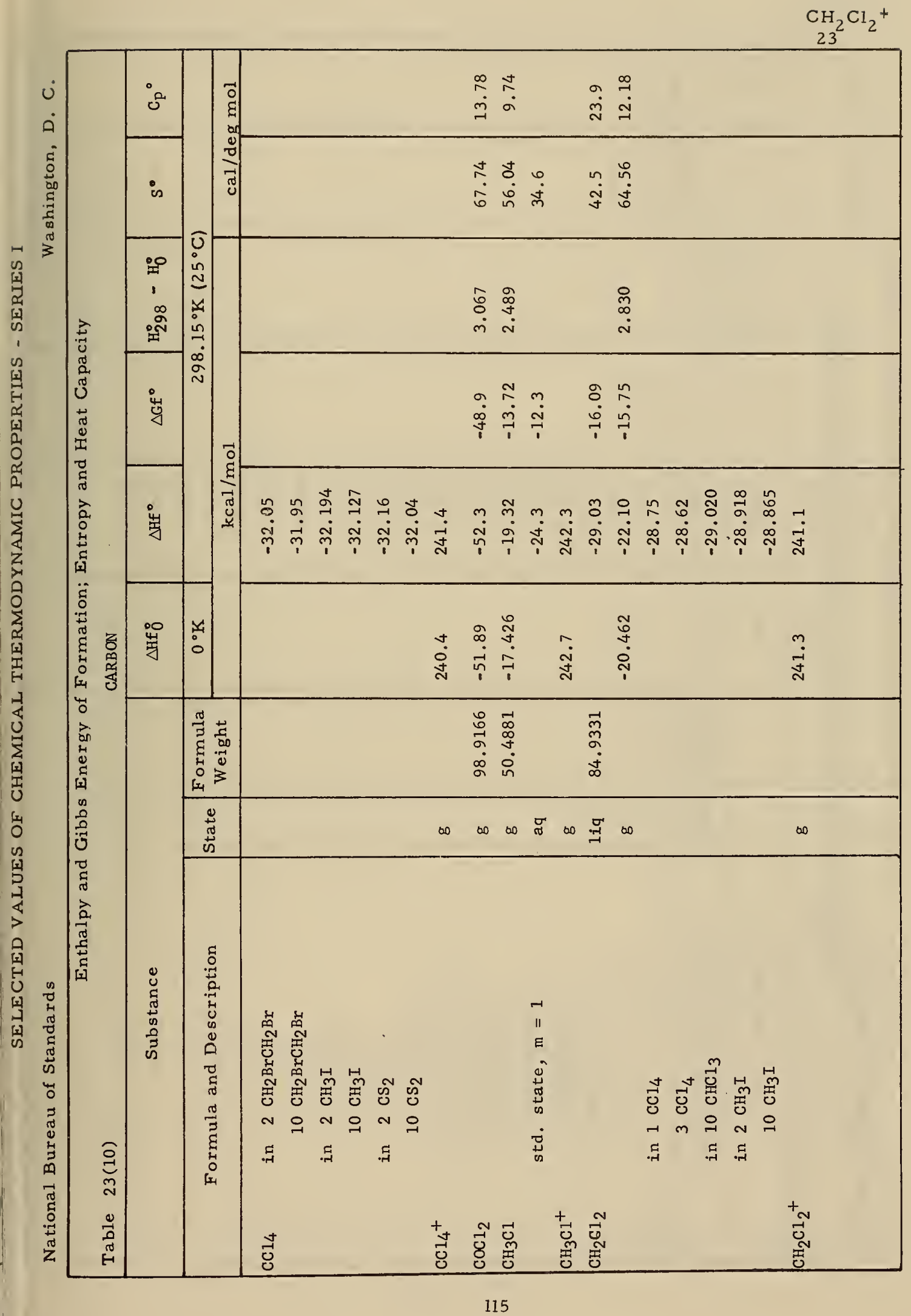




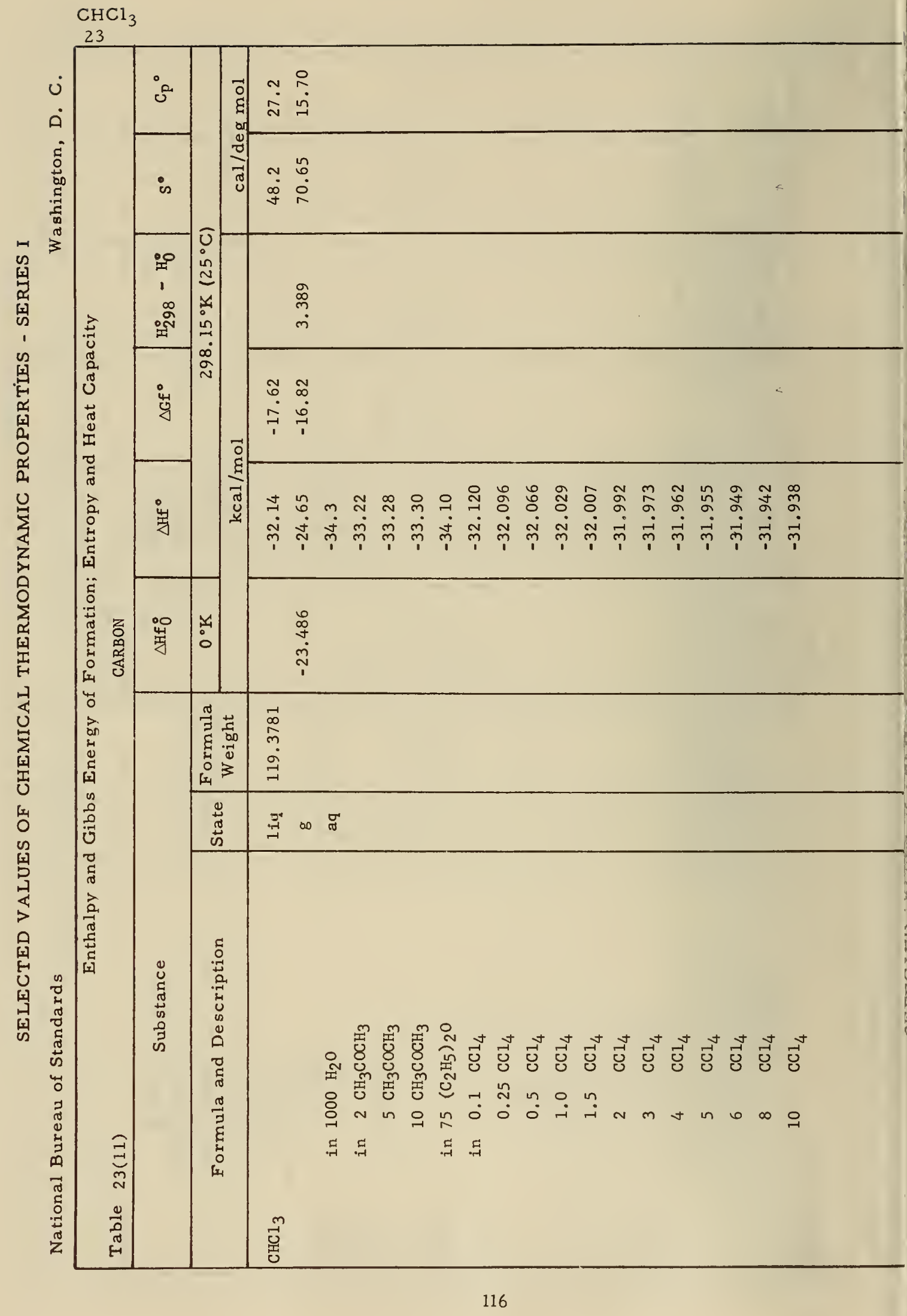




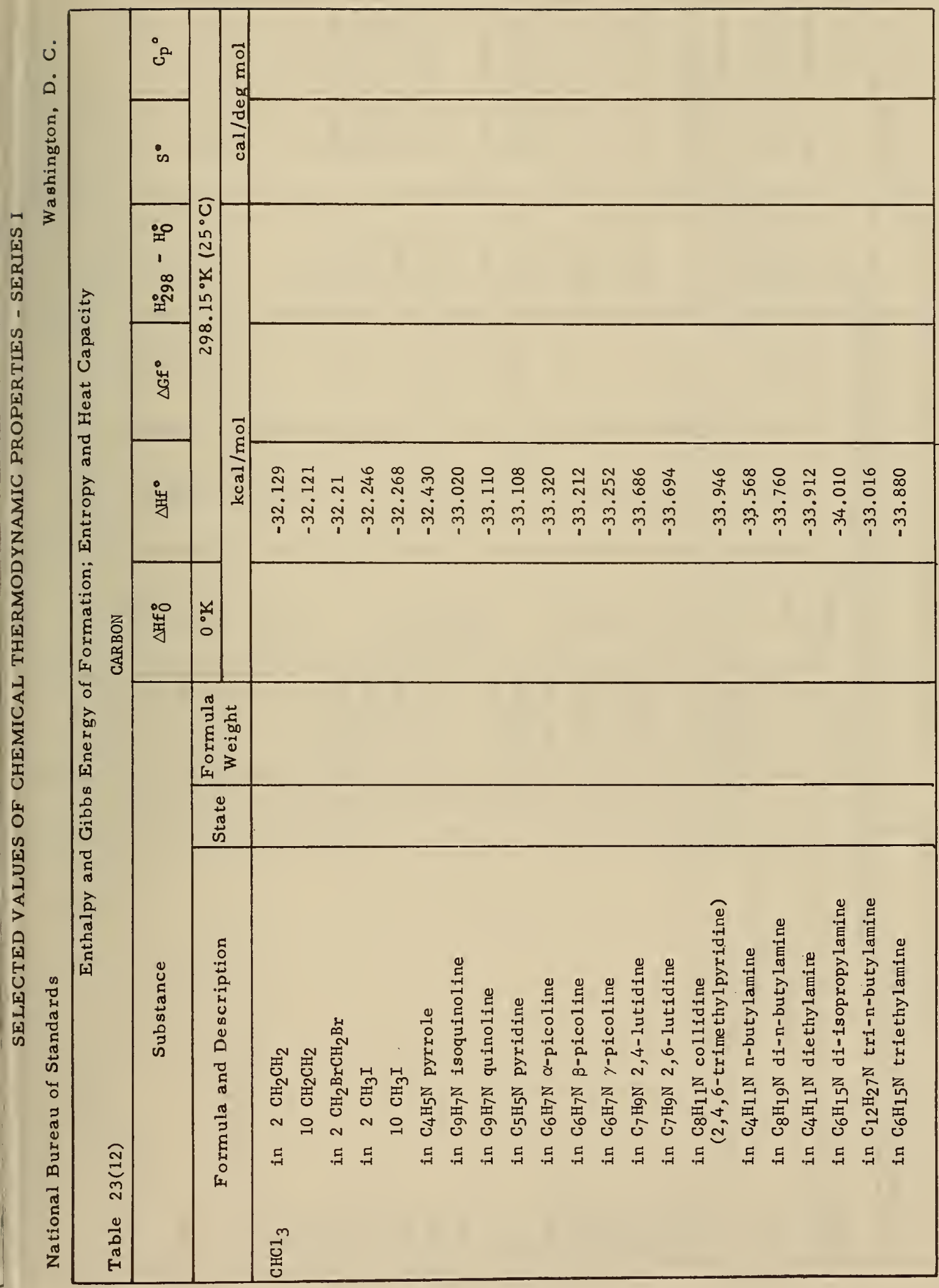




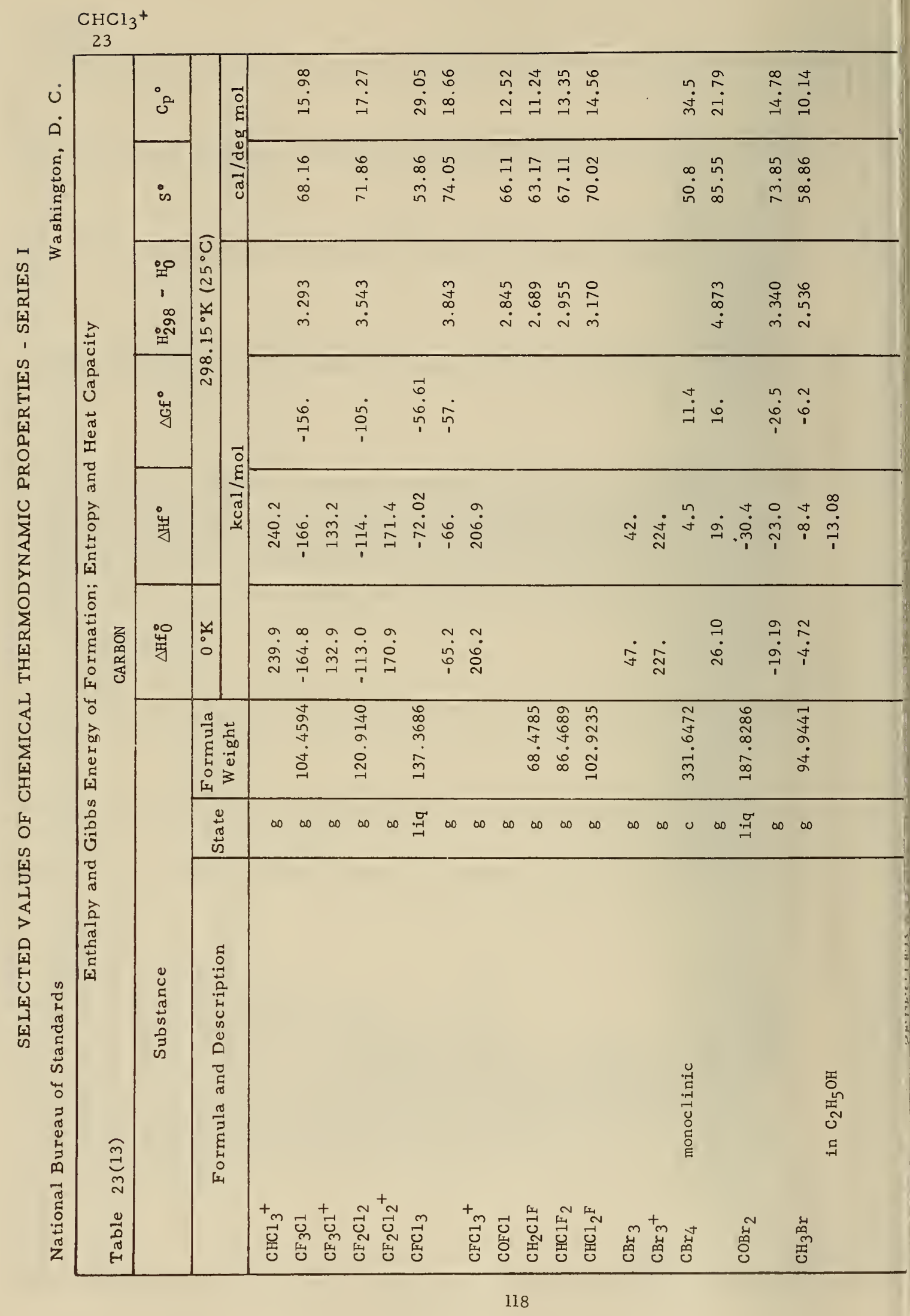




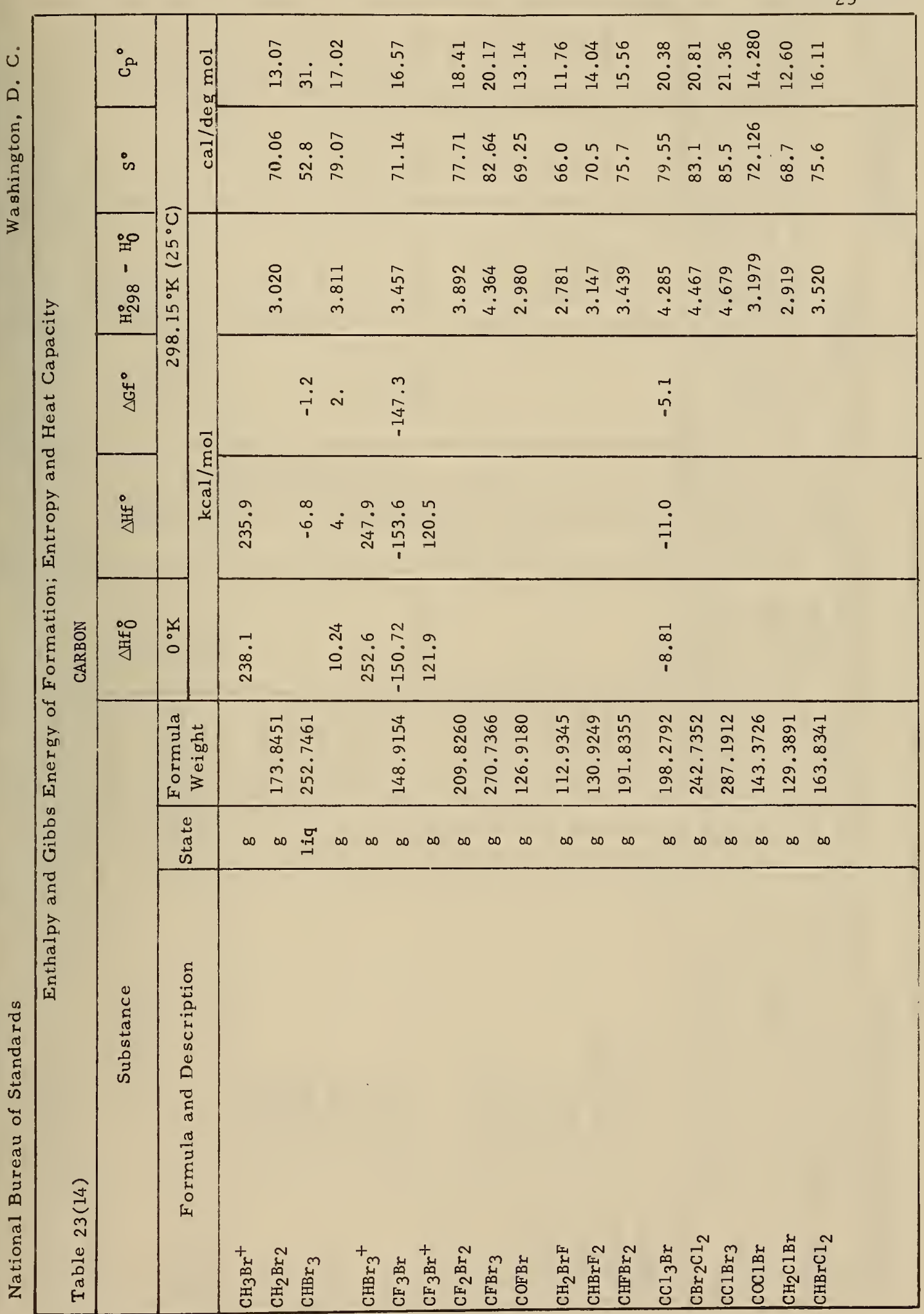




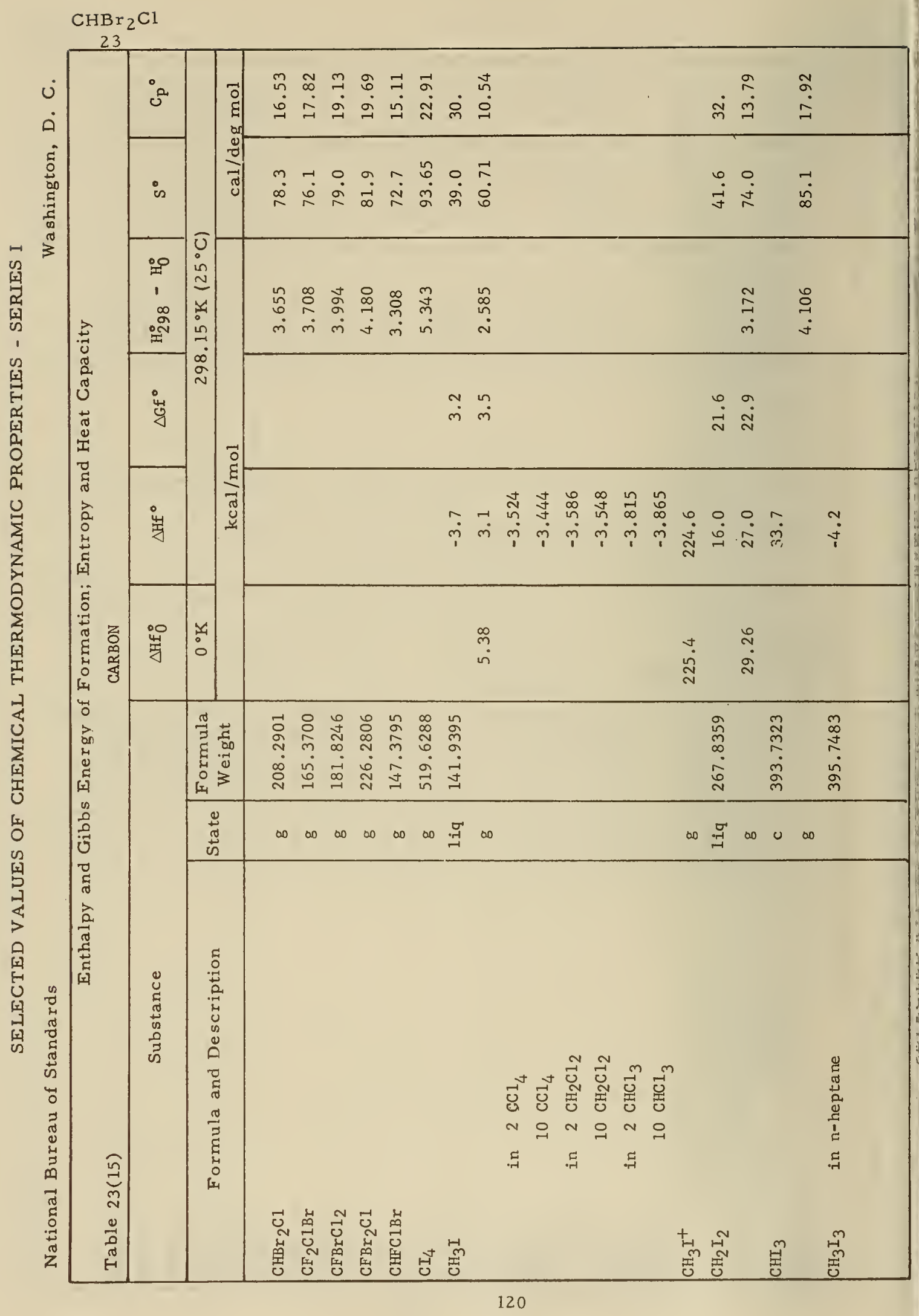




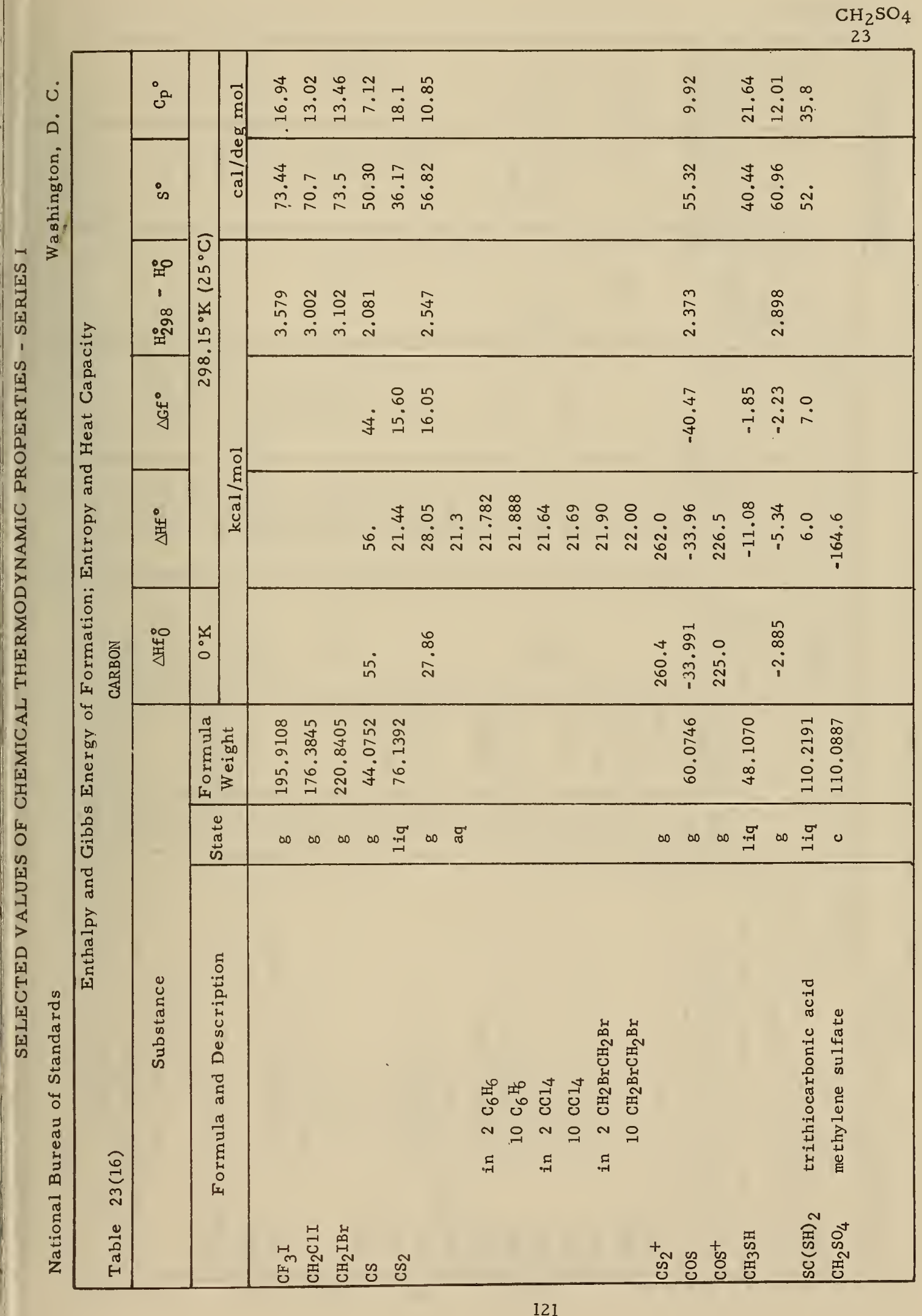




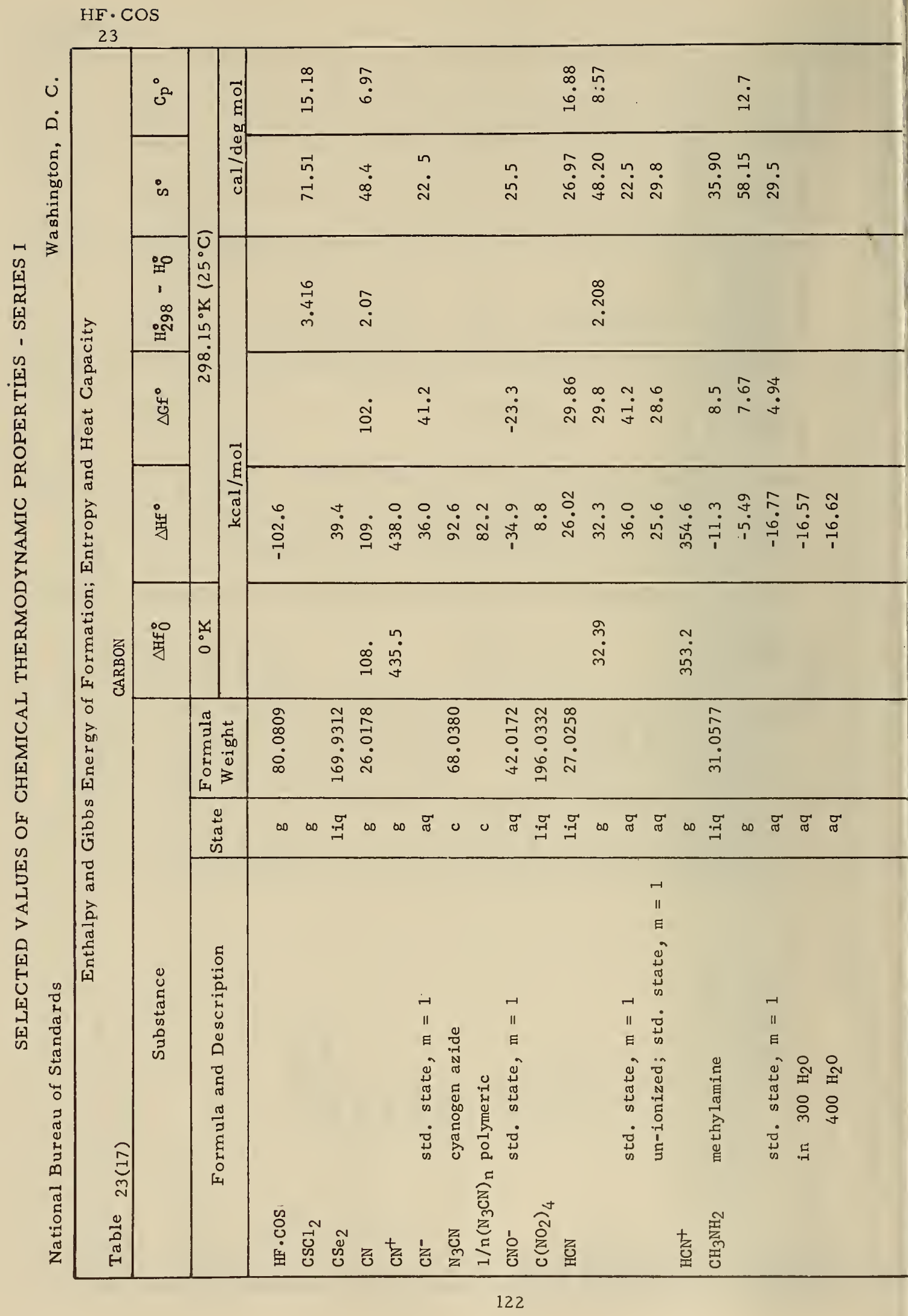




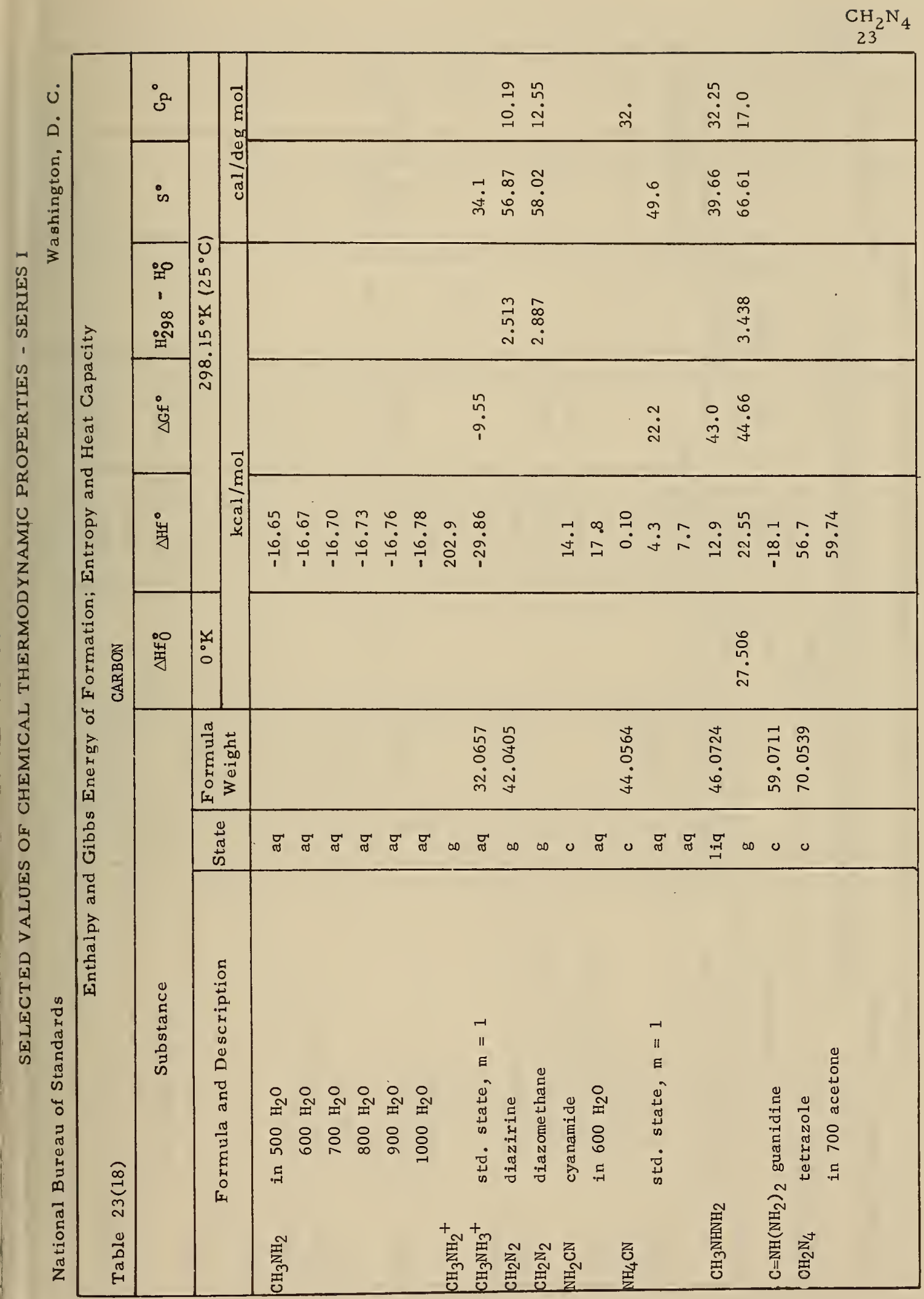


$\mathrm{CH}_{3} \mathrm{~N}_{5}$

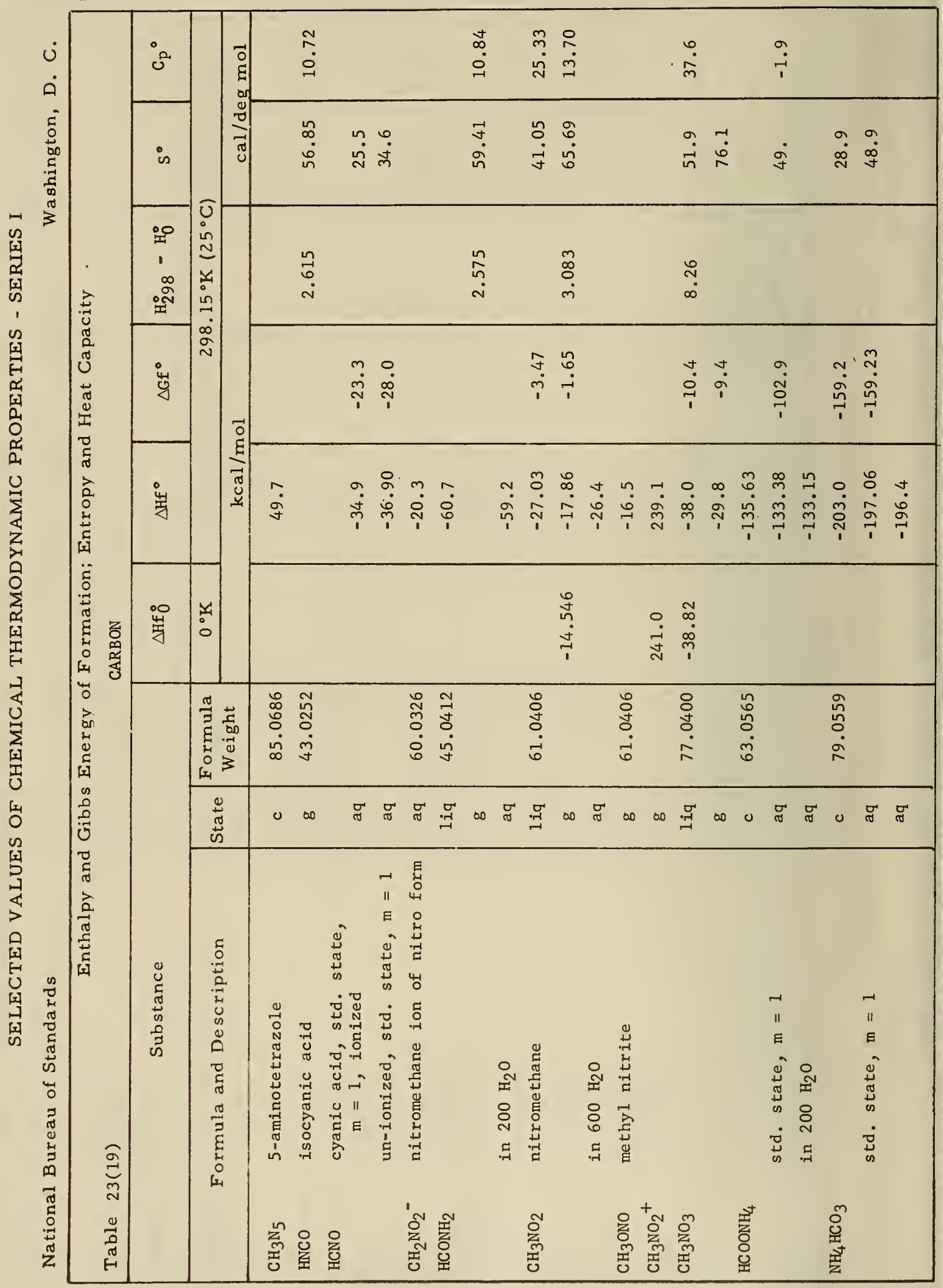


$\mathrm{CO}\left(\mathrm{NH}_{2}\right)_{2}$

23

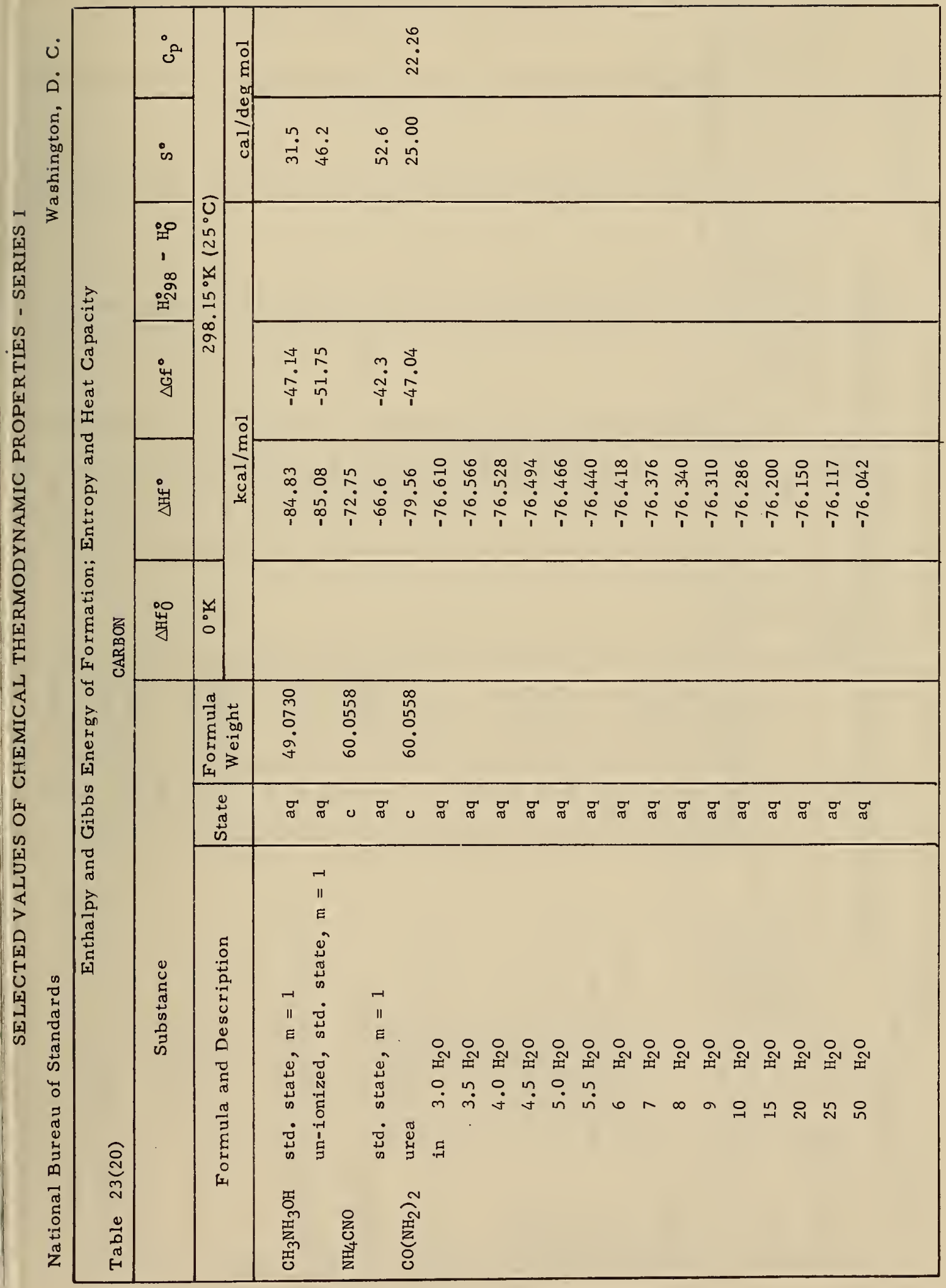




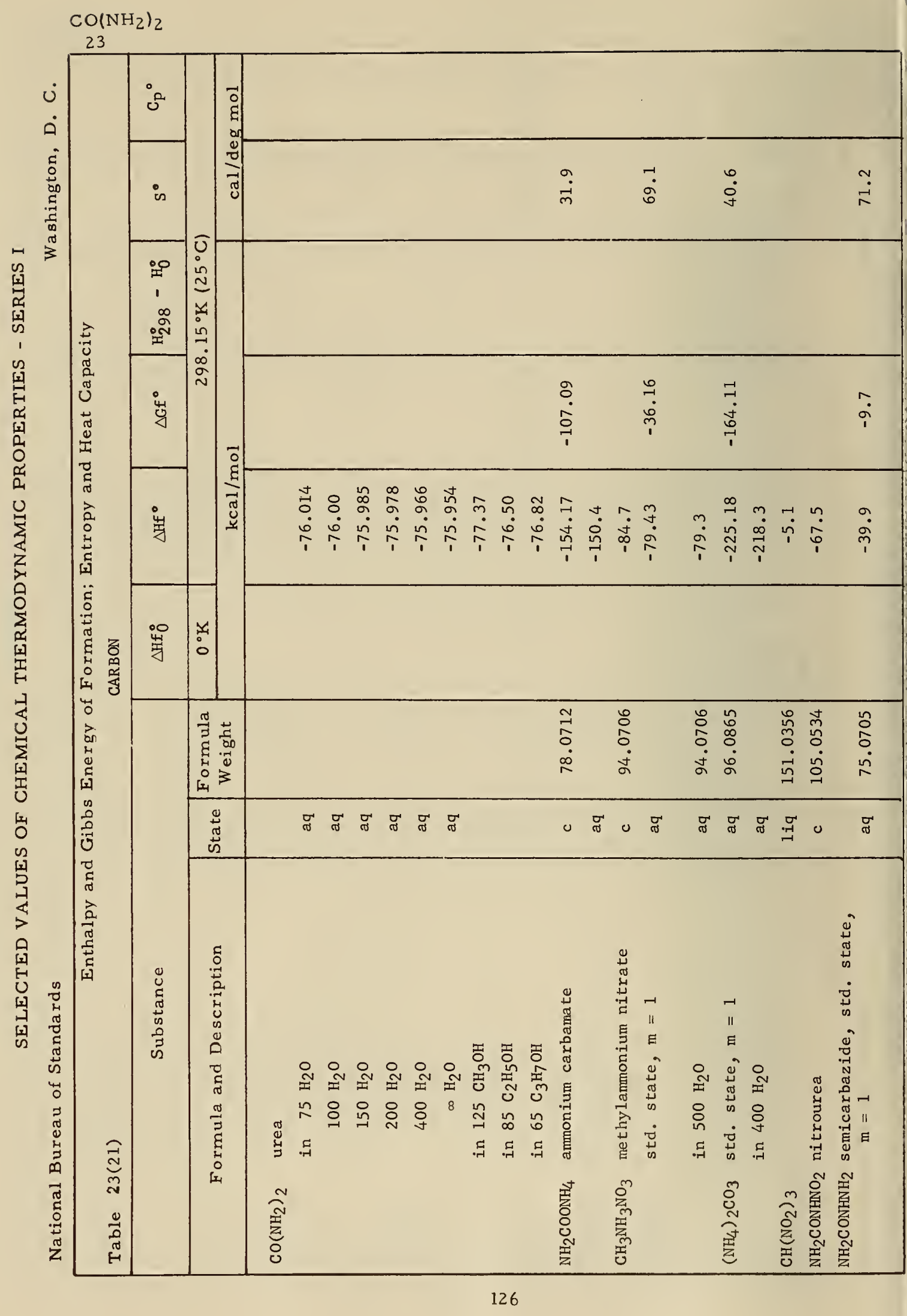




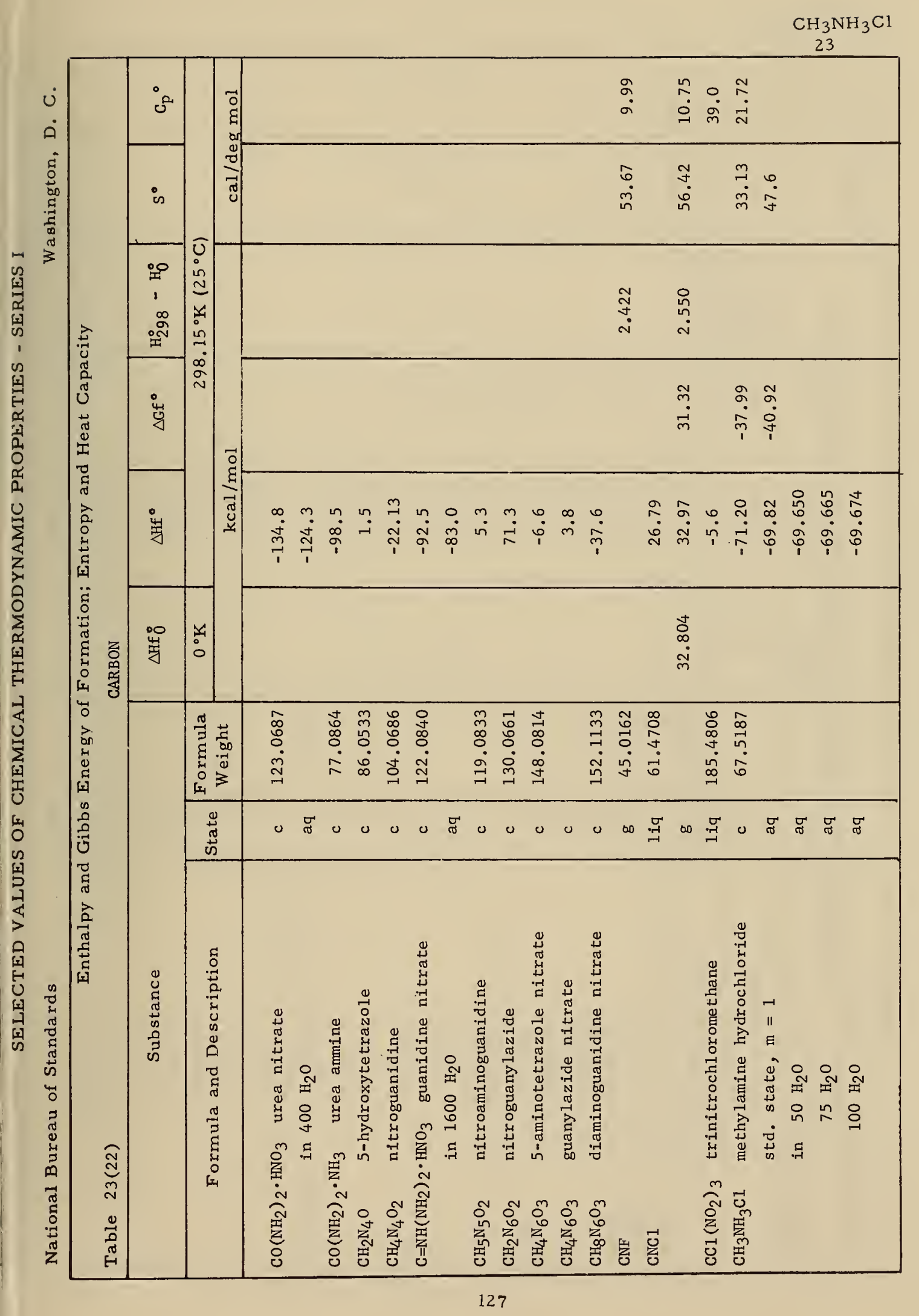




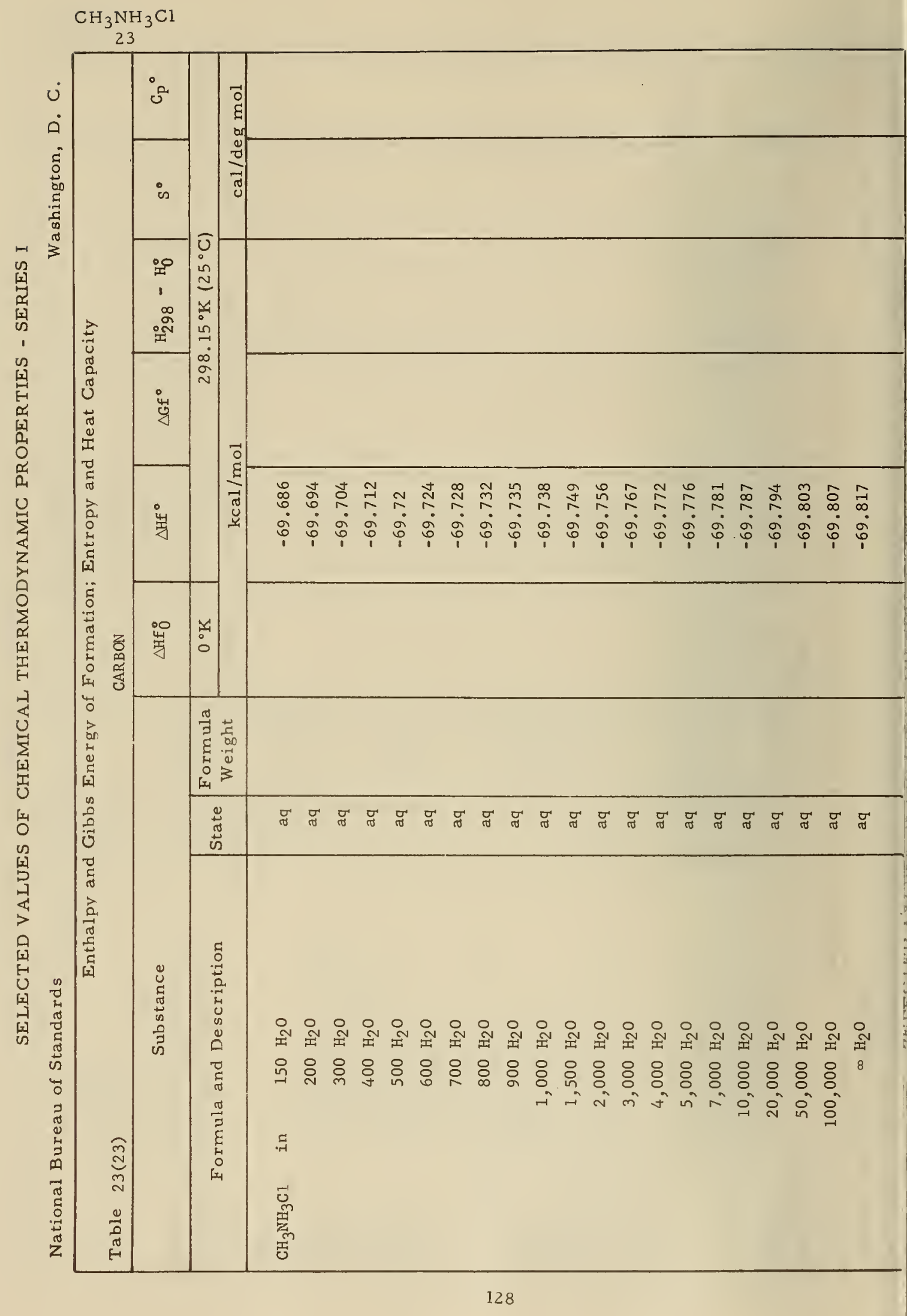




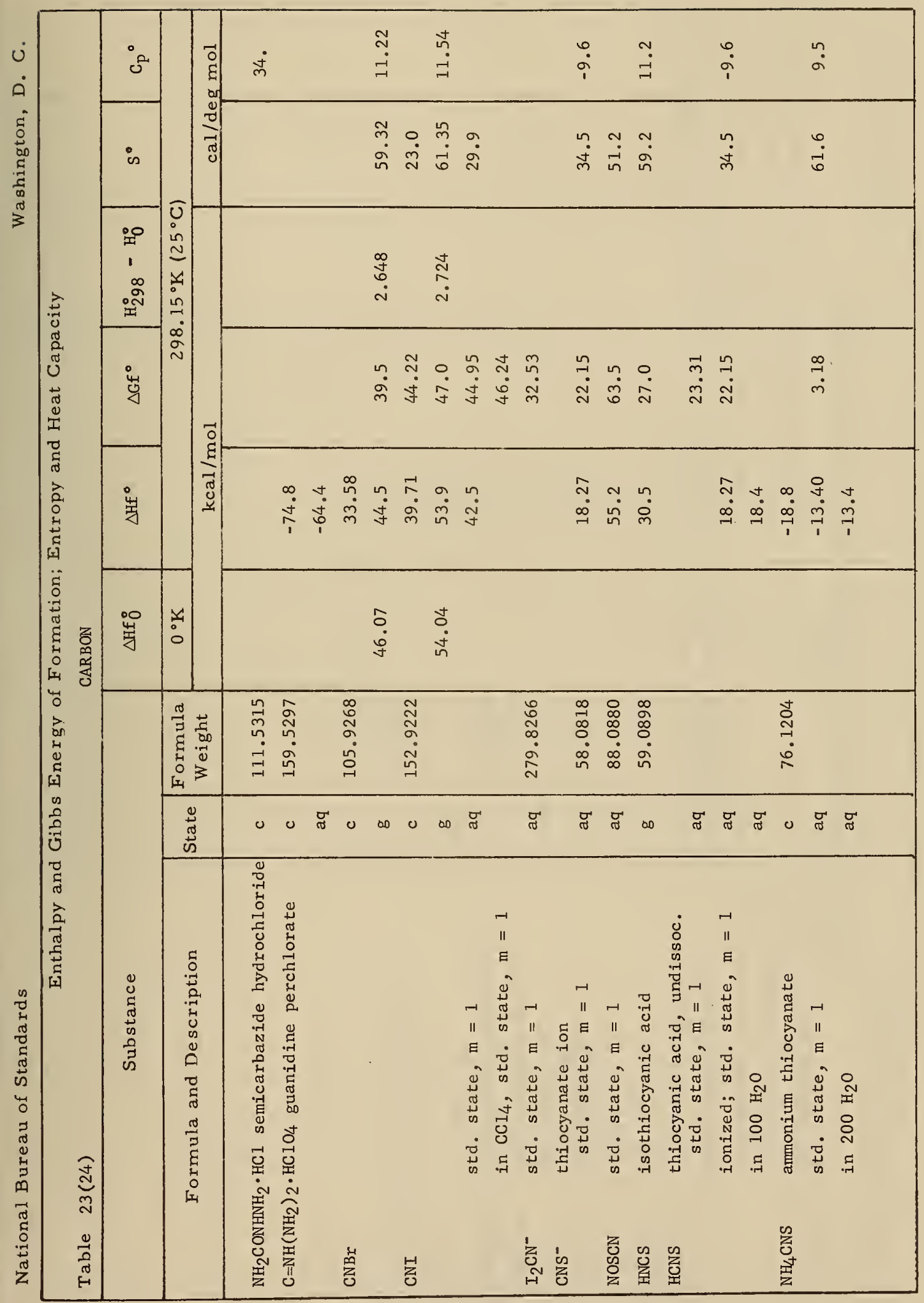




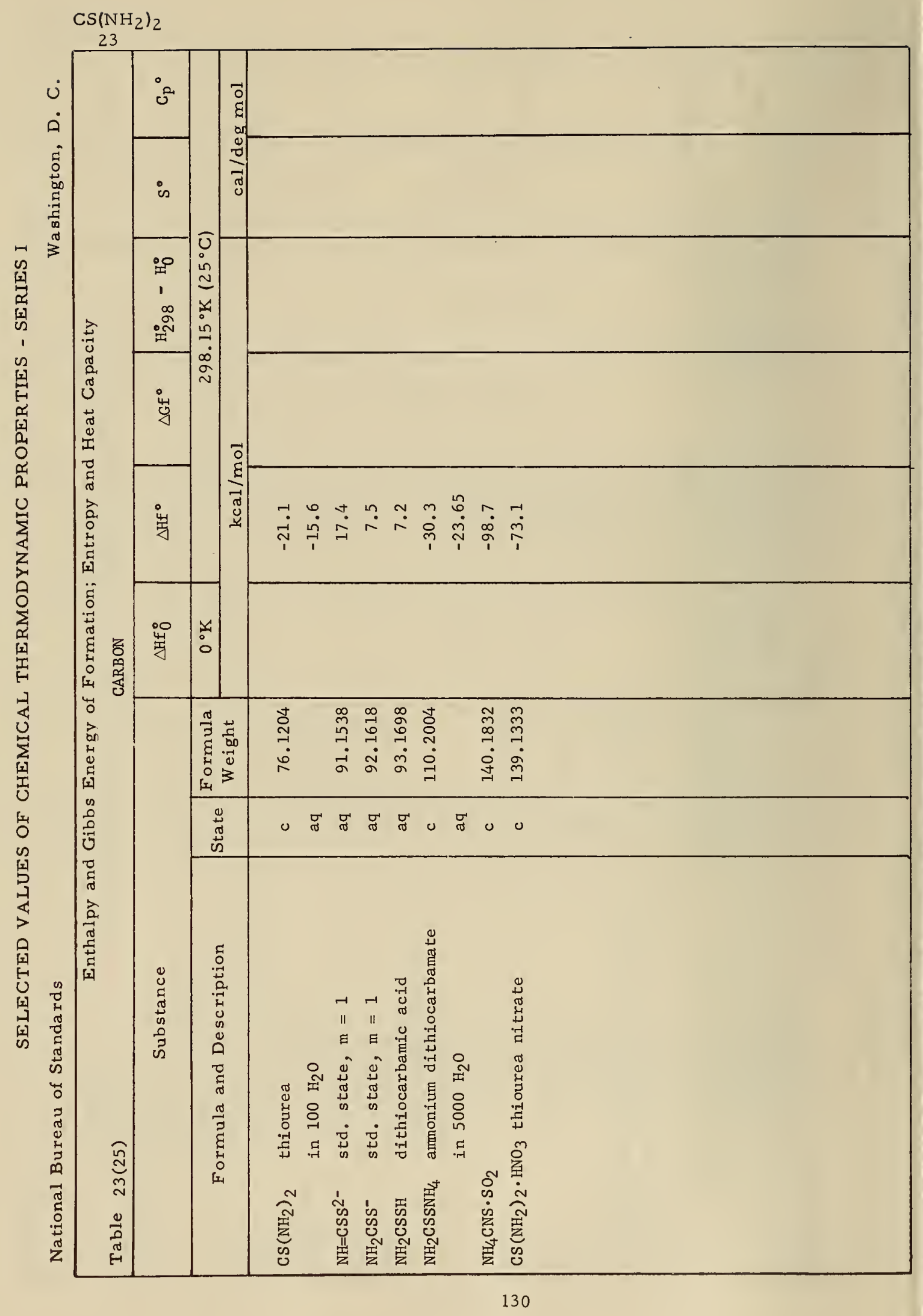




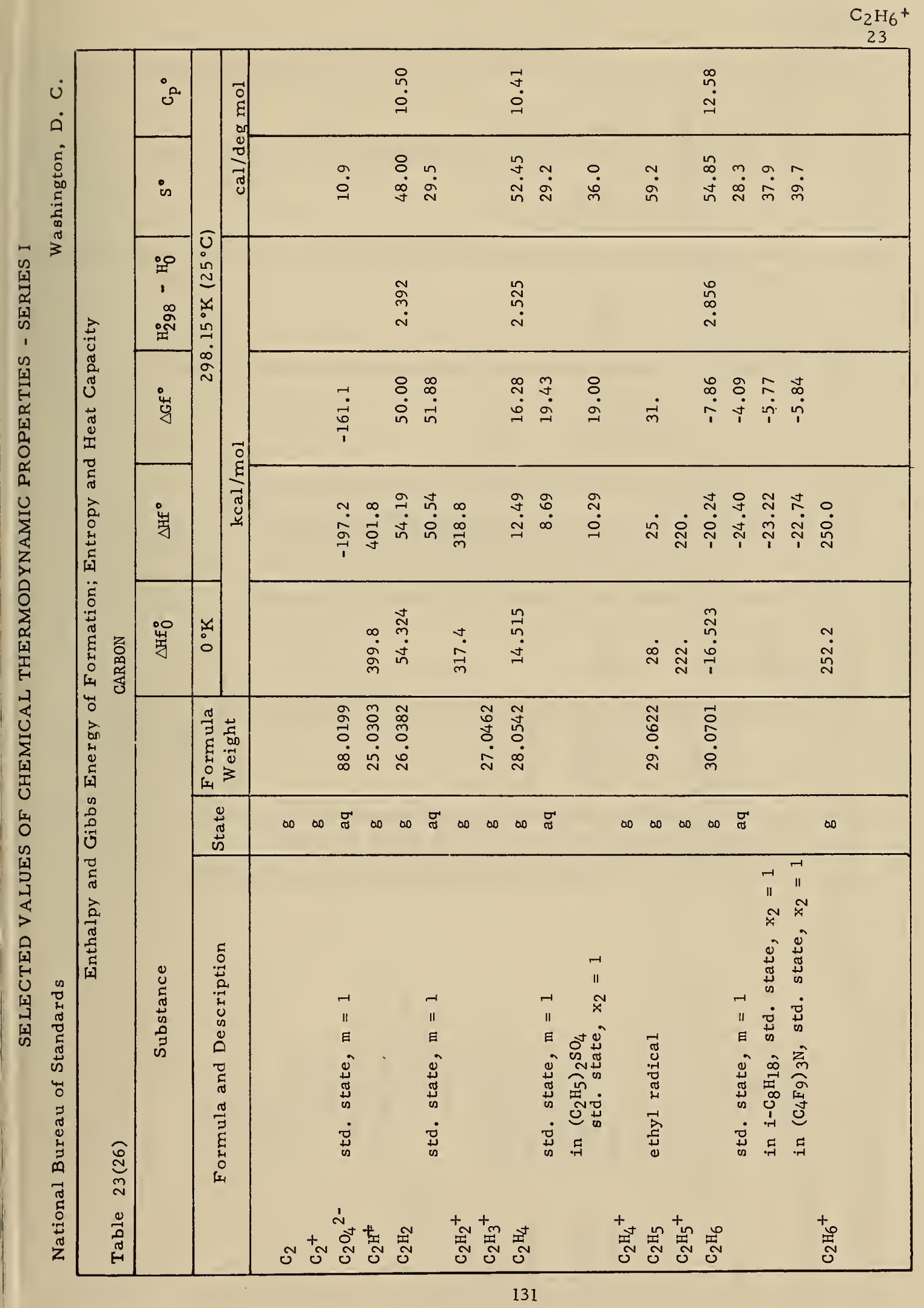




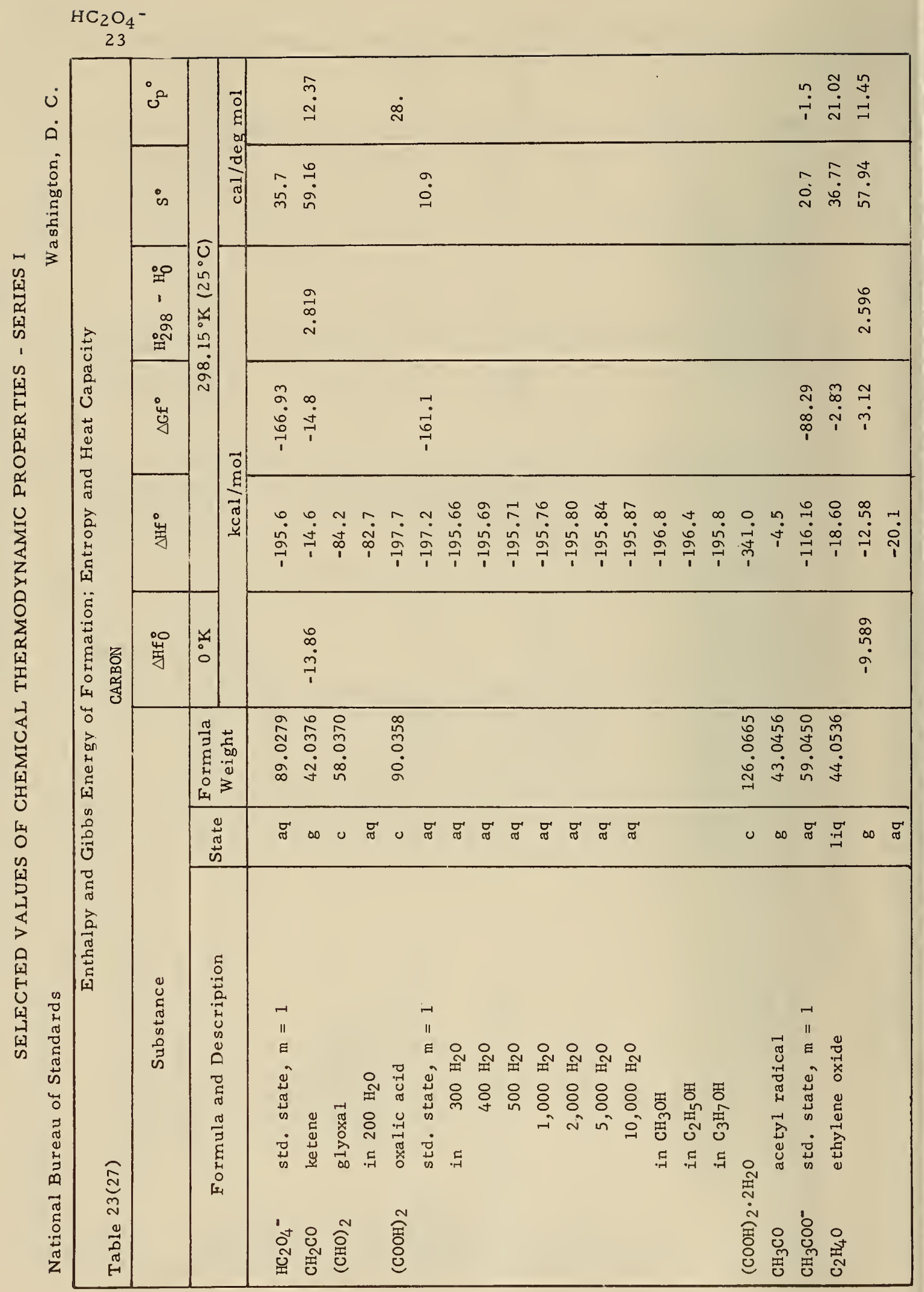




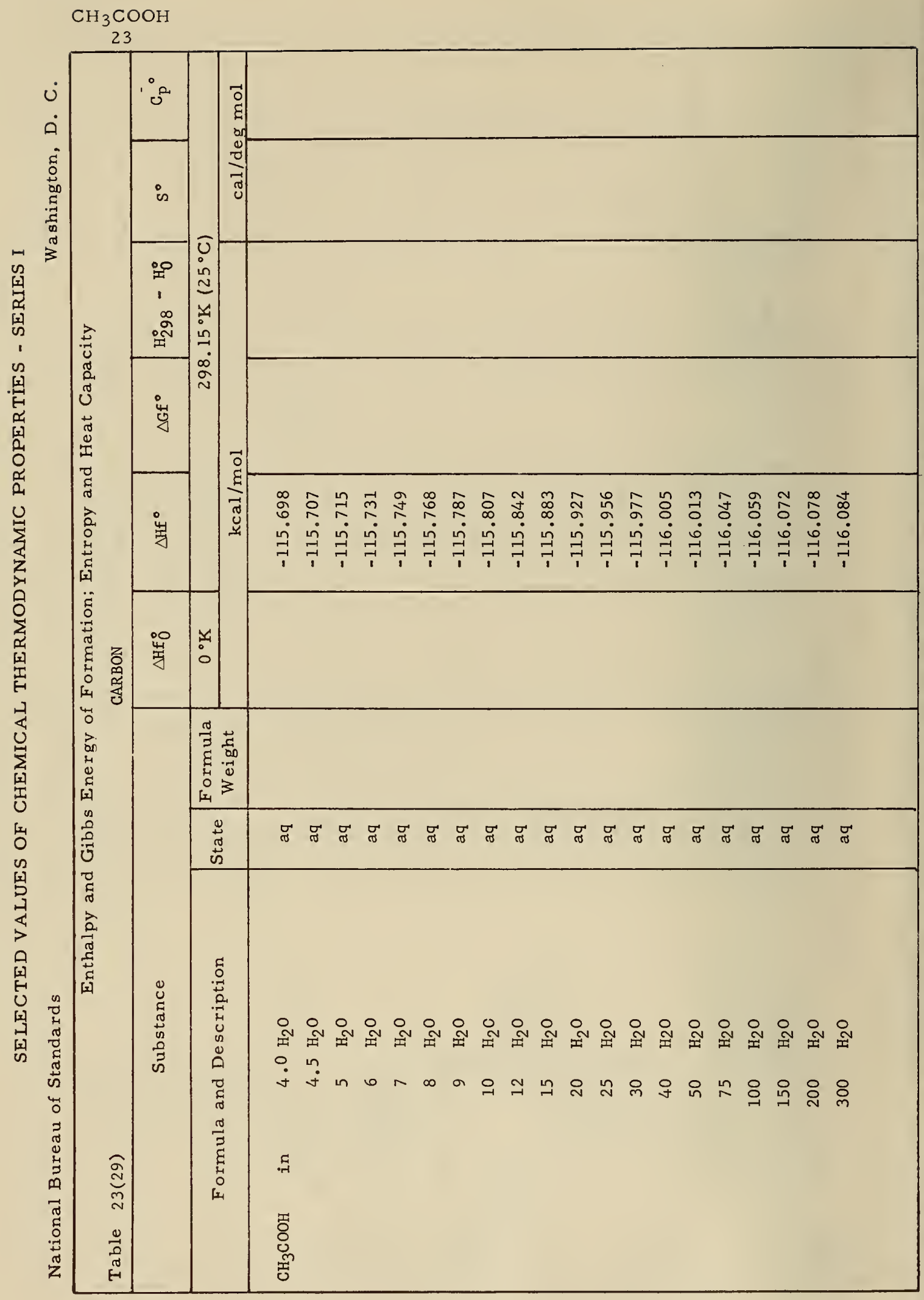




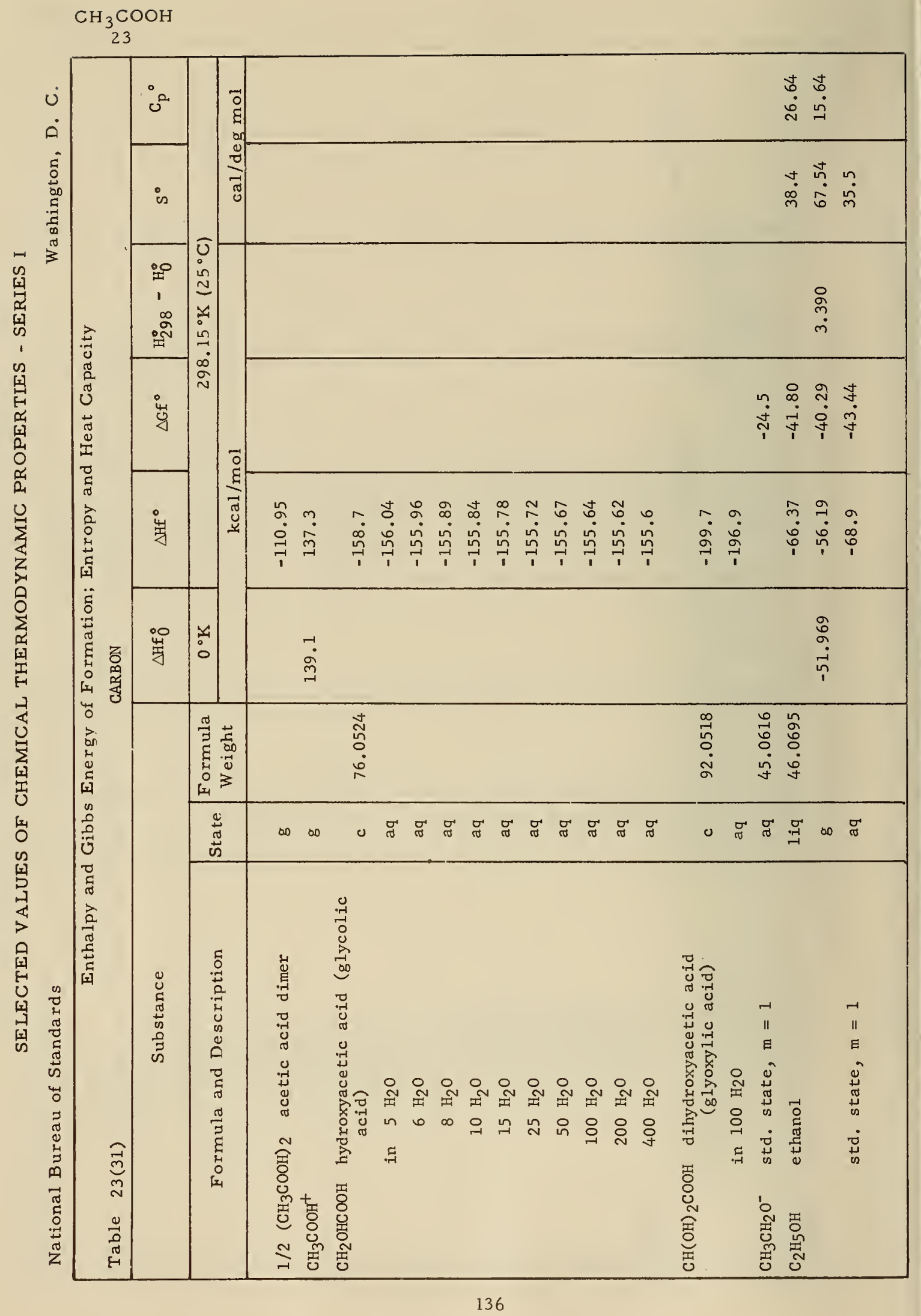




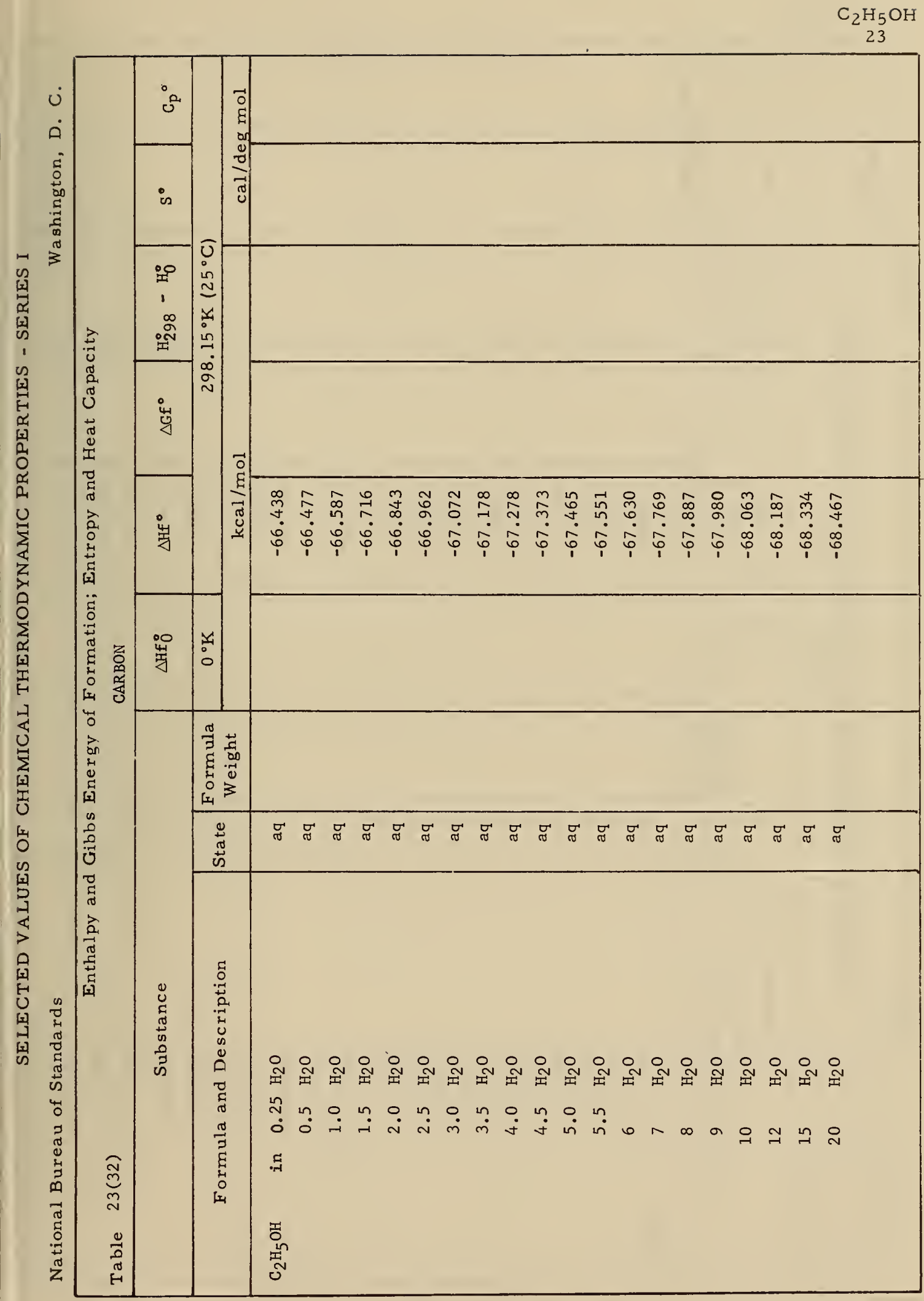




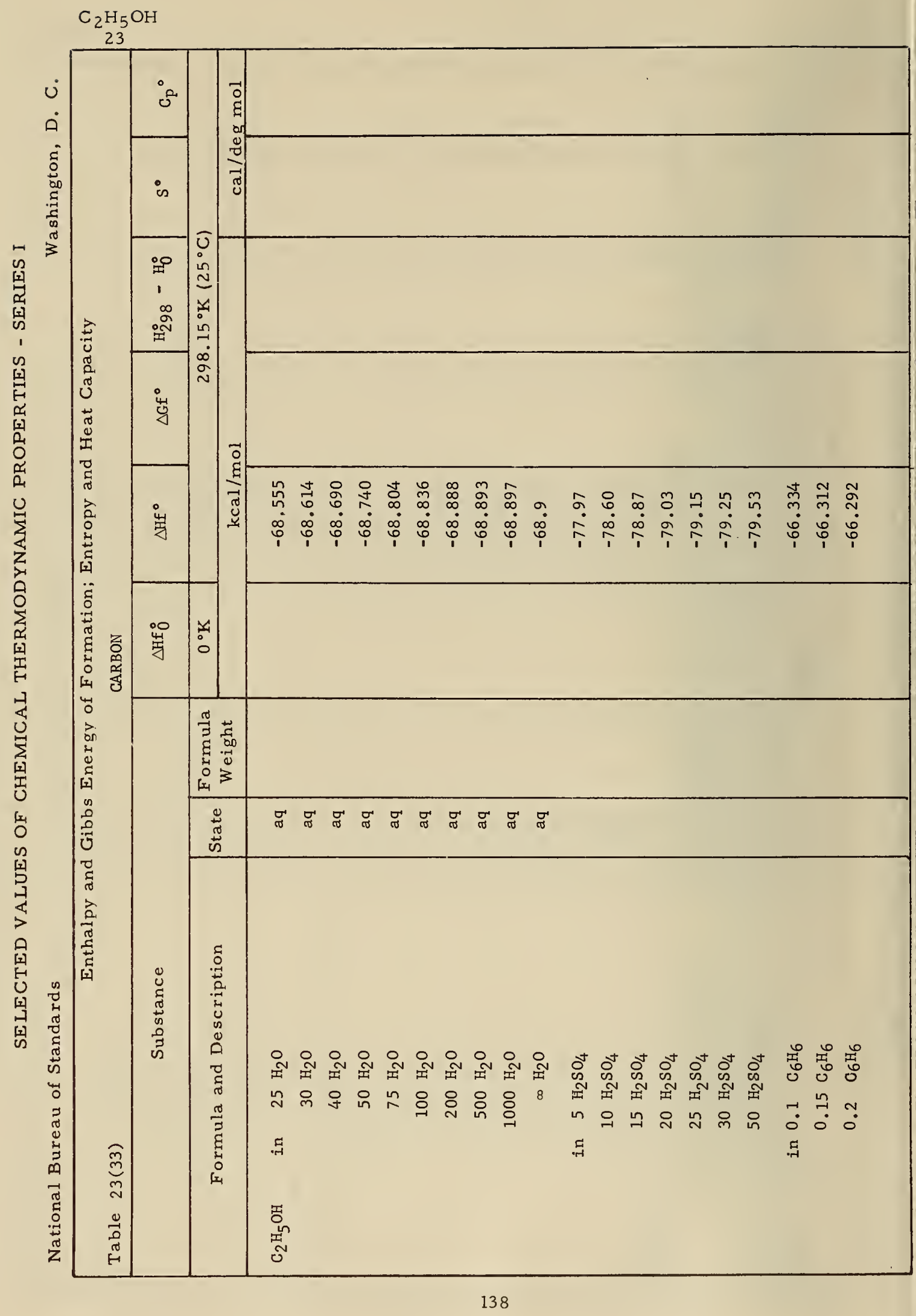




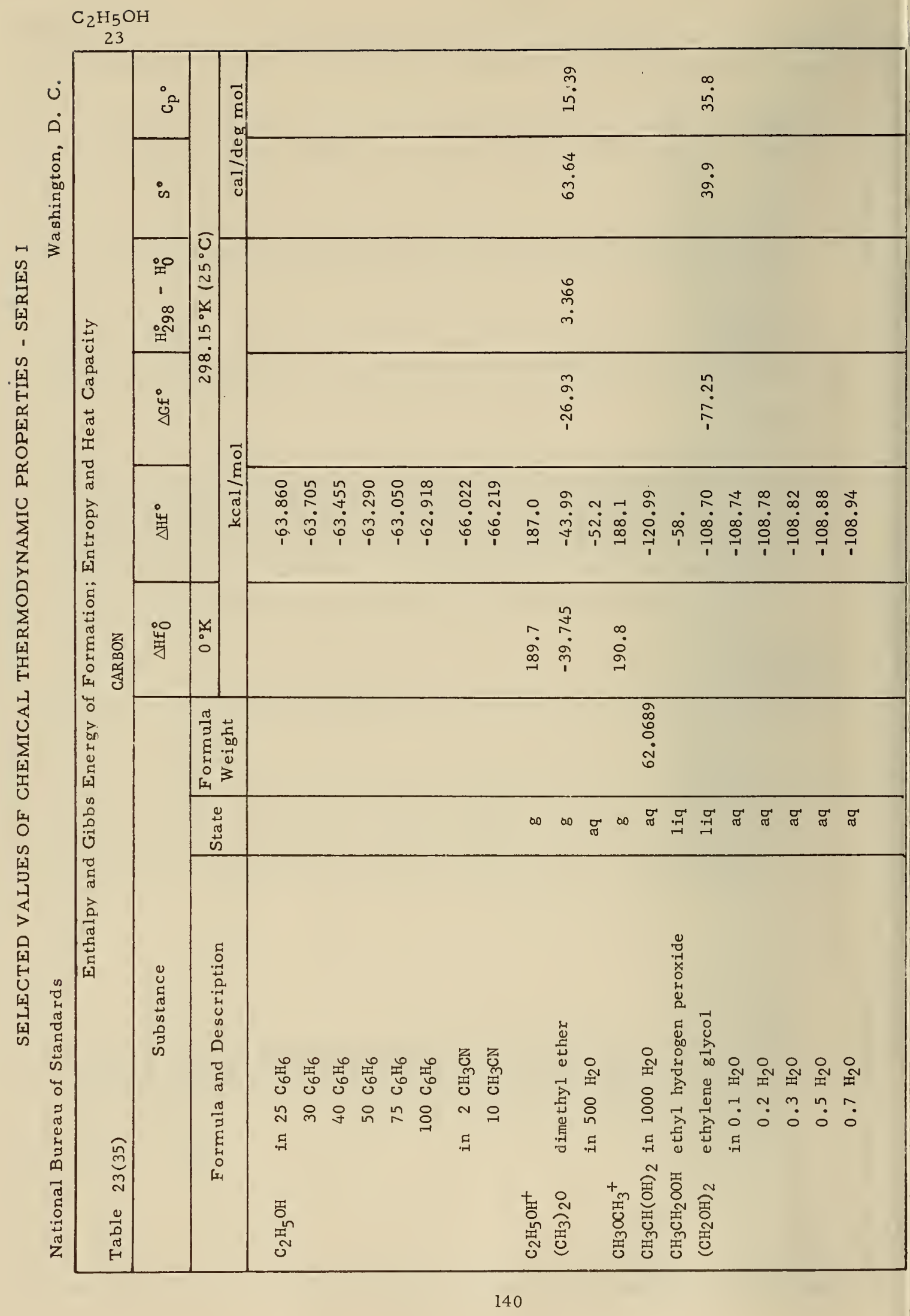




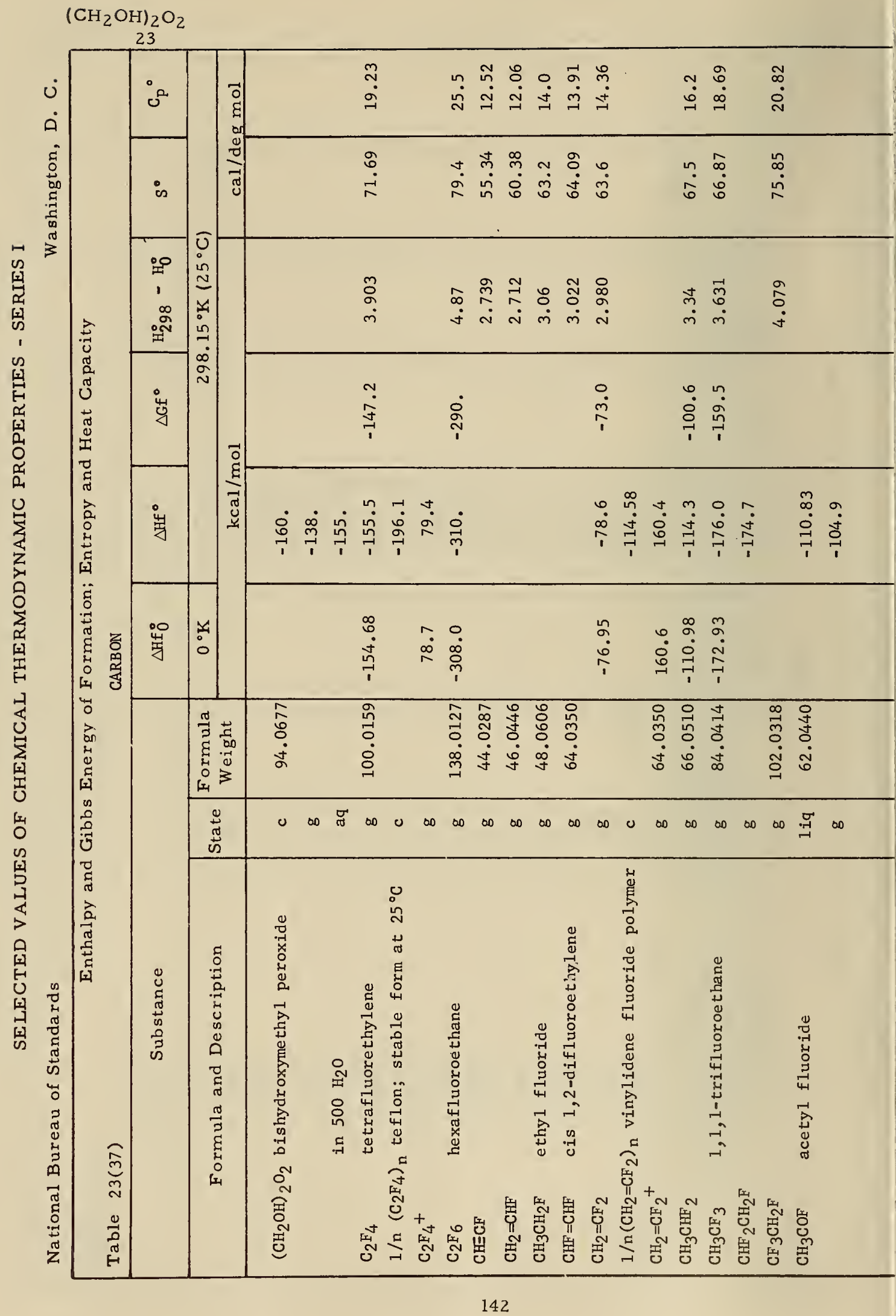




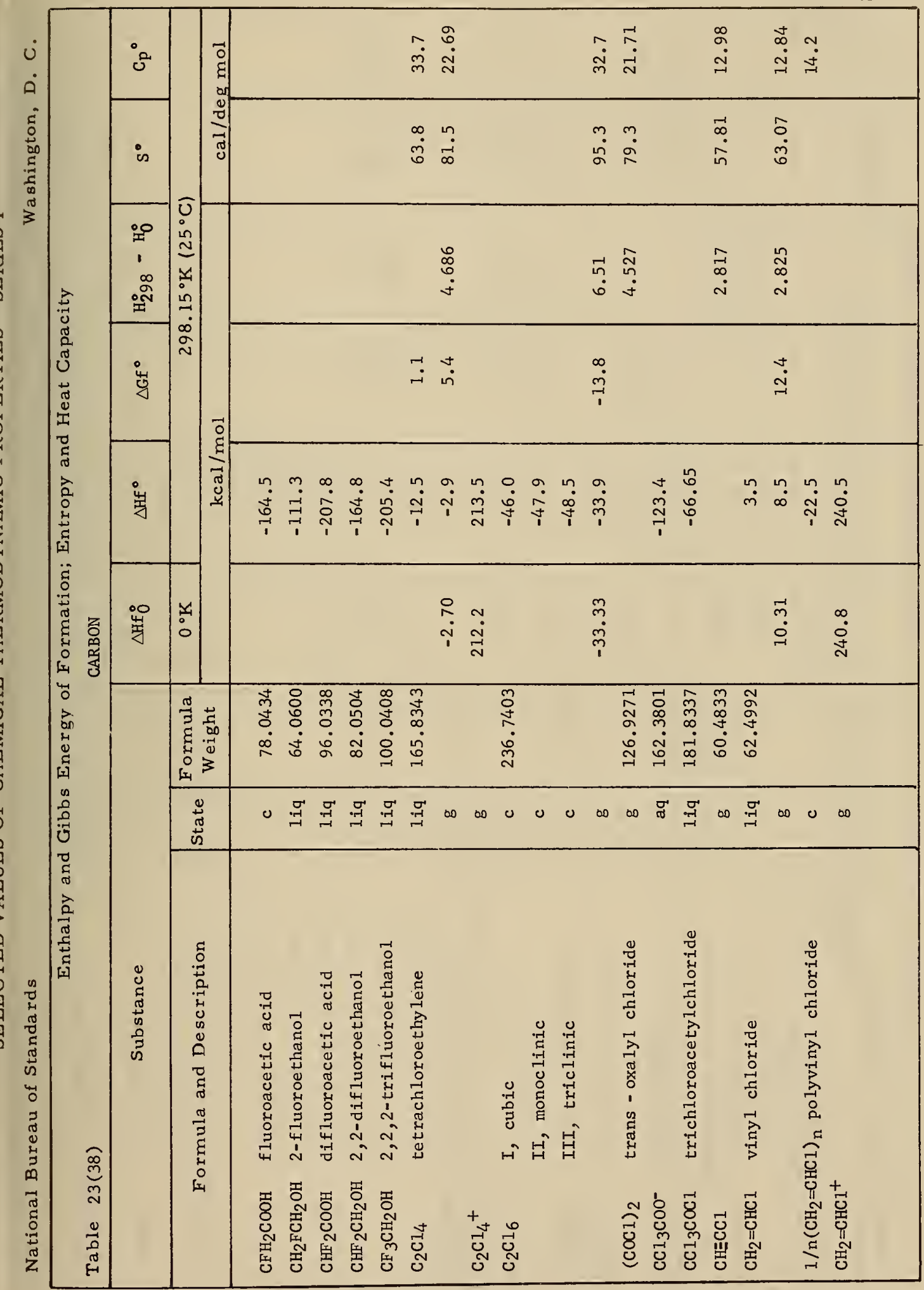




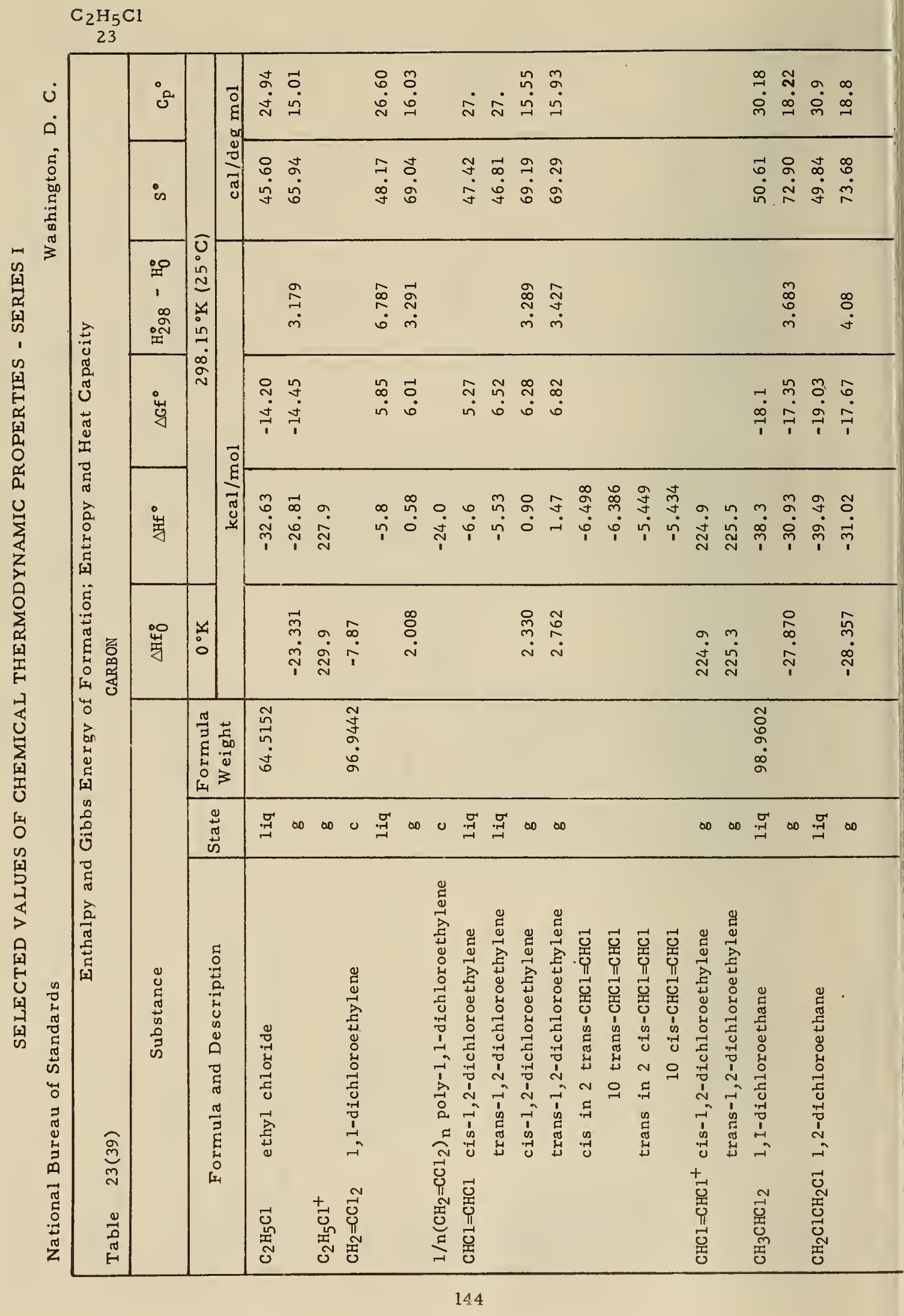




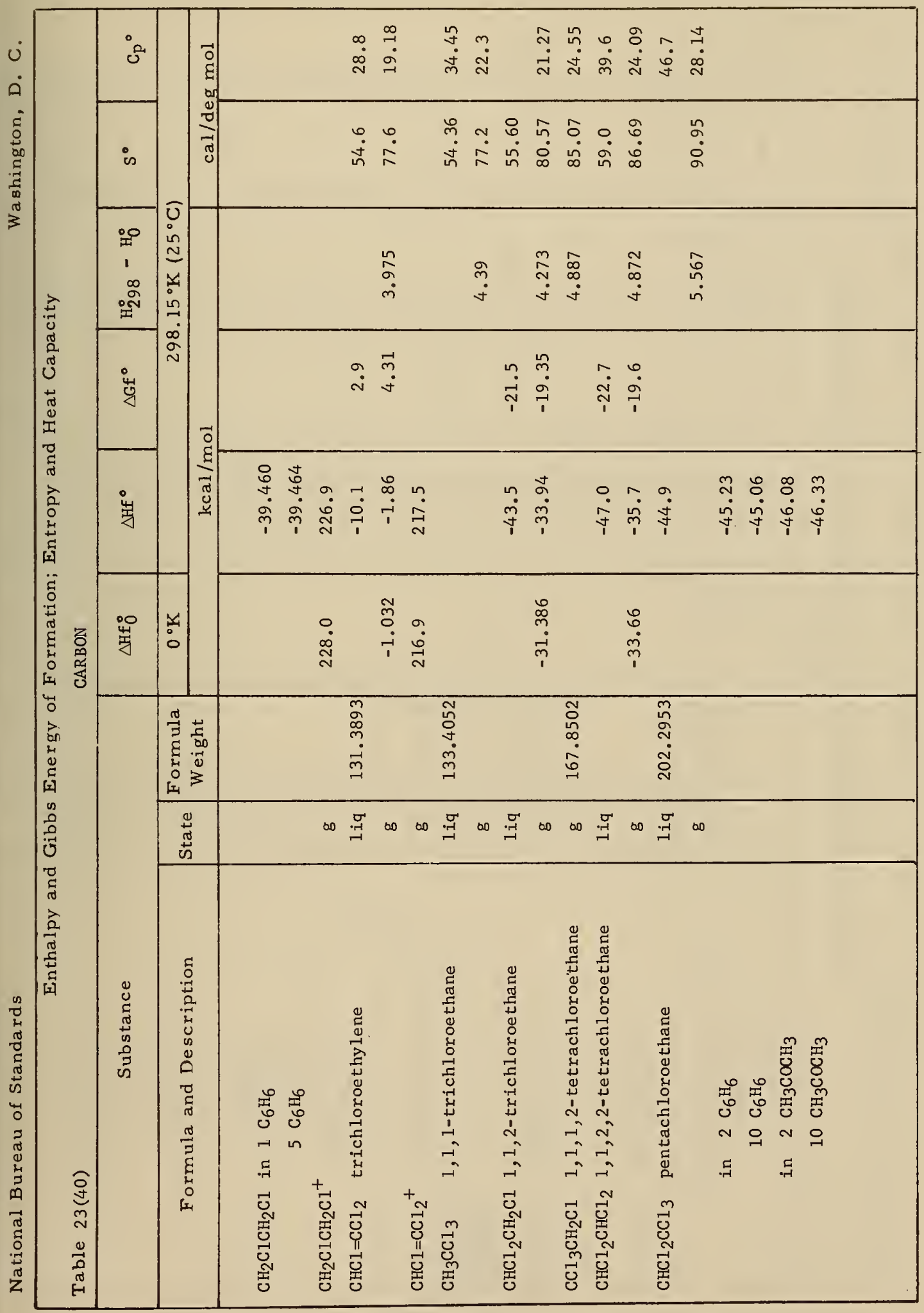




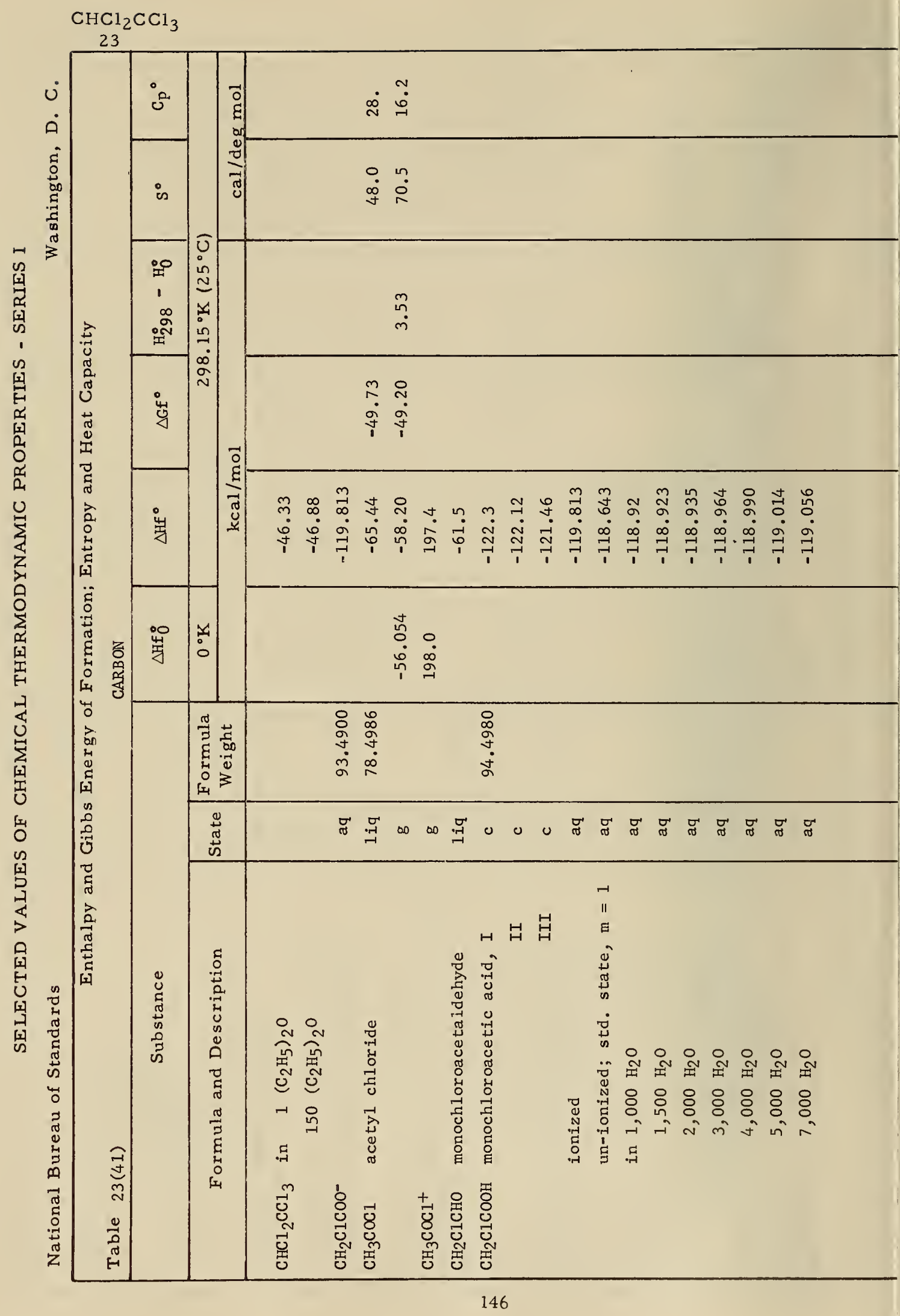




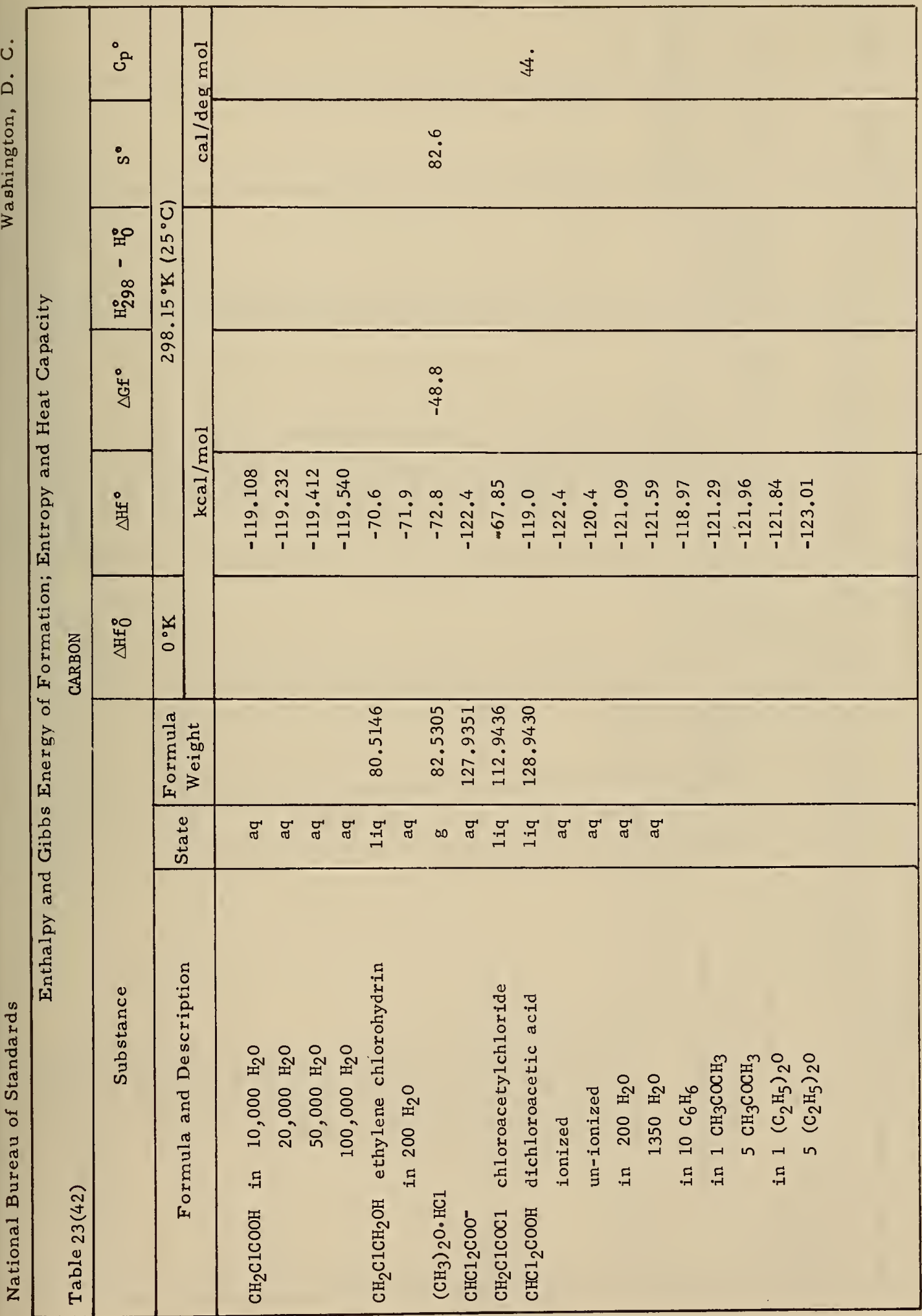




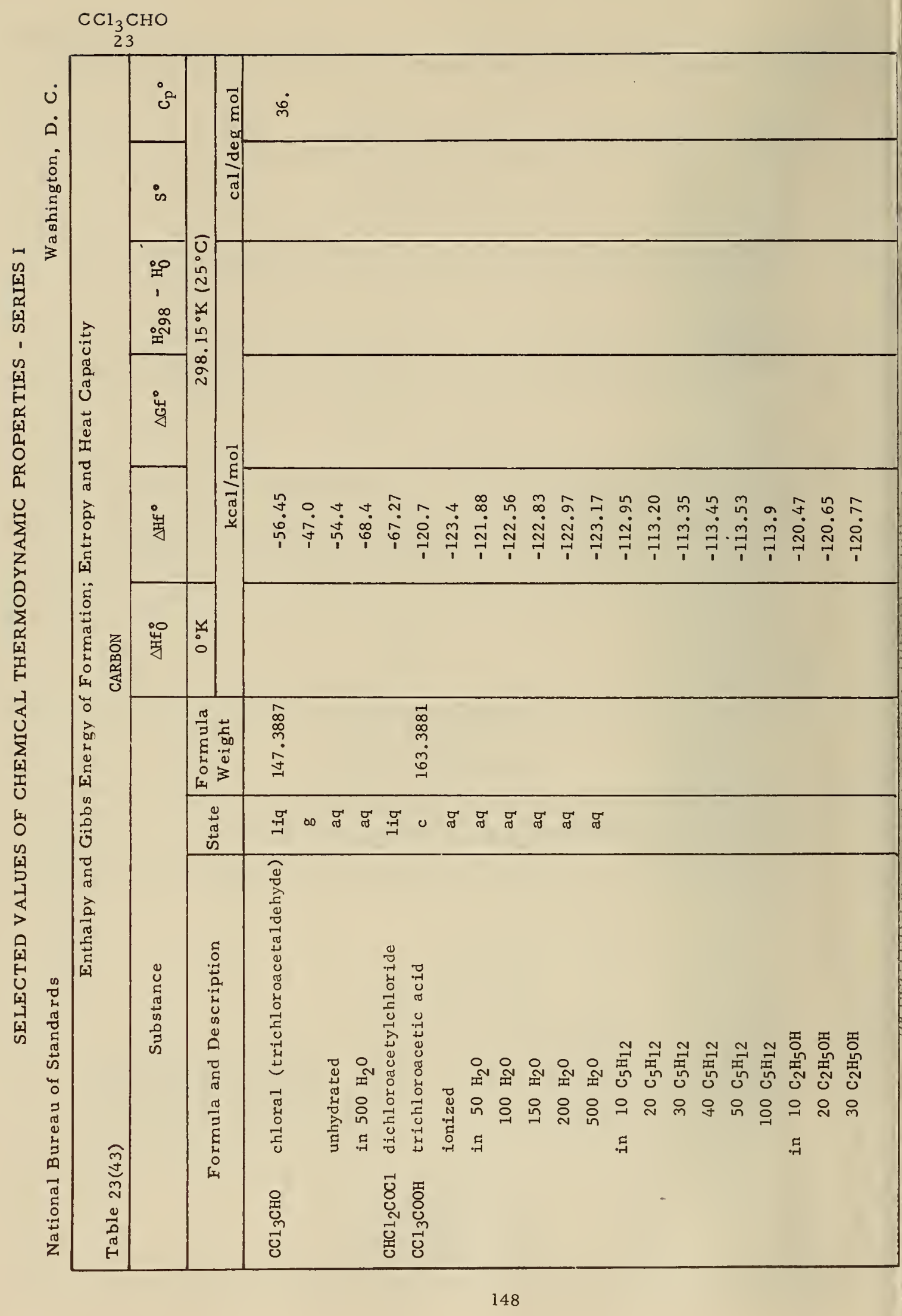


CFClCFCl

23

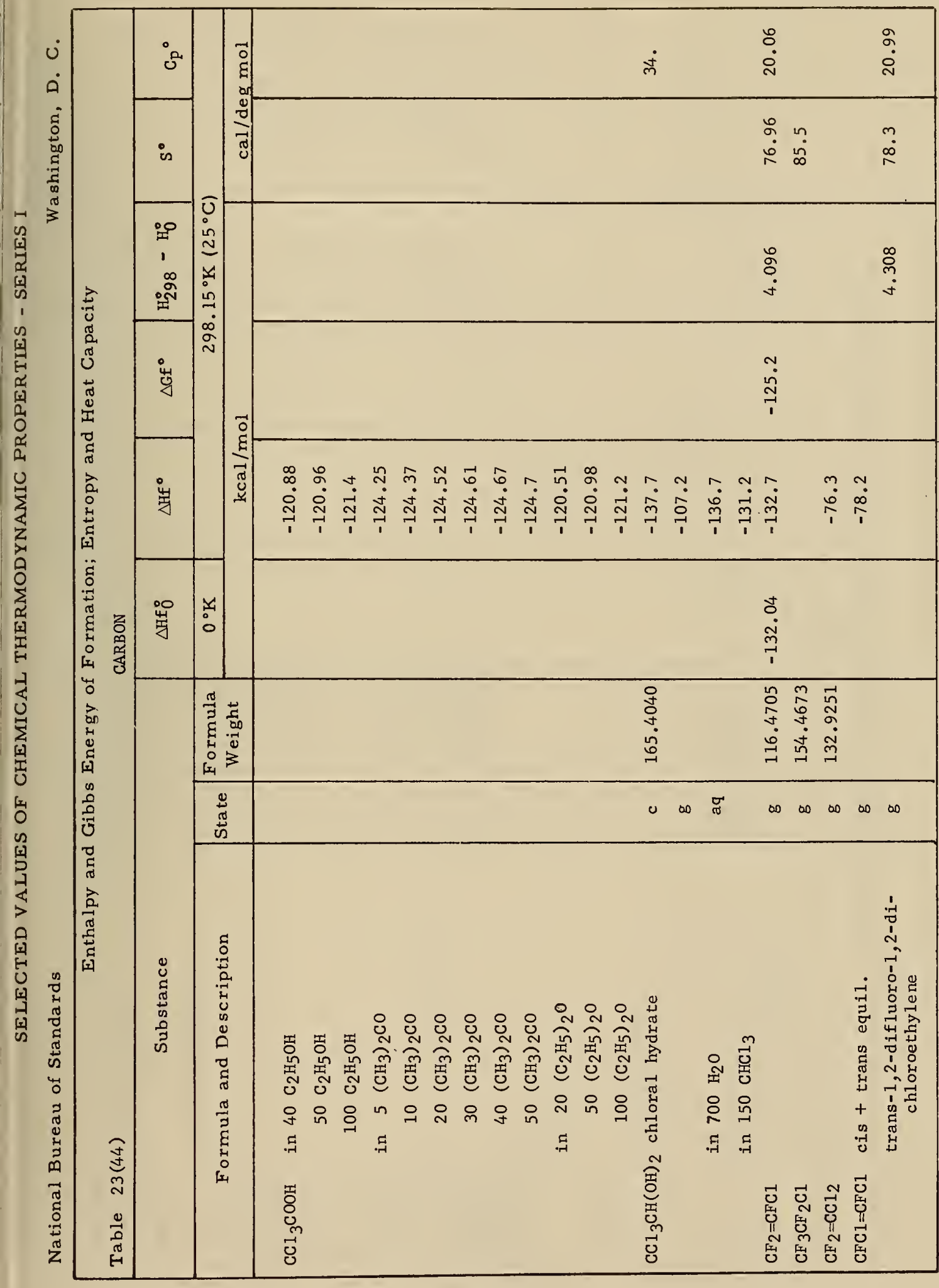




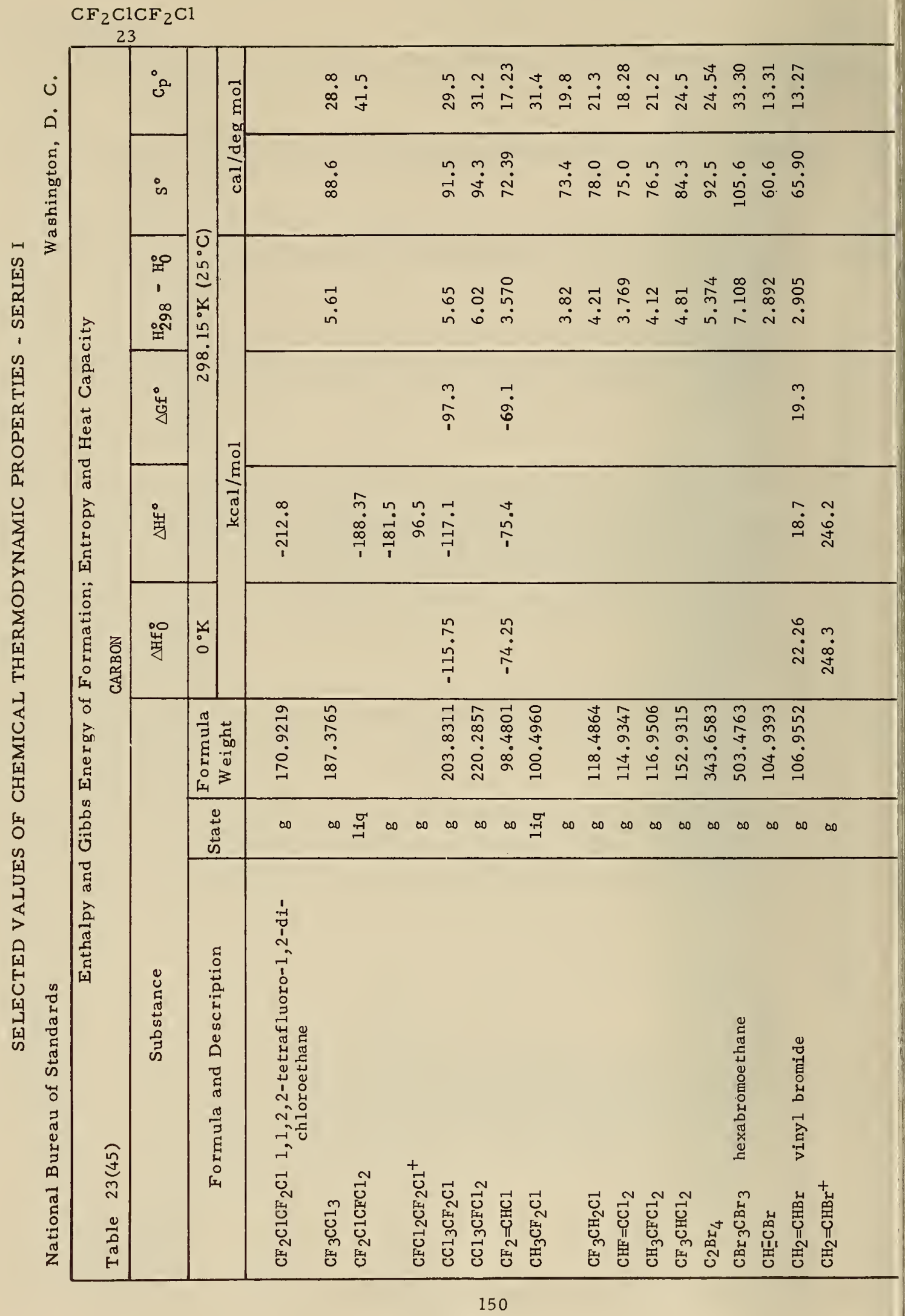




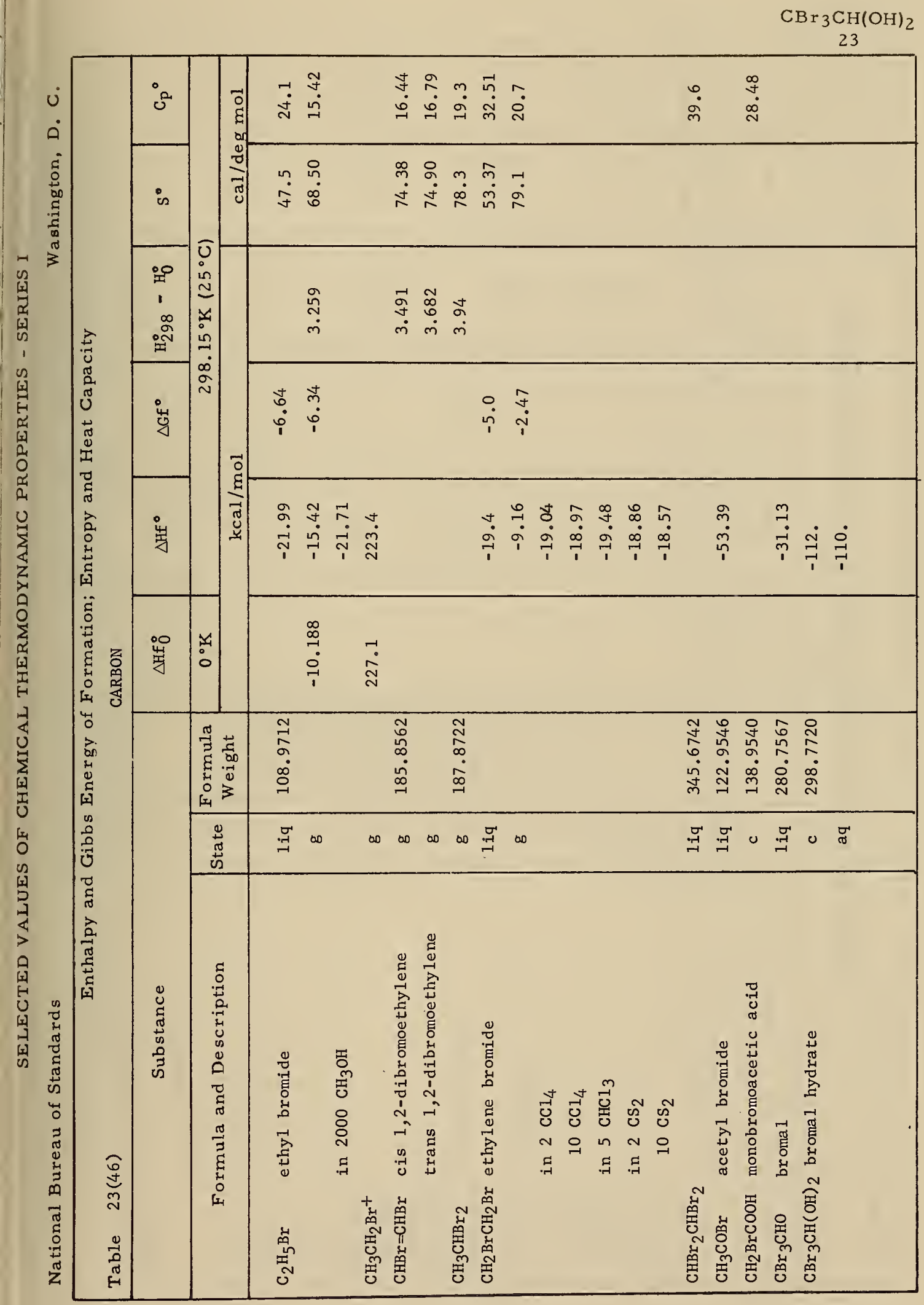




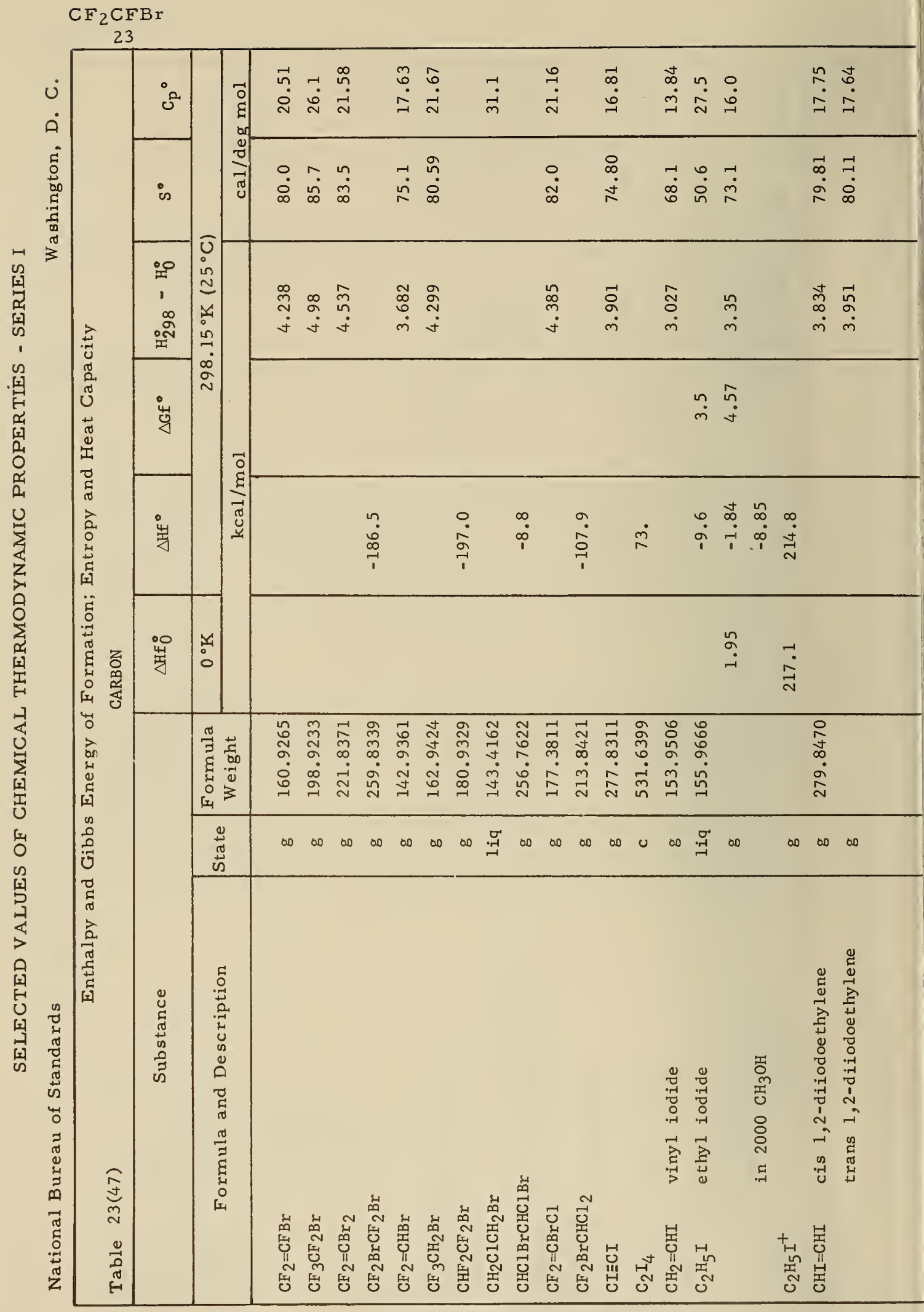




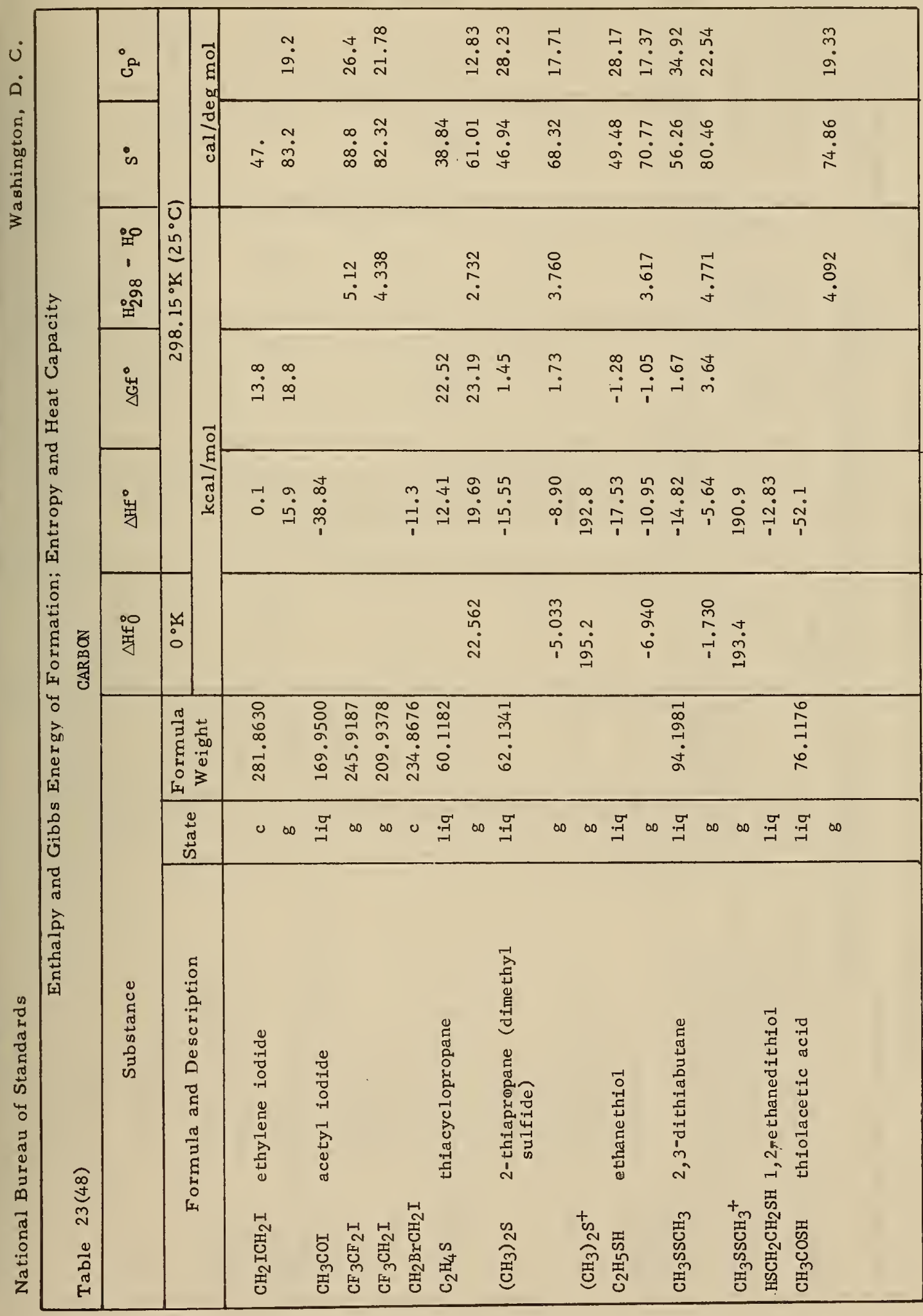




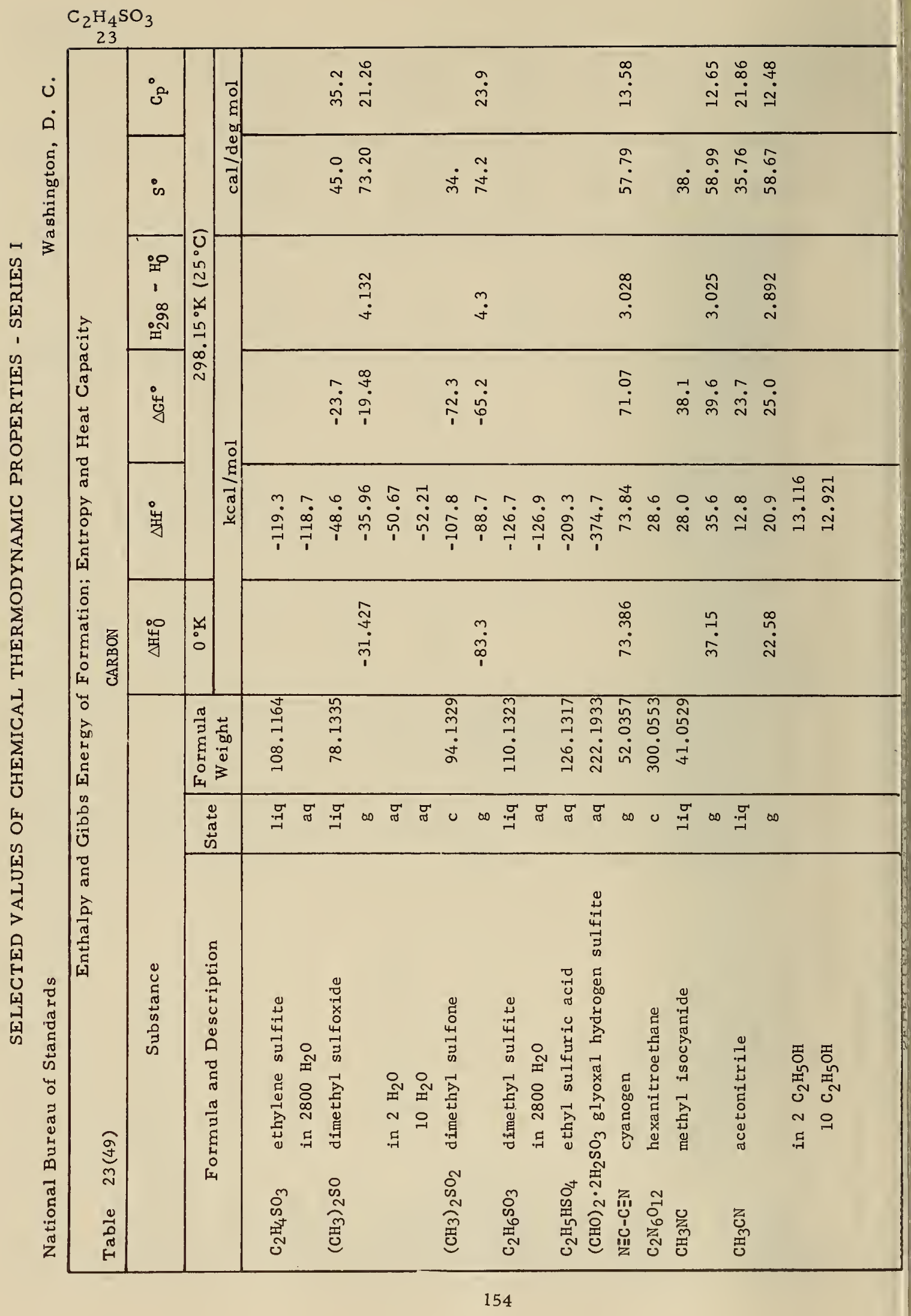




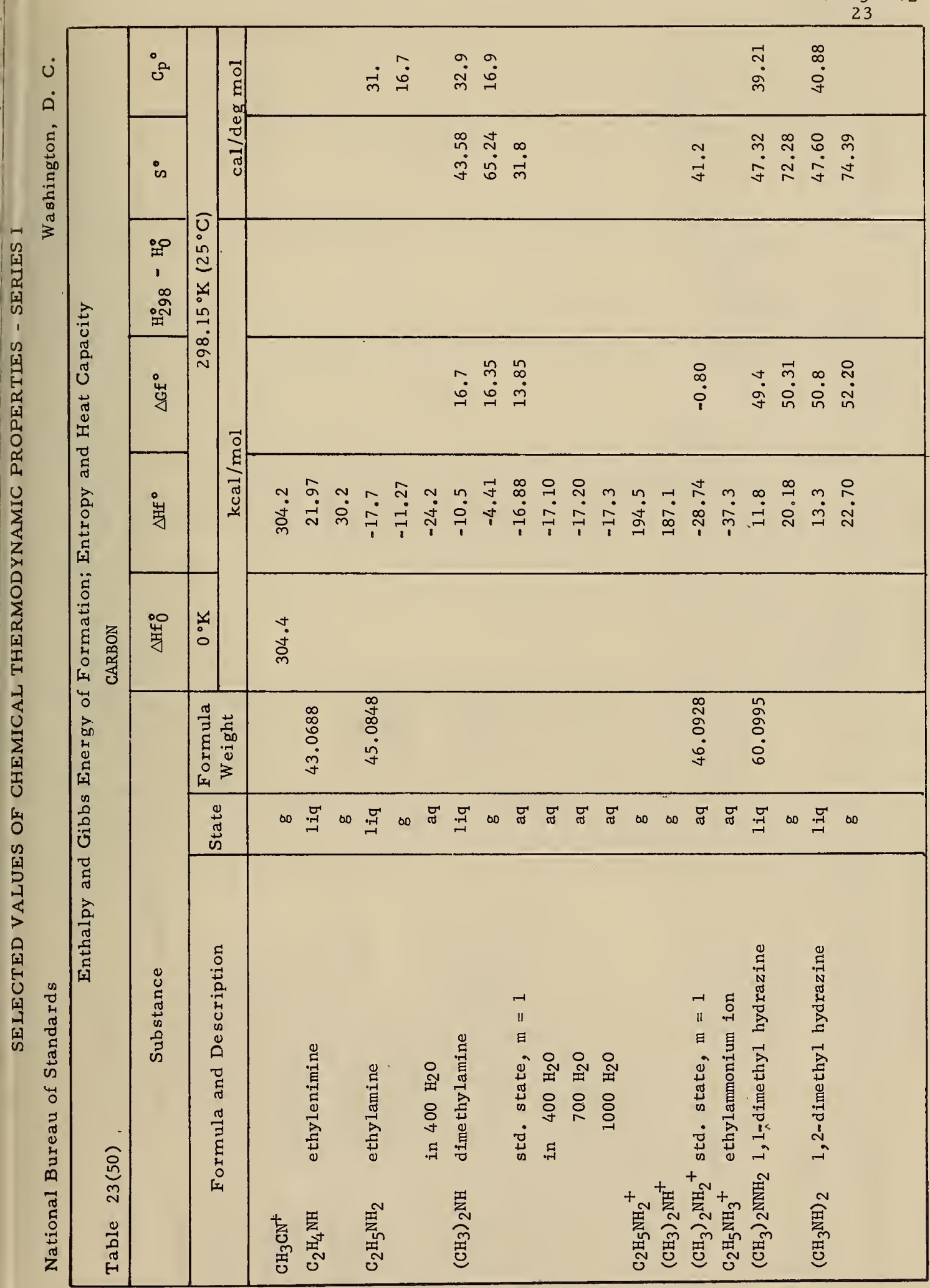




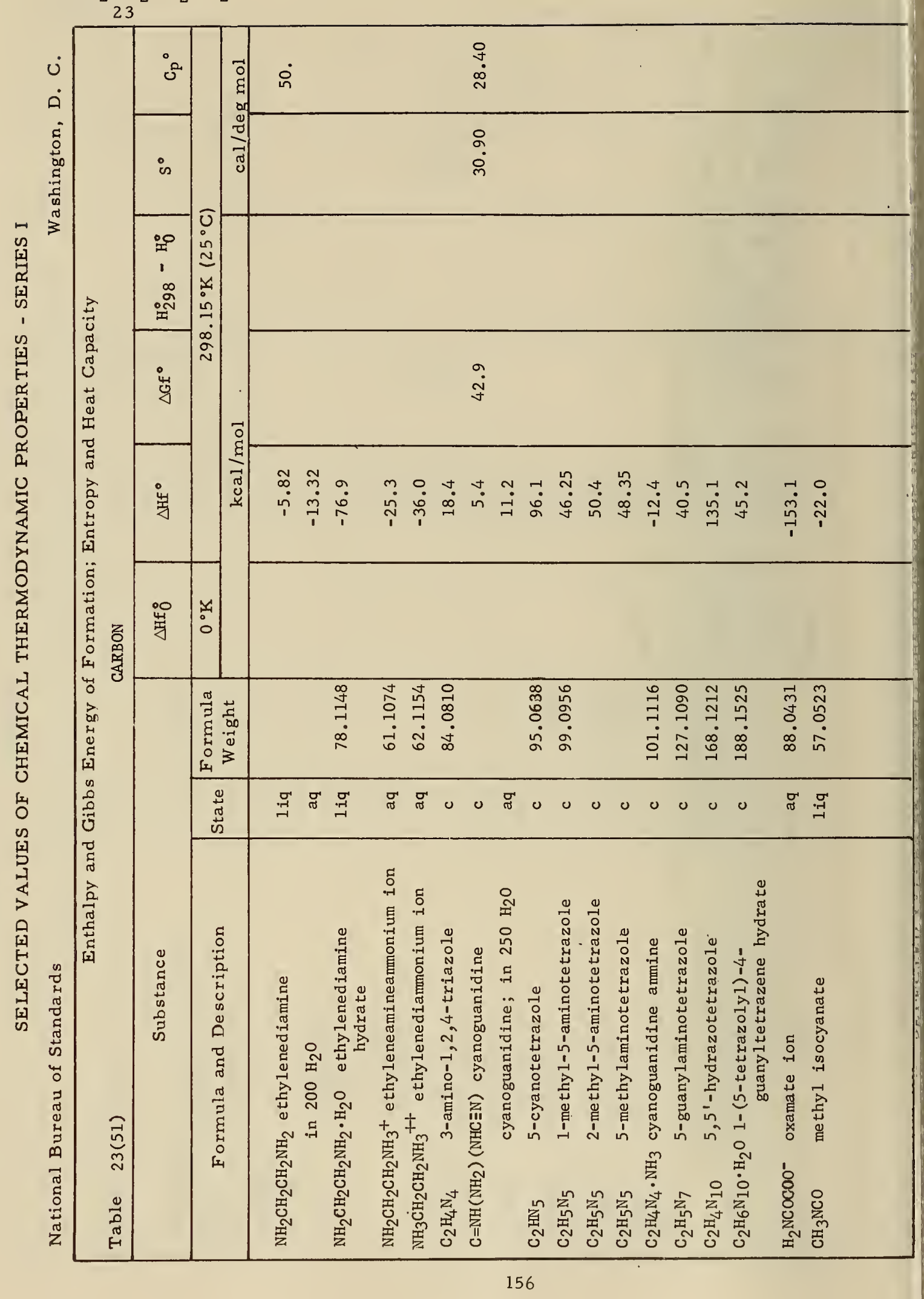




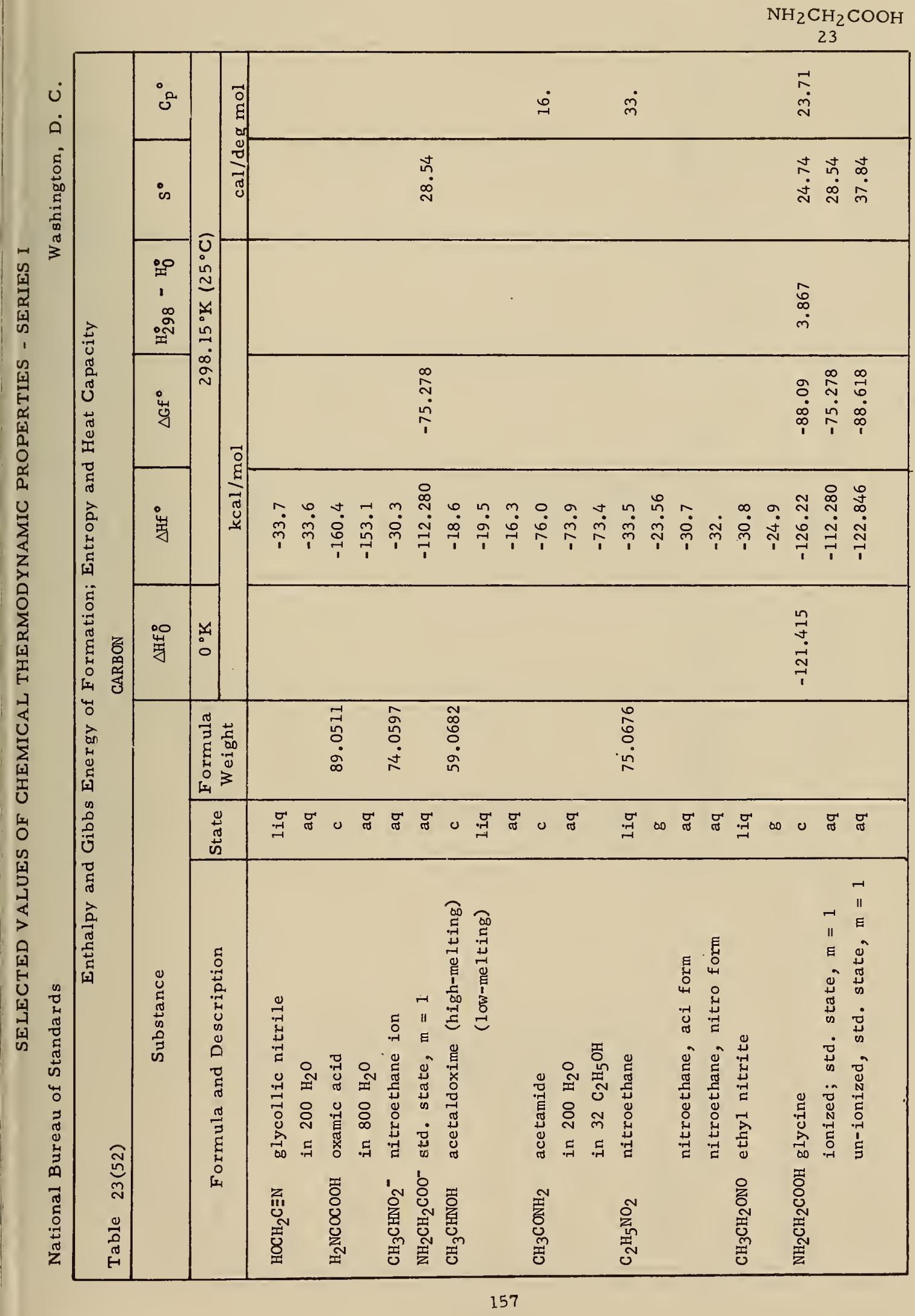




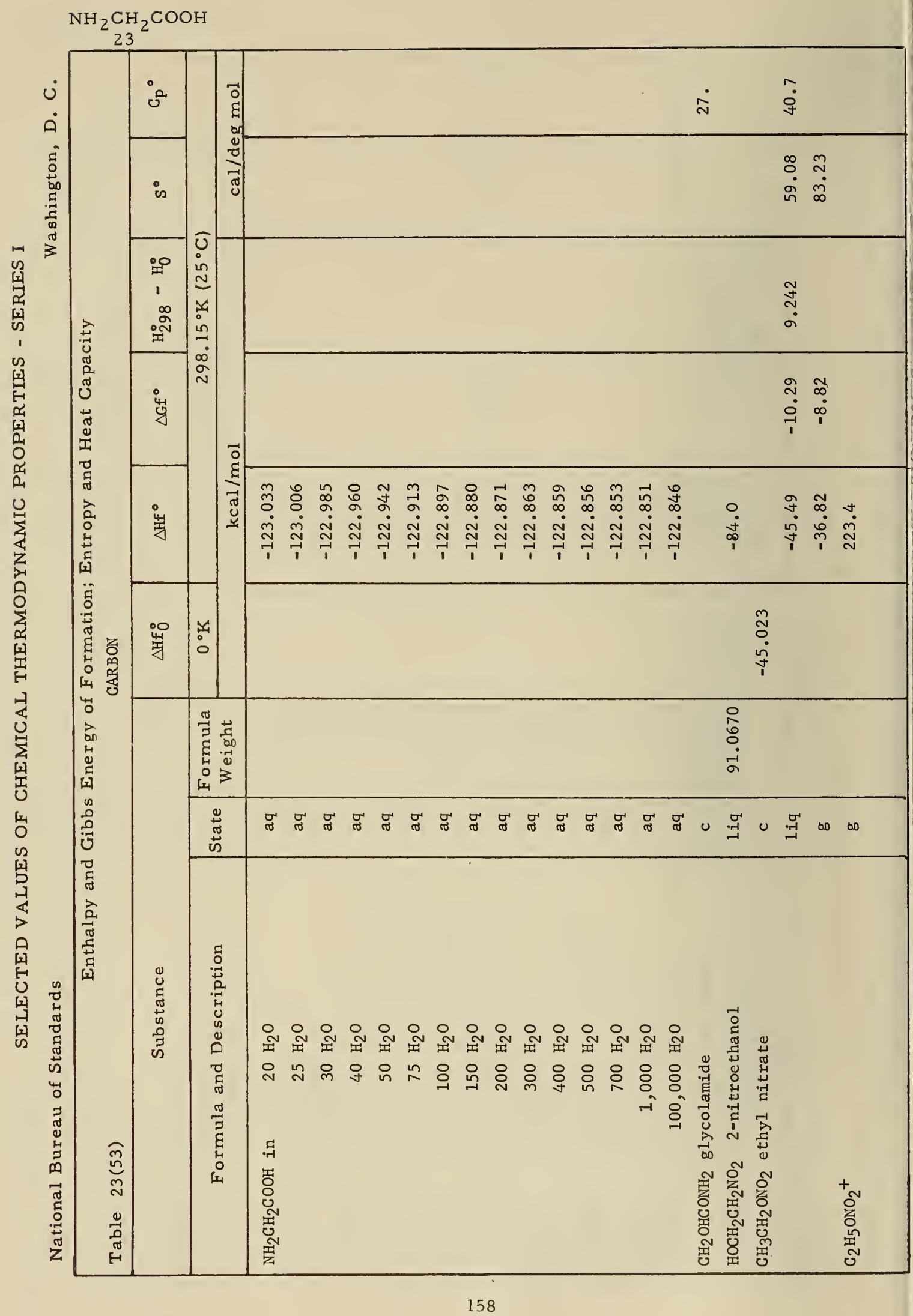




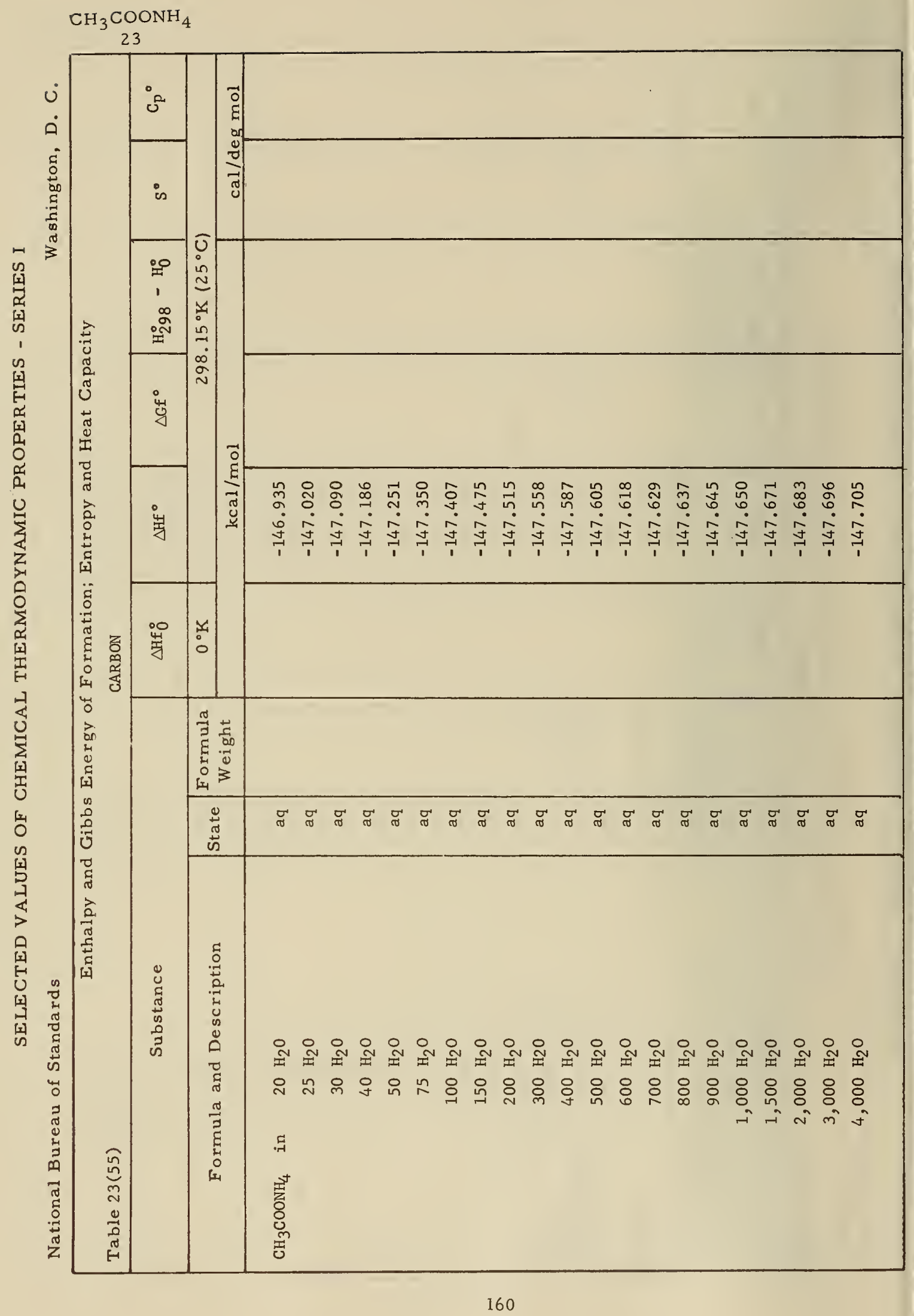




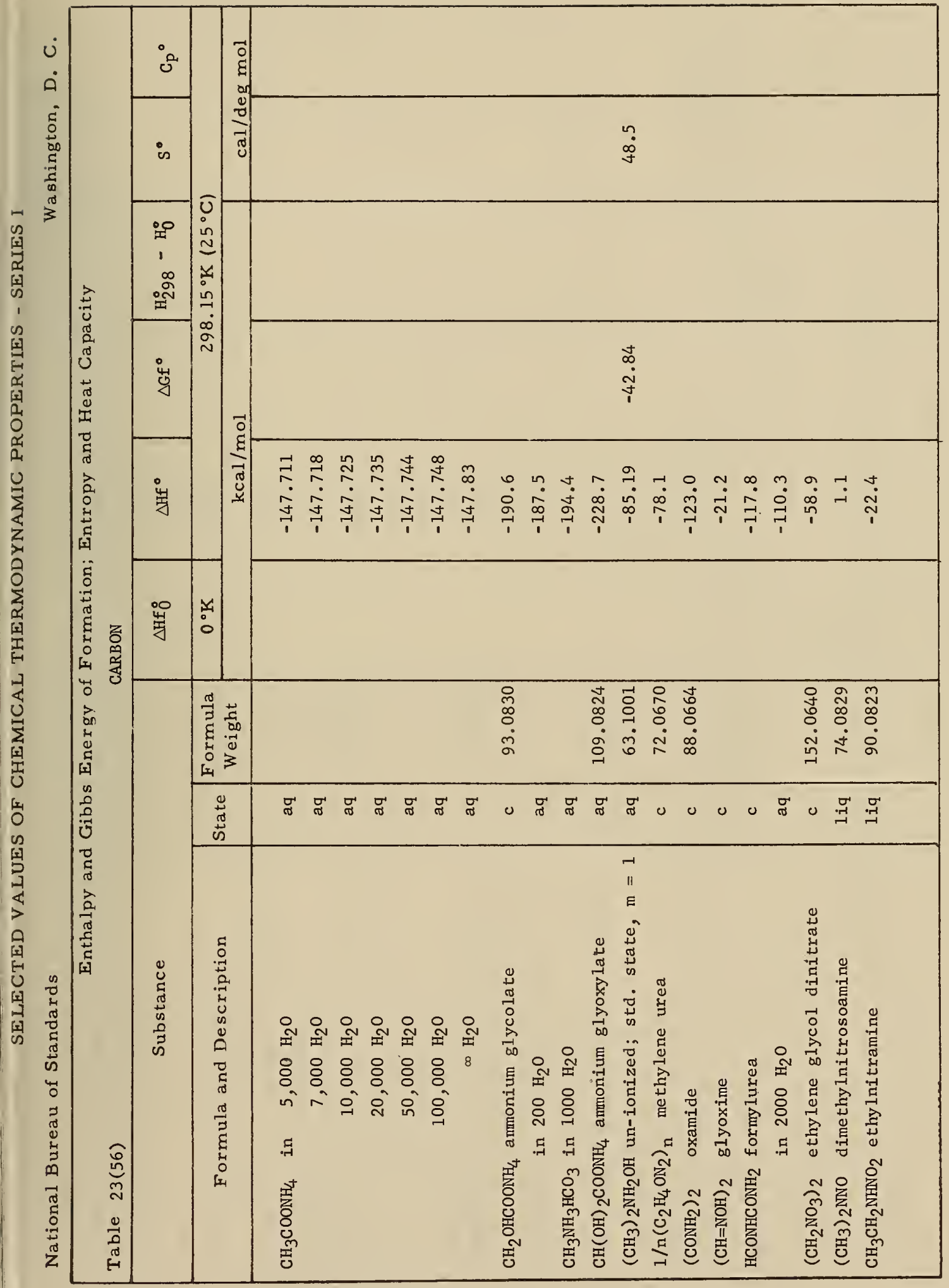




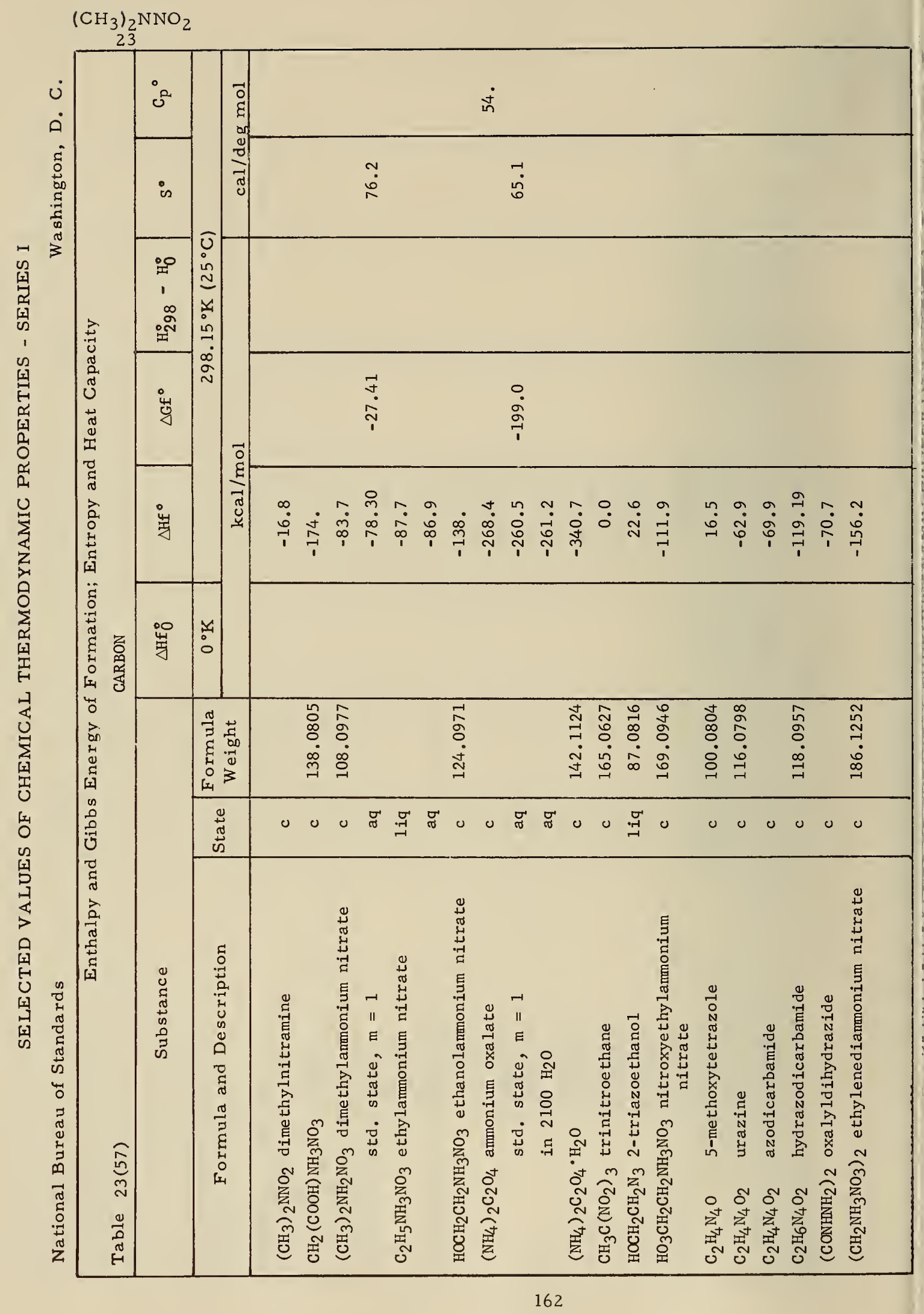




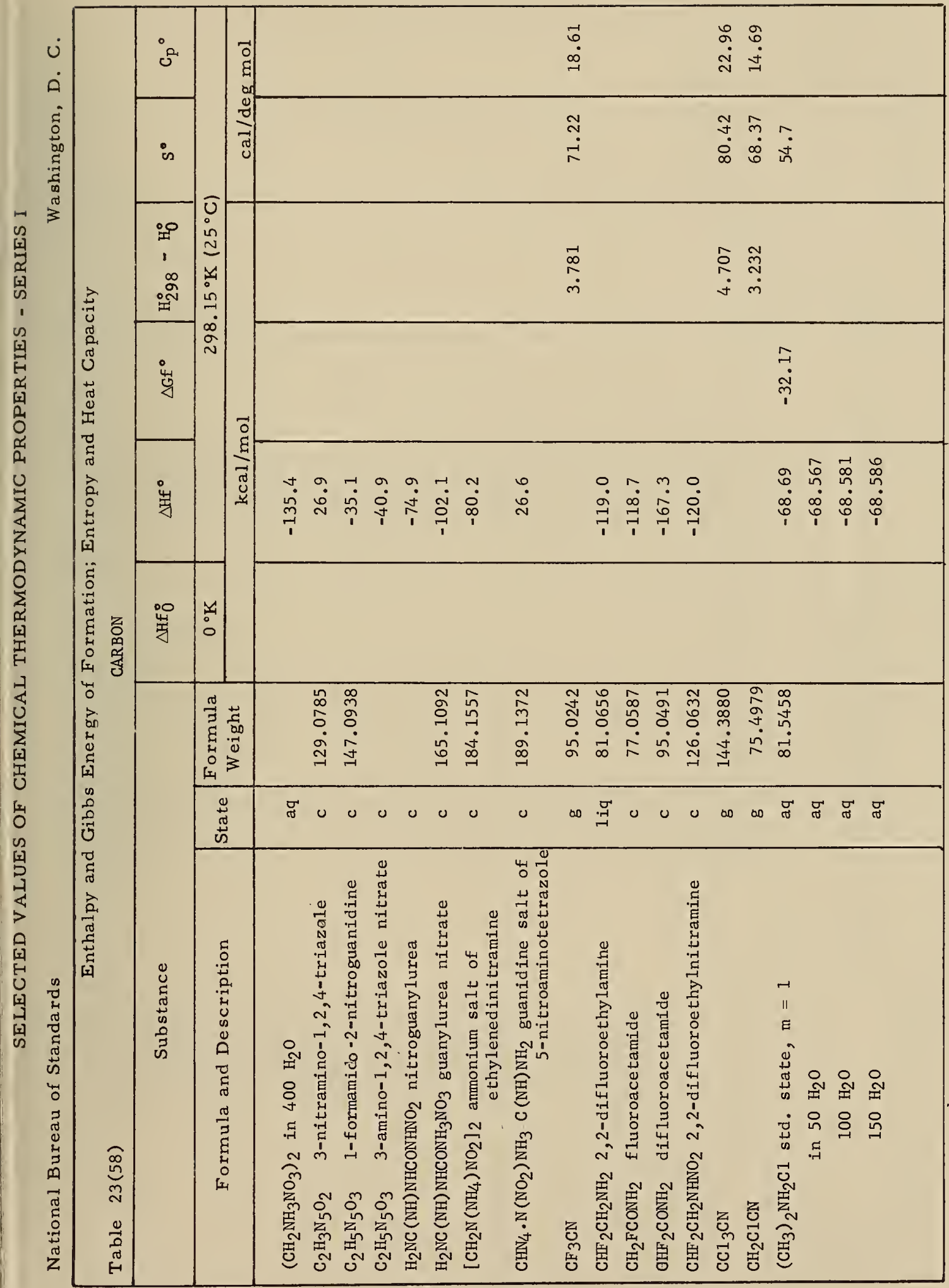




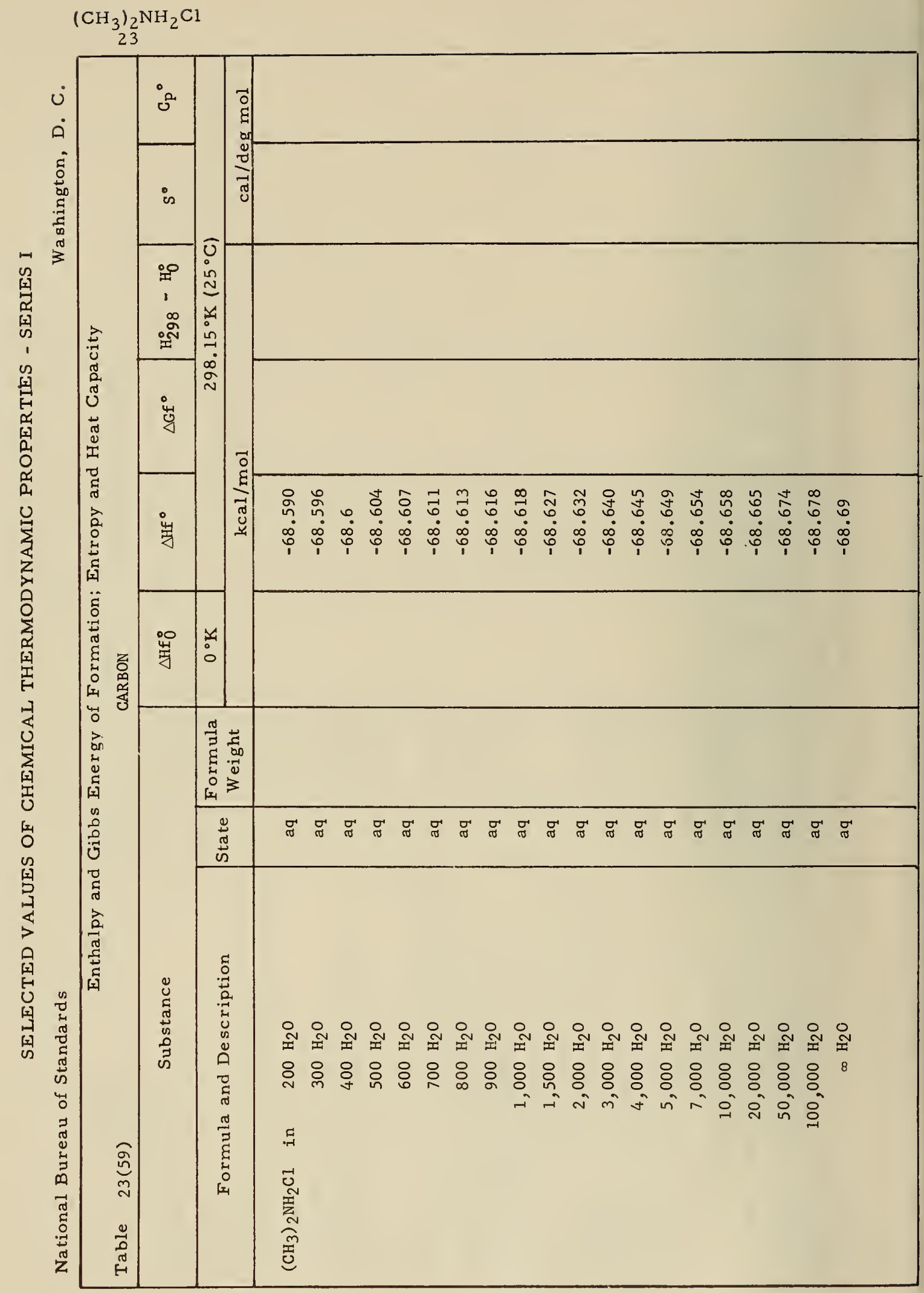




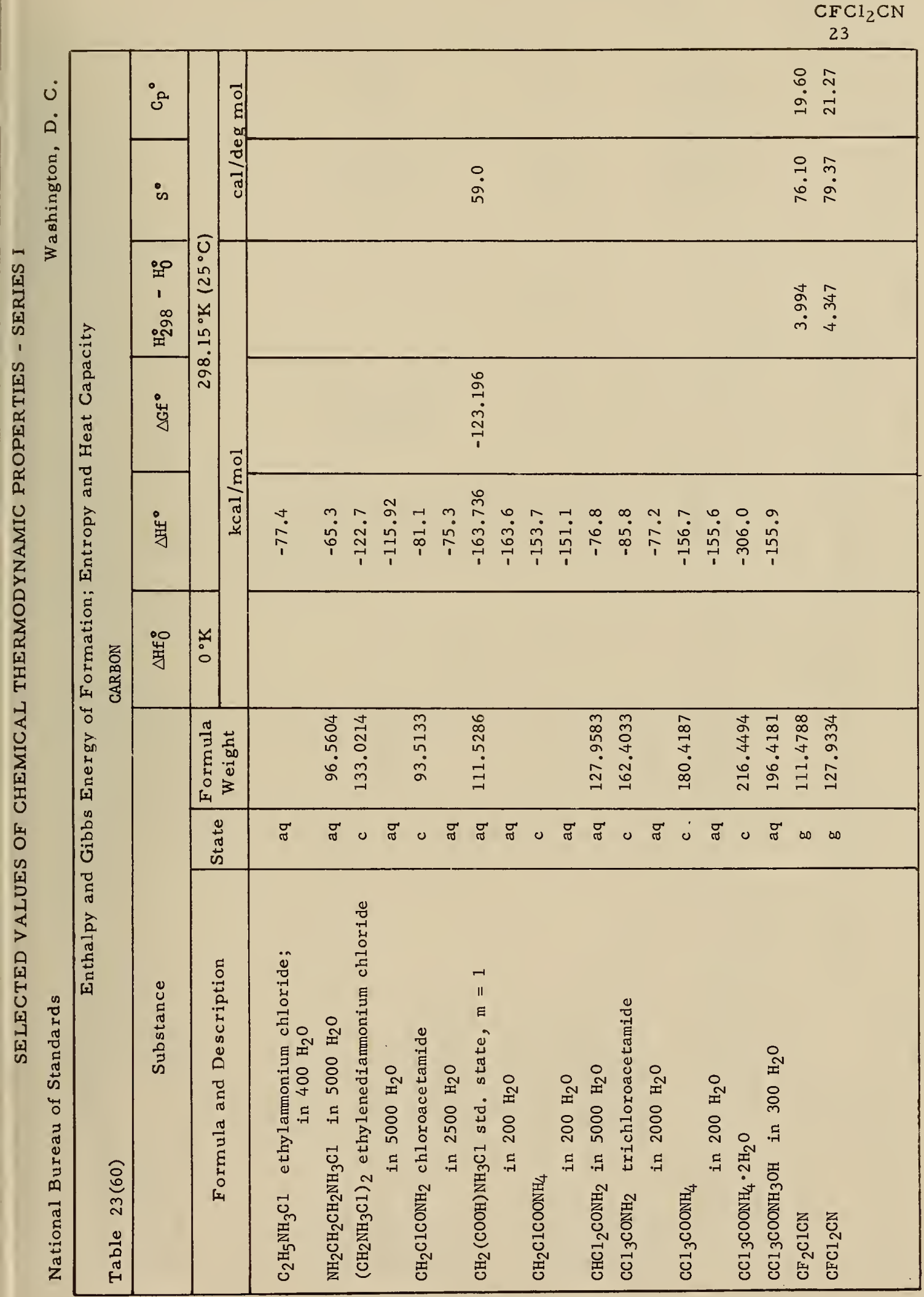




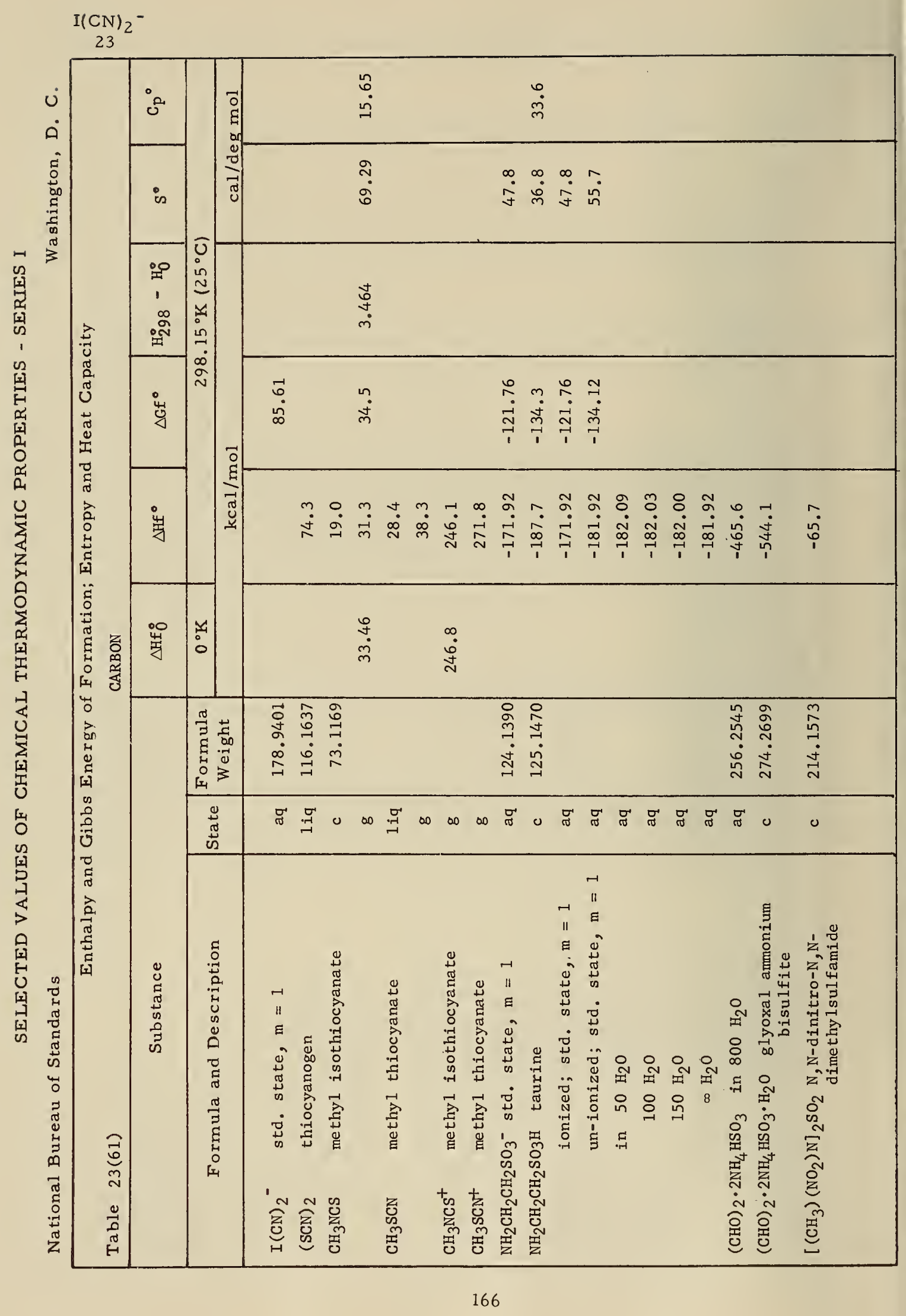




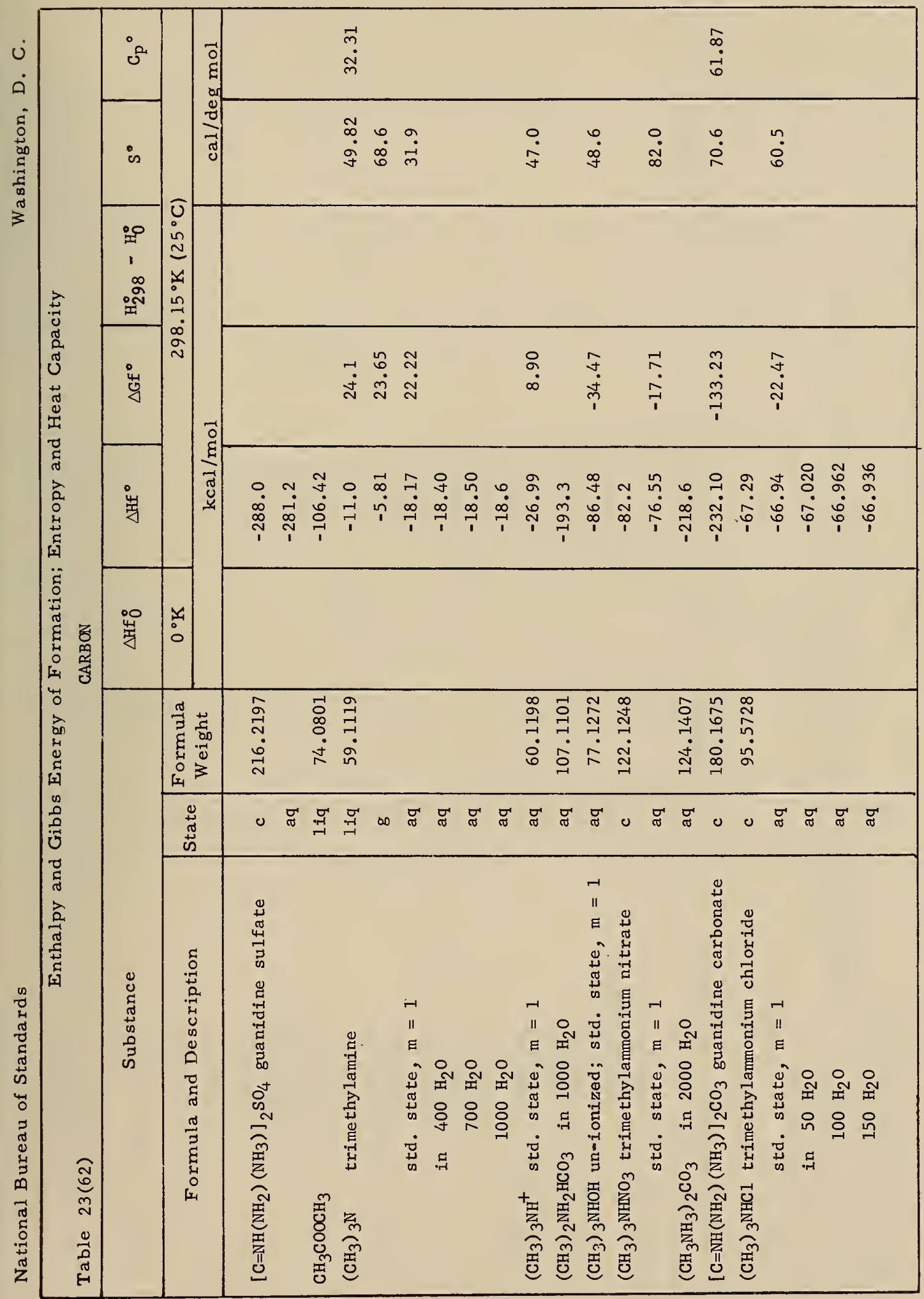




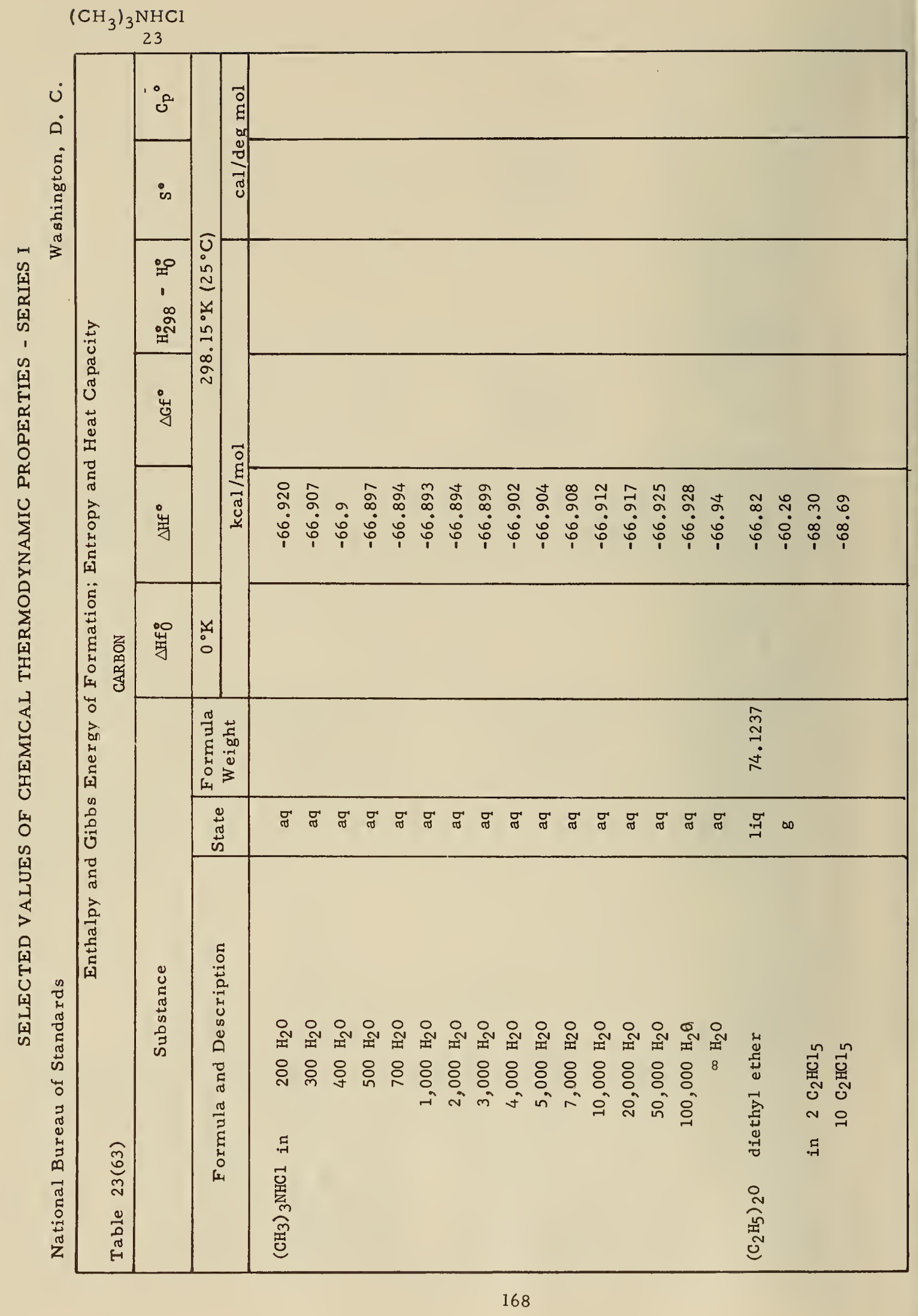




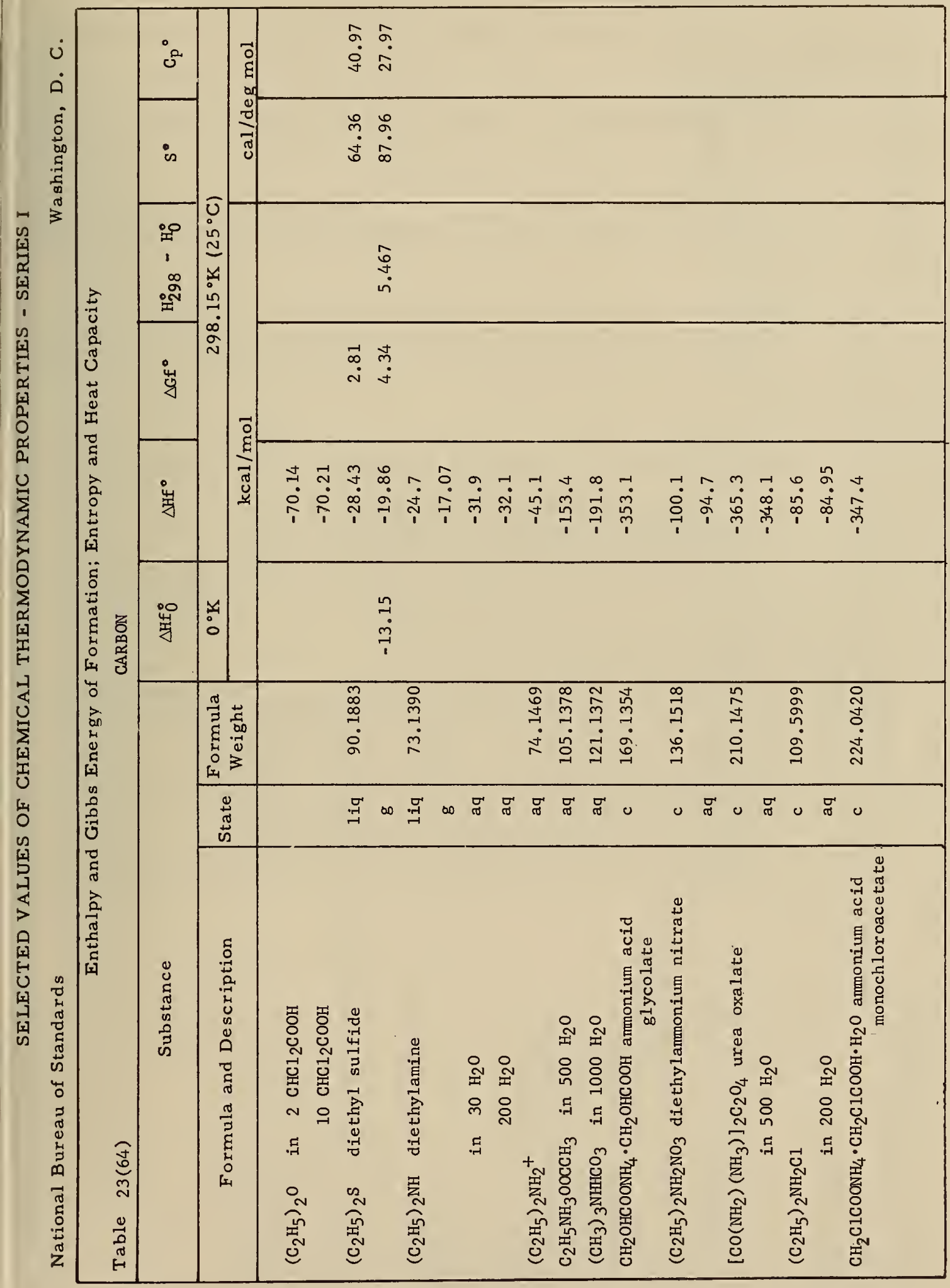




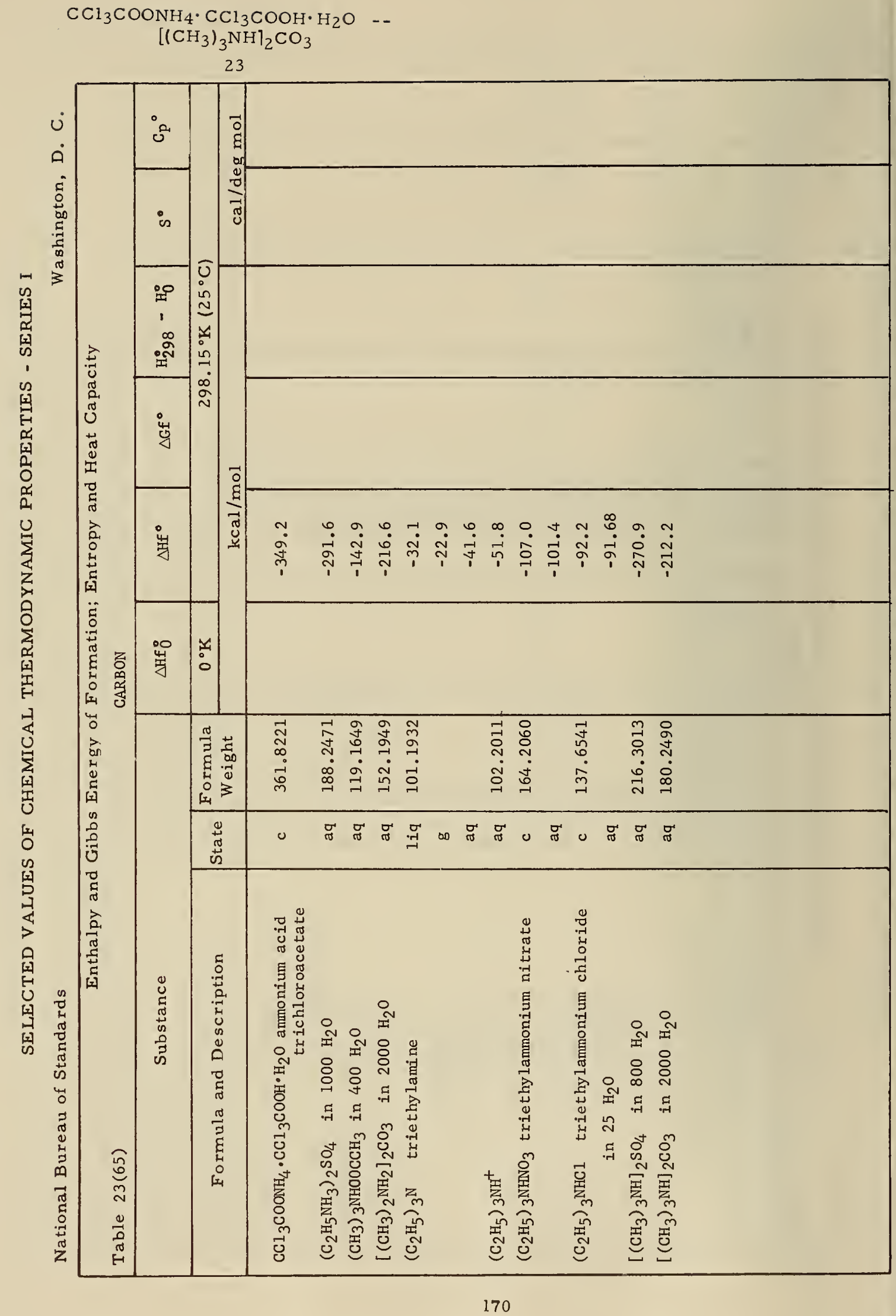




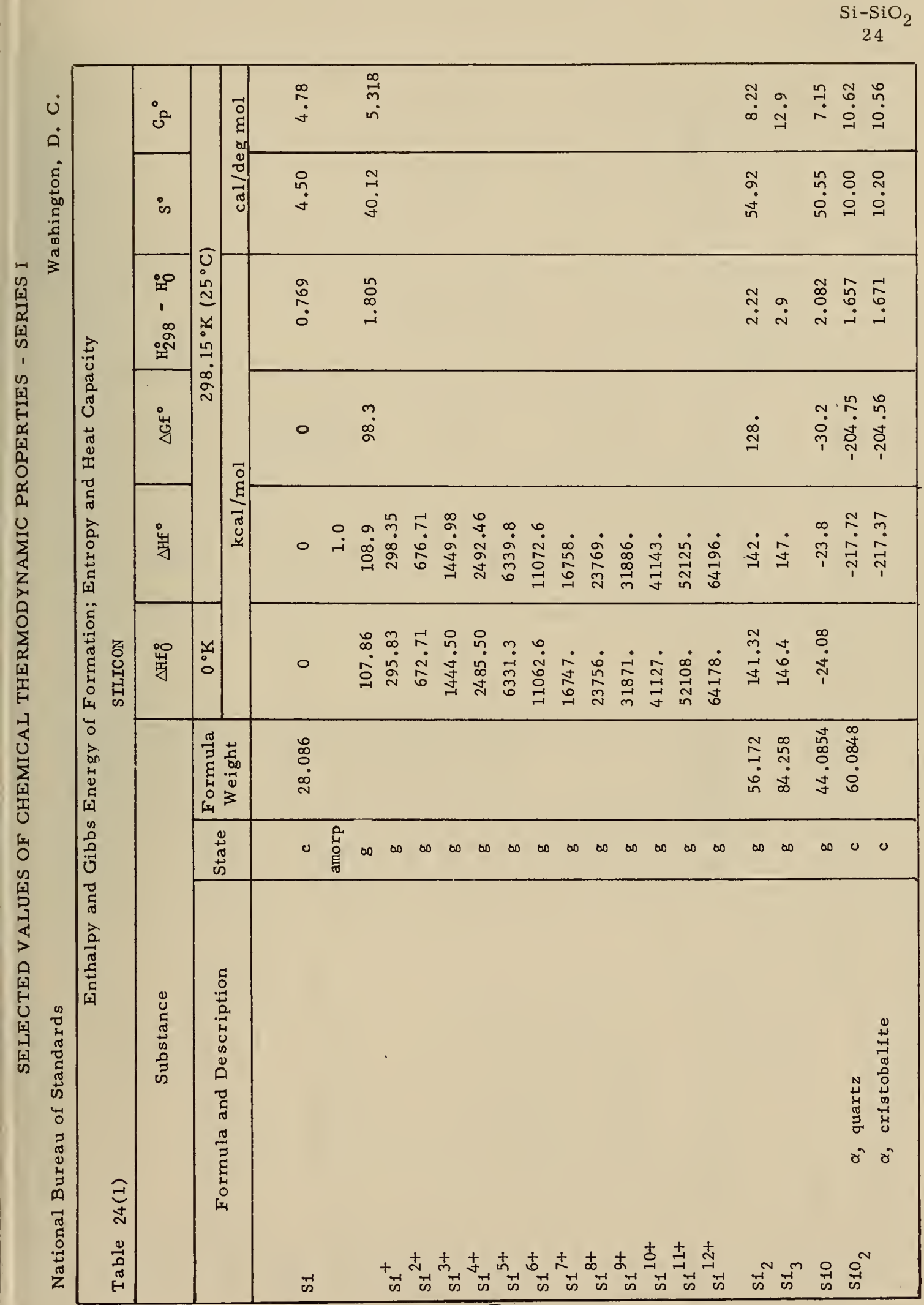


$\mathrm{SiO}_{24}$

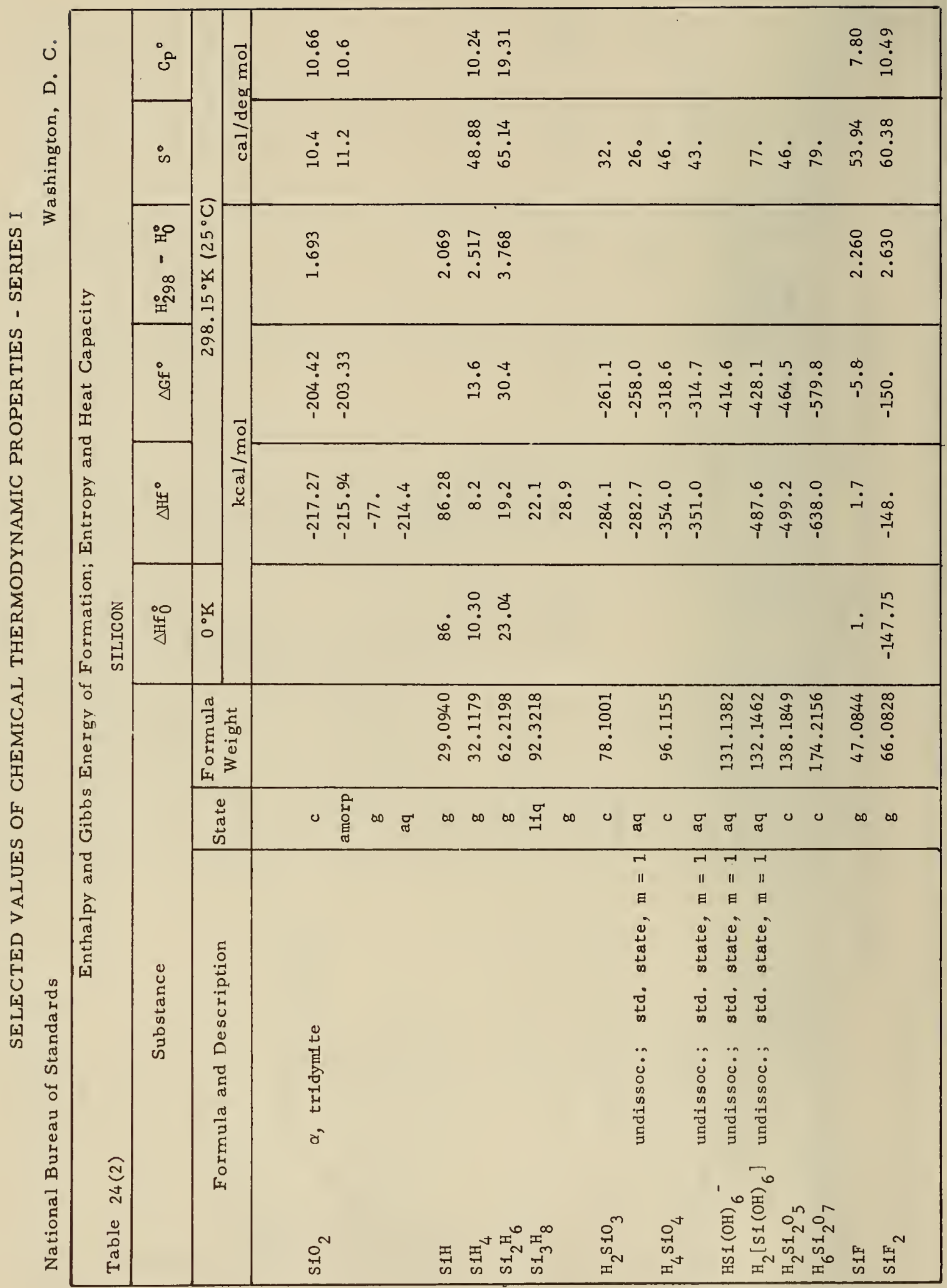




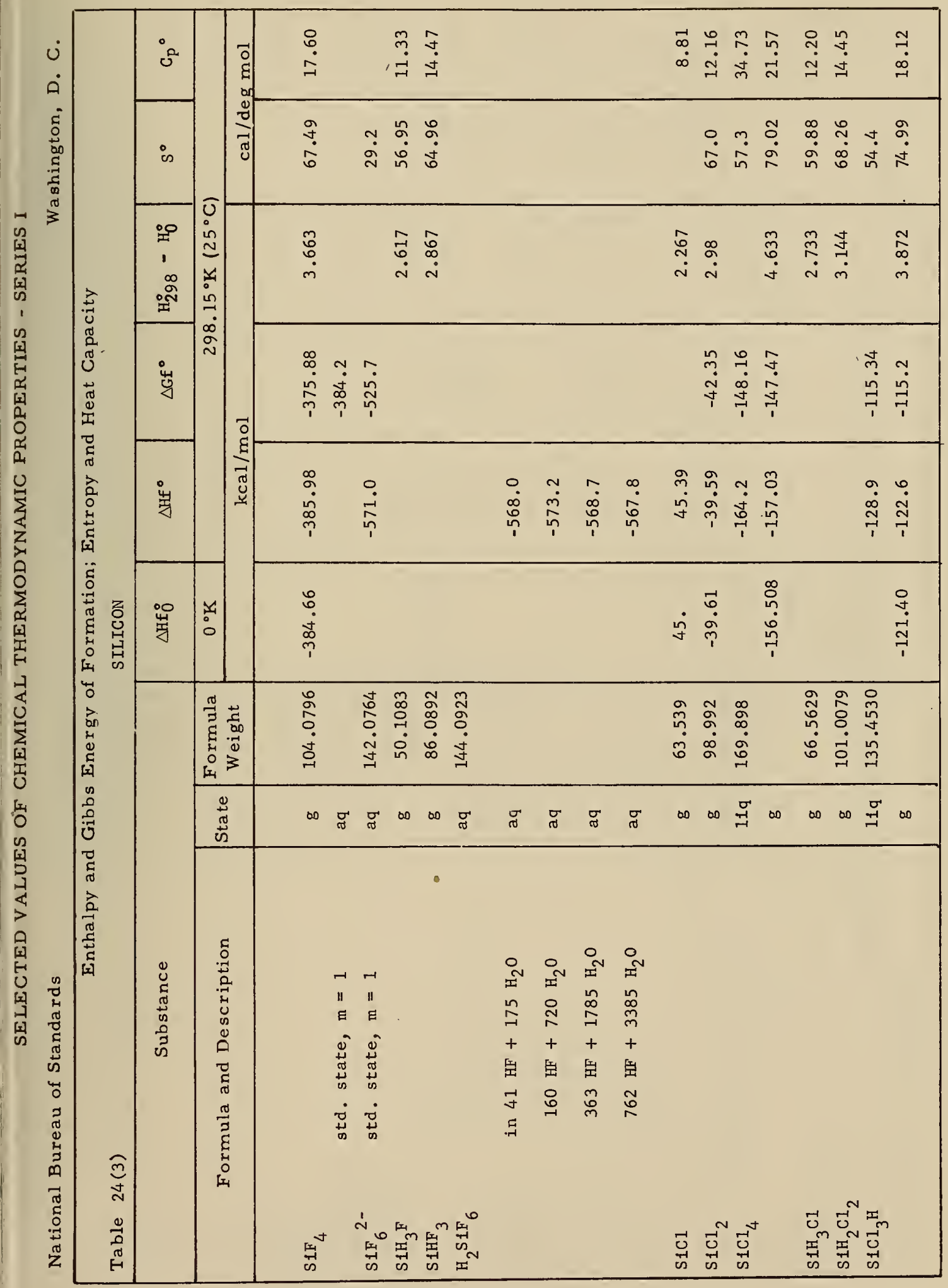




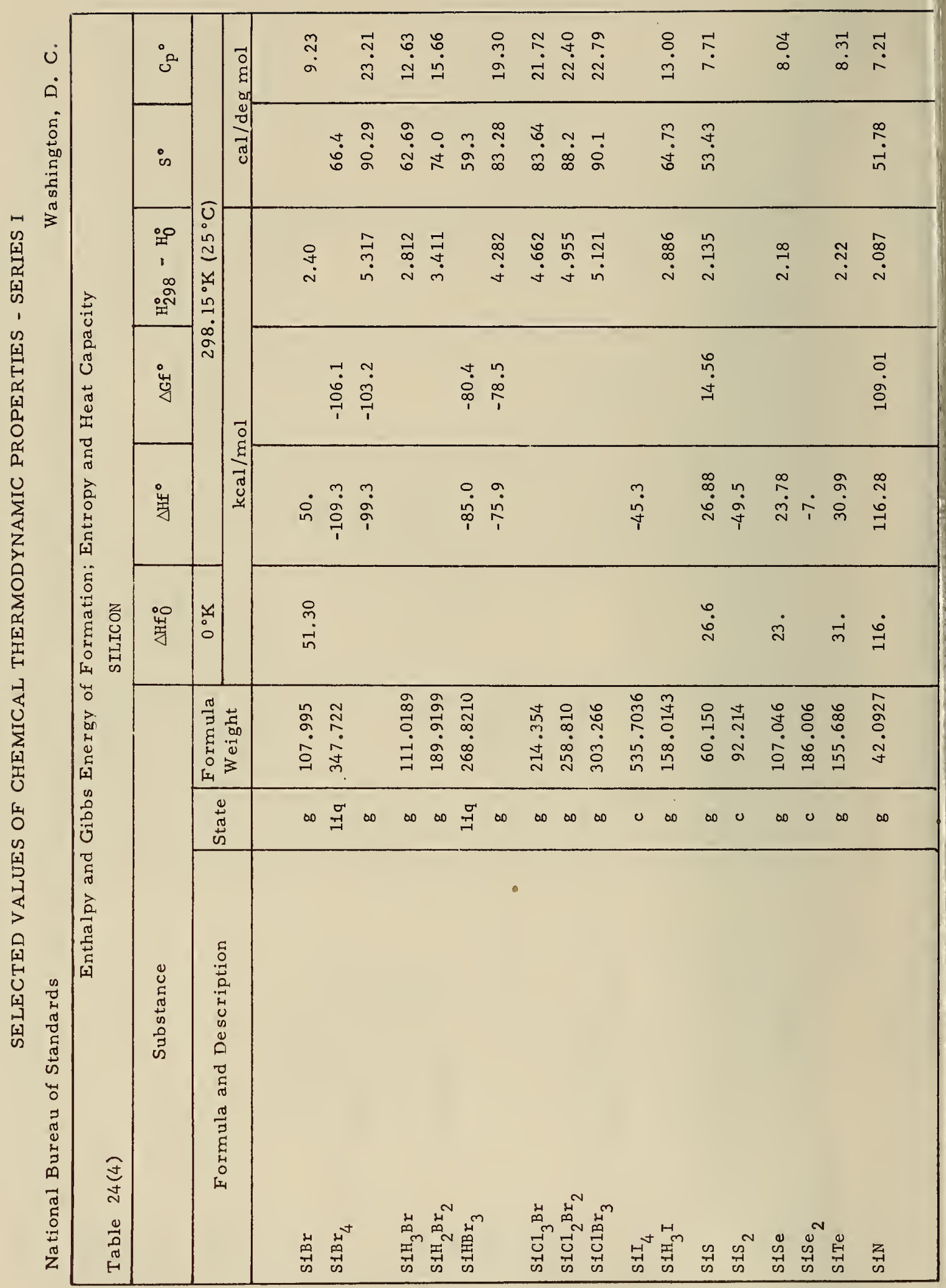




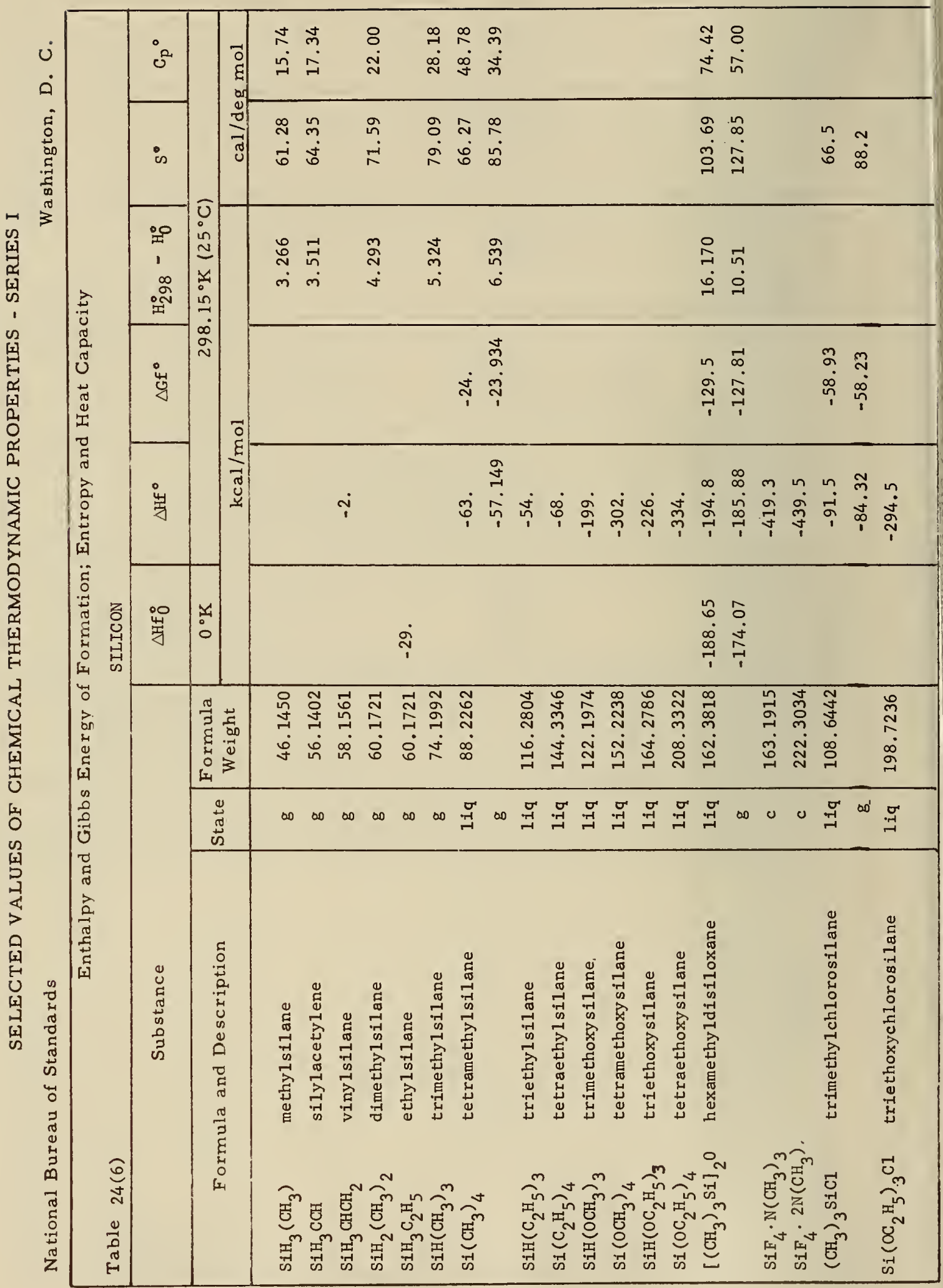


$\mathrm{Ge}-\mathrm{GeH}_{4}$

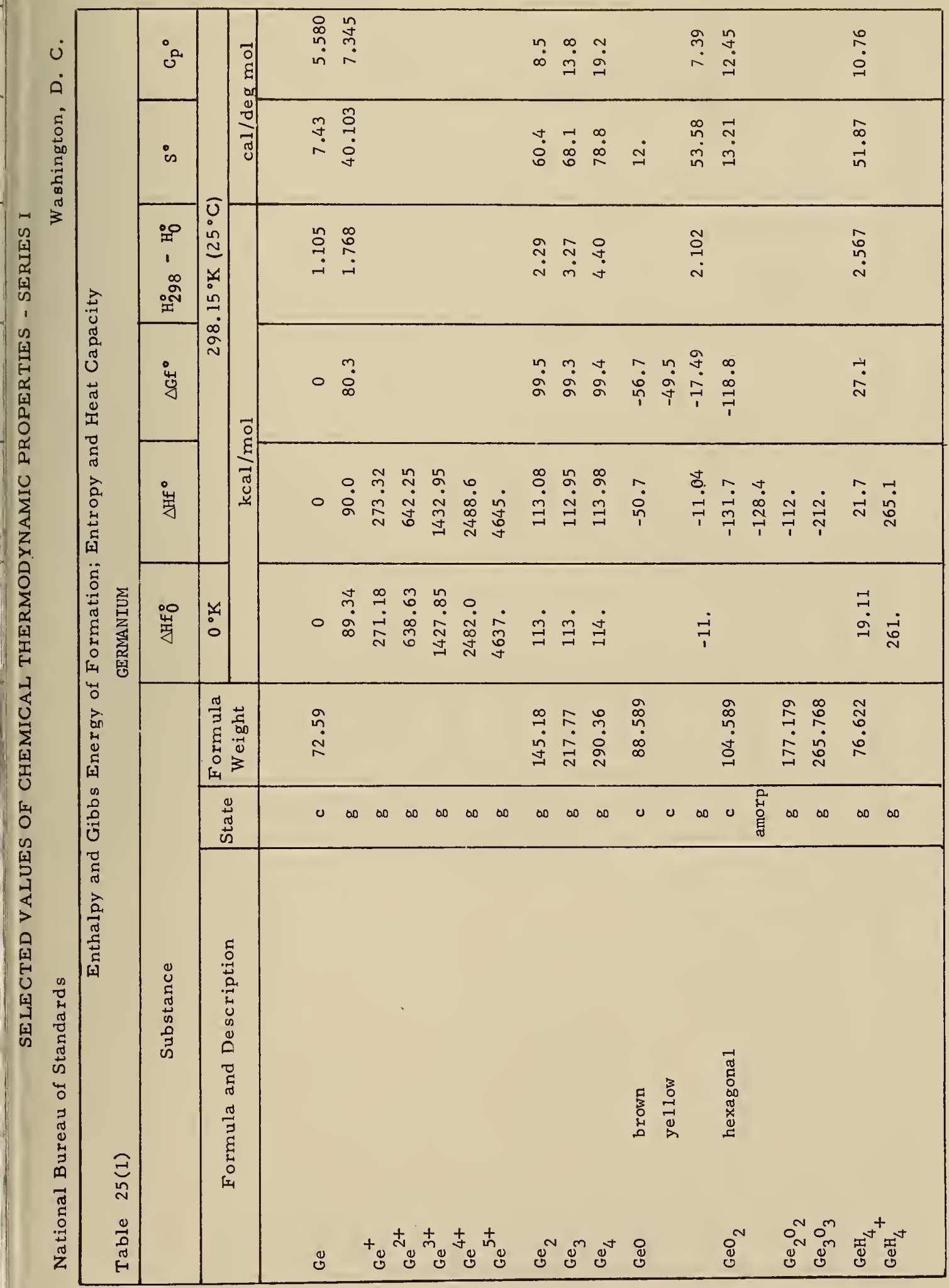


$\mathrm{Ge}_{2} \mathrm{H}_{6}$

25

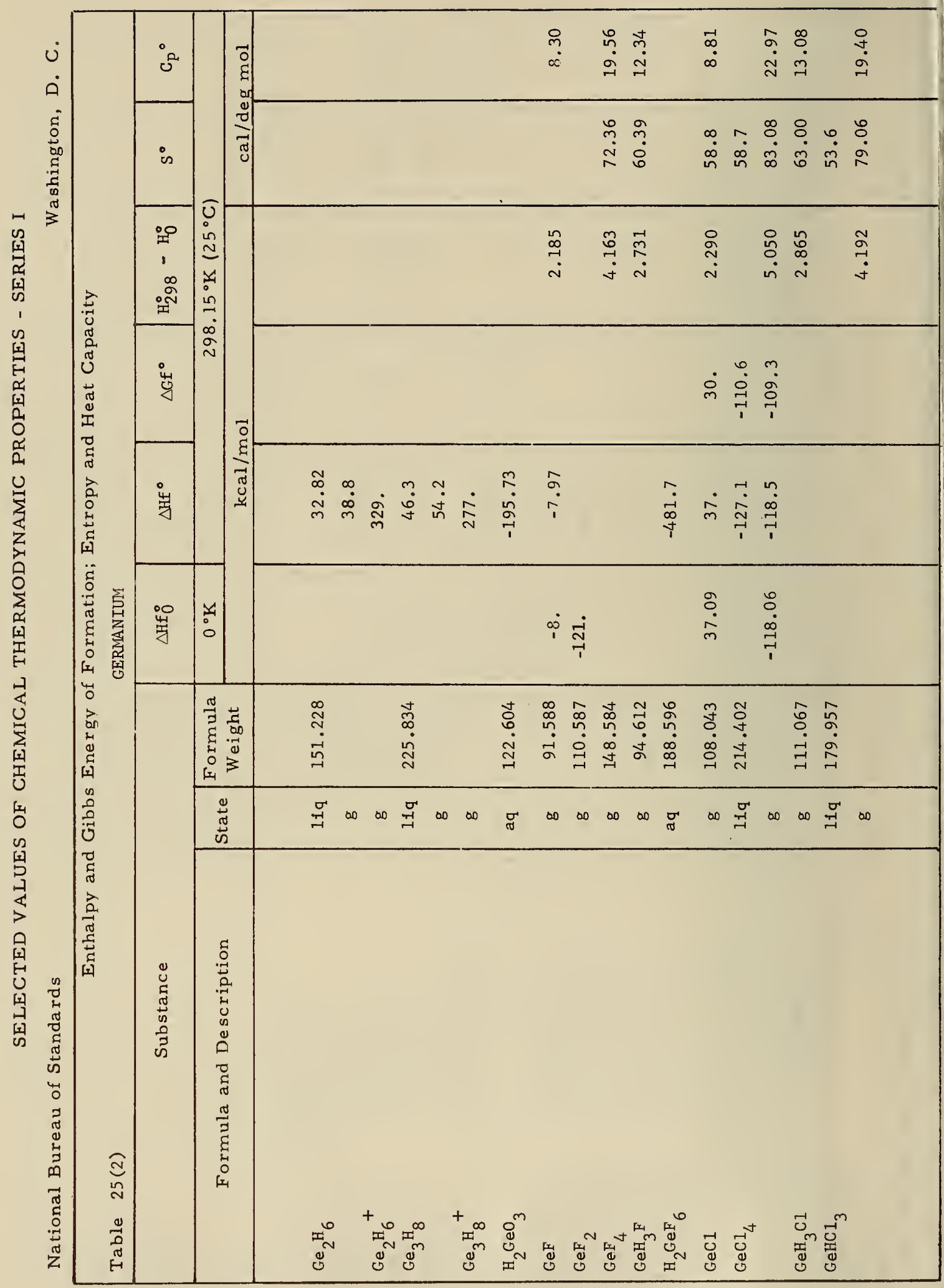




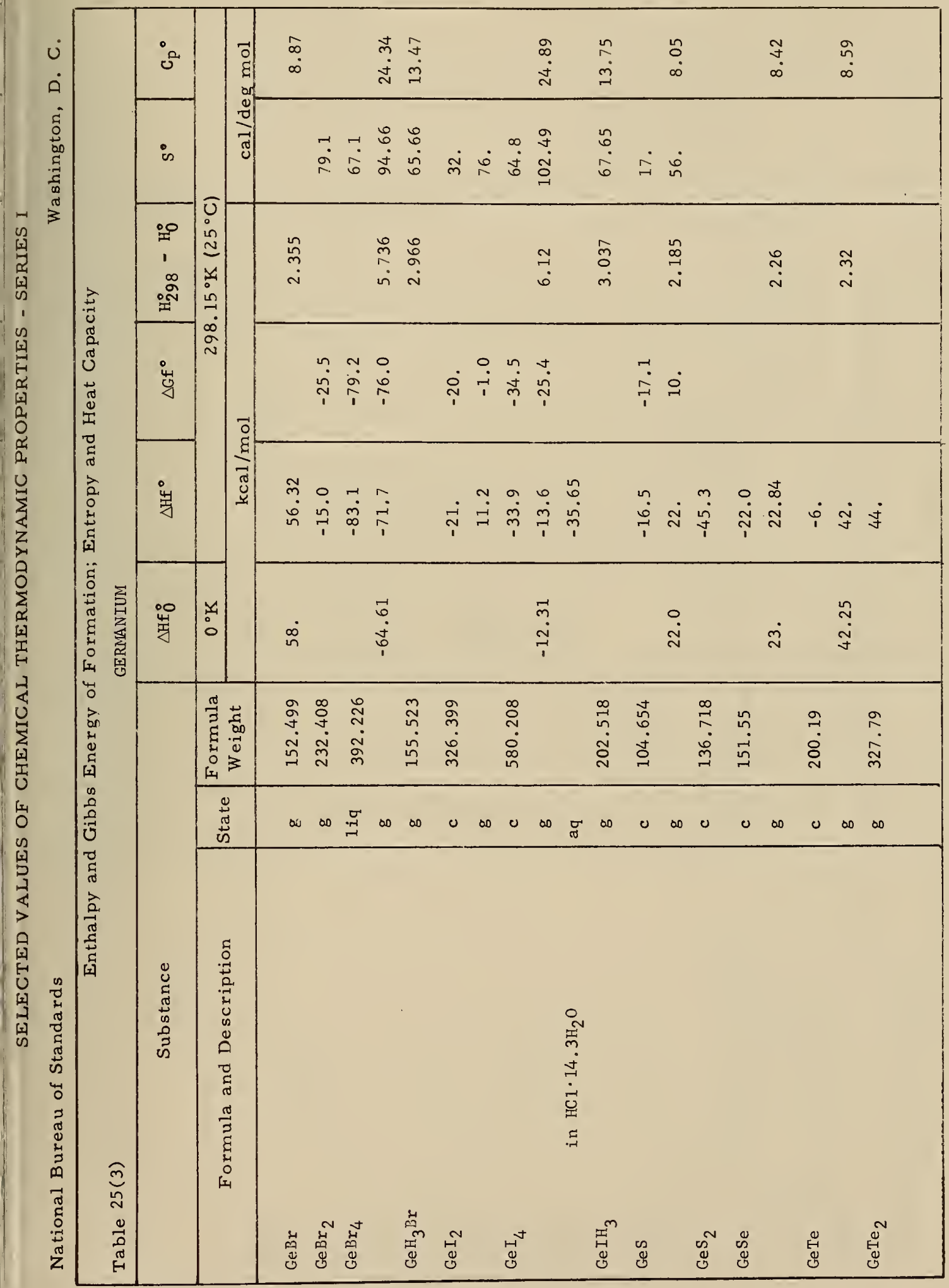


$\mathrm{Ge}_{3} \mathrm{~N}_{4}-\mathrm{Ge}_{25} \mathrm{SiC}$

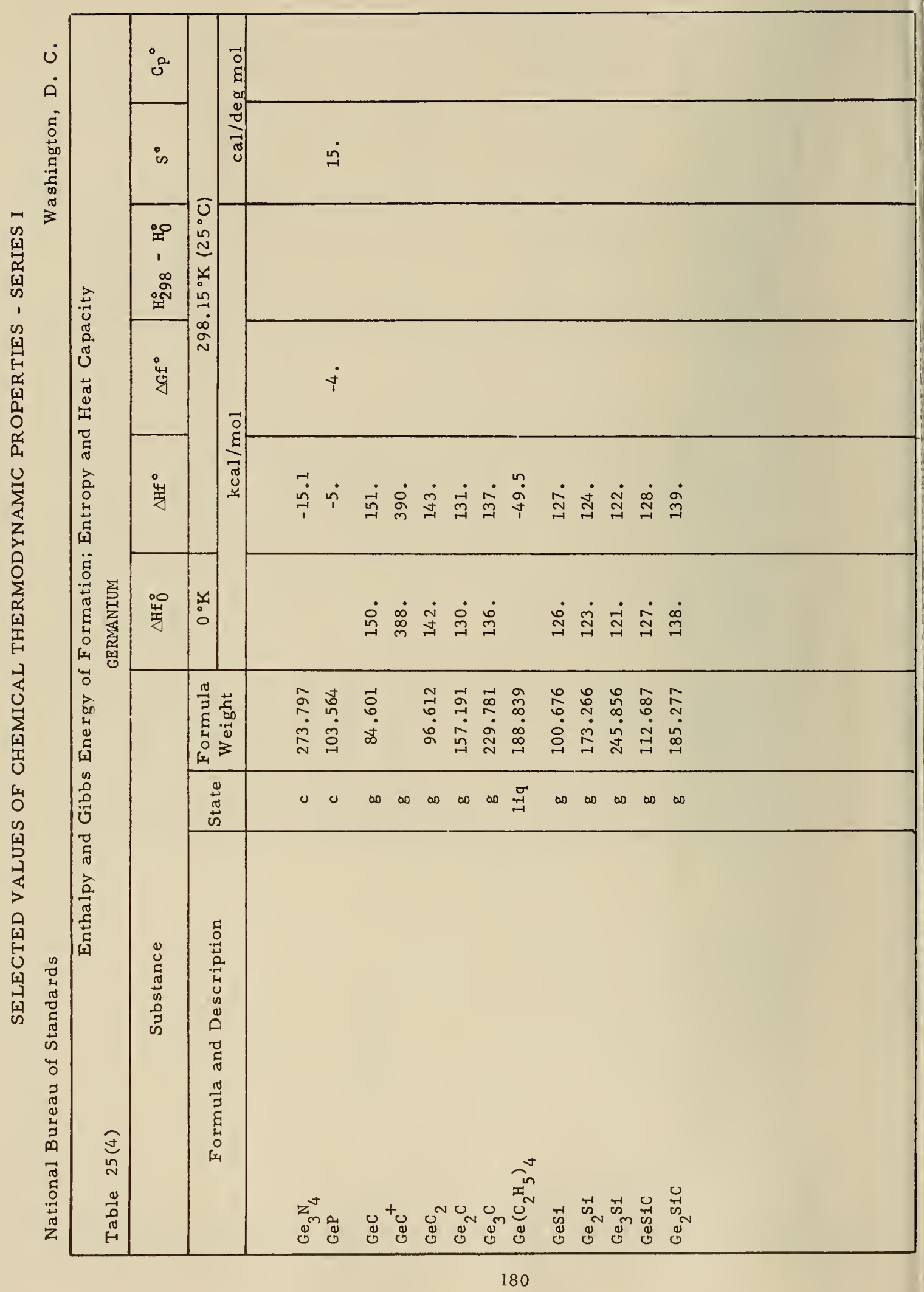




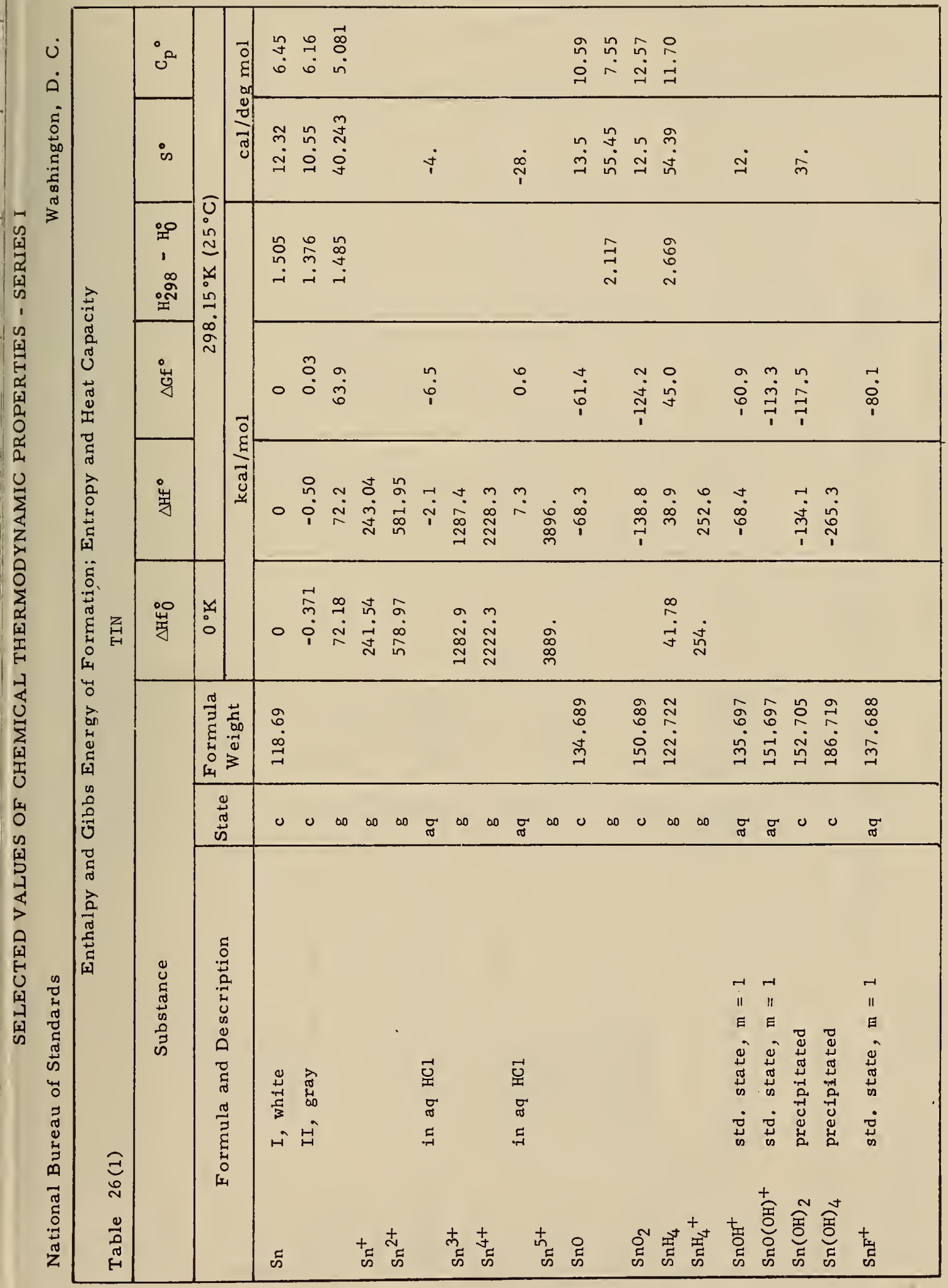




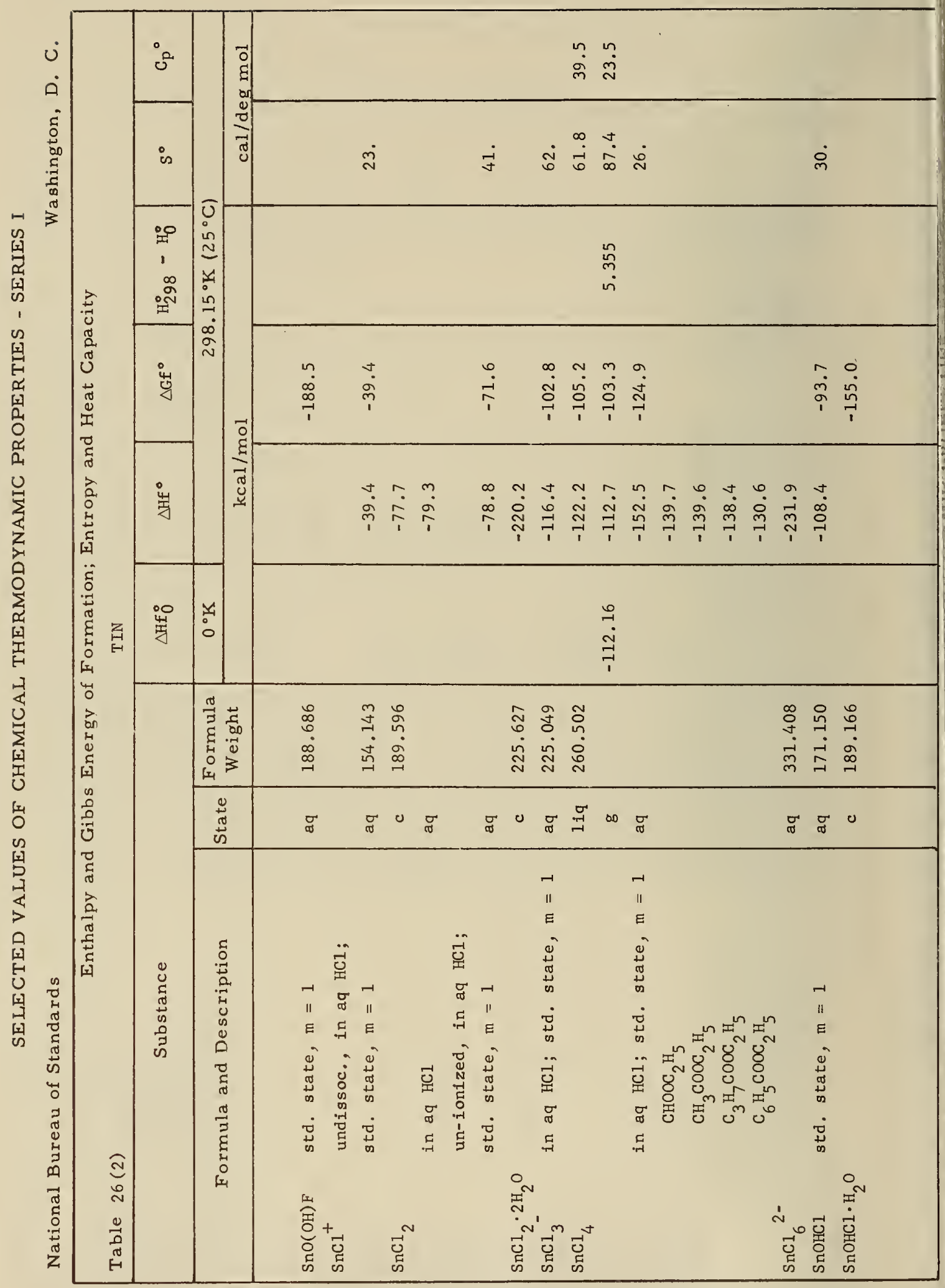




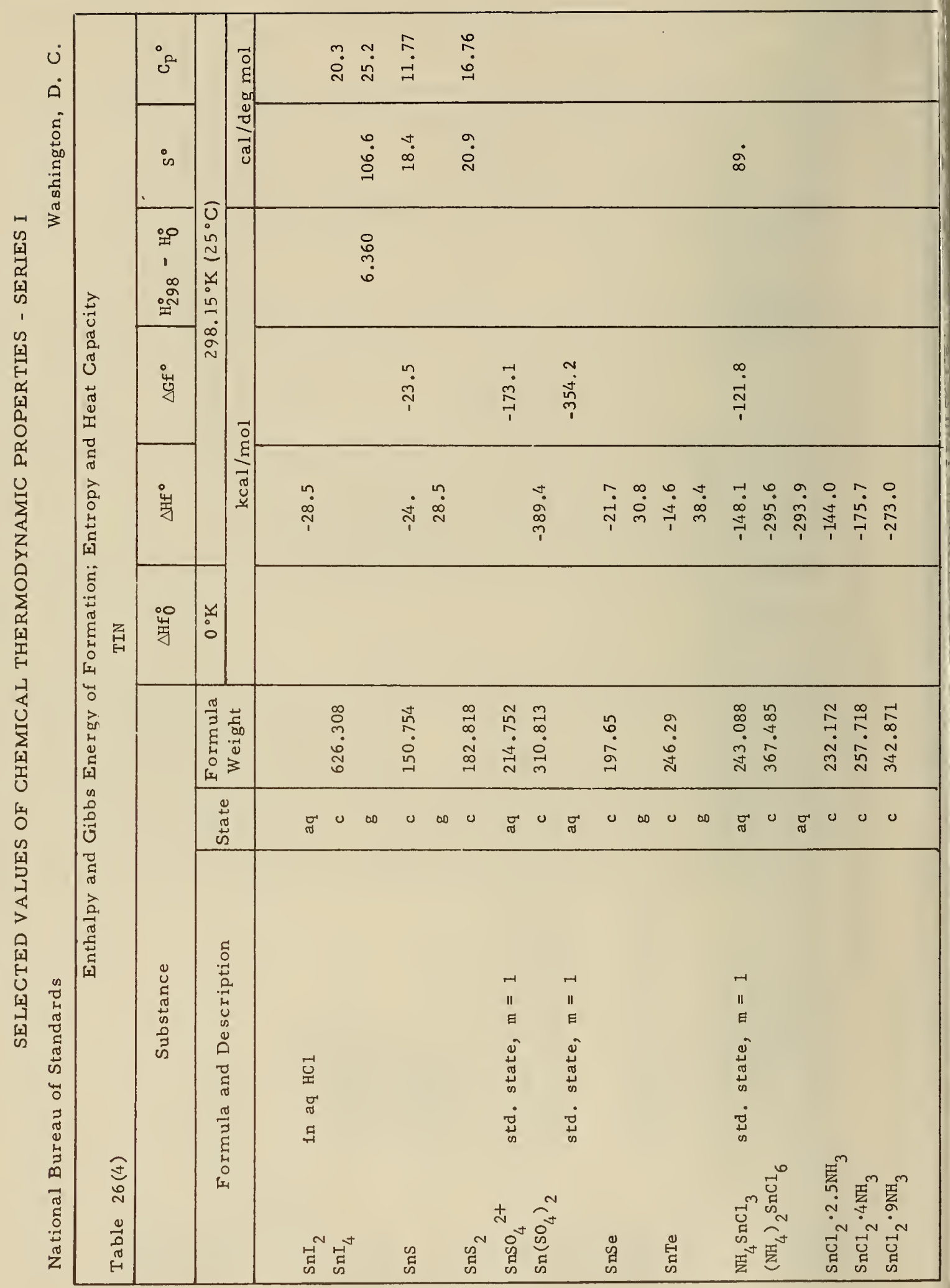


$\mathrm{Sn}\left(\mathrm{C}_{2} \mathrm{H}_{5}\right)_{2} \mathrm{H}_{26}-\mathrm{Sn}\left(\mathrm{CH}_{3}\right)_{3} \mathrm{I}$

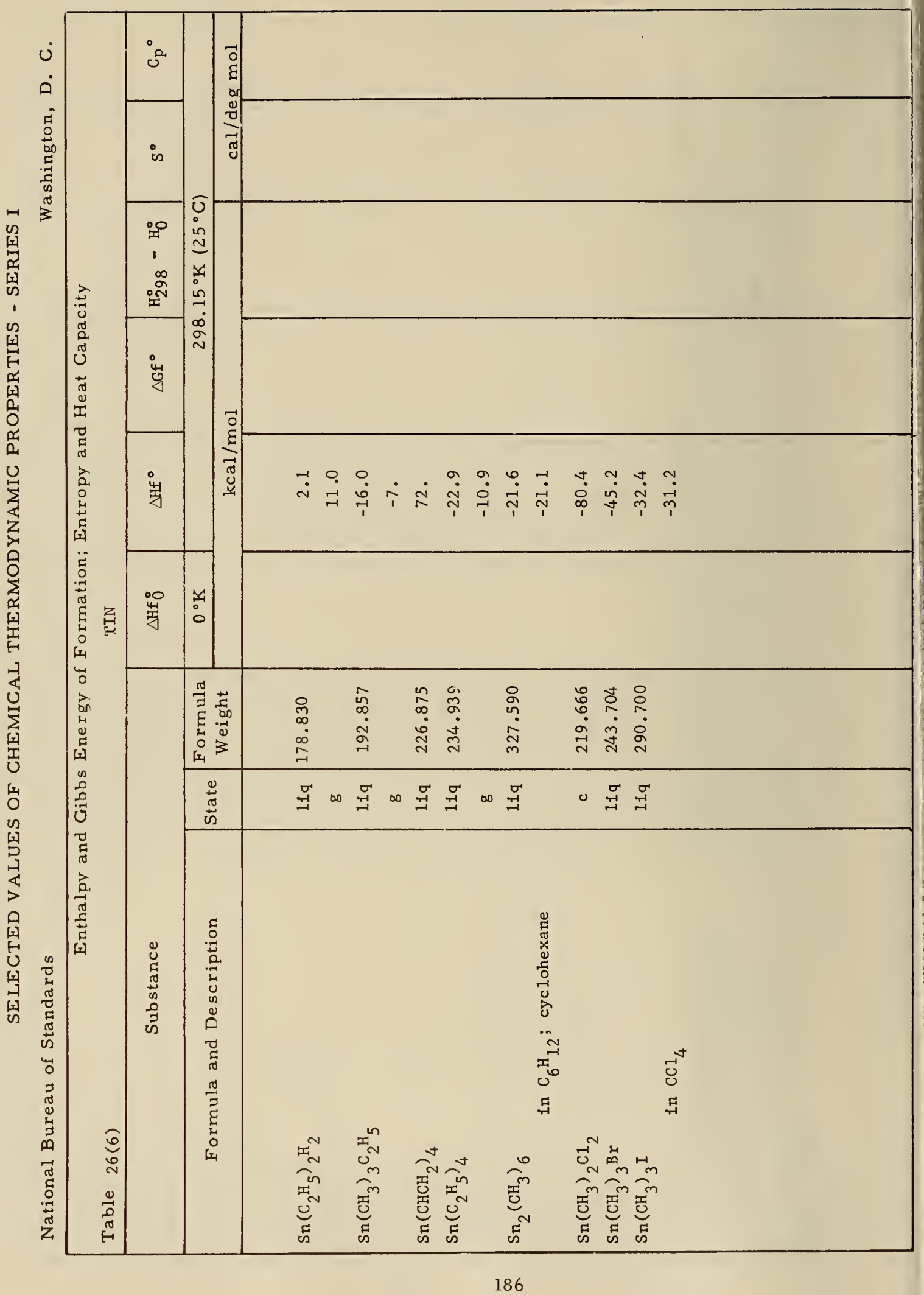




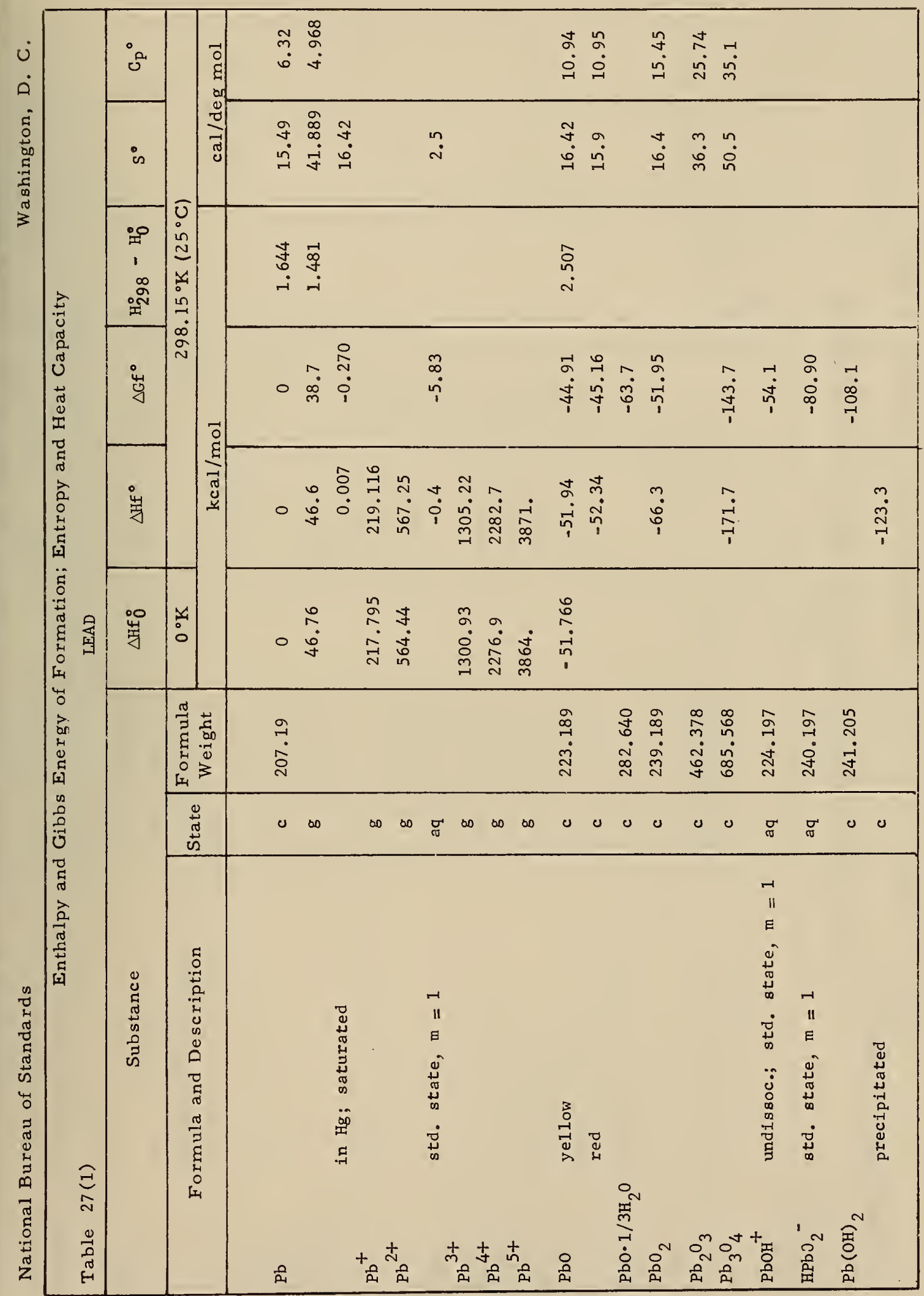




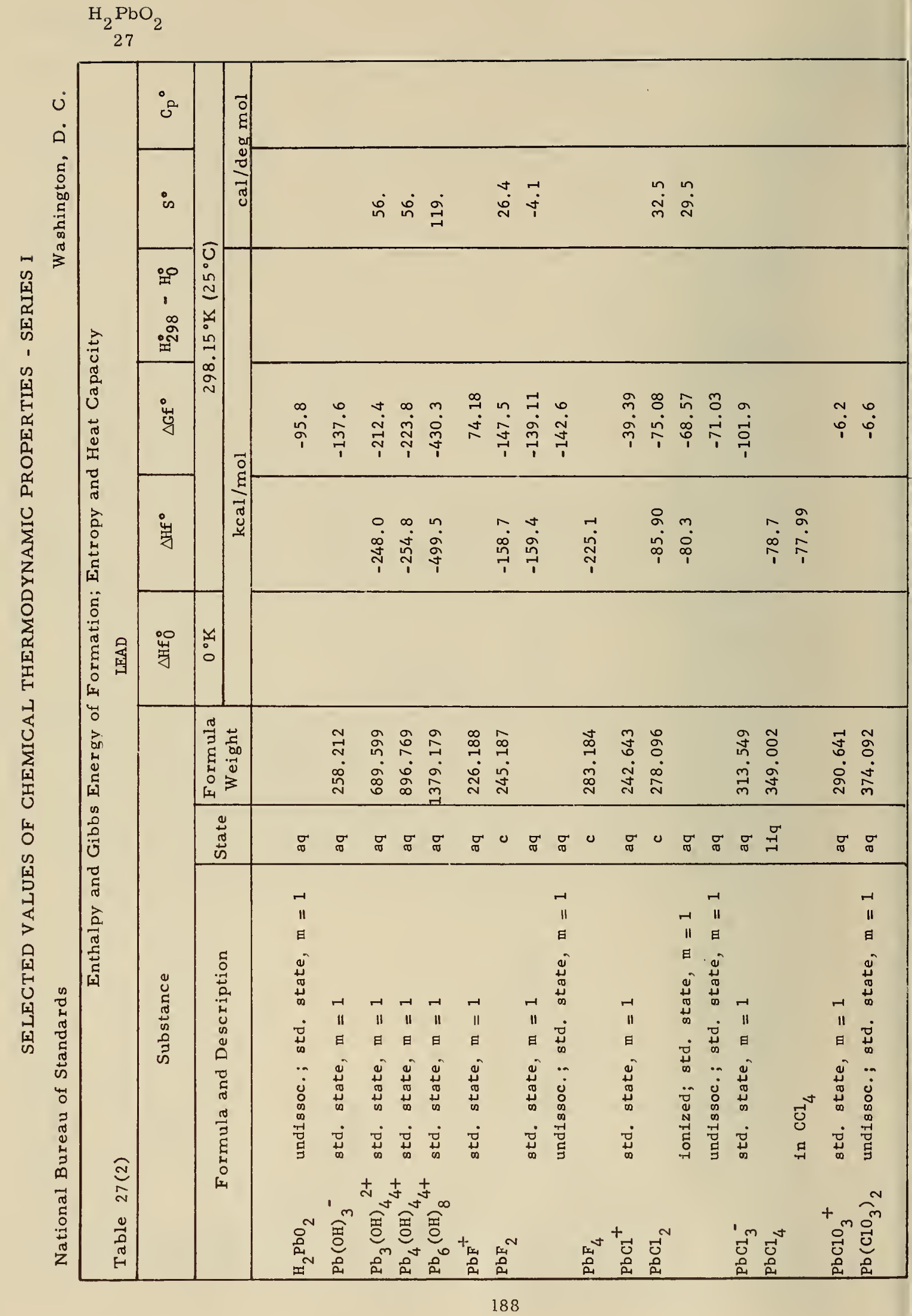




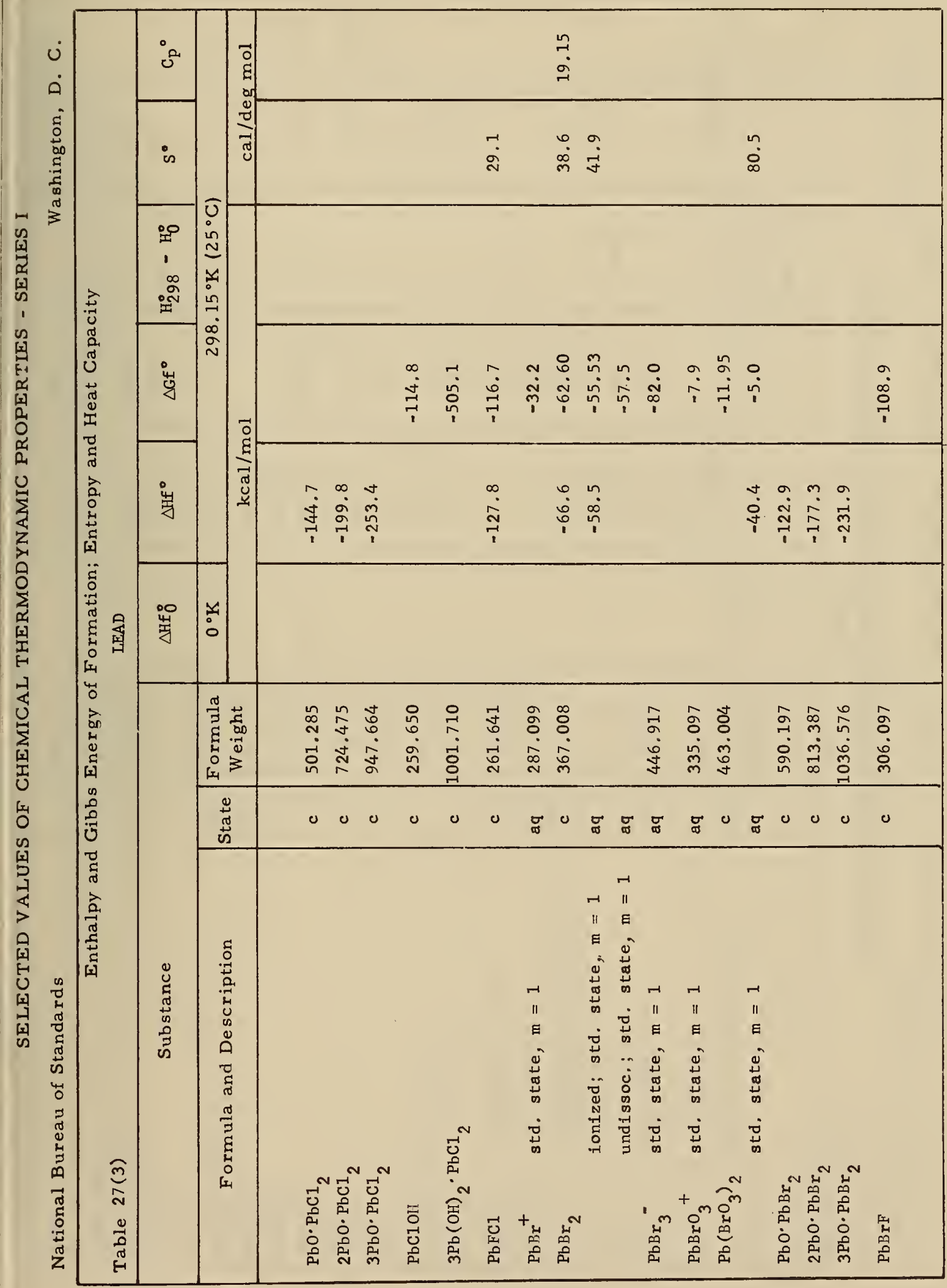




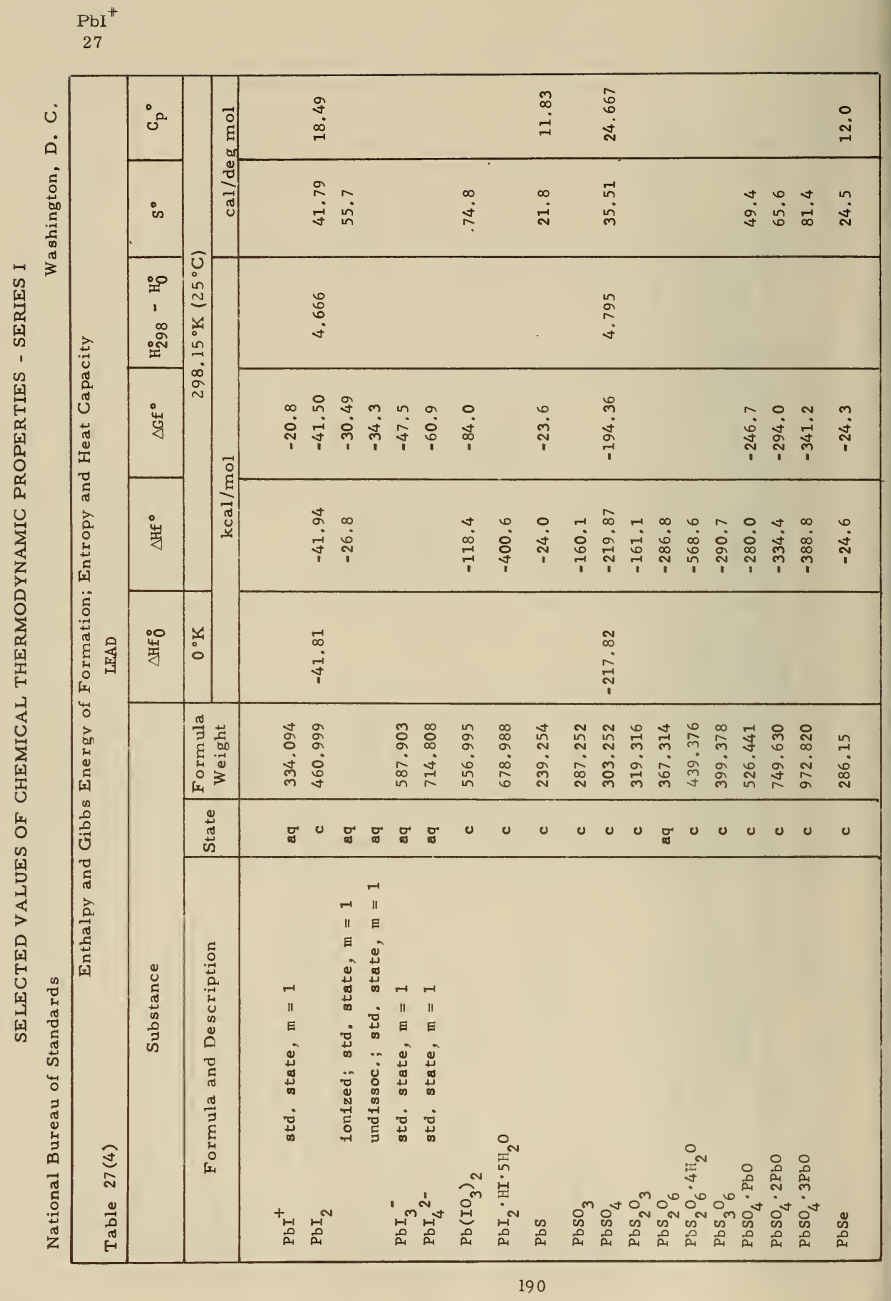


$\underset{27}{\mathrm{PbCl}_{2}} \cdot \mathrm{NH}_{3}$

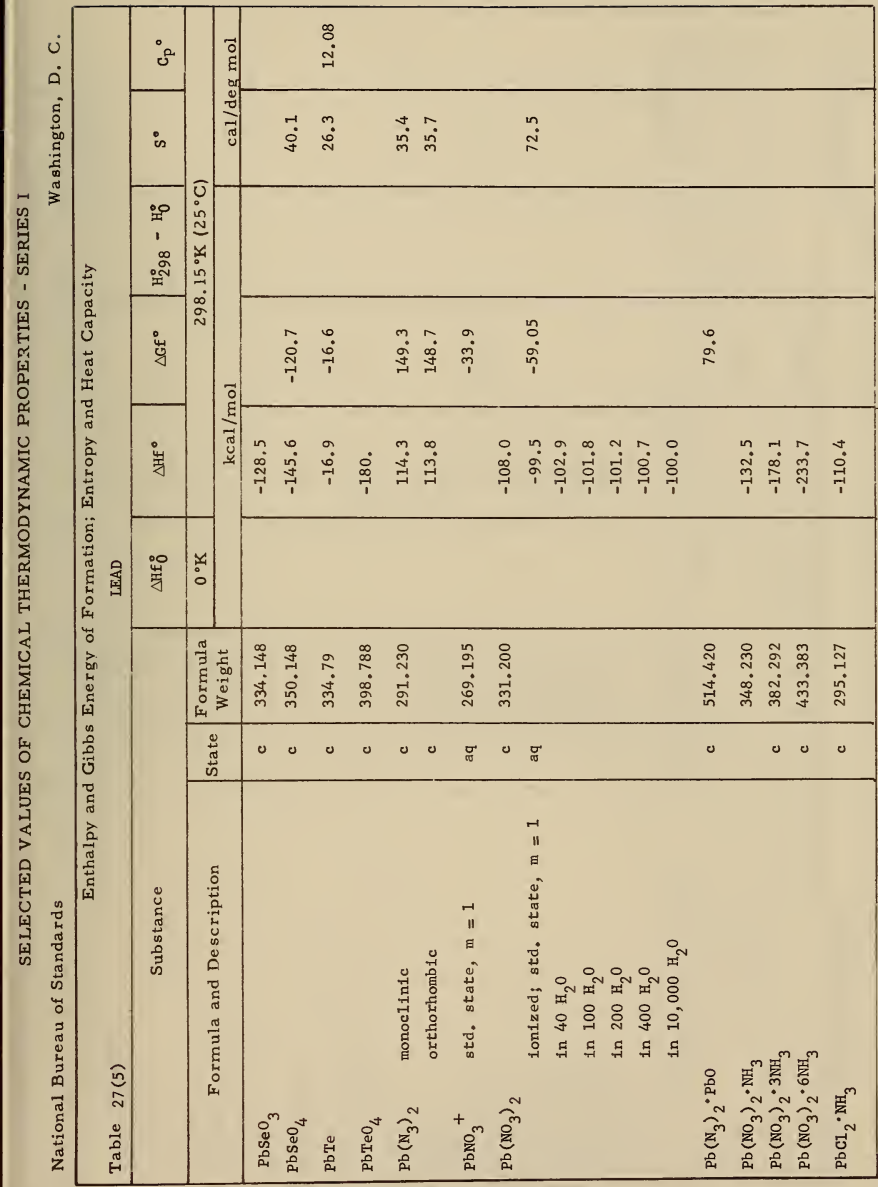


$\mathrm{PbCl}_{2} \cdot 3 / 2 \mathrm{NH}_{3}$

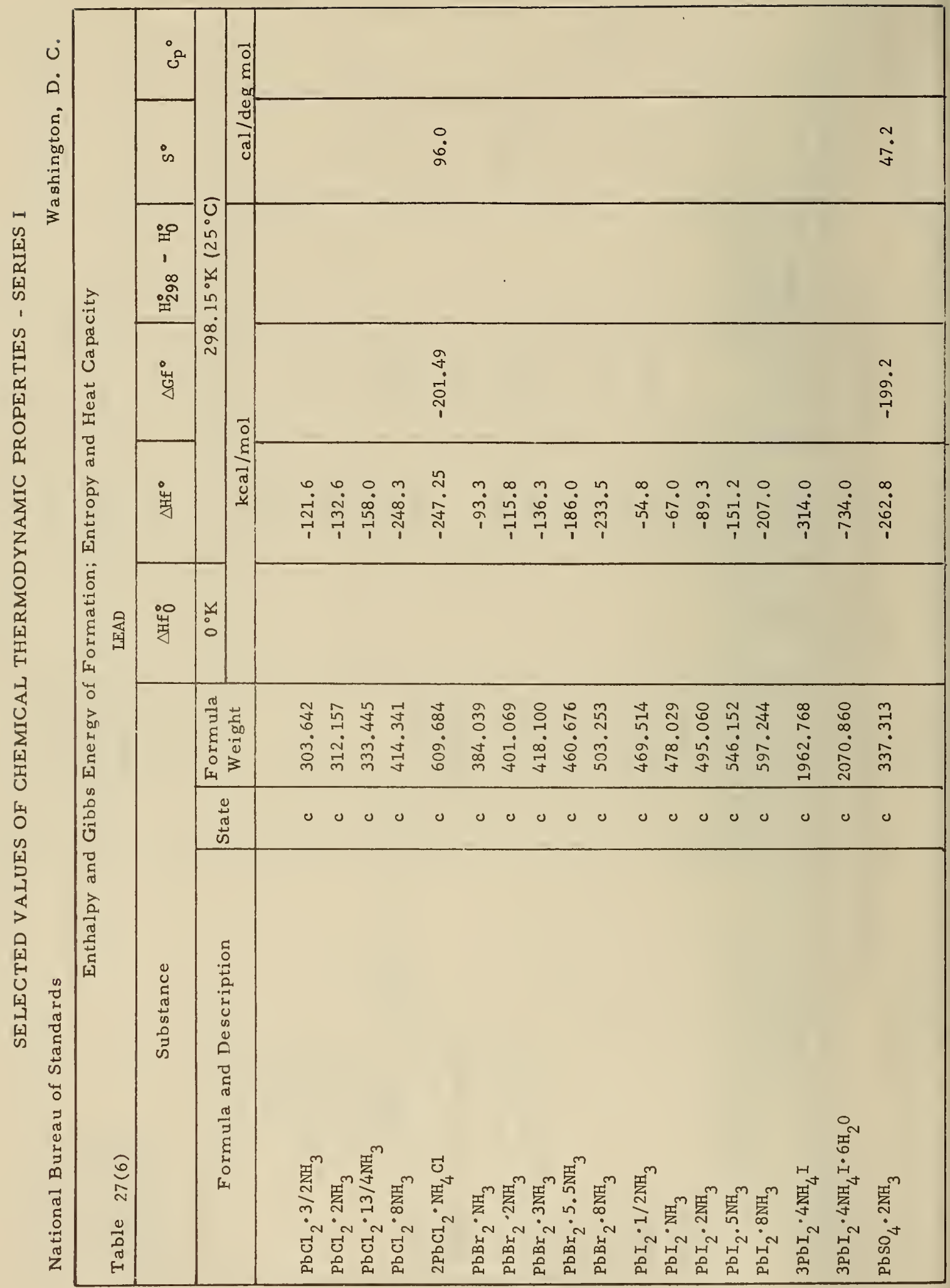




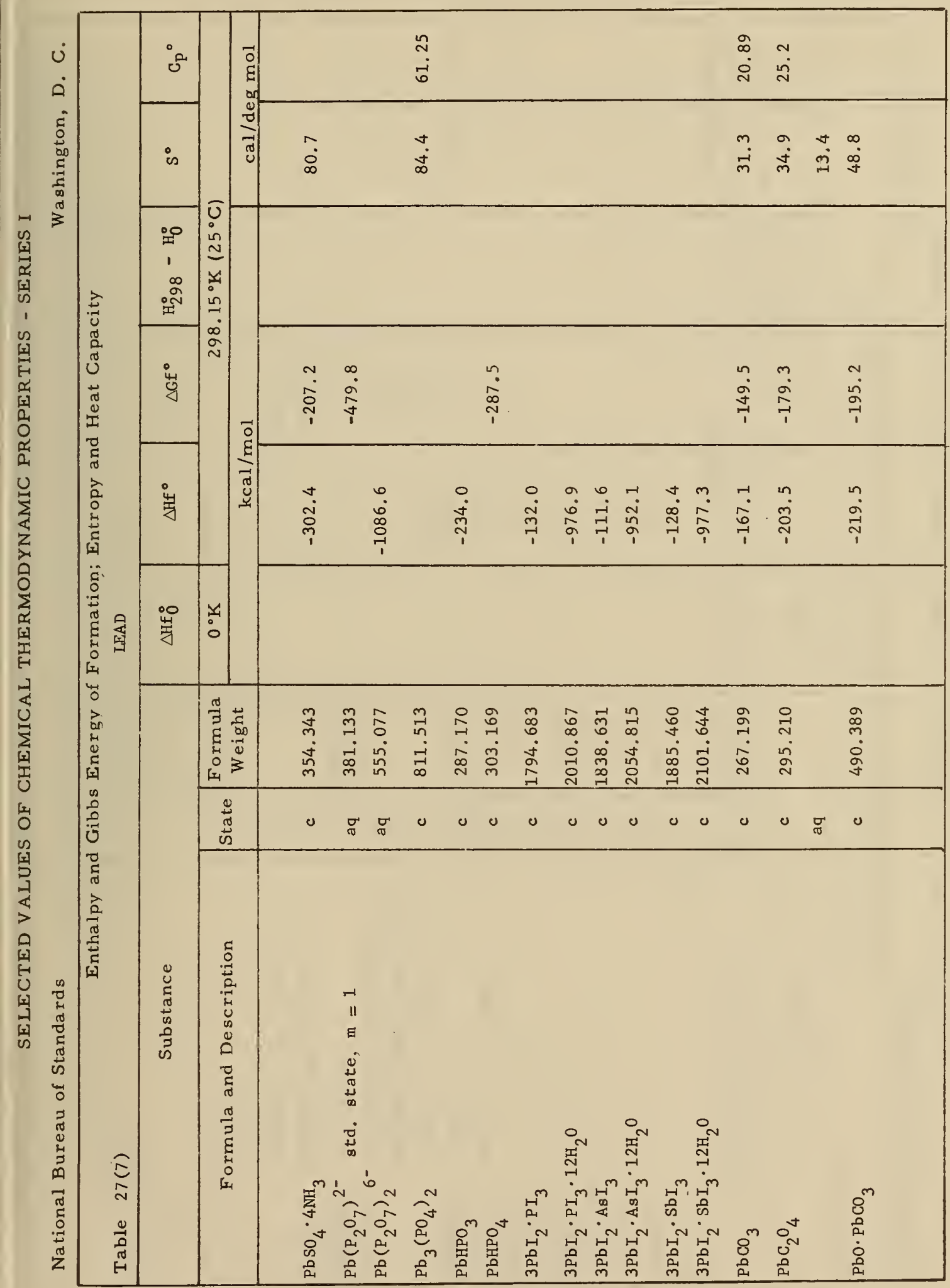


$\mathrm{Pb}\left(\mathrm{CH}_{3}\right)_{4}$

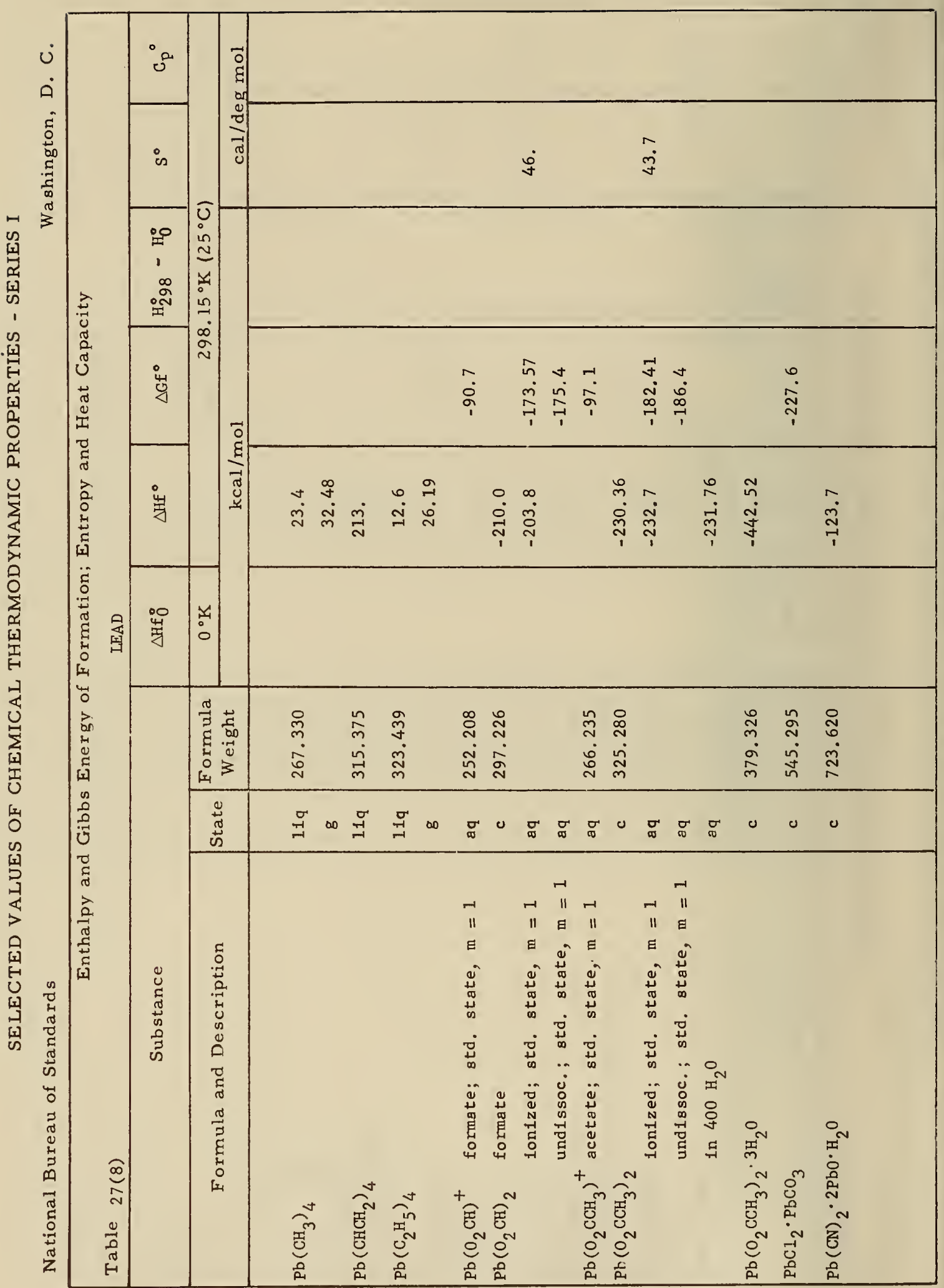




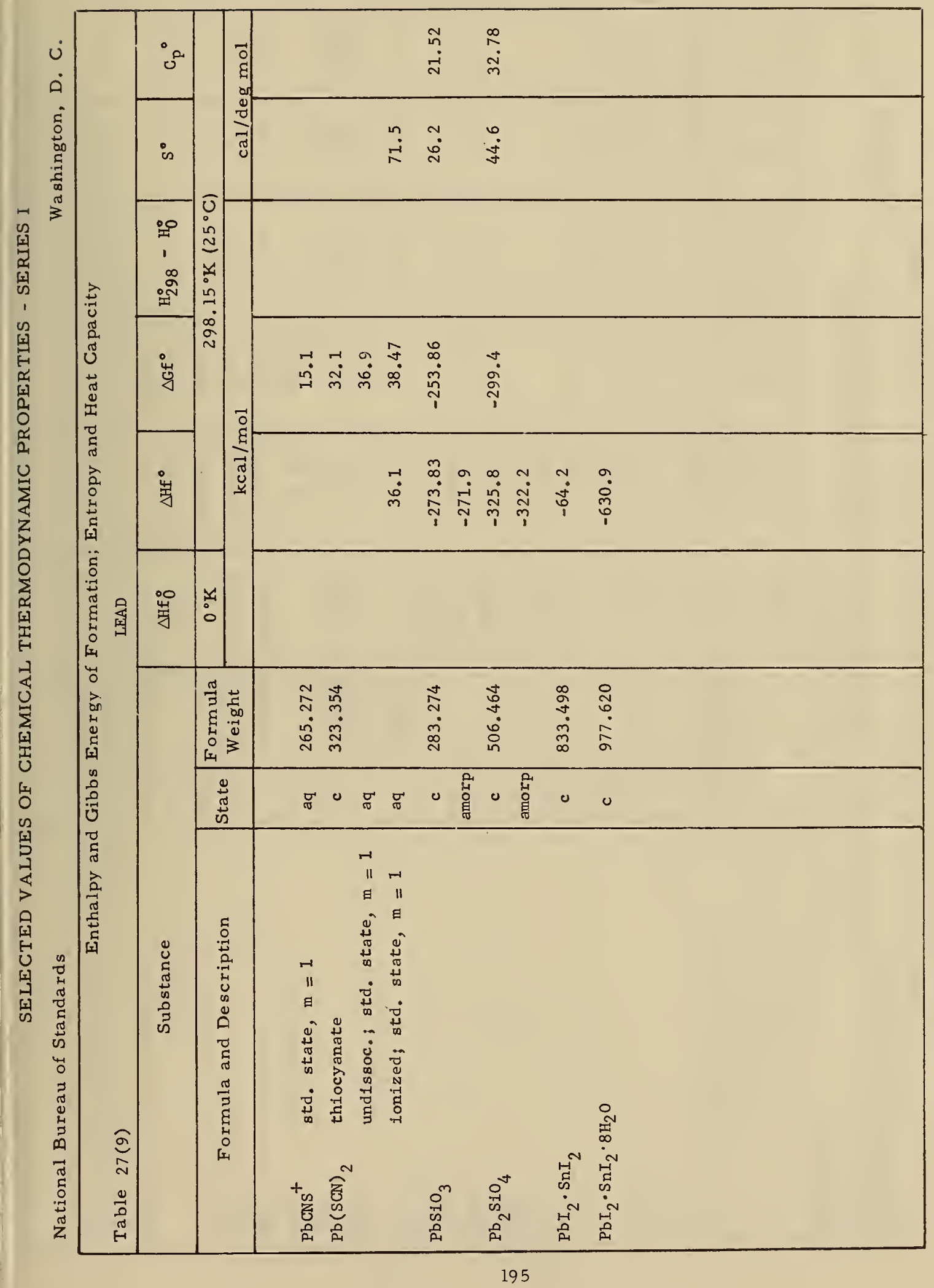




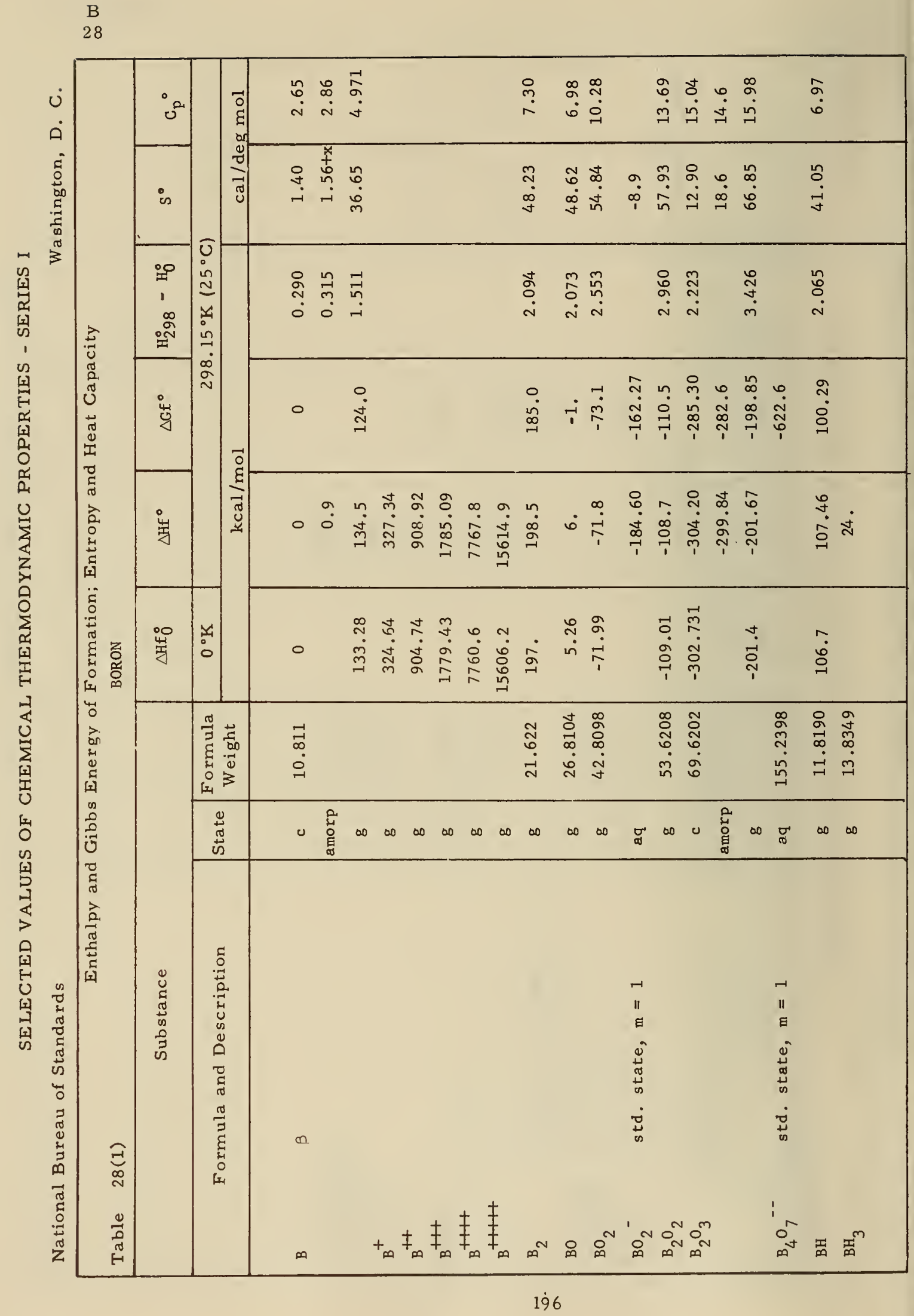


$\mathrm{H}_{3} \mathrm{BO}_{28}$

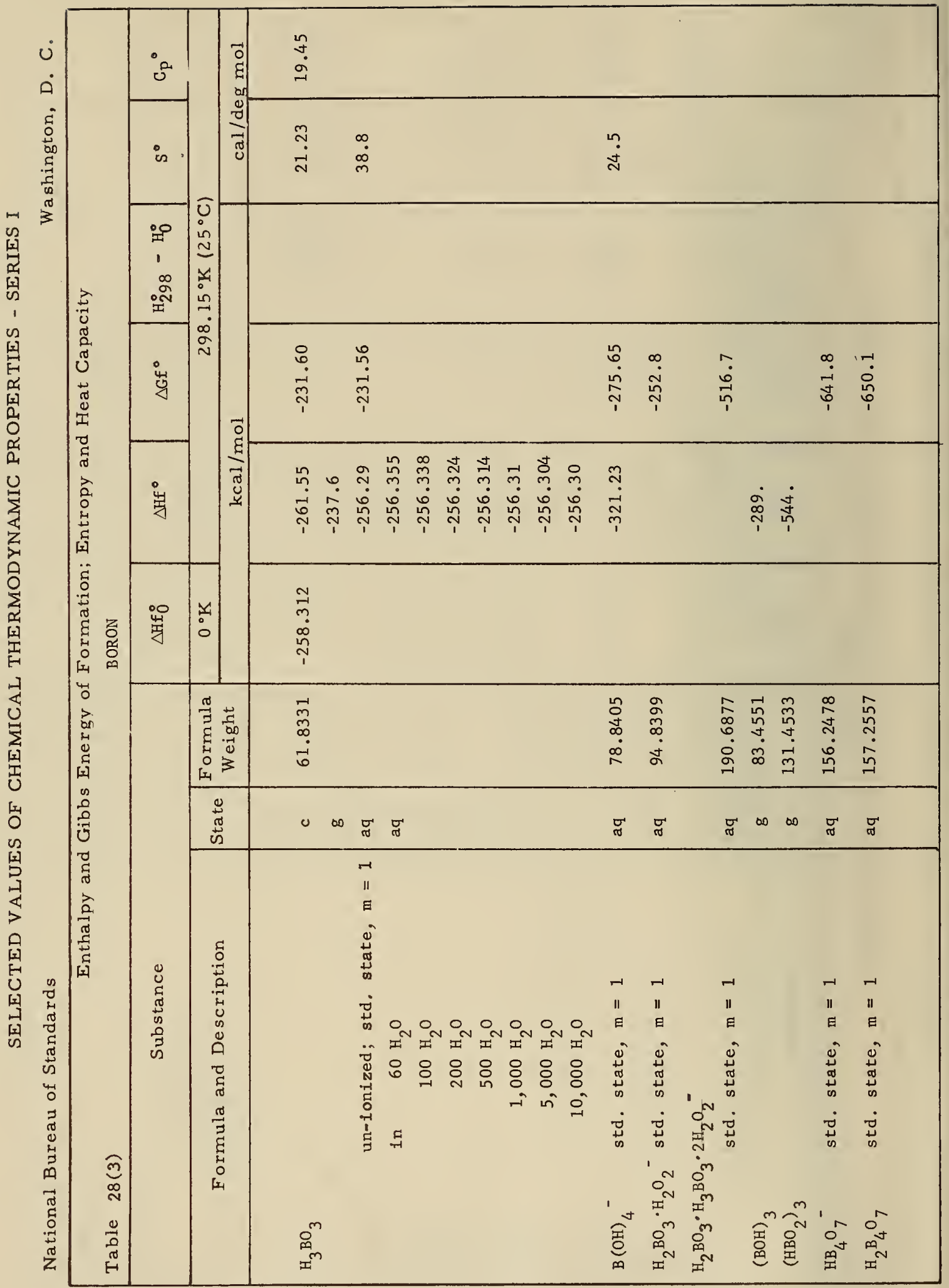




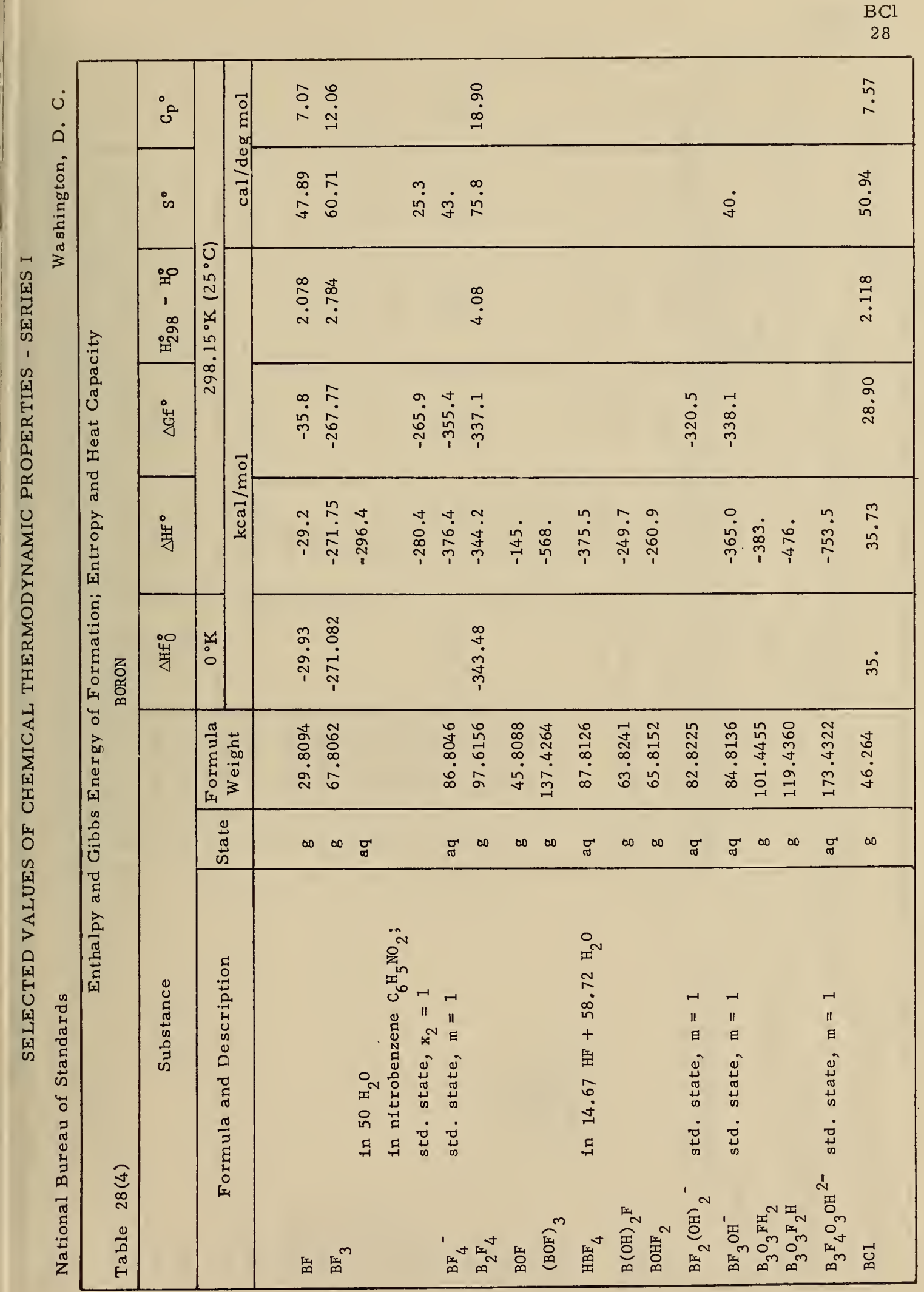


$\mathrm{BCl}_{3}$

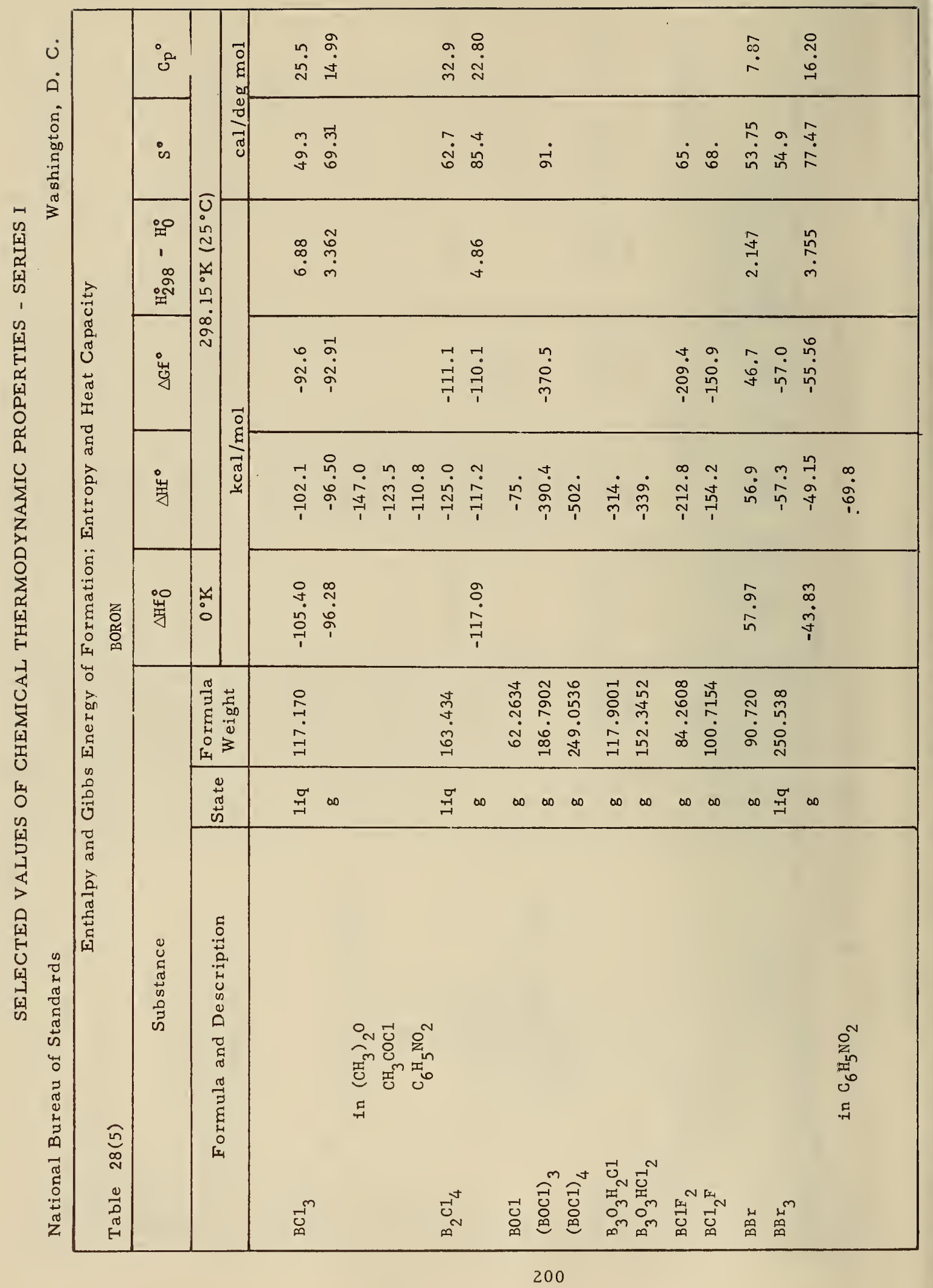




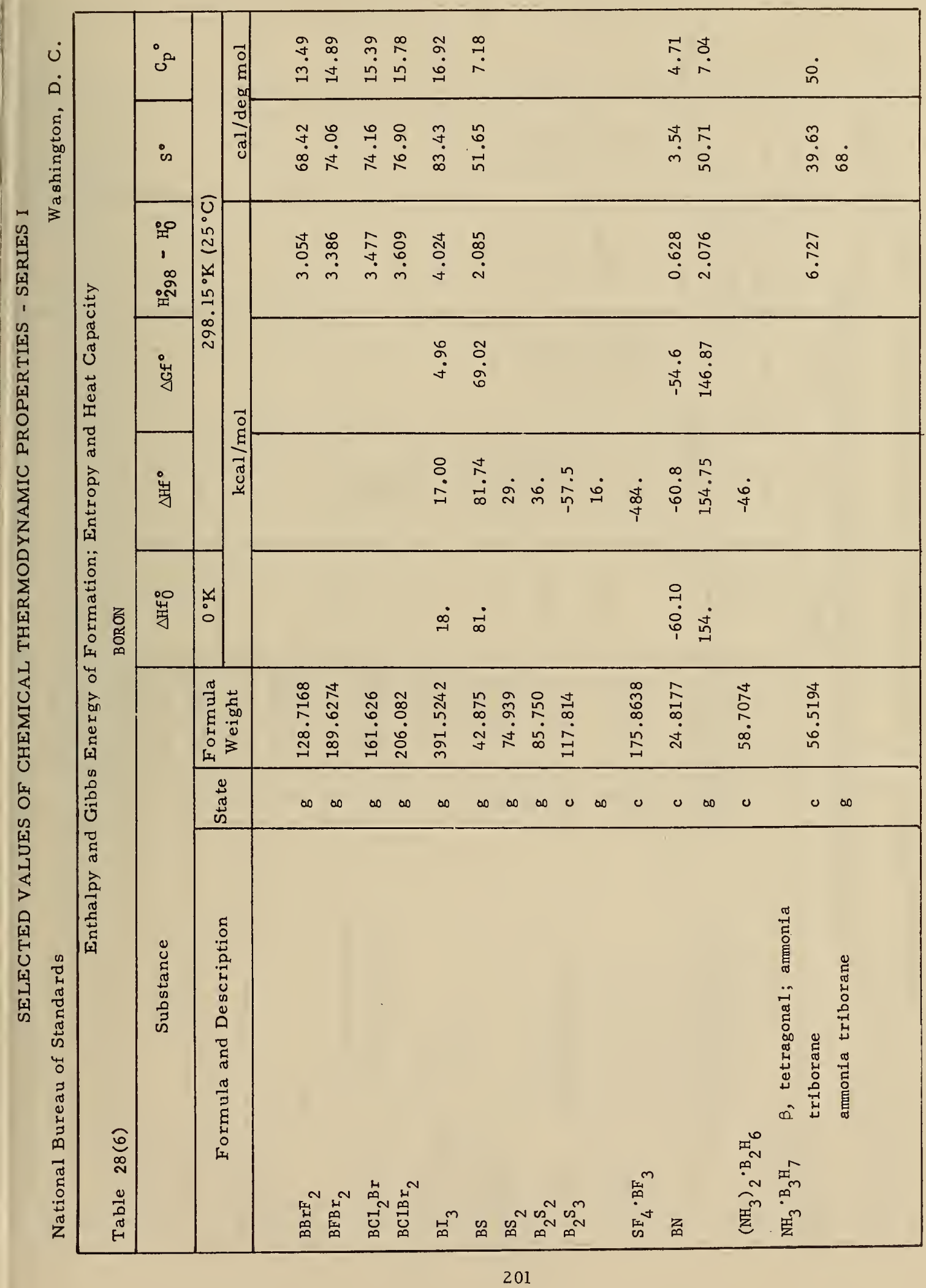


$\mathrm{B}_{3} \mathrm{~N}_{3} \mathrm{H}_{6}$
28

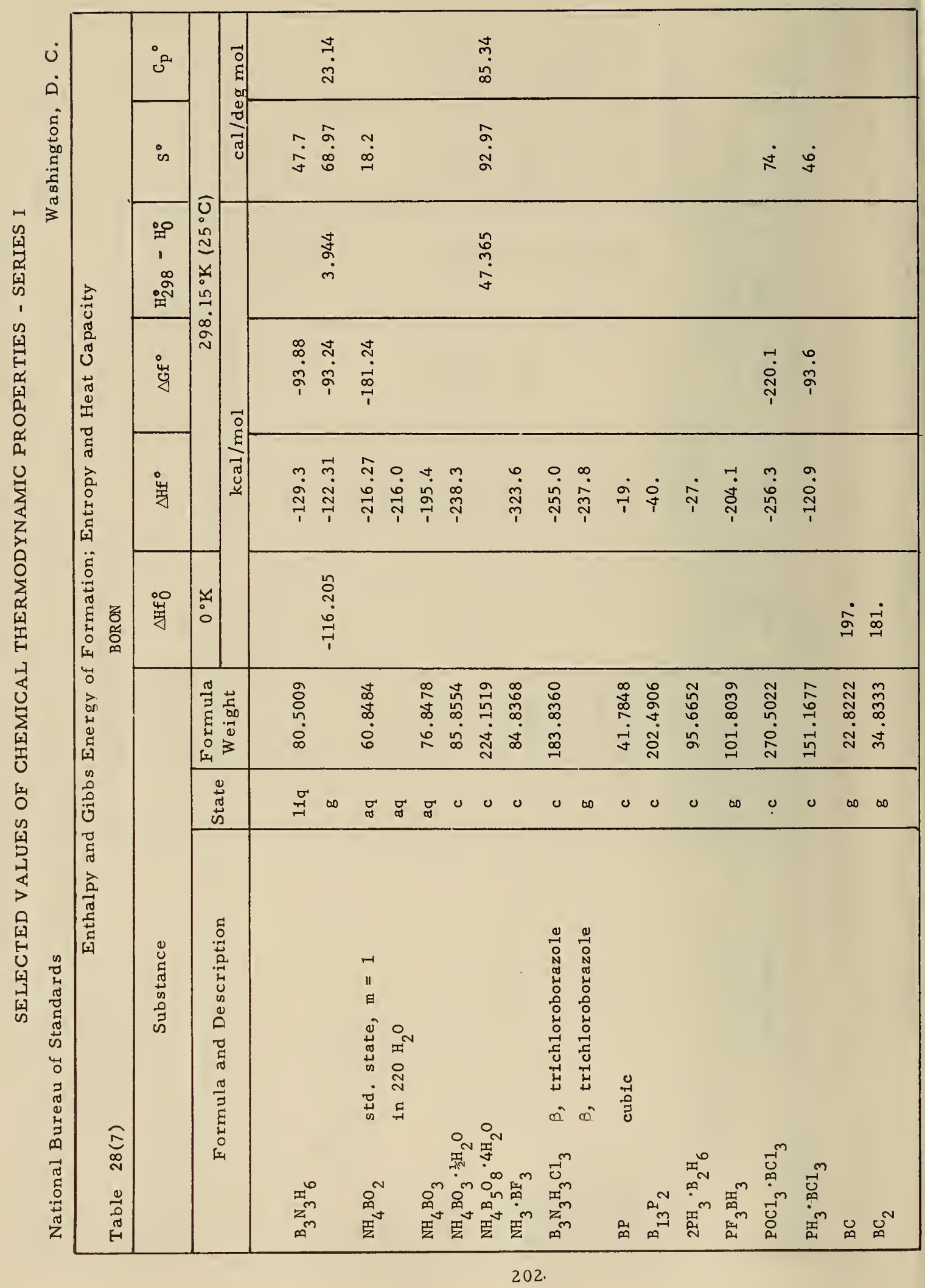


$\left(\mathrm{C}_{2} \mathrm{H}_{5}\right)_{28} \mathrm{O} \cdot \mathrm{BF}_{3}$

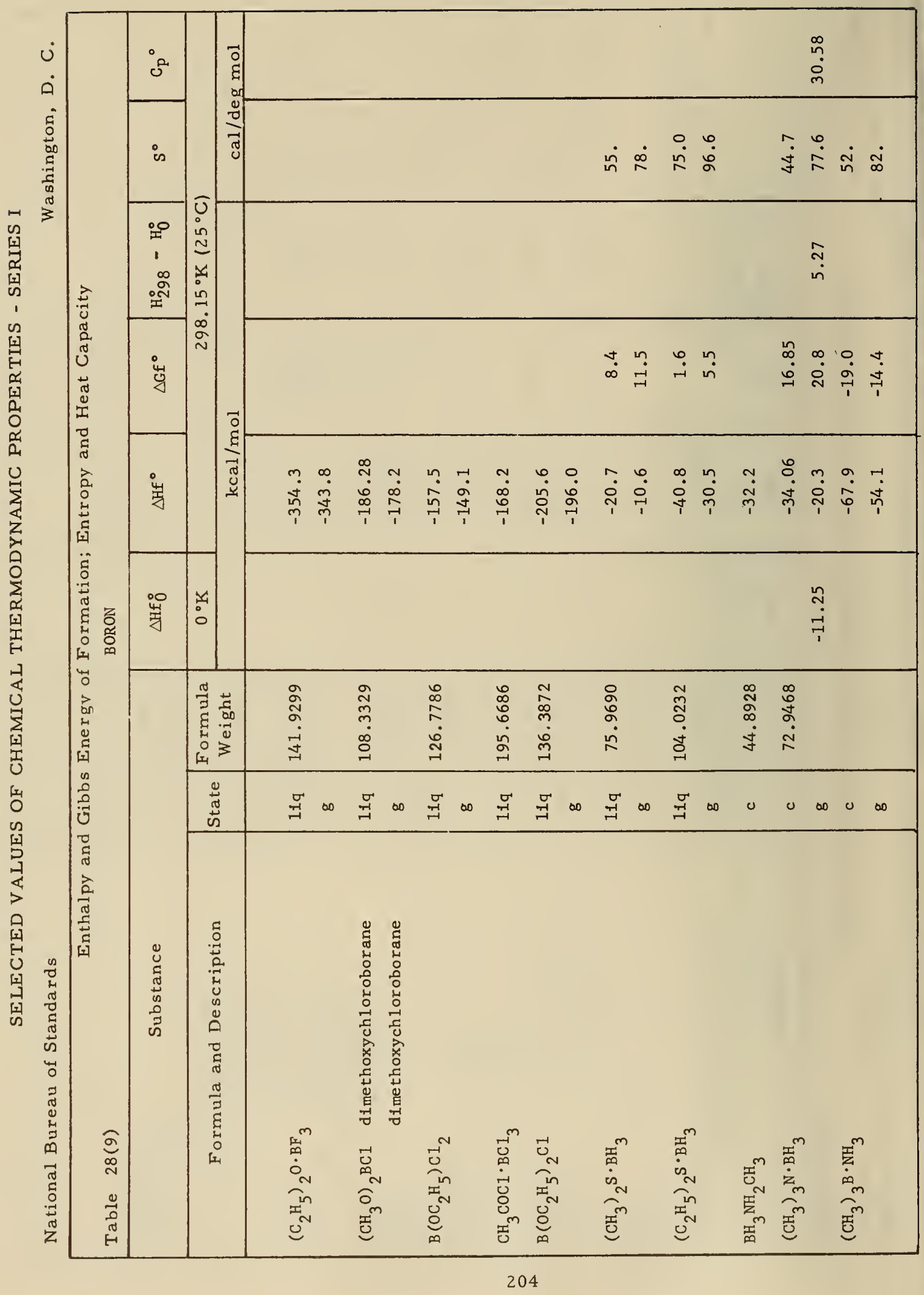




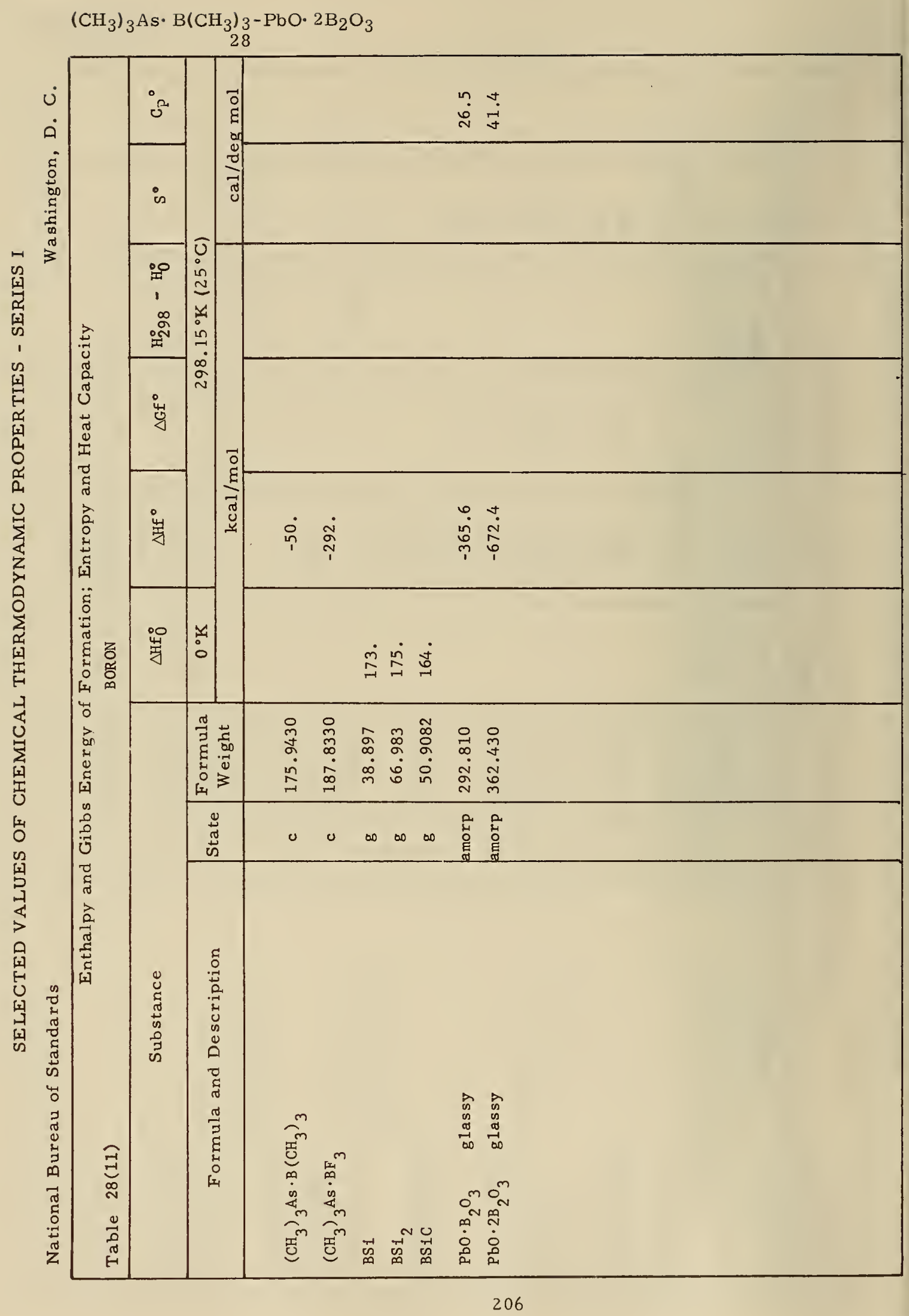




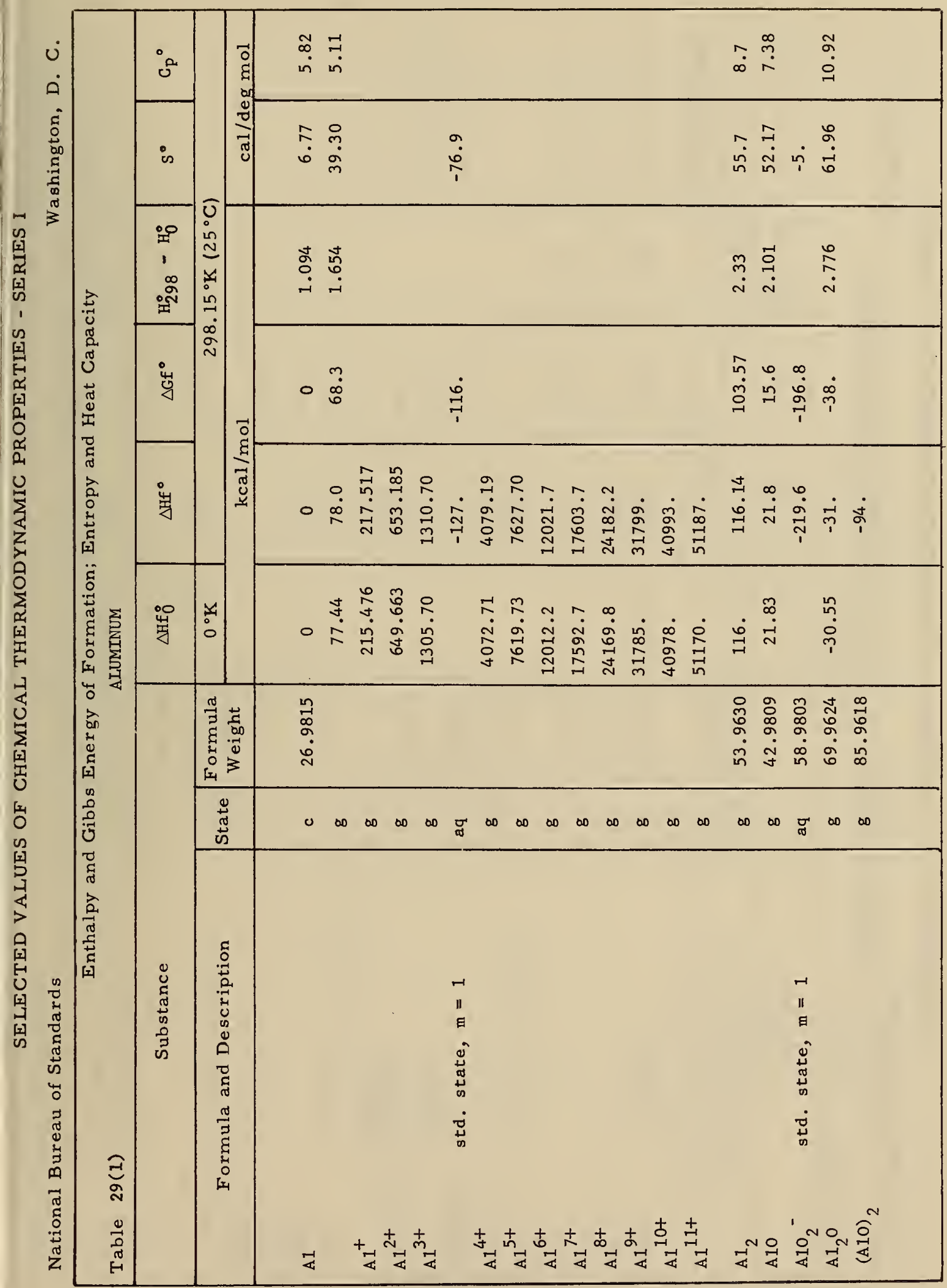




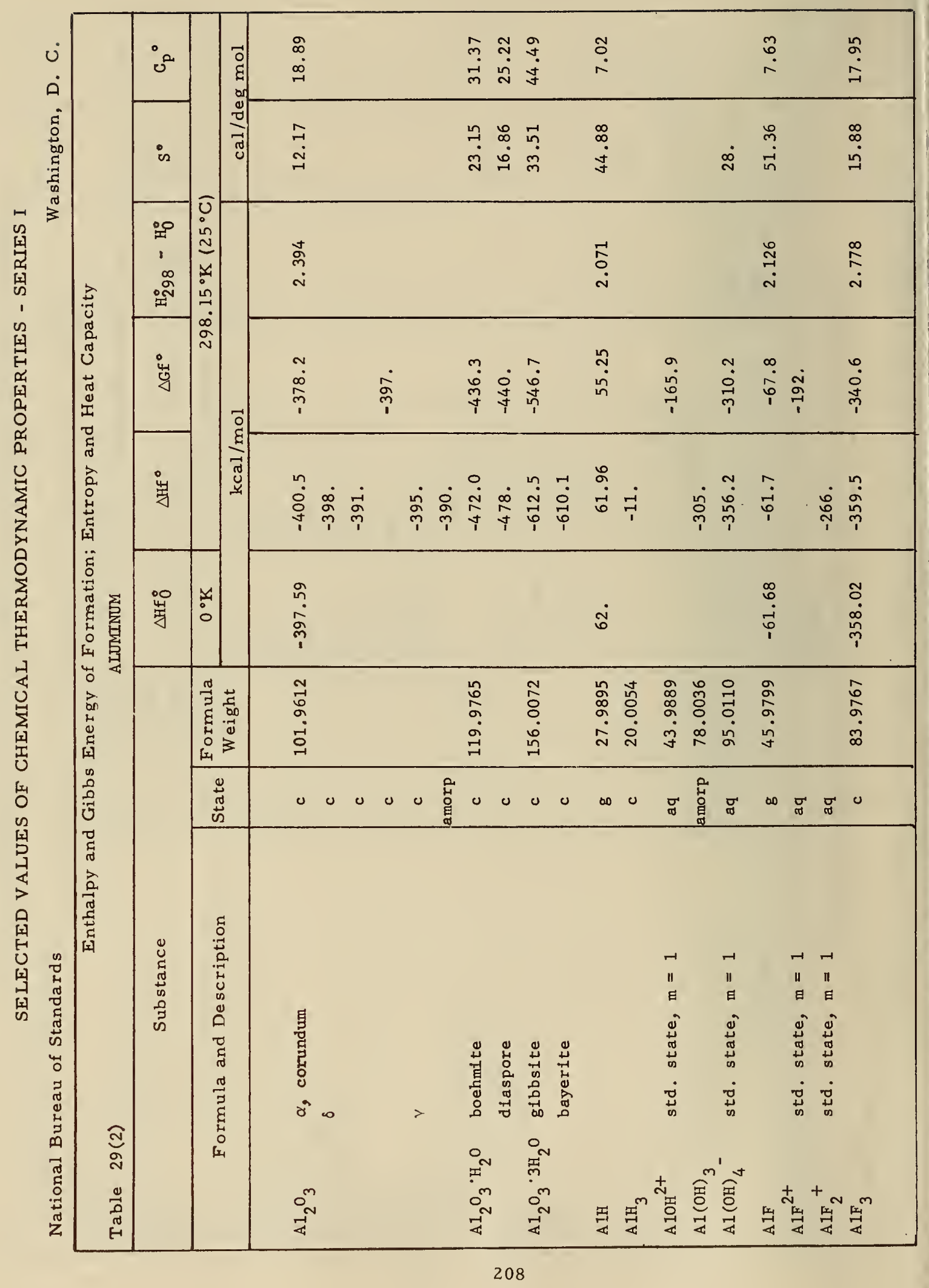




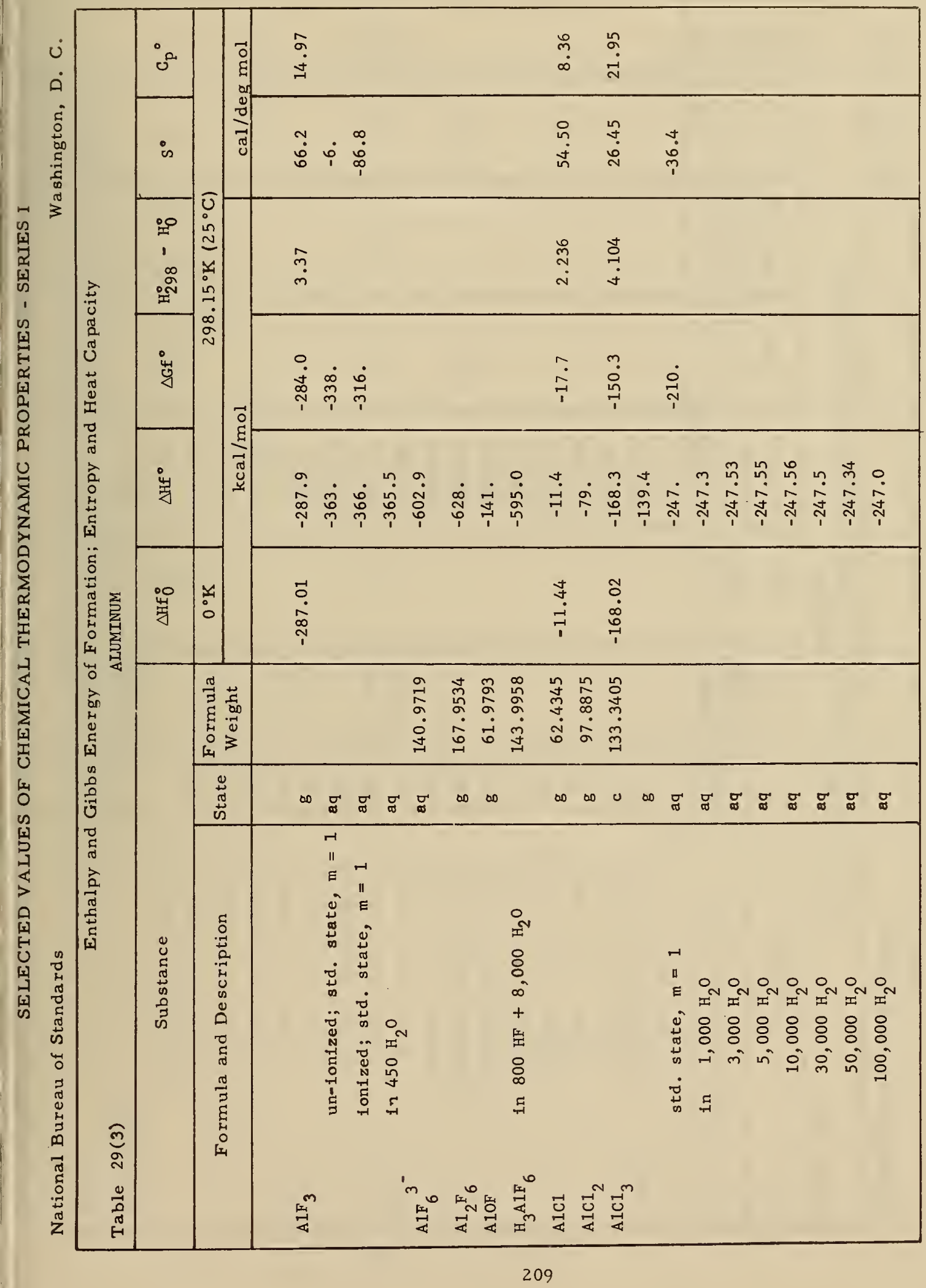




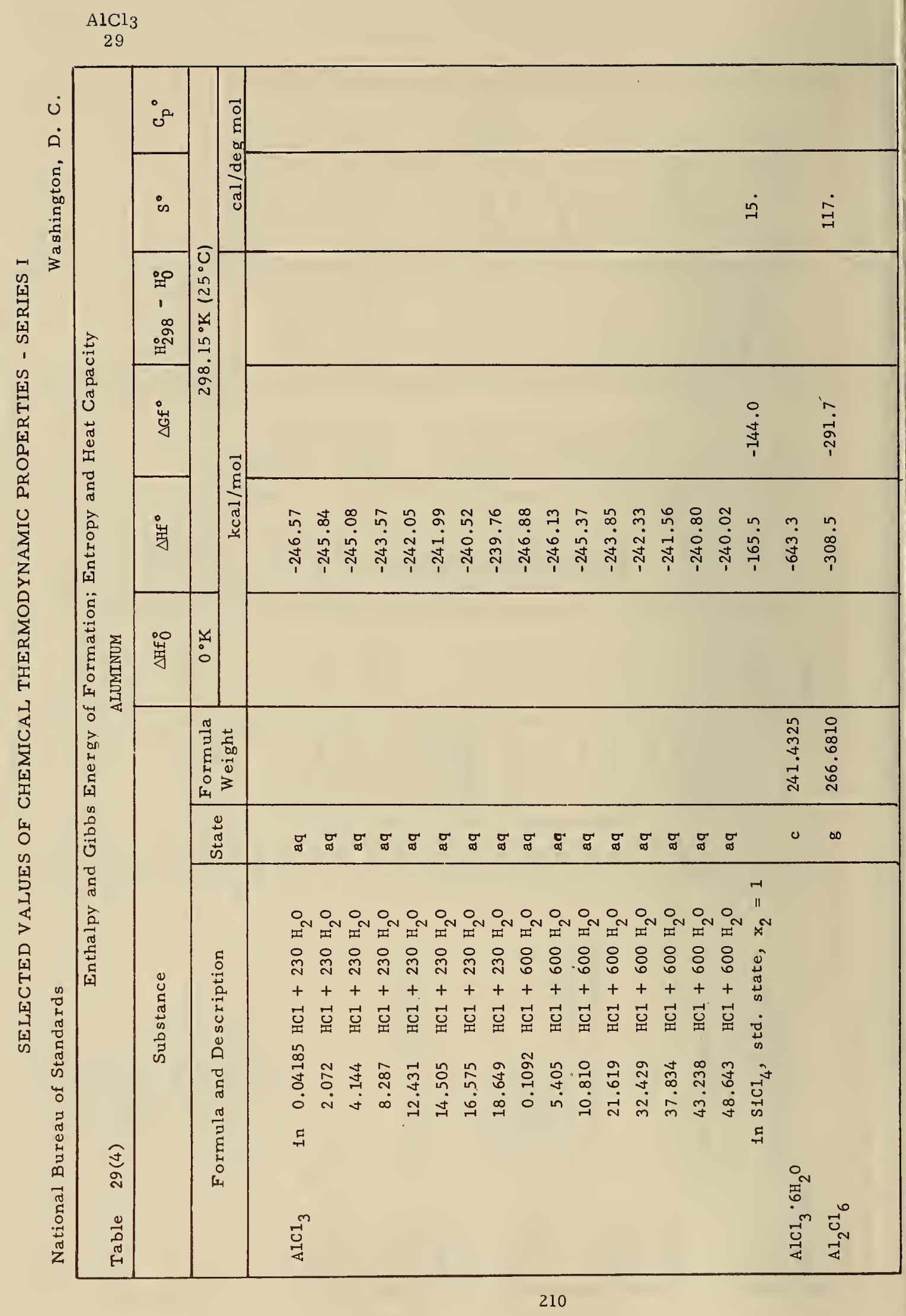




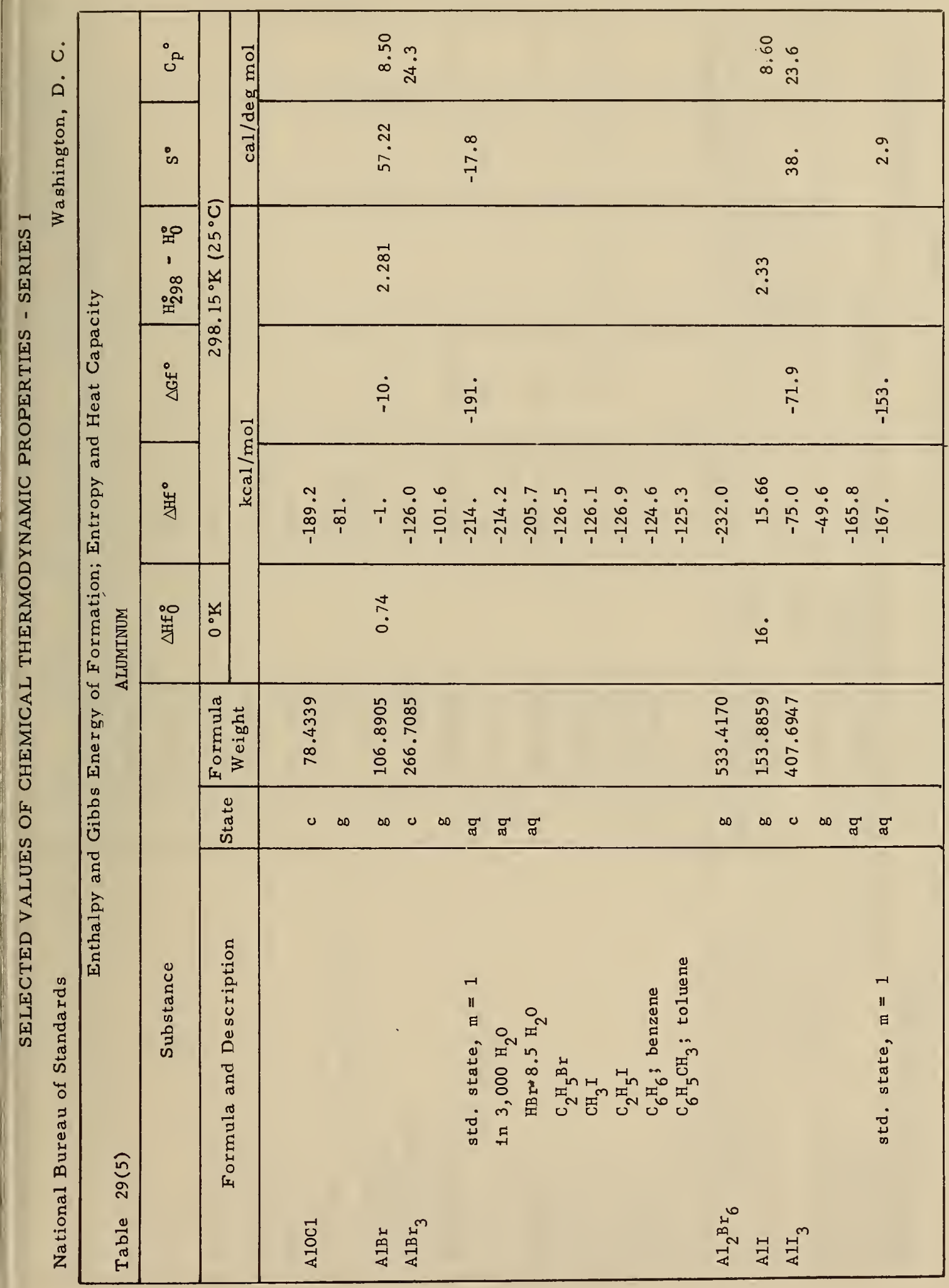




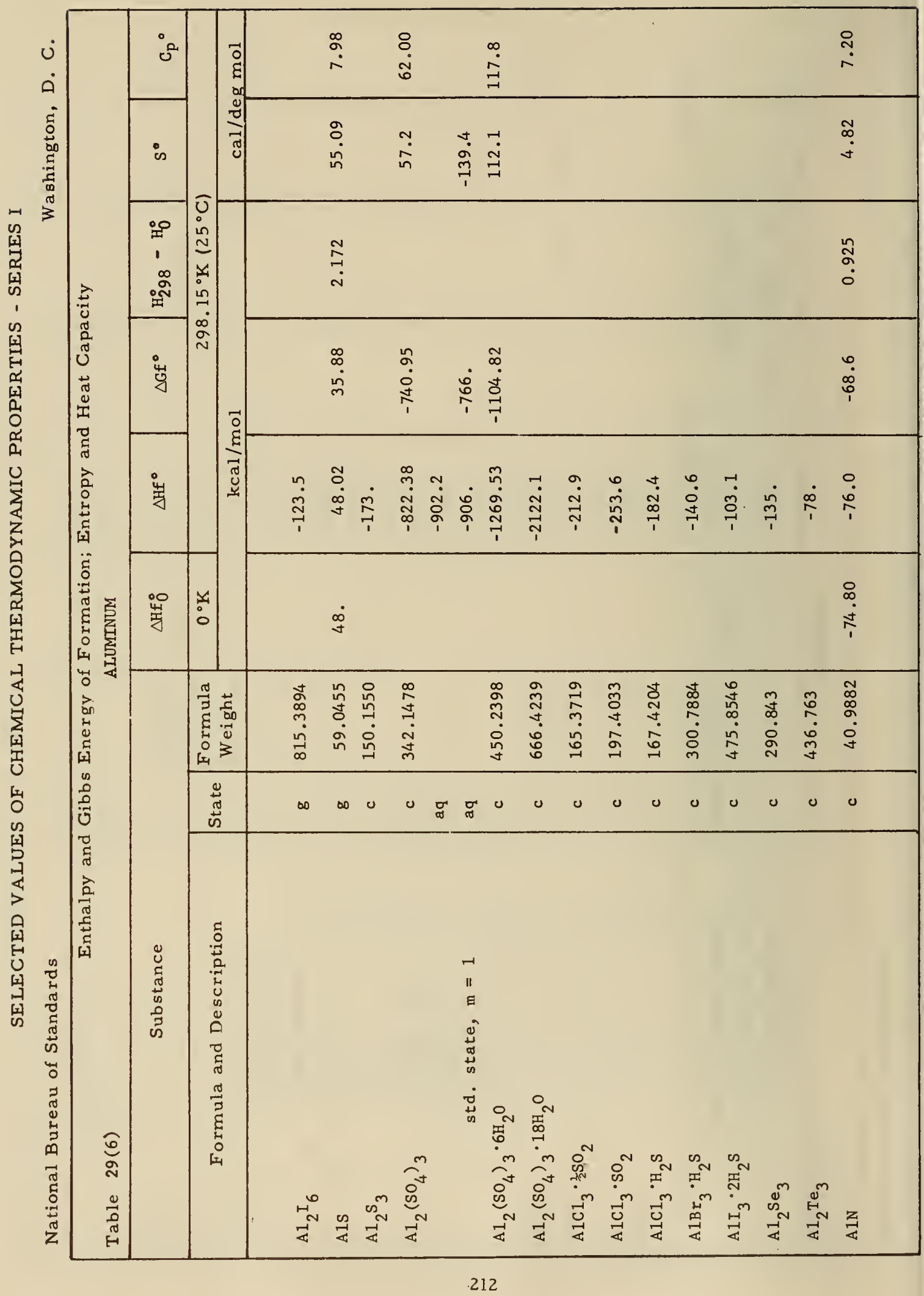




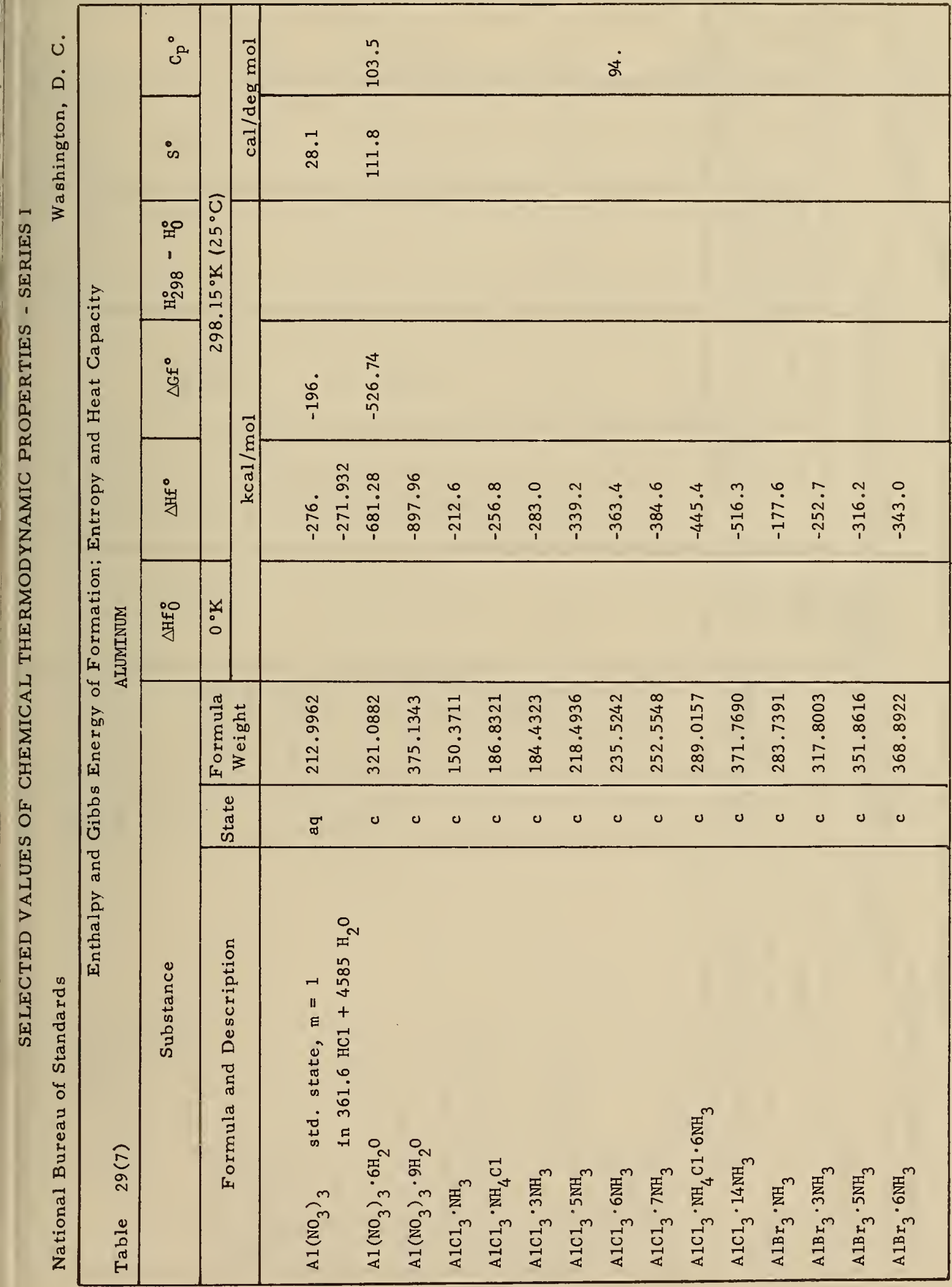




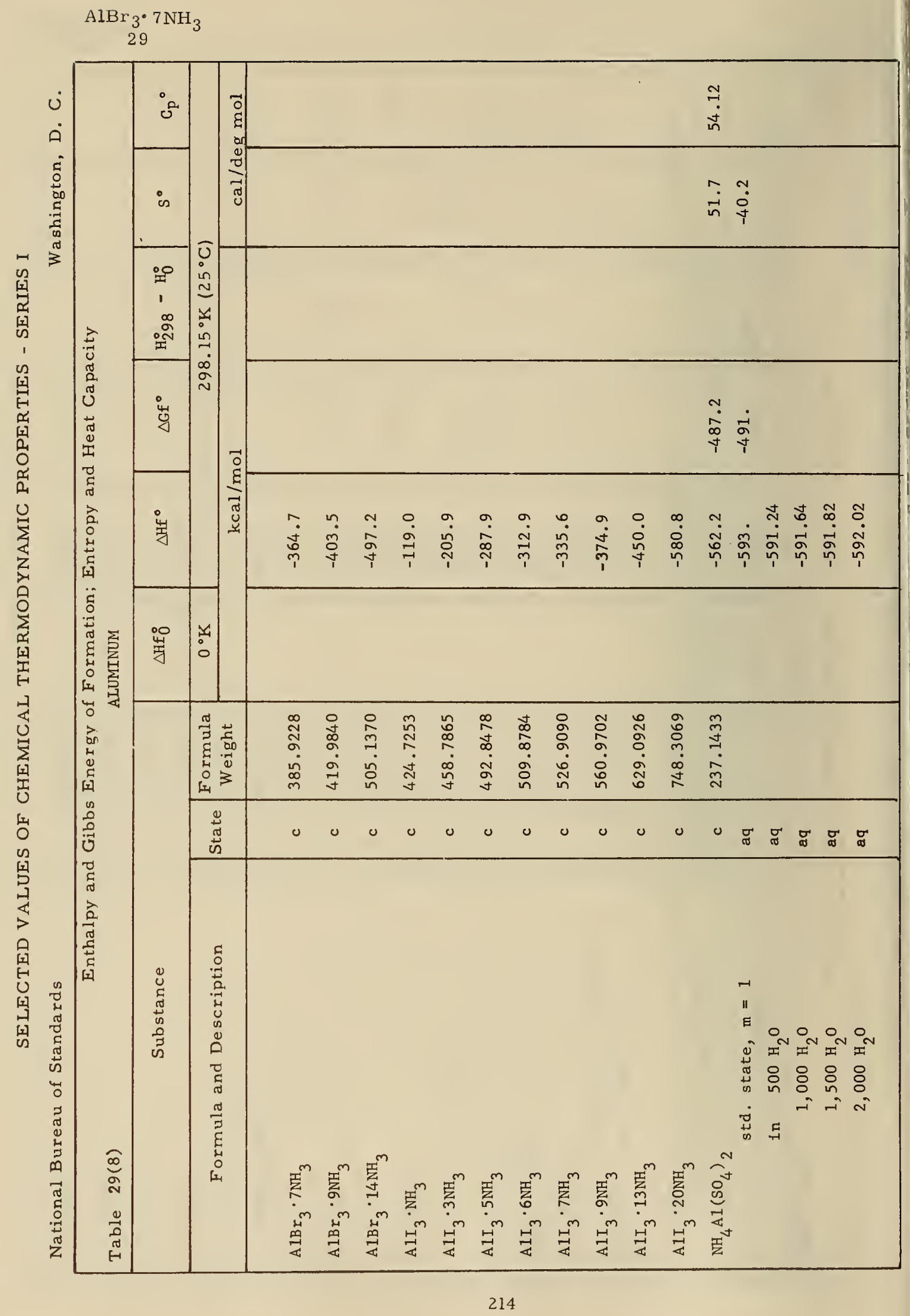




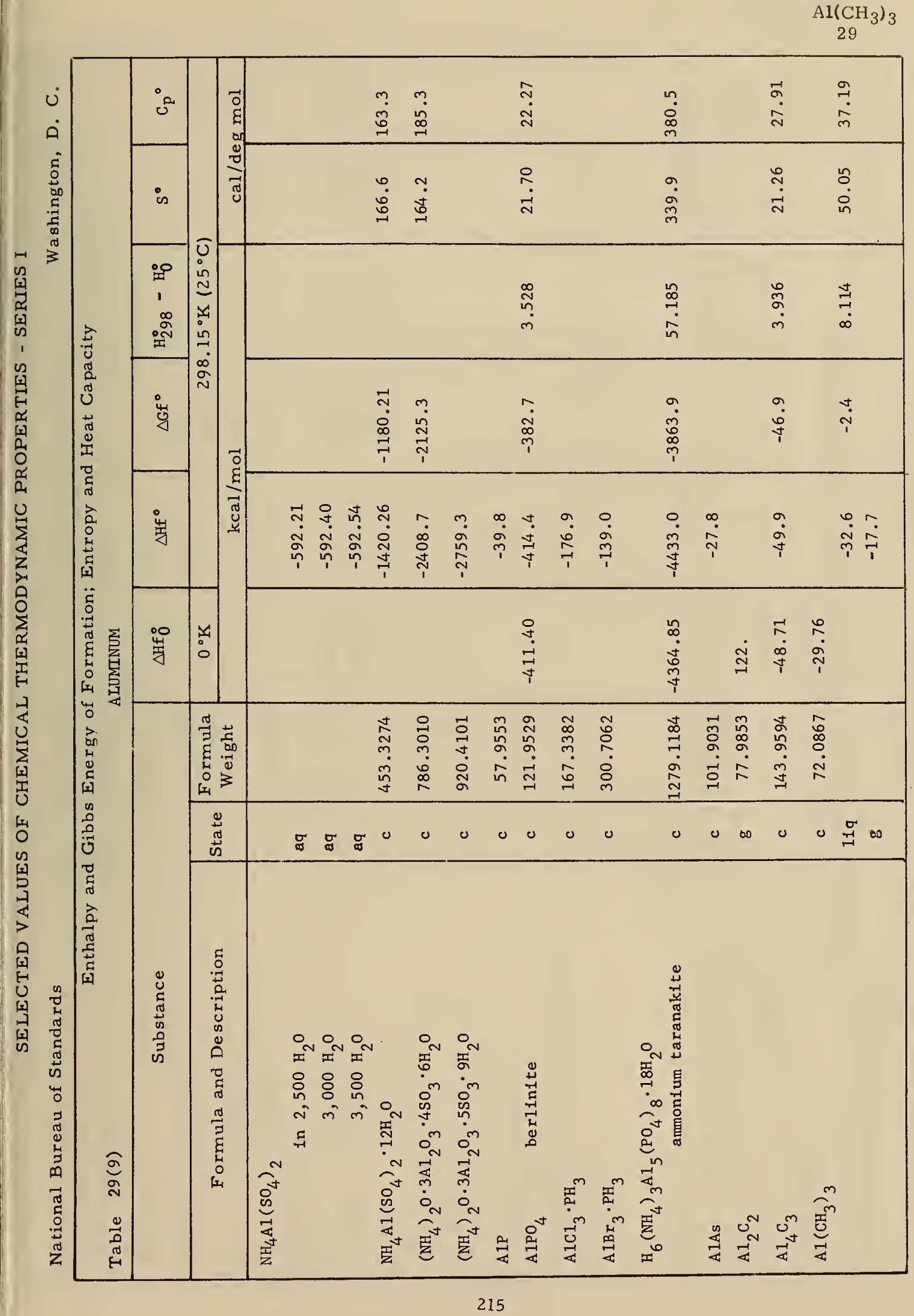


$\mathrm{Al}_{2}\left(\mathrm{CH}_{3}\right)_{6}$

29

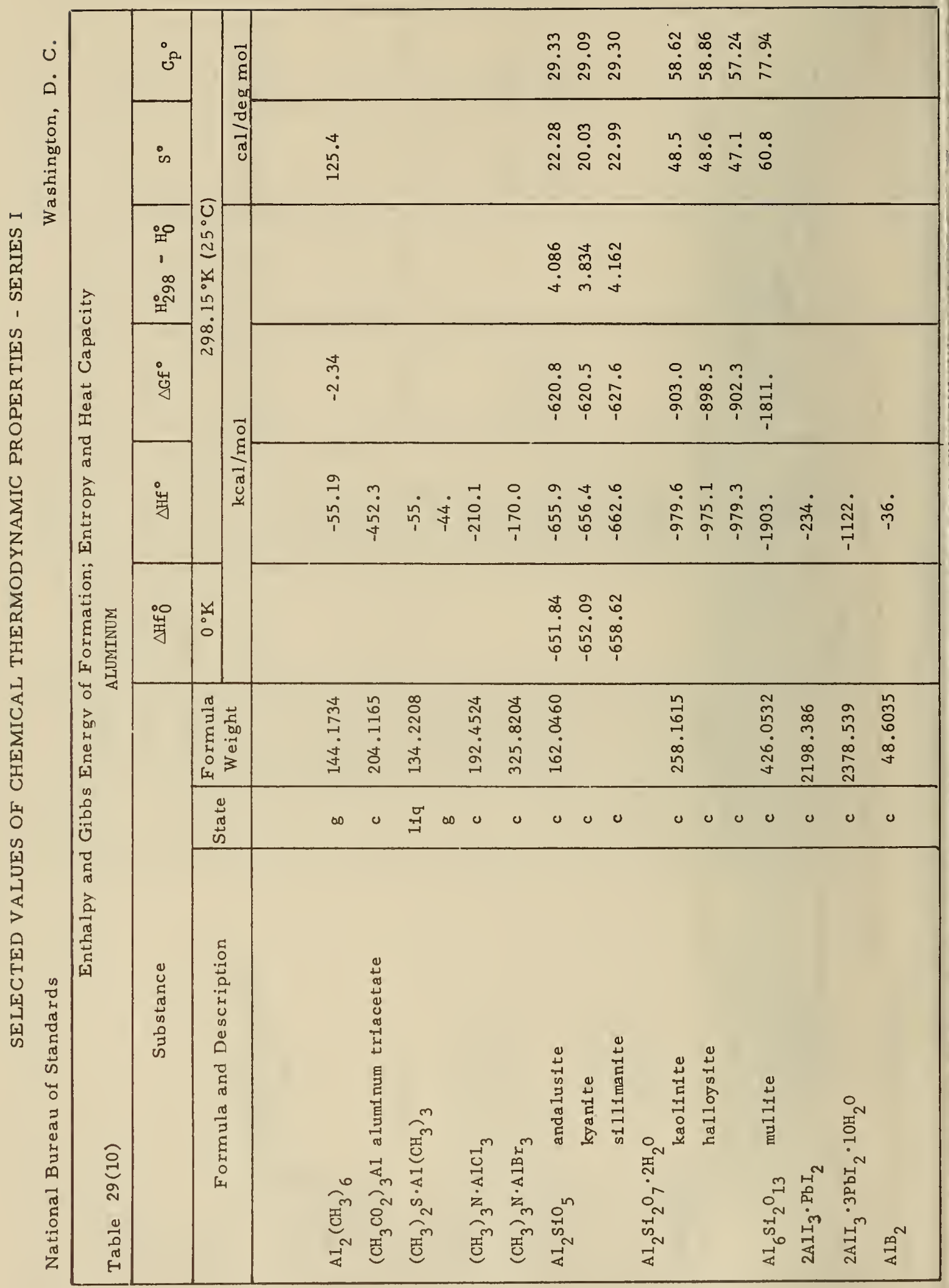


$\underset{29}{\mathrm{Al}\left(\mathrm{BH}_{4}\right)_{3}}$

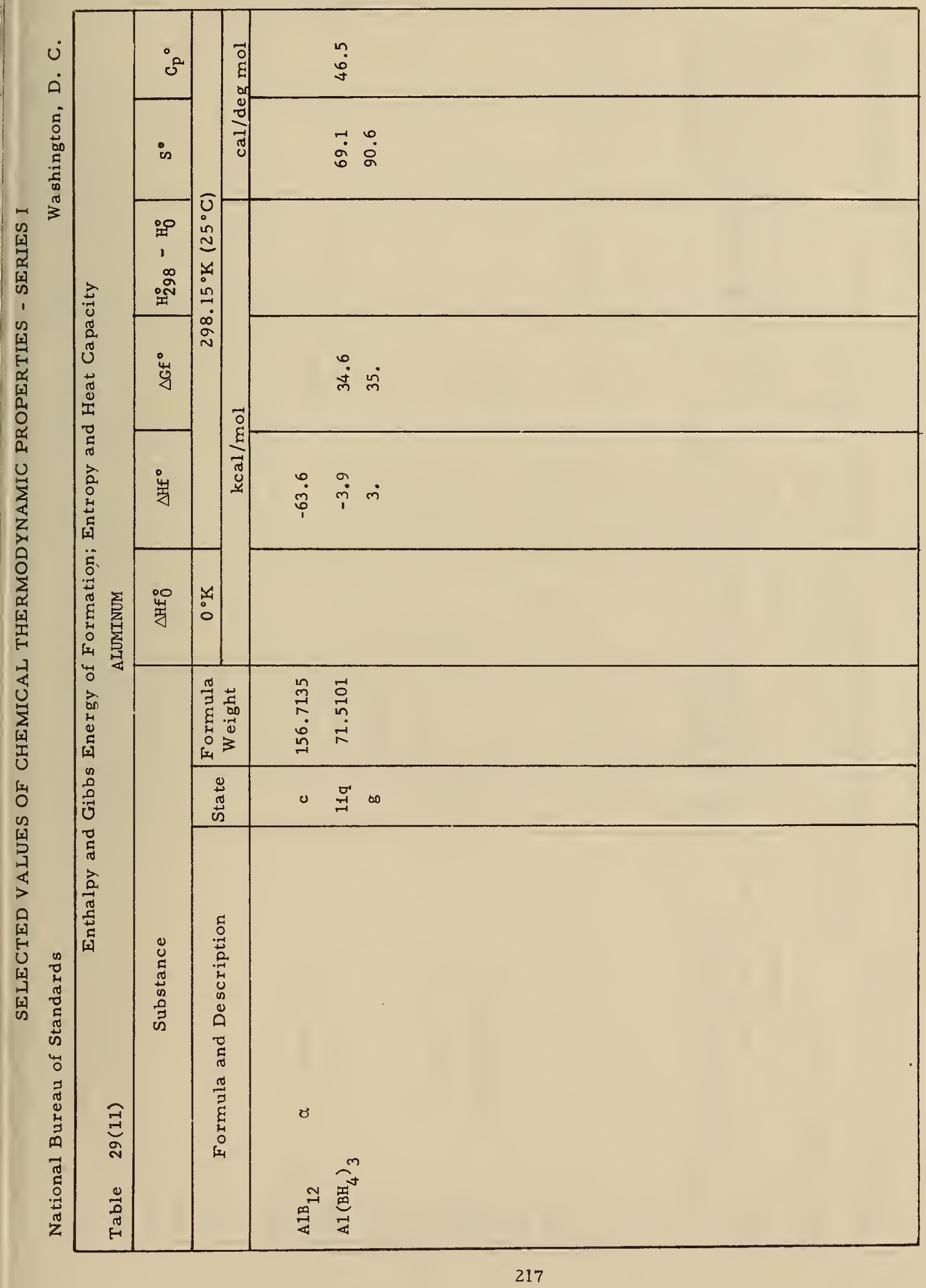




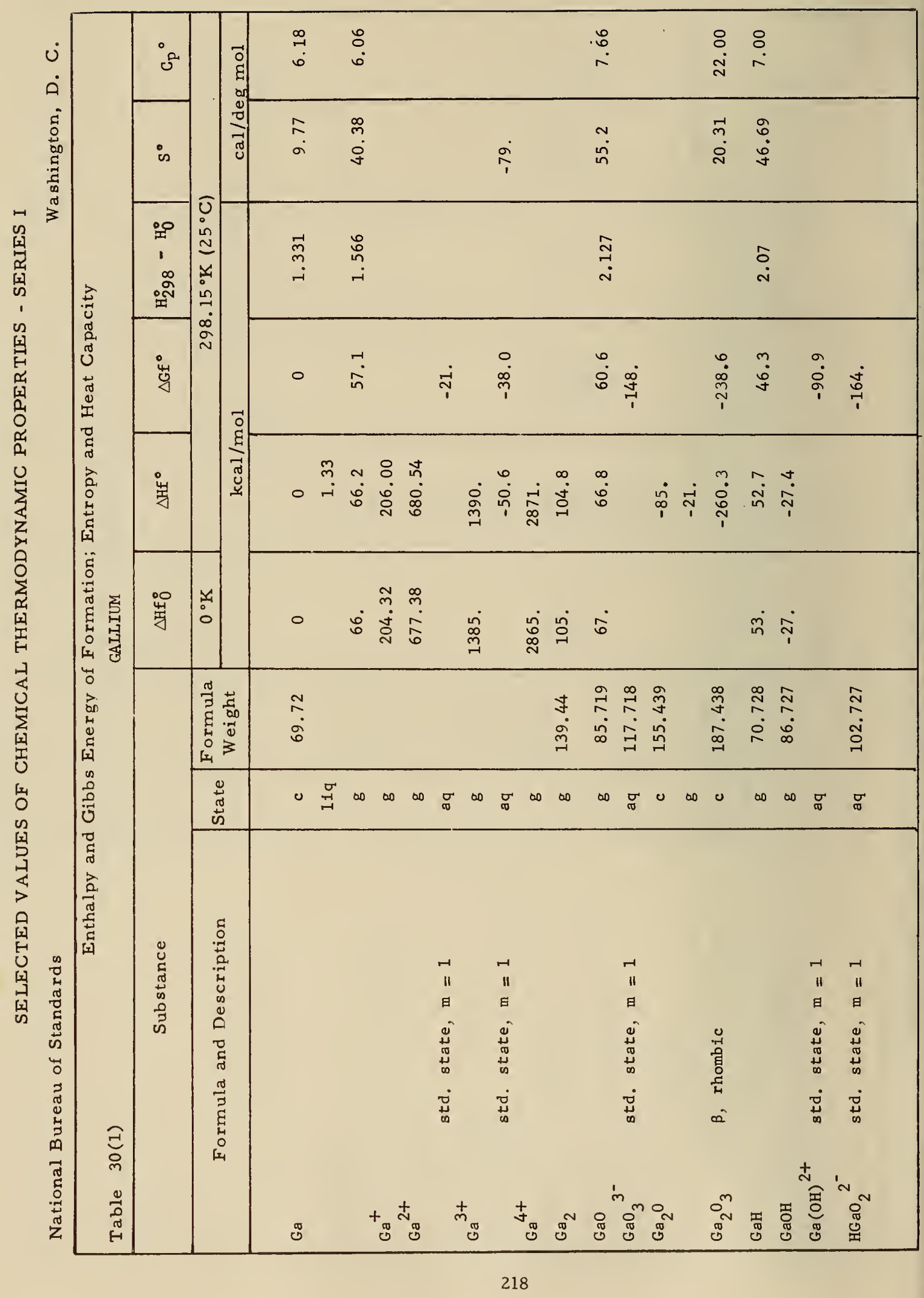




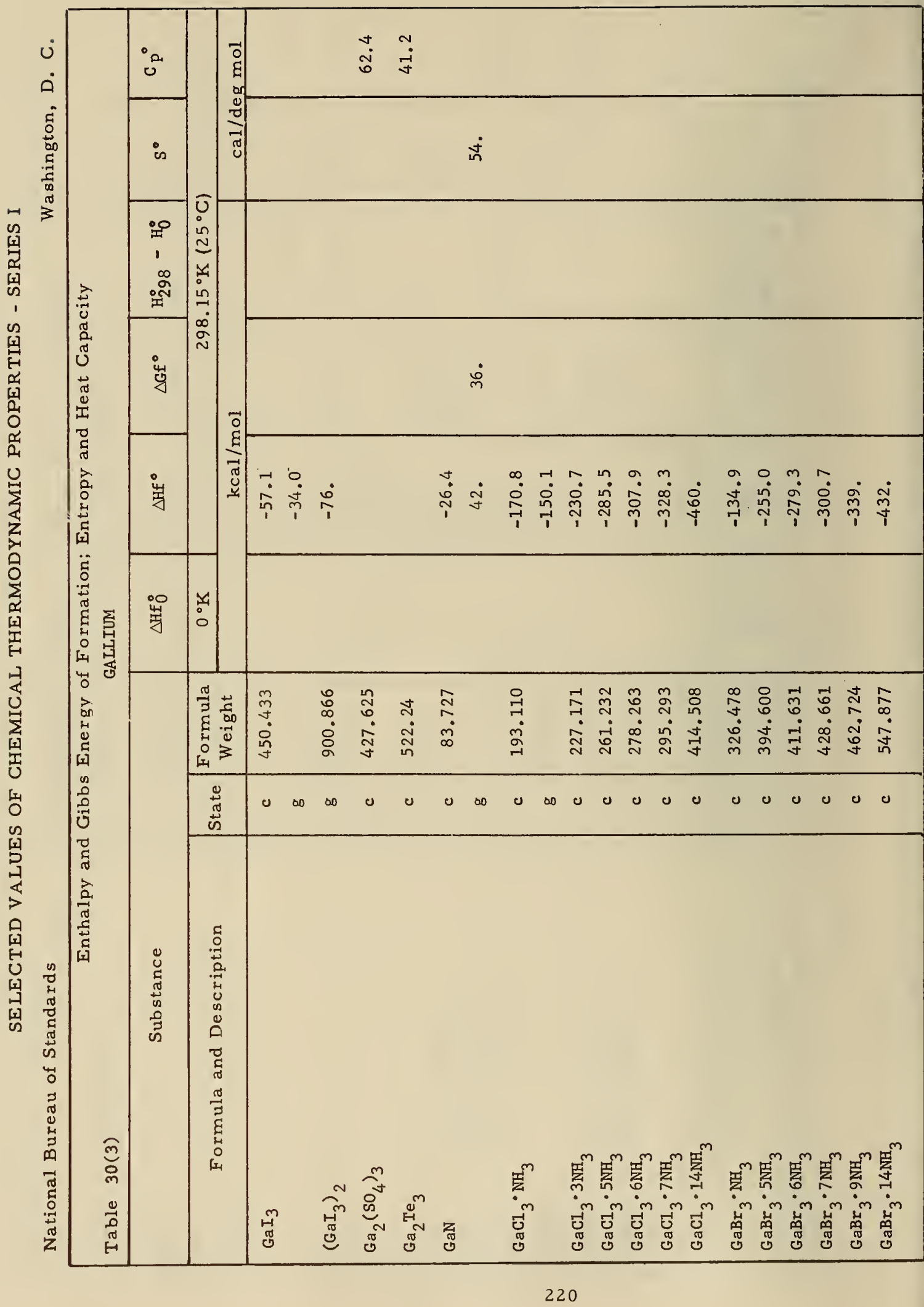


$\mathrm{GaCl}_{30} \cdot \mathrm{CH}_{3} \mathrm{Cl}$

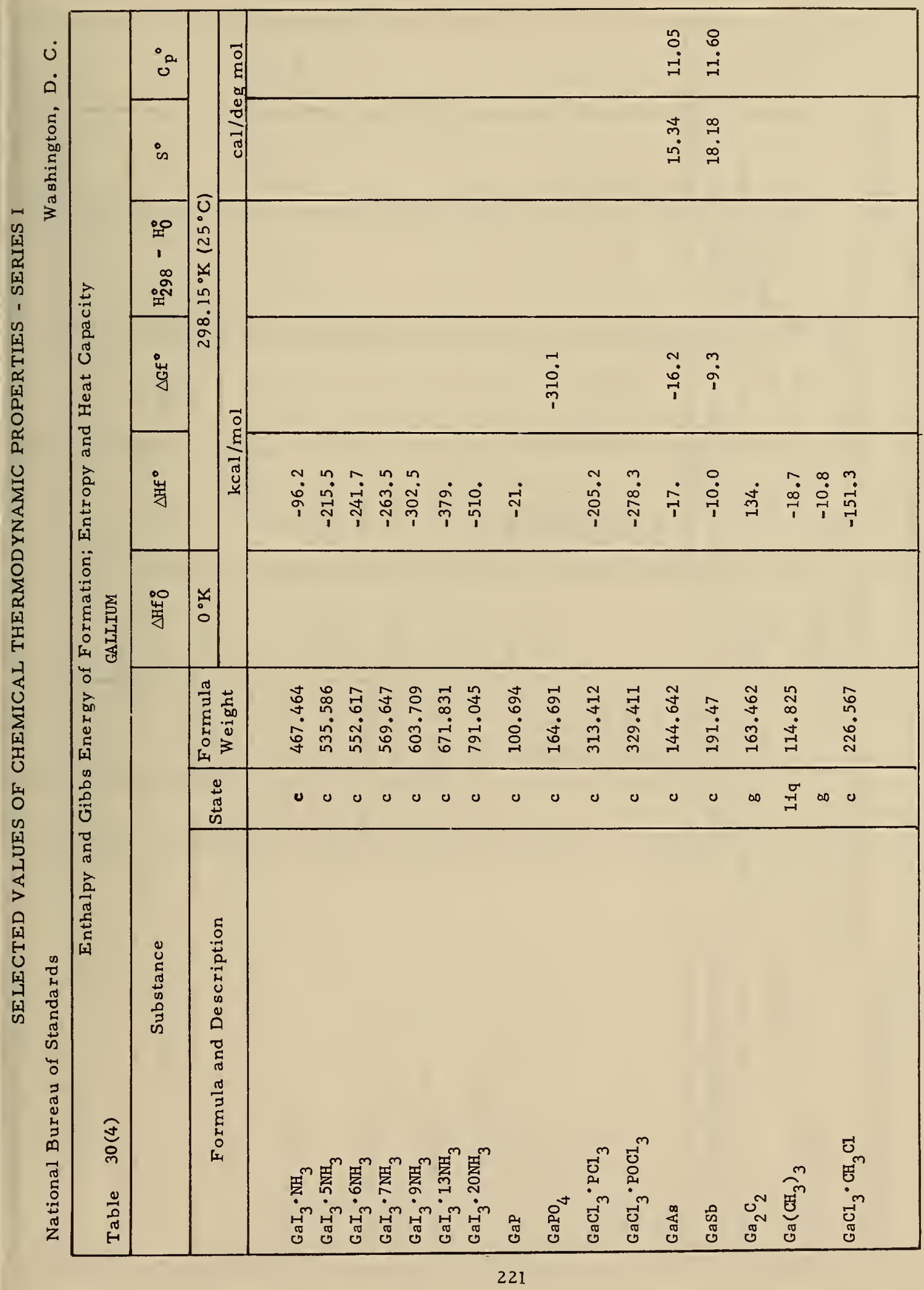


$2 \mathrm{GaCl}_{3} \cdot \mathrm{CH}_{3} \mathrm{Cl}-\mathrm{Ga}\left(\mathrm{CH}_{3}\right)_{3} \cdot\left(\mathrm{CH}_{3}\right)_{2} \mathrm{~S}$

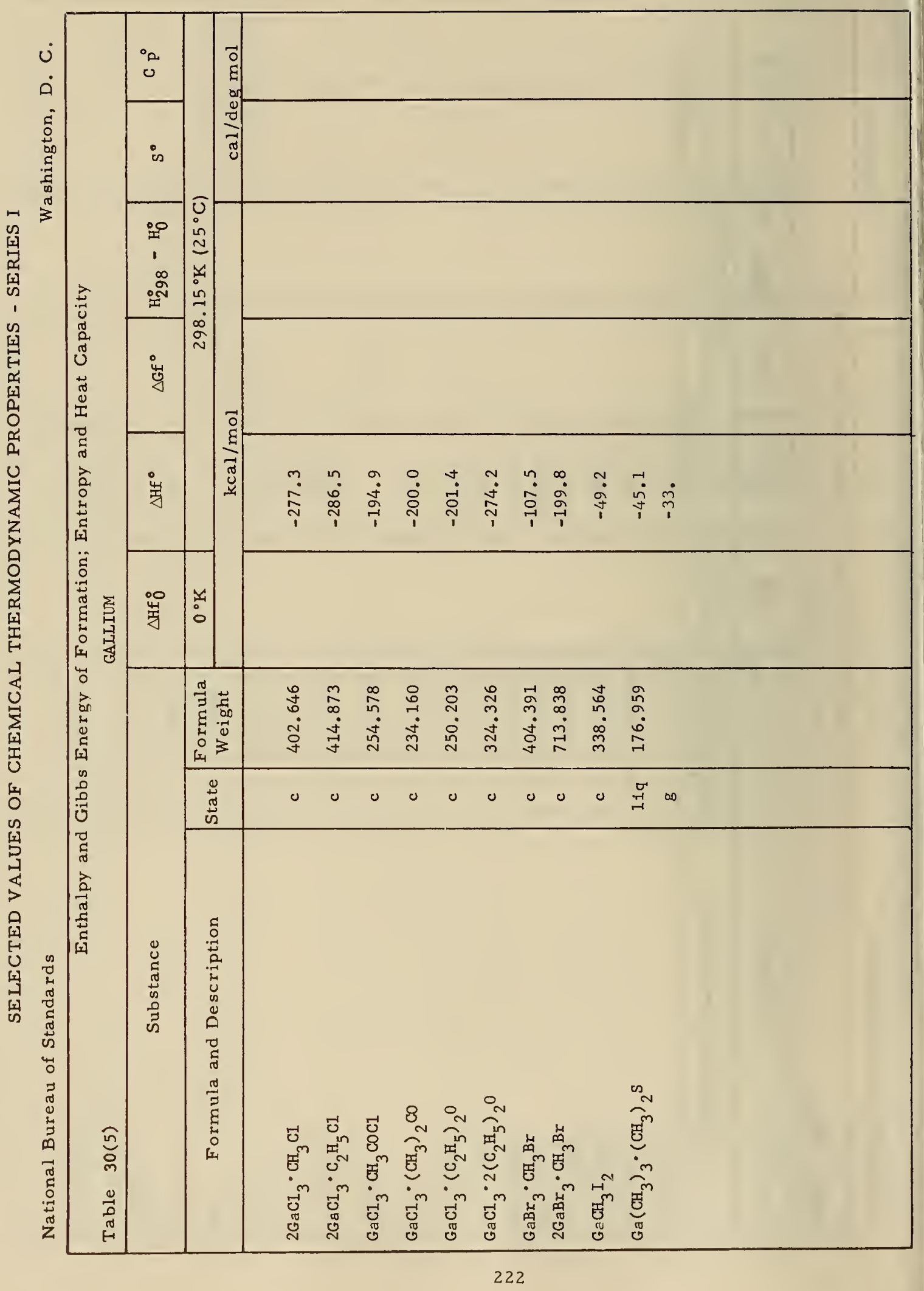




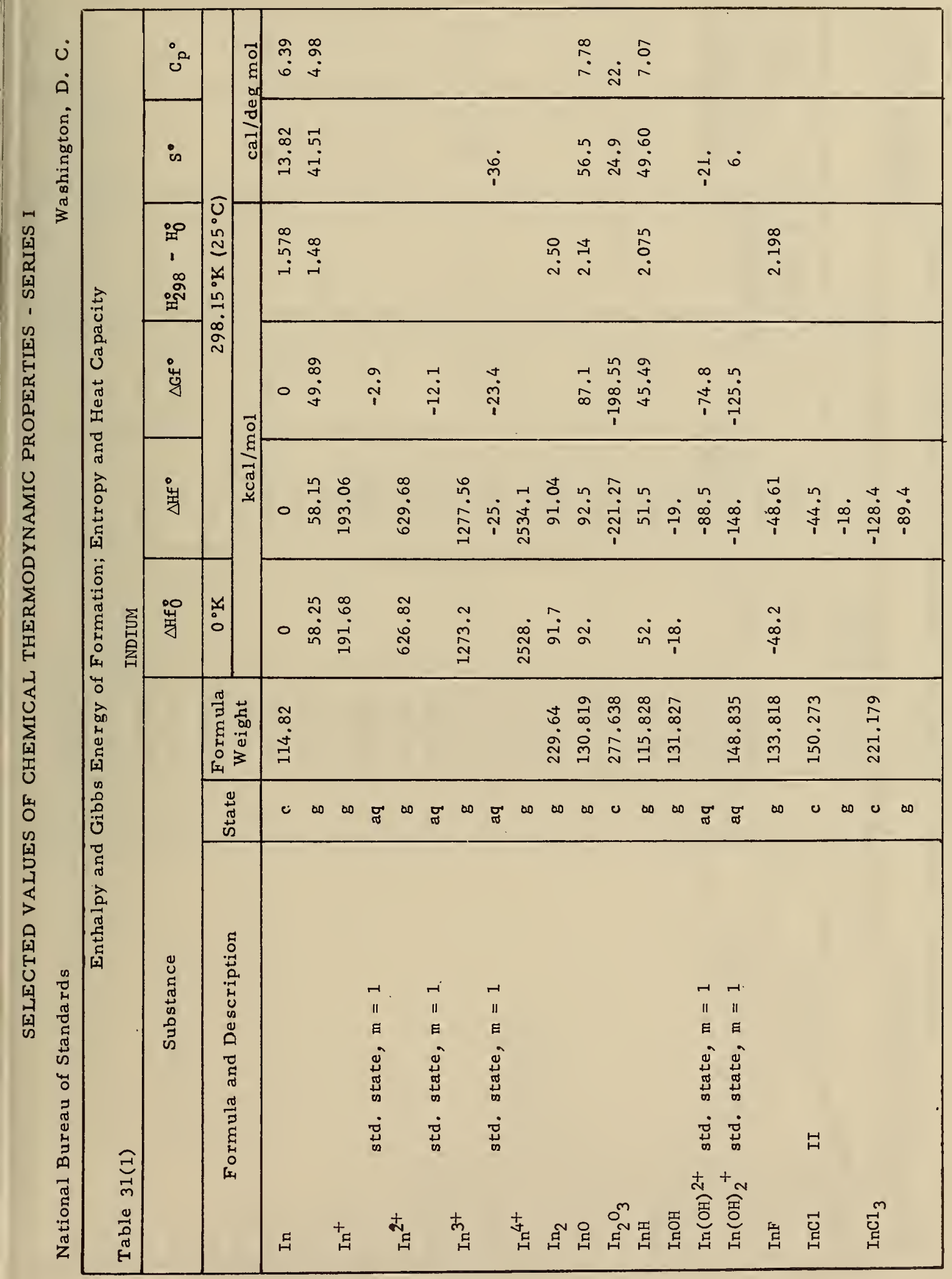


$\mathrm{In}_{2} \mathrm{Cl}_{3}$

31.

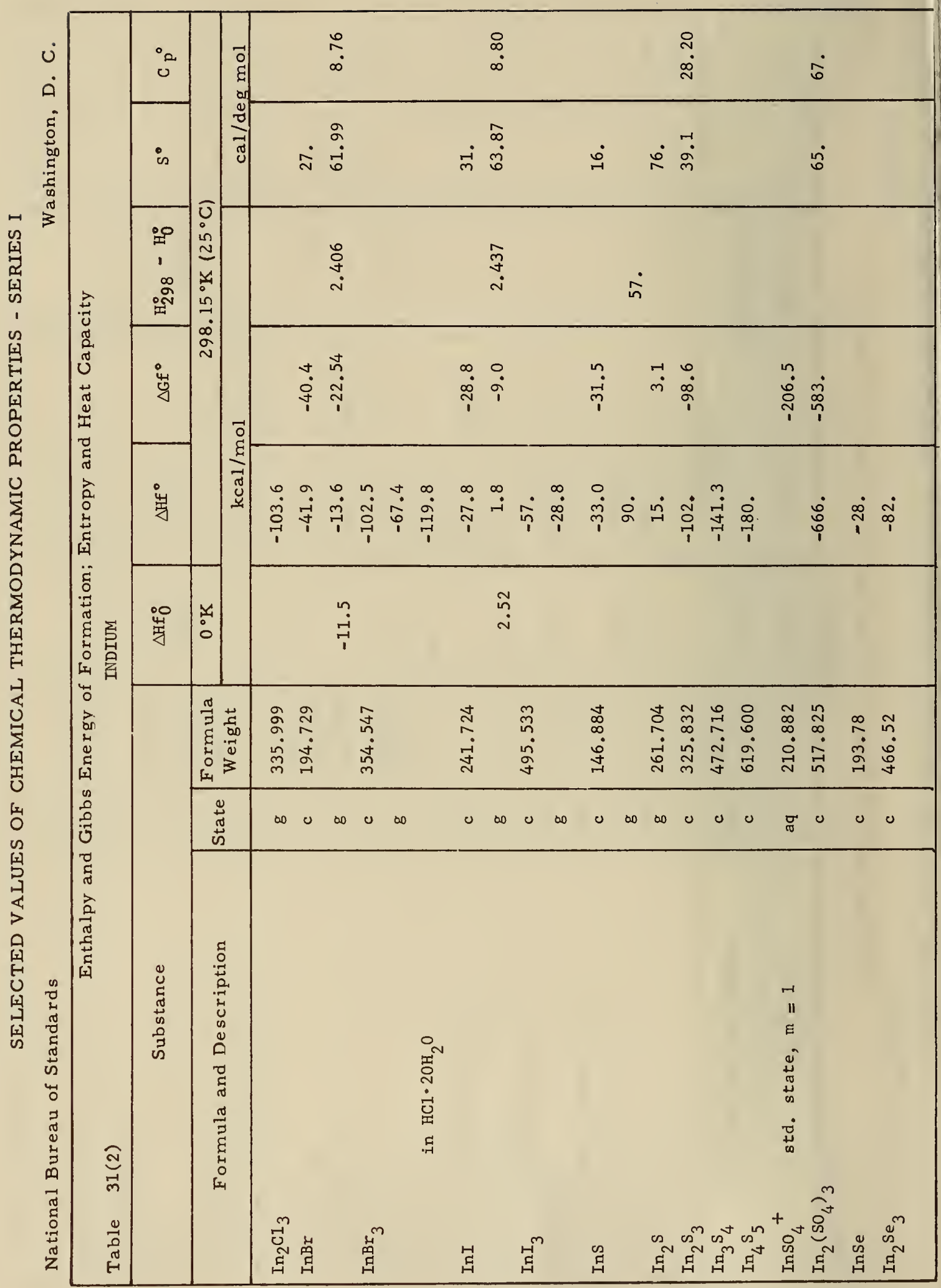




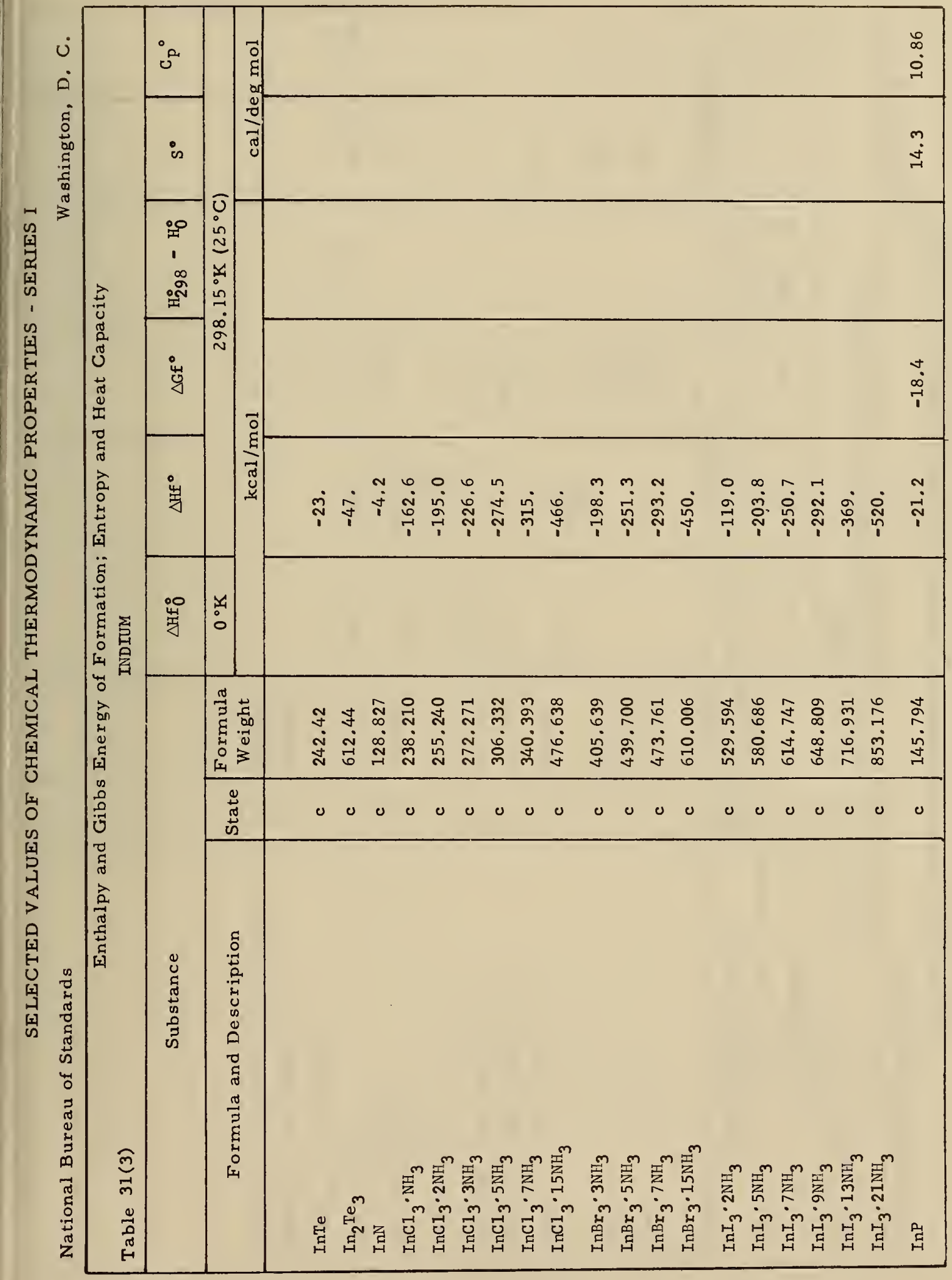


InAs $-\operatorname{In}(\mathrm{CNS})_{3}$

31

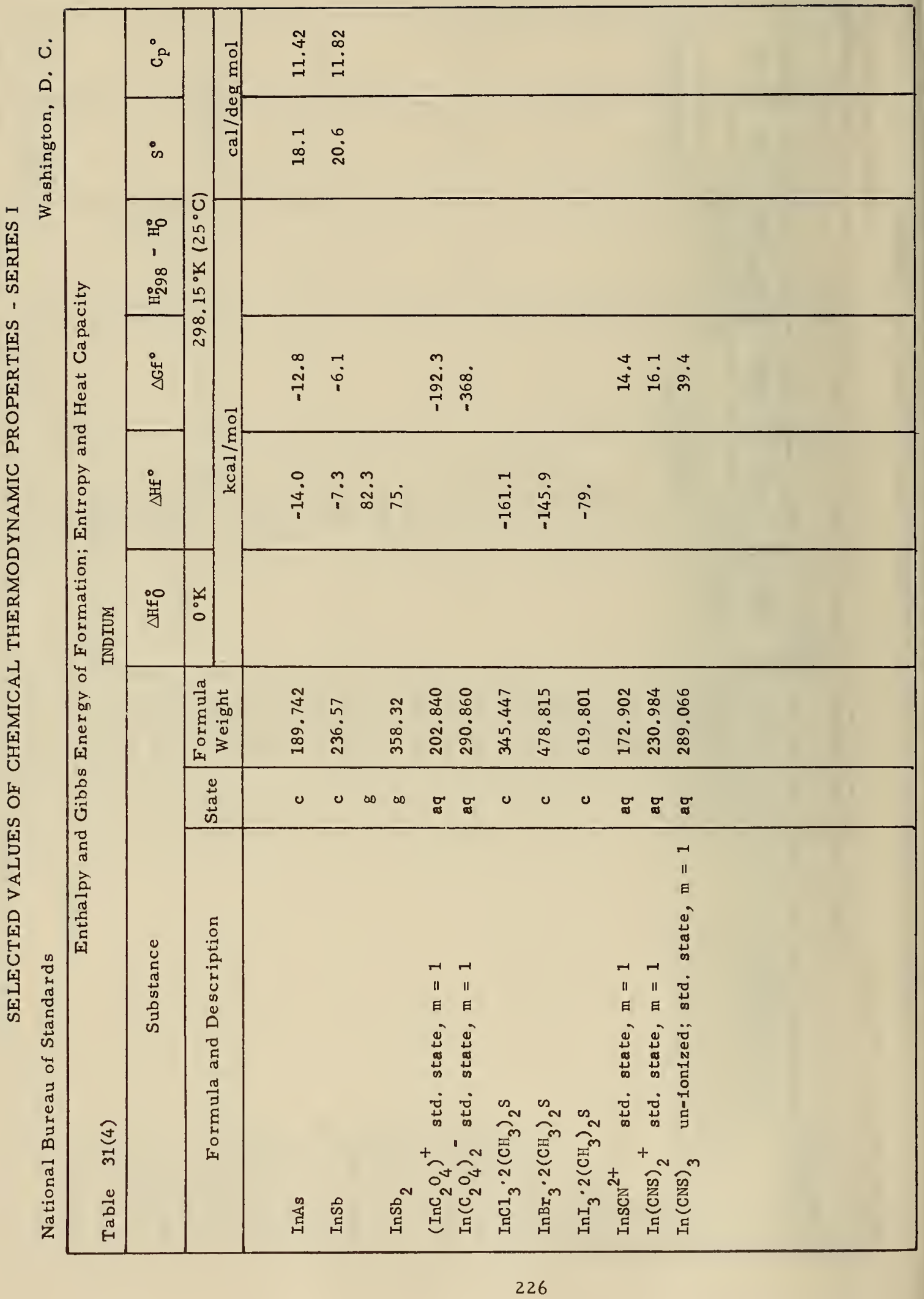




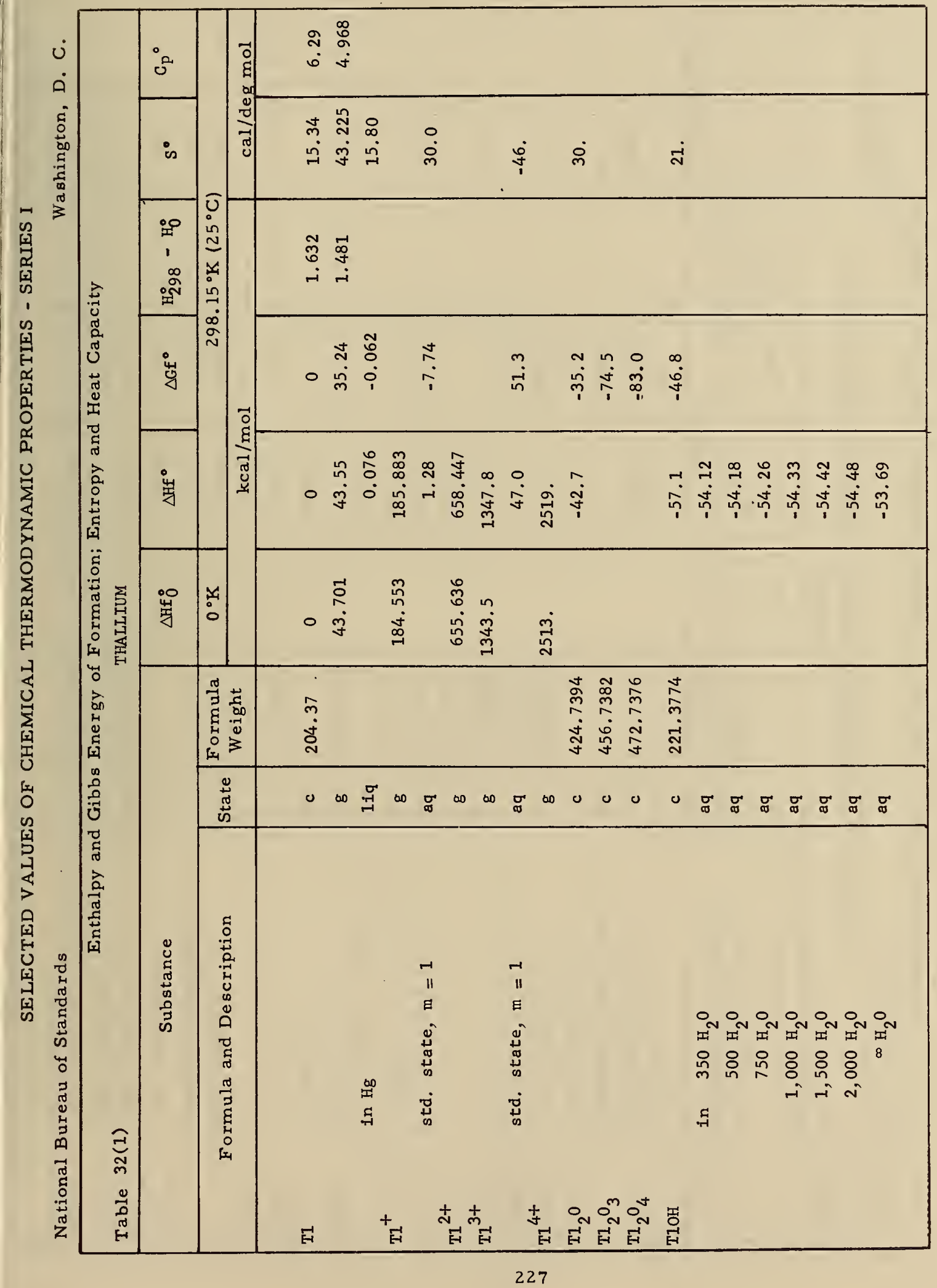




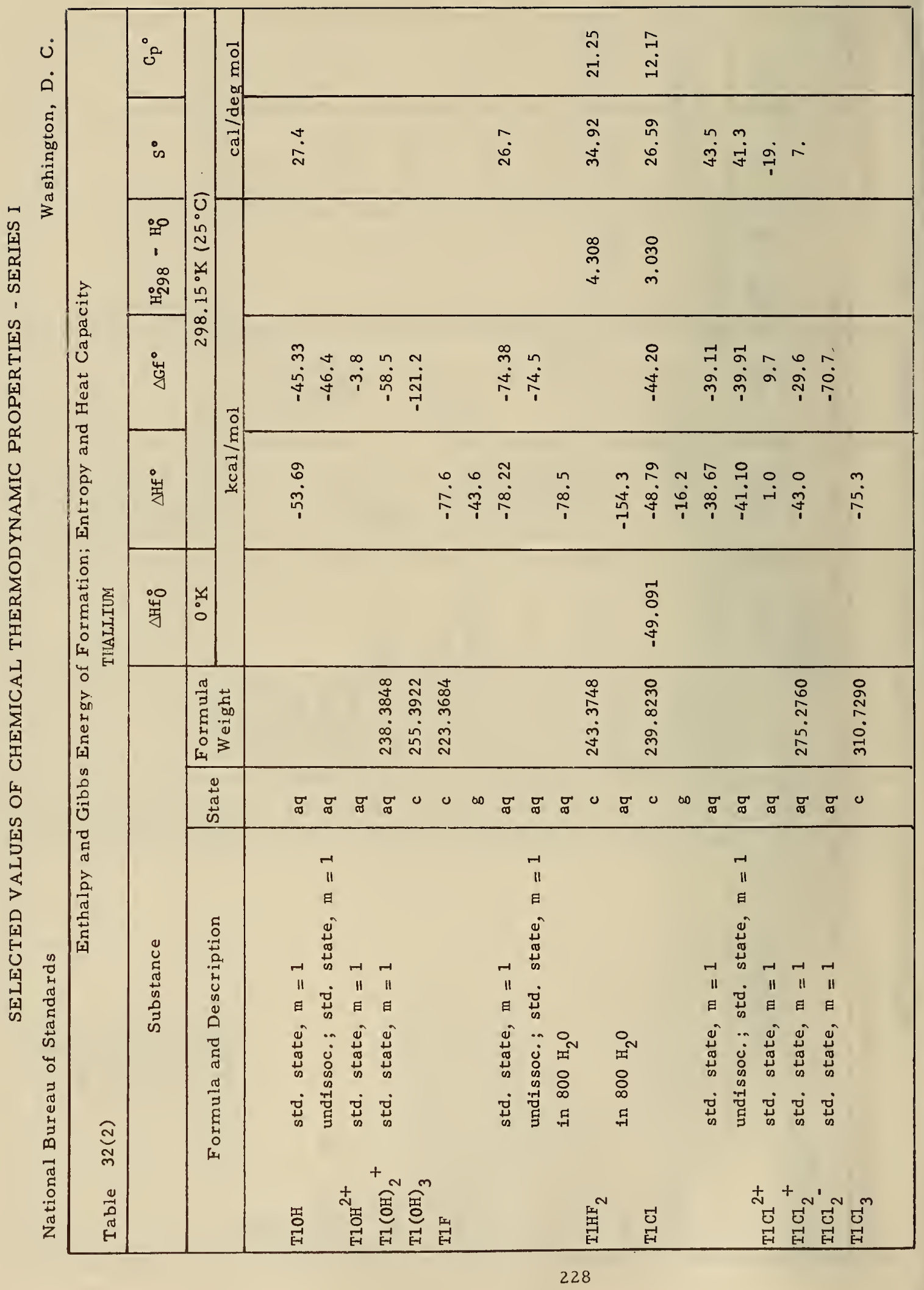




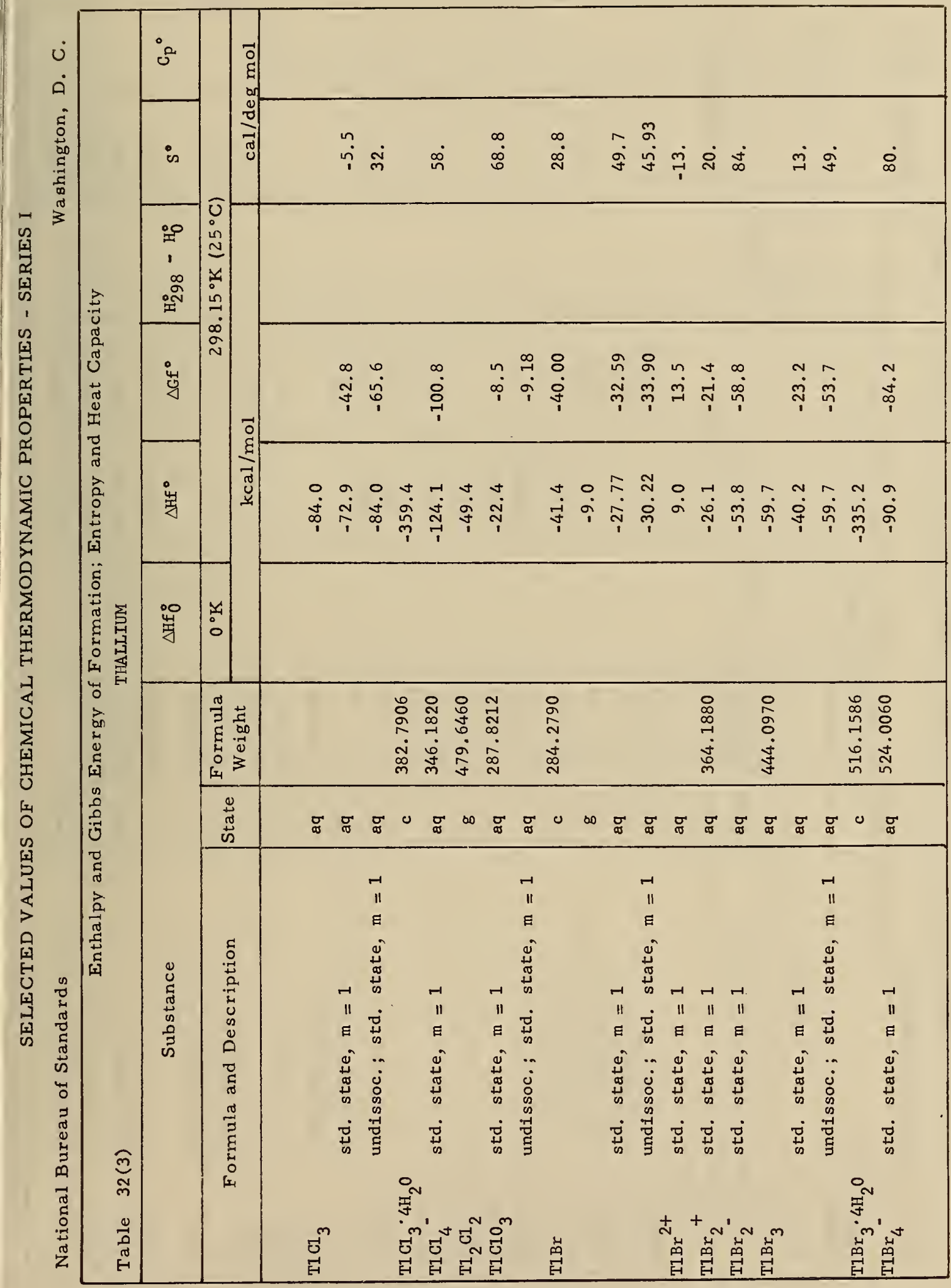


$\mathrm{TlBrO}_{3}$

32

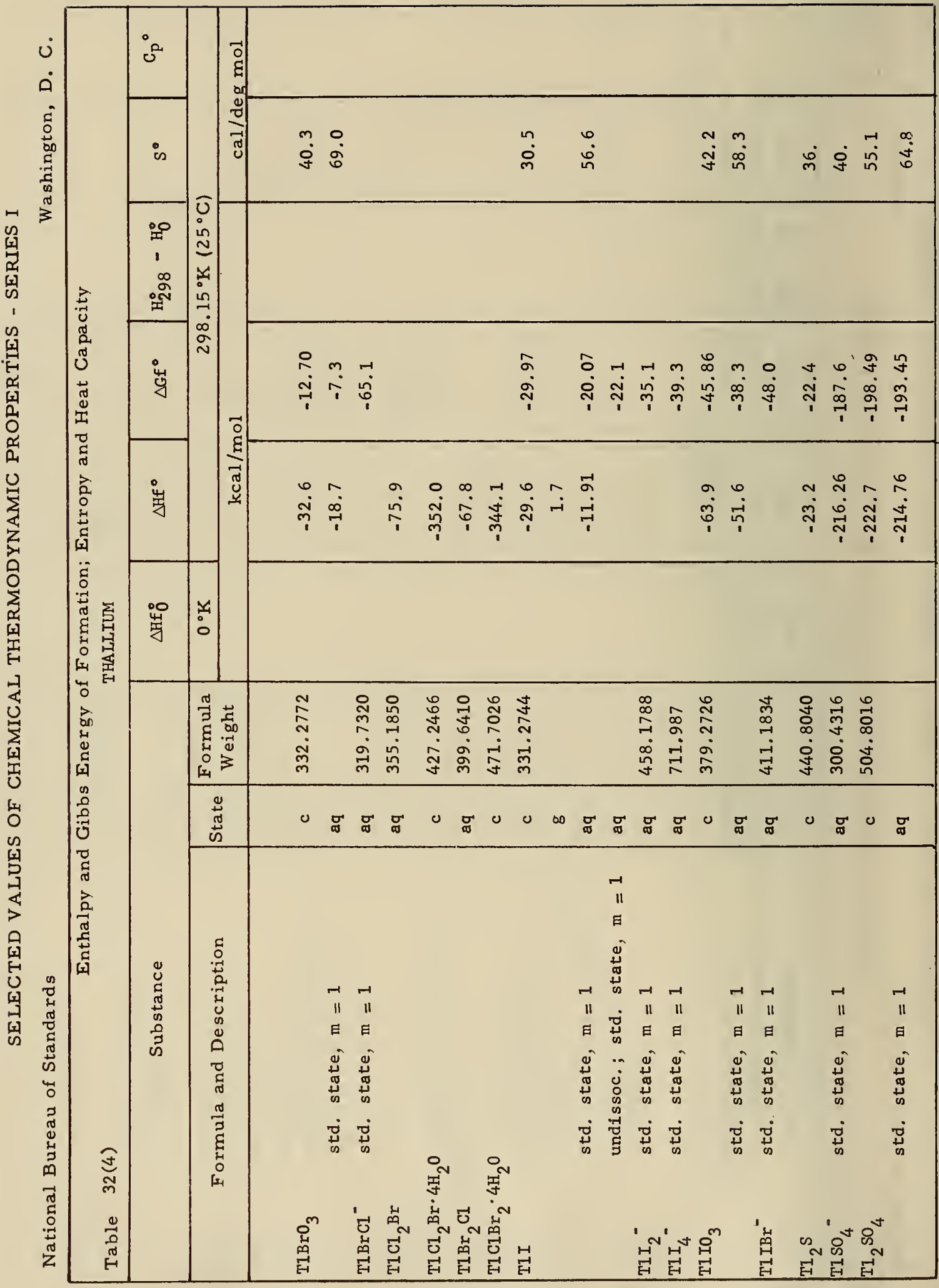


$\underset{32}{\mathrm{Tl}\left(\mathrm{CH}_{3} \mathrm{CO}_{2}\right)}$

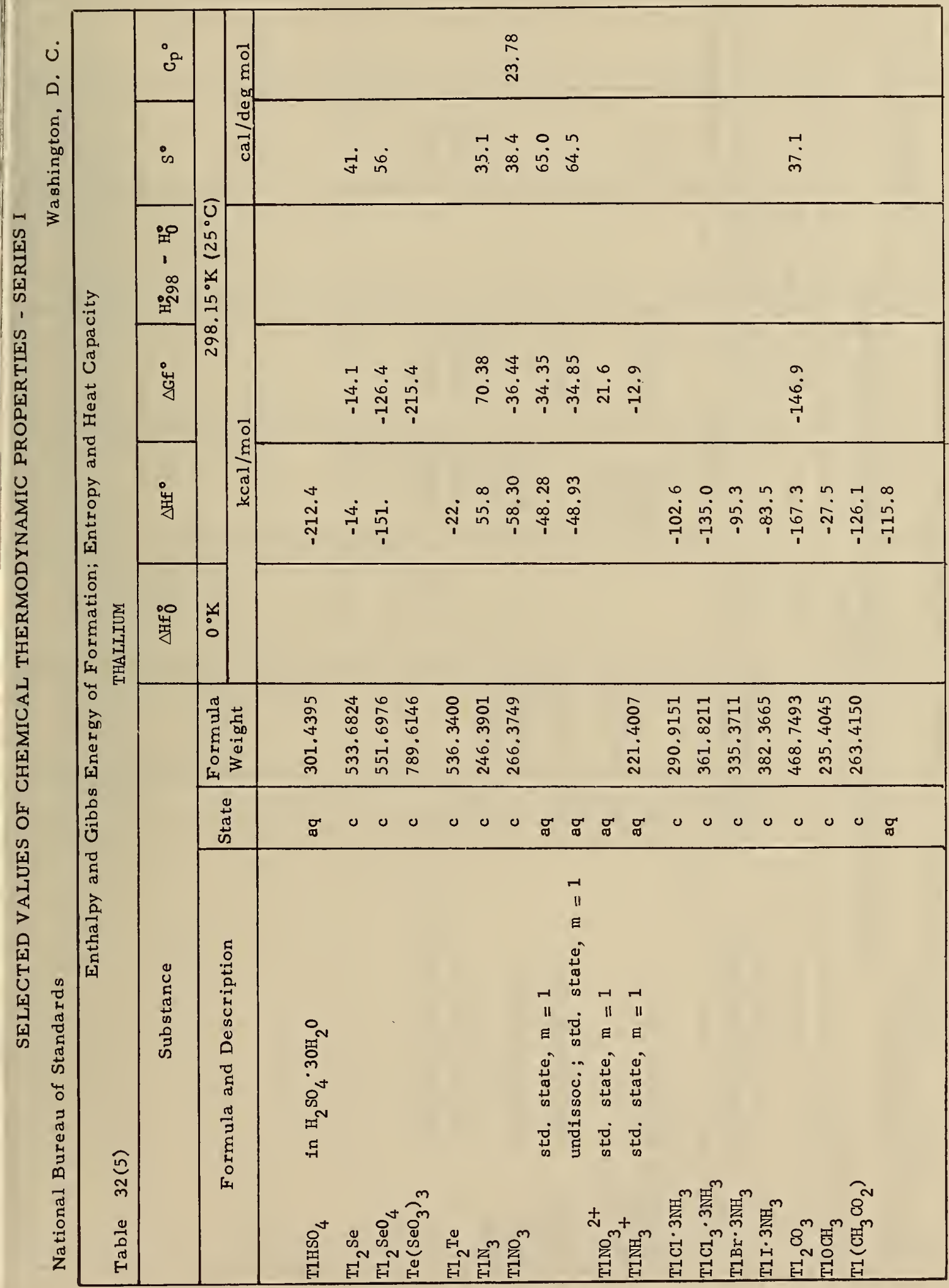


$\mathrm{T} 1\left(\mathrm{CH}_{3} \mathrm{CO}_{2}\right) \underset{32}{--} \mathrm{T} 1 \mathrm{CNS}$

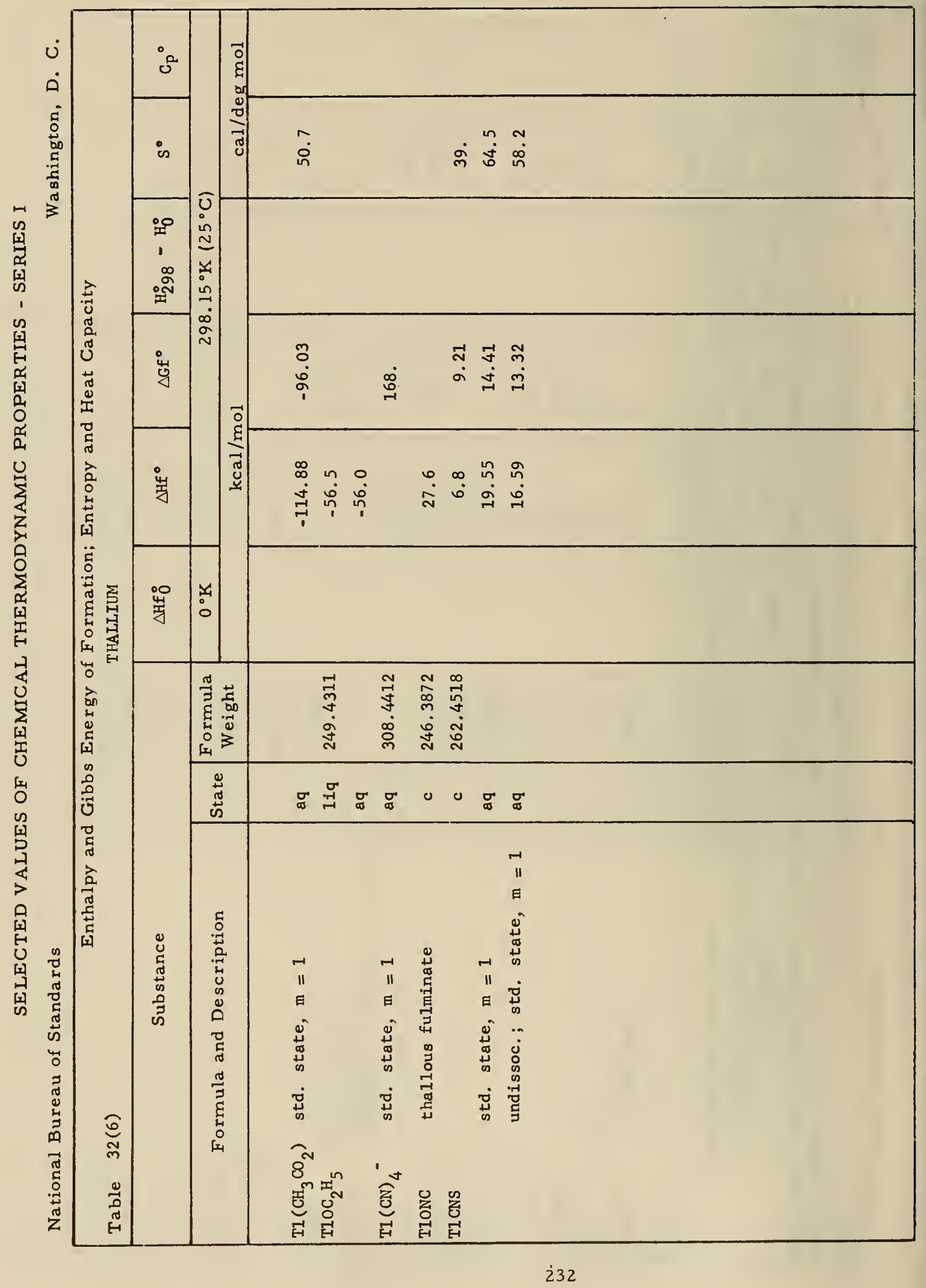




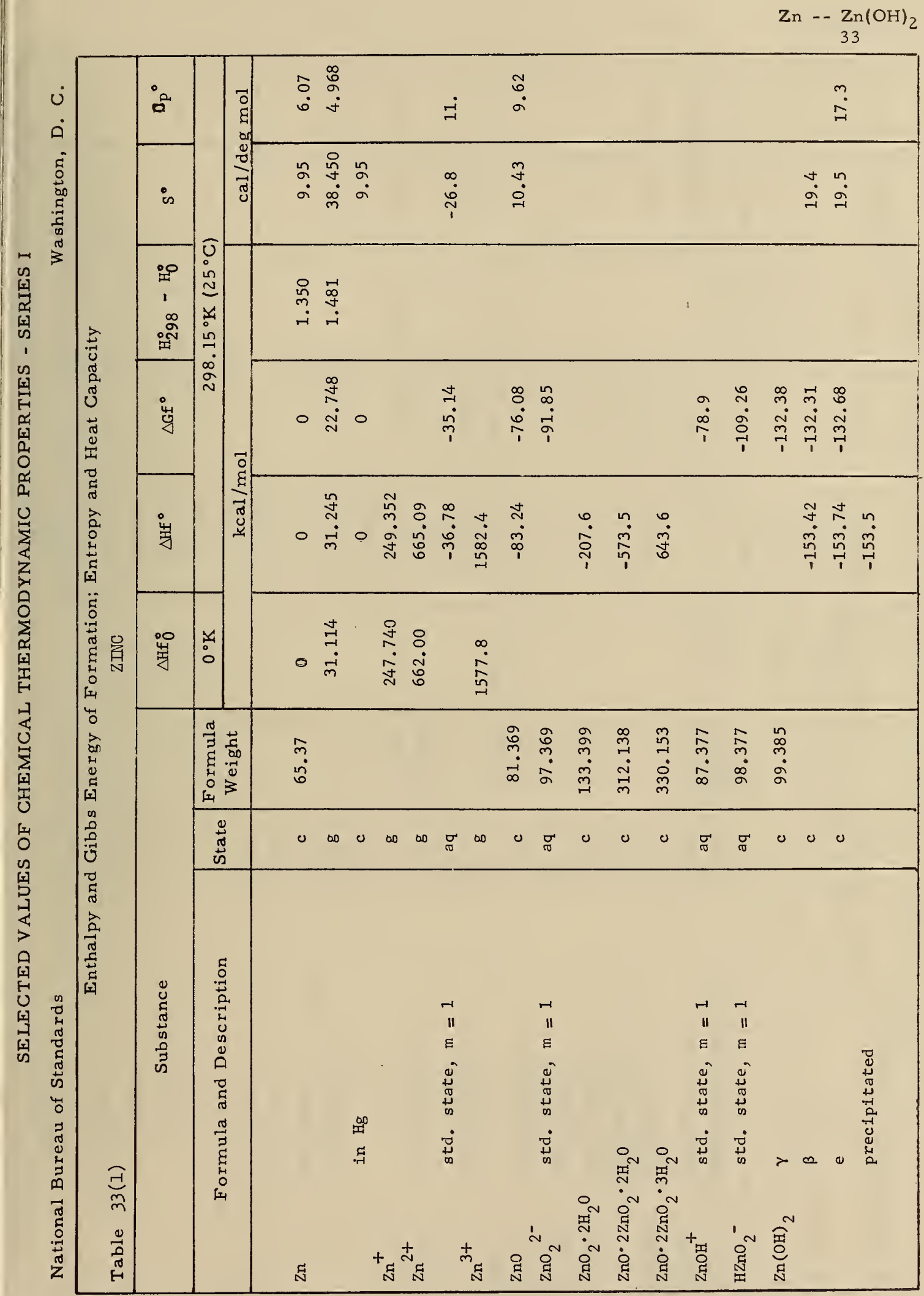




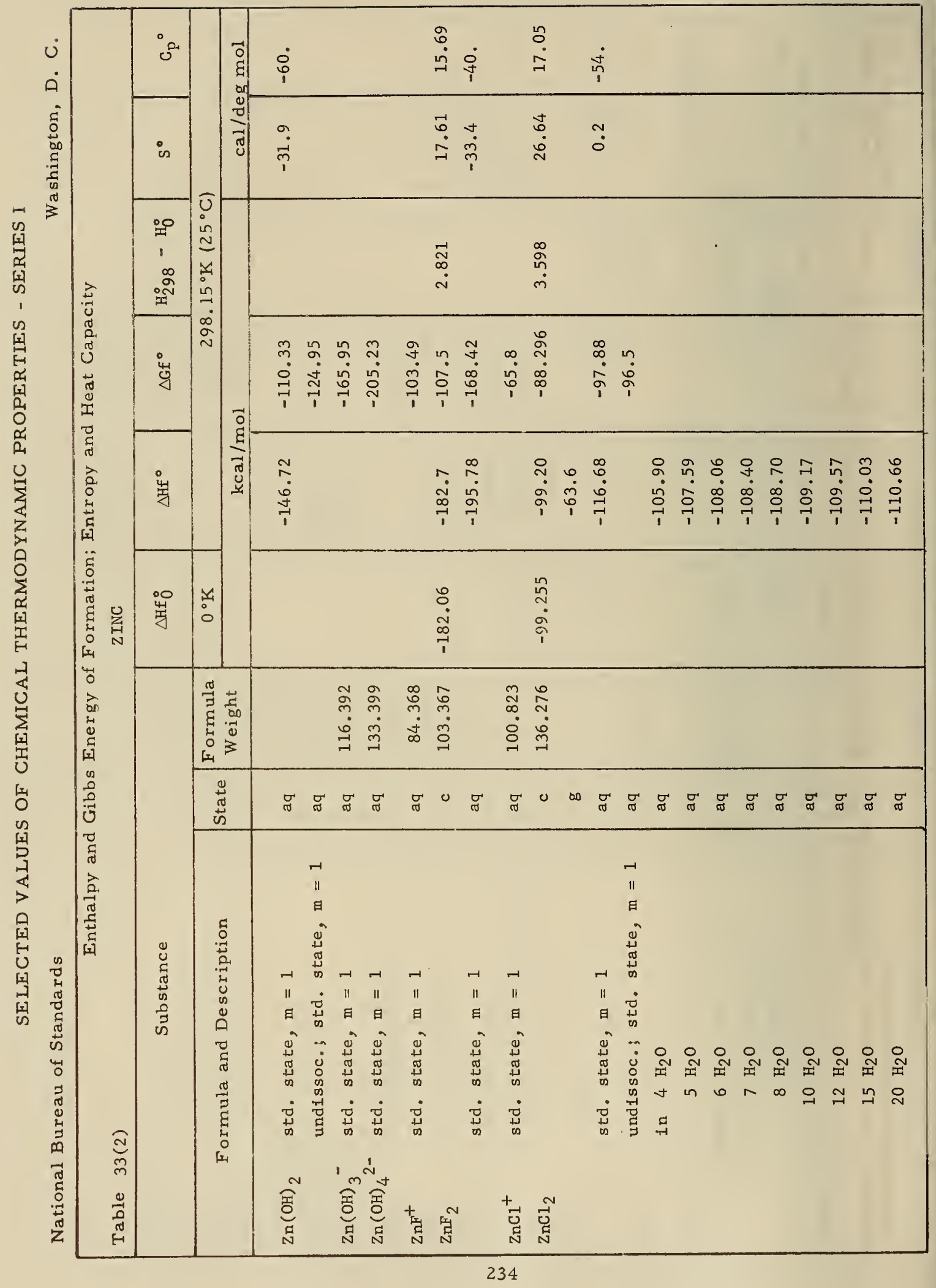


$\mathrm{Zn}\left(\mathrm{ClO}_{4}\right)_{2}$

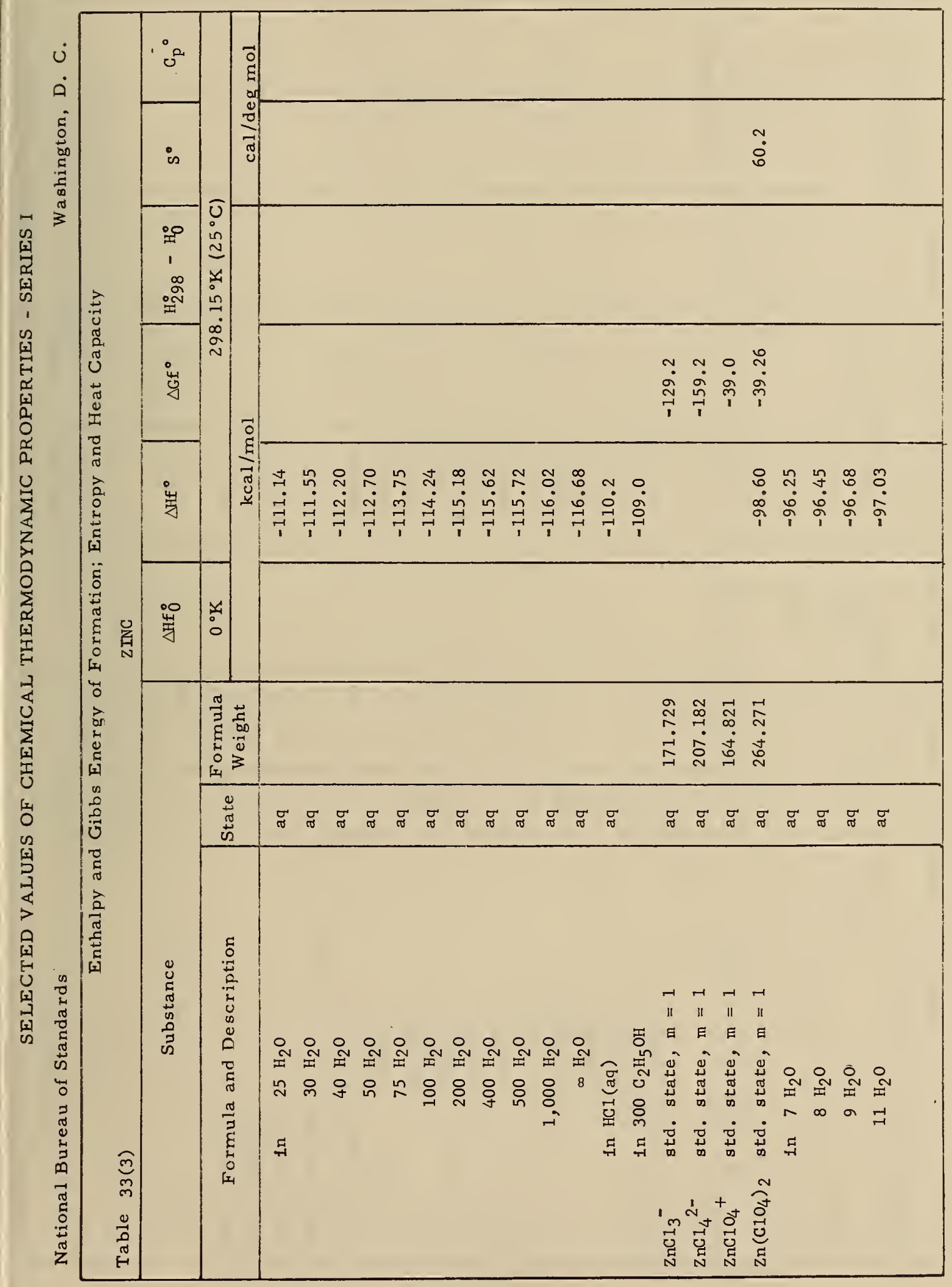


$\mathrm{Zn}\left(\mathrm{ClO}_{4}\right)_{2}$

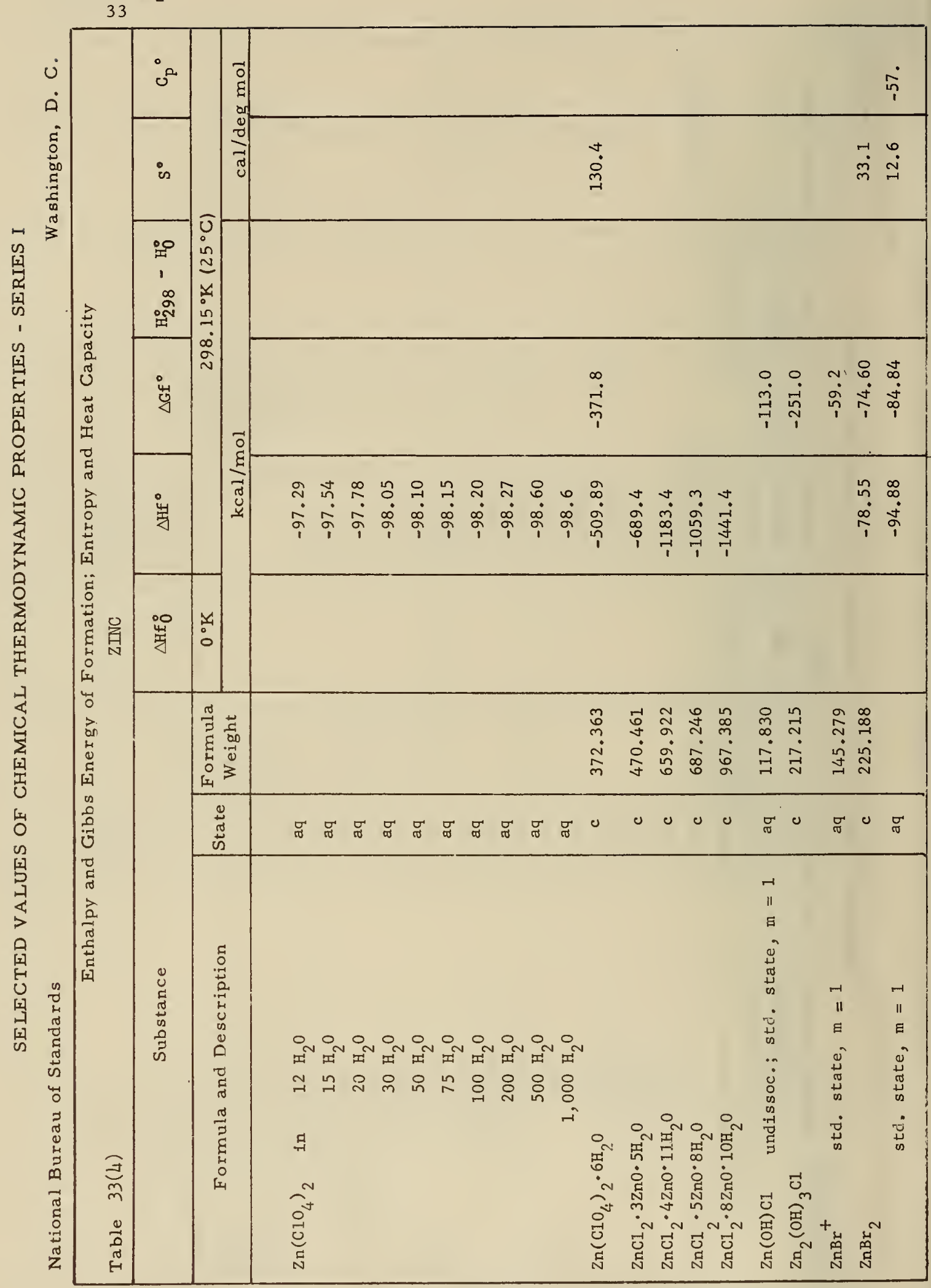




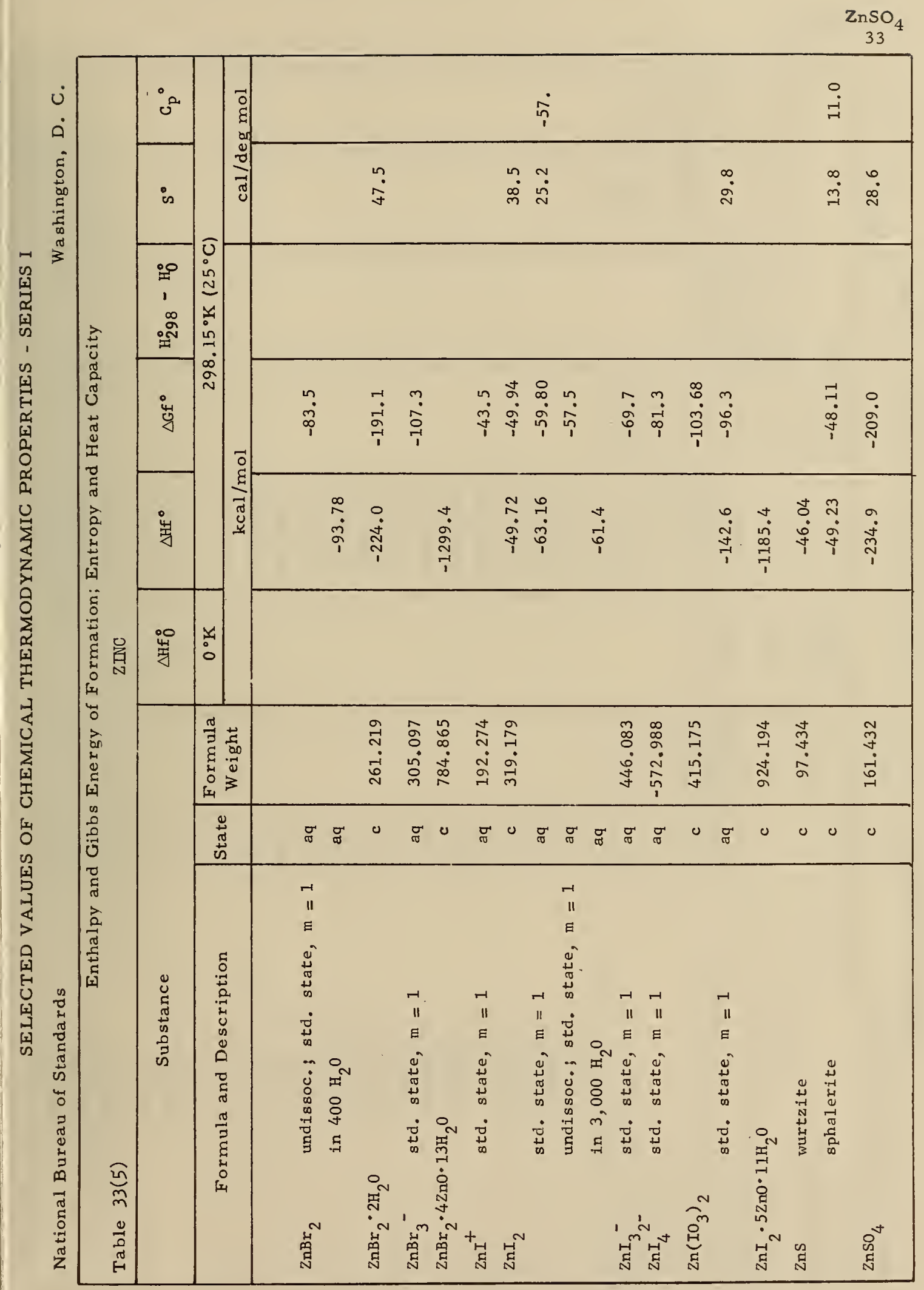




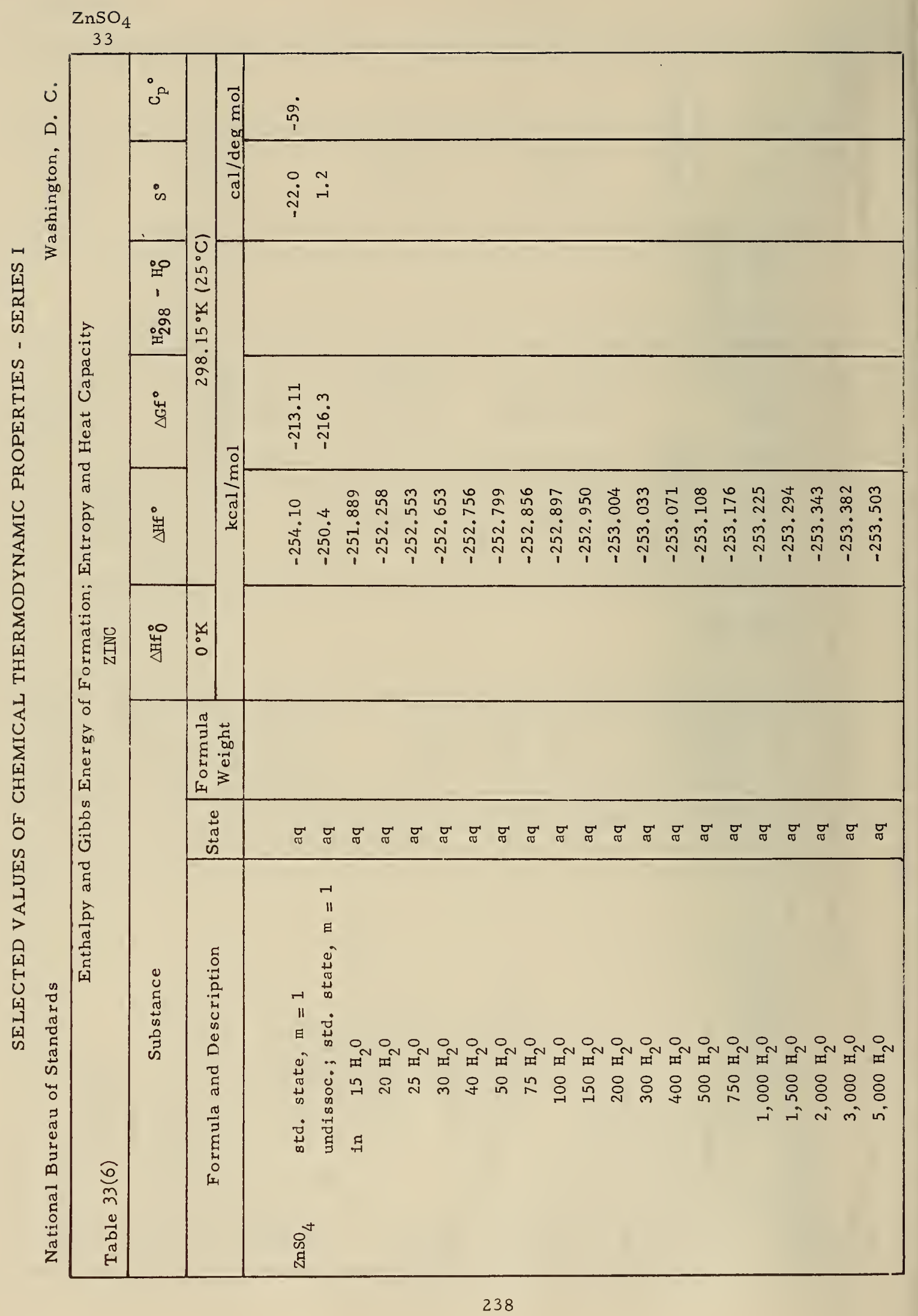




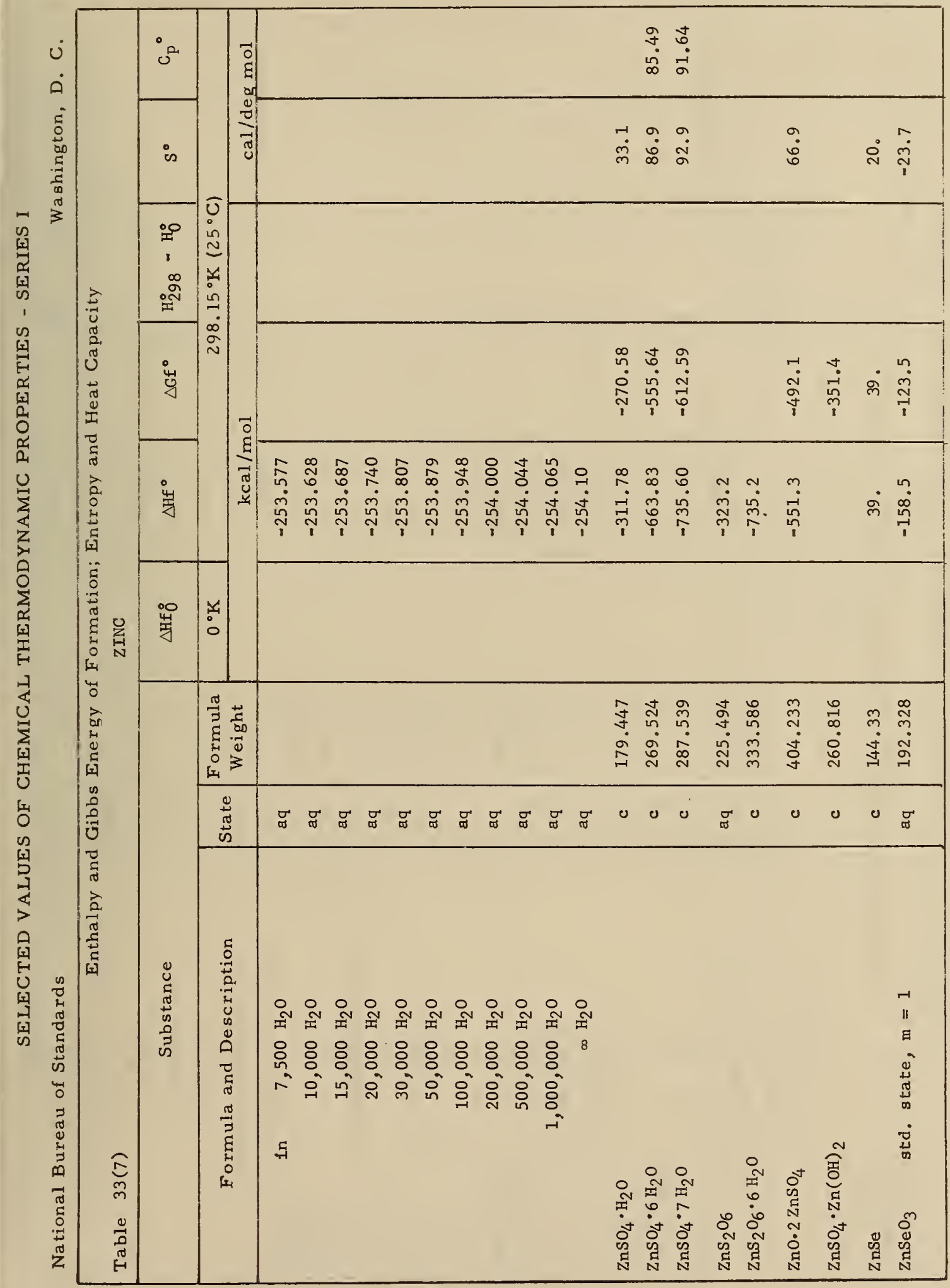




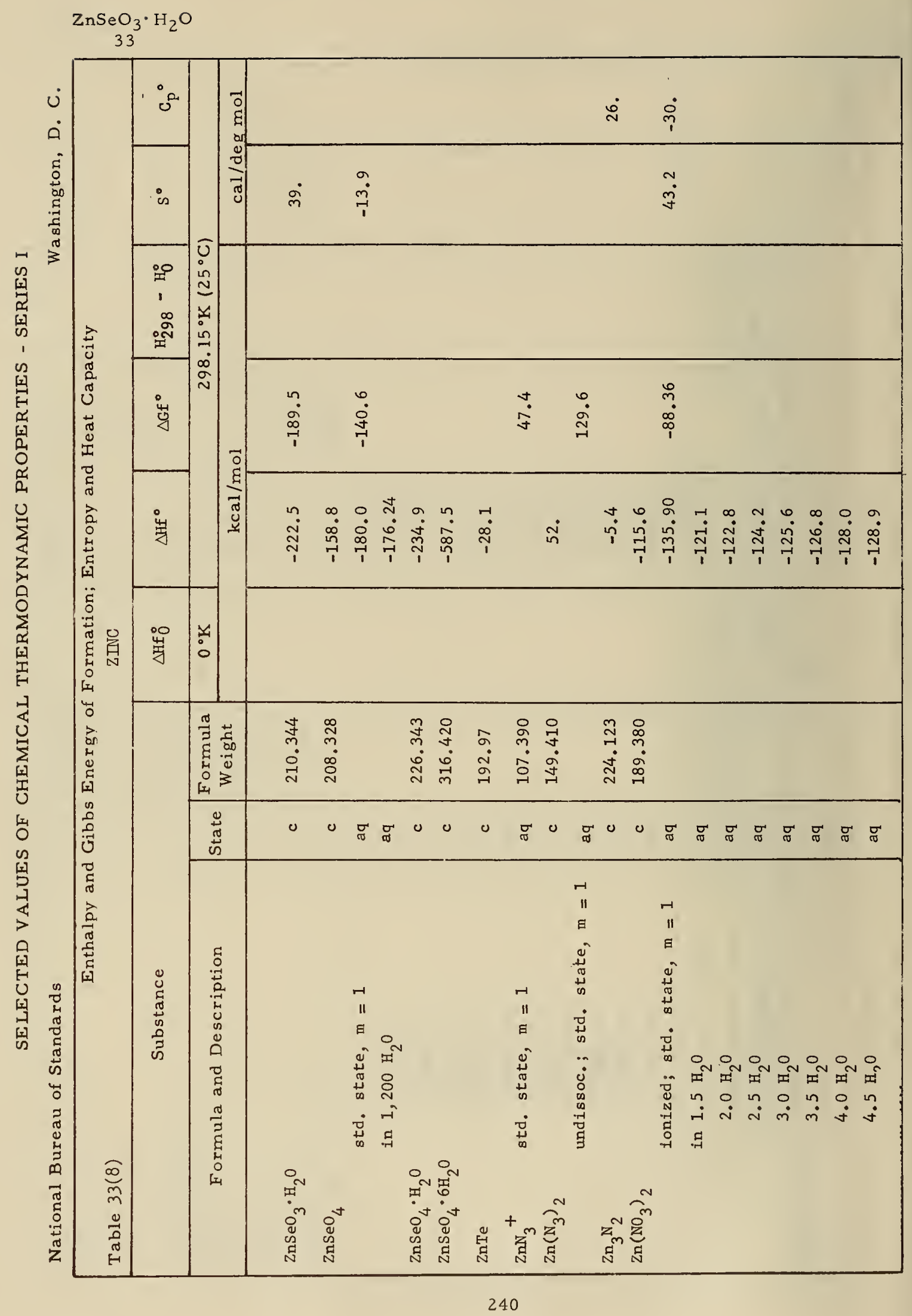




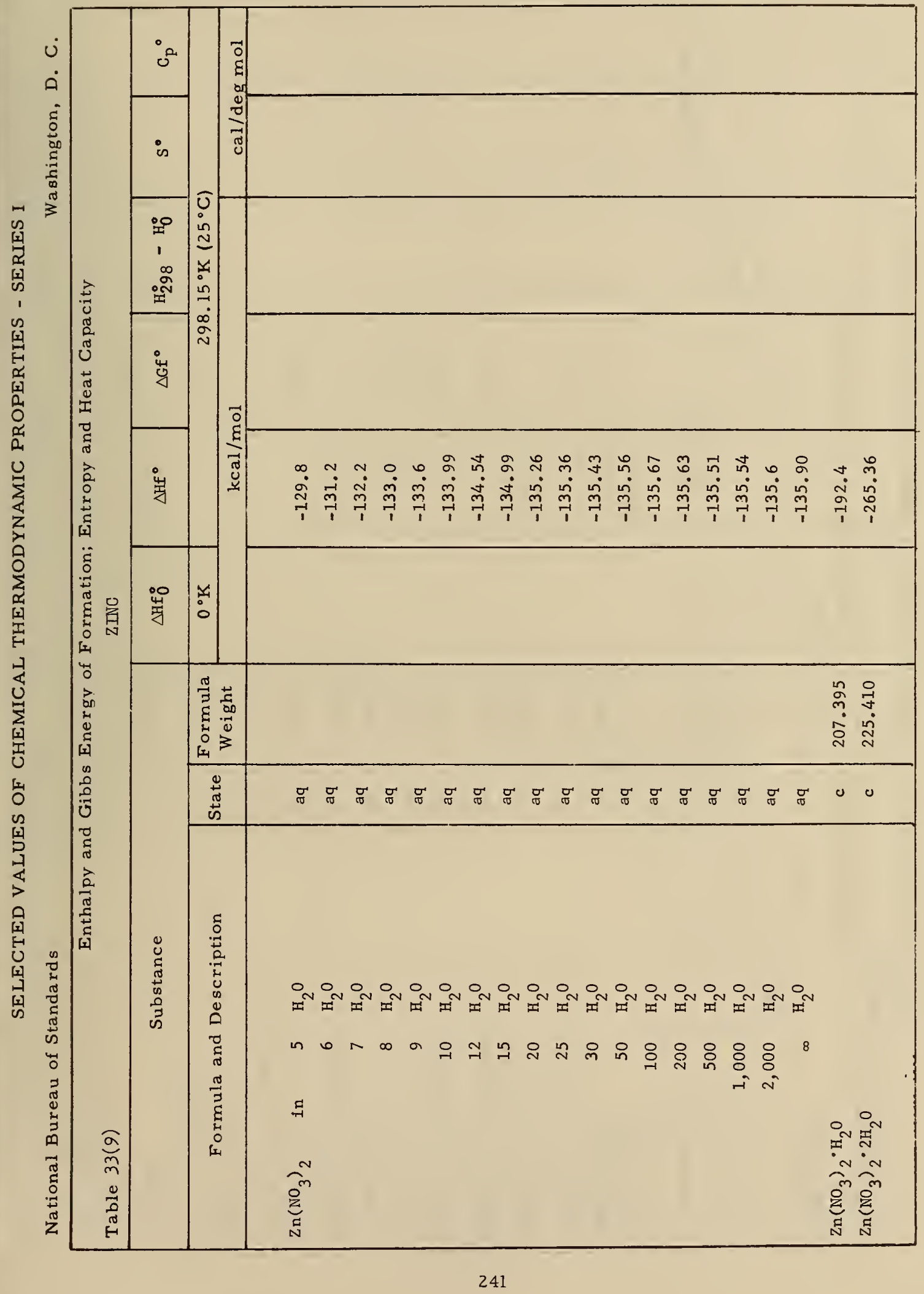




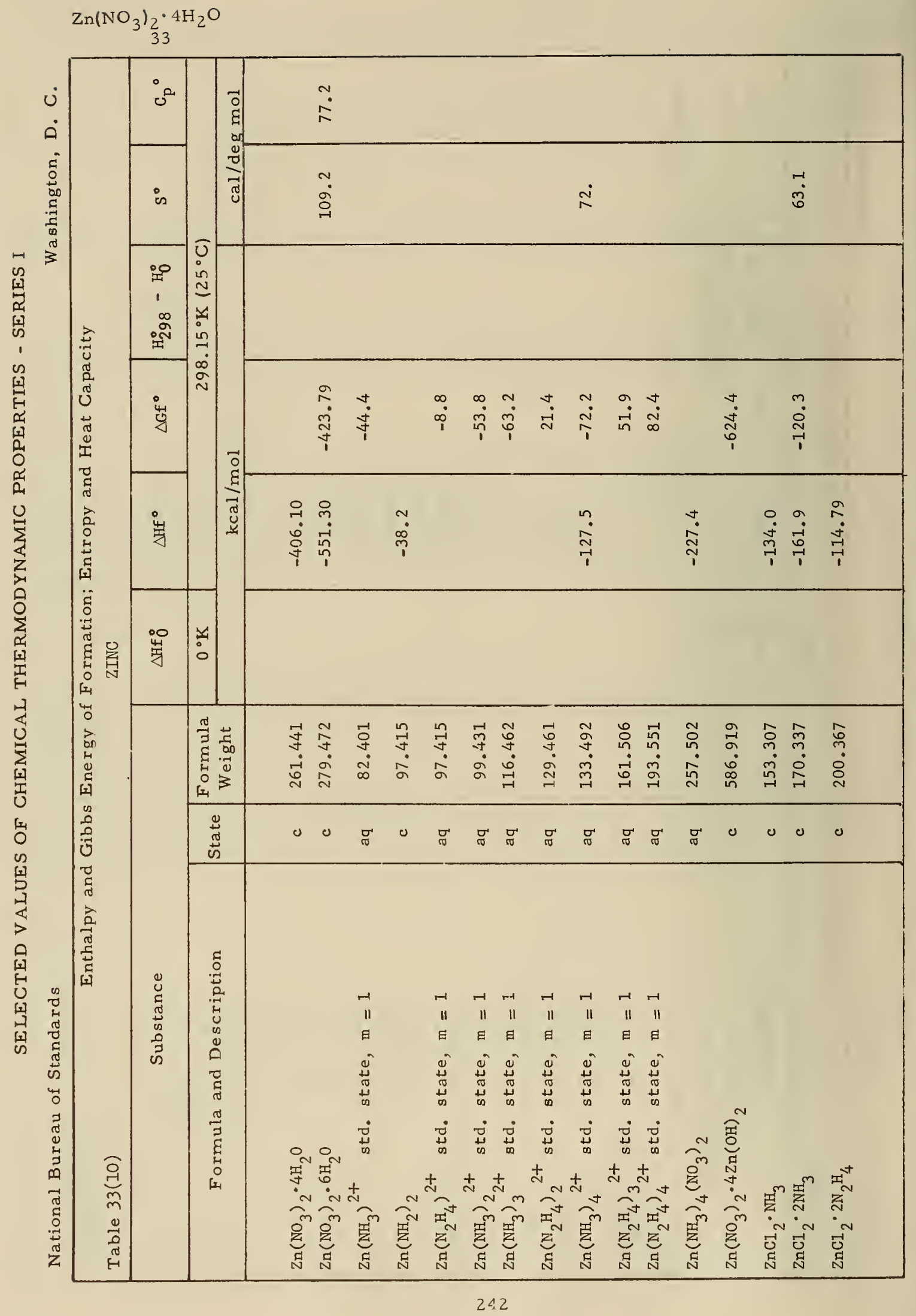




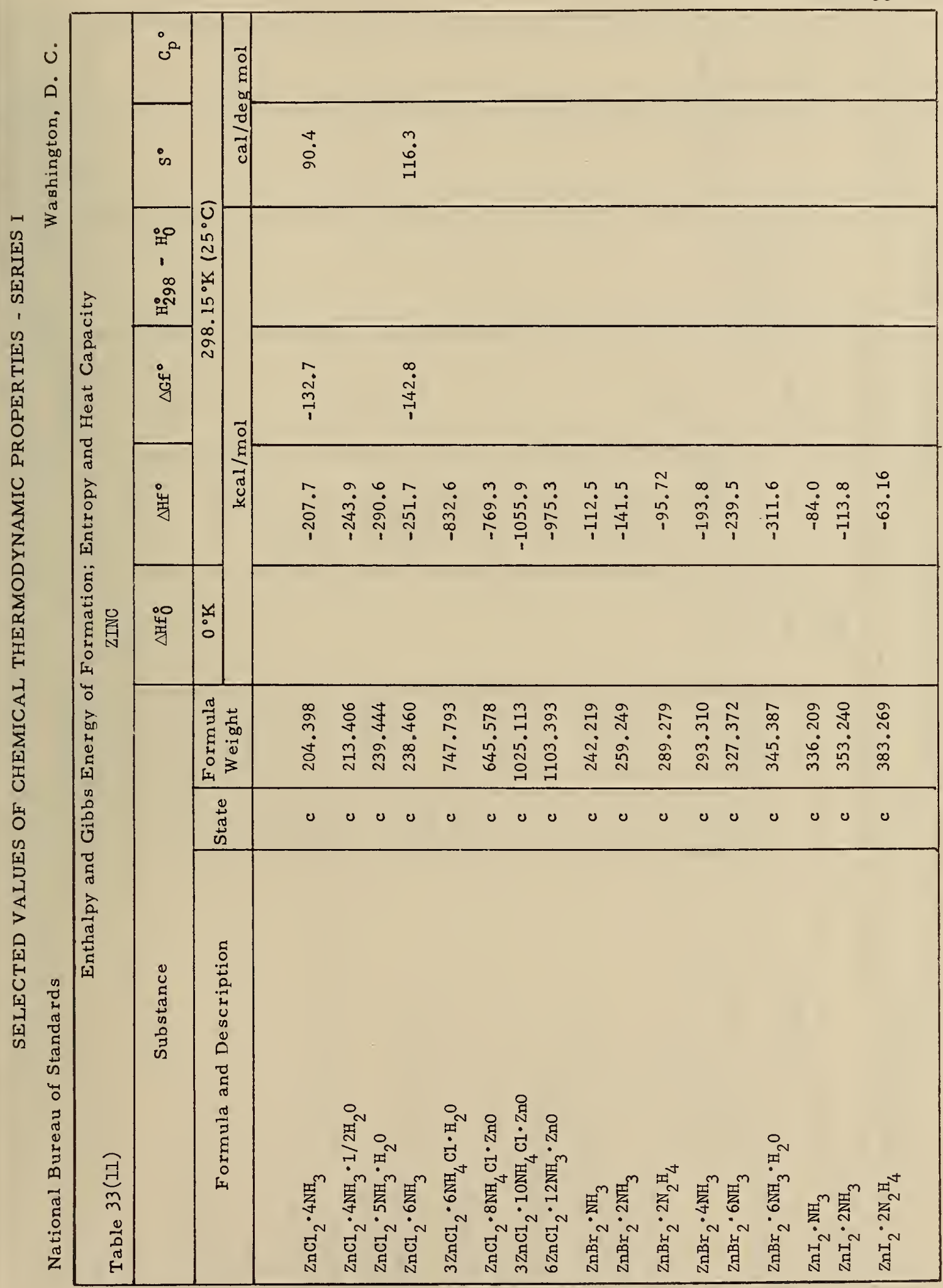




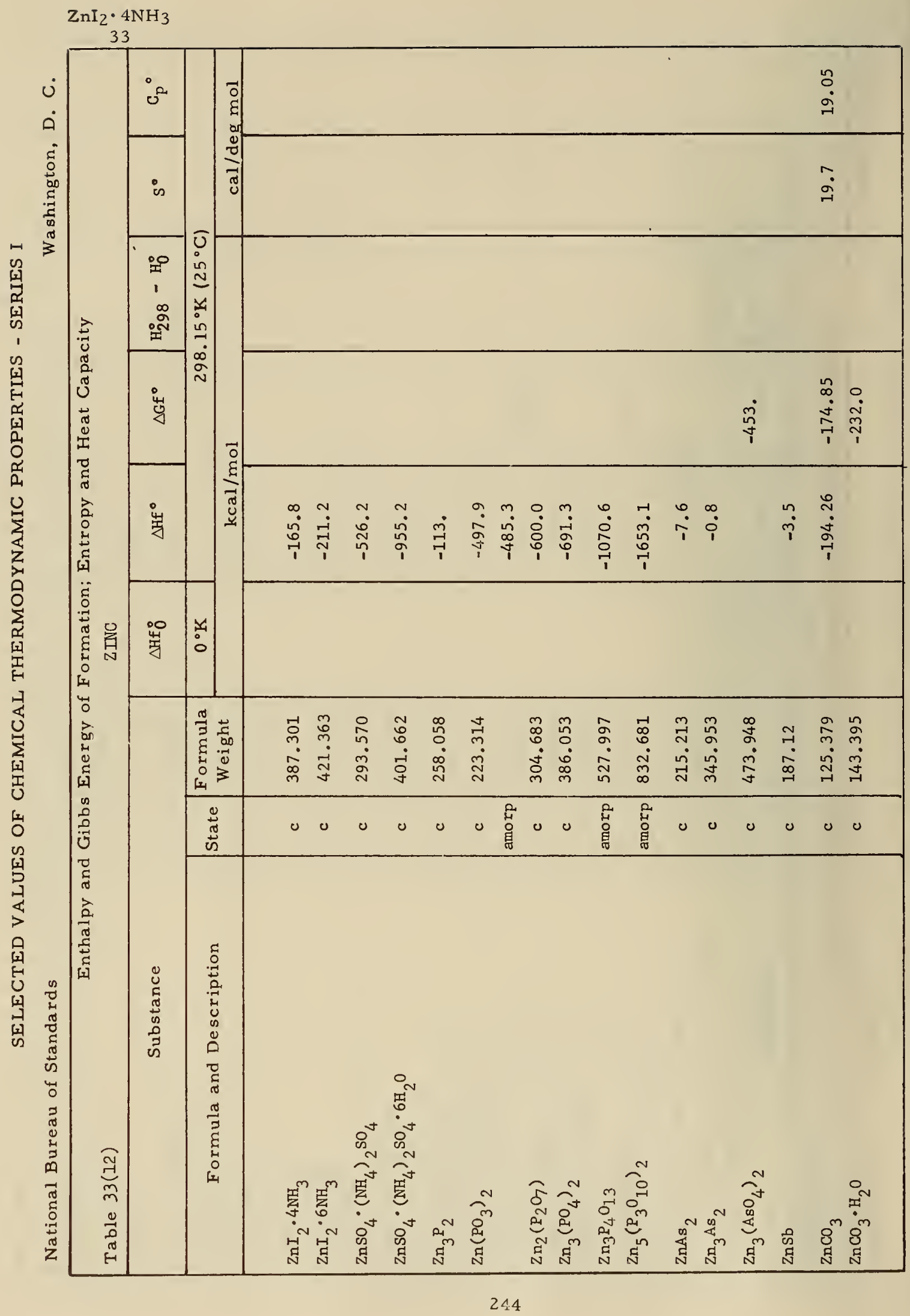


$\mathrm{Zn}\left(\mathrm{C}_{2} \mathrm{H}_{3} \mathrm{O}_{2}\right)_{2}$

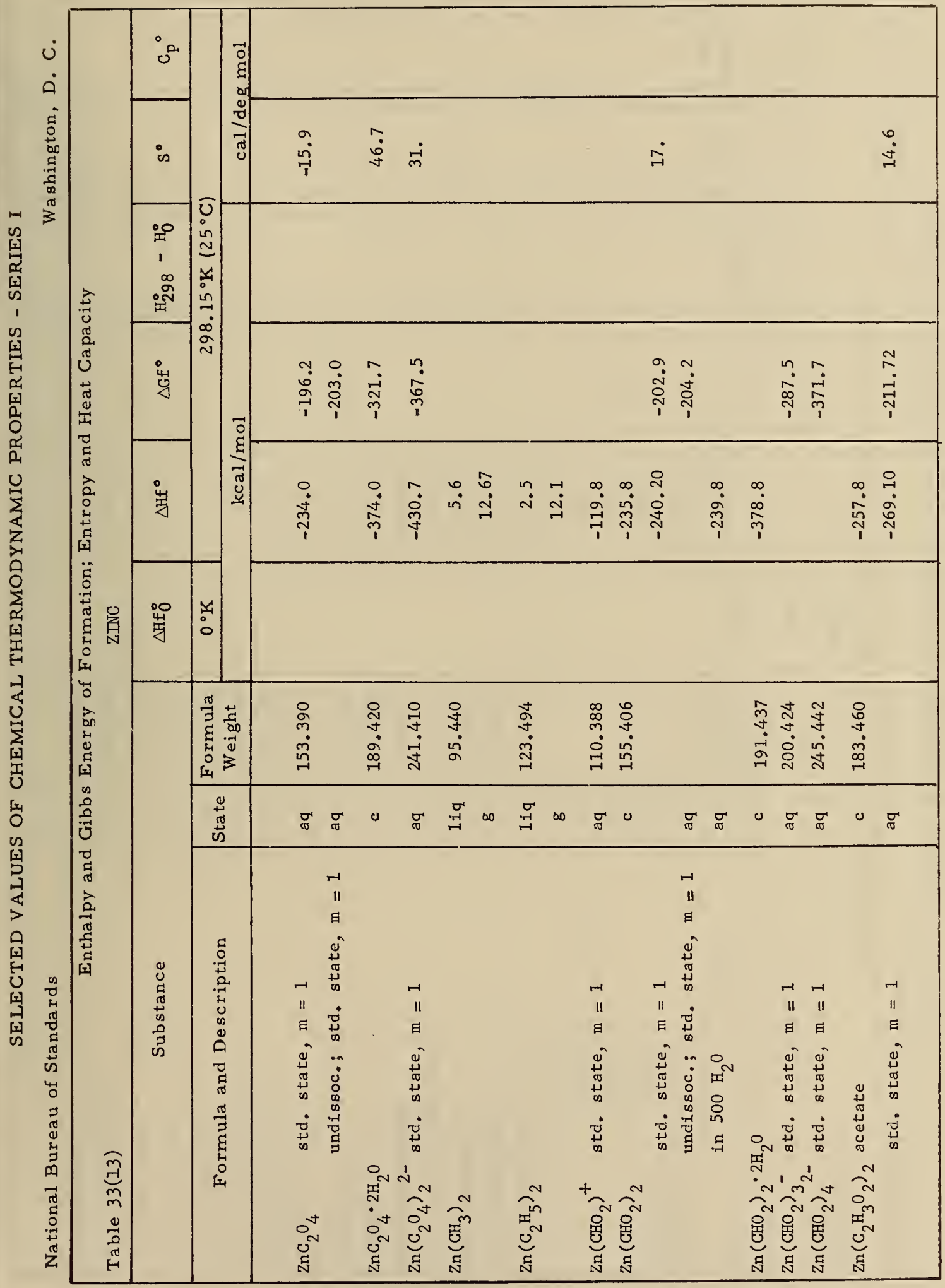




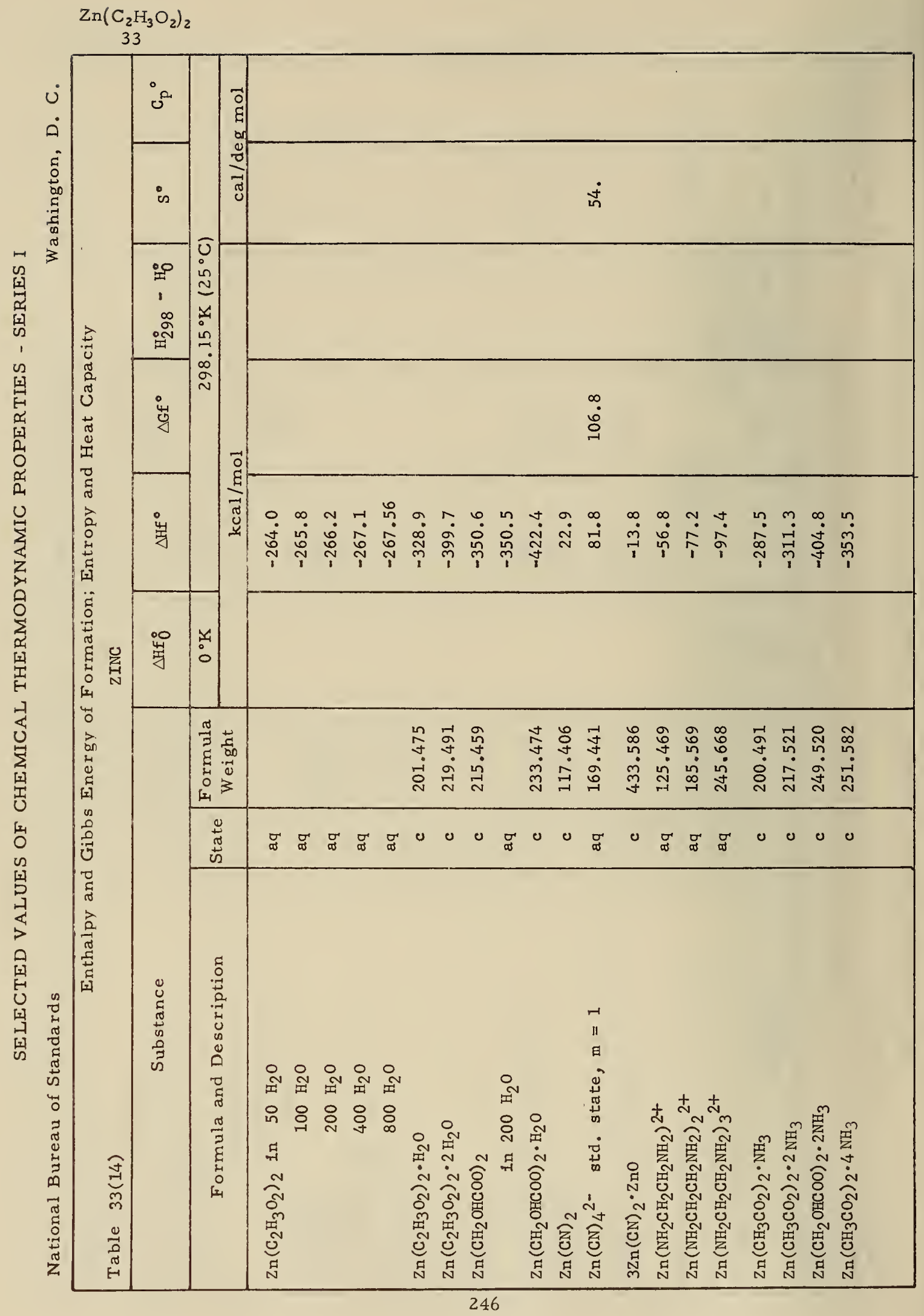




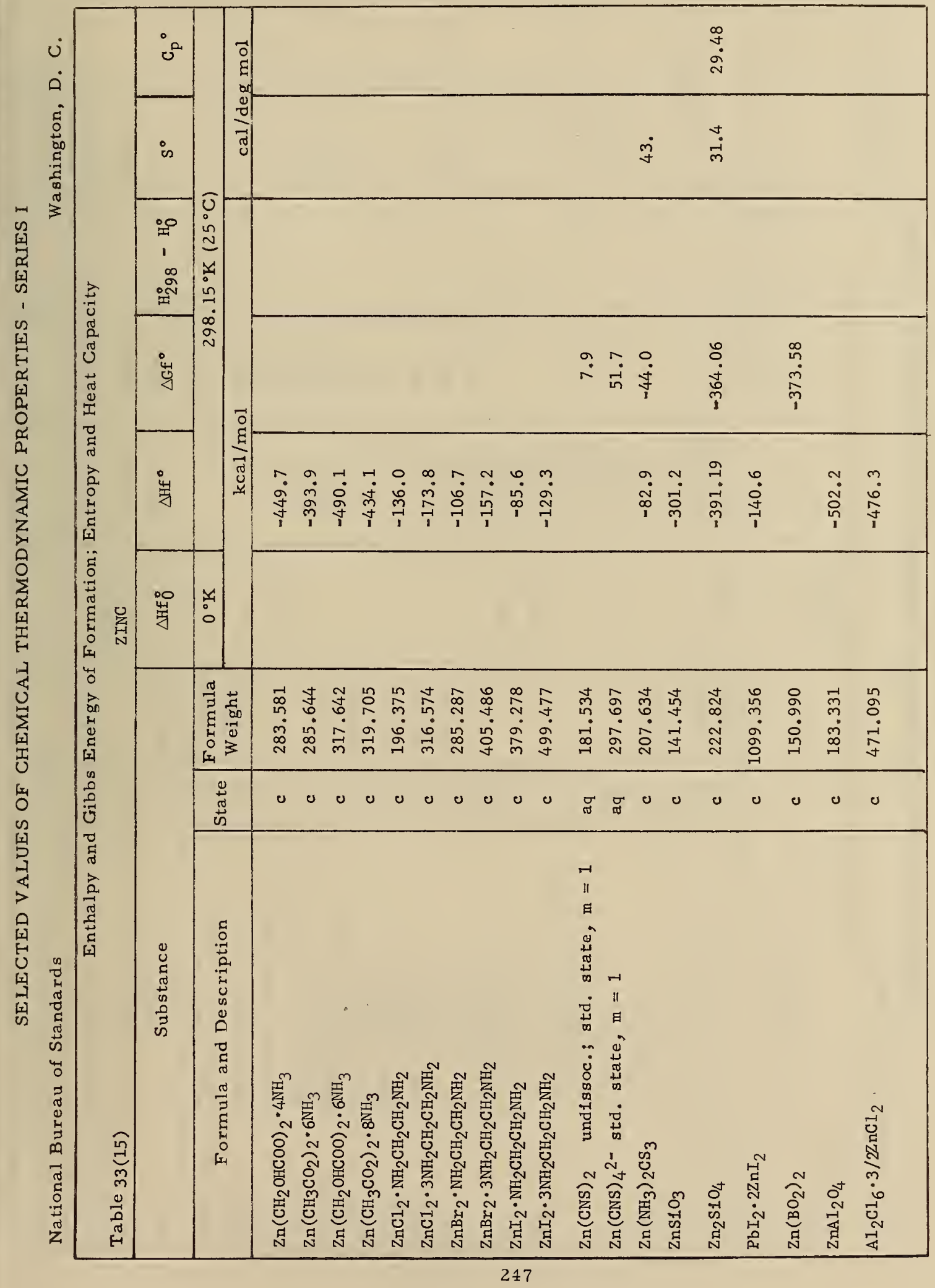




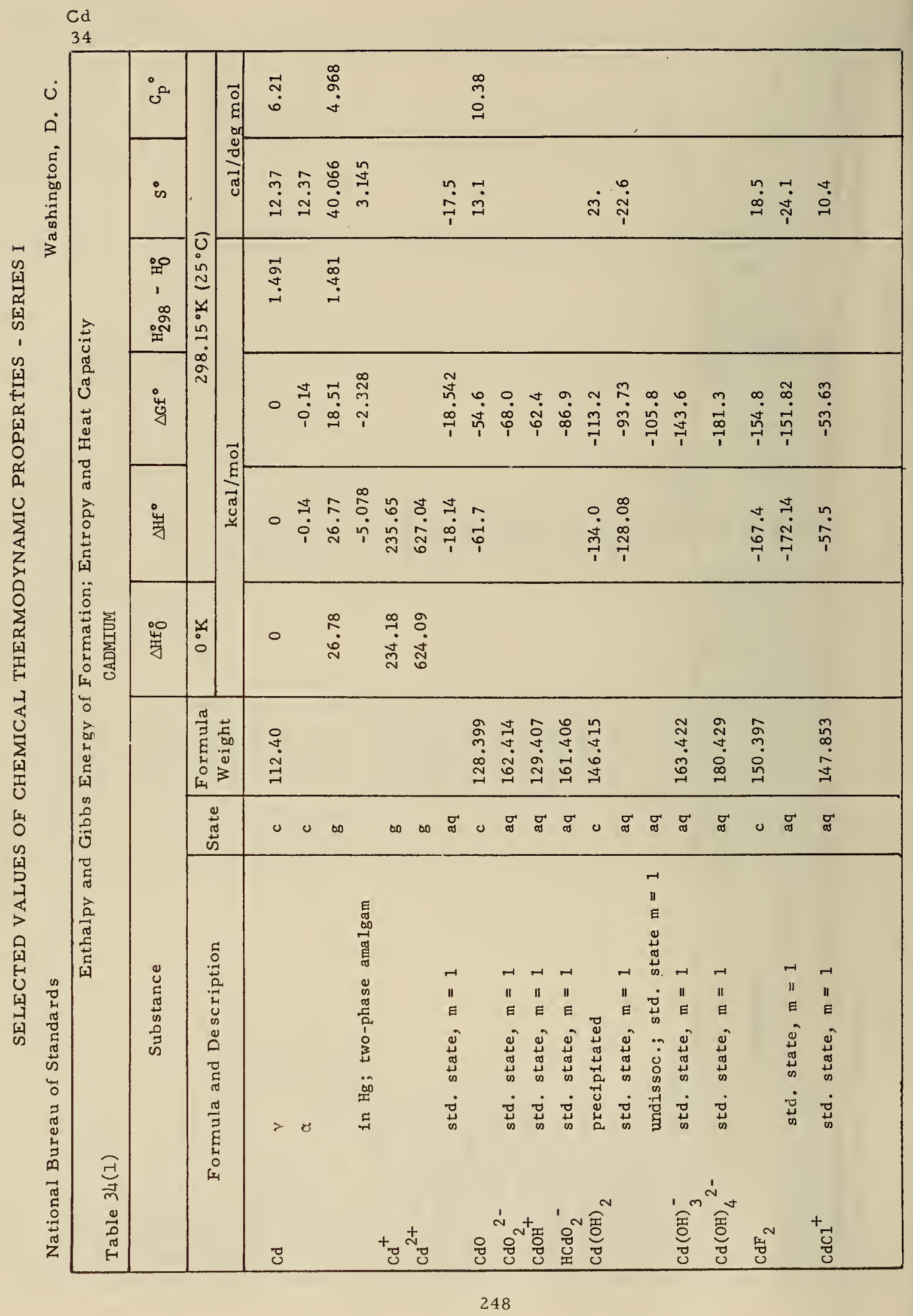


$\mathrm{CdCl}_{3}{ }^{-}$

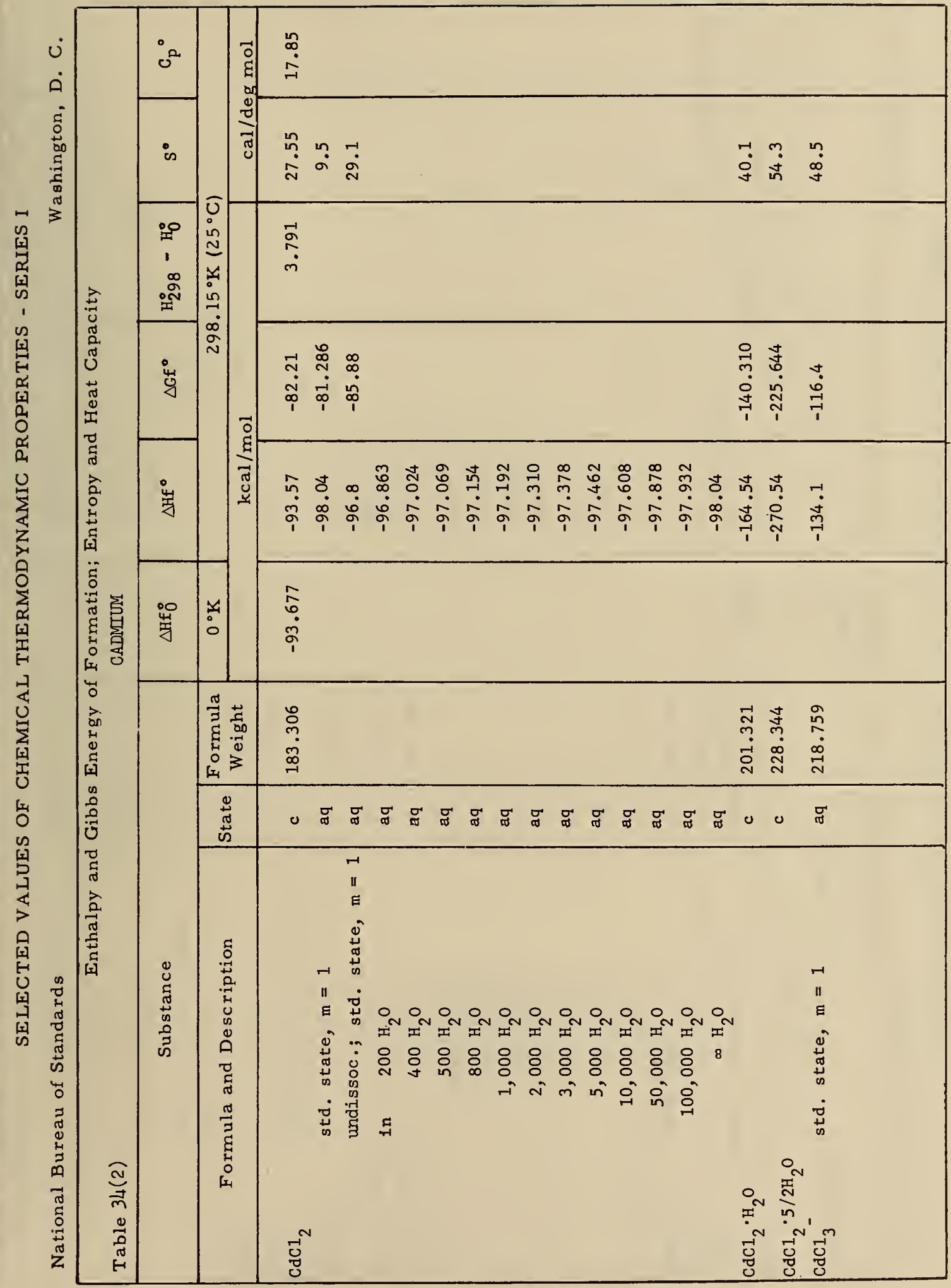




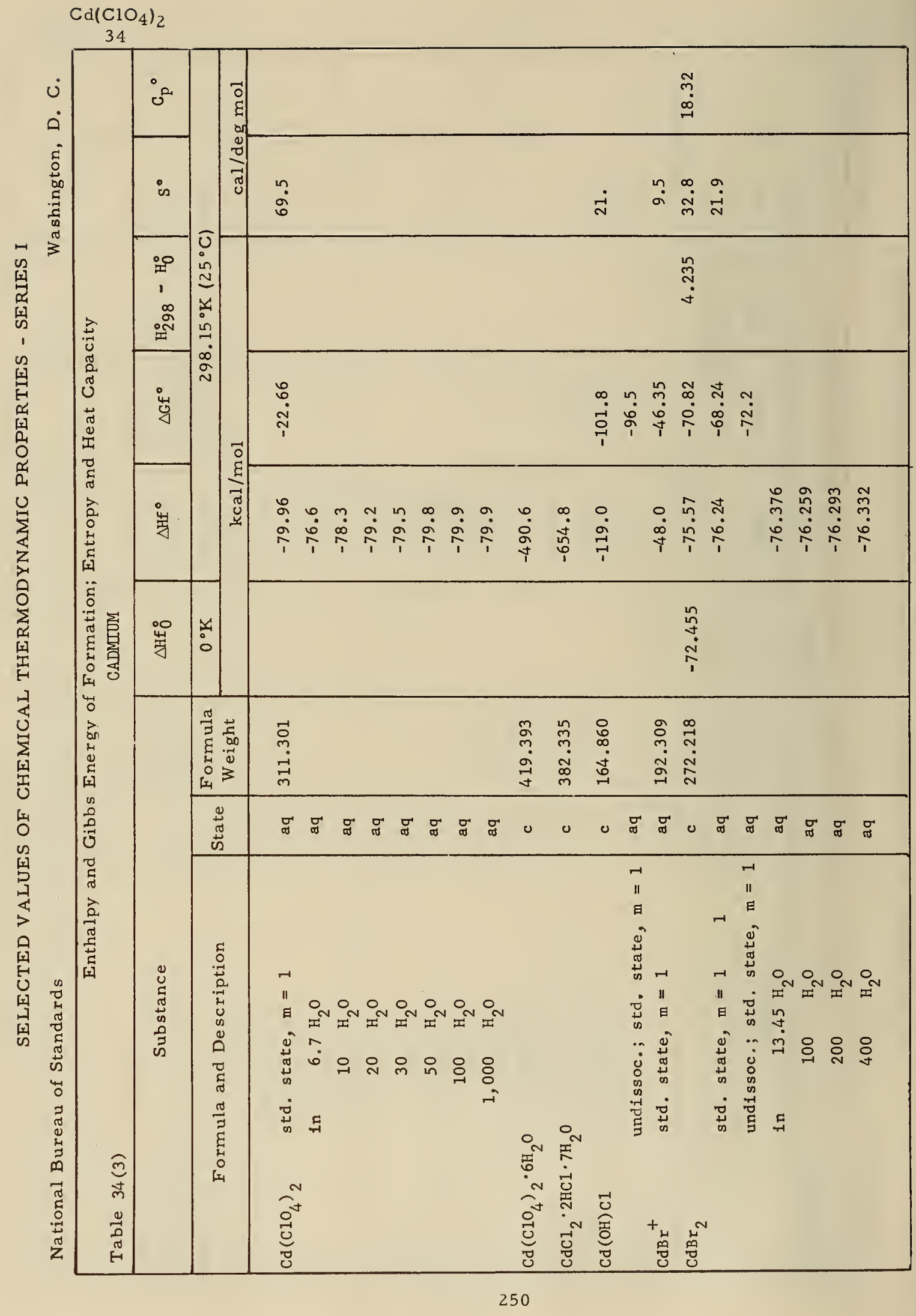




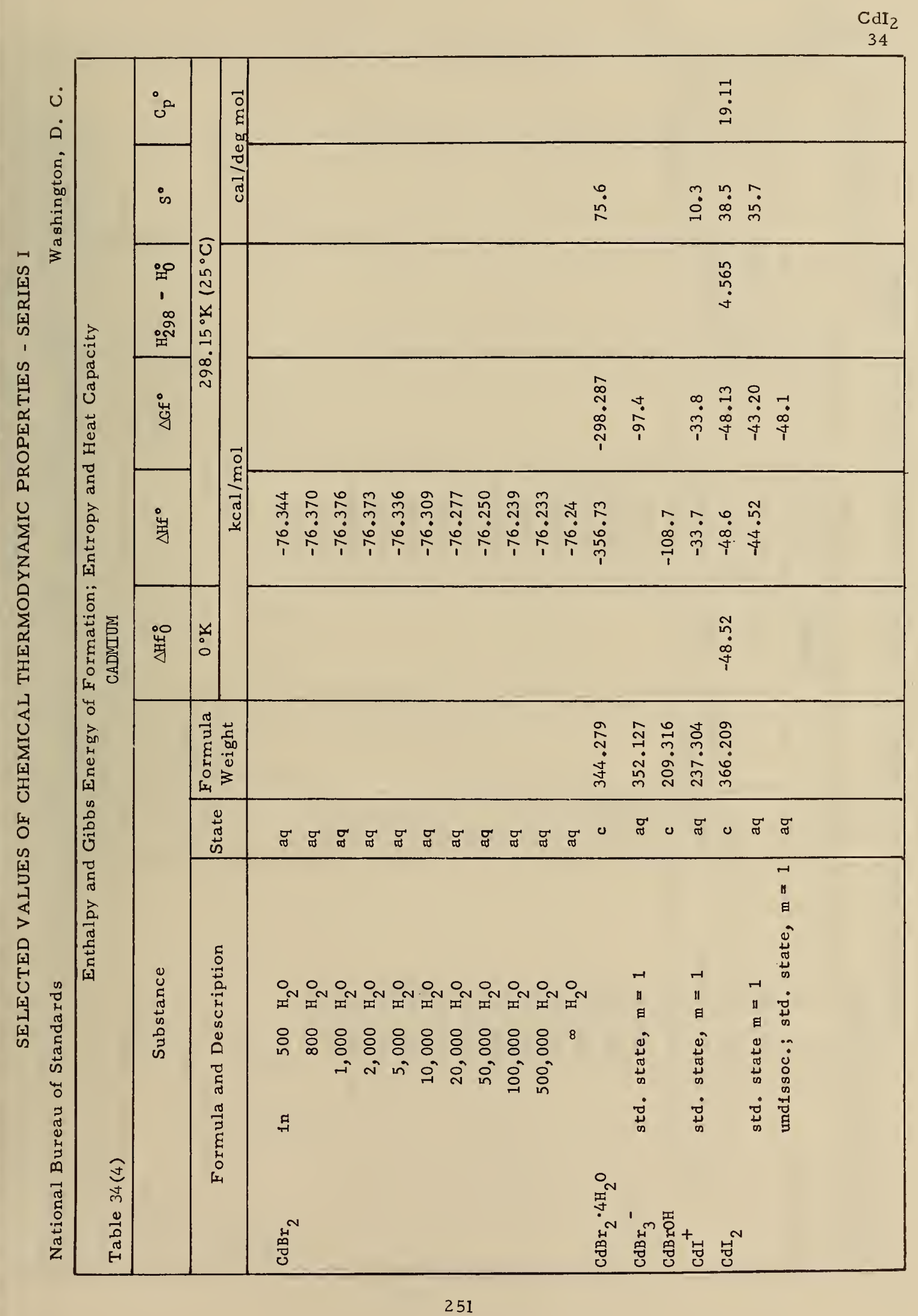




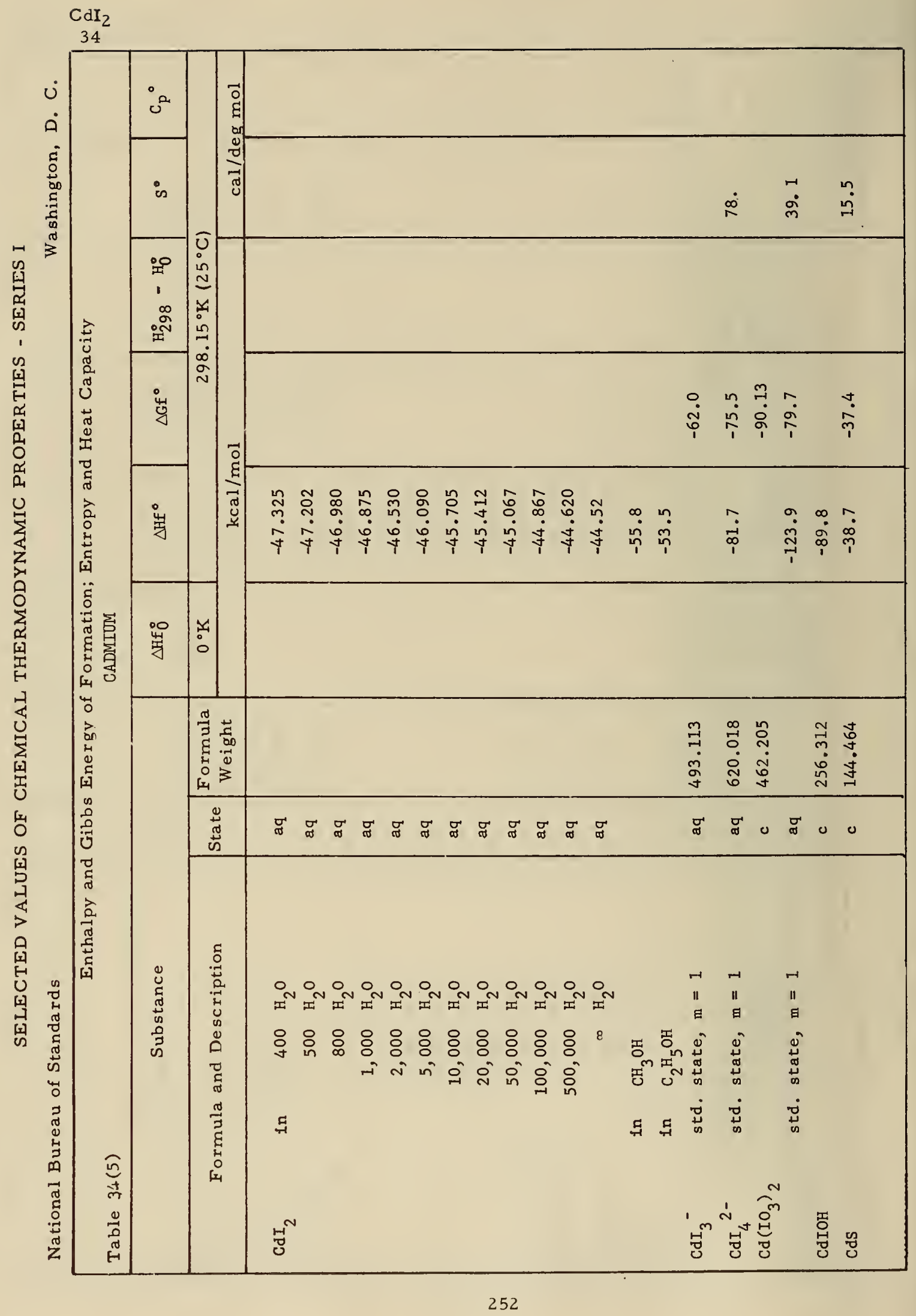


$\mathrm{CdSO}_{4}$

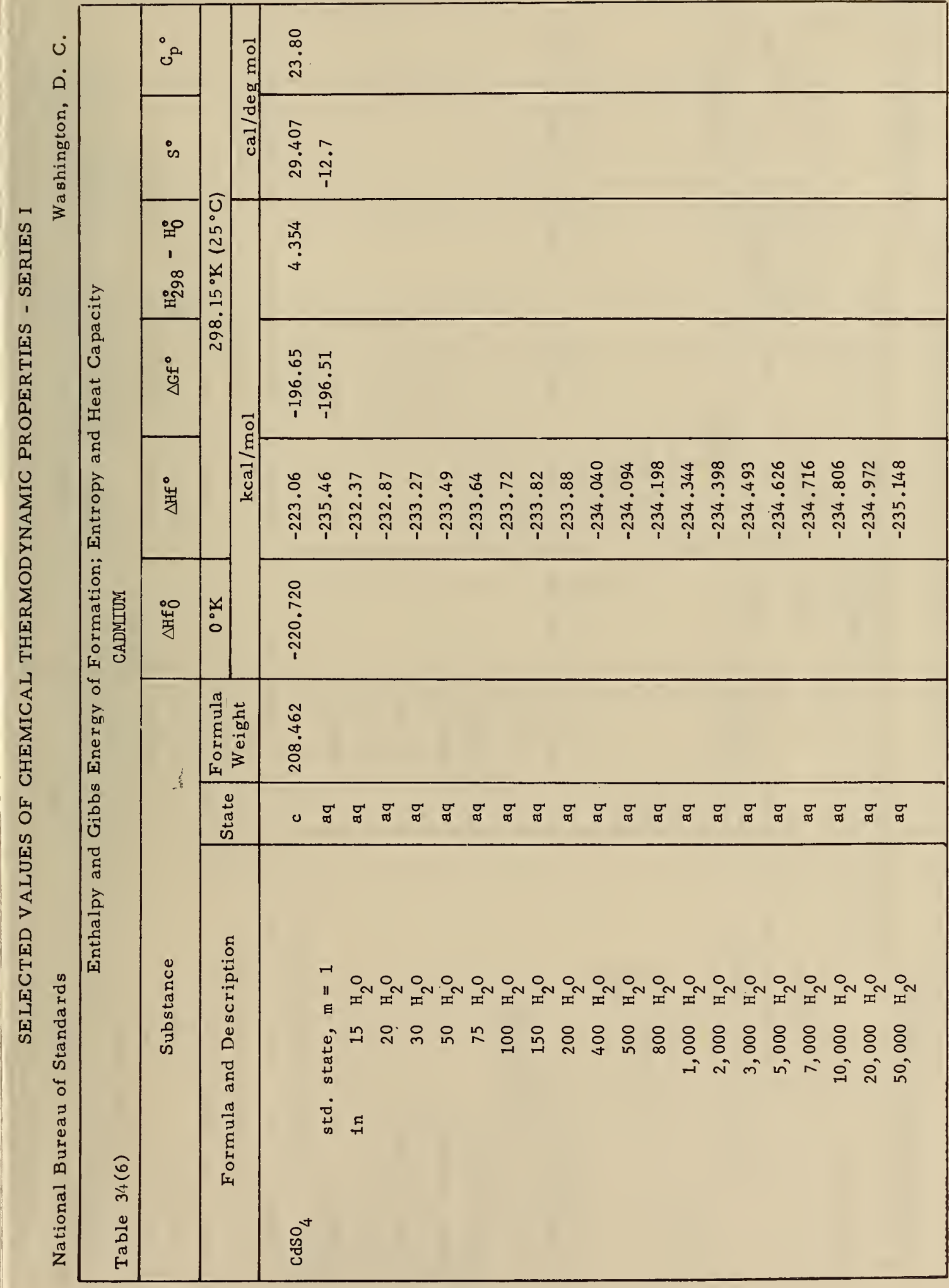




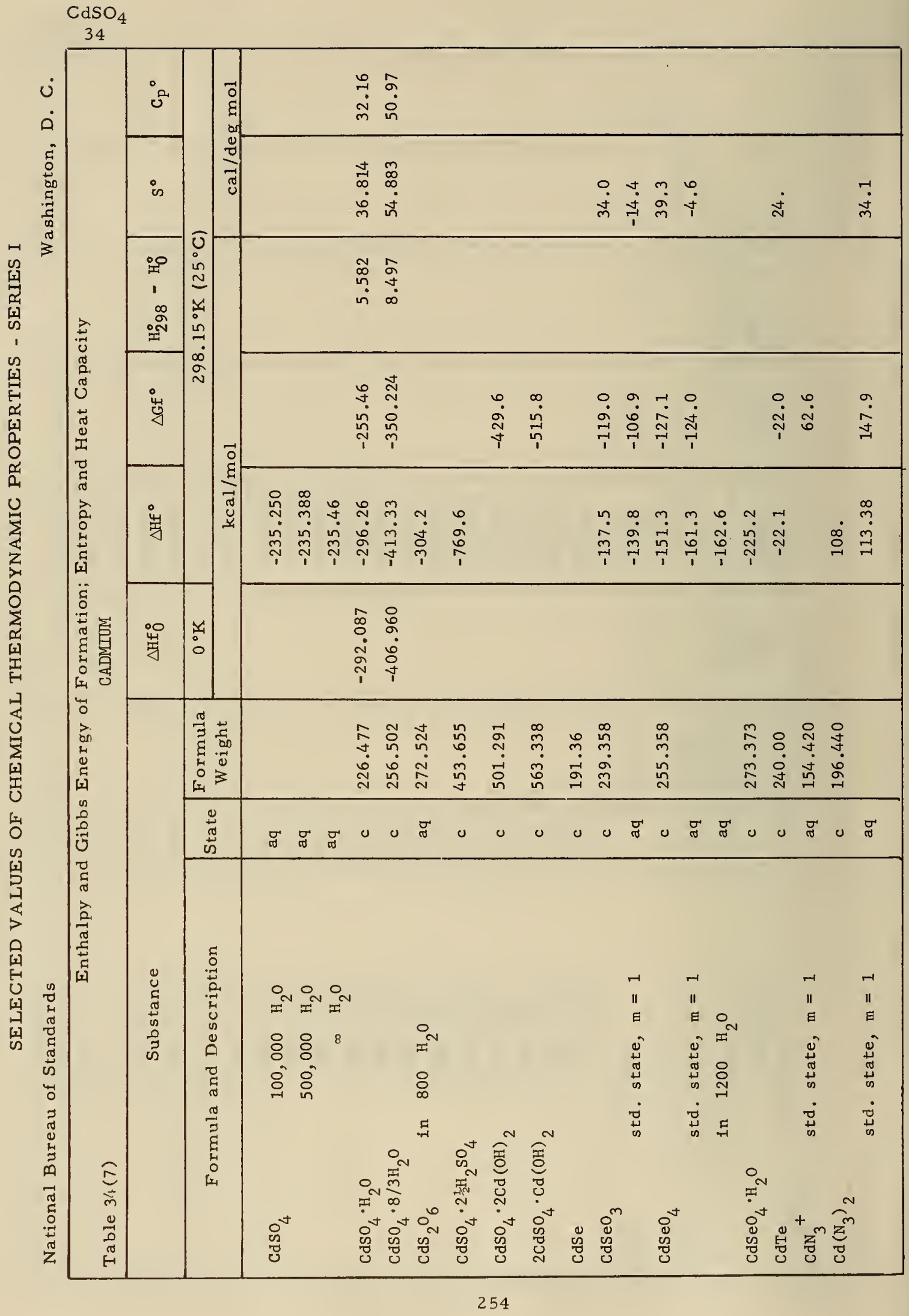


$\mathrm{Cd}\left(\mathrm{NO}_{3}\right)_{2}$

34

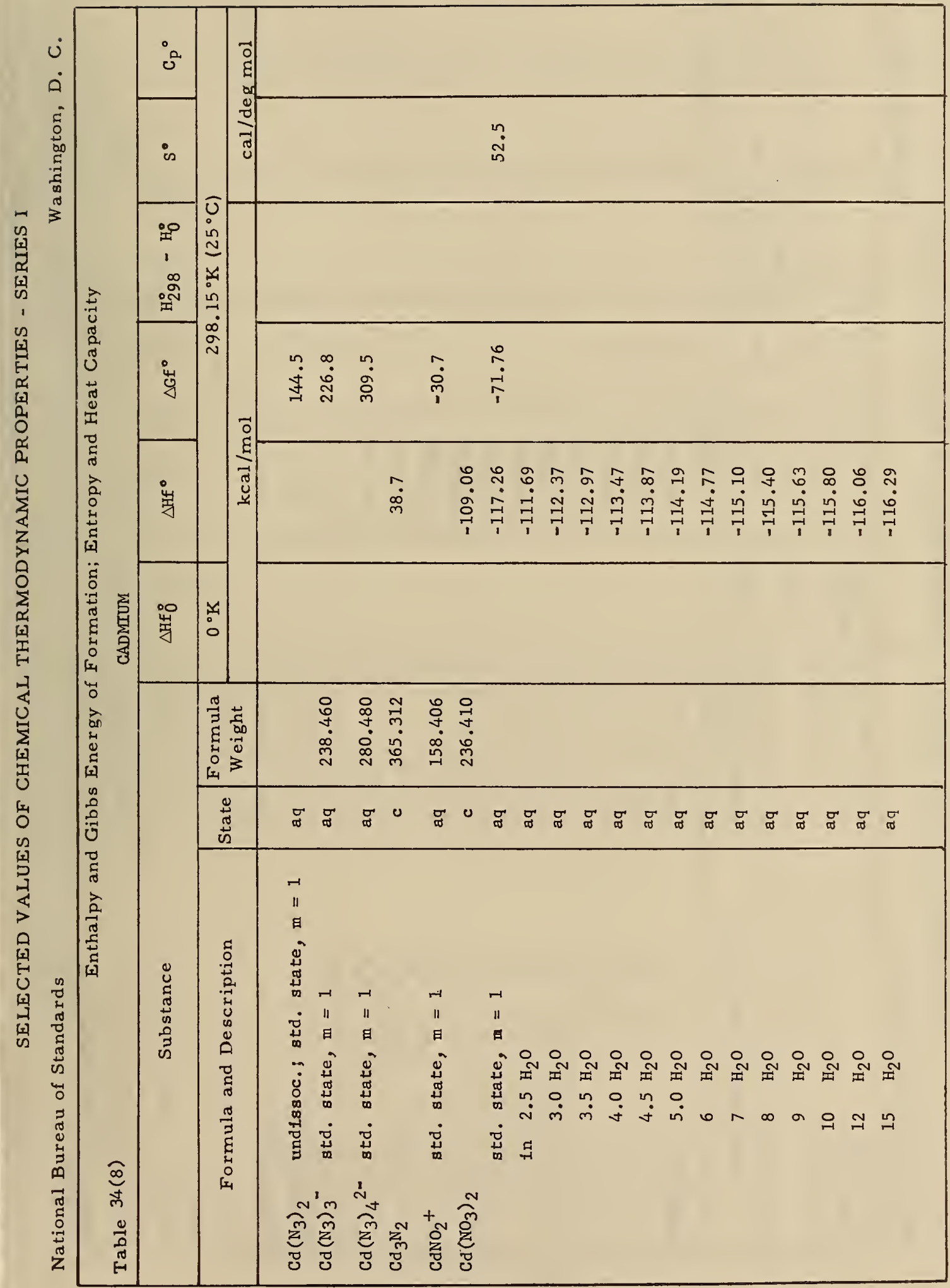




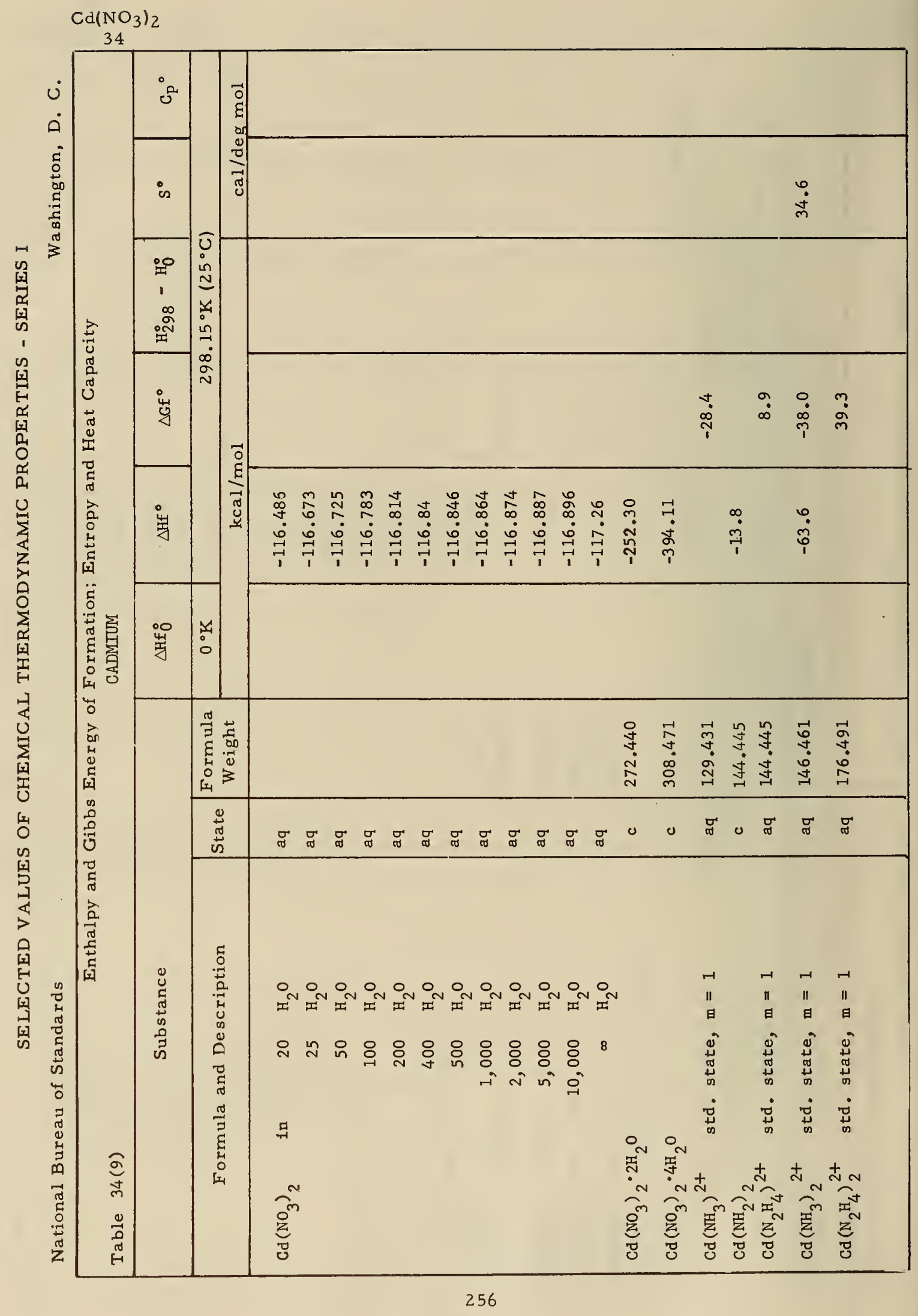




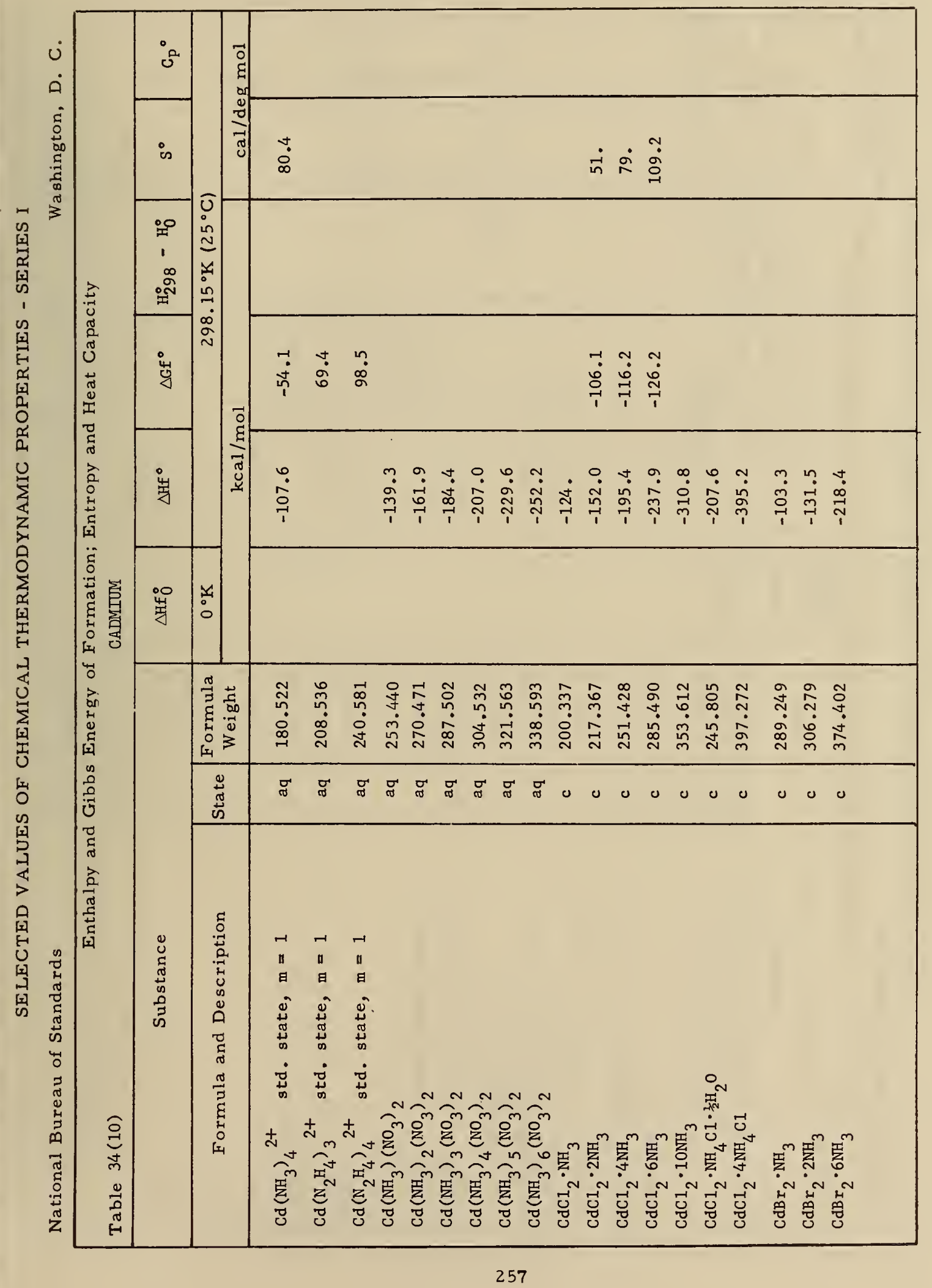




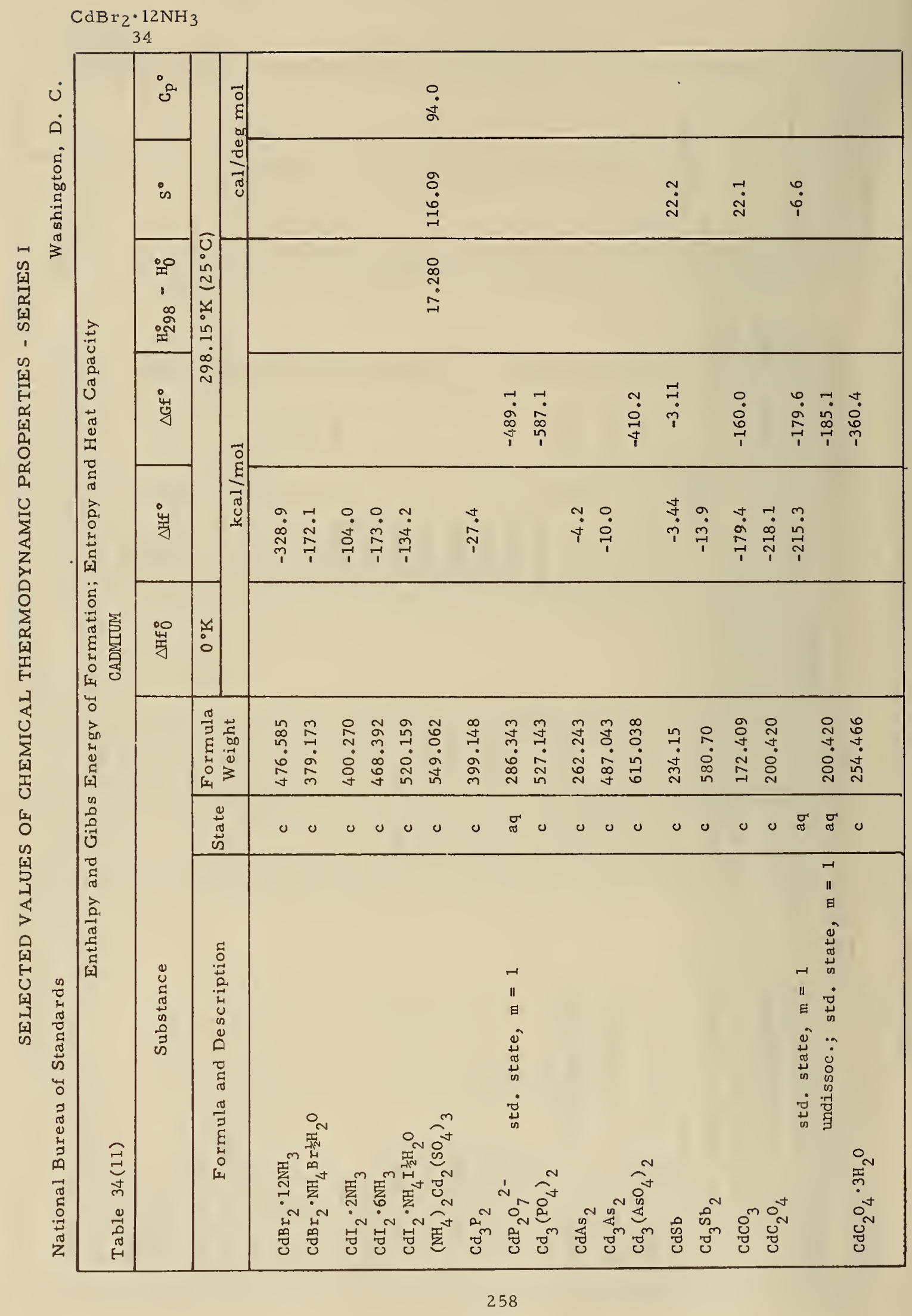




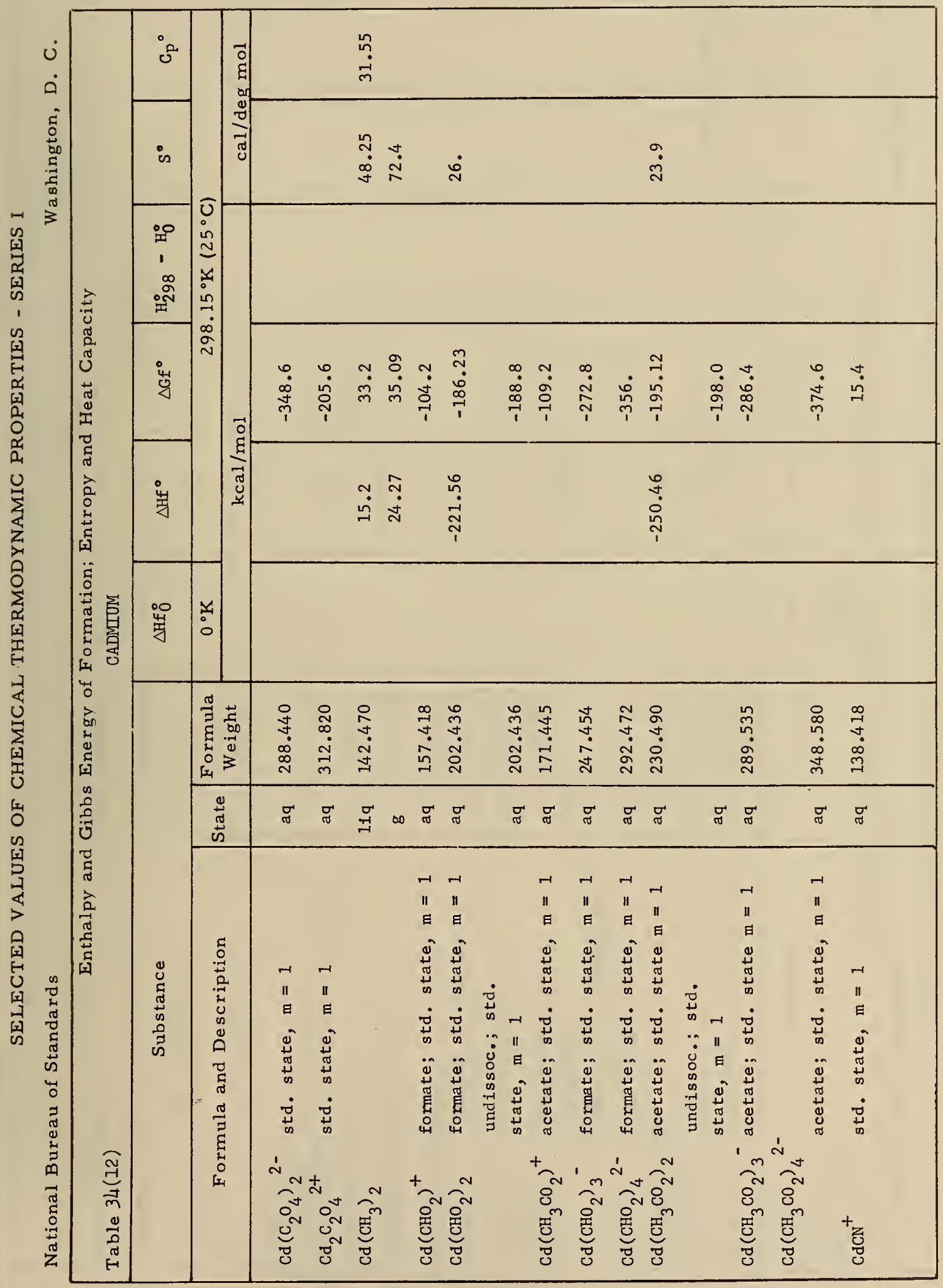




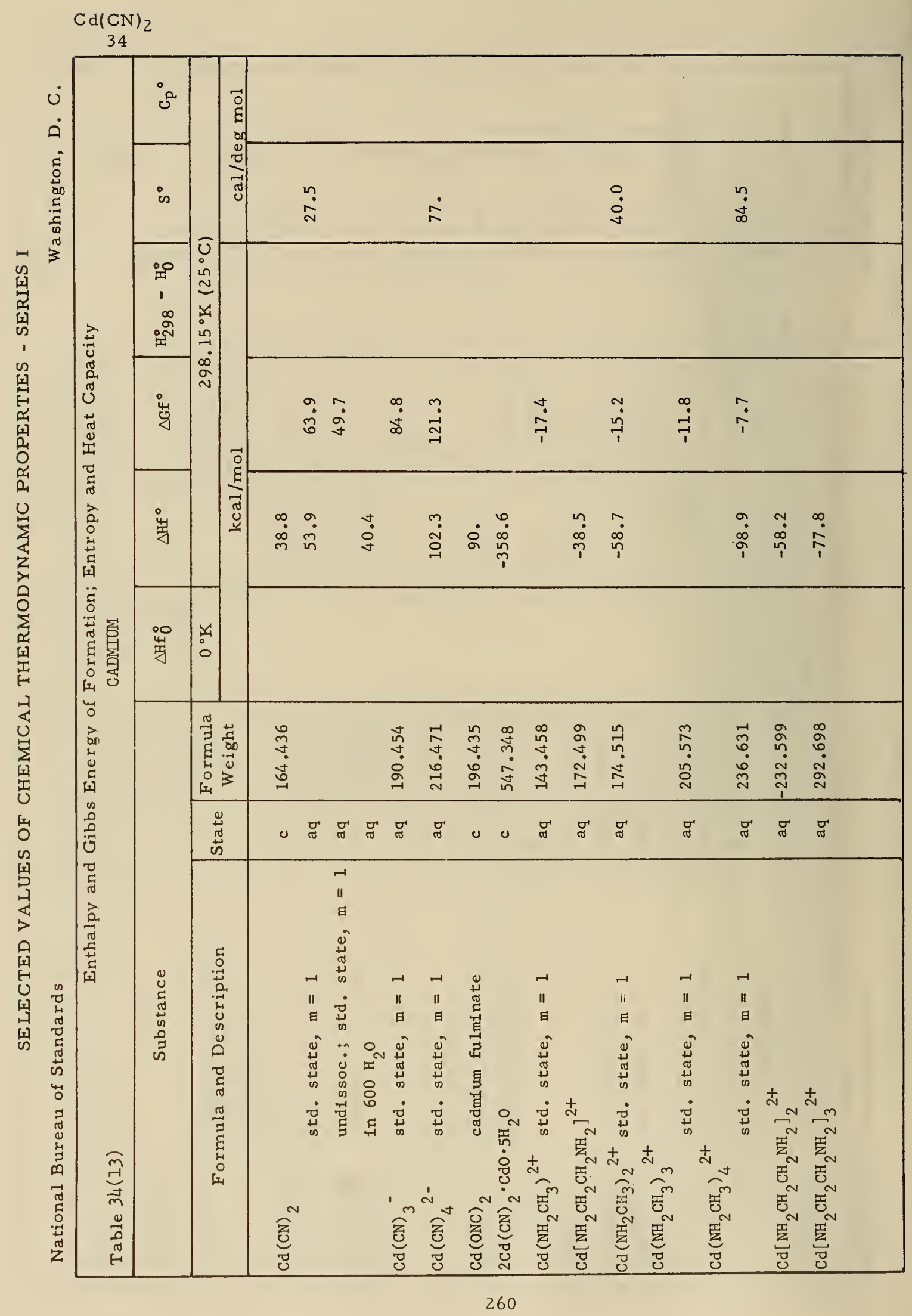


$\mathrm{Cd}\left(\mathrm{BO}_{2}\right)_{2}$

34

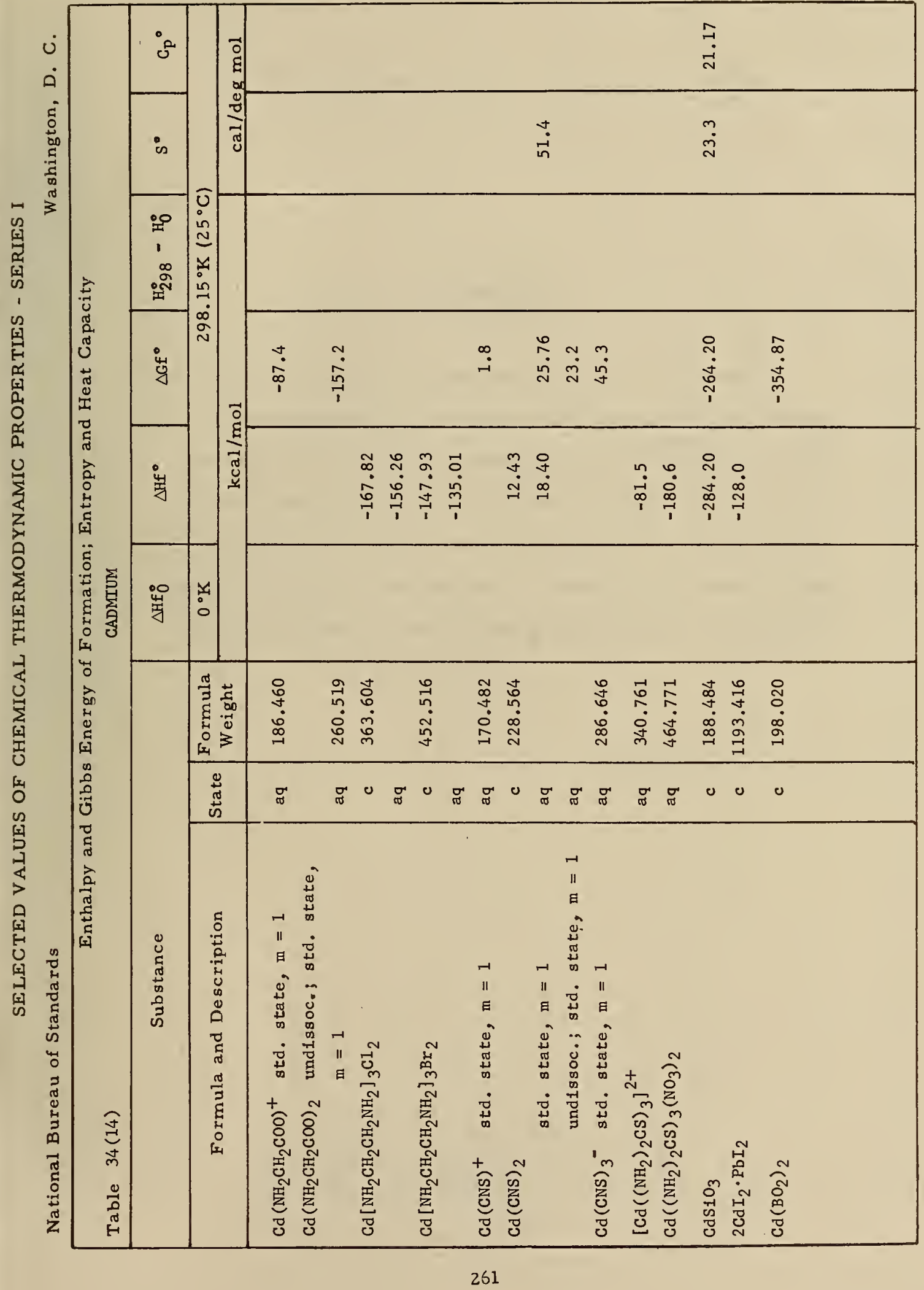




\begin{abstract}
APPENDIX
The order in which the tables of Series I of National Bureau of Standards Circular 500 are revised follows the Standard Order of Arrangement. However it has been necessary to evaluate the data on certain additional substances in order to complete the calculations for the tables given in this part. The values obtained for some of the se compounds are given in the following Table B.
\end{abstract}




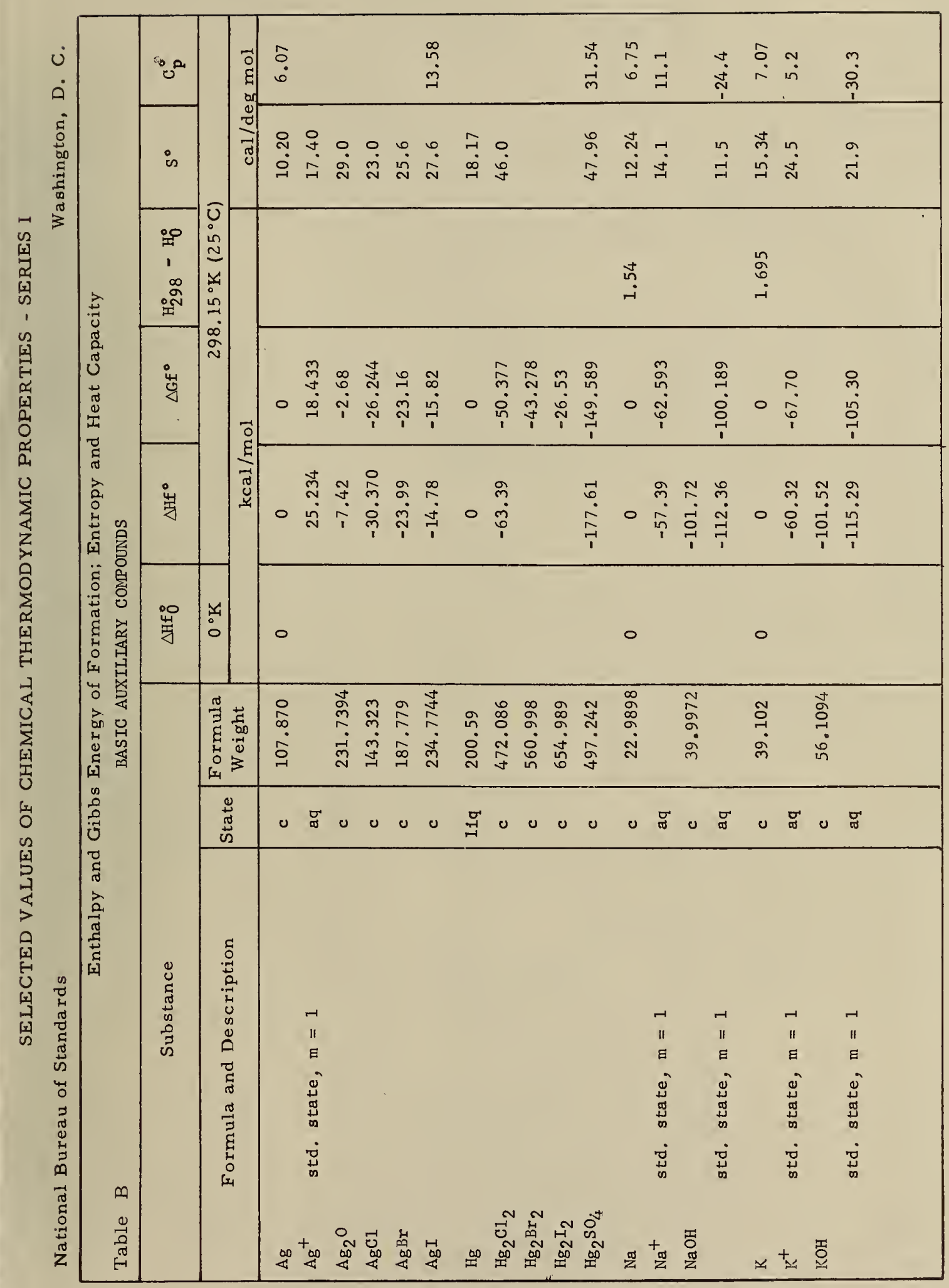


Index of Contents

\begin{tabular}{|c|c|c|c|}
\hline $\begin{array}{c}\text { Chemical } \\
\text { Symbol }\end{array}$ & Element & Table & $\begin{array}{c}\text { Page } \\
\text { Number }\end{array}$ \\
\hline $\mathrm{Al}$ & Aluminum & 29 & 207 \\
\hline Ar & Argon & 5 & 17 \\
\hline As & Arsenic & 20 & 95 \\
\hline At & Astatine & 13 & 42 \\
\hline B & Boron & 28 & 196 \\
\hline $\mathrm{Bi}$ & Bismuth & 22 & 103 \\
\hline $\mathrm{Br}$ & Bromine & 11 & 31 \\
\hline $\mathrm{C}$ & Carbon & 23 & 106 \\
\hline $\mathrm{Cd}$ & Cadmium & 34 & 248 \\
\hline $\mathrm{Cl}$ & Chlorine & 10 & 24 \\
\hline $\mathrm{F}$ & Fluorine & 9 & 21 \\
\hline $\mathrm{Ga}$ & Gallium & 30 & 218 \\
\hline $\mathrm{Ge}$ & Germanium & 25 & 177 \\
\hline $\mathrm{H}$ & Hydrogen & 2 & 12 \\
\hline $\mathrm{He}$ & Helium & 3 & 15 \\
\hline I & Iodine & 12 & 36 \\
\hline In & Indium & 31 & 223 \\
\hline $\mathrm{Kr}$ & Krypton & 6 & 18 \\
\hline $\mathrm{N}$ & Nitrogen & 18 & 61 \\
\hline $\mathrm{Ne}$ & Neon & 4 & 16 \\
\hline 0 & Oxygen & 1 & 11 \\
\hline $\mathrm{P}$ & Phosphorus & 19 & 84 \\
\hline $\mathrm{Pb}$ & Lead & 27 & 187 \\
\hline Po & Polonium & 17 & 60 \\
\hline $\mathrm{Rn}$ & Radon & 8 & 20 \\
\hline$S$ & Sulfur & 14 & 43 \\
\hline $\mathrm{Sb}$ & Antimony & 21 & 99 \\
\hline $\mathrm{Se}$ & Selenium & 15 & 56 \\
\hline $\mathrm{Si}$ & Silicon & 24 & 171 \\
\hline $\mathrm{Sn}$ & Tin & 26 & 181 \\
\hline $\mathrm{Te}$ & Tellurium & 16 & 58 \\
\hline $\mathrm{T} 1$ & Thallium & 32 & 227 \\
\hline $\mathrm{Xe}$ & Xenon & 7 & 19 \\
\hline $\mathrm{Zn}$ & Zinc & 33 & 233 \\
\hline
\end{tabular}



U.S. DEPARTMENT OF COMMERCE

WASHINGTON, D.C. 20230

OFFICIAL BUSINESS
POSTACE AND FEES PAID

U.S. DEPARTMENT OF COMMERCE 